

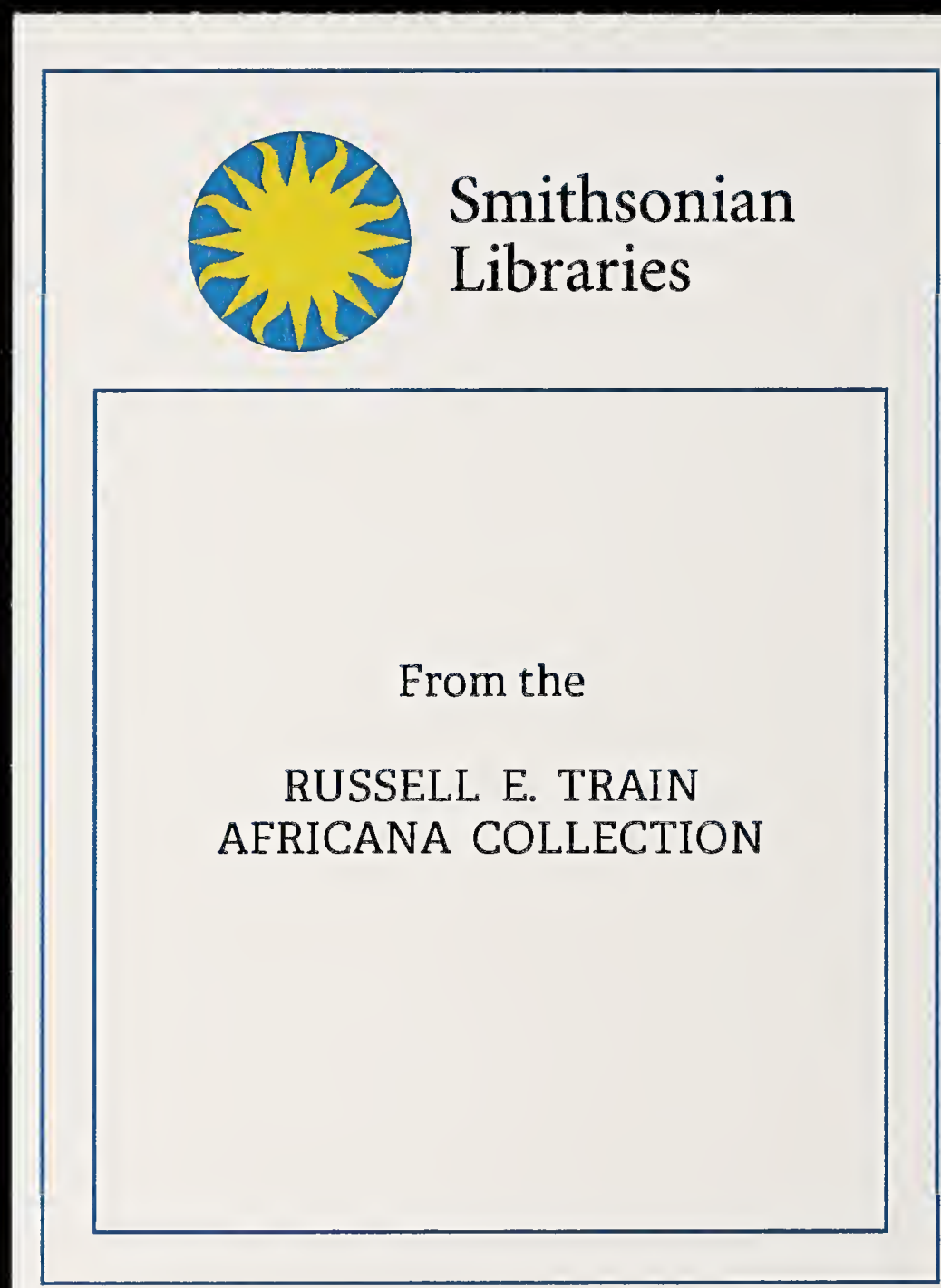




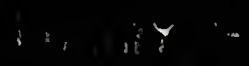

s

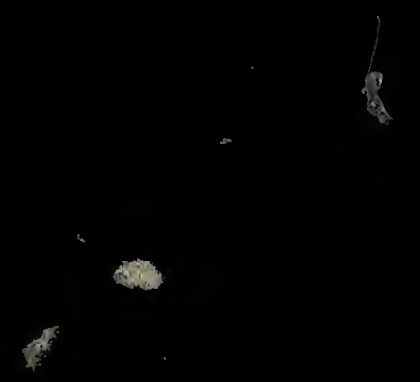

4

$+2$

s. 




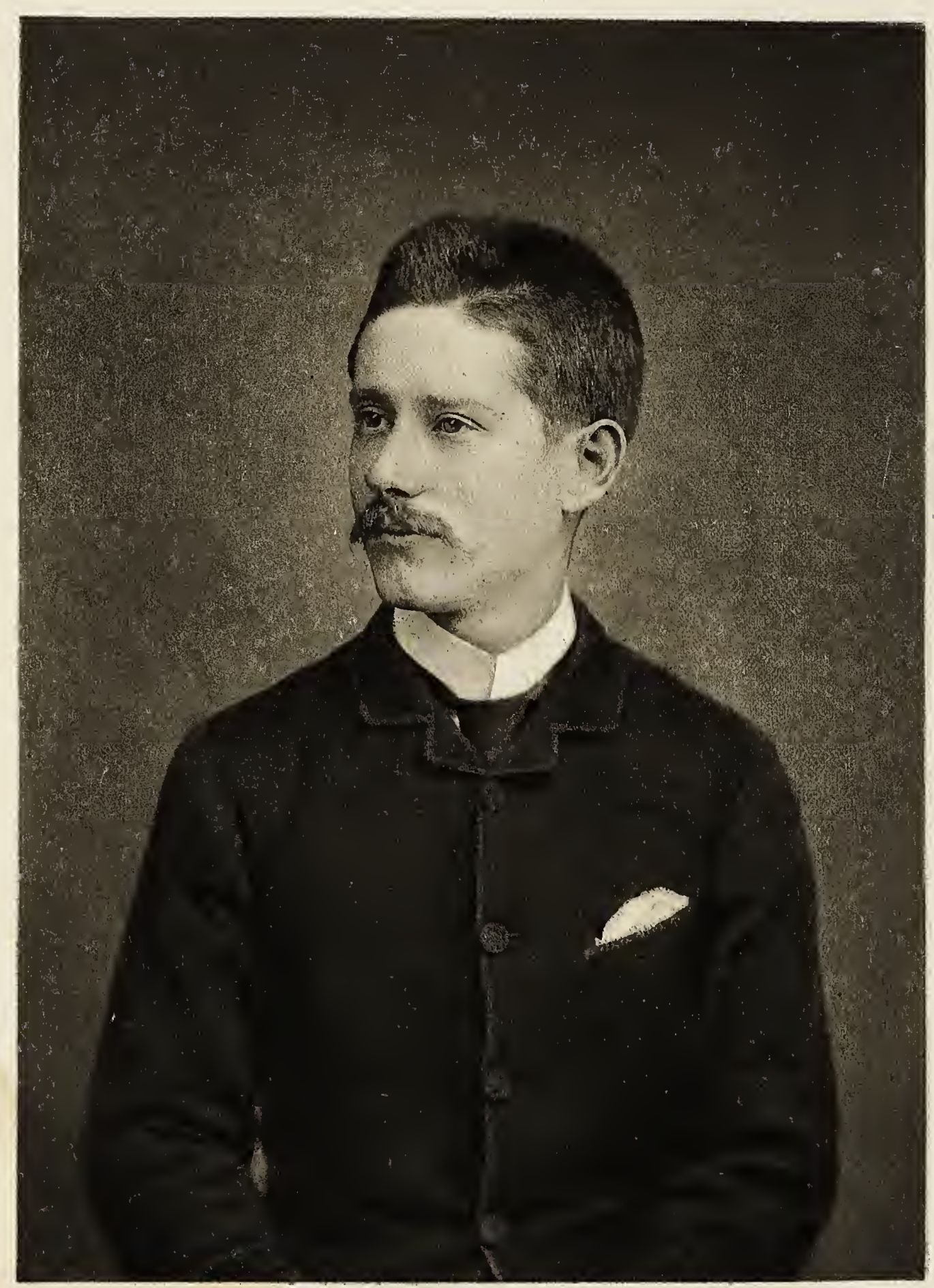

Tho bo aquatinte Bonussed Valadonke.

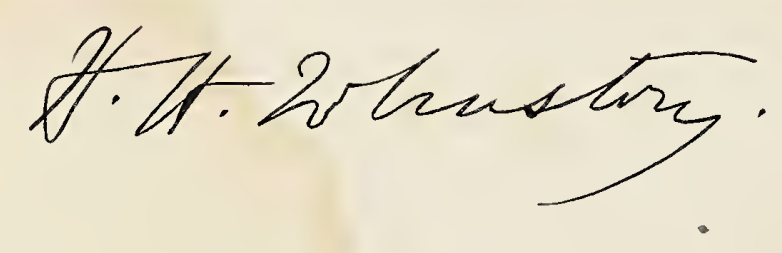


THE

\section{KILIMA-NJAR0 EXPEDITION.}

A RECORD OF SCIENTIFIC EXPLORATION IN

EASTERN EQUATORIAL AFRICA.

AND $A$

GENERAL DESCRIPTION OF THE NATURAL HISTORY, LANGUAGES, AND COMMERCE OF THE KILIMA-NJARO DISTRICT.

$3 \mathbf{Y}$

H. H. JOHNSTON, F.Z.S., F.R.G.S.

MEMB. ANTHROP. INSTITUTE, ETC.; LEADER OF THE EXPEDITION, AUTHOR OF "THE RIVER CONGO FROM ITS MOUTH TO BÓLÓBó."

WITH SIX MAPS AND OVER EIGHTY ILLUSTRATIONS BY THE AUTHOR.

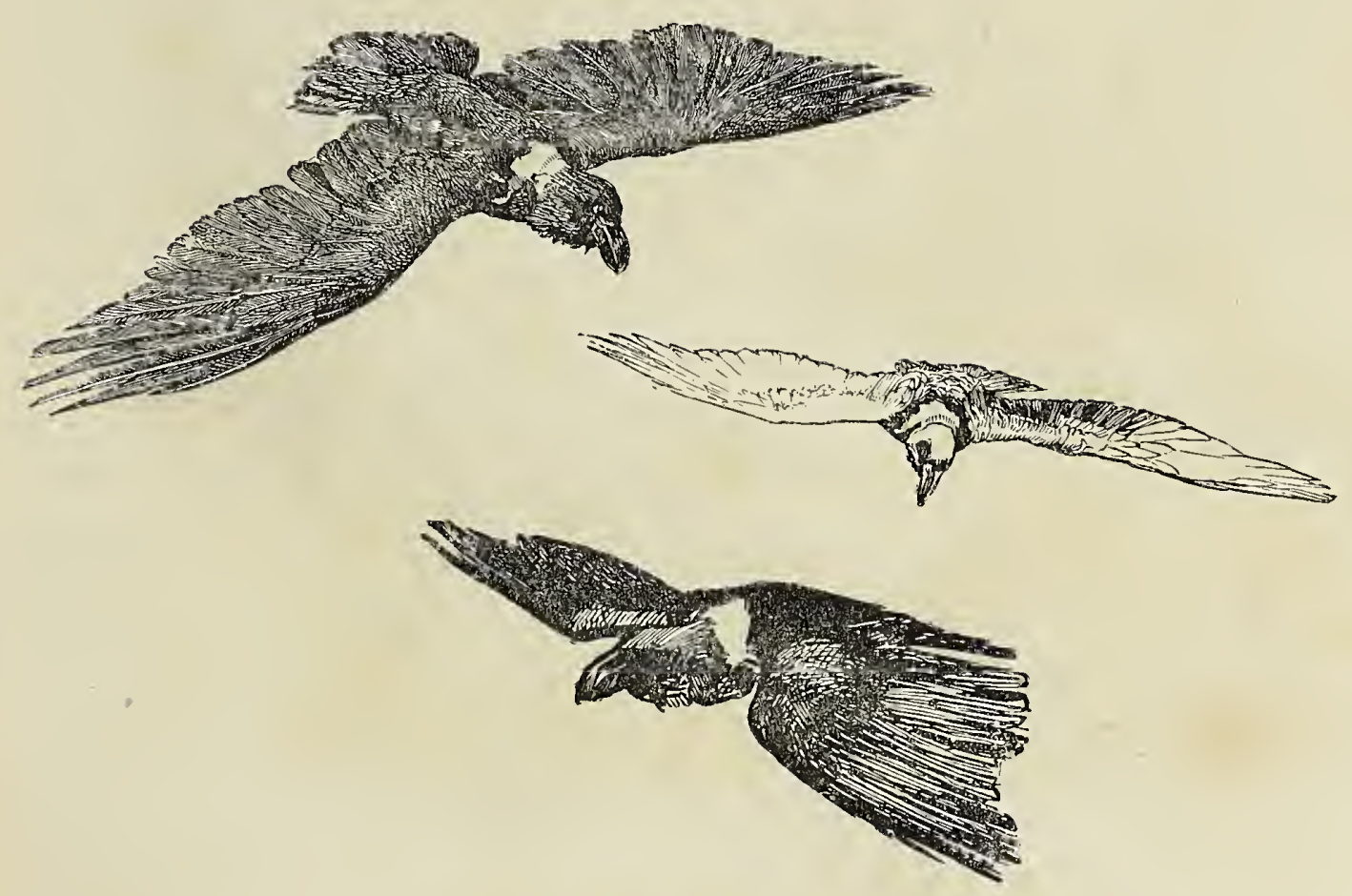

LONDON

KEGAN PAUL, TRENCH, AND CO, 1, PATERNOSTER SQUART. 1886. 
LONDON:

PRINTED BI GILBERT AND RIVINGTON, LIMITED

ST. JOHN'S SQUARE.

[The rights of translation and of reproduction are reserved.] 


\section{DT \\ 339 \\ k4 \\ 164 \\ 1886 \\ SCNHRB}

To

SIR JOHN KIRK, K.C.M.G., M.D., ETC.,

TRAVELLER, BOTANIST, DIPLOMATIST, AND GUARDIAN OF BRITISH INTERESTS AT ZANZIBAR,

THIS BOOK IS AFFECTIONATELY DEDICATED

BY THE AUTHOR. 



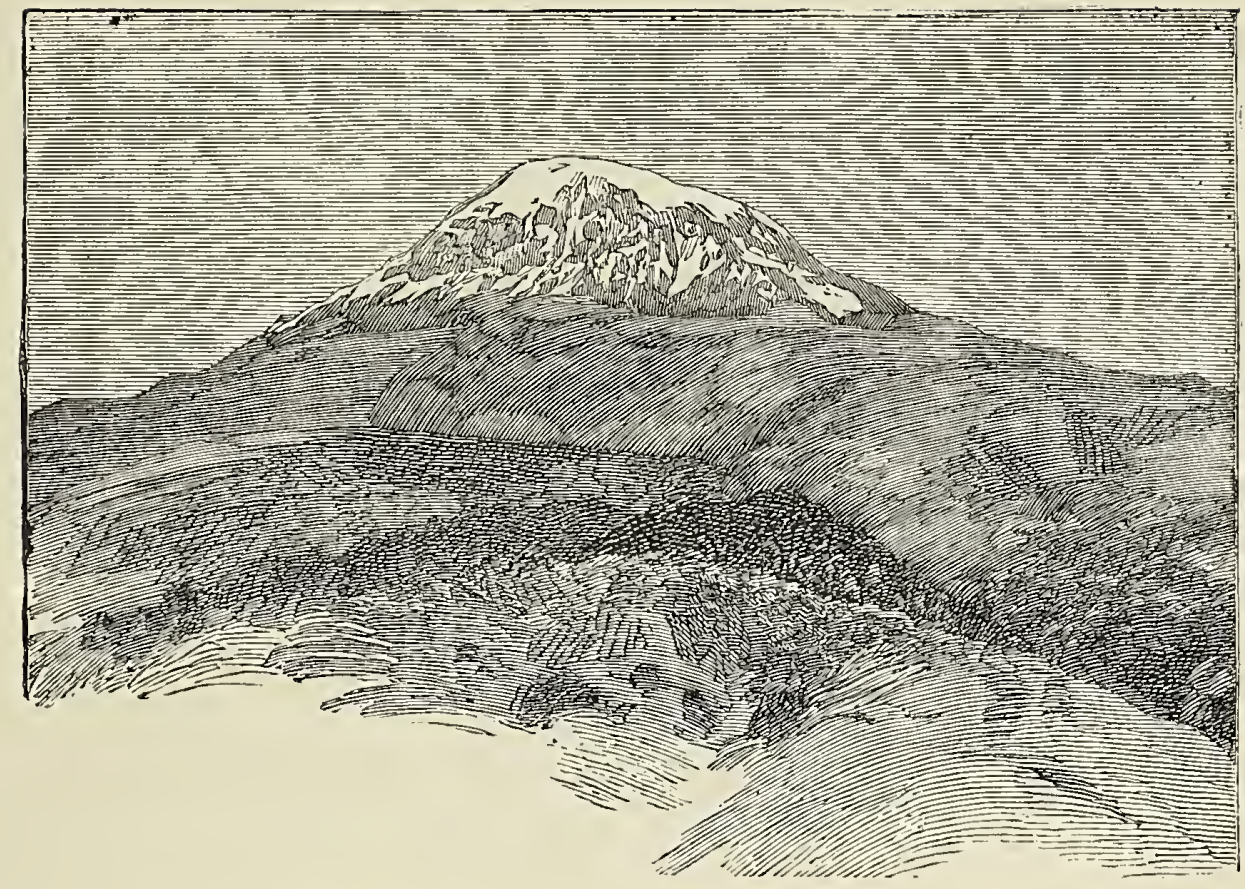

HaIL to thee, monarch of African mountains!

Remote, inaccessible, silent, and lone-

Who from the heart of the tropical fervours

Liftest to heaven thine alien snows.

*

* * *

*

I see thee supreme in the midst of thy co-maves,

Standing alone, 'twixt the earth and the heavins.

Heir of the Sunset and Herald of Morn,

Zone above zone, to thy snow-crested summits

The climates of Earth are displayed, as an index,

Giving the scope of the Book of Creation.

There, in the gorges that widen, descending

From cloud and from cold into summer eternal,

Gather the threads of the ice-gendered fountains-

Gather to riotous torrents of crystal,

And, giving each shelvy recess where they dally,

The blooms of the North and its evergreen turfage,

Leap to the land of the lion and lotus!

*

\%

*

Sovereign mountain, thy brothers give welcome:

Mont Blanc, in the roar of his mad avalanches,

Hails thy accession ; superb Orizaba,

Belted with beech and ensandalled with palm;

Chimborazo, the lord of the regions of noonday ;-

Mingle their sounds in magnificent chorus.

They, the baptized and the crownèd of ages,

Watch-towers of continents, altars of Earth,

Welcome thee now to their mighty assembly ${ }_{*}$

None has a claim to the honours of story,

Or the superior splendours of song,

Greater than thou, in thy mystery mantled-

Thou the sole monarch of African mountains.

Take, then, a name, and be filled with existence,

Yea, be exultant in sovereign glory,

While from the hand of the wandering poet

$\underset{*}{\text { Drops the first garland of song at thy feet. }}{ }_{*}^{*}$

"Kilima-NJaro," a poem by Bayard Taylor, circa 1555. 



\section{PREFACE.}

As the Kilima-njaro Expedition was initiated and supported by two of the most important among our British .Scientific Societies, it may perhaps seem excusable that I, who was its appointed leader, should venture to lay the general results of this enterprise before the public.

I do so only in the sincere desire to contribute, however feebly, to the mounting sum of our knowledge of Africa-that continent, which I look upon as the New World of the nineteenth century.

I cannot conclude these few prefatory lines without most heartily thanking every friend or chance acquaintance who by word or deed facilitated my task. It is pleasant to look back upon this expedition as having been provocative of nothing but kindness.

While the names of certain of my benefactors are mentioned elsewhere in the pages of this work in juxtaposition with their good deeds, I think this the most fitting place in which to record my special sense of obligation to Philip Lutley Sclater, Esq., Ph. D., Sec. Zoological Society; Edward L. Lawson, Esq.; Edwin Arnold, Esq., C.S.I. ; Carmichael Thomas, Esq. ; 
and, with all his faults, Mandara, Chief of Moši; who, though he once threatened to cut off my head, nevertheless in his brighter moods supplied me with much valuable information.

\section{H. H. JOHNSTON.}

London, November, 1885. 


\section{NOTE TO THE READER.}

IN the orthography of most African words and proper names in this book, especially in those which are written for the first time, I have followed what seems to me the simplest and most satisfactory phonetic system-that of Dr. Lepsius' standard alphabet.

As this may be new to some of my readers, I may mention here that the vowels are generally pronounced as in Italian, viz.:-

$$
a=a h ; e=e h ; i=e e ; o=o h ; \hat{o}=a w ; u=o o .
$$

In diphthongs, the sound of each vowel may be distinctly heard, as ai = ah-ee; ou =oh-oo.

Those consonants which differ in look from the Roman character, are-

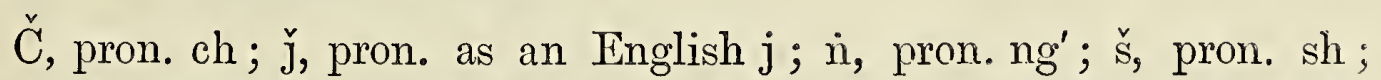
and others, which are of less frequent occurrence, are explained fully in Chapter XX.

As frequently recurring examples of this orthography, I may instance,-

$$
\begin{aligned}
& \text { "Čaga"-pronounced "Chaga;" } \\
& \text { "Moši" "Voshy;" and } \\
& \text { "J̌ipé" " " "Neepay." }
\end{aligned}
$$

I have only diverged from this system where the 
proper names from long use have accustomed us to other spelling. Thus I write "Galla," although properly it should be "Gala," and I have even avoided disfiguring the " $j$ " of "Kilima-njaro" with a v; although I fear the result of this lenity will be that half my readers will pronounce it wrongly. To avoid this I may, perhaps, for the benefit of the timid who always shirk African names, write its exact pronunciation in our clumsy English orthography.

This would be :

Killy-manjāhro. 


\section{CONTENTS.}

CHAPTER I.

INTRODUCTORY

PAGE

CHAPTER II.

SIR JoHN KIRK AT HOME

CHAPTER III.

The Start-Mombasa to Tatta . . , . . , 40

CHAPTER IV.

Tatta to Kilima-nJaro

CHAPTER V.

Arrival at Mandara's Court

CHAPTER VI.

Mx First Settlement on Kilma njaro

114

CHAPTER VII.

"HaLcyon Days".

142

CHAPTER VIII.

Troublous Thmes

CHAPTER IX.

An Anxious Period . . • • • • , . 184

CHAPTER X.

A Trip to Taveita.$\quad$. . . . . . . 204 
CHAPTER XI.

A. First Ascent

CHAPTER XII.

A Move to Marañu

CHAPTER XIII.

A Second Ascent

CHAPTER XIV.

Through the Forests of Kimawenzi and the Country of Rомво

CHAPTER XV.

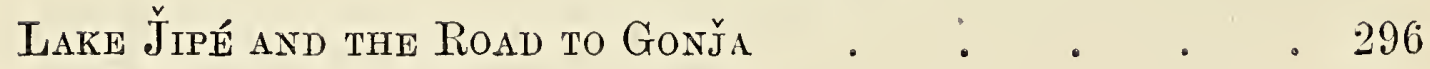

CHAPTER XVI.

GonJ̌a to LoNdoN

\section{CHAPTER XVII.}

Climate, Geologr, Botany, \&c. • • . • • . 322

\section{CHAPTER XVIII.}

ZOOLOGY

\section{CHAPTER XIX.}

ANTHROPOLOGY

CHAPTER XX.

The Languages of the Kilima-njaro District 446

(a) Masai.

Appendix 1. Comparative vocabulary of the Masai language.

(b) The Bantu languages of Kilima-njaro.

Appendix 2. Vocabularies of Ki-čaga, Ki-taveita, Kigweno, \&c.

CHAPTER XXI.

The Commercial Prospects of Eastern Equatorial Africa • 535 


\section{LIST}

nF

\section{MAPS AND ILLUS'TRATIONS.}

MAPS.

No. Toneral Tap of Fast Equatorial Africn

1. General Map of East Equatorial Africa . . to face 1

2. Route to Kilima-njaro . . . . . . . 16

3. Kilima-njaro to the Coast (valley of the Ruvu) to face 296

4. Masai languages . • . • . . to face 446

5. Map of Bantu languages . . . . . . 479

6. Kilima-njaro and its vicinity (Proc. R.G.S) . . the end

\section{ILLUSTRATIONS.}

TIG.

Portrait of the Author . . . . . Frontispiece

1. Sir John Kirk • • . . . . . . 17

2. Sir John Kirk at home . . . . . to face 21

3. Mtépé (with mat aail) . . . . . . . 22

4. Small mtépé and outrigger canoe . . . . . 23

5. A corridor in Sir John Kirk's house . . to face 25

6. Arab dau . . . . . . . . . 26

7. Fishing boat and outrigger canoe . . . . . 26

8. A Saracenic doorway . . . . . . . 27

9. Zanzibar Harbour from the Consulate . . to face 29

10. A view over the house-tops . . . . . . 28

11. Zanzibar orchids . . . . . . . . 33

12. Kigelia Africana . . . . . . . . 34

13. A street in Zanzibar . . . . . . . . 36

14. The bay of Mbwéni • . . . . to face 38

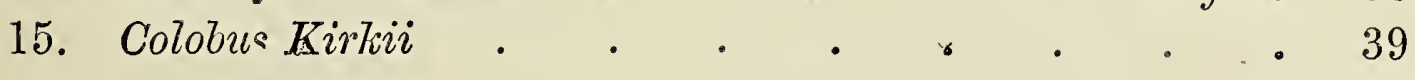


16. Mombasa . . . . . . . to face

17. The Shaws' house, Kisolutini ; the first mission station in East Africa

18. Virapan, my Tamil servant . . . . . . 62

19. Antelopes and ant-hills (the red hartebeest) . to face 65

20. Zebras . . . . . . . • . . 67

21. The first viow of Kilima-njaro . . . . to face 71

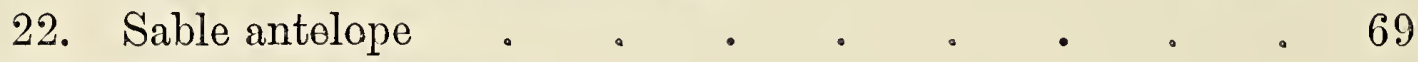

23. The strange creeper . . . . . . . . 82

24. The River Habari • . . . . . . . 83

25. Trees with honey-boxes . . . . . . 92

26. Mandara's left oar . . . . . . 107

27. View of Mandara's village from Kitimbiriu . to face 119

28. Head and shoulders of our cow . . . . . 121

29. A view towards Mačame . . . • . . 124

30. A view towards Ugweno . . . . . . . 125

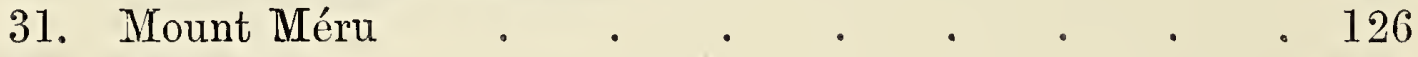

32. A kite .' . . . . . . . . . 128

33. Kibô in the early morning . . . . to face 136

34. A native dam . . . . . . . . 137

35. "Kitimbiriu" (our first settlement on Kilima-njaro) • 138

36. A corner of our settlement . . . . to face 143

37. Clematis and hibiscus . . . . . . . 147

38. A ravine in Moši . . . . . . . . 150

39. Kilima-njaro seen from above Moši ("palms and snow")

40. Mkindu palm (Phœnix sp.) . . . . . . 153

41. Caga doorway . . . . . . . . 157

42. Čaga storehouse and dwelling . . . . . 158

43. The captive . . . . . . . . . . 159

44. A soldier of Mandara's . . . . . . . 195

45. The Mkuyuni Stream . : . . . . . 207

46. Vulturine attitudes . . . . . . . 217

47. The Mpala antelope (AEpyceros melampus) • . $\quad 219$

48.' The Game country . . . . . . to face 220

49. Female Roan antelope (Hippotragus equinus, q) . . 224

50. My settlemenc at Taveita . . . . . . 227

51. Tree fern (Lonchitis pubescens) . . . . . 231

52. Kilima-njaro, showing both its snow-capped peaks to face 234

53. Raven soaring . . . . . . . . . 235

54. Kibô cloud-capped . . . . . . . 258 
FIG.

55. Kimawenzi . . . . . . . . . 265

56. Senecio Johnstoni . . . . . . . . . 268

57. Curious rocks, marked like a tortoise-shell . . . 270

58. Great-billed ravens . . . . . . . 271

59. The dome of Kibô from an altitude of 11,000 feet . . 278

60. Lake Čla . . . . . . . 291

61. Kilima-njaro seen from Lake J̈ipé . . . to face 298

62. Masai camp . . . . . . . . . 305

63. Musa Ensete, a wild banana . . . . . . 331

64. (a) Bunch of fruit of $M$. Ensete; (b) Single fruit, half natural size. . . . . . . 333

65. Branching borassus palm . . . . . . 349

66. Neotragus Kirkii . . . . . . . . . 355

67. Head of great-billed raven (Corvultur albicollis) . . 356

68. The Dying hornbill . . . . . . . 357

69. (a) The right manus or wing of young ostrich. (b) Scale feathers of young ostrich . . . . 360

70. Varanus lizards . . . . . . . . 362

71. A fish from the River Lumi . . . . . . 363

72. Colobus Guereza, var. caudatus. From the "Proceedings of the Zoological Society" . . . . . 389

73. Graphiurus capensis; ( $a$ ) foot, $(b)$ hand . . . 392

74. A Masai warrior . . . . . . . . 415

75. Men of Taveita making fire . . . . . . 435

76. A Čaga forge . . . . . . . . 439

77. Čaga utensils: 1. Wooden hoe. 2. Leather honey-case.

3. Gourd. 4. Wooden tray or dish. 5. Club made

from rhinoceros' horn. 6. Knife . . . 441

78. Čaga house . . . . . . . . 444 




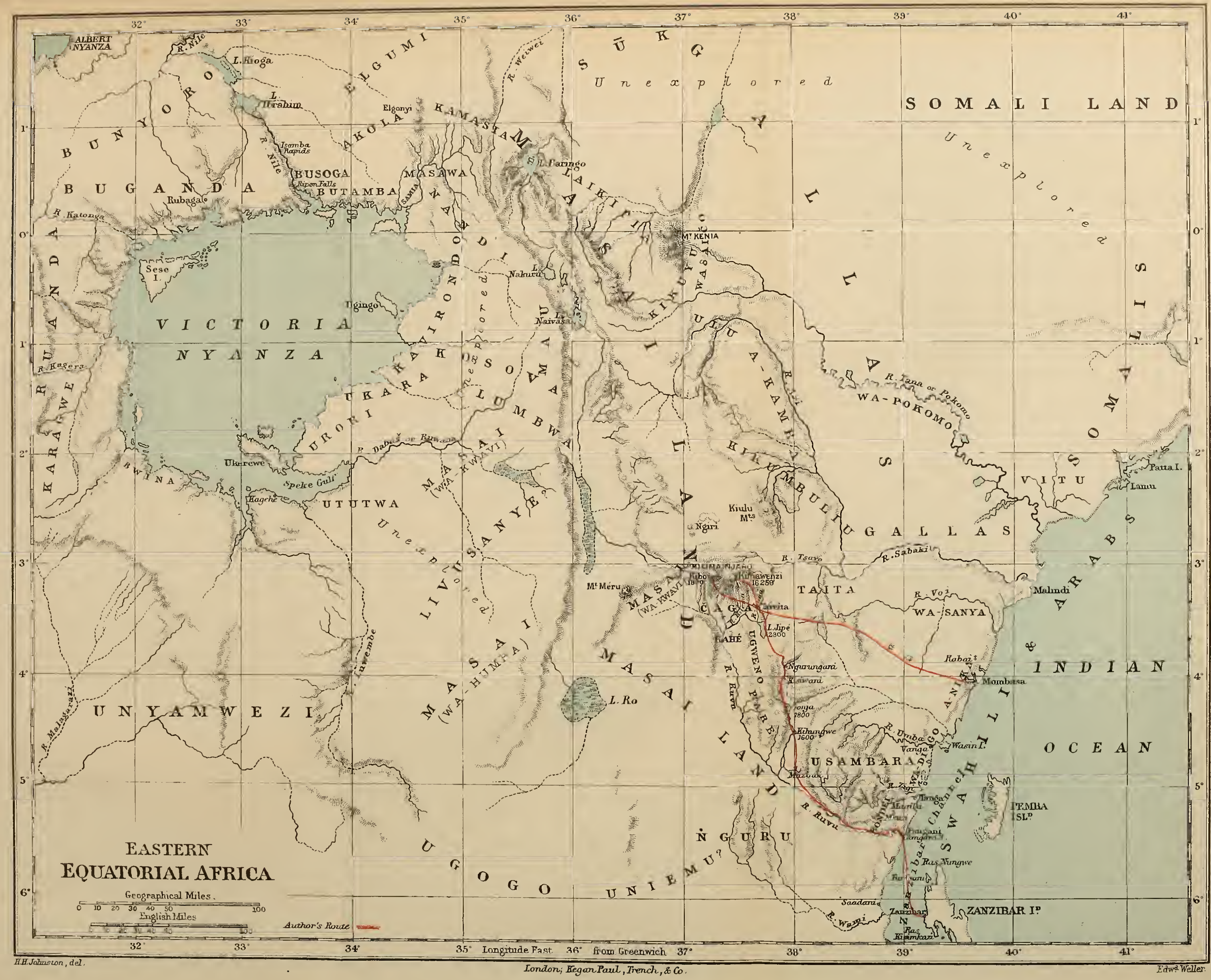





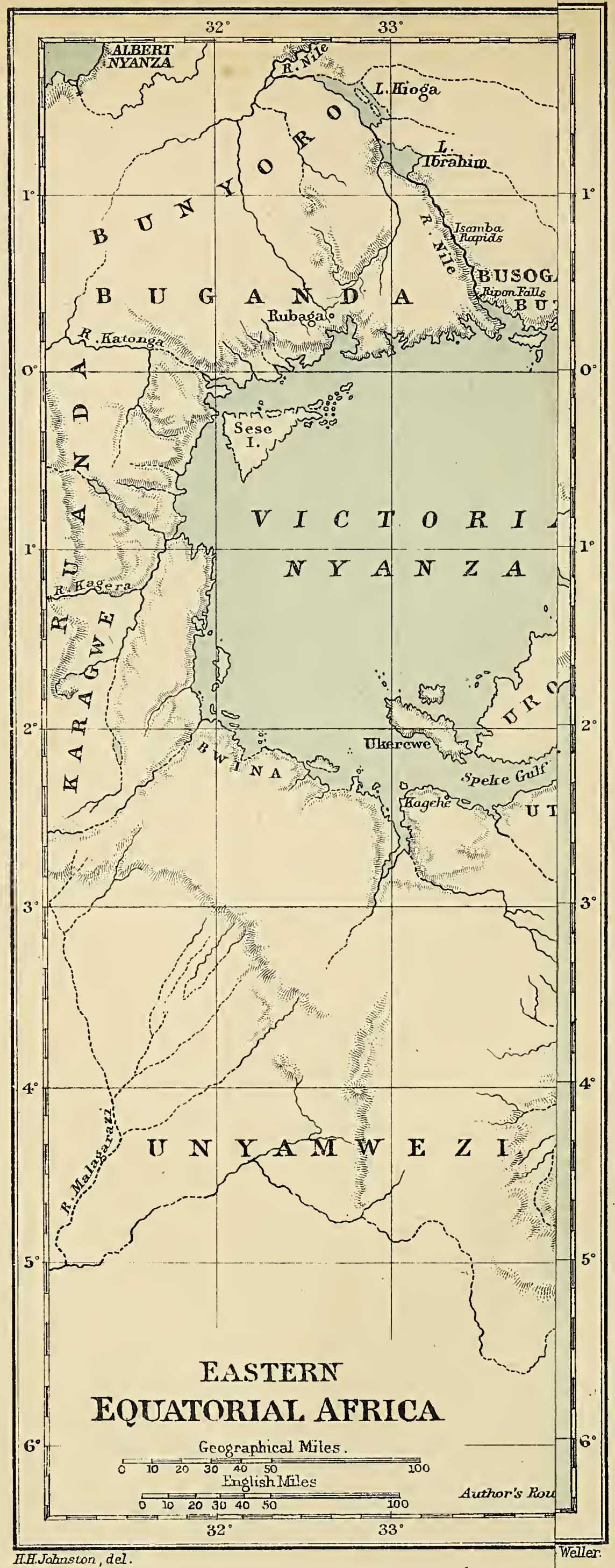




\section{THE KILIMA-NJARO EXPEDITION.}

\section{CHAPTER I.}

\section{INTRODUCTORY.}

Kilina-NJARO ${ }^{1}$ is the name currently given to a huge mountain-mass in Eastern Africa, consisting of two giant peaks and many lesser ones, situated below the third parallel south of the Equator, and at a distance, in a straight line, of about 175 miles from the coast. The highest of the two principal summits-Kibôreaches an elevation 18,880 feet above the sea, and the lesser peak-Kimawenzi-attains to 16,250 feet. Both ascend above the snow-line, no other point in the same clump of mountains doing so, and both are the craters of extinct volcanoes. The entire mass of Kilima-njaro seems to be due to volcanic upheaval, and it was doubtless at one time, and that geologically recent, the great vent of the volcanic forces of Eastern Equatorial Africa, which are still active in regions further to the north or west in the district lying between the Victoria Nyanza and the Indian Ocean.

Kilima-njaro, ever since its existence was positively known to modern geographers, has been claimed

1 From Rilima, mountain, and njaro, the name of a demon supposed to cause cold. This name is only known to the people of the coast, and is unrecognized in the interior. 
as the highest of African mountains, its chief summit reaching an altitude of nearly 19,000 feet. It is just possible that in the unknown region stretching between the Victoria Nyanza and Abyssinia loftier peaks may be discovered, or that Mount Kenia, which lies about 200 miles due north of Kilima-njaro, may be found after accurate measurement to exceed the height of the latter mountain by a few feet, but until this is done, the geography-books may still continue to put forward Kilima-njaro as the highest peak in Africa. Indeed, this they are likely to do for the next decade or so, whether he is superseded or not, for I have remarked that in all geographical questions, physical or political, it takes a sadly long time for increase of knowledge to penetrate the school manuals used in the instruction of the British youth. They always seem separated from the progress of discovery as the fixed stars are separated from our powers of vision. Just as the rays of light now reaching us from Sirius would be found illustrating a condition of things going on many years ago, so in most of the school geography-books, geographical knowledge is reflected a decade or so in arrears. I thint in most of them France is now deprived of Alsace and Lorraine, and the territorial unity of Italy is a fait accompli; but I fancy the Congo is as yet undiscovered, and Turkey in Europe still extends its suzerainty over " the Danubian Principalities," Servia, Bulgaria, and Montenegro. I took up one of these school class-books the other day and found that Mount Miltsin (12,000 odd feet) in Morocco was the highest known peak in Africa. Doubtless next year, in a later edition, the claims of Kilima-njaro will be considered, and just as these receive a tardy recognition, some adventurous traveller 
will bring to our knowledge another African Alp of mightier proportions and loftier summit destined to oust from his proud position the object of my recent journey, who, displaced from the homage of the eager geographer, must be content to linger still a few years longer in possession of the vague respect of the British schoolboy.

Although the mass of Kilima-njaro rises rather abruptly from a fairly level plain, it is hardly to be called isolated, and indeed it may be said that an almost continuous chain of mountain-ranges and independent peaks connect it with Abyssinia on the north, Natal on the south, and, possibly, also with the Cameroons on the west. Judged by the flora which clothes its higher regions, it may be almost regarded as the common meeting-ground of many forms peculiarly characteristic of these three widely separated mountain-districts.

To ascertain the relationships of the fauna and flora of Kilima-njaro, two learned societies-the British Association for the Advancement of Science and the Royal Society-at the instigation, I believe, of Mr. Sclater, the Secretary of the Zoological Society of London, delegated certain of their members to form a Kilima-njaro Expedition Committee, and funds to the extent of $1000 l$. were placed at their disposal. The great height attained by Kilima-njaro, and the fact that this snow-clad mountain-mass lies in the Equatorial zone, and exhibits an extraordinary range of climates on its broad slopes, were thought sufficient causes to give rise to or explain many curious features in its fauna and flora; moreover, a like condition of things-perpetual snow under the Equator-was only to be met with elsewhere in Central and South America, no mountains in other parts of the tropics reaching to 
the snow-line. In all cases lofty ranges lying in littleknown regions are interesting to students of natural history. Isolated mountains of great height are often like oceanic islands, and serve as a refuge and a last abiding-place for low types or peculiar forms, which in larger and more densely-populated areas find the competition too keen, and are extinguished in the struggle for life. Or, it may be, some species or genus, originally of a generalized type, becomes by various circumstances the inhabitant of an alpine range or a sea-girt island, and being thus removed and protected from the natural checks to its peculiar development offered by the contemporaneous evolution of its fellows, may, as it were, run riot in the absence of rivalry, and assume very eccentric and singular forms. Thus we can imagine that a pigeon something like the modern didunculus of the South Sea Islands once arrived in Mauritius, having perhaps hitherto had to contend with the usual dangers which naturally menace the existence of a meek-spirited, plump bird that is good to eat. But this pigeon, either chancing on Mauritius in the course of its long flights, or dwelling on the island at a date when its connection with a pre-existing continent was being severed, found itself in singularly favourable circumstances, plenty to eat and nothing to attack it-no animals of prey being left on the island. So in the course of time, no longer obliged to fly from foes or take long journeys in search of food, this pigeon became a dodo, huge, fat, and inert, with atrophied and useless pinions. Again, on the mountainranges of Sumatra, of Japan, of North America, also on the Alps of Europe, dwell queer, old-fashioned ruminants - goat-antelopes, capricorns, chamois which would have long since perished in the fierce, 
hustling life of the plains, or more probably have become moulded into some advanced and perfected type, like the great ruminants of the lowlands. There were these possibilities of zoology to encourage exploration; and another interesting feature in the fauna and flora of high mountains is that they often retain vestiges of an older nature, that has long since been supplanted in lower levels by a new reign. In this way Kini Balu, the lofty mountain of Borneo, preserves on its upper slopes an Australian flura long since superseded in the plains below by the vegetation of India. On the Alps reappear the butterflies of Arctic Europe. The Abyssinian mountains can show genera and species of animals and plants from temperate countries north and south, from Europe and the Cape of Good Hope, and consequently the question as to the relations of the fauna and flora of Kilima-njaro, the highest mountain known in Africa, with that of other regions, was one of great interest, and one which, however decided, might solve many curions puzzles as to the geographical distribution of living forms.

If we should discover around the snows of this huge mass of extinct volcanoes the gentians and edelweiss of the Alps, or even other semi-Arctic forms, these would arouse a supposition that during some past glacial epoch the frigid North had sent its children into Central Africa, following the ice and snow. Or should we find, as we ascended Kilima-njaro, the birds, beetles, butterflies, and plants of the Cape of Good Hope, or even the antique types of Madagascar, this might show that the clump of snow mountains had served as one of the last footholds of the older autochthonous African nature, which was dispossessed and driven into distant islands and remote corners of the continent by 
recent inroads of the lustier things of Europe; by the advent of the apes, and lions, and huge herbivora, which scattered and extinguished the feeble lemurs, insectivores, and edentates that heretofore prevailed. It might also be, in a lesser way, with man as it had been with lower forms of life, that the fastnesses of Kilimanjaro should prove the shelter of some poor type, some human relic of a race long passed away, whose speech, whose handicraft, whose superstitions would arouse new problems for the anthropologist, or serve as a happy link to strengthen imperfect chains of evidence.

Questions like these, which the existence of snowclad mountains in Central Africa inevitably suggested, were of sufficient importance to warrant the despatch of an expedition, which should obtain information and material to aid in their solution; and at one time it was proposed that Mr. Joseph Thomson should endeavour to combine with his journey across the Masai country (since so splendidly carried out) a prolonged journey on Kilima-njaro, and a consequent investigation of its fauna and flora. But for many reasons this plan had to be abandoned, and the British Association and Royal Society combined to organize a separate expedition, with the command of which I was entrusted some months after my return from the River Congo.

Kilima-njaro is supposed to have been vaguely known to the Portuguese as early as the sixteenth century, and inasmuch as these people held Mombasa for nearly 200 years, and Mombasa lies within 180 miles of the mountain, and is the point of departure and return of many Swahili and Arab trading parties, who visit the base of the snow peaks, it would indeed be curious if no rumours of the existence of such a mighty object of wonder ever reached the ears of the Portuguese. 
Enciso, ${ }^{2}$ a Spanish writer of the sixteenth century, mentions its existence, and calls it "Mount Olympus." Others have supposed that the legendary Mountains of the Moon had their basis of actual existence in Kilima-njaro; however this may be, putting aside vague rumours which in this case had a just foundation and in many other cases had no foundation at all, the first European who discovered Kilima-njaro and made its existence known to the civilized world, was Rebmann, a German missionary, who, wandering inland from Mombasa, first descried the wonderful snowy dome of Kibô, the highest summit of the mass, on the 11th of May, 1848. Being a simple-minded man, and overawed by the unexpected beauty and majesty of the spectacle which the distant snow-clad summit offered as it rose from a base of sombre forest into the clear blue sky, he fell on his knees and recited the 111th Psalm, seeming almost to think that a little pimple on the surface of our tiny planet was one of the chief and most glorious productions of the Creator. Rebmann had the good fortune to alight on

2 I owe this information to the kind researches of Mr. E. G. Ravenstein, F.R.G.S., the learned African cartographer. The following is a quotation from Enciso's great work, the "Suma de Geographia que trata de todas las partidas y provincias del Mundo," published at Seville in 1519 (later editions 1530, 1546), fol. 57.

(Translation.) "West of this port (Mombaça) is the Ethiopian Mount Olympus, which is very high, and further off are the mountains of the moon, in which are the sources of the Nile. In all this country are much gold and 'aiales fieros,' and here devour the people locusts (lãgostas)."

No gold has since been met with by succeeding travellers, and as to the "aiales fieros," neither Mr. Ravenstein nor myself can give any translation to the former of the two words. "Aiales" may be a name of a tribe, perhaps a hint at the Masai ; or more possibly it may be a printer's contraction of "animales"- "animales fieros"-_ fierce animals."

Enciso was a Spanish pilot, buthis information is evidently derived from the Portuguese, who held Mombaęa as early as 1507. 
Kilima-njaro in times of peace before the Arab traders and the slave trade had brought the curse of internecine war to the industrious and thrifty agriculturists who inhabited the fertile mountain-slopes. He consequently wandered about freely, through most of the little Čaga ${ }^{3}$ states, with a small following of some ten porters and but little baggage. On his return to the coast he communicated his discovery to Krapf, who shortly afterwards started himself for the interior, and discovered Mount Kenia, but only saw Kilimanjaro from a distance of forty miles. The results of these two remarkable expeditions were modestly made known to the geographical societies of Europe, but in Paris alone did the discovery of Kenia and Kilimanjaro meet with any practical recognition. The silver medal of the Geographical Society in that city was awarded to Messrs. Krapf and Rebmann, for making known the existence of snow-clad mountains in Eastern Equatorial Africa.

In England the missionaries' information was greatly discredited, because they had not been able to map out their journeys by observations for latitude and longitude, and could only fix the position of the mountains, of which they alleged the existence, by dead reckoning. As a matter of fact, they placed them with wonderful accuracy, considering the rough methods employed, and subsequent discoveries have corroborated their statements. Krapf only saw Mount Kenia from a distance of over forty miles, and Rebmann probably approached no nearer than fifteen miles to the snows of Kilima-njaro. Both could only

$3 \check{C} a g a$ (which is pronounced Chaga) is the native name for the inhabited belt, between 3000 and 7000 feet, stretching round the mountain. 
asseverate that they had seen snow, and both were accused of being deceived by their vivid imaginations. Their most relentless critic was a redoubtable person, for long years a terror to real explorers, Mr. Desborough Cooley, a kind of geographical ogre, who used to sit in his study in England, shaping and planning out the map of Africa (basing his arrangements of rivers, lakes, and mountains on ridiculous and fantastic linguistic coincidences and resemblances of his own imagination), and who rushed out and tore in pieces all unheeding explorers in the field who brought to light actual facts which upset his elaborate geographical schemes. Mr. Cooley proved in the most exhaustive and conclusive manner, that Messrs. Krapf and Rebmann could not have seen mountains capped with perpetual snow in Equatorial Africa, and, ergo, they did not exist.

However, Nature and Truth are relentless. They will not stifle or modify their accomplished facts to please any one. You would have thought that after the beautiful and logical manner in which Mr. Cooley had set forth that snow-clad mountains could not exist near the Equator (I suppose he forgot those of America), that Nature would have felt ashamed of producing anything unnatural and would have backed up Mr. Cooley's statements by whipping Kilima-njaro and Kenia off the land of Africa before any adventurous explorer could conclusively prove their existence. But no; after an interval ${ }^{4}$ of about ten years, in 1861, Baron von der Decken, a Hanoverian, went to Kilima-

4 Rebmann had made a second journey to Kilima-njaro soon after his first, intending to proceed due east to the Unknown Lake (Victoria Nyanza), but the chief of Mačame plundered him and compelled him to return unsuccessfully to the coast. 
njaro and stayed there from the end of July to the beginning of September, and was able entirely to corroborate the statements of the much-maligned Rebmann.

He was not able to ascend higher than 8000 feet, but on a succeeding visit in December, 1862, he attained an altitude of 10,500 feet, although on neither occasion did he approach anywhere near the snow. He made, however, an admirable survey of the whole southern slope of the mountain, which is still and has been our chief authority for the delineation of Kilima-njaro on the map. His researches were rather added to than superseded by the journeys of Thomson and myself. Von der Decken calculated the height of the two great peaks, Kibô and Kimawenzi, and considerably reduced the exaggerated estimate of their respective altitudes. He, however, erred slightly in under-estimating the height of Kibô, which he gives as only 18,700. My own observations make it 18,800, and Thomson gives it as 18,880. Von der Decken (still traditionally known on the mountain as the "Baroni") received the gold medal of the Royal Geographical Society for his careful surveys of Kilimanjaro and its vicinity.

In 1871, the Rev. Charles New, a missionary, who had been sent out to East Africa by the United Methodist Free Church Mission, made a journey to Moši, in Čaga, and thence ascended Kilima-njaro to the verge of the snow, reaching an altitude of about 14,500 feet. He spent the month of August on the mountain, but did not go over much new ground. Encouræged by his pleasant experiences during this trip and filled with a craving for further exploits in the same field of fascinating mystery, he returned to Čaga two years later, with the intention of pursuing 
his investigations. But this time his former host, Mandara, chief of Moši, disappointed in the quantity and quality of the presents brought to him by $\mathrm{Mr}$. New, robbed the explorer of nearly all he possessed, including his gold chronometer (given him by the Royal Geographical Society) and his silver aneroid. Then poor New, broken-hearted, and sick with anxiety and fatigue, turned his steps towards the coast, and died ere he reached Mombasa. I have an impression from what Mandara himself has told me, that his animosity and rapacity were aroused with respect to New by the latter's too vehement and perhaps injudicious harangues against slavery. Mandara declared that Mr. New had incited openly his subjects to rebel against him, but this I think highly improbable. It is possible that the missionary inveighed against slavery in such a way that Mandara dreaded lest his utterances should have the effect of arousing his serfs to a wish for freedom, and that he therefore robbed him and cast him out of his kingdom. This view of the case is supported by the accounts given by an old friend of New's, Kapitau, an intelligent and pleasantmannered coast trader, with whom I have had much conversation. This man retains an earnest respect for the missionary, and accuses Mandara of having wished to poison him.

After New's death, Kilima-njaro remained unvisited until quite recently, when, in 1883, Mr. Joseph Thomson arrived there, on his journey across Masai-land. He also visited Mandara, and was also robbed by that rapacious chieftain. Starting from Moši he ascended to an altitude of nearly 9000 feet, made a small collection of plants, and pursued his journeys, which ultimately led him nearly all round the base of the 
mountain. Mr. Thomson was the first who saw the northern aspects of Kilima-njaro.

I might also mention that Dr. Fischer, a German traveller, passed within some thirty miles of Kilimanjaro a little while before Mr. Thomson. He subsequently penetrated Masai-land as far as Lake Naivaša.

All these above-mentioned travellers had paid visits of a more or less fleeting character to Kilima-njaro, and few had studied in any way its natural history, or had attempted to make collections of any importance. Von der Decken brought back some beetles and one or two plants. New gathered and sent home a few specimens of the flora growing on the upper slopes. Dr. Fischer introduced us to a new Touraco ${ }^{5}$ dwelling in the vicinity of the mountain, and Thomson in his hurried ascent procured some twenty plants, nearly all of which were new to science. But in the main little of the flora or fauna of Kilima-njaro had been made known, and the object of my mission was to make collections which would materially aid us in settling the relations which this clump of mountains bore to other lofty African ranges in its peculiar forms of life. 'The Kilima-njaro Committee, taking into consideration the peculiar difficulties of African travel, hesitated to send out on this expedition any one who, though a trained naturalist, should yet have had no previous experience of the climate and mode of life in the dark continent; and although I professed little skill or capacity in natural history collecting (for you may be enthusiastically fond of the study of botany and zoology, and yet be a very poor taxidermist or herbalist), it was thought that my acquaintance with the 5 Turacus Hartlauli. 
difficulties of African expedition and the exigencies of travel in a barbarous country would enable me to conduct the expedition to Kilima-njaro with some chance of success. Unfortunately the sum of $1000 \mathrm{l}$. placed at my disposal, although sufficient with due economy to meet the ordinary expenses of the expedition, would not permit of European collectors being taken, the cost of the passage-money, salary, and keep of two men amounting to nearly half the sum already mentioned. However, this difficulty did not much concern me at the time, as one or two collectors were promised from the Calcutta Botanical Gardens, whose expenses would have been defrayed by their employers in return for a set of specimens collected. But on arriving at Zanzibar I was disappointed of their aid, for it was found at the last moment impossible to induce any Indian collectors to join an expedition to Central Africa. Consequently I had to depend on the chance aid of such natives of Zanzibar accompanying my caravan as might evince any taste for a collector's duties. Sir John Kirk, indeed, procured for me two men who had been with Dr. Fischer during his recent expedition, and who had an elementary knowledge of drying plants and skinning birds; but these men, on account of their superior attainments, were so exacting and difficult to deal with, that when they deserted me soon after my arrival on the mountain and went to a neighbouring chief to organize his slave-trading caravans, I did not miss them keenly. Nevertheless, after this, the entire charge of collecting fell upon me, adding to the already existing and by no means perfunctory cares of superintending the expedition. I not only had to conduct long and wearisome palavers with native chiefs, and talk them into acquiescence 
with my plans, I not only had to show the men how to build houses, where to construct roads and bridges, and lay out plantations, but I must also shoot and skin birds, gather and press plants, collect beetles, and catch butterflies. In a moist climate like that of Kilima-njaro the labour involved in making good botanical collections alone was very great, and in all this I had no help. My Zanzibar porters, although excellent, hardworking, faithful fellows, evinced no aptitude whatever for natural history collecting. In spite of my repeated and painstaking instructions, they would bring me flowers without leaves, and leaves without flowers. They preferred catching butterflies with their fingers to using a net, and thought that an insect in fragments was quite as satisfactory as a whole specimen. In short I found that if any work was to be of use in collecting, it must proceed solely from my own efforts. I merely mention these difficulties so that my readers may properly appreciate the character of the task I was called on to perform.

The instructions given me by the Kilima-njaro Committee were to proceed direct to Mount Kilima-njaro, reside in the vicinity of the mountain for at least six months, and collect as much as possible near the snowline. As already mentioned, funds to the extent of 1000l. were granted me, and besides that, the Royal Geographical Society generously provided me with a complete set of instruments for making astronomical and meteorological observations. I ought also to mention that Messrs. Howard and Son made me a most liberal present of quinine, an item of the outfit which would have amounted under ordinary circumstances to a considerable expense, and other leading purveyors treated me with great generosity, so that I was altogether most kindly supported in my under- 
taking. Having previously despatched my heavy luggage by British India steamship, I left London in the beginning of March, 1884, and travelled overland to Egypt, spent a week or two rambling about the highways and byeways of that unhappy land, joined my steamer at Suez, and quitted her at Aden with heartfelt joy, after a horribly uncomfortable voyage of eight days. At Aden I had a delightful experience of what British hospitality can do to cast a halo round the most unattractive spots. At the house of the Resident and Governor, General Blair, V.C., I spent a most enjoyable interval whilst awaiting the Zanzibar steamer.

I somewhat dreaded the advent of this vessel, for after my experience of cockroaches, rats, bad smells, and bad food in the steamer which had carried me to Aden, I anticipated a renewal of this purgatory on board the steamship of the same company which was to complete the journey to Zanzibar. But this was fortunately not the case. The Java, though an oldfashioned and not too speedy boat, was scrupulously clean, and her staff of officers were all that could be desired in kindness and skill. The fare was excellent, the weather perfect, the fellow-passengers few and agreeable; and our journey to Zanzibar was more like a trip 'on a friend's yacht. We stopped at Lamu, and lunched with Lieutenant Haggard, her Britannic Majesty's vice-consul, and then at Mombasa, where I went off for a lengthy conference with Captain Gissing, our vice-consul at that port, who was already kindly interesting himself in the equipment of my expedition, and engaging porters from the vicinity of that place to accompany me, for it was considered best by Sir John Kirk that I should start from Mombasa for Kilimanjaro. After my first brief visit to the place, however, 
I continued on my way to Zanzibar, to confer with Sir John Kirk, and to engage a certain number of men. Accordingly, one day in the middle of April, 1884, I awoke in the early sunshine, and looked forth on a crescent of white buildings rising above an irregular line of black shipping and black mud, and later on in the day landed at Zanzibar, and found myself in that busy mart of East African trade, whence so many expeditions and explorers have started for the conquest of Africa's secrets. Here I was soon enjoying the kind hospitality of Sir John Kirk, and feeling in the contemplation of the strange, varied life around me that the first chapter of my experiences in East Africa had pleasantly begun.

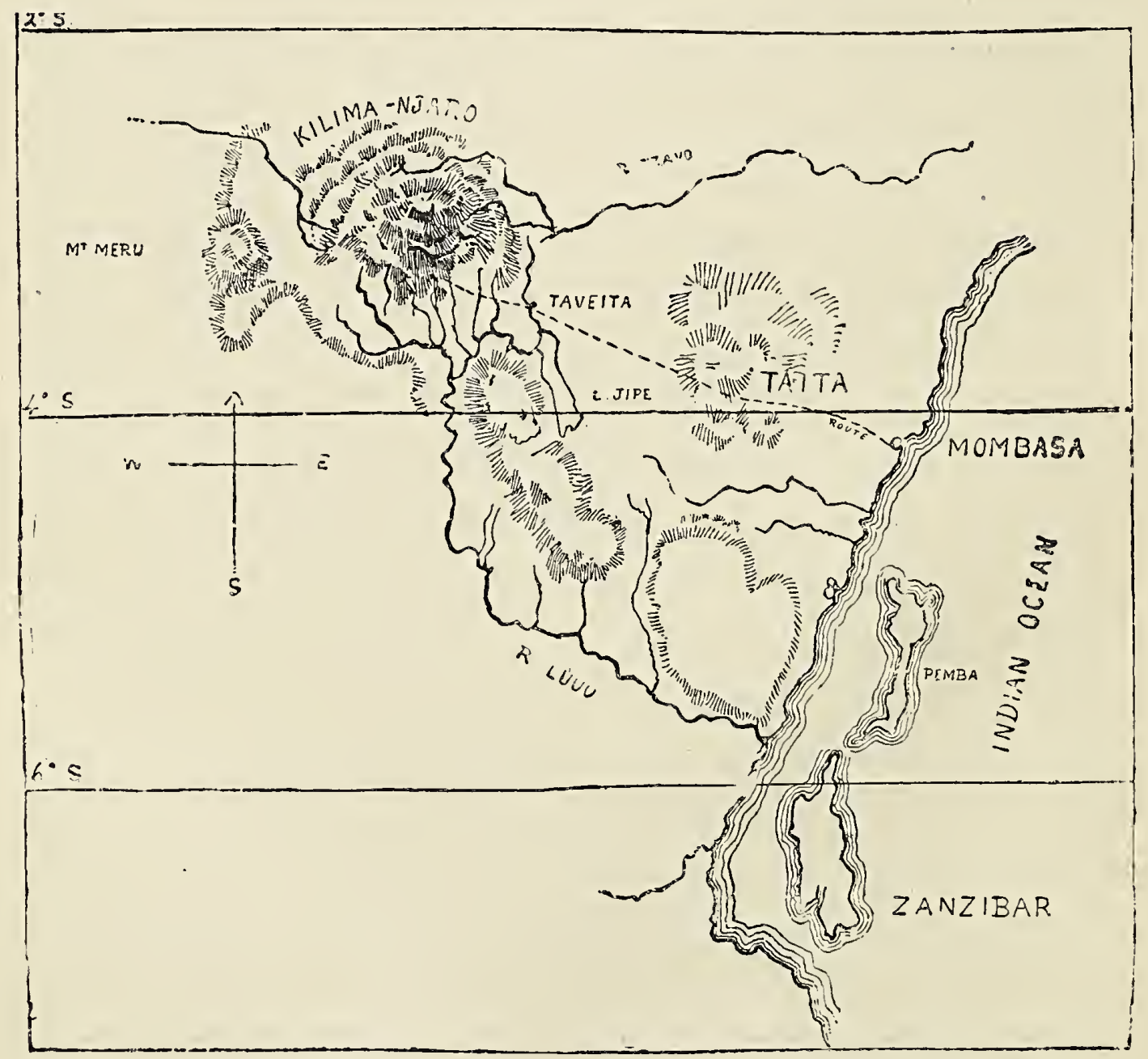

Map 2.-Route to Kilima-njaro. 


\section{CHAPTER II.}

SIR JOHN KIRK AT HOME.

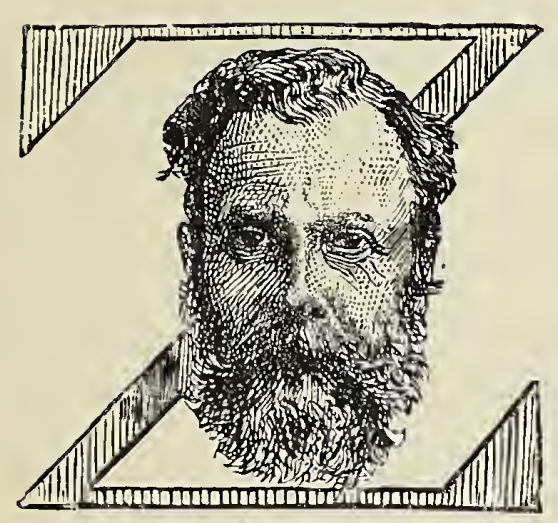

Fig. 1.—Sir John Kirk.

ANZIBAR, an island lying about twenty miles off the East Coast of Africa, under the sixth parallel south of the equator (I feel bound to furnish this information in the prevailing state of ignorance respecting African geography), has long been a nucleus of foreign rule along the eastern seaboard of the Dark Continent. Without going into the questions of its remote history, and considering whether it was or whether it was not distinctly known to the hazy geographers of classical days, we can feel pretty certain that, for nearly as many centuries as form the Christian Era, Zanzibar has been a place of resort for the Arab and Persian traders and slave-dealers of the Red Sea, the Persian Gulf, and the coasts of Sind and Gujerat. There was at one time a distinct Persian colonization of the East African littoral to the north of Zanzibar, and apparently also in Zanzibar itself, though here the intermixture of Persian blood in the local race is in no way as evident as in places on the mainland, such as Lamu, Malindi, or Magdishu. However, even in 
Zanzibar, distinct traces of Fire Worship remain engrafted on the African Mohammedanism of the inhabitants. After several centuries of quasi Arab rule, Zanzibar in the beginning of the sixteenth century came under the dominion of the Portuguese, whose language has left its traces in the Swahili vocabulary. When Portugal fell into the power of Spain, and her hold on Abyssinia and the Eastern Horn of Africa waned and faded, the Arabs reasserted their independence in Zanzibar, and the island remained in the possession of various Arab chiefs till the end of the last century, when the Imam of Maskat proclaimed and maintained his suzerainty over Pemba, Zanzibar, and the neighbouring coast.

In 1841, the East India Company first established relations with the ruler of Zanzibar, who had assumed the title of "Sayyid," or Lord of the Island. He was at the same time Sovereign of 'Oman, that East Arabian principality of which Maskat is the capital. Lieut.-Colonel Hamerton, the first British representative at the Court of Zanzibar, remained many years at his post, and was still in East Africa when Burton undertook his pioneer journey to the Lake regions. On his death General Rigby succeeded him as ConsulGeneral and Political Agent, and was in turn followed by several officials whose residence in the island was of short duration. At length, in 1873, Sir John Kirk, who had first come to Zanzibar as Vice-Consul in 1866, and who had for some years acted in a superior capacity, received his formal appointment to the post of Consul-General, and later on attained the further office of Political Agent. Sir John Kirk, who comes of an old Forfarshire family, was educated primarily as a doctor, and served as a physician to the British 
hospital at Renkioi, Dardanelles, during the Crimean War; but already, both at the University and during his serrice abroad, his taste and aptitude for natural history had so developed that he little cared to make the medical profession his ultimate career. In 1858 he accepted the post of naturalist to Dr. Livingstone's expedition to the Zambesi. When he arrived at the mouth of this river, the circumstances of the expedition were such that it became necessary for Dr. Kirk (as he then was) to lay his studies of natural history aside, and assume the arduous position of second in command, and direct personally the conduct of the land party. It was largely owing to his exertions and untiring labour that the unfortunate Zambesi Expedition was not an even costlier experiment than it eventually proved; and Dr. Livingstone found in his colleague and second in command a mainstay and help in several critical emergencies wherein the rest of his staff were of little service.

Shortly after his return from the Zambesi Dr. Kirk was offered the post of Vice-Consul at Zanzibar, and thus entered the service in which he rose successively to the ranks of Consul, Consul-General, and Political Agent. In 1878 he was made C.M.G., and in 1881 he was knighted.

There is no one living or dead who has so profoundly influenced the condition of Eastern Africa as Sir John Kirk. To him more than to any one else is owing the effective repression of slave-trading; and it is only quite recently that the full consequences of his steady anti-slavery policy began to appear and develop themselves into a healthy and beneficent solution of a difficult African problem. When Sir John first arrived in Zanzibar the Arab ruler of the island, the so-called 
Sultan, was little more than primus inter pares. He waś recognized as "Sayyid," or Lord, of Zanzibar, by the Arab nobles and traders, but his authority was most uncertain. Many of his subjects thought themselves superior to him in purity of blood and ancient genealogy, and whenever the wishes of their nominal ruler-merely one of themselves deputed to transact the Government business-clashed with their personal interests or predilections, they openly bade him defiance, and put their fortress-houses into a state of siege. The standing army was composed of a few miserable, beggarly Baluch mercenaries-ill-clothed, unpaid, and as cowardly as they were rapacious. Slaves were openly sold in Zanzibar, and the Sayyid was too weak to incur the displeasure of his Arab subjects by the suppression of a lucrative and easy trade. When Sayyid Majid died and the present "Sultan," Barghash bin Sa'id, succeeded him, Sir John Kirk set himself resolutely to acquire the confidence and friendship of the young Arab ruler, and, aided by his great knowledge of Arabic and Ki-Swahili, was able to converse with the Sayyid in strict intimacy, without the medium of an interpreter, so that he was enabled often to weld the will of Barghash to conformity with his own wishes by means of an earnest expostulation and half-playful sarcasm which would have sounded ill through the intermediary of some wily Goanese. So great was the influence already exercised over the Prince of Zanzibar after two years of personal intercourse that Sir John Kirk was able to exact from him as a favour and concession to friendship that which Sir Bartle Frere, with all his personal prestige and position, and with a fleet of ironclads behind him, failed to extort, namely, the 



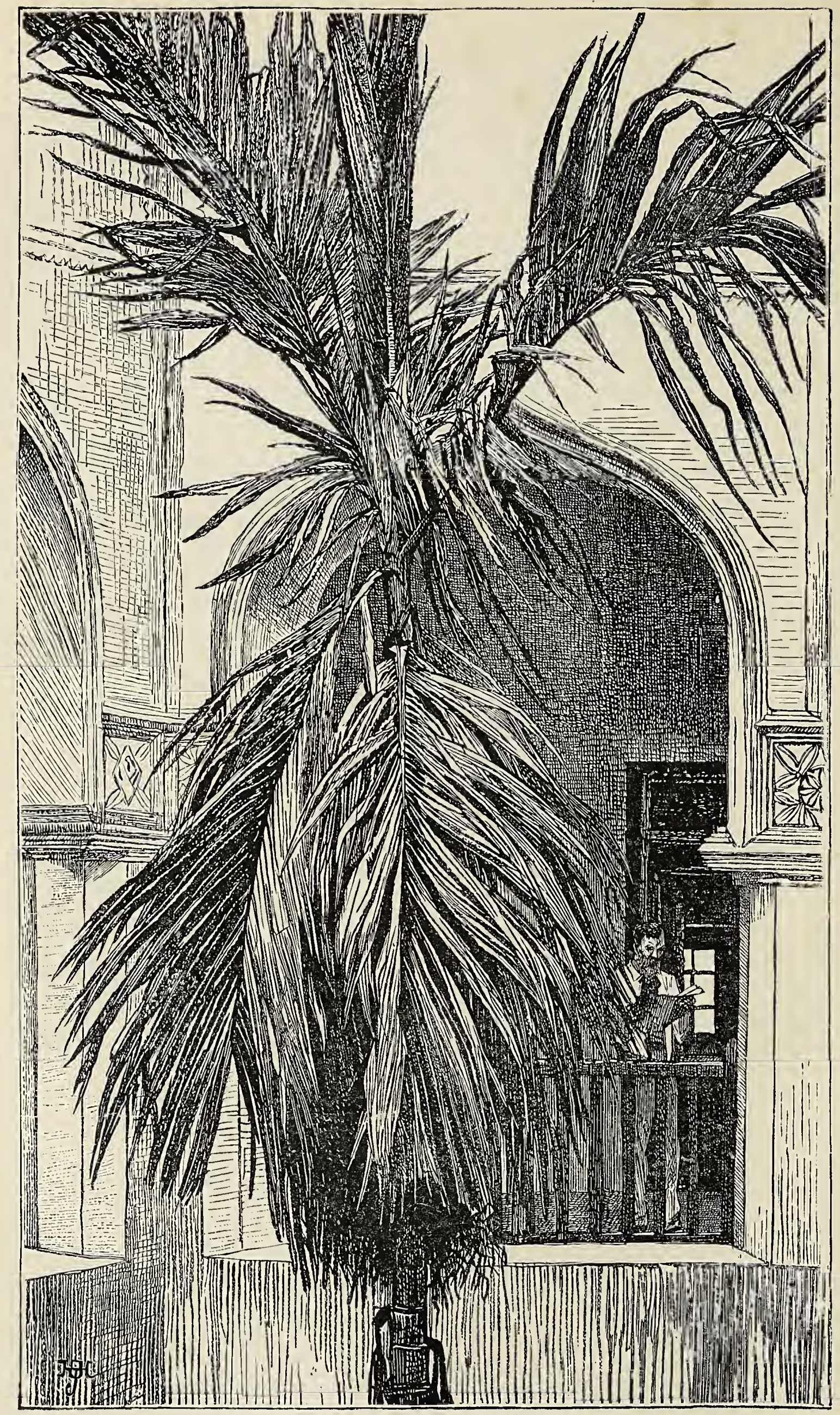

SIR JOHN KIRK AT HOMF.

'To face page 21. 
Sayyid's signature to a treaty for the suppression of the East African slave-trade. This, though refused under threats of bombardment, was granted after a few hours' conversation with Sir John Kirk, and the treaty, which during Sir Bartle Frere's mission had been persistently rejected by the "Sultan," was signed and sealed within a few hours after the envoy's departure, and overtook him in a rapid despatch-boat before he reached Aden. An amusing incident is recorded of Sayyid Barghash during the séance of deliberation which took place before he signed the treaty. Sir John Kirk was explaining to him the terrors and inconveniences of a blockade, how all supplies of provisions would be stopped, and the island reduced to starvation, and he wound up his effective picture by asking the "Sultan" what he would do then? "Why," said Sayyid Barghash, "I should just come and live with you, Consul."

It is owing to our present representative in Zanzibar that the Sultan has gradually assured and strengthened his hold over the East African coast between the Portuguese northern boundary and the No-man's Land of the Somali Deserts, thus keeping in hands friendly to England the richest coast-lands of East Africa and the trade-routes to the Central Basin. Sir John Kirk has little disguised his views about English influence in the Indian Ocean, and he steadfastly bears in mind that nearly the entire commerce of Eastern Africa is in the hands of British subjects, and that, to uphold our influence in the country, we should encourage to the utmost the thrifty settlers from Western India. $\mathrm{He}$ also feels, as any observant politician must, that much as we may admire and sympathize with the promptings to colonization which, like the desire for offspring late 
in life, are now animating so many old European nations, there is no reason why England should act as a political midwife, and assist in bringing to birth their late-born children, or neglect the wants of her own large family in order that her neighbours' weaklings may not die of inanition.

One of the firmest resolves of Sir John Kirk has been to keep Eastern Africa between $10^{\circ} \mathrm{N}$. and $10^{\circ} \mathrm{S}$. clear of foreign influences, and so to hold this littoral through our nominee, the present Sayyid, that whenever the cold fit shall be off and the hot wave of further colonization flow on again-whenever the irresistible spreading of the English people compels it to look towards fresh fields of enterprise-Zanzibar, city, island, and coast, may not be found in hands hostile to British trade. To Sir John Kirk alone we owe it that the Government of Portugal has not now included the important

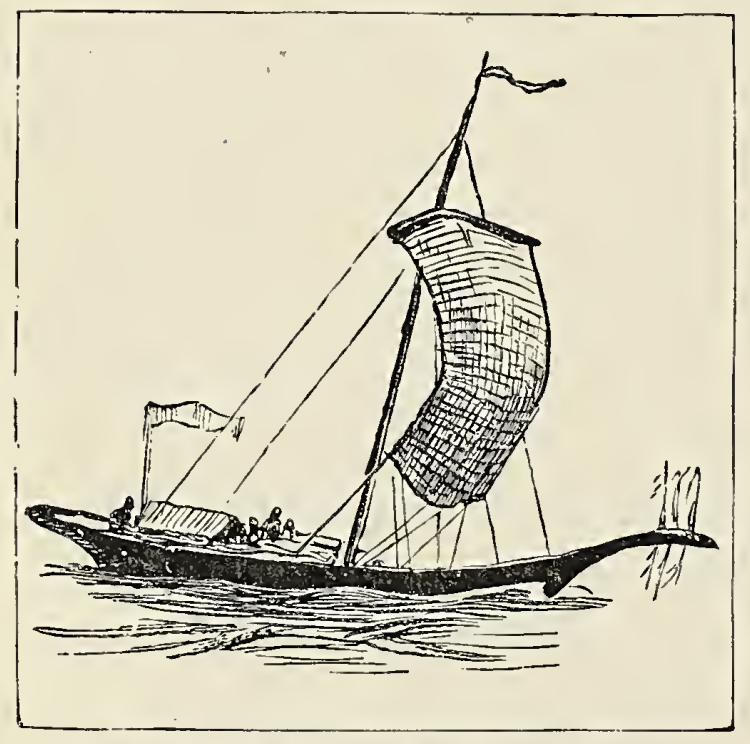

Fig. 3.-Mtépé (with mat sail). Rovuma river in its East African possessions; and the same person is responsible for having, with one English frigate, driven away the whole Egyptian fleet under McGillup Pasha, when, acting under secret orders from the Egyptian Government, the Khedive's East African Expedition proceeded to annex, occupy, and fortify the principal ports in the Sayyid's continental dorninions. About the manifold checks that French ambition and "protecting" zeal ${ }^{1}$ have received

\footnotetext{
${ }^{1}$ In remarks of this character I do not wish it to be supposed that
} 
in these Zangian regions I need not dilate, as they are questions involving political feelings of some acerbity at the present time, and would therefore be out of place in this book. But I might further recall to my readers that it is to the personal exertions of the British Agent and Consul-General that Zanzibar owes its line of telegraph, its mail service, its hospital, its observatory, its standing army (officered and commanded by Englishmen), its horticultural development, its projected sanitary reform, and possibly also the scarcely less precious introductions of lawntennis and afternoon tea.

The British Agency and Consulate-General in the town of Zanzibar is a handsome Arab house standing towards the southern end of the city, and just overhanging the sea, which at

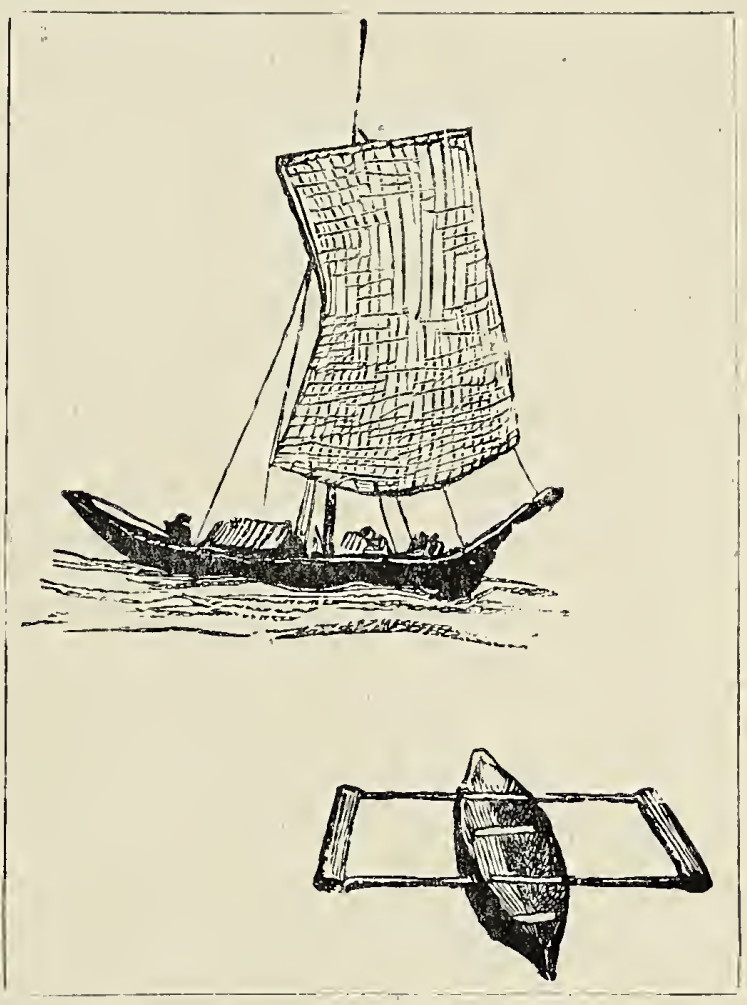

Fig. 4.

Small Mtépé and Outrigger Canoe. high tide lashes its protecting wall. The style of exterior and interior is purely Arab, or, to use a more

while ardently admiring all British officials who have but one singleminded purpose, viz. that of straining every effort to secure peculiar advantages for the power and commerce of their own country, I am hypocritical enough to think it immoral and unjust when the same object is held in view by the servants of foreign powersFrance, Russia, Germany, and the like. From their point of view they are acting quite rightly and deserve every credit from their fellow-countrymen for their determined efforts to thwart our healthy appetite, which must seem like greediness to them. Every one for himself. Self-denial only creates selfishness. 
accepted term in architecture, Saracenic. Entering from the narrow streets an iron gateway, you come into the grateful shade of a small garden, planted with spreading mimosas, cocoa-nut palms, and mangoes, and through the interstices of the foliage you look up at the high grey-white walls of the house, which are scarcely relieved in their monotony by the small and shuttered windows. The doorway is regularly Eastern, quite a "Sublime Porte" in miniature. Broad, shallow steps lead up to it, forming an admirably-arranged mise-en-scène for the grouping of white-clothed "Sikari" (consular guards) and Indian suppliants in gaudy costumes. The frame of the door, which is itself garnished with immense copper nails, is delicately and intricately carved in black wood, with arabesque designs and letter scrolls.

Entering here, you come upon a small recess, with ogival niches round the walls-a sort of anteroomand from this a winding staircase ascends to the firstfloor, when you find yourself in the interior gallery surrounding the four sides of the patio, or hollow square, which is the ground-plan of most Saracenic buildings. From the centre of the patio rises a graceful areca-palm, which contrasts pleasingly with the formal arches of the gallery. The house ascends to several storeys, and is surmounted by flat terraces of varying height; but round the patio, on the first-floor, the principal dwellingrooms are ranged. These are all Arab in characternarrow, high-pitched, lighted with little windows with deep embrasures. The walls are dead white, cut into by false arches of slightly horse-shoe shape, forming alternate recesses wherein shelves of pottery, bookcases, or cabinets may be placed. Within the arches, too, are further niches, cut deeper into the wall, with 



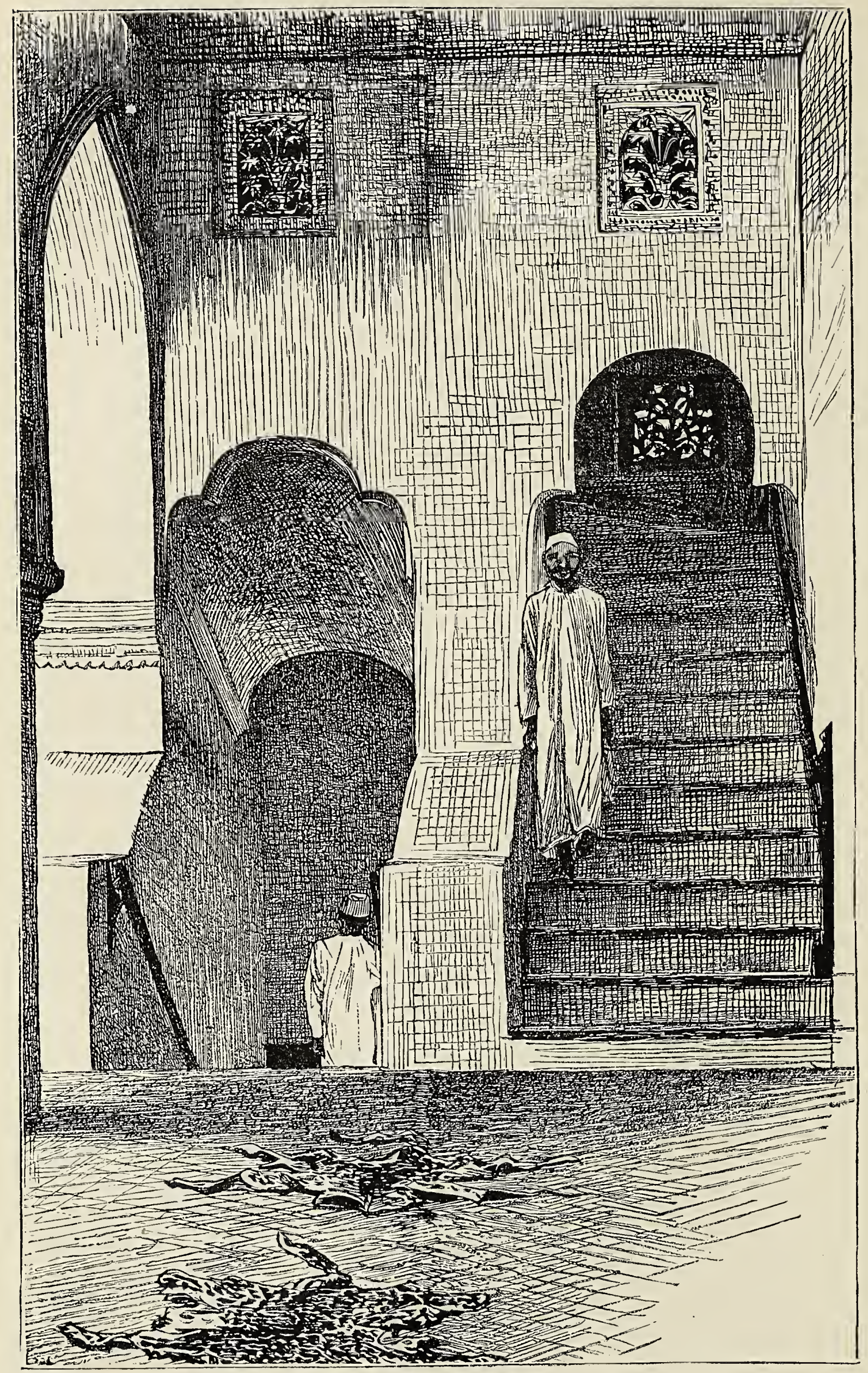

A CORRIDOR IN SIR JOHN KIRK'S HOUSE.

To face page 25 . 
a carved stone tracery at the back to let in air. These give an effect of lightness to the somewhat massive walls, and the little points of light gleaming through the windows of cut stone act as a point de mire in each recess. There are no pictures on the walls; nothing but coruscations of Oriental pottery, all of it got from Zanzibar and the neighbouring coast. The amount of beautiful Persian, Moorish, and even Chinese pottery and porcelain to be found in Zanzibar is really surprising. Much of it is hoarded up by old Arab families, who have kept it for generations in their households, and it only sees the light in occasional bankruptcies and auction sales. On many parts of this Zangian coast pottery is fastened into the walls of mosques or plastered on to tombs, whence-I say it with regretEuropeans do not hesitate to "loot" it, under the pretext that if they do not the degenerate descendants of the Oriental settlers will. At places like Lamu the most tasteful Persian porcelain, rich in colour and very old, was to be easily picked up but a short while ago, though the sudden rush of greedy travellers has diminished the supply. Much of this Persian pottery-great bowls of gorgeous tints, blue and gold plates, vases and cups-decorate the walls of the Consulate, and lend colour and brightness to its apartments.

The windows of two sides of the house look forth on the sea, and command the entire harbour. All the shipping becomes a study of ever-changing colour and form. The great black hulks of the steamers, surmounted by their tall masts and funnels; the snowsails of the daus coming into port; the "mtépé," or native barque, with a huge sail made of matting; the dismantled daus, with their brown rigging and masts and folded sails, lying at anchor in the blue still water : 
and the multitude of tiny craft, canoes with outriggers, and the canoes that are simple dugouts - all these form, together with the flags

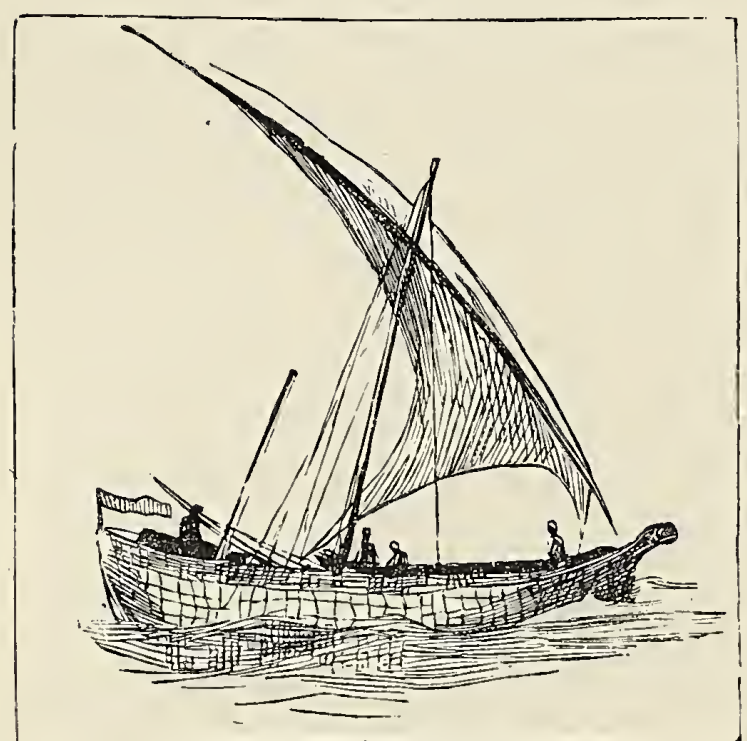

Fig. 6.-Arab Dau.

of many nations and the bright costumes of the native sailors, the blue sky, with its rolling cumulus-clouds, the placid sea, and the green islands on its horizon, an infinitely diversified panorama, rather than a picture, but a cheerful scene, full of bright activity, and a pleasant field of contemplation to an idle man in a rocking-chair on a shady balcony, who is able to rest inactive in his cool retreat, and watch the busy work going on around him.

If you look from the verandah of the Consulate towards the town of Zanzibar you have a scene of much picturesqueness and colour, and one which, focussed and framed by the latticework that is hung with creeping plants, becomes a real picture. You see the ships in the harbour, the canoes and rowing-

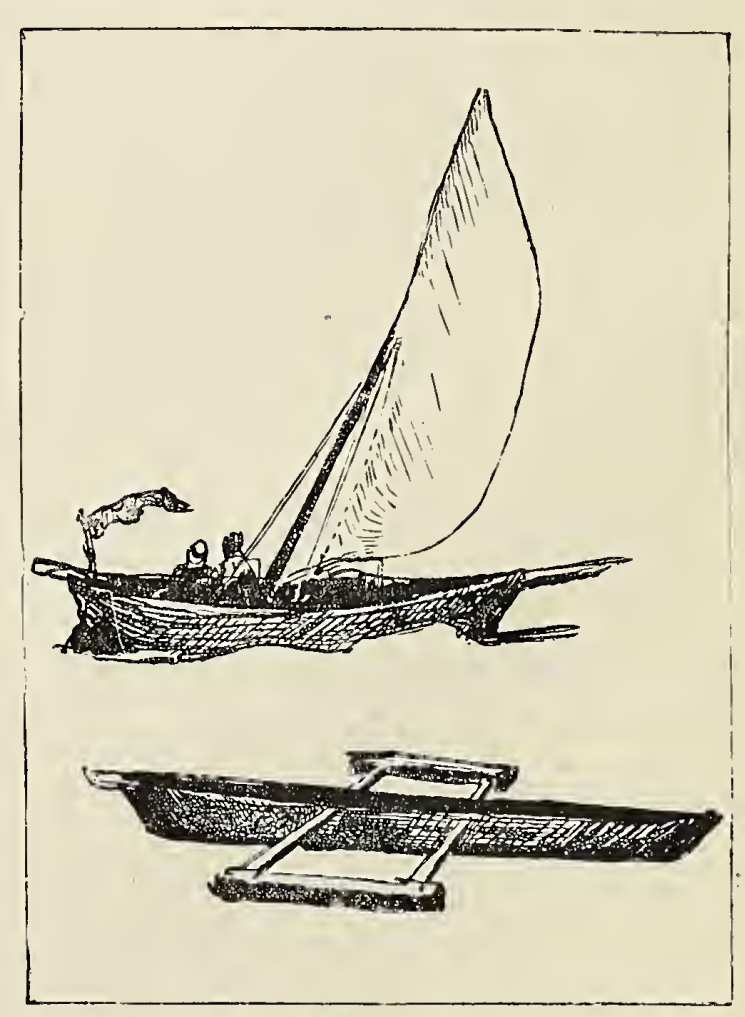

Fig. 7 .

Fishing Boat and Outrigger Canoe. boats skimming in and out among the large vessels, 
then lines of daus all drawn up along the shore of white sand, with busy crowds of men working round and about them, some unloading, some repairing, some looking idly on, others stripping for a bathe and playing at a peculiar game in the water, round the hulls of the half-floated daus, which consists in turning a somersault and bringing your legs down with a smack on your companions' backs. Indeed, the

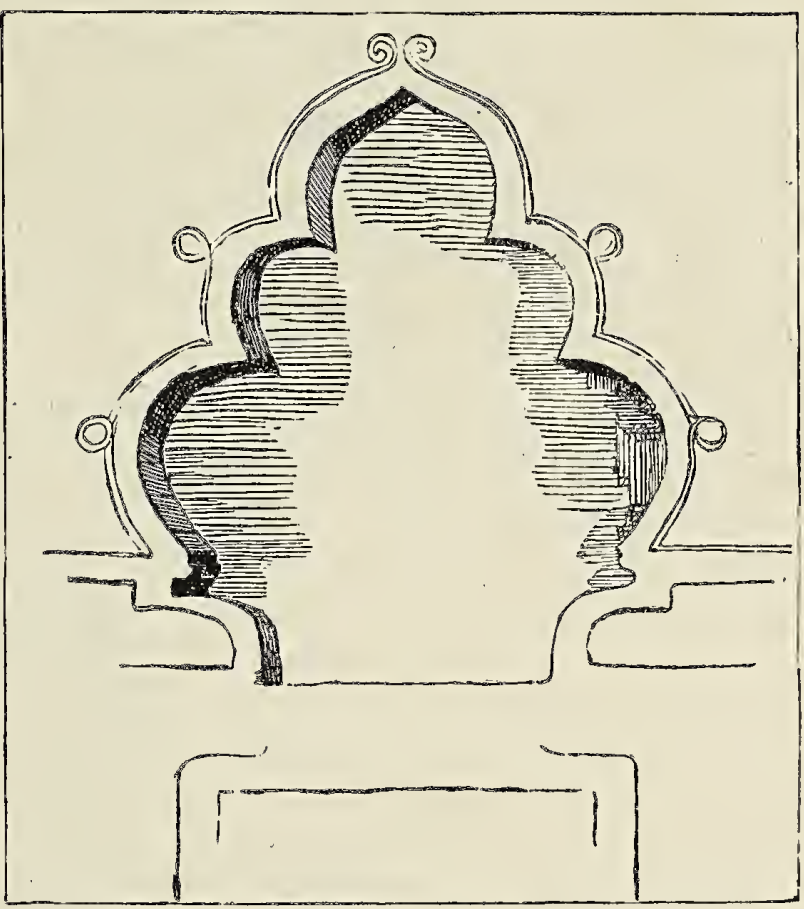

Hig 8.-A Saracenic Duorway. absence of all social restraint on the shore at Zanzibar might occasionally ruffle the sensibilities of those of our weaker sex who are supposed to be shocked at seeing life under somewhat primitive conditions. There are no "bathing regulations" at Zanzibar, and the beach immediately below the Consular windows is the favourite resort of " natives," who in complete nudity gaily chase each other along the silver strand, or plunge into the tiny billows and the black ooze of the nether shore. Indeed, the number of Indians who seem to choose the purlieus of the British Consulate for performing their ablutions (doubtless because they look upon it as a right of British subjects to bathe under their Consul's eye) render it necessary sometimes to despatch a Sikari for the purpose of driving the nude Hindoos to remoter shores, for should the Consul be entertaining the lady residents of Zanzibar 
at afternoon tea on the balcony, it is somewhat embarrassing for their gaze continually to encounter, not the black glistening forms of the burly negroes on whom nakedness sits with decency, but the yellow and obese Hindoos, who, with the figures and demeanour of middle-aged aldermen, are paddling up to their ankles with the innocence and unconcern of early childhood.

The buildings of Zanzibar along the shore-line are gifted with an adventitious beauty which is derived

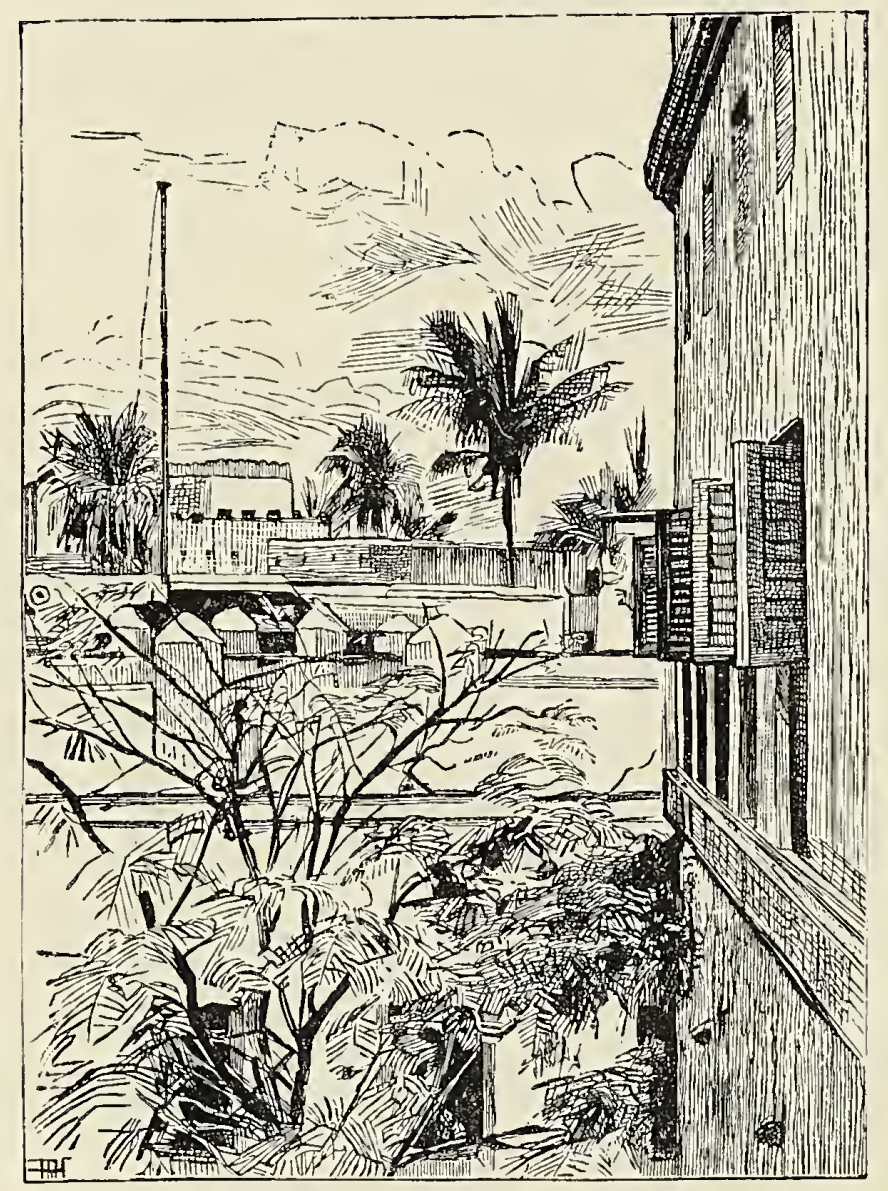

Fig. 10.-A View over the Housetops. from contrasts of colour, and light, and shade. The Sultan's clock-tower, which rises like a minaret above the flat-roofed houses, is in reality a structure of vulgar, tasteless design, but seen from a distance with its ugliness softened down, it lends considerable point to the harbour view of Zanzibar. The other buildings are little remarkable for elegance of exterior shape, but, being all whitewashed or of light-coloured stone, they form under the sun's rays a snowy, irregular mass, the outline of which tells out effectively against a deep blue or a storm-grey sky, and is here and there relieved by the green coco- 


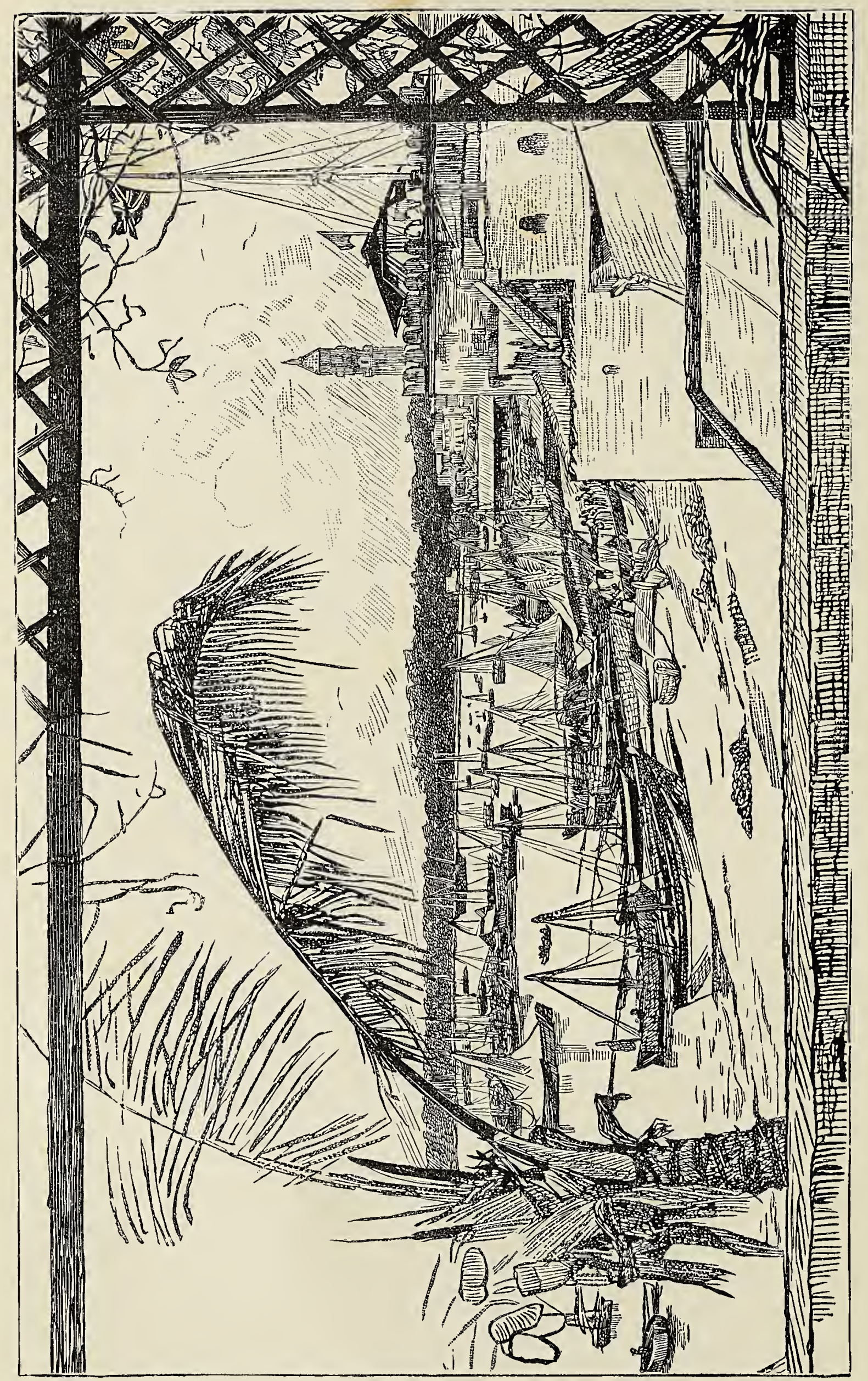

i 
palms or the flags of the Sultan's palace and the different Consulates.

This view at sunset becomes really beautiful. The eastern sky is a sombre blue-grey, and the water of the harbour reflects the same tint, unvaried in the evening stillness by a ripple. The long headland of dark green forest, which stretches out into the sea, lends a deepening tone to the darkened water and sky, and forms with them an effective foil, a neutral background to the white tower and the mass of white buildings which, turned towards the west, reflect on their sympathetic surfaces the warm glow of the sunset. In the daytime, under the blaze of a vertical sun, these houses of Zanzibar are disagreeably dazzling, but now, in this one quiet half-hour of the short evening, they glow with a soft pink radiance, and their tender blush-colour is heightened by its background of strangely-coloured eastern sky which, first becoming sombre blue with the sinking sun, for a brief while grows green with jealousy of the west and partial reflection of the sunset, and offers a complementary contrast to the houses at their pinkest. Then, along the shore, and on the blue bay, the shipping, turned towards the warm light of evening, loses its blackness and distinct outlines, and fuses into dusky brown, the mazes of masts and rigging seeming to part with their perspective and to stick together in one indistinct mass. As the shadows deepen and the rose-tinted houses fade into dull grey, the stages of the Sultan's tower are picked out with yellow lamps, and suddenly from the summit gleams out in cold radiance a star of more than first magnitude---Sayyid Barghash has fitted up his clock-tower with the electric light.

Any one visiting Sir John Kirk at home will hardly 
have set foot in his house many hours without remarking the arrival of an Indian gentleman in a suit of white clothes of half Asiatic, half European cut, with a magnificent gold-embroidered turban, a watch-chain, a ring, and an umbrella. This is Pira Doji, incorrectly known on board the mail steamers as "The Prime Minister of Zanzibar." He is really an astute Indian trader, who by his capacity for business and exceptional talents as a raconteur, has known how to obtain a very large share of the "Sultan's" confidence and esteem. Pira Doji is a most useful man to Sayyid Barghash. Without in reality attaining the position of Prime Minister or Grand Vizier (the Sayyid has no Ministers, and therefore rules cheaply), he has yet become a sort' of financial adviser to the Prince of Zanzibar, and is at the same time head-waiter at State dinners, man-of-business, negotiator in delicate matrimonial affairs, and the picker-up and retailer of all the town news. If Sayyid Barghash is mentioned in the Times, Pira forthwith goes to the "Sultan" with a copy of the passage scored round with red chalk. If a European resident in Zanzibar sprains his ankle, or beats his cook, the "Sultan" likewise hear's of it through the same source. Consequently all new arrivals at the Consulate become objects of interest to Pira, as likely to furnish "paragraphs" for his princely gossip. If ever a "Society" paper is founded in Zanzibar, it will have Pira Doji for its editor.

His Highness Sayyid Barghash having then heard of our arrival, and as much of our disposition, antecedents, present intentions, and future plans as Pira can glean from the Consul's household, it becomes incumbent on us to present ourselves, or get our 
Consul to present us, at one of the Sultan's Friday levées.

Drawn up before his tawdry palace (a ricketty building of many storeys, of no style whatever, and of execrable taste) is a smart-looking regiment of the New Zanzibar army, the men in white uniform, with red and yellow caps, and the officers in white trousers and magnificently embroidered tunics. At their head stands their organizer and Commander-in-Chief, General Matthews, who gives the order to present arms as the Consular party draws near. Then the Goanese band strikes up "God save the Queen," and we risk a sunstroke by walking through the serried ranks of soldiers with our helmets raised above our heads. In the entry to the palace more guards, Persian and Baluch, are assembled, and there are crowds of Arabs in gala costumes. Preceded by a kind of Master of the Ceremonies, we pass along corridors and apartments furnished in the Neo-Oriental (bastard French) style, and then ascend a strangely mean and poky staircase covered with scraps of faded kamptulicon. As we emerge on a small landing, coming up, as it were, from a stage trap, a tall, portly Arab leans over the stair-rail, and extends to each in turn a firm, plump hand. It is Sayyid Barghash come to greet his visitors half way; and though his cordial way of taking you by the hand and hoisting you up is merely a piece of formal courtesy, still it is of material assistance to you in emerging from the trap-like staircase. Preceded by the Sayyid, we are ushered into a long, narrow reception-room of Arab shape but later French decoration. Except for the fine Persian carpet which goes the whole length of the apartment, there is little to note that is pleasing to a critical eye. The furni- 
ture is red velvet and gilt wood. Round the walls are ranged medley assemblages of kitchen clocks, ormolu timepieces, aneroid barometers, thermometers, anemometers, telescopes, opera-glasses, musical-boxes, swords, spears, guns, pistols, toys of ingenious kinds, photographic albums, photographs glazed and framed and faded, and what not else. The upper end of the room, where the "Sultan" ordinarily sits, has a large mirror in the centre, and on either side of the mirror is a full-length oil painting of Sayyid Barghash. These two paintings are identical in every detail. They were manufactured in Paris. The Sayyid had a photograph taken of himself during his visit to London. It was in a sitting posture. He sent it to Paris with the order that it was to be enlarged standing, and then converted into two oil paintings. The Parisian artist, in no way at a loss, cut off the head of the sitting Sultan and stuck it on to the decapitated portrait of some Algerian Arab photographed erect. The combination was enlarged, and in due time gave rise to the two oil paintings in the palace at Zanzibar.

Sayyid Barghash bin Sa'id, the Prince of Zanzibar, Pemba, and the Zangian coast, is a man of about forty-five, as far as an Arab's age may be guessed. $\mathrm{He}$ is tall, somewhat corpulent, and not unhandsome. Were it not that his face betrays the traces of a too uxorious life, and that he has for some reason lately cut off his moustache and trimmed his beard to resemble an English tradesman's, he might even be called good-looking. His complexion is clear, his eyes large and fine, though faded with excesses, and his teeth white and perfect. The Sultan's feet are just of that ideal type that Sir Frederick Leighton loves to paint, and which, until I saw them peeping from 
Sayyid Barghash's sandals, I never believed to exist. The feet and hands of the Sultan of Zanzibar are the most beautifully formed I ever saw in a man, and he is justly proud of them; but alas! his symmetry ends at his ankles, for he is afflicted with elephantiasis-a not uncommon disease in Zanzibar, and his limbs are swollen and misshapen. Though he speaks no lan-

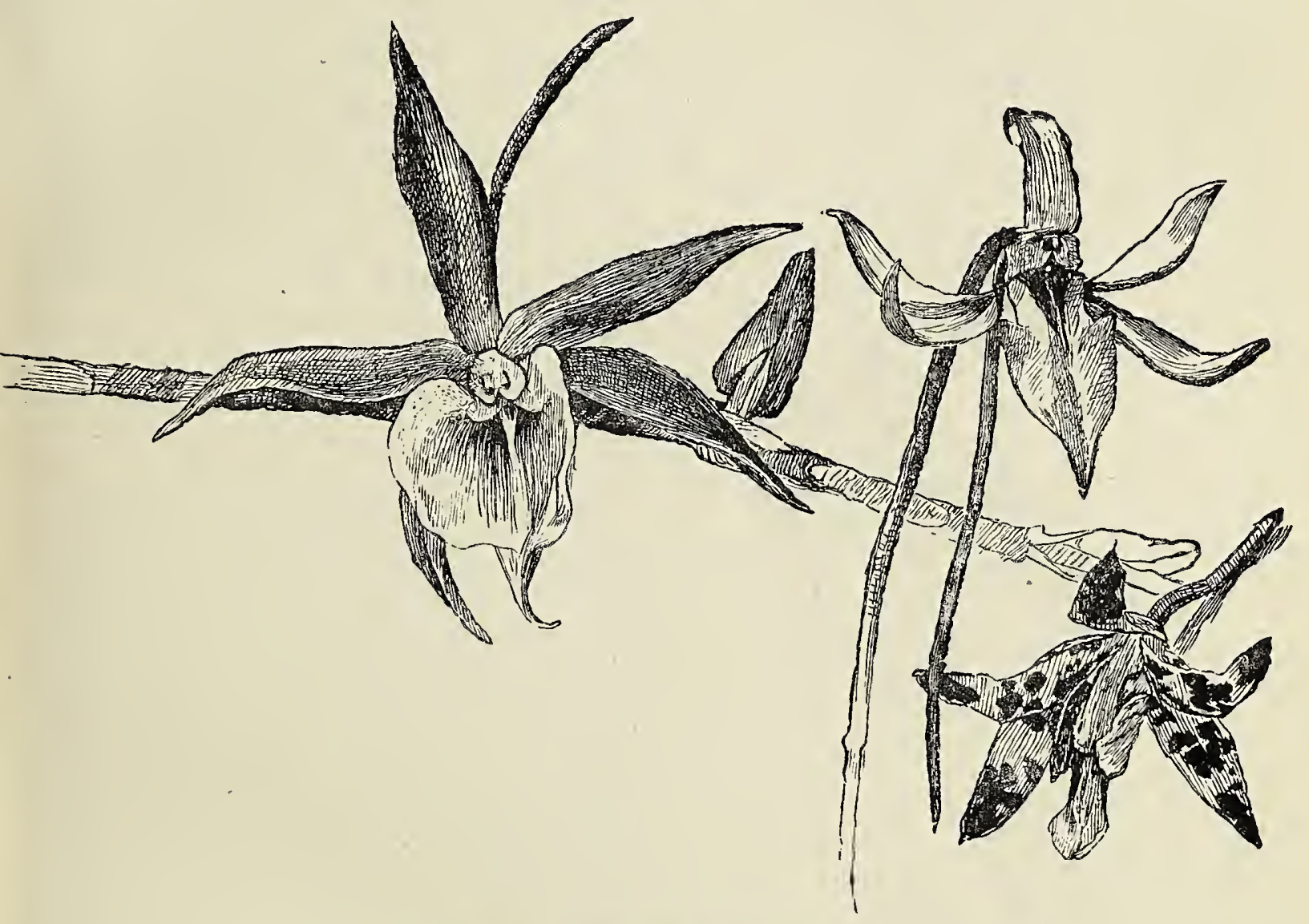

Fig. 11.-Zanzibar Orchids.

guages but Arabic and Swahili, he is a better-read man than many a contemporary Eastern Sovereign, and even aspires to the honours of an author.

One day four or five servants of the Sultan arrived at the Consulate, bearing about a dozen volumes of a work in Arabic. This was Part I. of a Digest of Mohammedan Jurisprudence written by the Sultan, and presented with his compliments to the British 


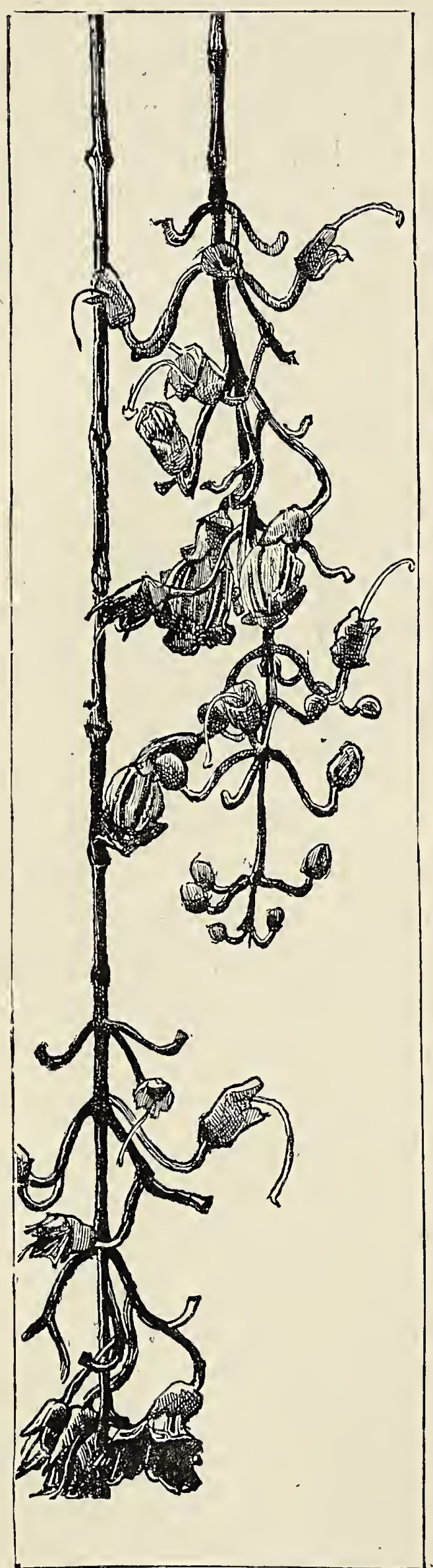

lig. 12.-Kigelia Africana.

Agent. In conversation, Sayyid Barghash is often sprightly, and all that he says is marked by intelligence and good sense. $\mathrm{He}$ is simple in his diction, for an Arab, and sometimes baffles verbose flatterers by his curt replies. I may remind my readers here of a little incident commented on at the time of the Sayyid's visit to England. At his first meeting with Lord Beaconsfield that statesman thought to set him at his ease by addressing him in somewhat high-flown Oriental parlance, and met him with the enigmatic question, "Which does your Highness prefer, flowers or jewels?" "I fail to see any connection between them," replied Sayyid Barghash in all simplicity.

An interview with the Ruler of Zanzibar, then, is not of that fade character which characterizes a ceremonial visit to most Oriental sovereigns. He poses you with many shrewd questions, and when the re- 
ception is over, the coffee and rose-sherbet drunk, and the Sayyid hands you down the well-like staircase, and you depart with the band playing "Rule Britannia," you feel that you have met a man who, had he received anything like an education, and had been trained by civilized ideas of morality to conceal, if not to bridle, his unruly passions, would have made no mean figure among the world's rulers and statesmen.

Sayyid Barghash is the son of the last joint ruler of Maskat and Zanzibar-Sayyid Sa'id. His mother was an Abyssinian woman. He has nearly a hundred wives and five or six children, one son only among them. He is brother to the present Imam of Maskat. His income is approximately $300,000 l$. a year, mostly derived from Customs duties.

Zanzibar, the chief town of his dominions, known as Unguja to the inhabitants, has a population of about 90,000. As regards trade it is the most flourishing and important place in East Africa, and the value of its exports exceeds at the present time 1,300,000l., of which ivory alone contributes $400,000 l$. The value of the imports is about $1,000,000 \mathrm{l}$., and they chiefly consist of cotton stuffs, kerosene oil, and rice. About 6,000 British subjects reside in the town, mostly Indians, and in their hands lie the whole retail and most of the wholesale trade.

The streets of Zanzibar are paved with a sort of coral "ray," sometimes cemented over, and are generally, from the nature of their paving, clean and inodoriferous. They are very narrow, and the houses in the Arab quarters are lofty, so that you may walk about most of the town in perfect shade. There are few really handsome buildings externally, yet many of the portals to 
the houses and mosques are gracefully designed in Saracenic style. Considerable Persian influence is

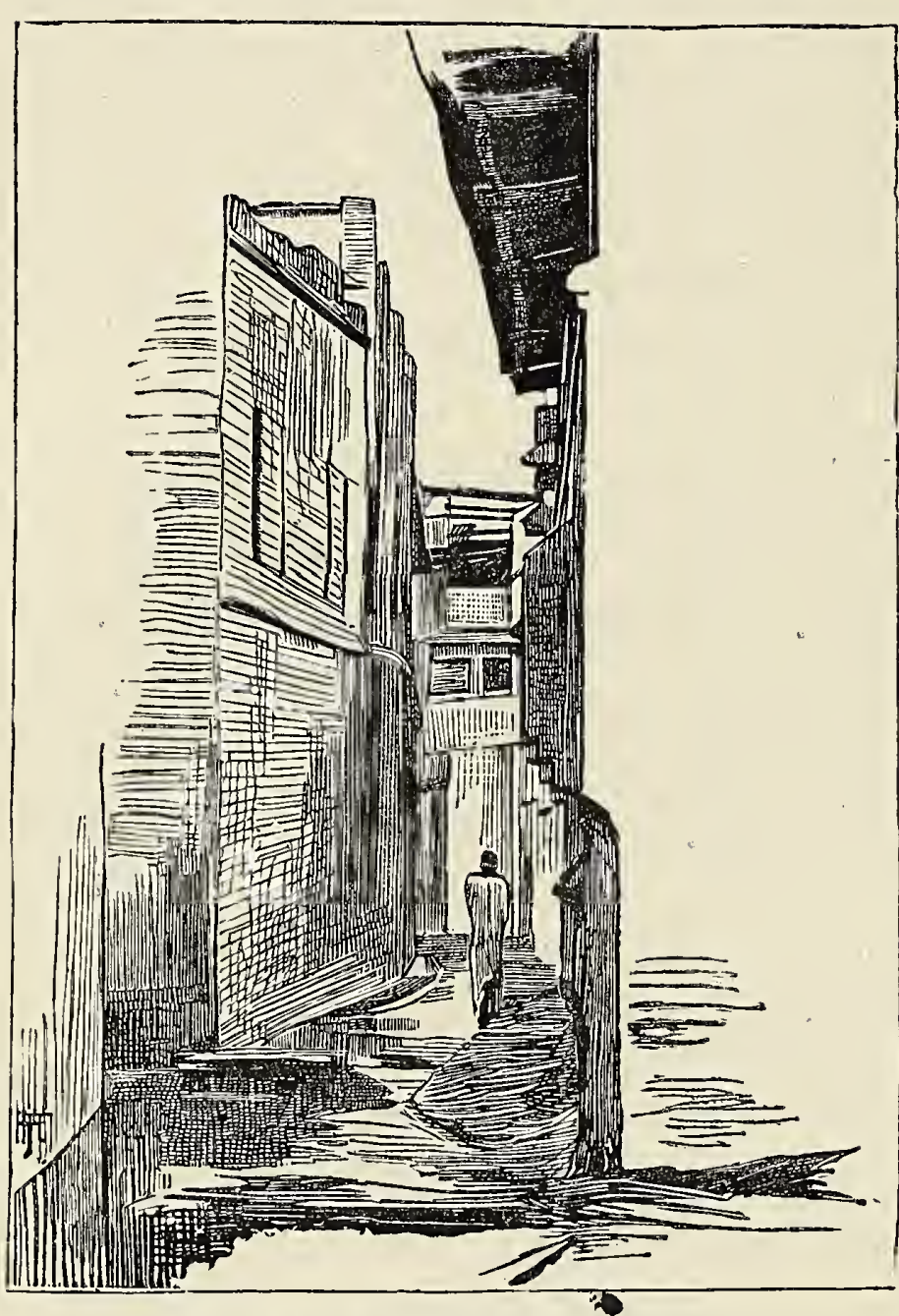

Fig. 13.-A Street in Zawibar. evident in the general architecture and interior decoration of the mosques and larger build̈ings, and the Persian pointed arch (different in shape from the Syrian or the Moorish) is constantly met with. In fact, to a student of Saracenic architecture, Zanzibar and the Zangian coast are very interesting, as they offer not only buildings of great age, some of the mosques dating back to the tenth century of our era, but of archaic style, recalling most unmistakably the kind of architecture met with in Saracenic monuments in Spain of the same age, showing thus how universal with the early Arab rule was that distinct architectural style which they developed from the late Byzantine. Just as there are words in Portuguese and Swahili ${ }^{2}$ derived

${ }^{2}$ Swahili is the name given to the predominant language of the Zanzibar negroes. It is derived from the Arabic "Sahel," the coast. Swahili belongs to the Bantu family of African languages, vide Chapter XX. 
from a common Arabic origin, so the resemblance between the architecture in Southern Portugal and Spain with that of Zanzibar may be explained by recalling the fact that the Iberian Peninsula and the Zangian coast both formed at one time extremities of Arab rule. While Zanzibar, however, resembles any other Eastern city, and differs little in outward aspect from Aleppo or Jaffa, yet the island to which it gives its name is thoroughly tropical African in its virgin state. The vegetation is rank and rich, and nearly every genus of the tropical African flora is represented among its plants. There are a few orchids, supposed to be peculiar, and possibly one or two ferns. Many trees have been introduced from India, and flourish in a way that exceeds their development in the mothercountry. Magnificent mangoes are planted all over the island, and the fruit they yield is justly celebrated for its flavour of strawberries and cream. Of course pine-apples, oranges, limes, and cocoa-nuts abound, and fruit here may be had all the year round in constant variety and great quantity. Many remarkable and many very beautiful productions in African flora, though by no means peculiar to this island, may be observed and studied here with greater facility than on the mainland. Of such are the magnificent blue Clitorea, the extraordinary Kigelia Africana, the exquisitely lovely Hibiscus schizopetalus, the Crinum lilies, and the gorgeous-leaved Crotons. The zoology of Zanzibar is purely African in its character, as far as it is yet known. Being separated but a few miles from the mainland, its birds and insects differ little, if at all, from the parent fauna. It possesses, however, at least two species (in common with its sister isle of Pemba) of peculiar mammals, viz. the Galago Zanzibariensis (a kind of 
Lemuroid), and a handsome monkey, the Colobus Kirkii. This latter, as its name indicates, was brought to light by Sir John Kirk; it was also extinguished by his means. Like most great men who have helped to extend the British Empire, Sir John has one dark blot on his escutcheon. Warren Hastings exterminated the Rohillas, Governor Eyre was accused of too summarily suppressing the Maroons; Sir John Kirk, more, perhaps, in the interests of British science than of British rule, has entirely destroyed an innocent species of monkey. The Colobus Kirlii had disappeared from nearly every part of the island of Zanzibar, but a rumour prevailed that it still lingered in a clump of forest as yet unvisited by hunters. Thither Sir John sent his chasseurs to report on the monkey's existence. After a week's absence they returned, triumph illumining their swarthy lineaments. "Well, did you find them?" asked the British Consul-General. "Yes," replied the men with glee, "and we killed them every one!" Wherewith twelve monkey corpses were flung upon the floor, and Colobus Kirliii joined the Dodo, the Auk, the Rhytina and the Moa in the limbo of species extinguished by the act of man.

When Sir John Kirk gets conscience-troubled, and the manes of the avenging Colobi (as negroes would believe) tamper with his health; when Zanzibar gets stuffy and feverish, and the official routine tryingly monotonous : he steals away, often on foot, to a little paradise he has created among the groves of Mbwéni, a tiny settlement on the coast of the island. Here he lives a life that is to him ideally happy. He chats with his tenants, who lead Arcadian lives of nothing to do and plenty to eat; he wanders in a shooting-coat amid the groves of coco-palms and the clumps of pandanus 


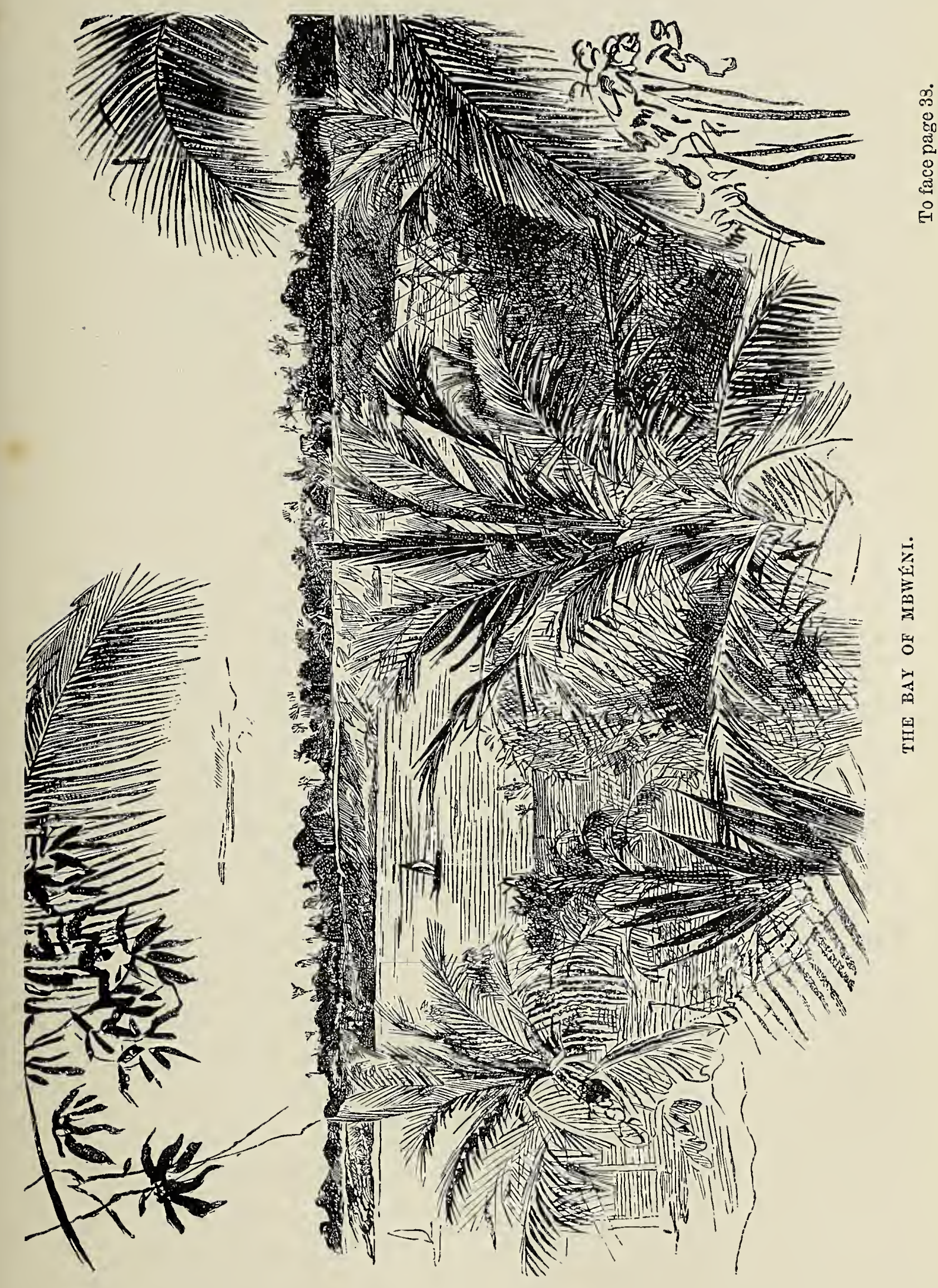



that border the sea; he photographs; and, above all, he gardens. Here, among his Cycads and his Orchids, his Ensetes and his Dracænas, spade in hand, a wideawake hat on his head, a rare flower in his button-hole, and rustic contentment irradiating his face-here, amid scenery which typifies a botanist's paradise, Sir John Kirk is emphatically At Home.

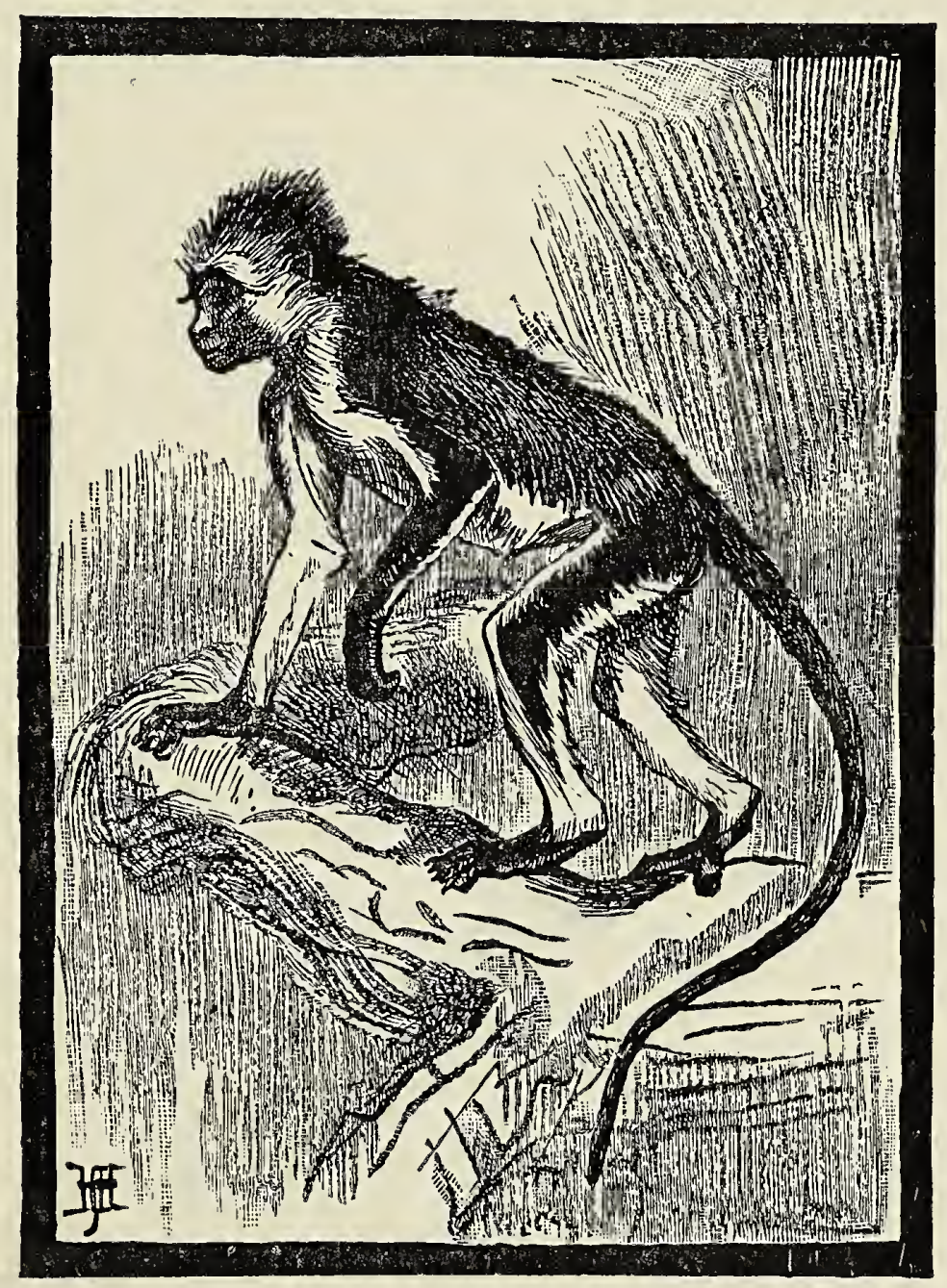

Fig. 15.-Colobus Kirkii. 
'IHE START-MOMBASA 'TO TAITA.

AFTER a month's sojourn in Zanzibar, most agreeably spent as the recipient of Sir John Kirk's hospitality, all my arrangements for commencing my expedition to Kilima-njaro were completed. I had hired upwards of thirty porters, most of them old employés of $\mathrm{Mr}$. Stanley's on the Congo, and despatched them to Mombasa in an Arab dau, while I followed in the mailsteamer going north, accompanied by my personal servant, a Tamil boy from Ceylon. I took leave of Sir John Kirk with considerable regret one dark evening after an unusually agreeable dinner-party, and entered a little rowing-boat, which was to take me to the steamer, with a feeling of such downheartedness that my calmer reflections told me Zanzibar was likely to prove my African Capua. After my own experience I could realize now how previous explorers had been unnerved and unfitted for the rough life of the wilderness by the luxurious and easy-going life in Zanzibar. Fortunately the steamer I was journeying in to Mombasa was the same vessel which had brought me down to Aden, so that I once more found myself among friends. The night I left Sir John Kirk's was stiflingly hot, and the steamer was full of passengers-I shuddered at passing the night in a poky cabin with three other 
inmates. The captain saw my hesitation, and offered most kindly to rig up a cot for me on deck. I accepted his proposal eagerly, forgetting the danger in it, of which both of us were unaware. The steamer, according to custom, would remain all night in Zanzibar harbour, and leave at dawn. Now-and this is the only reason I record this incident-there is no surer way of getting a bad fever than to sleep in the open air in a tropical port. The reasons for this are many and would take up a great deal of time and space to describe properly; I therefore confine myself to the dogmatic assertion, which $I$ here record in the interest of such of my readers as may be proceeding to the tropics, and are likely to be tempted to pass a quiet night in harbour on the cool upper deck instead of in their stuffy berths below. Sleep in the air as much as you like at open sea, but never when you are lying off shore in a port or land-locked bay. I paid the penalty of this one night's mistake in a very bad fever which attacked me soon after I landed at Mombasa, and left me horribly weak from its effects. Most fortunately, in my hour of extremity, I had fallen among friends. Captain Gissing, the Vice-Consul, was my host, and not only quartered me and my baggage in his Consulate, but also put up my thirty Zanzibar followers, an act of kindness for which I fear he was ill-rewarded by their noisy behaviour and continual squabbles with the populace of the town. So kind was Captain Gissing, that I was not made aware of this till after my recovery, and I beg to thank him again here for his considerate patience. The men were anything but bad fellows, but I suppose, finding themselves masterless with plenty to eat and nothing to do, they waxed riotous. In the meantime, the Rev. Mr. Hand- 
ford, of the Church Missionary Society, who had brought me round in the crisis of my fever, carried me off to his station of Frere Town on the mainland (Mombasa is an island) to effect my convalescence, which, so pleasant was the nursing bestowed on me under his wife's kind care, would have been quietly enjoyable had I not continually worried myself about my arrested work. However, my friends were not idle while I lay in enforced inactivity, and the Revs. A. Downes Shaw, of Kisolutini, and Thomas Wakefield, of Jomvu, were both busily engaging porters for my caravan.

At length I was so far recovered as to resume my preparations for departure, and I once more repaired to Captain Gissing's house to pack my vast quantity of baggage into loads of a more or less uniform weight, averaging fifty pounds apiece.

As yet Eastern Africa provides no other means of porterage than human labour, and all goods and chattels have to be carried on men's heads and shoulders. There are donkeys to be bought, it is true, but they never seem to do well on long journeys, and are in no way to be depended on; besides, at the time when I was staying at Mombasa, asses were both dear in price and poor in quality. Thirty of my men had been, as already mentioned, engaged in Zanzibar, and it would have been far better for the fortunes of my caravan had I recruited all the porters of my expedition at that place, for the men who frequent the capital and emporium of the dominions of Sayyid Barghash are of a better stamp than the worthless A-nika and A-rabai that inhabit the vicinity of Mombasa. Why this should be is a problem very difficult to solve, and one not altogether unsurrounded by thorny ques- 


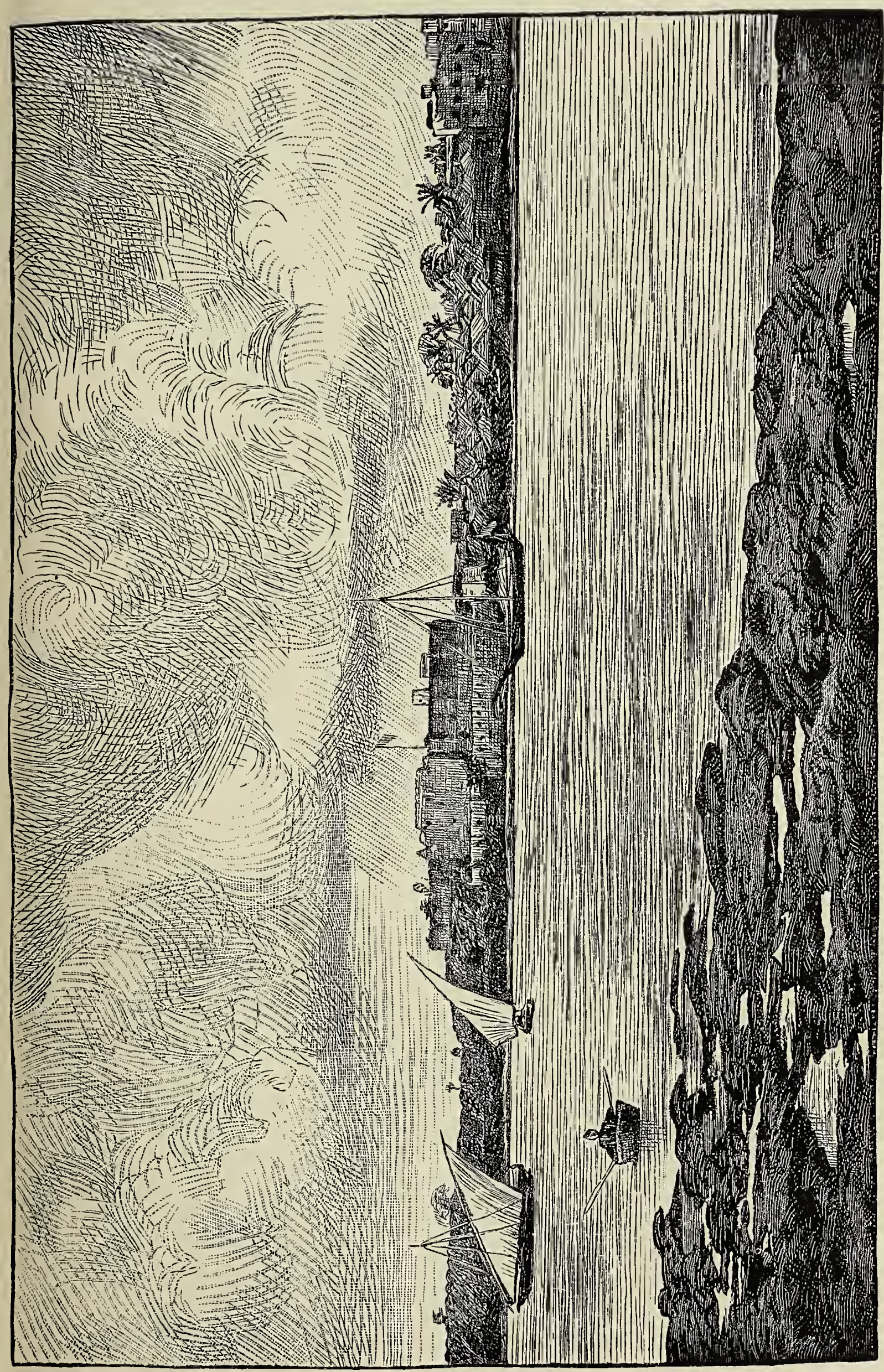

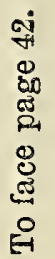



tions. I am afraid that in recording my downright bad opinion of the native carriers - many of them professing Christians-which are to be found in the vicinity of the English missionary stations near Mombasa, I am giving pain to my very kind friends, the missionaries who labour in those parts. I am sorry for this, for I am aware, more than any one perhaps, how thoroughly deserving of respect and support is their unselfish work in those regions. But truth must be told, and in the interests of travellers who succeed me in these districts, I warn them never, if they can help it, to engage porters at Mombasa. Independently of all questions of religion-Mohammedan and Christian alike-the inhabitants of the Mombasa district are a thoroughly bad lot. It is hopeless to win them by kindness, or infuse a spirit of discipline by sternness. They are liars, cowards, thieves, and drunkards. They were so when Krapf, the earnest pioneer of Christian missions, first came among them; they are so still, after nearly forty years of evangelization. Why is it that men got from Zanzibar, Pangani, Mozambique, or elsewhere, should be so much superior? It must be some inherent fault in the local race, because the few men whom I obtained from the Mombasa missions that were not natives of Mombasa, but had been trained in the mission schools, turned out all that could be desired.

However, being unaware of all this, I had already vicariously engaged the bulk of my porters at Mombasa, fearing to be disappointed at Zanzibar, as there is often a paucity of caravan-men in that place, owing to the constant demand. Even before I started for the interior, the true character of the Mombasa men began to dawn upon me, but I hesitated to take the 
extreme step of dismissing them and sending to Zanzibar for others, because this would, firstly, be very expensive, and secondly, for the reason that they were only engaged for one month to transport my goods to the mountain, and there leave me with my nucleus of thirty Zanzibaris. Moreover, I was feverishly anxious to leave Mombasa, feeling sure that I should never shake off the effects of my illness till I left the unhealthy coast; and without worrying myself' about a change of men, I had quite sufficient hindrance and vexatious delay in the purchase and packing of the necessary goods for sale and barter in the interior.

The great staple of East African trade and the chief currency of all countries lying inland, is "merikani," or American sheeting. I had to purchase several huge bales of this at Zanzibar and transport it to Mombasa, there to be split up into loads of five gora each. A "gora," or " jora," is about forty-two yards, and in sheeting of medium quality, weighs $12 \mathrm{lbs}$., so that each load of five gora weighed $60 \mathrm{lbs}$., and was a fair burden for a single porter. There were many other kinds of "cloth" ("cloth" becomes in Africa a generic name for all dry goods) to be taken. "Kaniki," or indigo-dyed cotton; gaudy red handkerchiefs from Manchester looms; "bandeira," or Turkey-red; "kikoi," or handsomely bordered waistbands, fringed every two yards; richly dyed stuffs from Western India and the Persian Gulf, "maskati," "dubhani," "sabhai," \&c. All these in common with the "merikani," had to be carefully divided into loads averaging 55 lbs. or 60 lbs.; each load counted and catalogued in its amount to check the stealing of any of its contents, and then finally sewn up in a peculiar kind of grass matting, very strong, and almost impervious to rain. 
Next, the beads had to be considered. It was necessary to take with the expedition different kinds and colours, for in East Africa, as I remarked on the River Congo, there are most varied and capricious tastes to consult among the natives, and scarcely two villages concur in their canons of taste. Thus, you must take different sizes of blue bead, called by the Wa-swahili majibahri, or "sea-water," for although an entire tribe may affect one shade of blue in their bead necklaces, yet each individual will have special opinion as to the correct size of the bead. Then there are large ruby-red beads and white ones, and tiny pink and medium-sized black, and transparent blue. When the beads are bought in sacks from the traders, they are only threaded on rotten, worthless thread, and it is impossible to trade with them before they have been re-threaded securely. For this purpose you purchase on the coast a stout twine, made, I fancy, from the fibre of a Raphia palm, and then you set your men to work to re-thread all the beads. This task, of course, gives them immense opportunities for quiet pilfering, for the beads in their eyes are almost like coinage ; so not only must you keep a sharp eye on the little groups of four or five merry black men who are so blithely slipping bead after bead along the yellow strings of palm-fibre, but each man's lot must be carefully weighed before and after its transference from the old thread to the new. Even with every precaution some loss always takes place during the process, and a day or two after this task is over you are surprised and grieved to see one of your most trusted followers reeling about the streets of the coast town, drunk on the proceeds of the misappropriated beads.

If you are likely to travel through countries ranged 
over by the Masai, large coils of iron wire must be taken, as these predatory people greatly value it, and turn it to many useful ends in their simple manufactures. Natives of all tribes in East Africa are also fond of copper and brass wire of every thickness, the very large sizes being coiled into bracelets or anklets, and the finer sorts used with much ingenuity to ornament gun-stocks, the hafts of knives, or the rods of spears. Finally, to this already extensive list of goods must be added a few sacks of cowries, barrels of trade gunpowder, tin boxes of percussion-caps, lookingglasses, large and small, butchers' knives, bells, mousetraps, and cheap musical instruments; while as presents for chiefs of special importance, fancy articles have to be taken, such as musical-boxes, accordions, guns of superior make, playing-cards, fine snuff, and gaudy picture-books. I was myself provided with a huge roll of coloured plates from the Graphic and other illustrated papers, which I found made a most satisfactory impression on chiefs of an æsthetic turn of mind, already cloyed with the cloth, beads, and brass wire of the ordinary trader. When all these wares had been selected, assorted, and packed, I had further to add to our encumbrances by purchases of food for myself and the men, as the country through which our journey lay was almost uninhabited and devoid of cultivation. For myself I added crates of potatoes and onions, and a dozen live fowls to my precious stock of preserved provisions ; while for the men, large quantities of Indian corn and beans were bought. How easily fed these Swahili porters are! What other race would be content to trudge twenty miles a day with a burden of sixty pounds, and be regaled on nothing but maize and beans? 
At length all my arrangements were finished. The men had received and spent their advanced wages, and had sobered down after the drunken spree by which they nearly always inaugurate a journey into the

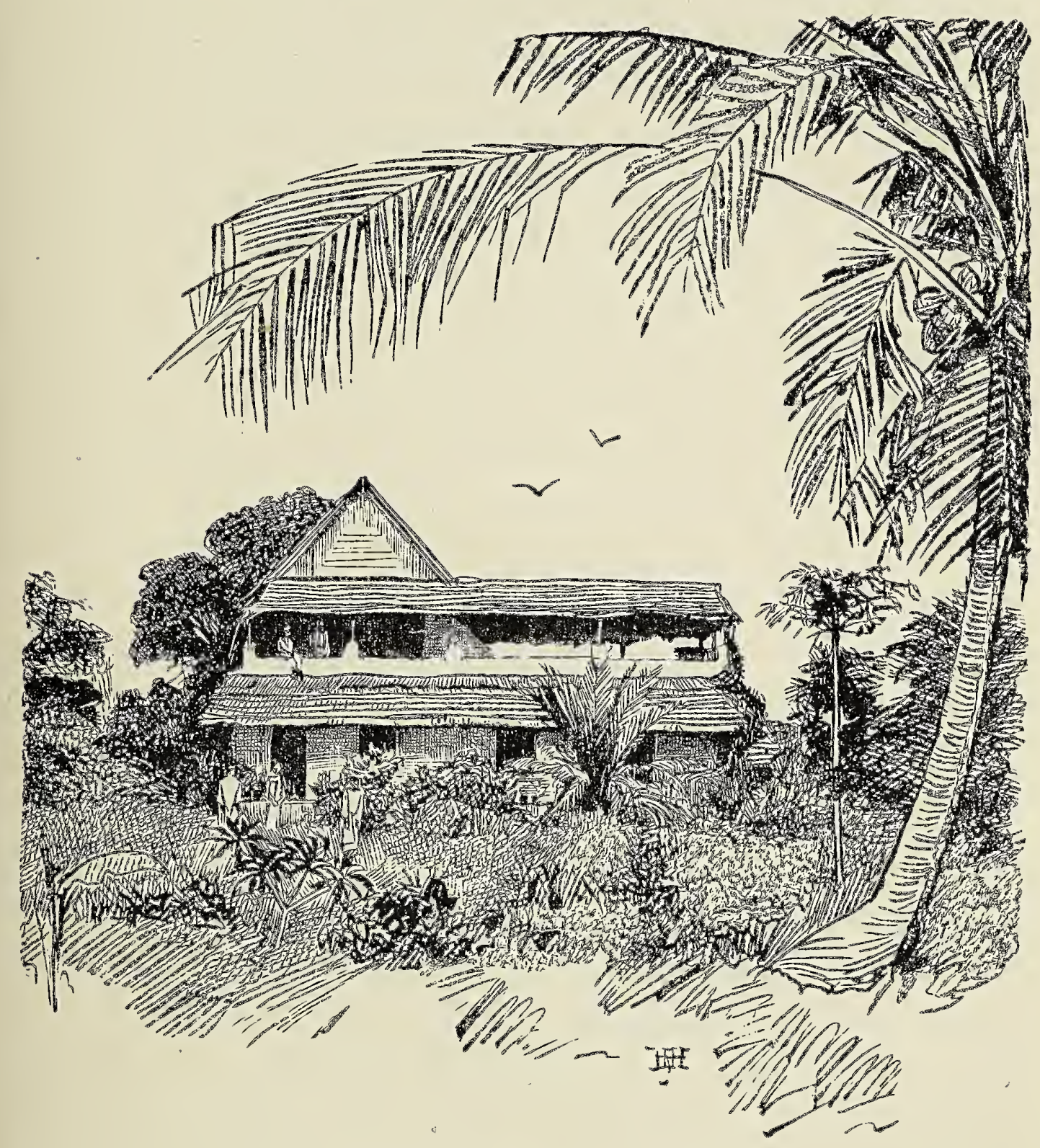

Fig. 17.

The Shaws' House, Kisolutini-the first Mission Station in East Africa.

interior. I myself was ready and anxious to be off. I longed for the bracing air of the inland plateaux to dispel the weakening fever from which I suffered, and gladly stepped into Captain Gissing's pretty skiff, in 
which the first stage of the journey might be made, for several tidal creeks extend inland from Mombasa for a distance of nearly twenty miles. My men journeyed by land, and we all met again in the vicinity of the mission station of Rabai. After one night spent with Mr. and Mrs. Wakefield at Jomvu, and a pleasant rest with the Shaws at Kisolutini, I was at length launched alone into the wilderness, rather relieved than otherwise at my unaccustomed solitude. My party consisted of one hundred and twenty men.

The first day's tramp into the interior was very trying. Owing to the scarcity of water, I had resolved to make a long march to a place called Gora, at a distance of about thirty miles from my starting-point. I gave my caravan a little start ahead of me, and followed leisurely in a hammock, feeling at first too weak from fever to be able to go on foot. In fact, what with anterior weakness and a blazing sun; I felt in such a stupid condition that I hoped, during the first day of my travels, to be allowed to journey peacefully without undue exercise of energy. But it was not to be, and perhaps fortunately so, since there is nothing that dispels the languidness of fever so speedily as the necessity for vigorous action. After some hours' easy jog-trot in my net-hammock, I came up with the bulk of my caravan, and found all the men reclining in the pleasant shade of a leafy wood. The Zanzibaris rose somewhat apologetically, and with a show of respect, but the men of Rabai and Mombasa merely looked at me with stolid unconcern, and several yawned unrestrainedly in my face when I questioned them as to the cause of this prolonged halt. The headman of these Christian-save the mark!--porters then informed me that his men considered the walk to Gora 
too long to be undertaken in a day, and had chosen this pleasant spot to repose in during the sultry hours. I called on the laggards to take up their burdens and go on; I maintained that I alone had the power to order a halt; that the morning was still fresh, and that if we rested now we should never reach the water-place by nightfall-in vain, I was only met with sullen looks and murmurs of dissent.

Now was the crisis in which my authority was to be asserted or for ever to be subordinated to the men's caprices. The Zanzibaris were waiting to see how I should act, and would gauge my disposition by the way in which I met my first difficulties. In fact, the scene in which this conflict of wills took place was not ill-disposed for effect. A slight depression or basin was sunk in the centre of the clearing, in which the dissentient porters and their loads were grouped, and around ran an amphitheatre-like rise of ground, whereon stood a file of Zanzibaris awaiting the outcome of our dispute before taking sides. No longer addressing an indiscriminate crowd, I called on one man to pick up his burden and take the road. He promptly and curtly refused, and as quickly my Indian servant had him by - the heels, whilst I soundly trounced him with his own walking-stick. This was quite a sufficient display of force. Whilst the recalcitrant porter was still screaming abjectly for pardon, and I was still gravely counting the strokes of the wand-eight! - nine!-ten!eleven!-the other men had hoisted their loads on their bullet-heads, and were falling into file along the narrow path, leaving my servant and myself alone with the victim of our wrath. The very hammock.men had disappeared, and hurried forward in an excess of zeal. But I was almost independent of them now. 
The temporary burst of just anger not only brought a flush of colour to my pallid face, but seemed to restore strength to my limbs, and I strode on now by the side of the caravan, exhorting and encouraging the men till we had all regained our good humour, and even the scapegoat himself emerged from sulky silence, and gave a half-humorous, half-dolorous account of his beating to the men walking near him.

I had now a little leisure to observe the character of the scenery through which we were passing. Therewere no hills at present in sight, and the view was bounded by the scrub and stunted trees which closed up round the narrow path. Nevertheless, the want of landscape beauty was atoned for by the vivid glory of the wild flowers, which now, at the close of the rainy season, were in perfection of bloom. That beautiful genus Commelyna (a monocotyledonous plant allied distantly to the spider-worts) gave us species with pale blue, ultramarine, and citron-yellow blossoms. I marvel that the Commelynoe, commonest of African flowers, have never been introduced by European floriculturists. Under cultivation they ought to yield beautiful displays of colour, and, as many species grow on the flanks of Mount Kilima-njaro in an English temperature, there is no reason why they should not supplant the lobelia in our garden borders, and yield a vivid sheet of rich blue blossoms far surpassing the feeble flowerets of the last-mentioned plant. Many other wild flowers make themselves noticeable by their abundance and beauty in this district between Gora and Rabai, which lies at about thirty to forty miles from the coast, and receives more rain and humidity from the not far distant Indian Ocean than the sterile steppes further westward. Great, tall, terrestrial orchids of the Lisso- 
chilus genus border the pathway, and display their graceful heads of blossoms, which are mauve, or bright yellow, or yellow and purple, according to the species. Then there are spotted-leaved aloes, with sprays of waxy-pink flowers, great prickly candelabra euphorbias, with tiny green inflorescence, and other smaller euphorbias with large, weird flowers of a dull, dead purple-brown. White and blue clitoreas trail over harsher shrubs, and enliven the grey-green bush with tender colour. Crinum lilies are lavish in squandered bloom, and the air is fragrant with a thousand odours, to which the flowers of acacias, climbing jessamines, and corissas powerfully contribute.

We reached Gora that night by the light of the moon, but as my tardy porters had lagged behind, I arrived at the camping-place without tent, bed, or provisions, and not only had to lie down to sleep supperless, but blanketless; and, as the night air was unusually chilly, my health was not improved by these privations. The next day we fortunately had but a march of sixteen miles to accomplish; nevertheless the men went very badly. We stopped in the morning at Samburu, a pleasant place, with once-cultivated plantations run wild. Here there was indifferent water in clefts in the rocks, and we set to work to prepare our midday meal. We waited for the laggards of the caravan until four o'clock, and then, too impatient to delay any longer, I took advantage of the cool afternoon and limped on to my next camping-place. By midnight all were at length reassembled, but I resolved in future, if it were only to avoid anxiety, to walk behind instead of before the caravan, and not to pass any one on the road; thus, I should always arrive simultaneously with my baggage. The following day 
I put this plan into operation, but its first results were not encouraging. About every half-hour the Rabai men would put down their burdens and compose themselves for a nap in the shade. As these intermittent siestas greatly deranged the uniform progress of the caravan, I objected, preferring to rest unanimously every two hours, but walk uninterruptedly whilst on the march. As the Rabai men were, however, of a different opinion, I now began to meet at every turn of the path a man's load without a man, and on inquiry was told that its whilom bearer had decamped into the bush. Lust of all I counted nearly a dozen of such abandoned burdens, and sat down desperate by the wayside, not knowing what course to pursue. However, my Zanzibar men stood by me like trumps, and many of them carried extra loads, and so brought all the things to our next camping-place at Ziwani.

Here we arrived at about dusk, although there was scarcely any ending to the daylight, for we were favoured with a brilliant moon. I now was able to review my men and rearrange the loads so that all the things might be carried on the morrow. I I retired at last to my tent, thoroughly exhausted, both with physical fatigue and mental anxiety. Throwing myself, or rather involuntarily tumbling, on my bed, I felt I was fainting, and just roused my energies sufficiently to ask my servant to open my wine-case and get me out some champagne. When a bottle of Moët and Chandon had been uncorked, and a tumblerful (alas for the delicate champagne-glass, I had it not!) ürunk, an effect as magical as that of the "hashish" given by the Sheikh of the Mountain to his deluded followers was produced. Before the foaming draught 
had passed my lips I was a poor, despondent creature of the earth, earthy, and tied to the base soil by physical fatigue and mental prostration; but no sooner had the sparkling wine entered my system than I was transfigured, transformed. My fever-dried skin broke out into grateful perspiration, the fitful pulse resumed a brisk and regular beat-no fainting now. I felt ready to march anywhere, and my blistered and ulcerated feet pained me no more. I ate my evening meal in a sort of tranquil ecstasy, and afterwards undressed dreamily, and steeped all my cares in the Lethe of sleep. And a cupful of champagne on an empty stomach had sufficed to work this happy change!

In case there are some of my readers whom this rhapsody (copied almost word for word from my diary) may offend, let them understand that I am singing the praises of champagne as a medicine, not as a customary drink. No one can inveigh more strenuously than I against the daily or even frequent use of alcoholic drinks in a hot climate. I believe that in Africa, as a general rule, and under ordinary circumstances, a man may with benefit to himself abstain totally from the use of wine, beer, or spirits. But, for the very reason that he rarely indulges in strong drink, when he does find himself in a state of physical or mental prostration, especially ensuing from attacks of fever, there is no more certain tonic than a little good champagne. I have seen cases in Africa, East and West, where a cupful of champagne administered at an apparently hopeless juncture has snatched a man from a sinking condition, and brought him back to life. I only took a dozen of champagne-and no other wine-with me to Kilima-njaro, and of this 
dozen eleven bottles were consumed at various crises in my adventures, when I felt my physical strength deserting me. Somehow the very knowledge that you have such a stimulant at hand braces your nerves with mental confidence, and the happy faith in its sovereign efficacy inspires you with a cheering belief that Death himself will flee before a goblet of champagne.

The name of our last camping-place, "Ziwani," had a pleasant sound to the thirsty traveller, for translated into English it means "By the pool," and would consequently suggest the close proximity of water. But, except under favourable conditions, this is not the case at the spot in question, and, as it happened, Taru, a day's journey from Ziwani, was the last place where we had been able to replenish our gourds and bottles. In consequence of such dearth of water it was necessary that the distance between Ziwani and Maungu (the next watering-place) should be covered in a day, and as this was thirty-two miles it meant a forced march of thirteen hours. My men had willingly allowed me to ignore the disagreeable necessity, fearing that I might, as I certainly should have done, force them to break the distance between Ziwani and Maungu by a night march-a thing they much detested, even when performed by the light of a full moon, having, like most Africans, a superstitious fear of night. But being themselves conscious of the long stretch of waterless country they had to traverse before reaching the mountains of Maungu, they, for once, were eager and ready to start before their leader's call, and consequently when I awoke from that delicious dreamless sleep caused by the timely draught of champagne, I found myself almost alone, while a strange and unwonted 
silence pervaded the camp. The head-man of the caravan was squatted outside the tent patiently awaiting my awakening. The Indian servant and the senior cook were busily preparing breakfast, while just sufficient men remained behind to carry my tent, bed, and cooking apparatus.

Learning the cause of my porters' disappearance, and far from disapproving such unaccustomed and unprompted activity, I hastily dressed, swallowed my breakfast, and also prepared myself for the long journey that lay before us. The bright slanting beams of an hour-old sun lit up the landscape so cheerfully that the purpose of covering thirty-two miles by nightfall seemed both feasible and easy of accomplishment. The air was fresh and buoyant, and either my potion of the night before or the change from the hothouse atmosphere of the coast to a more bracing climate had brought back strength to my limbs and courage to my heart, for I stepped out along the red path at three miles an hour and enjoyed the exercise. This rate of progress soon brought me up to the rearguard of those who had started with the earliest dawn, but whose energy had waned after two or three hours' hard tramp. Already, with stupid resignation, many were stretching themselves by the wayside, having first, to satisfy a moderate thirst, consumed in several gulps the remainder of the drinking-water which was to carry them through the day; and, this finished, they were prepared to lie down in utter hopelessness, feeling themselves unequal to the task of walking twenty-five miles to the next water-supply or twenty-five miles back to the last.

I should parenthetically remark that these East Coast porters, like most Africans, are utterly without 
prevision, and so long as they can satisfy the desire of the moment care little to provide for future wants as yet unfelt. On long journeys, where there is no water on the road, you will experience the greater difficulty in preventing your men dropping and dying of thirst, because, although they may have started. with an ample supply of drinking-water in their gourds-quite sufficient for the time required if carefully measured out -yet, in spite of warning and prohibition, they will squander the precious fluid, quench every slight attack of thirst, and consume it all in a few hours; then, during the long waterless tramp which ensues, they will wring your heart with the sight of their sufferings, and stagger along the dusty path with dry, swollen tongues, parched lips, and blood-shot eyes.

So it was on this terrible journey to Maungu. Towards midday, when the noon blazed in fierce white heat, when the sky was so hot and scintillating that it was devoid of all colour and shone like a silver shield, when the short, scrubby mimosas gave no sheltering shade under their thorny boughs, when escape from the overpowering dazzling sunshine was impossible, and the baked and heated soil seemed to burn the soles of my boots, and made the men who were still plodding on pick up their feet like the proverbial dancing bear-then I began to doubt whether my party would reach Maungu intact, for now it was useless to battle with the sullen sluggishness of many of the porters, who preferred lying in the road exposed to hard words and blows rather than toiling patiently and uninterruptedly on in the direction of water and permissible repose. So in sheer despair I left them to lie wherever they threw themselves, accepting in lieu of any other consolation their assurance 
that they would follow on in the cooler hours of the day. Now, even, it became with myself a desperate rush to reach the water-supply before I should suffer painfully from thirst. An examination of my own store of the precious liquid had revealed the appalling fact that not one drop remained, and the man who had been carrying my bottles and calabash confessed to having assisted in its disappearance. This was a serious matter; thumping the man did nothing towards allaying my increasing thirst. All that could be done was to journey on patiently but unremittingly in the direction of Maungu. There was no time to prepare food in the middle of the day: I pulled out a tin of hare soup from my provision box, opened it, and drank the undiluted liquor. The unfinished bottle of champagne was divided and consumed by myself and my patient Tamil servant, lending a factitious strength to our tired, overheated bodies, and so far buoying up our spirits that we strode on past man after man until we were well ahead of the cdravan.

Soon, however, I needed to rest more and more frequently, stopping at last to pause and pant in every patch of thin shade. Then my Tamil boy and the head-collector proposed that they should go on alone and return to meet me as soon as water was found. This I acceded to, and so was left completely alone. In this condition, hobbling along painfully, resting continuaily, and with foolish persistency painting, to my thirsting imagination, vivid pictures of cooling draughts, I toiled through the sultry afternoon, persisting doggedly in my determination not to give in till I was within measurable distance from water. Sometimes I did give way-stretched myself languidly under the faint patchwork of shade that 
some meagre bush afforded, and lay there during some minutes, vainly trying to moisten my dried lips with my parched tongue, and hoping that with the approach of night and its dewy coolness. I might overcome this raging thirst. Then the little lithe lizards would come and look at me with their heads on one side, and their bright eyes scanning me half-mockingly; an irate ant would nip my hot hand, which I had abandoned as if it no longer belonged to me, and carelessly placed on an unconsidered ant-hill, till at length, weary of my unrestful repose, I would stagger to my feet, and limp on for a few minutes in agony, as you always do when you have given blistered feet a brief rest and then commence walking again.

I will spare you a further recital of these very ordinary, everyday African sufferings, so interesting to me to ponder over now that I am writing about them in England, where thirst is almost desirable from the many pleasant ways there are of quenching it. I will suppose that I have stumbled over a rocky path in the waning daylight, toiled on the last dreary miles of the journey under a rising moon, and at length found myself amid a strange thicket of thorny trees, and weird euphorbias at the base of the hill of Maungu. In the camping-place where most caravans stop, I see a small fire burning, a man sitting, and a man lying down. The former is one of my natural history collectors and the other my Indian servant, Virapan, who has fainted. I question the collector, a man called Athmani, and he tells me the water lies in a cup-shaped basin at the summit of the hill (which is nearly 5000 feet high), and that his companion and helpmate, Mabruki, has gone to get some. Fancy when you have walked thirty-two miles 
for a drink finding your cistern lies some three or four thousand feet above you!

With what amount of patience I should have awaited the return of the water-carrier I do not know, but just at this juncture one of my porters arrived, and threw down his burden with a weary sigh. I remembered with joy the contents of the lumpy sack he bore, and rapidly untying its mouth took from it several cocoanuts. Filling a gourd with their milk, I was able to assuage the thirst of myself and my servant, who had returned to consciousness, and we then passed with equanimity the half-hour that elapsed before Mabruki came back from his quest among the rocks of Maungu, bearing gourds full of delicious water, clear and cool.

At this camping-place we remained until the afternoon of the next day, awaiting the coming in of all the laggards; but my patience was at last overtaxed, and I resolved to go on with a few followers to Ndara, the next camping-spot, where we should be in an inhabited country, and with pleasanter surroundings, for the vegetation in the vicinity of Maungu was singularly forbidding and ugly, suggesting some enchanted forest, and, moreover, the water-supply proved scanty and difficult of access. I left my head-man and a few followers to search for the missing men, and walked on to Ndara through the moonlight, stopping to sleep for a few hours before dawn. In the early morning we began to ascend and cross a rocky ridge, and on surmounting it looked out westward over the plains or mountain plateaux of Taita. Here our sight was gladdened by clumps of really green and shady trees, and we were further delighted by the first signs of evident culti- 
vation. Further on we met some natives, ugly, nearly naked, and very black, with huge rings of beads in their wide-lobed ears, and greeting them with effusive friendliness we induced them to follow us to our camp with a few eatables (sweet potatoes and corn-cobs principally), feeling in our delight at once more reaching habitable country an amiable desire to be on the best of terms with its inmates. We pitched the tent at the foot of Ndara Hill, near a pool of dirty water, whither large flocks of cattle came to drink.

In this not unpicturesque country of rocks and forest trees and lovely wild flowers I stayed during two days, and at last collected my caravan round me. Maungu was very nearly being a Moscow to my little army, but ultimately there was small loss in either men or goods. Some two or three porters had run back to the coast, leaving their burdens behind, while two miscreants who carried a case of spirit for preserving natural history specimens, had broached and drunk the alcohol, and, strange to say, still survived this extraordinary bout.

Before I leave Ndara, therefore, I may take this opportunity of describing, somewhat in detail, the men who were following me to the steeps of Kilimanjaro, and on whose fidelity the fate of the expedition entirely depended. The head-man of the entire caravan was Kiongwe, a pleasant-spoken, rather plain young man of about thirty, who had served much on the Congo, and had accompanied Stanley thither in his first expedition, in proof of which he wore a massive silver ring. Kiongwe (whose name meant in Swahili a "headstrong jackass," and who was therefore politely called by his inferiors "Shaongwe" in order that his name might not be too 
closely interpreted) was good-tempered, respectful, and fairly brave, but could not always be trusted with property, as he felt now and then an irresistible temptation to appropriate a little of his master's cloth and beads. However, he made a good head-man, for if-lenient to his own occasional dishonesty he watched well that no one else robbed me. The second in command was Abdallah, another old Congo traveller, and a learned Arab scribe. Excelling Kiongwe in politeness and suavity of demeanour, he also erred somewhat as regards strict honesty, but was on the whole a very good fellow. His manners and mode of life were quite fastidiously gentlemanly, and his person was always, and under every circumstance, clean and sprucely apparelled. Without being in the least religious he had a gusto for prayers, and all his leisure moments were employed in the rapid and glib recital of the Koran. I once asked him what would be his ideal mode of life. "Kusoma Muungu, sikuzote" "To be always praying to God," he replied, with the faintest hypocritical tone of self-satisfaction in his voice.

Then in order of precedence came Mabruki and Athmani, two natural history collectors, men who, by accompanying several preceding African travellers, had acquired a rough knowledge of preparing specimens. The further history of these two gentlemen will be disclosed as this narrative proceeds. My two cooks deserve a word of mention. Faraji, the elder, was a busy old man of the Yao tribe, who had accompanied Cameron' across Africa and further servéd a three-years' term on the Congo. He was the strongest man in the caravan, and his only fault was a somewhat large style of housekeeping, by which himself and his 
colleagues were amply fed out of the remains of my dinner. Cephas, the junior cook, often called Cephassi by the soft-tongued Zanzibaris, was originally a freed Nyassa slave. Educated at the Nassick Mission,

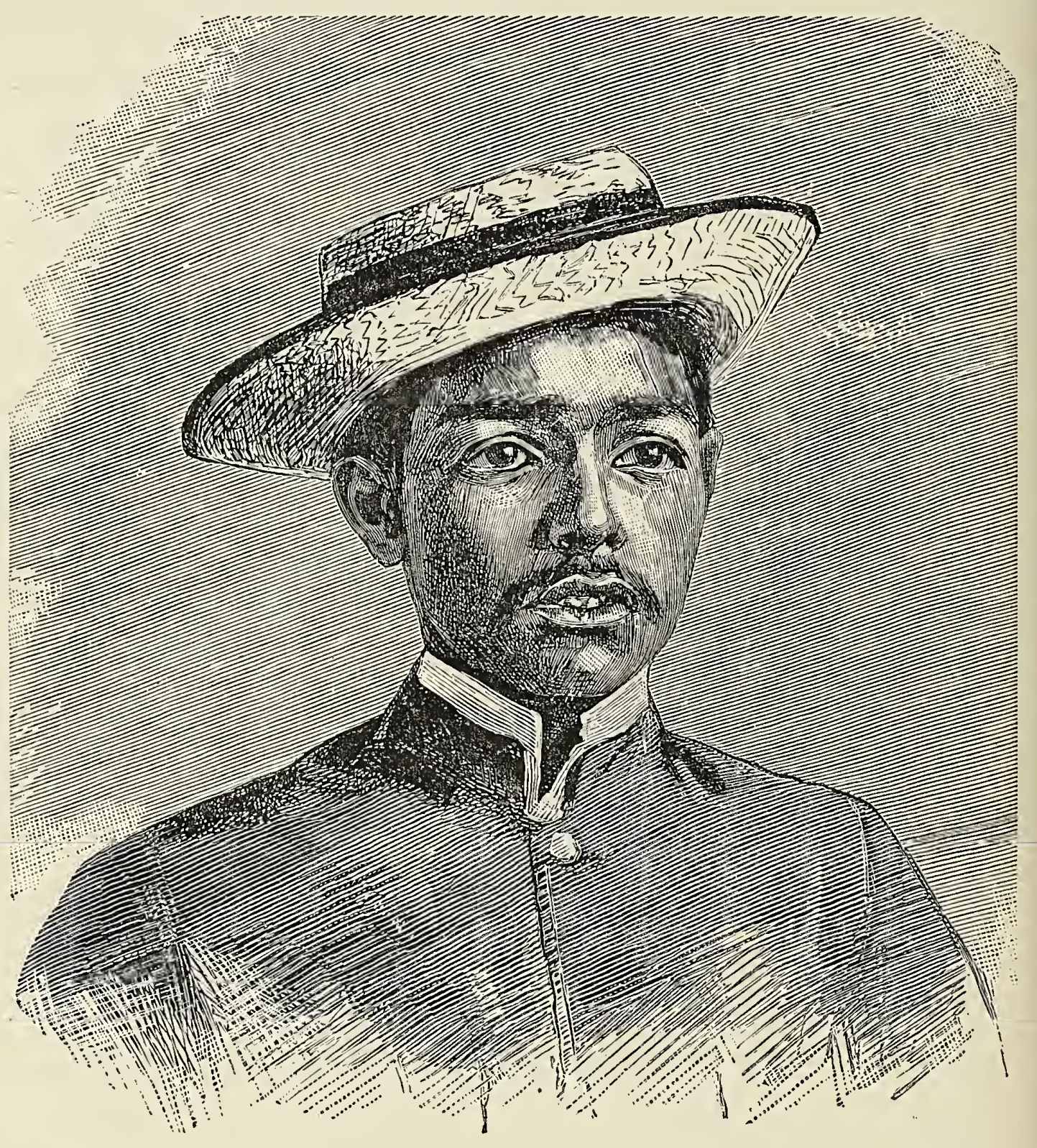

Fig. 18. - Virapan, my Tamil Servant.

near Bombay, he had been taught to cook in a way that generally procured him good situations. He had visited England and there acquired certain useful expletives which served him as augmentative, diminu- 
tive, intensifying, and modifying adverbs, and lent great expression to his simple English. Beneath the rank of the men already cited, whose wages were specially fixed, came a troop of Zanzibaris on their promotion, who received a uniform rate of five dollars a month. Among these, however, I had noticed already several as good servants or cheerful, conscientious men-Ibrahim and Kadu Stanley, especially. Ibrahim was nick-named "Mčekesaji," a word which you will find translated in Steere's dictionary "a merry, laughing body." Kadu Stanley was remarkable as having been an old servant of Stanley, to whom he had been given by Mtesa, King of Buganda. After the Zanzibaris came a herd of Rabai and Mombasa men, solely remarkable for their hopelessly bad disposition and for the quaint combination of Christian and heathen names they assumed. I had only engaged them to carry the bulk of my goods to Kilima-njaro, and when we had attained that goal I took leave of them without regret. 


\section{CHAPTER IV.}

IIAITA TO KILIMA-NJARO.

Havivg once more reassembled the men, rearranged the burdens, and left behind what we could not carry in the kind charge of a missionary who was temporarily residing on the summit of Ndara Hill, we started on a day's journey to Mwatate, passing through dense thorny bush, rocky defiles, and dried-up stream courses, and finally reaching, to my joy, the first channel of running water we had met with since leaving the vicinity of the coast. The ground along its banks had been cleared and cultivated; we crossed the stream on a rickety wooden bridge, and passed up through fields of maize and brakes of sugar-cane to our camping-place, under an umbrageous tree. Here pleasant-mannered natives greeted us; we paid the small present demanded as an indemnity for passing through their country and drinking "their" water, and then enjoyed a welcome rest amid surroundings of quiet beauty. The next day we were travelling through a Swiss-like country of mountain passes and richly fertile valleys, and at length came to Bura, a campingplace at the foot of the strangely peaked mountains of that name. Here we were nearly having a skirmish with the natives, who demanded an exorbitant pay- 


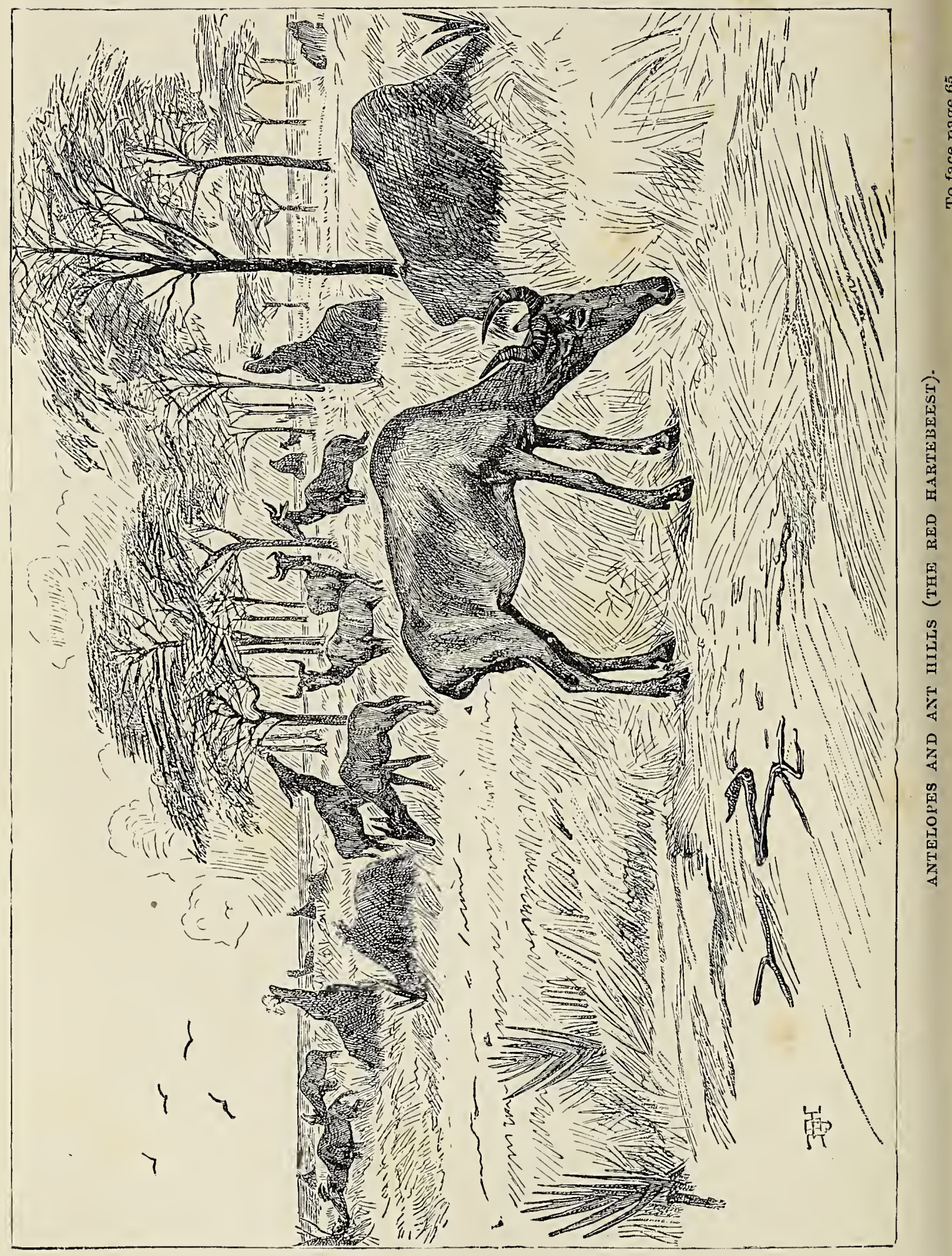


ment for the right of drinking from their river. However, a resolute attitude on our part preserved the peace, and we were soon on excellent terms with the Wa-taita, buying fowls, maize, and honey at a great rate. On the morrow we skirted the little river of Bura for a few miles, and then, reluctantly leaving its belt of rich, majestic forest, plunged resolutely into the waterless wilderness which separated us from the base of Kilima-njaro.

Although the journey before us was a far longer one than that terrible march to Maungu, it was, nevertheless, marked by no sufferings from fatigue and thirst, for I had the men now well in hand, and was careful to ascertain that no one had started without a due supply of water. The country we passed through was indeed a wilderness, but yet rather park-like in its aspect. There was an entire absence of undergrowth, and tallish trees with cedarlike crowns rose at regular intervals, looking, in their uniformity of unvarying red trunks and bright green compact foliage, like an unskilfully painted landscape. Other noticeable features in the scene were the tall red ant-hills and, strange imitation, the tall red antelopes, a species of hartebeest, ${ }^{1}$ resembling faintly in shape the form of a giraffe with sloping hind-quarters, high shoulders, and long neck. Being a deep redbrown in colour, and standing one by one stock-still at the approach of the caravan, it was really most difficult and puzzling sometimes to know which was hartebeest and which was ant-hill; for the long grass hiding the antelope's legs left merely a red-humped mass, which, until it moved, might well be the mound of red earth constructed by the white termites. The

1 Alcelaphus Cokei. 
unconscious mimicry was rendered the more ludicrously exact sometimes by the sharply-pointed, flaglike leaves of a kind of squill-a liliaceous plantwhich frequently crowned the summit of the ant-hill, or grew at its base, thus suggesting the horns of an antelope, rather with the head erect, or browsing low down. The assimilation cannot have been fancied on my part, for it deceived even the sharp eyes of my men; and again and again a hartebeest would start into motion at twenty yards distance and gallop off, while I was patiently stalking an ant-hill, and crawling on my stomach through thorns and aloes, only to find the supposed antelope an irregular mass of red clay.

The great plain which lies between the country of Taita and the eastern base of Kilima-njaro swarms with game, especially where the land slopes gently towards Lake Jipe, which may be descried to the southward as a narrow slit of silvery white lying between a band of dull green forest and the purple wall of the Ugweno Mountains. As we marched along herds of hartebeest, gnu, eland, and buffalo defiled before us, wending their way slowly along their own beaten tracks to the accustomed drinking-place, where, poor fools, some of them were sure to lose their lives, for, lying in ambush in the forest tunnel, down which the thirsty creatures rush to the water, would be either lions, leopards, or human hunters, armed with poisoned arrow and broad-bladed spear. But however much a keen desire to drink might blind them to danger when they are near their goal, they were wary enough now, and their sentinels kept a sharp look-out on our movements; only the giddy zebras-most inquisitive of animals - risked their lives by galloping up to inspect the passing caravan. The sight of all this game was 
potent enough to stir a hunting impulse in the soul of the most jaded traveller; and although I found it hard enough to plod along the dusty track in the rear of the caravan, and avoid the impulse to cast myself down and rest in every patch of sparsely scattered shade,

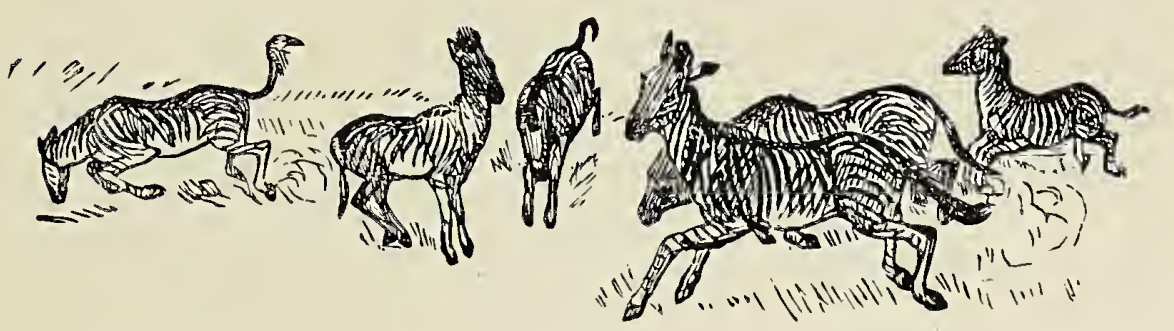

still I did every now and then make a sally at some wondering antelope that stood in the distance staring,

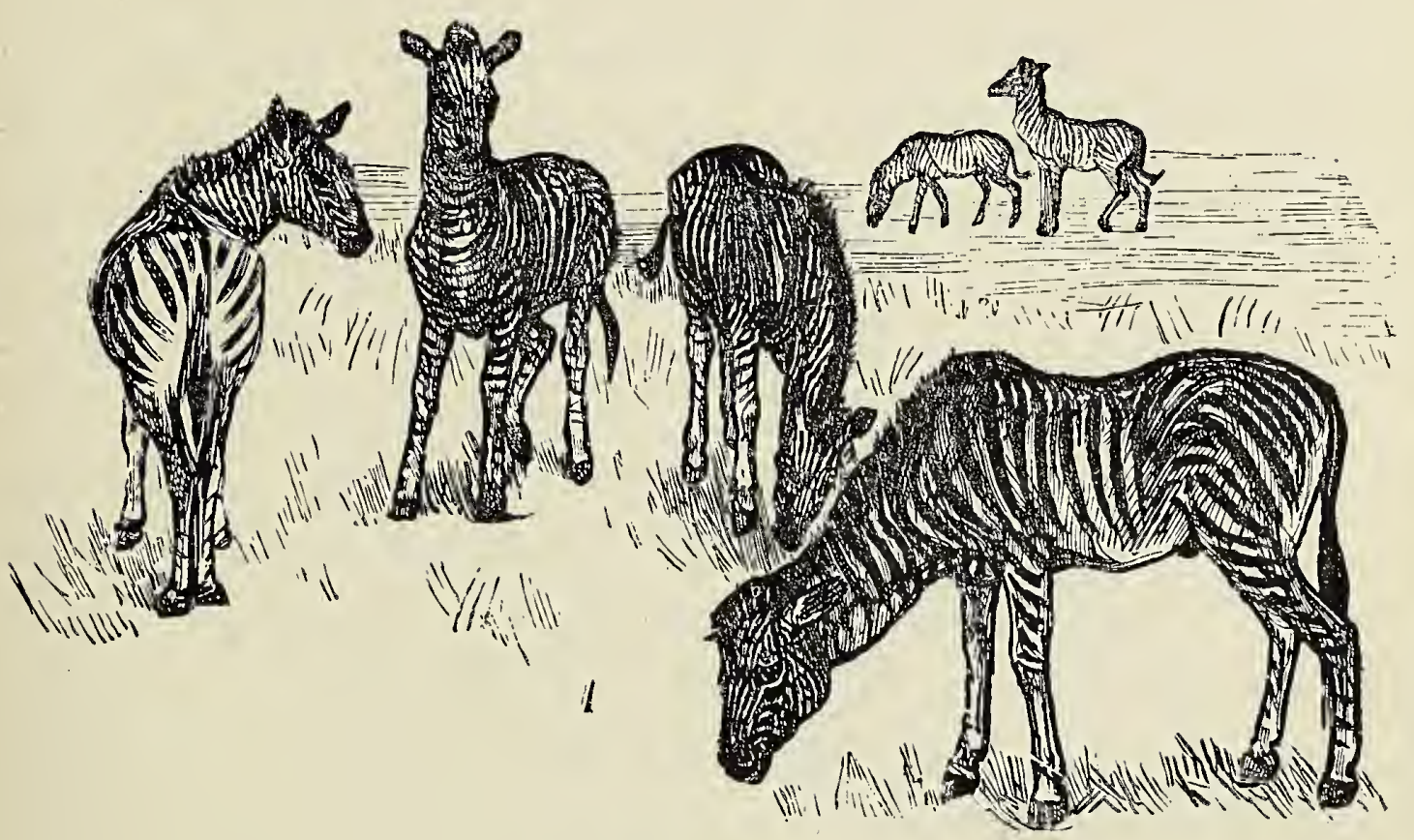

Fig. 20.-Zebras.

snorting, and occasionally stamping petulantly with its fore-feet at the strange, inexplicable, snake-like line of white-vestured men slowly winding over the plain. But my attempts at stalking, and my snap-shots were too impatient and hurried to meet with any definite 
success. The fact is, in African travel, it is not easy to combine the accomplishment of twenty or thirty miles walked every day on foot, with the exploits of the chase, especially when haunted by the knowledge that every minute's delay that separates you from your water-supply is dangerous. You leave the road just to stalk a group of zebras grazing not more than two hundred yards off, and you think if you can only creep up to that ant-hill and hide behind it, you will get a splendidly easy shot. Well, the ant-hill is reached, but the zebras have moved off a little farther, and now there is a stumpy mimosa-tree between you and your aim. However, it is a matter of a few paces to crawl up to it and fire from behind its branches. You reach the tree, and just as you are going to raise your gun you crack a dead twig, and the zebras move and trot off some distance farther. Now it is too long a shot to risk, but as the game is grazing peacefully and unsuspiciously again, you may just as well creep up a little nearer and then fire. So you go down on allfours in the grass, and crawl along, putting your hands invariably down on cruel thorns or sharp twigs every time they touch the ground; your back aches with the snake-like posture you assume, and when at length you cautiously raise your head above the grass and dare to look frankly before you, you find the zebras have moved on again, and you either crawl after them, infatuated with the love of hunting, or in desperation foolishly fire your gun at a distant speck, and of course miss, when all that remains of the animals you have stalked is a light cloud of red dust hanging in the hot air. And now you become fully conscious of how foolish you have been to leave the caravan. How hot the sun is! And your blistered feet ache as 
you limp back through the stubbly grass to find the track once more, of course tripping up a dozen times over unseen stumps and stones, and finally reaching the road to see your caravan represented by a few white specks in the extreme distance, these white specks now hurrying on with aggravated speed, just as if they knew you were limping painfully after them, and wished to pay you out for the many times when, they being tired and halting, you, burdenless and fresh, had remorselessly driven them on. And so with many sensible reasons you vow that nothing shall tempt you from the road again, for, even supposing you killed anything, can you stop the caravan for many hours while the meat is cooked and the skin cured? Of course not, why-and here you interrupt these reflections by exclaiming excitedly to your servant, "Oh, look here; I can't stand this. Give me my gun-sh! don't you see that sable antelope-there! standing under the shade of the big tree;" and so hurriedly taking aim you fire, and oh! joy, the antelope falls, evidently wounded, but, alas! not to the death, for it is up and off again before your next shot can finish the work, and like an idiot, you forget your sore feet and fatigue, and go racing after it over stocks and stones till once more you find it is in vain

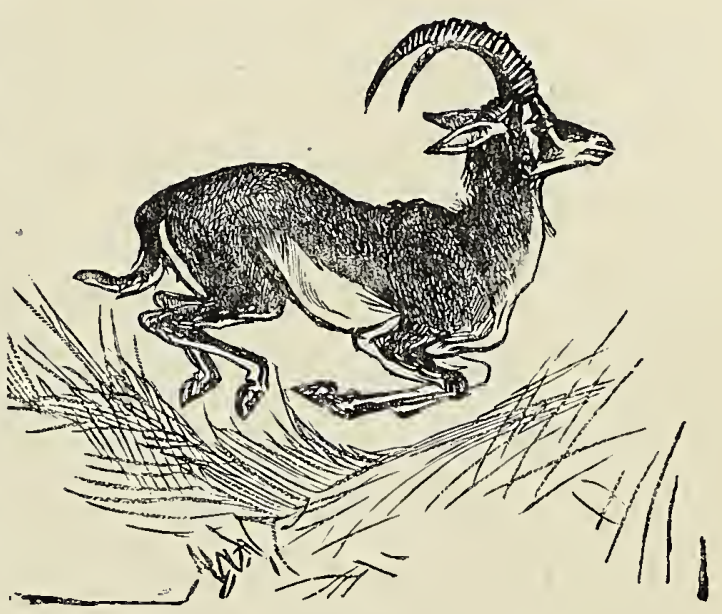

Fig. 21. Sable Antelope. to combine the cares of a marching caravan and the pleasures of the chase.

The expedition had been toiling on across the hot 
plains of Lanjora through the sultry afternoon, and now towards evening stopped to lay down its many burdens amid the dusty tufts of scorched grass round the base of a great mimosa-tree. Only one hour might we rest, for water lay two days behind us and one long day's journey in front, and we intended but to stretch our tired legs on the lumpy soil until the obscurity prevailing after sunset was dispelled by the uprising of the full moon. Then beneath her cooler rays we should journey on towards our goal for half the night, and so be spared a longer walk through the heat of the morrow's sun. The day had been sultry, and, though the rainy season was over, the western sky was a mass of lurid clouds, which in one part of the horizon were particularly dark and concentrated. I knew what caused this, and what object these cloudmasses were jealously concealing like the courtiers and officials who surround the person of some Eastern emperor ; and I, who had journeyed many weary miles to see the greatest snow-capped mountain of Central Africa, impatiently longed for some giant broom to clear the sky of those heavy mists and vapours which now hid him from my gaze.

Slowly a globe of yellow-white rose in the east and mounted into the clouds, from whence a softened light descended, and showed the track across the plain winding away like a crooked snake towards the west. With many an impatient sigh and grunt the weary men took up their burdens, and I, no less tired, but compelled to show my porters an encouraging example, staggered on to my blistered feet and limped along in front of the caravan, which, once more on the move, jogged on with little heart till midnight. Then we could no more; so, making fires to keep off the wild 


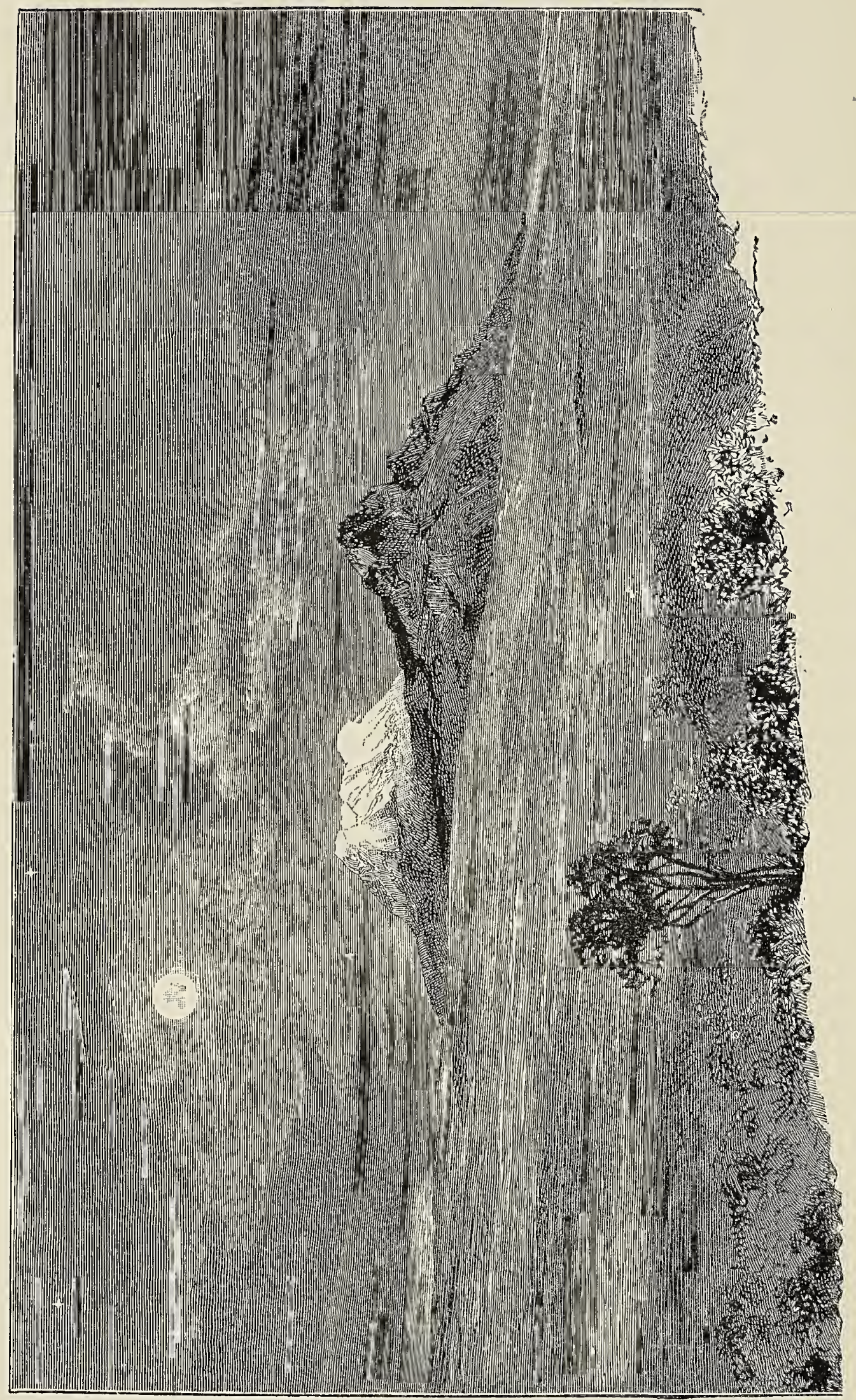

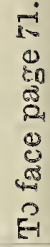


beasts, we stopped to rest till dawn. With the falling temperature of the small hours, a brisk wind arose from the heated plain and swept the clouds from off the sky, all except the mass that obstinately clung to Kilima-njaro. Feverish and over-tired, I could not sleep, and sat and watched the heavens, waiting for the dawn. A hundred men were snoring around me, and the night was anything but silent, for the hyenas were laughing hideously in the gloom outside our circle of expiring embers. At five o'clock I woke my servant Virapan, and whilst he was making my morning coffee I dropped into a doze, from which, at dawn, he roused me, and pointed to the horizon, where, in the north-west, a strange sight was to be seen. "Laputa!" I exclaimed; and as Virapan, though he had read "Robinson Crusoe" and the "Arabian Nights" in his native tongue, had never heard of "Gulliver's Travels," I proceeded to enlighten him as to the famous suspended island of Swift's imagining, and explained my exclamation by pointing to the now visible Kilima-njaro, which, with its two peaks of Kibó and Kimawenzi and the parent mass of mountain, rose high above a level line of cloud, and thus, completely severed in appearance from the earth beneath, resembled so strangely the magnetic island of Laputa.

Kilima-njaro was weird in the early flush of dawn, with its snowy crater faintly pink against a sky of deep blue-grey, wherein the pale and faded moon was sinking, and the stars were just discernible; but as the stronger light of perfect day prevailed, and the clouds which concealed the base of the mountain disappeared, its appearance was disappointing. Owing to an atmospheric illusion Kilima-njaro, which was in 
reality about forty miles distant, appeared to rise from the plain just beyond a distant clump of trees, and its greater peak of snow, so distinctly crater-like in form, together with the lesser and more jagged Kimawenzi, were as hard and commonplace in look as the cheap Italian water-colour drawings of Vesuvius, charged with "body-colour," and devoid of ærial effect. Kilima-njaro, now, was not imposing, and I soon ceased to realize its great height when it looked not much farther off than the farther groups of trees. As the day grew warm it was once more hidden behind layers of clouds, and I marched on towards my destination somewhat disappointed.

For some two days since leaving the mountains of Taita we had been crossing a waterless tract with poor herbage of dusty-brown or yellow-white, and grey, withered trees, and real verdure had been denied us; but now on reaching a point within some thirty miles of Kilima-njaro a change of an agreeable character came over the scene. ${ }^{2}$ Tall umbrageous trees cast a welcome shade over the short herbage, which was closely cropped like a lawn by the many herds of antelopes. The bushes were vividly green, and some of them bore tufts of bright-coloured flowers. Many birds frequenting the bushy trees attested the proximity of water-we were, indeed, close to a little affluent of Lake Jipe-and the feeling that we were now without threatened thirst added to the pleasure of the morning's walk, and promised for the future less arduous journeyings. I was, therefore, beginning to relax my strict watch over the men, and knowing

2 We were within the benign influences of the mountain, and had entered the area of perpetual moisture surrounding its cloud-capped peaks. 
there was no need for hurry now that we were perceptibly nearing our goal, I was sauntering along easily in advance of the caravan, when my servant Virapan tugged me by the shoulder, and said, "What is that big animal, sir?"

I looked along the path in front, and saw, to my great astonishment, a lion quietly trotting ahead of us. As he heard the sound of a voice he unconcernedly looked round, gave us one penetrating glance, made a few hesitating steps, and then stopped to stare again. A mad impulse to fire seized me, and although my sporting gun was behind with the caravan, I took the Snider from my servant's hands, aimed it hastily, and fired. No sooner had the smoke cleared away than I saw the lion bounding away in great leaps over the low bushes, evidently untouched by the bullet. He entered a dense mass of thorny acacias and there stopped. My head-collector coming up, we followed him to this refuge, and I can assure you I felt then anything but comfortable, for we could see, amid the thickly-interlaced twigs, literally nothing, while a deep ominous growling reached our ears, so strangely divested of "locality" that we could neither of us determine the exact spot from which it proceeded. We now decided to withdraw with all due caution, and backed respectfully from the presence of the king of beasts till we had once more regained the road, where we found most of the carriers awaiting anxiously the result of our encounter. Disliking to be baffled, I proposed that we should organize a regular battue, and drive the lion from his shelter, but nobody liked the idea except my Indian servant, who was inadequate for the task, so I reluctantly abandoned what might have been a spirited lion hunt. Towards the afternoon 
of this day, which had begun in such an exciting manner, first with the view of Kilima-njaro and next with the lion, we left every trace of sterility behind us - the very mimosas and acacias becoming changed and improved in their appearance, exhibiting more foliage and less thorns - and the track winding through superb avenues of lofty umbrageous trees. After many days of journeying in a sun-scorched wilderness my tired eyes here rested with delight on the soft green of the exuberant vegetation, while I no longer tramped along a stony road under a blazing sun, but followed a soft leaf-covered path plunged in absolute shade. We were now in the precincts of Taveita, but before we actually entered that African paradise we were obliged to halt at a gateway in the forest where the path was blocked with an immense structure of tree-trunks. Just a tiny aperture was left, an entrance three feet high in the shape of a delta, and through this we all had to wriggle and crawl, while several of the loads would scarcely admit of passing through, and only the most ingenious twisting and turning effected this end.

The first barrier passed we found ourselves in a small square chamber, really a space between two gateways, where in times of war and rapine suspicious visitors could be inspected and interviewed before being allowed to enter. There was, however, no one to scrutinize us in this gateway, because the "passport" regulations of Taveita have been greatly relaxed of late years, but a few decades back this elaborate hindrance to free transit was the only protection the wretched Taveitans had against the merciless assaults of the Masai robber bands. By erecting these wooden obstructions across the only feasible approaches to their forest stronghold 
they checked the impetuous onslaught of the brigands, and were able, moreover, to kill many of the bewildered Masai with their guns before these people could creep round or destroy the barrier. A's the Masai never throw their spears, but always use them and most of their other arms in hand-to-hand conflict, they are naturally at a disadvantage when opposed to an enemy who has entrenched himself behind a slight fortification and can use his firearms to advantage.

Passing in through a second and easier doorway, we found ourselves in full view of banana plantations, standing out in glistening green against a background of stately forest. Here and there small groups of beehive huts stood in a clearing, surrounded by tall wooden fences. We had fired a salute of guns when approaching Taveita, to announce to its inhabitants, with many a sonorous boom re-echoing through the forest alleys, that strangers were arriving with peaceable and friendly intentions, and a wish to trade. As I was in the act of crossing a narrow rivulet, by means of the slippery stem of a banana that has been thrown across it, I caught sight of the first natives, who were on their way to inspect our caravan, and when I looked up, and they saw my white face and strange costume, a glad shout of surprise went up from their wide mouths, and they pushed forward to seize and shake me by the hand.

Such an unusual and demonstrative welcome gave me a pleasant impression of Taveita to commence with, and this, I am glad to say, was strengthened as time went on. Its inhabitants were, however, not only remarkable for their bonhomie and kindly disposition, but presented other notable characteristics which were not long in impressing themselves on my observation. 
Firstly, their hair was generally worn in long strings, where the wool was stiffened with fat and red clay into a number of rats' tails. There were generally one or two incisors knocked out in the upper jaw, the lobes of the ear were enormously distended with wooden cylinders or rings, and lastly, the Wa-taveita, like most of the natives of Inner Eastern Africa (and unlike those of the West), were totally ignorant of what we call decency. I would like to express this more delicately by saying that they were innocent of all clothing, but this was not the case, as many of the inhabitants wore cloth, or skins, round their shoulders, either for adornment or when the weather was chilly with breezes blowing off the snow-capped mountain.

I felt at home with the Wa-taveita from the first, for they were thoroughly conversant with Swahili, the coast language-the French of Eastern Africa, and as I also knew this tongue we had at once a medium of ready communication. So the natives who had come to meet our caravan, and trotted along by my side to direct me to the accustomed camping-place, chattered as we went and not only asked for, but imparted, information. One of the first questions was, "What is your name, white man?" "Johnston." "Jansan?" they shrieked laughingly. "Why you must me Tamsan's (Thomson's) brother." (Mr. Joseph Thomson, on his way to Masailand, had passed through Taveita, leaving a very pleasant impression behind him. As by an odd coincidence we were both white, and our names, in the natives' pronunciation, only differed in the initial consonant, the evident inference was that, to use the natives' phrase, "We were of one mother.") It would have been of such little use trying to disabuse them of this happy and likely idea that I accepted tacitly the suggested 
relationship, and it was soon noised about Taveita that Bwana Tamsan's brother was come, and many of Thomson's old friends flocked to greet me.

Our camp was established in one corner of a vast clearing, nearly square in shape, whereon certain Swahili traders, en route to Masai-land, had built a temporary and straggling village of palm-thatched huts to accommodate their wives and concubines during their absence in the wilds. As soon as my tent was up, and - my goods were properly stored and placed under the supervision of a trusted man, a food allowance was measured out to the hungry porters of the caravan. That is to say, a bale of cloth was unpacked, and each man received three ells (or "hands," as they were here called) of white American sheeting, which was to pur. chase him sufficient food for three days. After the distribution of cloth the men dispersed for the rest of the day to forage in the Taveita market, and I was free to attend to my own affairs and to receive my new acquaintances. Firstly, however, the tent was closed, and I had a good and much-needed bath, for almost since leaving the coast water had been so precious that we had feared to lavish even a teacupful on the toilet. But here we had a glorious running river, crystal clear, and cool; and were it not for the inconvenient publicity which a dip in the stream itself would occasion at this moment, I should have strongly preferred it to a cramped bath in the hot tent. Nevertheless, a wash of any kind and a complete change of clothes was very refreshing, and when once more my tent door was thrown open to the throng, and I appeared before the elders of Taveita seated on my camp chair, I felt sure my white face was several shades lighter than on my arrival. This little colony of quiet agriculturists, known as 
Taveita, is unlike the neighbouring states in being a republic, or commonwealth, administered rather than ruled by an oligarchy of four or five important men known as the "Wa-zēe,", or elders. There are really two entirely distinct races inhabiting Taveita-the Wakwavi, a tribe of settled Masai who have turned from lawless robbers into honest, thrifty tillers of the soil, and the Wa-taveita proper, a people of Bantu stock, allied in origin to the A-kamba farther north and the Wa-čaga of Kilima-njaro. The Wa-taveita predominate over the Wa-kwavi in numbers, and the elders are mostly of the former stock. These functionaries had come to greet me with little gifts and offerings such as they deemed most acceptable to me, and, of course, expected an equivalent present on my part. One man had brought a baaing, reluctant sheep, and tied it to the tent-pegs. Another thrust into my lap a couple of fowls, strongly fastened together by the legs, but otherwise not disturbed in equanimity, for they pecked inquiringly at the buttons of my jacket. A third member of the Taveitan Legislative Council pointed to a basket of corn-cobs as his donation, and so on. Each in return received about twice the value of his free-will offering in cloth and beads, and, I am sorry to say, in accordance with African custom, they at first affected to be dissatisfied with the return-gifts, and tried to haggle for an increase, but finding this "try on" of no avail, immediately resigned themselves to the inevitable, and marched off very contentedly with what they could get. The remainder of the day was utilized by the men in buying food, while I availed myself of the unwonted rest to reciuit my strength, and so did nothing in the way of active exertion beyond skinning a few birds. 
About half-past 7 a.m. on the morrow we resumed our journey towards Kilima-njaro. I was going to establish myself at the Court of Mandara, chief of Moši, a state on the southern flank of the mountain. Until my return from East Africa so little was known of the politics of Kilima-njaro, that it was popularly supposed there was but one paramount ruler of the district, and he, Mandara, chief of Moši, who had sent letters to and exchanged presents with Sir John Kirk, and had seen, perhaps, each of the four or five Europeans who had approached Kilima-njaro. The way to his country lay first west, then north-west of Taveita, and the distance to be traversed was some twenty-seven miles.

After leaving our camp we first had to cross the River Lumi, over which a curious bridge was thrown. Some years ago the Wa-taveita were much inconvenienced by repeated floods, which rendered their river (fed from the snows of Kilima-njaro) dangerous or impossible to ford, and consequently cut off one-half of the colony from communication with the other. The idea of bridging this five-yard-wide rivulet was too difficult for the native mind, so the elders of Taveita contracted with a Swahili trader to do the job. The price was to be a bullock. The trafficker in ivory and slaves was not long in his operations. Selecting one of the finest and straightest trees growing on the summit of the river bank, he set to work with his followers, and with repeated chops severed its trunk near the base. The tree fell forward straight across the river from bank to bank, needing but the lopping of its superfluous crown of leafy branches to from as satisfactory a bridge as the natives required. As, however, its trunk remained rounded like a cylinder, 
and was polished and extremely slippery with the constant passage of naked feet, it offered anything but a secure foothold, and as a fall from any part of the bridge would be rather dangerous, I preferred fording the stream on a man's back to risking the transit of the tree-trunk, although all my men, with heavy burdens on their heads, crossed it without mishap.

Leaving the river, we walked for about two miles through very magnificent forest, where Raphia palms reached a great development; next we emerged abruptly on an unattractive wilderness of low thorny shrubs and coarse grass. The land rose gently before us towards the huge mass of Kilima-njaro, which was at present screened with louring ..clouds. In the middle distance, were broken chains of jagged hills, interspersed with isolated hillocks and mounds of conical shape, suggesting the idea that when the great discharge of eruptive matter from the two huge volcanoes of Kibô and Kimawenzi was temporarily or permanently checked, the sick earth broke out all over the irritated surface with minor pustules and pimples through which the disturbing matter was discharged, the present aspect of the mountain and its vicinity being the result of the scars and hardened scabs of these now healed-up earth-boils. We walked for some ten miles over an unattractive country devoid of water, and little better than desert. The hills were sparsely overgrown with sad, grey-Iooking trees, almost leafless or else sprinkled with scanty foliage of an olive-green. In the rolling plains at their base there was little to break the monotonous yellow of the withered grass. Now and then was seen a Bauhinia shrub or stunted tree, with its bifid leaves that afforded as little shade as the poor foliage of the eucalyptus, 
or a thorny mimosa with flattened crown and red trunk, like a conventional tree from a child's box of toys; or, lastly, a few inconspicuous nameless shrubs, with leaves of a shiny grey colour, like those of most plants living in semi-desert countries. Once or twice we crossed the dry bed of a torrent and found therein a more varied but scarcely more pleasing vegetation. Rampant euphorbias, with fleshy, snake-like, coiling stems armed with horrid spikes, trailed themselves triumphantly over unresisting shrubs; acacias, which from sheer viciousness had almost done without leaves to bestow all their productive powers on the development of terribly efficacious thorns, threw out their cruel grappling-hooks over the path and ripped up our faces, hands, or clothing as we passed. Other plants of the lily tribe (debased and wicked members of a beautiful family) grew like swords stuck in the ground point upwards, and woe betide any careless person who put his hand on the apex of their rigid, bladelike leaves-their rapier-points would pierce his palm as readily as a sword of steel. But as we had crossed a ridge stretching out into the plain, and our path, from sloping upwards, descended a little on the other side, this fantastic vegetation, befitting the precincts of some horrid mediæval monster's lair, modified its repulsive character, and became intermixed with shrubs and grass of vivid green, while to our joy we descried some half a mile ahead a belt of dense purplegreen foliage, which in these African wildernesses always denotes the presence of water. In fact, a few minutes' walk took us from the dull white glare of the hazy noontide in the open, shadeless waste into a cool, delicious bower of deep green shade, where at first, so great was the contrast, we blinked our eyes and could 
see no details. Then I made out a clear limpid stream slipping along over small stones, or forming still, quiet, mirror-like pools be-

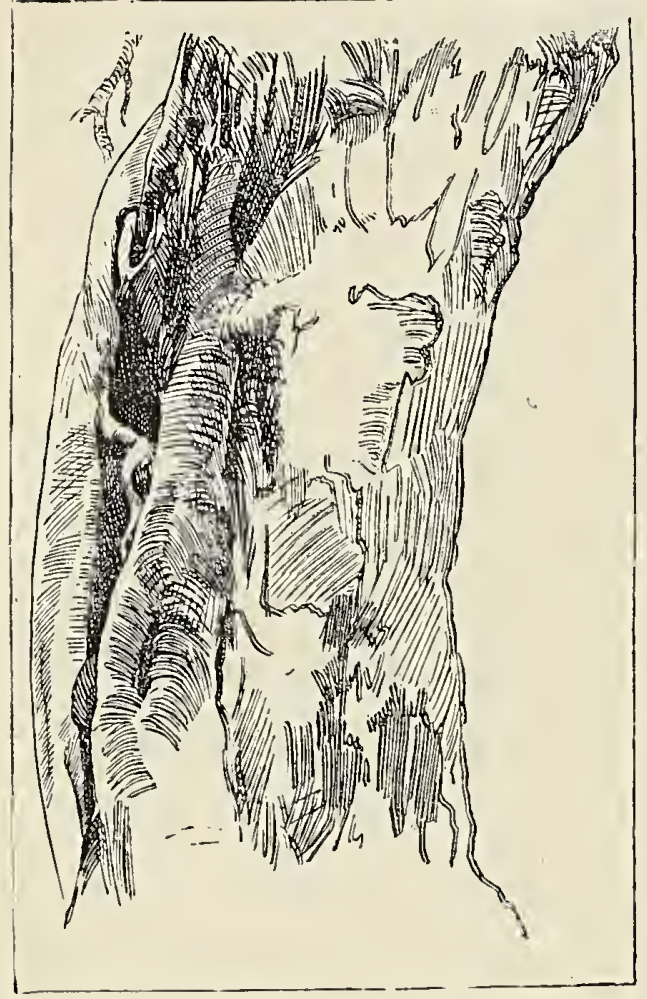

Fig. 23.-The Strange, Creeper. tween grey walls of smooth, massive tree trunks, which resembled stone in their colour and polish. Often the severity of these broad wooden bulwarks would be tempered with rich masses of foliage depending from the smaller boughs above, and breaking up with graceful and fanciful detail the somewhat formal outlines of the vista. The tree trunks that bordered the stream. were many of them singularly broad in girth. In one or two cases they were grappled with by parasitic figs that wound themselves round their stout victim like vegetable boaconstrictors, or, as in the example illustrated, like some huge, long-bodied lizard. In the shade of this green tunnel, where the little river-which the Swahili traders call the Mto wa Habari, or "River of News"-bored its way through the forest belt, we cast down our burdens and prepared to rest and eat our midday meal. Succeeding the white glare of the shadeless open country this sweet and cool retreat beneath a dense over-arching canopy of foliage was inexpressibly soothing after our weary walk from Taveita. The men went off to the other side of the stream, and were lost to sight in the woodland; I only 
knew of their presence by the occasional murmur of voices coming from their camp, and by the blue curling smoke of their cooking fires, which ascended in gentle puffs through the network of leafy boughs. My portable table and camp-chair had been unfastened, and the former was set up on a level patch of sward

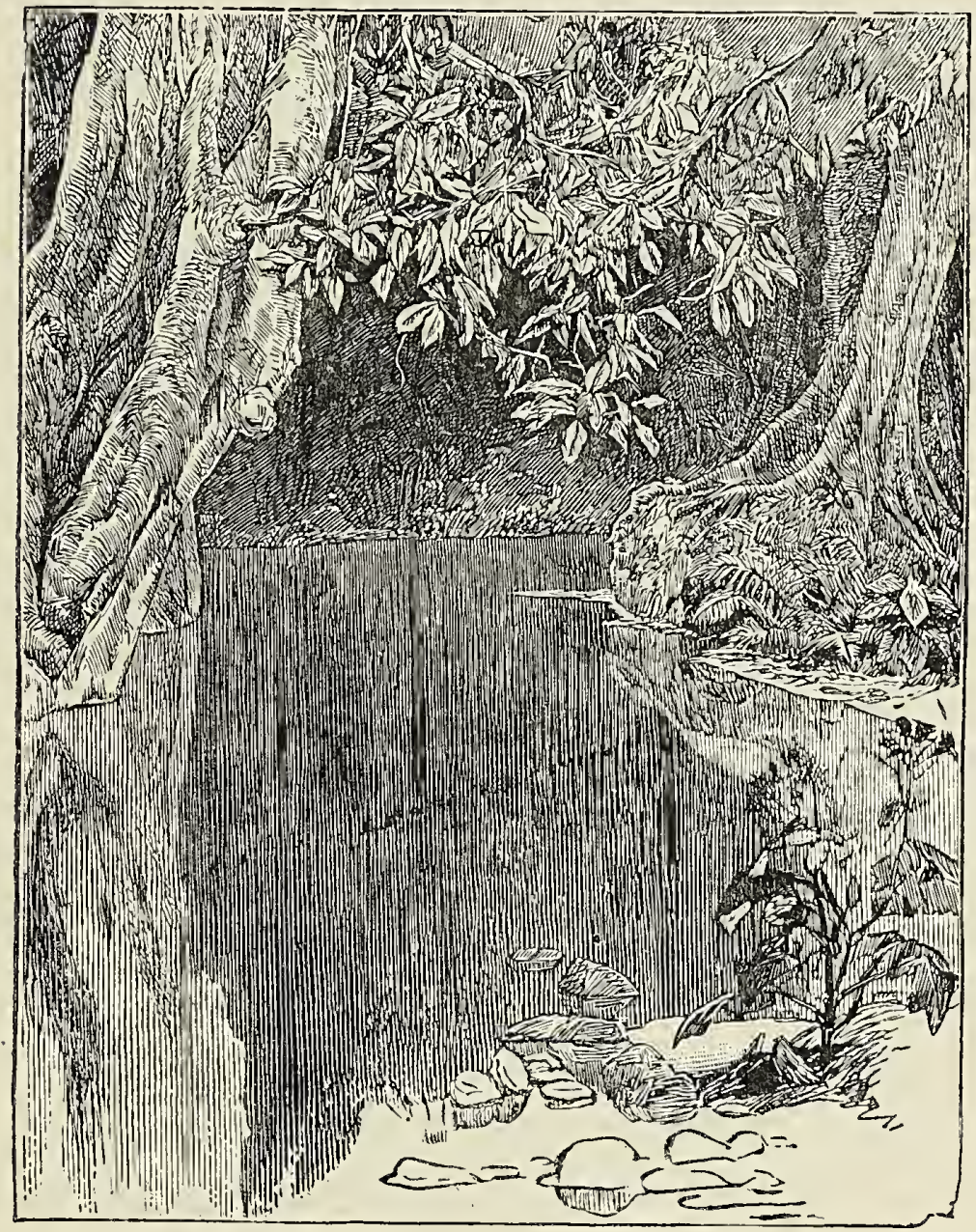

Fig. 24. - The River Habari.

by the waterside, and was quickly covered with a snowy cloth from the canteen, while my servant further laid it with the enamelled iron plates and knife and fork and napkin for my solitary meal. To pass the time and forget my impatient hunger whilst the repast was being prepared, I sat down on my camp-stool and made the rough sketch of the stream which is preG 2 
sented here: but my artistic labours were gladly laid aside at the announcement that lunch was ready, and I sat down with keen satisfaction to my tempting table, which had been further brightened by a little bouquet of wild flowers gathered and arranged by Virapan. Would you like to know what I ate? If so, I will endeavour to describe this one meal, so that you may better realize how I ordinarily fared in Africa while on the road. There was a plate of fowl soup to begin with, nicely flavoured with onions; thickened with a little maize-flour and rice. Two thin slices of toast lay beside it, made from some loaves my cook baked while we rested at Taveita. After the soup was finished came a little good curry made from the soup meat, and flavoured with cocoanut milk (for we had carried a sack of cocoa-nuts from the coast). Then, when the curry is eaten, a fresh plate was brought me, and a dear old battered calabash about half-full of delicious honey, which tastes like the smell of mimosa blossoms; and after eating some of this spread on a slice of Taveitan bread (which deserves its recipe in brackets: two pounds of maize-flour, half a cup of palm wine, a quarter of an ostrich egg, a pinch of salt, and a spoonful of butter), I wound up my lunch with a cup of fragrant tea, and sat over an old book, while my men packed up the impedimenta once more, and started again on the road towards Moši.

The afternoon was sultry, and we felt so meritorious in having accomplished our ten miles before lunch, that there was a general disposition to take things easily; besides which, our path led us through much more pleasing country than in the morning. We crossed a biggish stream (which rises near the summit 
of Kilima-njaro, and is called the Kilema River), then a smaller one, and at last, near our preordained camping-place for the night-a charming "almost-island" (this term sounds more expressive than peninsula), nearly surrounded by the little Mkuyuni River. You could hardly imagine a more romantically beautiful spot than this in which I camped. It was only approachabie at one point-where a huge tree trunk spanned the tiny gulf between the bank and the island, and formed a bridge over which to pass to and fro. It was this fallen tree which had made our campingplace a peninsula, for in lying across the stream its lower branches acted as a kind of dam by stopping all the stones, earth, and refuse washed down by the rivulet, and so forming in time a firm barrier that sent all the water careering round the other side of the island. In the centre of this pretty peninsula rose a gigantic sycamore fig-tree (which among the Swahili traders gave its name to this stream-Mkuyu -a sycamore; Mliuyuni-the place by the sycamore) -and under the vast canopy of its mighty branches the whole caravan encamped, feeling tolerably protected from the weather by the leafy thatch o'er head.

In all my previous African experiences I had never known what it was to be in real danger from the attacks of lions. The king of beasts had hitherto exhibited a provoking shyness and a persistent dislike to cultivate my acquaintance-so much so, that I often used to complain that I gained nothing from my wish to know the lion at home and that I might learn more about him in Regent's Park than in the savagest wilds of Africa. But ever since the troubled night which we spent at the Mkuyuni, I ask no more for leonine visits, especially in the darkness of the small 
hours, and will content myself with an occasional journey to the Zoological Gardens, where I can see this grandest of cats in a safe and comfortable cage. Soon after we had retired to rest on this occasion, when the men had begun to snore round their fires, wrapped up in dusky white cloths like so many mummies, and when the leader of the caravan was curling himself snugly between the blankets, the most terrific roar you ever heard startled us all into sudden wakefulness. Though the lion that uttered it was probably forty or fifty yards distant, the sound of his thunderous bellow seemed to come from our very midst. I sat up in bed and looked uneasily around. me, but nobody complained of being eaten, so I lay down again, and even began to think this very interesting and very African, full of local colour, and so on. But now on our right and left, on either side of the river, a chorus of loud roaring began. The night was as yet pitchy dark, for the moon would not rise till the early morning. We could see nothing beyond the blaze of our cordon of fires. However, feeling that it was despicably tame to lie still in bed and go to sleep while my porters shivered with fear, I arose, took my gun, and fired into the bushes where the roaring was loudest. T'his, the men informed me, was the unwisest thing I could do ; of course I killed nothing, and the noise of the firearm, instead of aweing the lions into silence, only seemed to exasperate them. I certainly never heard anything like the noise they, made. My men averred that we were surrounded by ten beasts-I suppose they distinguished ten various roarings; certainly, the next morning, when we examined the precincts of our camp, the many footprints of different sizes which were marked in the soft 
vegetable soil of the surrounding woodland and in the red soil of the river bank, indicated unquestionably that a whole troop of lions had been in our immediate vicinity during the night. I noticed a curious fact connected with the unseen approach of these beasts. Whenever a lion was nearing our camp, and before he attested his vicinity by a roar, we were, when we had learned to read the warning, made aware of the fact by the sudden nervous twittering of the small birds in the branches above. It was a tremulous diapason of fear, most singularly impressire. On several subsequent occasions the approach of large wild beasts has been signified to me in the same manner.

The morning that succeeded this disturbed night saw us taking the road soon after sunrise, all in the best spirits at the approaching termination of a long tramp. We walked on for about two hours through low forest country, clad with scrubby trees rarely exceeding fifteen to twenty feet in height-an undergrowth of large-leaved solanaceous plants, which grew so regularly and on a soil so tidy and devoid of weeds or grass, that I at first took the country to be cultivated, and imagined these thriving herbs to be some kind of native tobacco. The wild flowers (ground orchids, hibiscus, clematis, and a kind of sunflower) were very beautiful and quite brilliant in their displays of colour. Within about an hour's journey from the confines of Moši the path divides into two tracks, one going still due west and keeping to the plains, the other turning round towards the southern flank of Kilima-njaro, and mounting upwards. Here, at this junction, we encountered some rather disreputable Wa-swahili, shabbily clothed (it is the wearing clothes, by-the-bye, which enables one in this country to distinguish between the 
Wa-swahili, or natives of the coast, and the people of the interior), and armed with Snider guns. They were courtiers of Mandara's, sent thoughtfully by that chief to meet us, and see we did not take the wrong road. Their greeting, however, was too familiar and impudent, to my taste, and I began to have a lurking presentiment that these scampish parasites of the chief of Moši might prove inimical to my mission; for, in the interior here, white men are looked upon by the coast traders as spies on the slave trade, and though outwardly fawned on and flattered from fear, yet are secretly, thwarted and hindered in every possible way, especially as regards the native chiefs, whom the $\mathrm{Wa}$-swahili are desirous of alienating from enlightenment. However, keeping these reflections to myself, I toiled along the ascending path, and after an hour's stiff pull, caught a glimpse of an enchanting land. Hitherto our track had led through thick bush, with every view of the surrounding country shut out. Now we had entered a clearing, near to cultivation, and nothing impeded our view. Northwards the vast mass of the mountain stretched upwards into the heavens, its twin peaks shrouded in heavy cumulus clouds, and below the clouds, the billowy swell of hill upon hill and ridge succeeding ridge was a deep sullen blue under the heavy shadow of lowering cumuli. Then came a few lines of dark purple-green forest, still in shade, and, in the middle distance, where the sunlight broke upon the scene, the gentle, rounded hills gleamed out against the sombre background with their groves of emerald-green bananas marking the commencement of the cultivated zone. Nearer to us succeeded deep ravines, with thread-like cascades, clumps of tidy forest-just a few tall trees left growing out of religious veneration-smooth, sunny downs, 
whereon flocks of goats were grazing, patches of freshlytilled soil, cultivated fields, hedge-lined lanes, and lastly, the red denuded hill, the No-man's Land, the Pisgah, on which we were standing to gaze on this Promised Land, towards which for thirteen days we had been toiling through the wilderness. There was, however, no preordained restriction to my entering it, nor was my lieutenant qualified to play the part of Joshua, so I, who had been pausing here to let all my followers come up with me and regain their breath, once more took up my staff and marched into Mandara's country. A ravine and a small stream separated us from the collection of bee-hive huts and gardens which formed his capital, and before crossing I stopped and gave the order for a salute of twenty-one guns to be fired (Mandara had heard from the Arab traders that such was the number of guns accorded to independent Royalty, and insisted on it). This accomplished I climbed the steep red path before me, and arrived at a kind of open green shaded by fine spreading trees. Here a lot of men were squatted with their shining broad-bladed spears stuck upright into the ground. They took but little notice of me, and I afterwards found that Mandara's soldiers think it beneath their dignity to be surprised at anything. I nevertheless scanned them with considerable interest. Many were in their war-paint and were dressed to imitate the dreaded warriors of the Masai. On their heads would be either a huge circlet of ostrich feathers, or an imposing head-dress made from the black and white mane of the Colobus monkey. The same animal's skin, with its long silky hair, of a most startling contrast in colour, was roughly fashioned into a covering for the shoulders, arranged so that a short lappet hung over the breasts, and the 
linder part of the skin covered the back, while the long white tail of the monkey was disposed in such a manner as to suggest its being actually a caudal appendage of the wearer. Other soldiers wore, in place of Colobus skins, huge thick capes round the neck and shoulders, resembling the fur capes of our coachmen. These were generally made of cock's feathers (black), or of the short, dark feathers of the ostrich. Round the ankles were short " raffs" of goat-skin, and often a "ring" of goat-skin-that is to say, a tag of hide with a slit through it-was thrust on to the finger. The lobes of the ears were distended with plugs of wood or hollow wooden rings, or hung with an infinitude of very fine steel chains (a local manufacture). Various other ornaments or charms decorated the body, but in all cases adornments and coverings were so disposed as to strictly avoid any purpose of what we should call decency, these people of Kilima-njaro, like those of Taveita, showing no idea of employing clothes for concealment.

I had time to pause and make these observations, for we had come to a halt. After passing the groups of soldiers whose attire, or the want of it, has just been described, we had gone through a hedge of dwarf dracænas and scarlet-flowered aloes, and were arrived on another open space at the back of Mandara's compound. Hereupon we were directed to pitch our camp. The tent was soon up, and the loads were carefully piled in front of it, packed as compactly as possible, so as not to excite too much cupidity by a rash display of wealth. When this was finished, a messenger from Mandara arrived leading an unwilling goat. This animal was killed in my presence, skinned and cut up, and a small piece of the hide was made into a ring for 
my finger, which I was instructed to wear immediately as a sign of friendly peace, a similar bit being cut off and sent to Mandara for the same purpose. ${ }^{3}$ The flesh of the goat was then handed over to my cook, to prepare for my next meal, and, as a matter of fact, it turned out delicious eating, for the slain animal was a plump young gelding, specially fattened for food.

Being informed that Mandara would not pay me a visit until the afternoon, preferring that his guest should eat and refresh himself after his long journey, I had a little leisure to look about me, as far as the laughing, staring crowds of Caga people who thronged the encampment would allow. We were here about 3500 feet in altitude, relatively at the foot of the mountain, but yet with splendid views over the plains, which lay fifteen hundred feet below. All around were signs of agriculture of a high order, and though the people were naked, one could see they were anything but savages. There was nowhere a congeries of houses that could be called a town, but the whole country, where it was cultivated, was equally inhabited. Here and there the yellow thatch of a bee-hive hut peeped out from the green fronds of the banana groves. The fields were intersected with numerous runnels of water, diverted at different levels from the parent streams in the ravines above. The air was musical with the murmur of trickling rivulets and tinkling bells, for the flocks and herds were now being driven in from the pastures to the natives' compounds, to be shut up from the afternoon heat. Wherever the ground was not in cultivation it was covered with brilliantiy-coloured wild flowers-

3 This practice is called by the Wa-čaga "Kisonio." The skin is generally taken from the animal's forehead, and the ceremony is equivalent to blood-brotherhood. 
balsams, hibiscuses, dissotises, green and white ground orchids, scarlet aloes, and numberless species whose

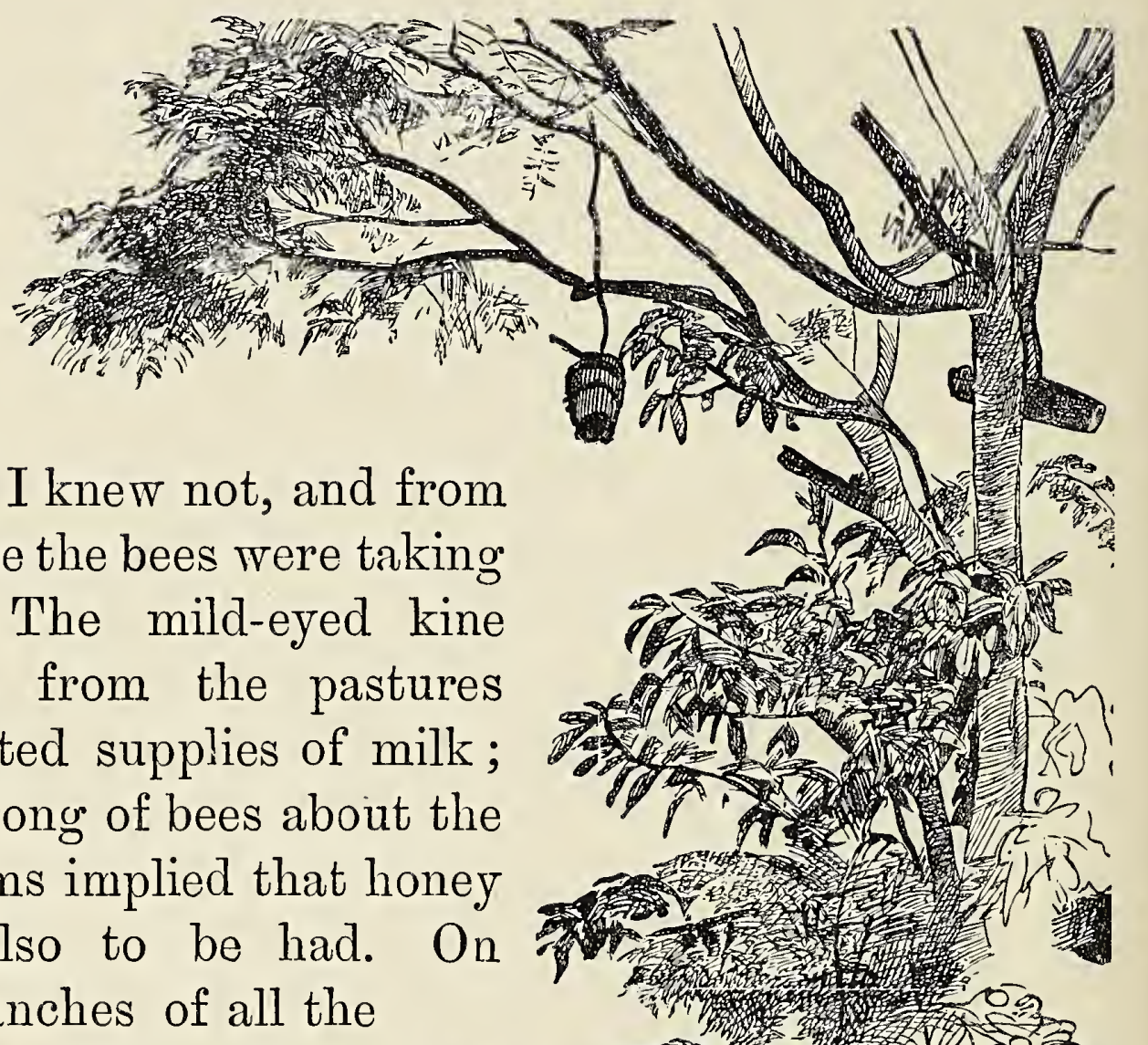

names I knew not, and from all these the bees were taking toll. The mild-eyed kine driven from the pastures suggested supplies of milk; the throng of bees about the blossoms implied that honey was also to be had. the branches of all the big trees hereabouts were hung oblong cases-
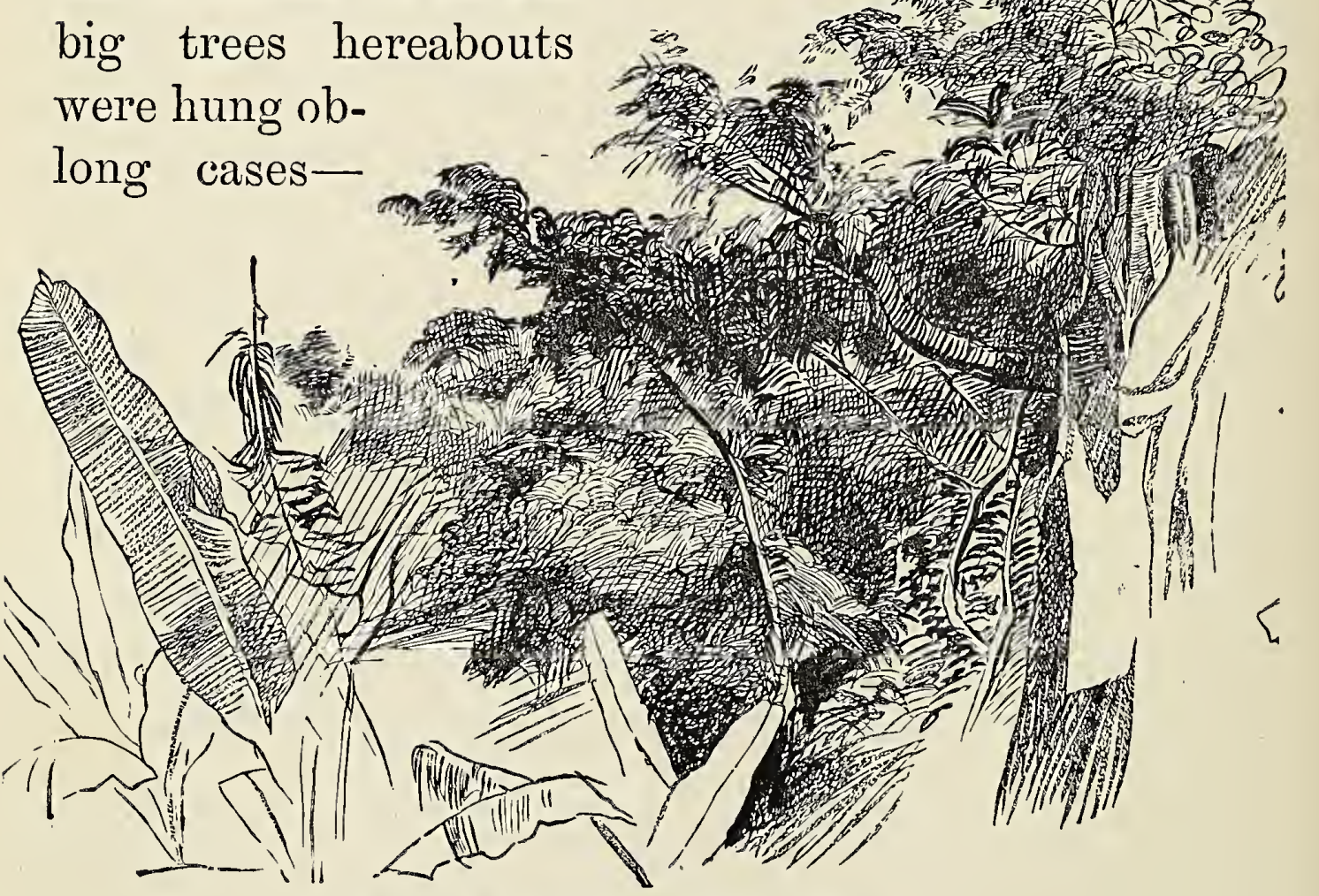

Fig. 25.-Trees with Honey-bozes. 
boxes-made of bark, in which these half-domesticated bees constructed their hives and stored their honey. These "honey-boxes," called by the natives "Mizinga," which word is also applied to cannons on the coast, are familiar objects in East Africa, and may generally be met with in the vicinity of villages. 


\section{CHAPTER V.}

ARRIVAL AT MANDARA'S COURT.

Berore describing my first interview with Mandara, the chief of Moši, it may be well to say a few explanatory words about his actual position and previous career.

By Sir John Kirk's advice I directed my steps to his kingdom and capital in the first instance, for we both imagined that I had only to conciliate this personage in order to be able to range free and undisturbed over the whole of Kilima-njaro.

It was, however, a great mistake- -though one I was a long time finding out-because Mandara ruled over a very small tract of land, and only up to 6000 feet altitude, and being at constant war with his neighbours, and his little kingdom in a continual state of blockade, his protection as far as it influenced a peaceful residence on the upper slopes of the mountain was worse than useless. Had it not been that the time spent perforce in Mandara's country was of little use for natural history purposes-for I could not forget that I had come out principally to study the alpine district near the snow-line, and not the rich but more typically African fauna and flora at lower levels-I should little regret the mouths I passed in Moši, for I regard Mandara as one of the most remarkable Africans I have 
ever met. $\mathrm{He}$ is a man whose portrait should be placed with certain others of his contemporaries, Rumanika, Mtesa; the Kasongo, whose lineaments stand out sharply amid the obscurity of Savage Africa, and whose names, so associated with the pioneers of African exploration, will certainly not fall into oblivion.

As far as we can trust to his own traditions as to his ancestry, it would appear that his grandfather was a younger brother of the ruling chief of Mpoko, or Mpokomo, a state lying to the west of Moši. He seems to have been a great warrior, and protected his few subjects so zealously against the raids of the Masai (who at that time menaced the very existence of the Čaga mountaineers), that he formed them in time into a prosperous and thriving community. The origin or etymology of the name Moši (pronounced in English "Moshy") is not very clear. In the language of Taveita it means "smoke," which, from the fact that at all times puffs of white smoke arising from the constant burning of weeds are to be observed, when the land is seen from the plains below, is a not improbable derivation; still it may be more likely drawn from some term in Ki-čaga, the language of the country. As it is sometimes pronounced Muši or Muži, I thought it might have been akin to the common Bantu word " muji," a town or settlement; but as that term becomes "muri" in Ki-čaga, I am still at a loss. However this may be, Moši is the well-known name on Kilima-njaro of the little state founded, as tradition goes, by Mandara's grandfather. This hero is supposed to have fallen in battle with the Masai, and his second-some say his third-son inherited the power. He strengthened his position by marriage, and espoused several princesses of the reigning families in the vicinity of his 
kingdom. From one of these was born Mandara, or as he appears first to have been called, Makindara. The explanation of his name, like that of his state, is not so clear in meaning as are most specimens of African nomenclature. His own subjects pronounce it "Mandara" (Mangdara), and the other inhabitants of the mountain "Makindara." I have sometimes fancied it might be a contraction and corruption of Mange-ndara = Mandara, viz. the Chief Ndara.

Mandara's mother seems to have been a very shrewd and clever woman, and under her long regency the state of Moši flourished. Apparently in those happy days peace prevailed among all the sections of the Čaga people inhabiting Kilima-njaro. Or at least there were no internecine wars, and the only conflicts were occasional skirmishes with the Masai, whenever those rovers tried to extend their cattle-raids to the mountain pastures. But then came the cursed slavetraders-the Swahili Arabs, or Arabized Mohammedan half-breeds-from the Zanzibar coast. Finding the united inhabitants of Čaga ${ }^{1}$ too strong to submit to forcible slave-raiding or kidnapping, they tried to effect their purpose by introducing discord into the local politics. Selecting some particular chief-especially a young, ambitious man like Mandara, when he commenced to reign - they gave him rich presents, and filled him with flattering speeches, and persuaded him that if he took advantage of the unprepared state of some of his neighbours, and suddenly marched an army into their territory, he might not only reign as paramount chief over C̆aga, but would also make a nice

1 At the risk of reiteration I might remind my readers that Čaga is the native name of the entire inhabited districts on the slopes of liilima-njaro. 
fortune out of the sale of slaves. Mandara was not loth to play the rôle of conqueror. He had made friends with the Masai and even obtained their assistance, and he therefore proceeded, under the instigations of the Arabs, to harry, burn, kill, and enslave his peaceful neighbours and countrymen of many little Čaga states. For some time he carried all before him, and the Kilima-njaro market was a famous one for the slavetraders of Mombasa. Mandara, and other chiefs whom in turn they induced to play the same policy, supplied them with slaves at about the cost of two dollars each, and though quite fifty per cent. of them died before reaching the coast-for these poor mountaineers cannot stand the climate of the plains, and perish of fever and nostalgia-still the remainder being remarkable for their skill in agriculture, fetched a high price among the wealthy Mohammedan landowners of Zanzibar. At length a reaction took place. The outraged Wa-čaga formed a league (which is still in force) against Mandara in defence of their hearths and homes, and in spite of his valorous army and his skilful defence, the fortune of war so far turned against him, that he was compelled to fly from his country as an exile. When this reverse in his fortunes took place is not very clear, and Mandara limself is reserved on the subject; but it would seem to have been some ten years ago. The causes which led to his reinstatement are also left to conjecture; but I fancy that his enemies, content with their revenge, retired from his country, and that Mandara, with the help of his friends, the agricultural Masai of Aruša, was enabled to return to Moši. Since then his martial ardour has somewhat cooled, and although he still devotes much time and attention to the drill of his army (which con- 
sists perhaps of 1000 men, the pick of Moši's manhood), it is more for purposes of defence. He occupies at present somewhat the position, in Kilima-njaro politics, of a Napoleon who has returned from Elba, but prudently avoids a Waterloo.

Though this remarkable savage never, in his most successful days, ruled over a larger territory than the postal area of London, yet the fame of his intelligence, his kingly manners, and his bravery extended far and wide in Central Africa, borne by the Swahili traders, who journeyed in all directions between the Victoria Nyanza and the Indian Ocean. Slave-traders and slave-kidnappers though these men are, their influence over Africa has had a certain civilizing tendency.

These strange Arab mongrels, who have become almost an independent race, merit the designation of Africa's land-carriers. They journey for purposes of trade over nearly all the district which lies between the Victoria Nile, Abyssinia, the great lakes, the Upper Congo, and the Zambesi. After visiting such a chief as Mandara they may find themselves at the court of Mtesa, the late chief of the Uganda, and they will carry the fame of one king to another. Mandara alleges that he held communication (I suppose this consisted in the transmission of Arabic compliments) with Mtesa of Uganda, and with Mirambo of Unyamwesi, by means of such far-travelling traders as Jumba Kimemeta, in whose company Mr. Thomson crossed Masailand. This is quite possible; at any rate through the Swahili merchants Mandara first heard of her Majesty the Queen, of Sir John Kirk (the "Baloza"), and of Sayyid Barghash of Zanzibar. The same itinerant pedlars informed this Central African savage, who has never been thirty miles from his birthplace, nor visited 
a civilized settlement, nor seen the ocean, or a ship, of the leading factors in Oriental politics, how the Waingrezi (English) possessed India; how the Wa-fransa (French) had tried to conquer Madagascar with their "manowari" (men-of-war); and how the Wa-dachi (Deutsche $=$ Germans) were making treaties with the chiefs of Usagara. It is no doubt largely through Swahili merchants that the mind of Mandara has been prepared, since my departure, for the acceptance of the suzerainty of Sayyid Barghash of Zanzibar. He was shrewd enough to know that before the advent of Europeans he could not stand alone, and he greatly dreaded the coming of French or Germans. His suspicions and fears of these two leading European nations were positively ridiculous, considering that they both ignored his existence, and had never at any time evinced the slightest wish to annex Kilima-njaro. All that he knew of them was of course derived from the exaggerated accounts of the Wa-swahili, and it is a curious thing that these people of the Zanzibar coast should so detest the French and Germans. Some of the traders, I know, confuse the Belgians with the French, and imagine it is the former nation that has (happily) abstrasted the Upper Congo from the slaveand-ivory-hunting operations of the Zanzibaris. But what can these people have known of Germany and the Germans hitherto to bear so marked a grudge against the children of the Fatherland? Curiously enough the European power most liked and respected by the Zanzibar traders is England, though for half a century we bave tried our hardest to ruin the slave-trade, on which the prosperity of the Zangian Arabs has been so largely based. Yet every bombardment or capture of slave-daus only seems to add to our prestige, and the 
fame of the mighty English "manowari," and the quiet, resolute man who directs their operations, is yearly carried farther and farther into Central Africa by the very men who have suffered most by our antislavery policy. It is really astonishing to find that there are villages on Kilima-njaro where the naked and savage inhabitants know of no other fact beyond their physical horizon, except that towards the rising sun there is a vast sheet of water, on which mighty iron canoes deal indiscriminate death to the enemies of a great white man, sometimes called the "Baloza," 2 who is the sultan of the coast.

Pursuant to these ideas Mandara had sent presents and greeting's to Sir John Kirk, seeking his friendship, and during my stay on the mountain, Mandara applied to me for a Union Jack to fly over his mud and wattle citadel, as a sign that he was under the protection of my country. As I feared this emblem of just rule might be made to cover a multitude of sins committed in its name, and that the slave-raids of this African prince might be justified by the British ensign which his bandits would flaunt before them, I transmitted this request to the consideration of Sir John Kirk. Various complications prevented its concession, and eventually, frightened at the rumoured coming of the Germans, Mandara accepted the suzerainty of the Sultan of Zanzibar.

Mandara has seen all the Europeans who have ever visited Kilima-njaro. Rebmann, the missionary who first told us snow-mountains existed in Africa, passed through his country, when Mandara was, according to his own account, about three years old. Von der

2 Baloza (Baluz) is a Persian term for consul, which is used in Zanzibar to indicate Sir John Kirk. 
Decken-still remembered as the "Baroni"-came thither when the chief of Moši was a youth and under the tutelage of his mother. Mandara received the missionary New on his first journey to the mountain, and enabled him to make his two partial ascents, in one of which he just reached the snow-line.

On his second visit to Kilima-njaro in 1873, Mr. New was robbed of all his valuables by Mandara, and retired broken-hearted to the coast. Mr. Joseph Thomson fell into his clutches in 1883 , on his journey to Masai-land, and though he was forced to make a much more generous present than he at first intended, yet he frequently admits that Mandara afterwards treated him and his caravan with really royal hospitality. Before I arrived in his country he had made friends with Sir Jobn Kirk, and I took with me important letters from our Consul-General at Zanzibar, officially recommending me to Mandara's good offices, and though in after-times you will see that I had very strained relations with our variable friend, yet such was the respect he bore for the wide-stretching English power, that, though he had me utterly defenceless in his clutches, without the strength to resist or the means to run away, and in spite of eager covetousness of my valuable property, he never robbed me of a pennyworth by force, nor ever allowed his people to do so.

Before coming to Kilima-njaro, I had read everything that was written about Mandara, and my curiosity as to his appearance, and my anxiety as to the impression I should create in his imagination, were excited to the utmost. My vagrant habits have sometimes led to my being presented to personages that the world holds distinguished, but in no case did I 
ever anticipate an introduction to a temporal or spiritual magnate with more anxiety than my first interview with the Sultan of Moši. I had formed an exaggerated estimate of his power for good and evil, and fancied that the fate of my expedition lay in his sable hands. Nor was I alone in this impression, for the men of my caravan held Mandara in excessive awe and dread, and the rabble of Rabai, who were already grovelling before him, would have cut my throat cheerfully if that had been pleasing to the great chieftain, in whose power they were. To do Mandara honour-for I was told by my men that he was very sensitive as to appearances, and measured a man by his cloth-I had donned a white shirt with a collar in which some little starch remained, a smart coat, and patent leather boots, and this attire, although perhaps becoming, was uncomfortable at the close of a long, hot march, when I wished to unbend in easy costume. I therefore hoped that the ordeal might soon be over. Presently, whilst I was fidgeting about inside my tent, getting rather tired of the intense curiosity I aroused among the simple country-folk, who thronged the precincts of my camp and were not ashamed, like the soldiers, to express their awe and surprise, I heard a distant shouting, while loud cries and complaints arose nearer and nearer at hand, and then were seen the civilian subjects of Mandara fleeing in all directions, and being vigorously chased from the scene by a number of lithe young men perfectly nude, and armed with long and supple wands. These were the police of Moši, and their object was to disperse the vulgar herd from the precincts of royalty, their sovereign being then on his way to pay a visit to the white stranger. Kiongwe soon entered my tent, and said 
in an agitated whisper, "Mandara has come, and is waiting to greet you." I left my tent in as composed a manner as possible, and sought Mandara with my eyes. He was not difficult to distinguish from his body-guard. With a natural instinctive feeling for effect he had grouped his soldiers in a semicircle round him, and placed himself somewhat in front, with a crescent of fierce-looking warriors behind, each man holding his shining spear-blade erect and glistening, thereby edging the dark background with a bright shimmering band of steel. The first impression Mandara produced on me was that of a grand old woman! The full, rounded, beardless face, the somewhat graceful column-like neck, and full bosom, with above all the head-dress - a red handkerchief, worn as women wear it in Zanzibar-and the sweeping folds of the long faded cloth wound loosely round his body, gave one the impression of a superb virago rather than of an African chief in the prime of life. Mandara, like a towering sibyl of fire feet ten inches, planted his spear in the ground with an emphasis that long made the blade quiver, gave me one very sharp look out of his only serviceable eye (the sight of the other is destroyed), and then for the moment took no direct notice of my presence, but commenced a long and animated chat with his head policemen, listening apparently with much amusement to their account of the summary way in which the populace had recently been dispersed, and occasionally laughing in a right royal manner, showing, as he did so, a splendid set of teeth.

At last I was nettled by this apparent disregard-it is always dangerous to be too meek and unassuming with African chiefs-so I asked my head-man in an 
audible tone which of the people present was Mandara, affecting to search for him among the crowd. There was a silence. Then Kiongwe, in the most cringing tone and manner, approached the chief with many a deprecating salaam, affected to kiss his hand, and then begged to inform him that his master, the white man from Zanzibar, the "Consul's child," was here, and desired an interview. Mandara's gaze now rested on me with a benign and singularly winning smile, which effaced the preceding impression that his somewhat heedless manner had produced. I advanced a few steps and said, in rather a hesitating voice, in the middle of a profound silence, "Sultan, the Baloza (Sir" John Kirk) sends you many greetings, and hopes you are well." I had spoken in Swahili, and he replied fluently in the same language, and in a voice pleasantly modulated and different from the hoarse speech of his subjects, "Child of the Baloza, I am pleased to see you. I like your face." Then, after a short pause, in which his dignity relaxed, he advanced towards me, took my hand, and said, almost in a coaxing manner, "Tuzumgumze! Let us chat." At this signal all his followers and mine, who had hitherto stood "at attention," relaxed their attitudes with one accord. No one spoke, but they all sat down, making as they did so that unanimous shuffling which you hear in church when people arise from their knees and sit down to arrange themselves for the sermon; and this analogy was further carried out by the chorus of throatclearings and hurried coughs which rapidly went the round of my circle of listeners, who were desirous of removing all physical obstacles which should prevent them from thoroughly hearing and understanding the words of wit and wisdom about to fall from our lips. 
The chief began the interrogatory. "What pretty boots you have got on!" he said. To which I could think of nothing more original to reply than, "Oh, do you think so?" "Yes, they are very fine-"vizuri sana ; have you got a pair that would fit me?" This was a question that required rather a diplomatic answer. I had but one pair of patent leather shoes, and I judged from what I saw of Mandara's foot that they would be quite inadequately sized, so I replied, vaguely, "I will look and see." But the chief's attention had already wandered to other subjects. He pressed me with the most varied questions, sometimes too impatient to wait for an answer. "What is the braid on your coat made of?" "Silver." "Is silver the same as that white stuff on the top of Kilimanjaro?" "And have you come all this way from Ulaya (Europe) to gather the glittering thing that makes Kibô shine in the sun?" "Why is your sultan called Queeny?" "The Arabs tell me Queeny is a woman; is that true?" "Did Queeny send you here?" "No; the Waalimu (wise men) of England have sent me, so that I might see everything there was to be seen on Kilima-njaro, and come home and tell them all about it." "What did they do that for?" "Because they love knowledge." Mandara pondered a moment, and then he glanced up and said quickly, "Look! you can write, can't you? All the Wa-zungu (white men) can. Very well. See everything hereaboutsI will show you-and then write it all to the Waalimu of Ulaya. Your men and mine shall take the letter to the coast, but you shall stop with me, always-eh? Always. I like you; and besides, I want a white man to teach me how to write, and to show my Mafundi (artificers) how to make cannon, and instruct 
my soldiers to fight like the soldiers of Sayyid Barghash of Zanzibar. You know Bwana Mafiu (General Matthews ${ }^{3}$ )? Well, I want you to be my Bwana Mafiu." I made no reply to these embarrassing propositions, thinking it better to preserve a discreet silence and gain my ends patiently. Then Mandara continued, in a plaintive voice, "Bwana Tomsen (Mr. Joseph Thomson) came here; I liked him; he was generous, and he spolie well of my country; but he would not stop. 'Baroni' (Baron Von der Decken), and Bwana New (the missionary) have both been here, but they came and went. Now," he added, laughing grimly, "the Baloza has sent you here to see me; well, I don't want you ever to go. Do you hear? (Usikia?) Never! Now, come along to my liouse and show me the presents you have brought." So the meeting was adjourned. Mandara gathered up his skirts, not ungracefully, and stalked off to his compound, whilst I hastily unpacked and arranged the gifts I had brought him, which were as follows: A handsome embroidered "joho" or Arab coat; a "kanzu" (long shixt-like garment); a "kilemba" (stuff for a turban); several "vikoi" or waistbands, and a scarlet fez; a musical-box, many coloured pictures, looking-glasses, mouse-traps, knives, bells, two small barrels of gunpowder, boxes of caps, and a bar of lead.

Accompanied by Kiongwe, Cephas, and others, I went to his reception-shed. Here he was surrounded by the Swahili courtiers, and seemed in a good humour, apparently appreciating the presents I had brought. Whilst he was examining them, occasionally slapping his thigh with a delighted gesture, or making

\footnotetext{
3 An English officer, the Commander-in-Chief of the Zanzibar army.
} 
a curious whistling sound with his pursed-up lips, I had leisure to examine his appearance thoroughly. Of fine height, as I have already observed, probably five feet ten or eleven inches, his frame was splendidly modelled, though the rounded form of his contour indicated a slight tendency to fleshiness. His face was a peculiar one, rather broad across the cheek-bones, with fine arched brows, good forehead, a slightly hooked nose, wide, thin-lipped mouth, and firm, rounded, resolute chin. One eye, as has been already remarked, was biind, and had a vacant glassy stare, but the other was bright as an eagle's, and lay glittering under an eagle's brow. The general aspect of his face, especially the hooked nose and bigh cheek-bones, reminded me of the traditional likeness of the North - American Red Indian Chief. Mandara's ears, however, were all his own. The fashion of his country and people he had certainly carried to excess. The lobe of both ears had been pierced, and the distended aperture of one had become so enlarged that a great wooden riug had been forced into the centre. I can best explain it by a drawing, as words are quite inade-

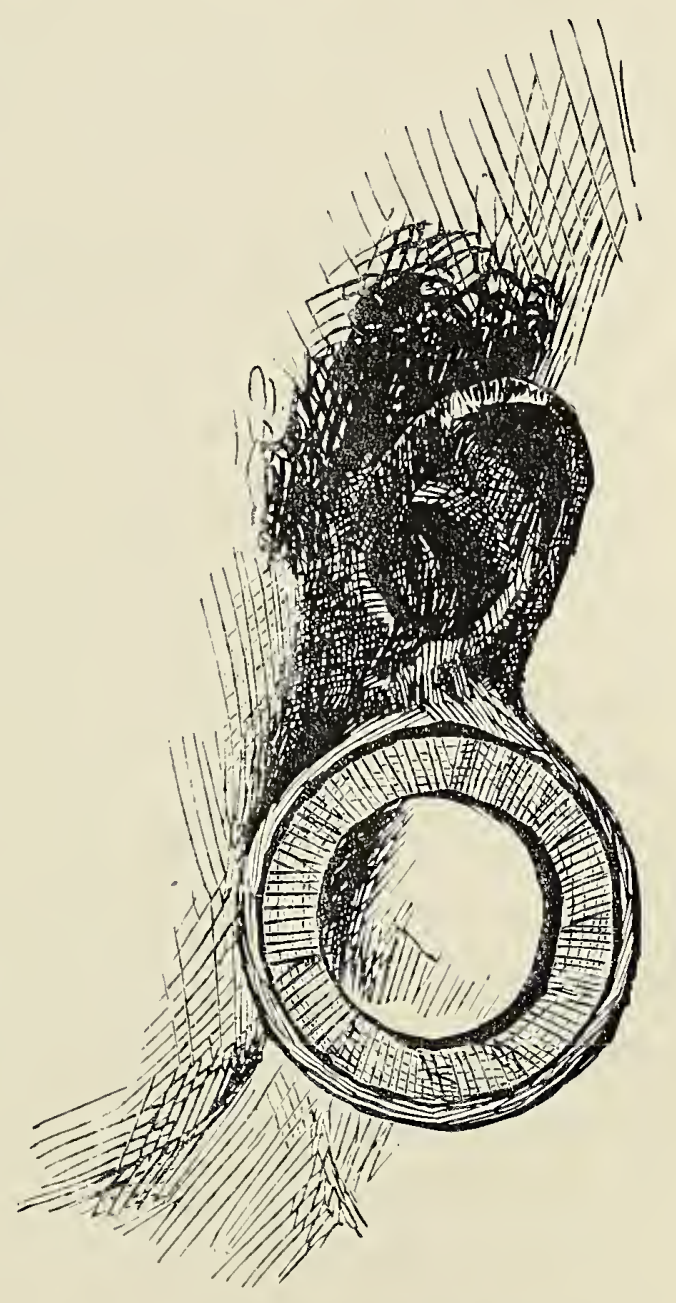

Fig. 26.-Mandara's Left Ear. quate. Fortunately, although Mandara would never 
allow me to take his portrait, I was once able surreptiously to sketch his left ear. The lobe of the other ear was hung with a few small steel chains, and was less remarkable. He had a row of splendid teeth, though there was a slight, probably artificial, space in the centre of the upper incisors. Through this aperture he would often squirt his saliva or his mouthful of banana-beer whenever he grew animated. The colour of his skin was a bluish brown, if you can realize such a combination-I mean a glossy umber with a bloom on it-and there was an entire absence of hair on his face, and the wool of his head was shaved close. As he says he can remember Rebmann's visit to Kilima-njaro (which took place in 1848), and was about three or four years old at the time, his approximate age at the present time would be about forty years. When I saw him he looked somewhat older, but this is evidently due to premature age creeping over him after a life of unrestrained passions. Mandara had a singularly winning smile, utterly unlike the African grin. While his somewhat curling, cruel lips would relax and display the glistening teeth, his brows would be puckered in a half puzzled, half petulant manner, and at the same time his one, round, living eye, into which all his strong feeling was concentrated, gleamed and glanced with roguish merriment. As he sat and played with his presents, like a great child, impatiently wanting the Swahilis to explain everything in a breath, this smile would constantly pass over his face, and lent it each time a very pleasing, kindly look. He was evidently in a thoroughly good temper on the day of my arrival. He listened attentively to the reading of Sir John Kirk's letter, examined the seals of the Consulate, asked 
numberless questions, and chattered to me as freely as though we were old companions. All questions about building, settling, choosing a site in his country, he deferred to a lesser "palaver," to be arranged by his attendants. Indeed I noticed, that whenever Mandara wished to drive a hard bargain, and this desire never deserted him even in his most gushing outbursts of friendliness, he negotiated it through intermediaries, and never treated directly with me on matters of business, having a royal dislike to saying disagreeable things. Accordingly, on this occasion, when he had exhausted his surprise and delight at the coloured pictures, when he had ceased to turn the handle of the musical-box, and had rung all the bells till their hammers were unhung, and, sure sign of an exhausted brain, had begun to yawn, I craved permission to withdraw, which was gracefully accorded, and I retired to my tent, followed by two Wa-čaga leading: fat sheep and carrying bananas as the Sultan's contribution to my dinner.

Early the next morning I rose and dressed, and was some time performing an unusually protracted toilet, for I had the rare opportunity of being able to dress at my ease without pulling down the tent and hurrying off the men with their loads. On raising the canvas flap, and going out into the fresh morning sunlight, I was somewhat surprised to see Mandara with a circle of soldiers round him inspecting my goods, and carrying on an active conversation with the Zanzibaris. I saluted him gravely, but he returned the greeting, as I thought, somewhat coldly. However, he came and sat down in my deck-chair, and then cast his dangerous gaze around my tent and its furniture. Singling out my dressing-bag he begged 
to examine it, and I could not refuse; so he passed all its contents through his hands, uttering constantly his curious whistling exclamation, "Tu, tu, tu!" of admiring astonishment. He asked for nothing but an old toothbrush, and though I proffered a new one in exchange, he stuck to his first choice, and resolutely carried it off. After he had left me his counsellors arrived, and the rest of the morning was taken up in bargaining about the amount of goods to be paid for a building-site and permanent settlement in Moši. I say "permanent settlement" because Mandara declared at the time that this first payment was to be the last, and that by coming to terms with his delegates I purchased the land outright and for ever, retaining the power to sell or otherwise dispose of it to any one else. This first agreement he never repudiated, although we afterwards squabbled about the extent of my plantations. The price for the land was fixed at 210 yards of American sheeting, three dozen handkerchiefs, and about thirty pounds of red beads, all of which were immediately paid, and we were informed that on the morrow we might quit Mandara's presence, and fix on any unoccupied site that pleased us. These preliminaries concluded, I began to enjoy a little well-earned repose, and settled down to sketch some of the scenery, which was lovely enough to move even exclamations of admiration from my stolid Zanzibaris. Above me, to the north, rose majestically the snowy dome of Kibô, ${ }^{4}$ untouched by mist, and clearly cut against the smalt-blue sky. The middle distance was hidden, and the trees of the foreground

4 Kibô, I might remind you, is the highest summit of Kilima-njaro. Kibô means in Ki-čaga simply "whiteness." We should pronounce it "Keebaw." 
seemed to touch the snow with their waving tops. Below me, on the other side, lay stretched a vast plain, marked, as on a map, with rivers, mountains, and forests, and stretching away into hazy space, where it mingled with the low-lying strata of cloud. We were only 3,500 feet above the sea at Mandara's, and relatively at the very foot of the mountain; but the view on all sides, above and below, was unusually magnificent. I was interrupted in my sketching by a messenger from the chief. I could not at first understand the import of his message, as he spoke in Ki-čaga, but with the aid of an interpreter I ascertained he bore a request that I would go and visit one of Mandara's wives who was sick. Hearing the cause of her indisposition was a virulent ulcer, I took with me the necessary ointments, and followed the messenger alone, being conducted to a quiet little square inside a palisade, where, in three beehive huts, dwelt the three principal wives of Mandara. I was introduced to the ailing lady, who scarcely glanced at me, merely sticking out a leg, on which festered a hideous sore. She had been fanning it to keep away the flies before my arrival, but now quietly surrendered it to me, imagining, poor simple thing, that I should immediately cure it. I explained to her, however, that recovery would be slow and gradual. Then laving the ulcer in cold spring-water, which was brought to me in a broken gourd, I applied to it the kind of ointment recommended in my medicine-book, and, bandaging up her leg, added much good advice, and left. I suppose my simple skill had made a due impression, for I was hardly back in camp and sketching once more when the messenger arrived again, informing me there were more of Mandara's wives 
needing my assistance, and insisting on my starting to see them without delay. Feeling annoyed at these constant demands on my time and medicine-chest, I nevertheless complied, in order to keep on good terms with the chief, but this time I resolved to use a coarser and scarcely less effectual remedy for open soresparaffin-of which I had an ample store. So, with a small tin of this mineral oil, more lint, and more linen bandaging, I again followed the messenger, and this time was taken to a different quarter, where I entered a large, low-pitched, round building, with a peaked roof-in fact a big beehive hut. The interior being only lighted by the low doorway, it was at first impossible to distinguish anything in the gloom, especially as a curious odorous steam, and the smoke of a wood fire mingled and rendered the obscurity inside denser. At length, however, I could make out that the building was divided into a certain number of stalls, separated in the centre by a broad lane. On one side were milch cows, some four or five, each with a calf, and each in her separate stall; on the other were about the same number of women, one or two with children. They evinced little surprise or amusement at seeing me, and all but the sick one went on with the food-preparing avocations they were already engaged in. I dressed the woman's ulcer with paraffin, left her some oil for a further application, and withdrew, half-stifled with the ammoniacal odours of this stable-harem. Once more back in camp I had many further calls here and there to visit patients and treat the most varied disorders, from a broken arm to insanity and blindness. In all cases it was hoped that I should effect immediate cures, and had I commenced a series of miracles, no surprise would have been 
elicited, so great was the implicit faith in a white man's "healing-magic." But now, somewhat nettled at the calm way in which I was ordered about, I intimated that all who wished for medicine or medical advice must come for it in person, and wait my pleasure to be attended to. In no wise rebuffed, the subjects of Mandara thronged the precincts of my tent, and would have overrun everything and sullied all the clean appurtenances of my little habitation, had I not formed a stout barrier of bales and boxes, and set a strong guard to keep order among the rabble. Then one by one I saw the sick, the maimed, the hopelessly diseased, and, in a fer hours, had made more saddening acquaintance with the ills that flesh is heir to-even in a pristine, savage state-than had been afforded to me under any previous circumstances of my wandering career. The whole of that evening I patiently inquired into each complaint, and, to the best of my poor ability, administered medical relief. 


\section{CHAPTER VI.}

MY FIRST SETTLEMENT ON KILIMA-NJARO.

VERY early in the morning of the succeeding daythe second after our arrival in Moši-I began to prepare for the last stage of my journey, the search for a suitable site on which to establish my principal and central collecting-station. Various considerations must influence me in my selection. Firstly, it must not be too low down on the mountain, so as to be inconveniently far from my collecting-grounds; secondly, it must not be too high up or my men would suffer unduly from cold, and we should induce no natives to bring their food supplies for sale. Again, I did not wish to build too near Mandara's court in case that monarch should honour us with an inconvenient amount of his society, and always have me at his beck and call; on the other hand, if I journeyed too far into the wilderness I lost the protection Mandara was able to accord me and would, consequently, nullify the object of my settlement in Moši, which was to be enabled to pursue my avocations quietly and economically by living with a very few followers under the ægis of a powerful prince.

I, therefore, after long consultation of the imperfect map, decided that a certain prominent spur of the mountain in the north-east of Mandara's country 
(orerlooking the bed of a rivulet) would best answer my purpose for a secure and pleasant settlement. After experience showed me that this almost accidental choice would have been a strangely fortunate one, and had I made a permanent residence in Mandara's country, I should have eventually built there. But on my indicating this selection to the chief on my arrival, I could see that it met with his secret disapproval. He really feared that in establishing myself on this distant spot I should be too independent of his caprices. Yet he did not countermand it, but merely nodded and said enigmatically, "We shall see-kešo, kešo" (kešo! fatal word = 'to-morrow'). However, I was determined to show him that I intended to have my own way. Accordingly, I prepared actively for departure on the morrow. I thought it ominous that no guides or message came from Mandara's court, but I, nevertheless, affected not to notice this, and gave the order cheerfully to shoulder loads and march. Only thirty men-the Zanzibarisresponded. The Rabai porters sat sullen and immovable, and raised not a finger to their loads. I asked them if they had understood me. "Perfectly," they said, "but Mandara had given them orders not to move." "But," I exclaimed, "I am your master, $I$ pay you, and I command you to take up your loads and follow me to the last stage of the journey." "What do we care for your commands?" they replied. "Why Mandara could kill us all in a moment, and who could resist him? And you-why you daren't even beat us, because you know we should tell the missionaries." This was indeed bitterness for me, especially the feeling that I was impotent to harm these wretches. Unfortunately, they had all received 
the greater part of their wages in advance, and had carefully stored up their dollars before quitting the coast, so that the threat of depriving them of the small remainder of their pay, if they failed to complete the contract, had little effect. Mandara, it appears, had tried to cajole and frighten the Zanzibaris into joining the strike, but these true-hearted Mussulmen had informed him that they had but one master and that the white man, and him only would they obeyan answer for which Mandara ever afterwards bore them a grudge. I therefore in my difficulty turned to them for counsel. Kiongwe, the head-man, whose experience under Stanley had made him a reliable adviser, proposed a daring solution of the quandary, namely, that he should proceed forthwith to Mandara's, present him my salaams, and inform him I was now ready to start, and waiting only for the promised guide. On this errand he went, and found Mandara in the best of humours, and apparently grieved to hear of the mutiny in my camp, though his one eye twinkled as he said so.

A compromise was arrived at. Kiongwe was informed that I was free to go wherever I chose, but that Mandara advised me to select the site which his delegates would show me. As I had a hundred loads and only thirty men willing to carry them, I had better put my goods under his charge, and he would take care of them until they could be removed in instalments to the selected site. I was rueful when Kiongwe returned and communicated the result of his interview, because I felt how utterly I had placed myself in Mandara's power. Moreover, I dreaded lest the proposed "taking charge of my goods" were not a pretext for exacting a huge ransom. However, 
I submitted to fate, and after events showed me that I had misjudged Mandara. The site he had selected for my settlement was not quite equal to the one I. would have preferred, as regards natural history purposes, but it was not far removed in distance, and certainly had many peculiar advantages. As to the goods placed under Mandara's care, I can only say they were made over to me absolutely intact.

Nevertheless, not foreknowing the happy termination of my troubles, it was with a somewhat anxious heart that I accompanied my thirty Zanzibaris, following as speedily as possible Mandara's nimble soldiers. These, our guides, sped along in front, skipping uphill like goats, and making nothing of the slippery, clayey descents, slimy with recent showers, where we had carefully to walk sideways to avoid a headlong tumble. But these glissades were only accidents along the winding track; our general direction was upwards. We left the spur on which Mandara's residences stand, wound along a little artificial watercourse which irrigated the chief's banana plantations, then attacked a very steep hill-side, up which we clambered almost on all fours, clutching at grass tufts by the way, stopped to breathe under the spreading branches of some magnificent acacia-trees, where the bold, grey monkeys peered at us wonderingly with their blue faces, and ducked their heads and chattered at our ugliness; again mounted up, up, up, till our knees grew palsied, and our chests ached; passed through rich hedges of glossy-leaved dracœnas, pink-flowered aloes, spreading fern-fronds and fruiting brambles, turned the corner sharply, and entered on a less fatiguing portion of our route.

How charming was the journey now before us! 
After such a tiring ascent, wherein we were nearly compelled to relapse into our pristine mode of locomotion-in fact to imitate those great baboons who scampered away from us on all fours up the lanes, disturbed in their raids on the banana clusters; we were now able to stroll at our ease, though such was the exhilaration of the scene, and the freshness of the morning air, that I skipped and tripped, childlike, along the level path. And such a path! Like a tiny towing-track it followed a Lilliputian canal, cut along an artificial channel in the hill-side, or, to express it more clearly, diverted from the parent-stream before the hill was a hill in a far-off valley, and now pursuing its tranquil course and gentle descent along the swelling bosom of the mountain, while the original rivulet descended below in wasteful cascades. Both path and irrigating channel hung seemingly in mid-air, jutting out from the mountain-side with a thousand feet of tree-choked ravine below and five hundred feet of bracken-covered hill above. Therefore, as we marched along so gaily, we looked down on the velvety tops of the bushy trees with which the sheer descent of rock and fern was studded, and up through the wide, orangetinted bracken fronds at the bright green banana groves that crested the summit of the hill. Then we rounded the prettiest little clump of woodland imaginable, pushed out like an ornamental shelf or bracket from the wall of hill, and positively suspended over the green gulf below. This, indeed, was a "hanging-wood," and I almost hesitated at first to follow the path that hung upon its edge, fearing lest the weight of our passing troop might break down the border that supported path and stream, and send us tumbling into the valley beneath. But this was a danger more fanciful than 


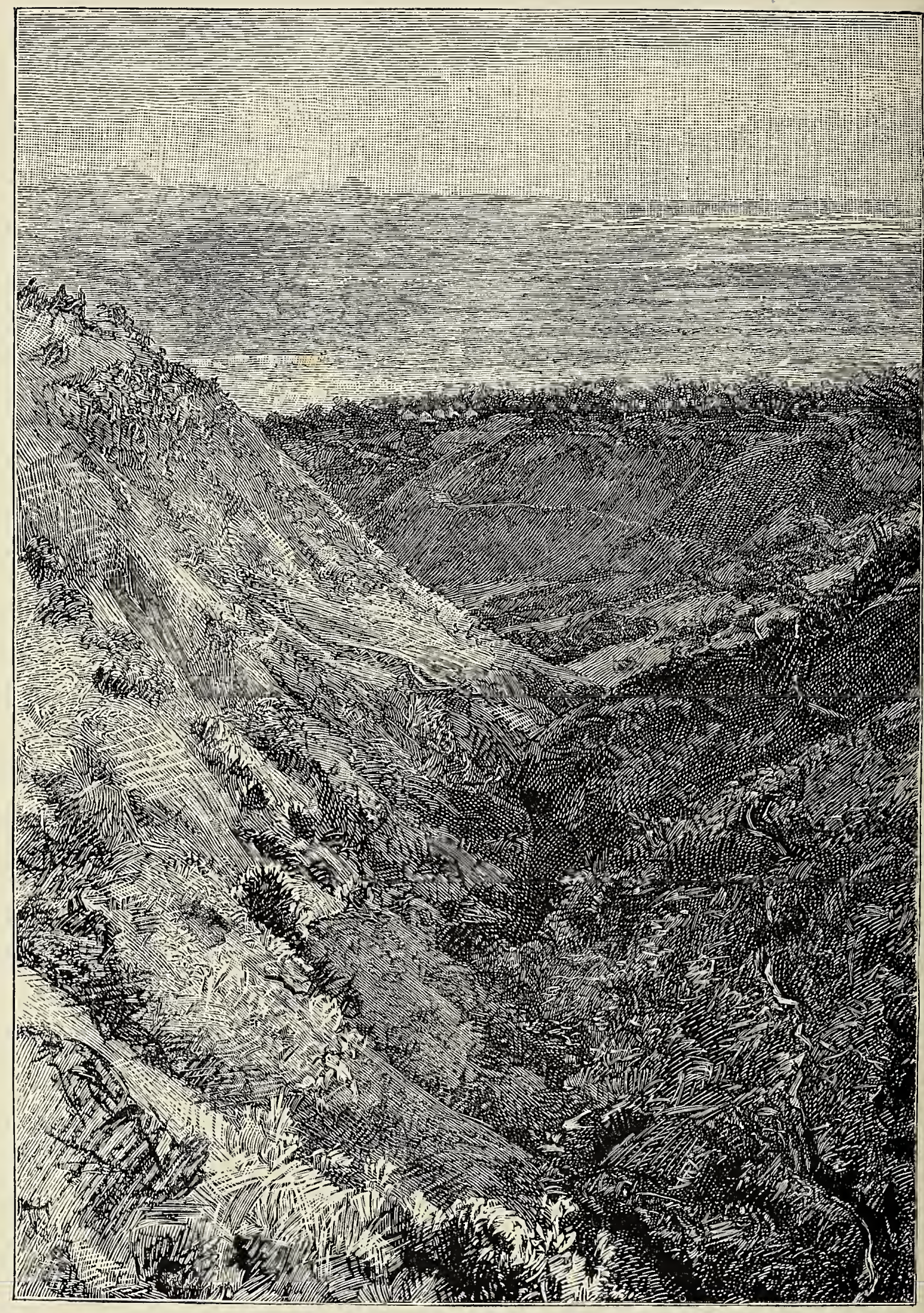

VIEW OF MANDARA'S VILLAGE FROM KITIMBIRIU.

To race page 119. 
real, for the ledge was firmly buttressed underneath by the strong roots of the forest-trees clinging to the rock. As we skirted this great ravine we arrived at a point where it narrowed, and where the difference between valley and hill was less. Here the little rivulet, which farther on its course lay a thousand feet below, was on a level with the path, and here it was made to give birth by careful damming to artificial canals, which started away on either side to irrigate the terraced hillplantations with their sluggish flow. Where we crossed the pretty stream was in a shady hollow. It had expanded to a shimmering pool; large sycamore figtrees with spatulate leaves rose above its banks. Tall arums, with pale yellow flower-sheaths, and untidy Isolepis grasses, whose heads of streaming filaments looked like green mops, studded its flattened banks, and we jumped in a few seconds from stone to stone across its shallow flow, crossing at the same time both stream and valley, and finding ourselves commencing the ascent of the opposite hill, and, but that we now had the widening gorge between us, seemingly retracing our steps to Mandara's town. His little beehive huts, on which we had. hitherto turned our backs, now reappeared behind the shoulder of the opposite hill, but when our climb was done lay more than a thousand feet below us. Here we had reached our destination.

There are numberless spurs or buttresses of the parent-mountain on the southern side of Kilimanjaro. Some are bold, serrated, and abrupt; some are rounded and nearly flattened on the top. On one of these Mandara's residence is placed, on another, of more imposing height, I was about to build; and there are yet others, and others, and others, stretching out westward and eastward into the great plain below. 
Each one of these spreading buttresses is separatedfrom its neighbours by a ravine, which, as you ascend it, will gradually narrow and narrow until it disappears, and the two diverging spurs of the mountain converge into the parent mass, so that the general effect of Kilima-njaro from the south would suggest a tree-trunk poised on its spreading roots. In each ravine there is a rivulet, and along the crest of each buttress, or it may be somewhat to the side, meanders an artificiallytrained stream, diverted from the rivulet at some higher fountain or waterfall, and carried in a gentle descent along the brow of the hill. This, of course, is the handiwork of man, but so industrious have been at varying times the Bantu inhabitants of Kilima-njaro, that there is scarcely a spur descending from the southern base of the mountain that is unprovided with the irrigating channel-or, it may be, three or four channels at different elevations-running along its sloping crest or flanks, and keeping its terraced gardens supplied with water. In those parts where wars have devastated the country, and where the hills are no longer cultivated or inhabited, these former runnels of water still remain, although from want of care the chanuels may have dried up and become turfed over.

In half an hour I had fixed on the site for my settlement, and remained there alone to guard the first instalment of my goods while my men returned to bring the rest. By the end of the afternoon everything had safely arrived, and for the first time during many weeks I knew what it was to be free from care, and be able to enjoy an afternoon of idleness. I no longer cared now whether the men of Rabai ran away or not. My goods were safely landed at my destina- 
tion, my wearying tramp over wold and fell, sharp rocks and scorching sand, was at an end, and I was free to rest with the satisfaction of finding that $m y$ brightest anticipations of Kilima-njaro scenery were realized. No more desperate marches after water, only to find it hidden away in the crevices of lofty hills. There, alongside of me, in front of me, as I sat in my deck-chair on the broad brow of the hill, swirled the water in its artificial channel, brought by man's patient ingenuity to keep us company in our eyrie. A little way off me lay my men, their. work for the day concluded. They had with happy abandonment thrown themselves down on the sweet turf, lying half somnolent in fragrant beds of mint and clover, crushing with their dead weight many a delicate ground-orchid or purple-red dissotis. The tent had been pitched, and the cook's fire was sending up a little column of smoke, which stood out bluish-white against the green background of the rising hillside. A goat and kid, a cow and calf, presents from Mandara, munched peacefully the rank grass round the bushes, but save for the occasional smothered tearing noise they made when crop-

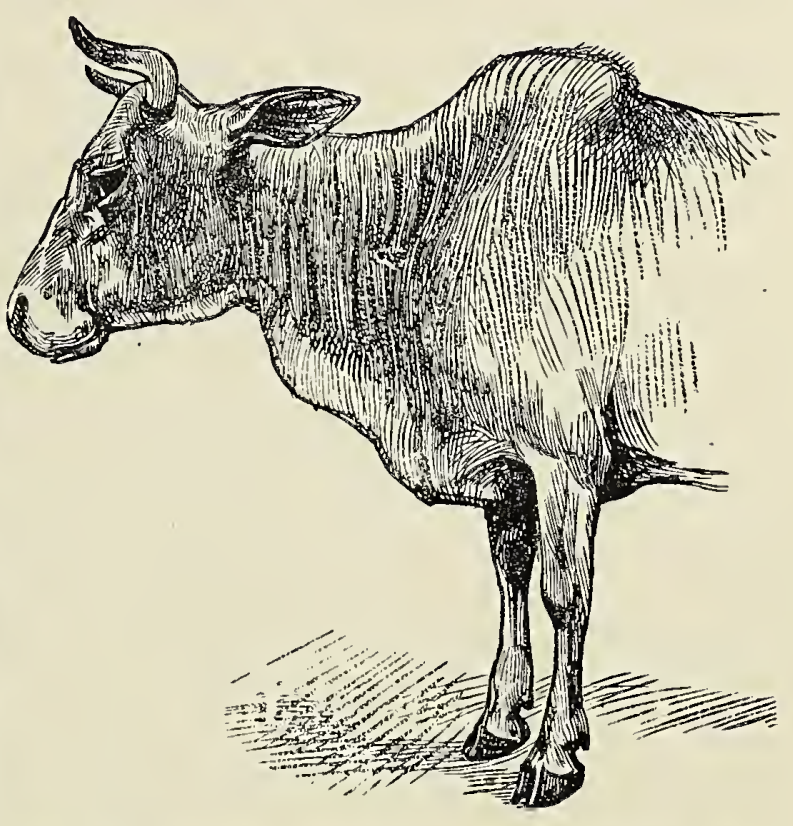

Fig. 28. - Head and Shoulders of our Cow. ping the herbage, and except the desultory conversation between the two cooks, no sound broke the dreamy silence. By a thoughtful order of Mandara's, no native was allowed to visit my encampment the first 
day of our arrival, so that, until we had got all our goods safely stored, there might be no temptation to steal. Consequently my attention was undistracted, and totally given to the examination of my new surroundings.

The site of my first settlement on Kilima-njaro lay about two miles to the north-east of the capital of Moši (in latitude $3^{\circ} 17^{\prime} 30^{\prime \prime} \mathrm{S}$. , and longitude $37^{\circ} 25^{\prime}$ E.), on the brow of a fine hill nearly 5000 feet above the sea; but, of course, not much elevated above the surrounding country. On either side yawned a deep ravine, with a stream flowing through in its depths; but at the back the hill, which was only one of the many spurs of the mountain-side, joined the parent mass, and might thus be easily approached without much serious climbing. It would have been a splendid site for a city, and, indeed-who knows ?-may be some day. I sometimes amuse myself by thinking that when-as it must be sooner or later-Kilimanjaro is colonized by a superior race, and fair cities spring up on its breezy heights, some of them may arise from the original sites of my various stations, and when they look back with complacency on their prosperous career and some aspiring archivist starts to write their history from its earliest commencement, my insignificance may be rescueả from utter oblivion as the first inhabitant and the pristine architect of their foundation. Perhaps in the city museum may be preserved some curious relics of my stay-a champagne-bottle, a petroleum-tin, or an empty jar that once contained arsenical soap; and in the municipal library, perhaps even a copy of this book may be found, in which the passages descriptive of the city's ancient site may be eagerly discussed and quoted. In 
the interest, then, of a possible futurity, I will complete the history of my settlement in Moši, the native name of which was "Kitimbiriu." On the summit of this elongated hill-colline, or "little neck," is a French name which describes it well-was a nearly level and broad plateau, three sides of which descended almost precipitously into the valleys below. With a very little work it might have been made unapproachable save from the north, where it joined on to higher ground. Along one side and then across and down the other side flowed a tiny artificial canal of clear water brought from a tumbling stream higher up the mountain, and carried along this hill from above in a very gently descending channel. Thus we had water at our very door, and needed not to seek it in the ravine a thousand feet below. It seemed so strange and quaint to find a placid brooklet flowing along high ground up in the clouds and at the edge of a precipice. All this was due to the patient industry of the Wa-čaga of Kilima-njaro, who prefer to live on the tops of hills for safety, and therefore carry their water in artificial channels from the heights above, and make it flow the whole length of these inhabited spurs, while the parent streams go dashing down the valleys, descending in cascades of 70 and 100 feet, till they flow far, far below the placid canals which water the hill-crests stretching out into the plains.

In the centre of my settlement a large and spreading tree gave a pleasant shade in the warm noonday, and further sheltered my habitations from the occasional high winds; and lastly-and this, I suppose, no afterwork of man can alter-the view to be obtained from this site was almost unequalled in Čaga. "All the world," said Mandara once, "can be seen from 
your windows;" and though, of course, it was not a strictly true assertion, it was plausible when uttered in view of such a splendid expanse of country-such a veritable map of Eastern Africa as might be seen from Kitimbiriu. The two snow-peaks of Kibô and Kimawenzi rose above us to the north. Looking westward we might gaze over the whole belt of inhabited country as far as Mačame, near the great western

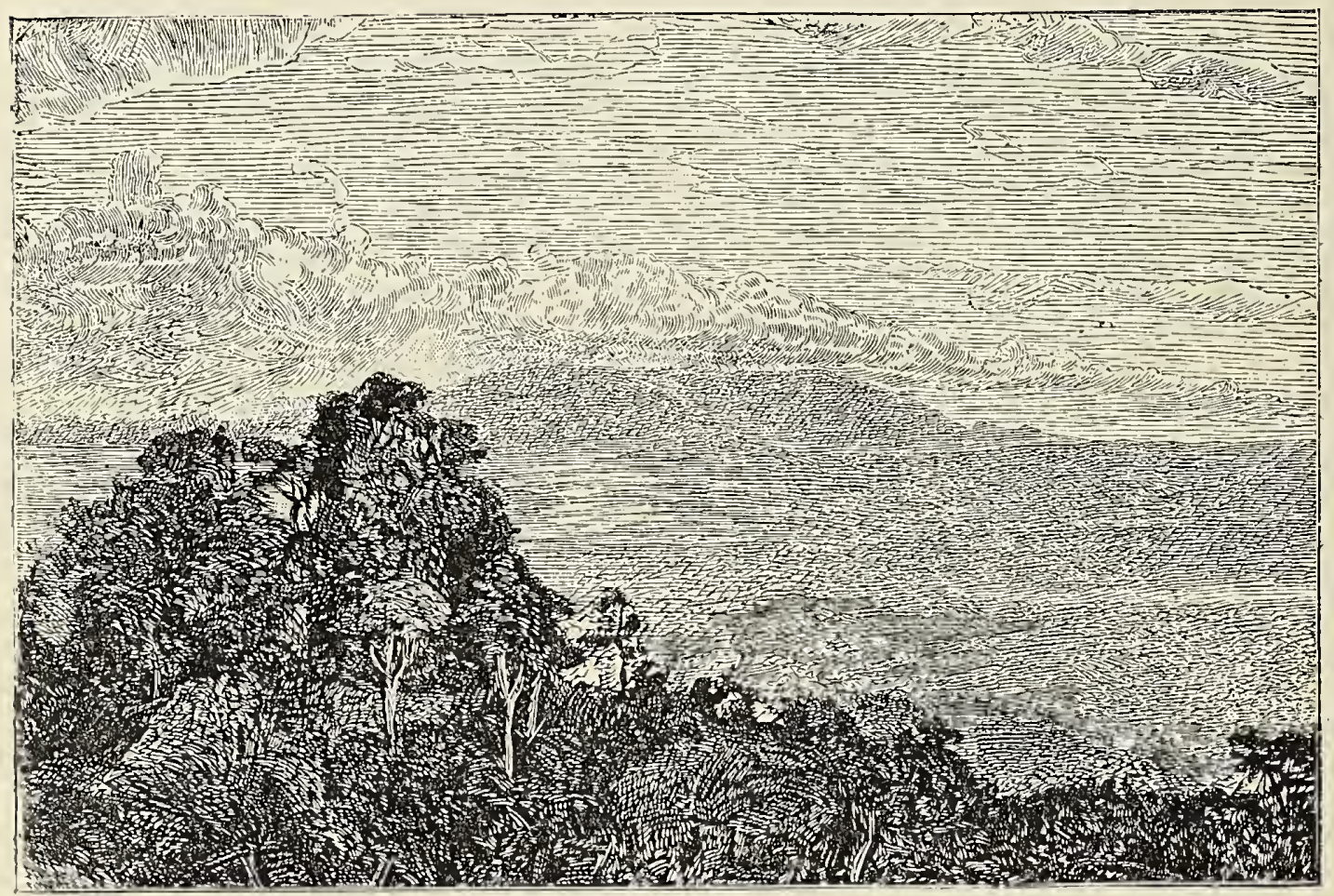

Fig. 29.-A View towards Mačame.

shoulder of Kilima-njaro, which stretches towards Méru. Many a forest-crowned hill intervened; and in the foreground the scenery was a bewildering maze of banana plantations in their glinting, vivid green, of maize-fields, of patches of red and freshly turned-up soil, and dark purple blots, which were isolated trees left standing in the cultivated land. Then there were the bare, sheep-cropped downs forming stretches of pale green colour, and the hill-sides clothed with 
feathery bracken, which at the season of my arrival (June) was dried to a vivid yellow. All these varied tones, too crude and startling in the foreground, became harmonized into a beautiful green and purple patchwork in the middle distance, and faded away near the horizon into a calm and tender violet, broken here and there by the blue puffs of smoke which everywhere mark the inhabited zone; for the natives of Caga are perpetually clearing the land of weeds and

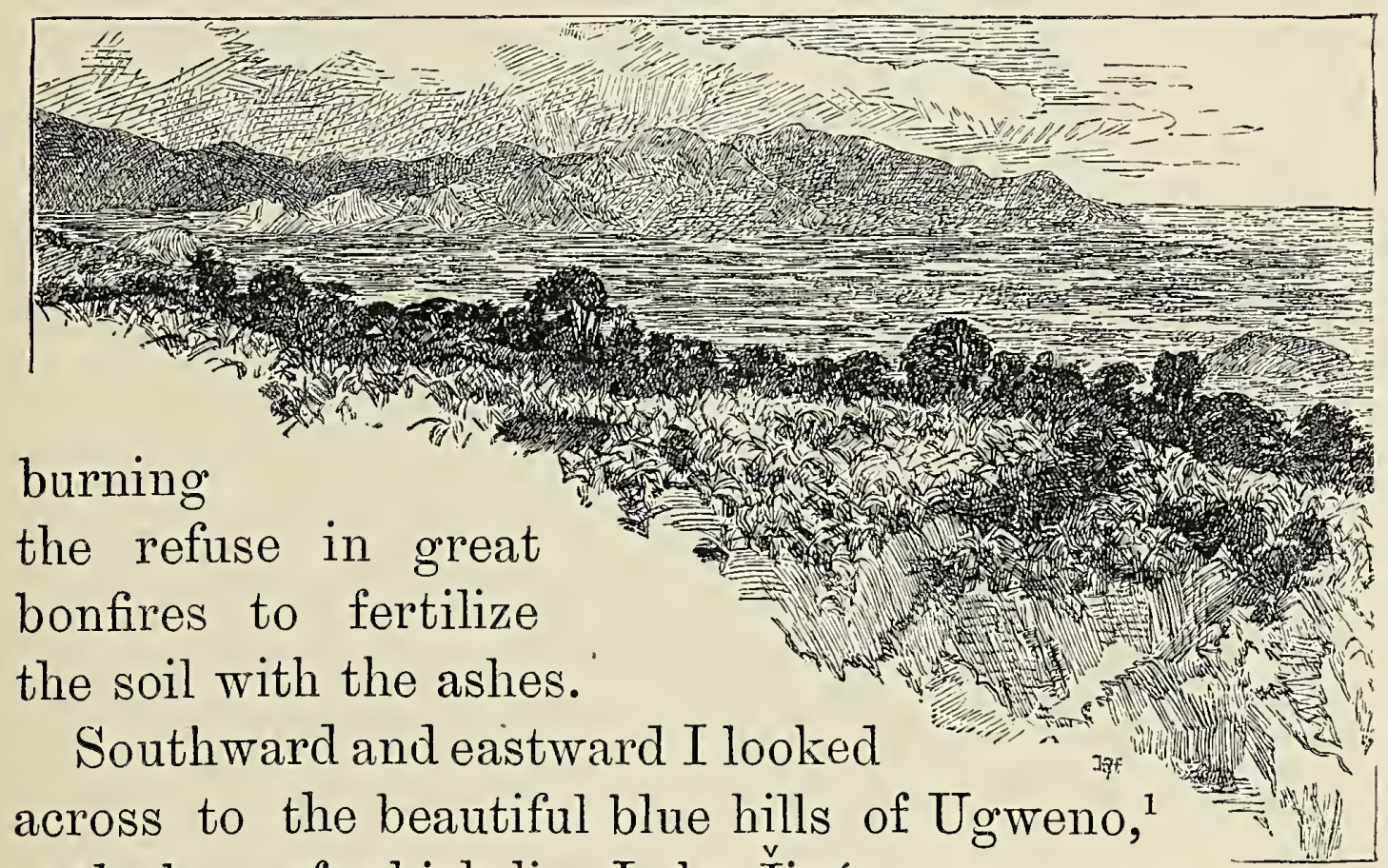
at the base of which lies Lake J̌ipé. The lake cannot be seen from the elevation of Kitimbiriu, but mount

A View towards Ugweno. a thousand feet higher and you will descry it like an oblong mirror at the base of the purple hills.

1 The country of Ugweno is very interesting, and offers the most lovely landscapes in its midst, combining peaks of 7000 feet, rich forests, cascades, green lawns, and peeps at the lake below and the silver windings of the Luvu. The Wagweno speak a tongue that is evidently more archaic than that of the Wa-caga. They are an inoffensive but very timid, wild people; much harried formerly by the cruel Masai. Now they live so high up in the hills that they are in safety, but, on the other hand, lack good soil for their crops and pasture for their cattle. 
But in all this range of view there was no grander object for the eyes to rest on-scarcely excepting the snowy dome of Kibô-than Méru, the grandest mountain in symmetrical shape that Africa can boast. It rises, a perfect pyramid, to the west of Kilima-njaro, and springs heavenward from the sunny plain till it reaches a height of nearly 15,000 feet. $^{2}$ I wish I could paint it for you as I saw it at the close of this tranquil

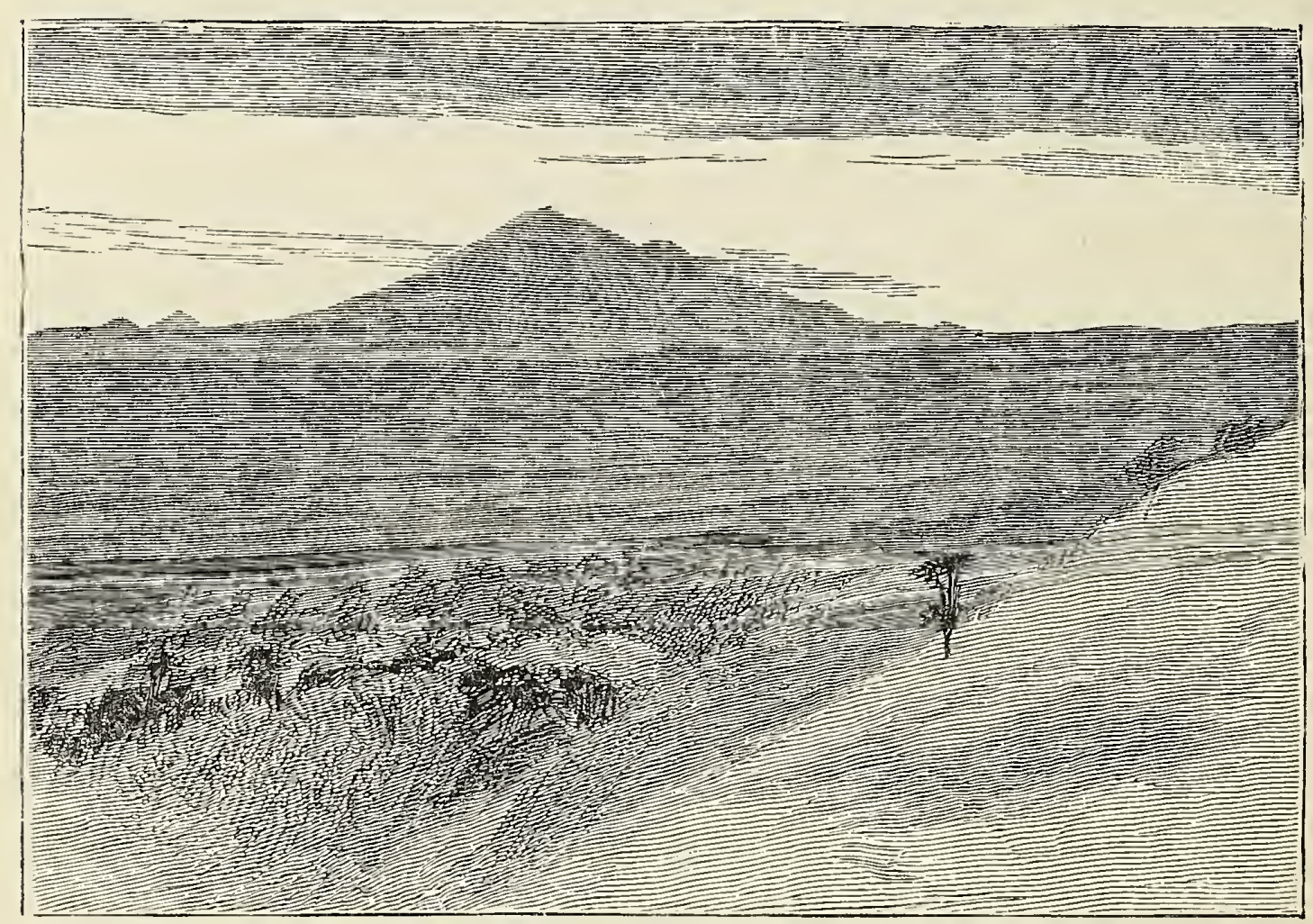

!Fig. 31.-Mount Méru.

afternoon when I lay resting and awaiting my dinner on the hill-top of Kitimbiriu. Imagine, first, a western

2 The height of its apex is 14,700 feet. It is occasionally, but rarely, tipped with snow. Méru lies nearly due west of Kilima-njaro, in lat. $3^{\circ} 15^{\prime} \mathrm{S}$, and long. $36^{\circ} 40^{\prime} \mathrm{E}$, and is visible across the plains for a distance of at least seventy miles, and is at all times a majestic object. It is said to be inhabited by a gentle race of agriculturists, akin in origin and tongue to the Wa-čaga of Kilima-njaro. At its base dwell tribes of Masai, who are great cattle-keepers, and whose herds of kine range over the vast green plains that lie between Méru and Kilima-njaro at the upper waters of the Luvu River. 
sky of clear, pale gold, deepening into orange just close to the horizon. Over this hangs in the upper heaven a thin sheet of greyish purple cloud, semi-opaque, semitransparent, letting a little of the warm ground show through, sharp edged, and so disposed at a slight angle as to appear like the border of a dusky curtain prepared to drop over the scene. This foil enhances the vivid glory of the golden belt which stretches across the sky. Then out of a serrated horizon of unimportant peaks and cones rises the clear, dark blue pyramid of Méru, its outline just a little tampered with by Nature, so that it may not be rendered too formal. The sumrnit is slightly flattened, and on the right side a jagged notch breaks the uniformity of its long northern slope. The accidental effect of colour is as beautiful as anything. Seen by this light there is no subtle interweaving of tints. The whole mass of Méru is one clear tone of dark grey-blue, and the brilliant band of sky behind is an unvaried positive gold. Just to break the almost decorative look the formal contrast bears, there is one faint, delicate smear of cloud stretching right across the upper half of mountain and sky. Méru is cut off from the middle distance by a long, undulating, purple line marking the farthest westward spur of Kilima-njaro. The centre of the picture is a rich, dusky-green plain, interwoven with lines of purple and brown to mark the distant clumps of forest bordering the river-course. In the more distant foreground stretch out the nearer buttresses of Kilima-njaro, long lines of hillocks, crested with occasional umbrageous trees, but more often clothed with banana groves of pale, pure green. These interwoven lines of hill stretch upwards from the vague obscurity of the middle distance till they culminate in the great 
simple shoulder of the down rising across our ravine. This is a plain grassy slope with white goats browsing on it, but in the immediate foreground it is dropping into the more misty depths of the widening gorge over whose purple abyss soar and wheel in high relief a few brown vultures.

It was most delightful thus to look forth from my eyrie on the many lands spread before me as on a huge and living map, and also to feel that I was safe from all attack on the part of the lawless rovers of the plains. My gaze stretched away, even into parts of Africa that are unknown and unvisited of white men, and I could scan the natural features of these countries at a glance, and correct the disposition of their rivers and mountain ranges on the map. Sometimes, when the partial mists rose over the nearer hills and valleys, and the brow of my hill seemed to be an island floating in the air, the effect was a most pleasing and novel one. I, my men, my huts, and my domestic animals seemed to be sailing over Africa in a giant balloon. Below us, beyond the mists, were the sunlit plains, the lines of velvet forest bordering the winding streams, the stretches of open

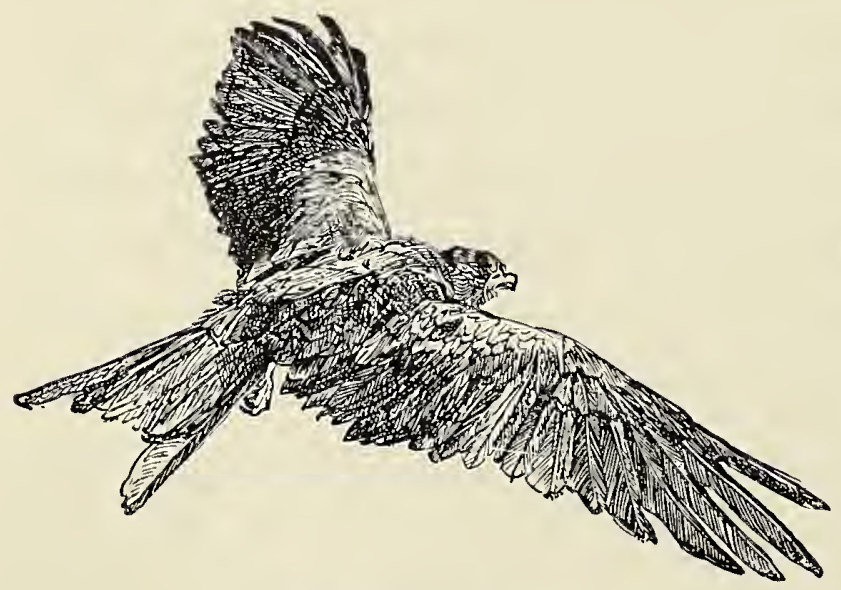

Fig. 32.-A Kite. pasture-land like lakes of grass, green amid the darker forest and the purple hills. Then, at our feet, rolling clouds of grey vapour, and, standing out in strong relief against this vacuous background, the soaring kites who wheeled and poised with outspread pinions 
just below my feet, seeming like the birds which accompanied Solomon when he flew through the air on his magic carpet, as the Arab legends tell us.

Throughout the four months of my residence in Kitimbiriu the beauties of the scenery never palled and never grew monotonous. With such varied atmospheric agencies the effects around us changed like the designs of a kaleidoscope, and rarely came two alike. Sometimes, perhaps at early dawn, everything would be veiled in blank mist, save only the summit of Kibô, and this would gleam out above the clouds, like some supernatural vision, rosy in the effulgence of the coming dawn. Or, it might be, in the noontide every trace of vapour would have vanished, and the velvet forest lie glowing in gold-green light and dusky purple shadows, every detail strongly marked, while the precipices, jutting rocks, and shining nevées of Kibô were discernible with startling clearness, though the peak lay distant nearly fifteen miles. In the afternoon, perhaps, the sky was hung with dense curtains of purple-grey cloud, and the plain below lay in monotonous blue shadow; only away to the west, behind the pyramid of Méru, the heavens exhibited one clear, cloudless belt, which the descending sun turned to refulgent gold, and against this relief, as on some antique illumination or decorative design, the peak of Méru and the jagged hill-tops at its base would stand out in a simple tone of indigo.

On the morning succeeding my arrival I had little leisure for observing the scenery, although I felt in high spirits and very much the better for my long, dreamy, restful afternoon of the day before, spent idly in the contemplation of the matchless landscapes round me. Perhaps for this reason I was inclined to relent in my just wrath against the Rabai porters, and 
pay them the remainder of their wages and let them go. Or it may have been a message from Mandara, asking me to overlook their mutiny of the day before, and send them back to the coast with their money and food allowance, which decided me to this act of forgiveness, for such powerful advocacy was not to be slighted. Accordingly these creatures were summoned from Mandara's village, ranged in line by my Zanzibaris, and received their "chits," or slips of paper, which they were to present for payment to the Consul on the coast. On each "chit" was written the amount of the man's wages, minus fines for misbehaviour, or plus a present for well-doing. Further, perhaps, was a line or two of writing to serve as a " character," good or bad, as the case may be, which Captain Gissing, when he payed them at Mombasa, would doubtless enlarge into a stern upbraiding or kindly commendation. I fear, however, from what I remember of these men, that he would have been more occupied in rebuking than commending, for a worse stamp of men than the Rabai porters I have rarely met with in Africa, and I think most other travellers' experience is the same. Their first evangelist, Krapf, describes them in despair" as a "crooked and indifferent generation of heathens," and although the generation of which he wrote may have passed away, the one to which it has given place amply illustrates the principle of heredity by perpetuating with increased force the ancestral badness.

It was with considerable relief that I dismissed them from my settlement in Čaga and turned to my faithful Zanzibaris, who were setting to work with bright activity to make our little colony inhabitable. Twenty of these Zanzibaris were allowed to lie by and 
rest, for I intended to send them shortly back to Taita. to fetch the goods there left behind in the missionary's house, when so many of the Wa-rabai deserted; but of the remaining twelve, each man received his appointed task. Abdallah was made supervisor of the working men; Mabruki and Athmani were already engaged in drying , plants and skinning birds under my tuition; Faraji and Cephas were building a kitchen; Ibrahim was sent with Baher, Farijala, and Mwali Mnyani to take spades and clear the site for my house; Abdallah bin Saleh was to cut grass and attend to the goat and cow ; Mguu collected firewood for the cooks; while, most important task of all, to Kadu Stanley was given the post of gardener-he had to dig up a piece of soil, divide it into neat plots, sow it with my English seeds, and hedge it round about with a sturdy palisade. The day succeeding my arrival I had already put into my kitchen-garden the seeds of mustard and cress, radishes, turnips, carrots, onions, tomatoes, borage, sage, cucumbers, and melons; and at the end of my first week in Čaga, I was already eating a salad of my own growing.

We did not, however, sink at once into this life of quiet colonization. During the first few days of my stay I was much annoyed by continual visits from Mandara's parasites; wretched bankrupt Swahili traders or runaway slaves, who had taken refuge with the chief of Moši from their creditors or owners; and, in the sense that a one-eyed man is king amongst the blind, so this rascality of the coast quite lorded it over the simple savage, and affected to consider itself on a par with the white man. From the first time, however, that I met them on the road to Čaga, when they were sent to welcome me to Mandara's country. 
I felt it would be a struggle for supremacy between us. They were secretly enraged at my coming, fearing to lose their influence over the fickle chief, and seeing much hindrance to the slave-trade, which they, the ex-slaves, were so profitably organizing. Accordingly, from the very first they sought to thwart me, and, without resorting to any overt act of malice, intended to render my stay in the country impossible. Before I had barely occupied my settlement a day they began making constant visits to my tent, coolly demanding this and that article in the name of Mandara. At first I simply declined, but, after one or two refusals, their ringleader, an ape-like, shrunken man, marked with small-pox, said in a threatening tone, "I tell you what, young man (kijana), if you are not more generous, you will never be able to stop here." - I immediately seized my stick, and jumped after him ; but he had gathered up his skirts and fled, followed by his companions. At this juncture there was but one course to be pursued. I called to me two or three of my men, took my walking-stick, and started on the road to Mandara's house. Arriving at his village green, I saw his Swahili parasites lolling about, some of them affecting to play with much interest a game like "draughts," called bao, although I saw them watching me out of the corners of their eyes. All, however, studiously remained indifferent to my approach, and for a second I paused, irresolute as to how I should announce myself to the chief. Then I called to the nearest man, who was stooping over one of the bao players, and told him quietly to go and tell Mandara I desired an interview. He kept his back turned to me, shrugged his shoulders, and smiled scornfully at his comrades. My temper rose, but, apart from 
this, I knew these curs only cringe to force. I raised my stick, and brought it down with a sounding thwack on the shoulders of the inattentive man. "Now," I said, "you pig, you slave, go and tell the chief I have come to say good-bye." He looked startled and hurried off. Presently I was summoned by a Čaga warrior to approach, but before I reached the hedge of dracœnas that bounded Mandara's enclosure the chief himself came striding to meet me, not, as I had nerved myself to meet him, with knitted brows and sullen scowl, but with a charming smile and beaming face. Taking both my hands in his outstretched palms, he said, "What! has my white man come to see me already? How good! Now we must have a chat. Bring a seat there, and a cup of "tembo." This winning manner quite altered the tone of my feelings, and, after such graciousness, I felt that peevish complaints sounded very ill from my mouth. However, I braced myself to the disagreeable task, and told him resolutely that I must leave if any further demand for presents was made. "You know, Mandara, I am a poor man. The Wa-alimu (wise men) of Ulaya have not provided me with many goods. I cannot afford to give you constant gifts. If you really want me to build here and live in your country, you must leave off asking me for presents."

Mandara, at these words, looked around on all present with well-acted astonishment. His one bright eye grew sad and perplexed under his knitted brow, as he said, "What is the white man saying? I don't understand. Why does he want to go?" My men then told him, with averted looks and in tones of deepest respect, that the white man was offended because Mandara's Swahilis came asking for frequent 
gifts for their chief. "Oh, is that all?" said Mandara, who had of course instigated the whole affair, and had sent these men to sound me gently, and see if I was of a generous and yielding temperament. "These men don't know what they are saying; they should converse with the white man's servants, not with him. But," he said, "we are wasting our time over little words-manéno madogo. Between the white man and Mandara only great affairs should be treated of, or else general and light conversation (zumgumzo). I am Sultan here, am I not? (An eager and hurried assent on every one's part.) "And this is the Baloza's child. Let him settle here in peace, and not concern himself with the conversation of slaves." Here he affected to scowl at the Wa-swahili, who bore all this tirade very stolidly, as if a pre-arranged comedy was being carried out. However, I was not to be outdone in amiability, and so I heartily shook Mandara's great paw, and drank sour tembo (which I detested) with an affected enjoyment quite touching in its hypocrisy: Then a bright idea crossed my mind and I said-seeing that Mandara expected a reply to his oration-"Mandara, I have got a little tale (hadithi) to tell you." "I am listening," answered the chief. "Once, do you know, in Ulaya, there was a man who had a hen (none of the Wa-čaga have heard of geese) which laid him every morning a golden egg. And the man was very pleased at first, but after awhile he got impatient, and he said, 'Instead of waiting' for many days till I get a good sum from this hen's eggs, let me cut her open now, and get out all the gold at once.' And he did so, and found nothing inside. Now, wasn't that a foolish man, Mandara?" "Ye-es," replied the chief thoughtfully, "perhaps he 
was." Then he sipped more tembo, and reflected. After a pause he turned to me and continued, "And now $I$ will tell you a tale. When I plant a seed or a sappling here in my plantation, I let it grow quietly at first-I do not pull it up to look at its roots, and I do not pluck its early blossoms or its tender leaves. I wait until it is mature, and then," he added thoughtfully, looking straight before him, "if it fails to bear abundant fruit, I cut it down."

Then our conversation ranged over the most varied subjects-European life, a description from me of an ironclad-manowari (man-of-war) as Mandara called it - the history and configuration of Čaga from Mandara, whose notion of local geography was singularly correct - the Caga language, the English tongue, and so on.

The interview ended in rapturous friendship. Mandara declared himself my father, claimed me as a son, and announced, almost hysterically, a complete community of goods (a statement to which I inwardly demurred). "Whenever the white man wanted a cow or a goat, he would just take them from the herds of his father Mandara, and whenever Mandara desired a handsome gun or a European bed, he would use those that belonged to his white child."

As an earnest of this happy arrangement he sent for a splendid ram, with an immensely fat tail, a ewe, and a lamb, and handed them over to me as a little "kitowéo" (relish), to take back to my camp. I then shook his great hand enthusiastically, and with many a parting shout of "Kwa-heri (good-bye), Mandara," "Kwa-heri, mtoto wangu!" (good-bye, my child), I turned my steps back to Kitimbiriu, my men enthusiastic over the "manéno mazuri" (fine words) which had passed between their master and 
the chief of Moši. Of course on my return I made up a quantity of the things he most coveted, especially a number of packets of European seeds, and sent them to him as an equivalent for the sheep. After this interview the relations between Mandara and myself assumed such a friendly character, that I felt myself able to rely entirely on his goodwill as a protection against the rapacity of his followers. Consequently, the very next day I despatched twenty men to Taita for the purpose, already mentioned, of bringing the last instalment of goods left behind.

When these had departed, I was now at liberty to turn my attention to more congenial studies. I installed my two collectors in a quickly constructed hut, unpacked the bales of botanical paper, the cases of taxidermist paraphernalia, and other necessaries in natural history collecting, and set to work to amass and preserve as many specimens of the fauna and flora around me as I could obtain. Having given every man his allotted task, and being able to trust the general supervision of the settlement to my Indian servant, I was freer in my movements than I had been for a long time, and could ramble about alone all day with the certainty of finding everything going on well when I returned. With a light heart I was able to explore the beauties of my African Switzerland. Hirst of all, I desired to obtain a sketch of the snowy dome of Kibô. This, the highest summit of Kilimanjaro, was not always on view. For weeks together he would be swathed in clouds. But should you be an early riser, you would hardly fail to catch a glimpse of him just at sunrise, when before the cold breath of morning the unfolding clouds part and scatter, and disclose his splendid crown of virgin snow, irradiated 


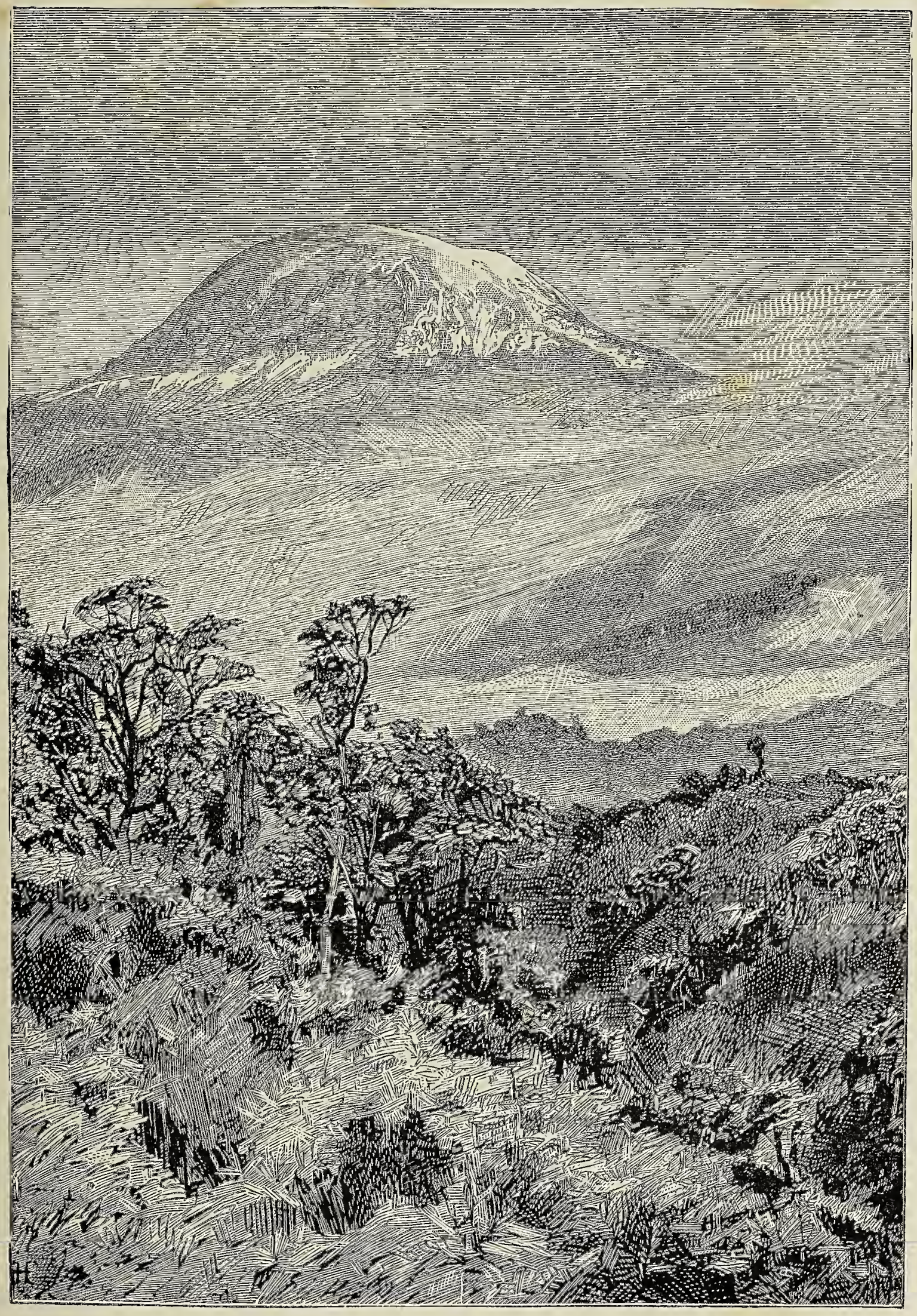

KMBO IN THE EARLY MORNING.

To face page 136. 

with the pale pink sunshine. Thus it was that within a few days of my arrival I had my first good stare at, and began my first detailed sketch of Kilima-njaro's highest peak, which the coast people call " the mountain of the Snow Fiend," and the Masai more reverently term " the Home of God." I hurried a short distance from my camp to the edge of the ravine, whence there was little to obstruct the view, and there, squatted amid the crushed bracken fronds at the commencement of the precipitous descent, I looked across first to the opposite hill, crested with feathery trees, acacias, sycamores, and palms, and then to the swelling forest-clad heights beyond, gloomy and sombre in the shade, as yet untouched by the sloping sunshine. Above these a vast white sheet of fleecy cloud, uniform and flat, and crowning all, as if cut off from the lower earth, and floating majestically in the pale blue heaven, the snowcovered dome, with its blemishes of shadow and blaze of preponderating light like that of the disc of the moon.

The jealous clouds, however, granted me but a

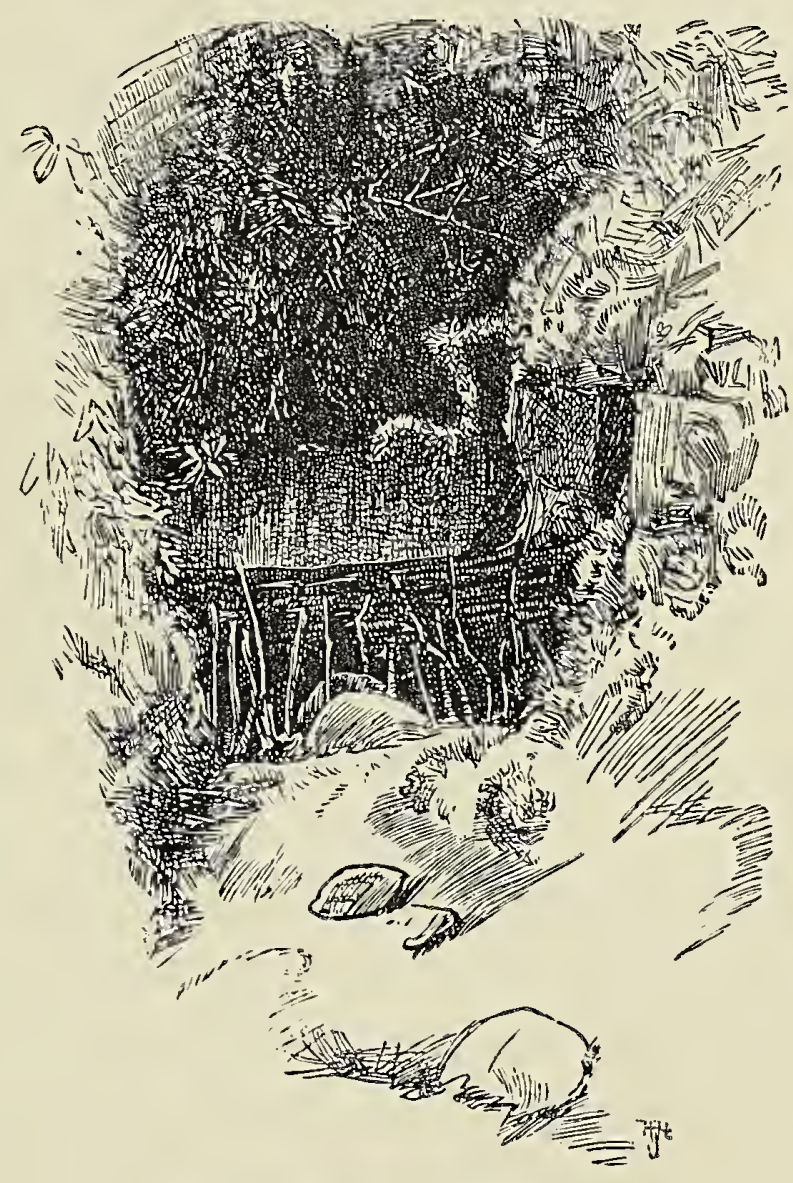

Fig. 34.-A Native Dam. poor half-hour in which to sketch the features of their 
monarch, and I was compelled to defer the completion of my work to other opportunities. Meanwhile, I extended my walks, gun in hand, and a collecting. portfolio on my back, in all directions, but my first favourite stroll was up the valley of our little stream. Following the tiny path which ran parallel with our

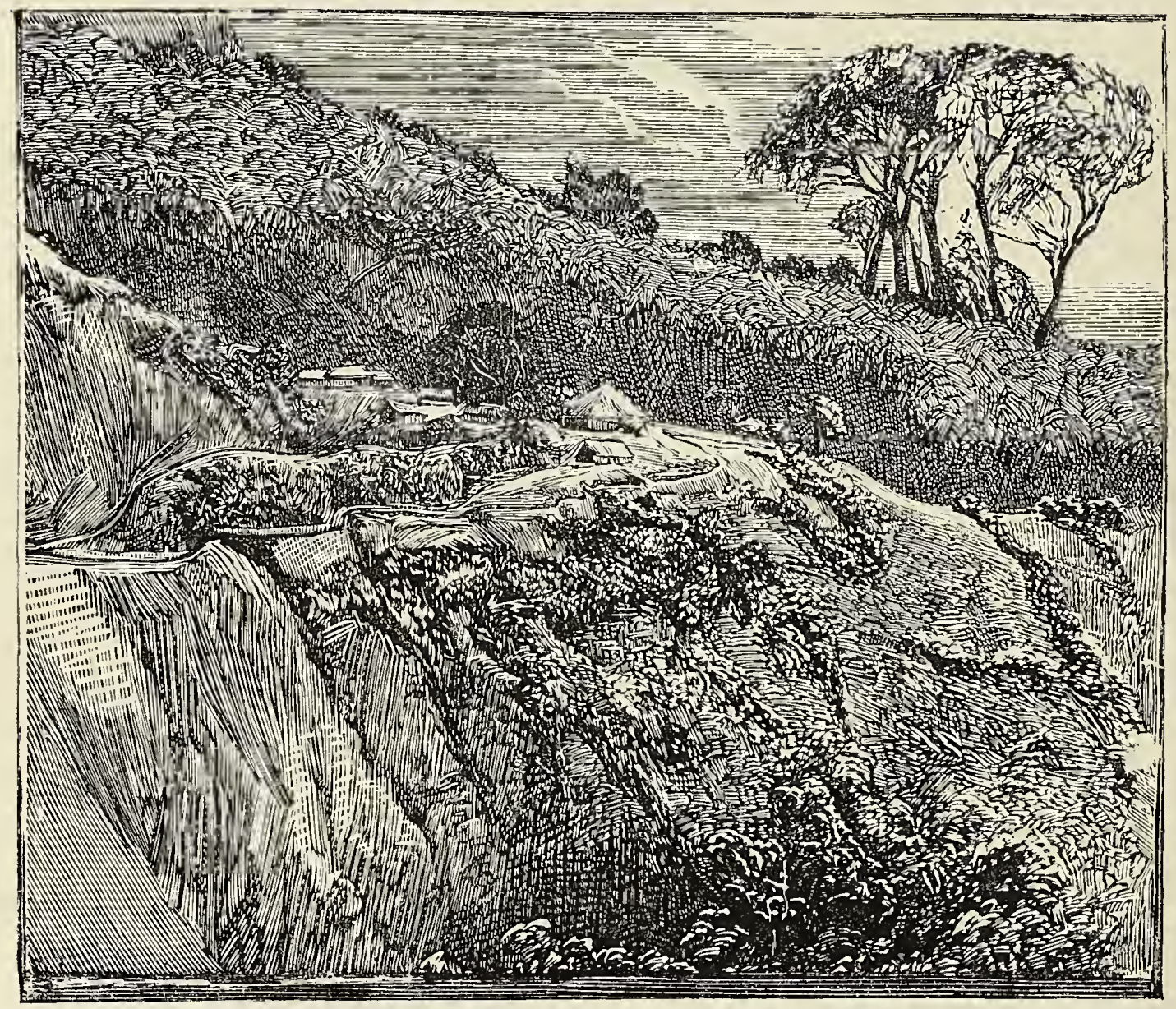

Fig. 35.- "Kitimbiriu" (our First Settlement on Kilima-njaro).

irrigating channel, I came to the place where the latter branched off from the parent stream. Here, at will, a passing native could cut off our water-supply by laying a packet of grass and mud athwart the little channel, and, therefore, bearing this in mind, and regarding also the fertility and beauty of the rich valley (full of the alluvial soil washed down from the 
hill-sides by the rain), I resolved that hereabouts my principal plantations should be made. I obtained Mardara's consent to the plan, and accordingly set my man, Kadu Stanley, to work at once, directing him to clear away the brushwood, burn it, mix the ashes with the soil, and then plough the whole field up and break the clods of earth. Soon many a rich bed of dark red earth was sown with seed, and separated from its fellows by little runnels, along. which, once a day or oftener, water, diverted from the nearést waterfall, was turned. Indeed, perpetual irrigation was here much simplified. The plenteous stream went bounding through the valley, with a cascade every hundred yards or so. From the head of these waterfalls nothing was easier than to divert a stream on either side, carry it along a banked-up channel above your plantations, and turn the water wherever you willed into the network of tiny trenches which intersected the plots of ground.

However, artificial irrigation seemed almost a superfluity in Čaga, where never a month passed without rain, and where the climate was as moist as that of Devonshire. I soon began to find that my first care must be to get a rain-proof roof to sleep under. Our primal houses were roughly made in a very few days. The men proceeded to the forest, cut a certain number of poles, used those that were forked at one extremity as "uprights," and laid the horizontal rods across them, tying everything securely with long lithe strips of wetted banana fibre. Then to this rough framework they affixed a number of smaller sticks, until a rough lattice-work was formed, and finally, the whole, roof and all, would be neatly thatched with the old fronds of the banana-tree, resembling brown paper in 
look and texture. (By-the-bye, when civilization extends to Africa and people have got beyond the stage when they only seek for gold or diamonds, it strikes me that sun-dried banana leaves would form an admirable material for paper-making, superior to esparto grass.) Provided the roof was done with care, it ought to be completely rain-tight. As it was, a little patching generally had to take place after the first shower. No windows, of course, were made. Light was obtained from the open doorway, which was closed at night by a mackintosh curtain and a door of wooden framework. Inside, the earthen floor was stamped hard by men's feet, and before inhabiting the house numerous fires were burnt on the ground and their ashes pounded into the beaten earth. Of course a trench or moat, to carry off the heavy rain, was dug all round the house, so that it generally happened that these hastily-constructed abodes were wonderfully dry and snug. When the house was built for my own occupation I had a large mat made from plaited strips of the useful " migomba" (dried banana leaves), and thrown down on the bare floor of beaten earth. Then, on this, one or tswo wild beasts' skins or a bright-coloured Zanzibar " mkeka" (dyed grass mat), added quite a comfortable look to the interior. My bed was mounted in one corner, my portable table stood in the centre of the dwelling, boxes of necessaries were arranged along the walls, my washingbasin was poised on a roughly-made tripod, shelves were hastily rigged up to support the lighter articles of my equipment, and lastly, nails and hooks were knocked into the accommodating rafters, and from these depended all the heterogeneous articles that would let themselves be hung up. 
Similar habitations were constructed for my men, paths were cleared and open spaces mowed, and soon, where before had been little but the pristine wilderness, rose the first decided outlines of my little colony. 


\section{CHAPTER VII. \\ "HALCYON DAYS."}

ABout a month was spent in the calm and contemplative occupations described in the last chapter.

This period seemed in one way to pass all too quickly, for the days slipped by one after the other, and no date stood marked out prominently by extraordinary events; and yet for the amount of work performed and for the changes in our environment, that first short term of our residence on Kilima-njaro was an age, a cycle of history, especially for the natives. While two-thirds of my men were tramping to Taita and back to fetch the rest of my goods, I, with the remaining third, was hard at work during every twelve hours of daylight. Not only did we build the temporary houses and plant the kitchen-gardens I have already described, but we installed our cows and goats in a spacious stable, constructed with sufficient strength to resist a night attack from leopards; we set going a poultry-run of eighty fowls; and we established a primitive dairy, wherein the milk from our animals was laid out in large flat wooden dishes (bought from the natives), and produced such a liberal quantity of cream that when enough had been taken to churn into butter (this operation was really performed by shaking in a large bottle), the remainder served to enrich my 



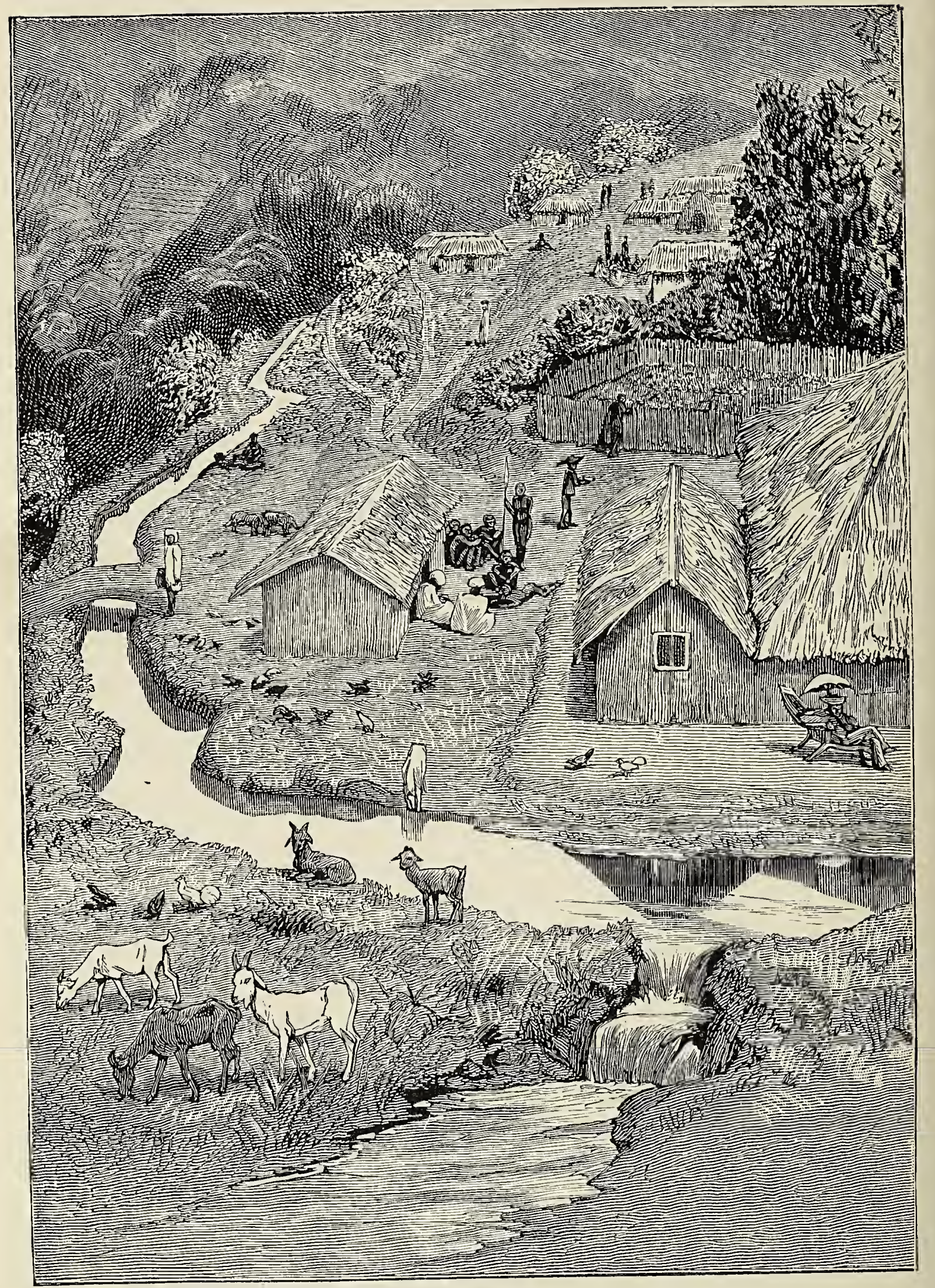

A CORNER OF OUR SETTLFMENT.

To face page 113. 
afternoon tea or early breakfast. One morning towards the close of this most tranquil period my heart really swelled with proprietary pride, when I saw on my neatly-laid breakfast-table the first new-laid egg's of my poultry-yard, the first radishes from my garden, the first loaf from our home-made oven, together with the adjuncts of our dairy, a pat of butter and a jug of cream. With opulence came refinement and the renaissance of art. I was now no longer content to lodge in a hut, however dry and snug. I wanted a spacious house. The ground being cleared and levelled, I planned out with pegs and twine a residence of ample size and regular proportions - 26 feet long and 18 feet wide, with two "wings" of 9 feet square at the sides. The roof was to rise to a height of 12 feet at the apex, in the centre, and slope down to 7 feet at the sides. The interior of the main building was to be again divided lengthways by inside partitions into two equal portions, one-half to furnish a long salon and reception-room, and the other to be subdivided again into three compartments, which would be respectively used as bed-room, bath-room, and store-room. Of the two wings, one would become my servant's room, and the other a pantry where the crockery and table-gear should be kept. It was altogether a grand scheme, a majestic design, and when my six or seven builders were initiated into the plans they tapped their open mouths'with their hands to express their admiration for such a bold flight in architecture. But the fact was that, like many ambitious projectors, my plans were too vast for the means at hand for carrying them into operation. During three months this great edifice was constructing, and a few days after the last touches were put 
to its embellishments I had, alas! to leave Moši for good, and my deserted palace doubtless remains behind (white ants and natives permitting) to testify to future explorers, by its (relatively) cyclopean proportions and harmonious design, that an ambitious white man once sojourned in that spot.

While my building of clay and wood may prove but fleeting evidences of my long residence in Moši, the roads I made, and even the bridges over the shallow streams are likelier to subsist. One of my first actions on entering a savage country and residing there, though it may be only for a day or two, is to get men, axes, sickles, and spades, and clear a path from somewhere to somewhere else through the dense bush. It always seems to me that in so doing I am opening up, however feebly, the land to civilization. Moreover, if you are going to collect in the forest and study nature there, it is much pleasanter to have a decent path along which to walk to your basis of operations. So my broad tracks stretched right away in many directions from the settlement, and along them I could go backwards and forwards to my work.

So even was the tenor of my ways during this firs month in Moši, that I can find no striking events worthy to lay before you, other than the mild domestic incidents of this bucolic life. As one day was the repetition of another, I may describe pretty accurately how a whole month was passed by retailing to you the petty incidents and occupations which made up the sum of my existence between awaking from my slumbers in the morning and retiring to my well-earned rest at night.

One typical day of my first month's residence in Kitimbiriu shall be taken from my diary and laid 
before you, with a little filling in of details and addition of explanatory information, necessary to my reader's, but superfluous in my own journal, where I write from one day to another with due regard for my memory of recorded events and observations.

About seven in the morning (in these equatorial regions it is scarcely light till nearly six) I hear the plashing of water in my bath, mingling with the last echoes of some fantastic dream-perchance some incongruous vision of English life that has come upon me in my heavy morning slumber-and I gradually awake, with many a sigh and groan, to find my servant Virapan filling my bath with several kettlefuls of warm water and a pail of cold from the stream, whose murmur I occasionally hear coming as a second to the treble of the cackling hens and bleating goats. Ah! how I hesitate to leave the shelter of my sheets and blankets! Though the slanting morning sunbeams pierce the crevices of the thatched wall, and fall in golden paillettes on the matted floor, the thermometer still marks little over fifty, and the air is sharp and keen, even within my sheltered hut. Nevertheless, the steaming bath will soon be lukewarm if I dally, and moreover breakfast-and in this healthy life I love my meals, and look forward to them with tender longing-cannot be laid until the bath is out of the way, so with one impetuous bound I am out of the sheets, my pyjamas are flung off, and I can sponge myself with the warm water which, in the tropics, is so much healthier and more beneficial than the icy douche which strong-minded, generally disagreeable, people affect in England.

I find my pen was leading me into a detailed description of my toilet, an act so purely superfluous and 
uninteresting to the reader that I am glad I stopped short in time. Give me a quarter of an hour after my bath, and I am clothed, and brushed, and spruce, and standing at my cottage door lustily ringing a small hand-bell. When its last brazen tinkle is silent, cries are heard from the distant huts of my Swahili porters. "Tayari, Bwana, Tayari. Aya! Kazi, Kazi!" "Ready, master, ready. Work, to work!" These ejaculations are meant somewhat to appease me while the utterers are turning regretfully from their couches or their niresides, and donning their scanty garments. Then nine or ten men come running down the incline, for their quarters are higher up the hill than mine, and hastily form themselves into a line in front of my door.

I call over the roll: "Cephas?" (Cephas is the chief cook, and is engaged in cooking my breakfast, so I excuse his reply.) "Faraji ?" "Ndimi, Bwanahere I am, sir," comes a cry from the cowshed, where milking is going on. "Abdallah?" (Abdallah is for the time being head-man, and Minister of Public Works in my Cabinet. He is slightly deceitful, invariably courteous, always tidy and smartly dressed, rather a rogue but an accomplished one.) "Hapa, Bwanahere, sir." "Farijala?" "Yes, sir." (Farijala has been an old mission boy, and retains "Yes, sir," as the last fragment of the English tongue. $\mathrm{He}$ also sings "Te Deums" when at work, imagining them to be popular English melodies. He is a good, willing fellow, thoroughly honest.) "Ibrahim?" (Ibrahim is the best man in the caravan. He is short, fat, with an enormous mouth, and always in a good temper.) And so I go through the list of names till the twelve are accounted for. This task over, I then have to 
attend to small ailments of some. This man has an ulcer, that a stomach-ache, another complains of a cough, more often the maladies suddenly assumed are of a less tangible character, like the neuralgia of civilization. "A pain here, sir, oh! so bad. I'm afraid I can't work to-day." "Oh, nonsense! you ate too much yesterday. Go and chop some firewood, that'll do you more good than medicine." And so all are finally told off to their tasks-two to attend to the gardens, one to get firewood, one to herd the goats, sheep, and cow, another to look after the fowls, five to build the big house or cut the roads, as the case maybe. Faraji and Cephas of course attend to the cooking, and nothing else.

Now I am a free man, and may go for a stroll in the fresh morning air before breakfast is served, walking along the path that fringes the crest of the narrowing hill-spur on which the settlement is placed, gazing, perhaps, at the majestic snowpeak of Kibô which rises sharp and clear above the morning mists, or gathering wild flowers to deck my breakfast - table.

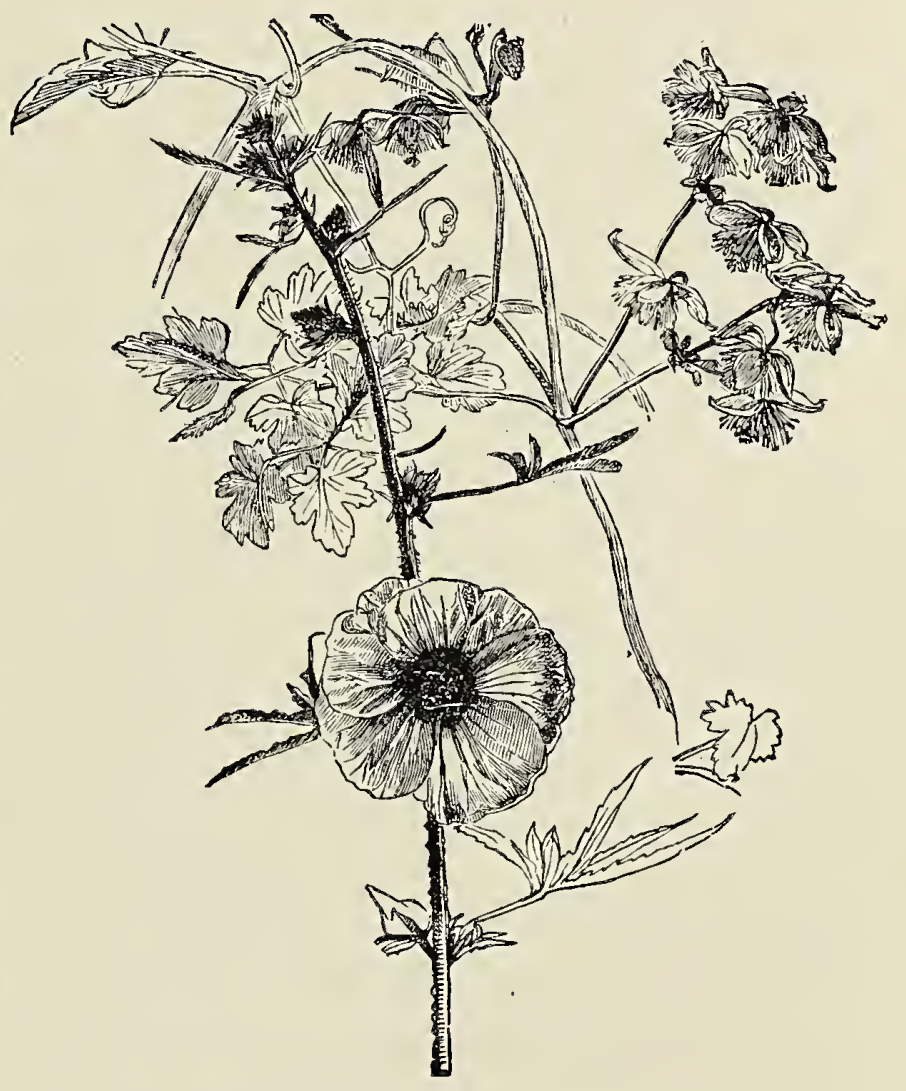

Fig. 37.-Clematis and Hibiscus.

Here grow gorgeous dissotises, large-petalled mauve- 
red flowers, primrose-yellow and purple-centred hibiscuses, creamy-white clematis, with thick, woolly petals, and many lovely blossoms of balsams, and a mauvewhite thing like phlox-quite a glowing mass of colour in my natural garden, which makes me hotly refute the theory that the tropics cannot produce flowershows equal to those of the temperate zone.

I come back in answer to the earnest appeals of Virapan, who assures me breakfast is getting cold, but I must yet delay my sitting down till my floral treasures are placed in water, and put in the centre of my repast. I must describe to you my breakfast-table. I have a right to pride myself on its appearance, as most of the good things it bears are our own local productions and not imported from Europe, and I want it to preach a little lesson that will show how much Africa may be made to yield in the way of comfort when comfort is sought. Of course this applies more to the resident than to the traveller, who cannot stay long enough in a place to develop its resources.

Firstly, there is a nice snowy cloth spread over the table, then the silver is bright, and the enamelled iron plates are clean, all details which are due to a little supervision over servants' work. The grateful steam of coffee comes from a pretty cafetière, a little white jug contains hot milk from my own cow, there is a pat of fresh butter of our own making lying in a cool green leaf, a nicely-baked loaf, made from maize-flour and eggs (and in a long parenthesis I might explain that the flour is of our own grinding and sifting, and the eggs are from our own poultry); and lastly, there are grilled kidneys from a sheep we killed yesterday, fried bananas as an entremet, and a bowl of honey.

Of all these delicacies, only coffee and sugar are 
extraneous, so that I hope thus to show how much comfort and good living may be extracted even from savage Africa.

When the meal is finished I set out to visit my plantations. They are situated about half a mile from my house. The walk thither takes you along the little stream which supplies a canal, or, to use a more expressive Cornish word, a "leat" of water to our settlement, and the ground has been cleared and planted near the waterside, so that irrigation is easy. Here is working Kadu Stanley, a bright, willing Mganda boy, given by King Mtesa of Buganda to Stanley, when he visited that monarch in 1876 . Kadu has sojourned several years on the Congo, and after his return to Zanzibar has taken service with me. I have made him head-gardener.

Here are planted all the seeds I have brought from England, together with potatoes, onions, \&c., brought from Zanzibar, and many native vegetables as well. Already, after a month or six weeks, the growth is surprising. Radishes are still in good condition for eating, the mustard and cress have run to seed, turnips are nearly ready, carrots and cucumbers are coming up, and sticks have been already placed in long rows for the peas and beans. The purple-green shoots of the potatoes are springing up wherever "eyes" have been planted, some of the onions are in flower. The only recalcitrant thing is spinach, which for some reason will not flourish.

I leave Kadu and go onwards up the valley, sketchbook under my arm, and my small bird-gun in my hand. Across the stream there flits a large kingfisher, grey and rufous brown and verditer-blue, with red beak. Like the real aboriginal kingfisher, he feeds 
only on insects, as there are no fish in these streams. Fishing has been quite an afterthought with the kingfishers, and is a pastime by no means shared by all the members of the group. Many Australian species, the halcyon of the Cape Verde Islands, and this common East African halcyon found on Kilima-njaro never attempt to catch fish, even though they be near streams well stocked with piscine prey, but content

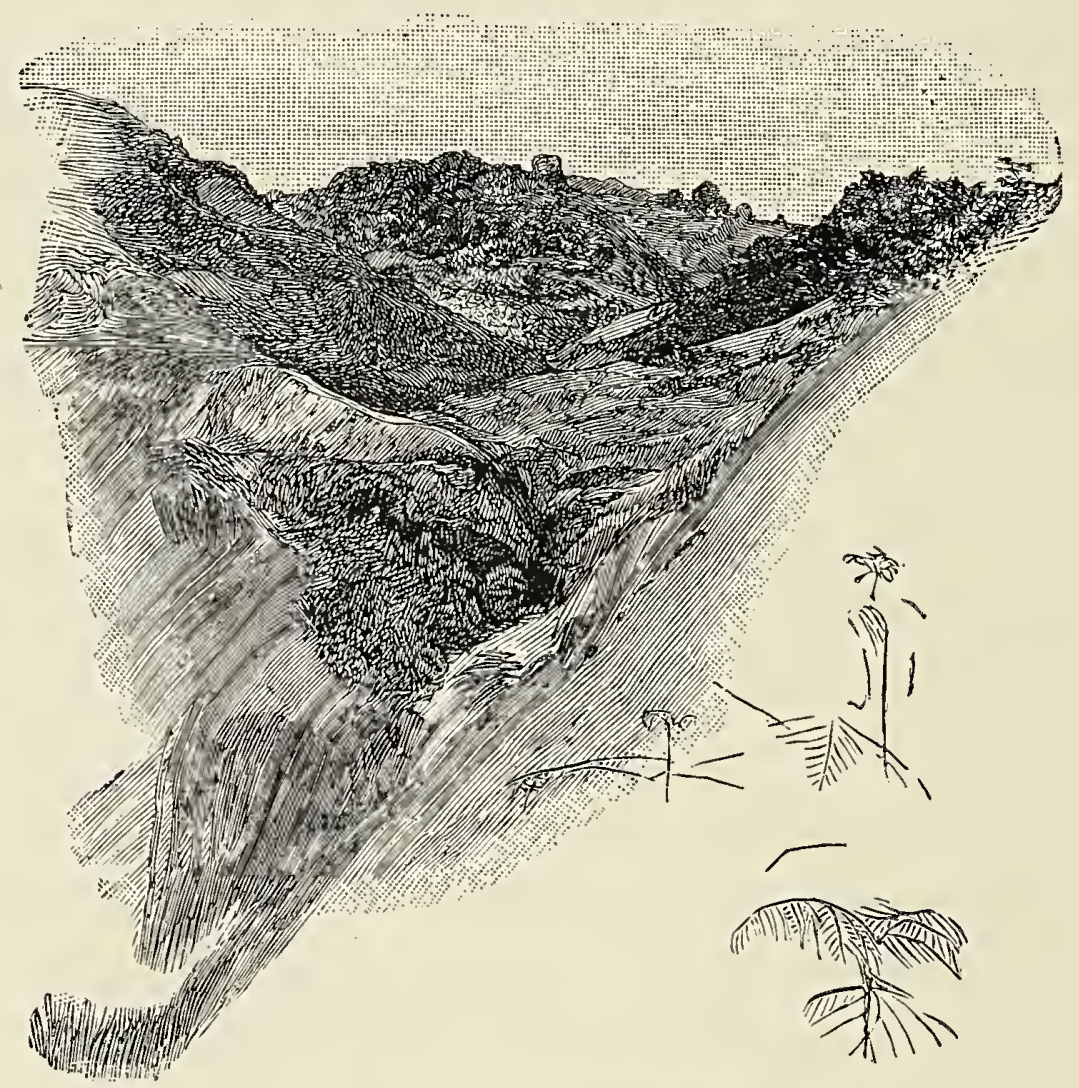

Fig. 38.-A ravine in Moši.

themselves with the variety of insects that haunt the waterside. I shoot this kingfisher just to identify him, and afterwards, when his little stomach is opened, the carapaces of beetles and remains of grasshoppers are found within.

Now the stream I am ascending becomes two streamlets, and the valley bifurcates into two ravines, while the broad slope of a hill faces me, so I leave the 
pleasant path along the waterside and toil up the clayey ascent. But when I have reached the level crest of this bracken-covered height, I slip into a smooth and level track, winding along between low hedges of strychnia and dracœna, and giving off many side turnings which lead to native compounds and enclosures. Several maidens pass me shyly, going to market with bananas or neat baskets of millet meal or bags of Indian corn. Some of the bolder, who have perhaps met me before in the market-place, or at Mandara's, give me the Čaga greeting, "Mbuia" (friend), to which I heartily reply, "Mbuia, mbuia." How strange it is! In all probability many of these Čaga girls have never seen me or any other white man before; yet we meet in a lane suddenly, and beyond a somewhat timid shrinking to one side, there is no fear and no surprise exhibited. Each after the formal greeting wends his or her way tranquilly. And yet, to imagine a similar contrast, suppose some English country girls, say in the most rural depths of Somersetshire, were suddenly to come upon a naked black man striding along a leafy lane, armed with spear and shield, and decked with strange adornments, necklaces of human teeth, and such like, would they not in all likelihood shriek for help, or giggle convulsively, or in some obtrusive fashion display their amazement? Yet these African maidens, to whom I, clothed where they are accustomed to utter nakedness, with aneroid hanging round my neck, sketch-book under my arm, and gun in hand, suddenly appear, merely give me a modest greeting and a shy look, and quietly pursue their way.

After a further ascent I arrive on the summit of a rounded hill which considerably o'ertops its fellows 
for miles round, and offers views of unexampled magnificence in all this lovely country. To the north, without a single fleck of intervening cloud, rises Kilimanjaro, the whole central ridge and both the peaks completely visible. The eye first rests irresistibly on the splendid snowy dome of Kibô, absolute in whiteness under the glare of the vertical sun, with a few faint purplish blots, like the crater-shadows on the moon's face, coming out where the bare rock breaks through the snow, and then in the few hollows, gaps, or crevasses, tender cool shadows of pale blue break somewhat the dazzling effect of unsullied white. Below the snow-cap of Kibô lies a great stretch of purple moorland broken up dimly into ravines, cliffs, hillocks, and ridges by shadows of deeper tint, but seen with the eyes half shut seeming a band of purple colour merging into a colder bluish tint where it reaches the distant snow, and becoming darker and sombrer where it mingles with the middle distance of dark-green forest. To the left of Kibô, a rounded descent of the mountain-mass stretches down with some few jags and modulations till it passes away into the far-off plain, and to the right of the snowy dome a ridge nearly horizontal reaches to the sister and minor peak, the jagged Kimawenzi, which has merely patches and streaks of snow resting amid its strange black peaks and pinnacles. ${ }^{1}$ The background to the entire scene is a sky of intense blue, which is almost free from cloud save for a few vapourous cumuli lying behind the centre ridge of the mountain. In the middle distance are grandly swelling, rolling hills, magnificently wooded with, in some cases, a forest growth so uniform that, looked down on from a height, its surface

1 Vide illustration of Kilima-njaro, p. 234 . 


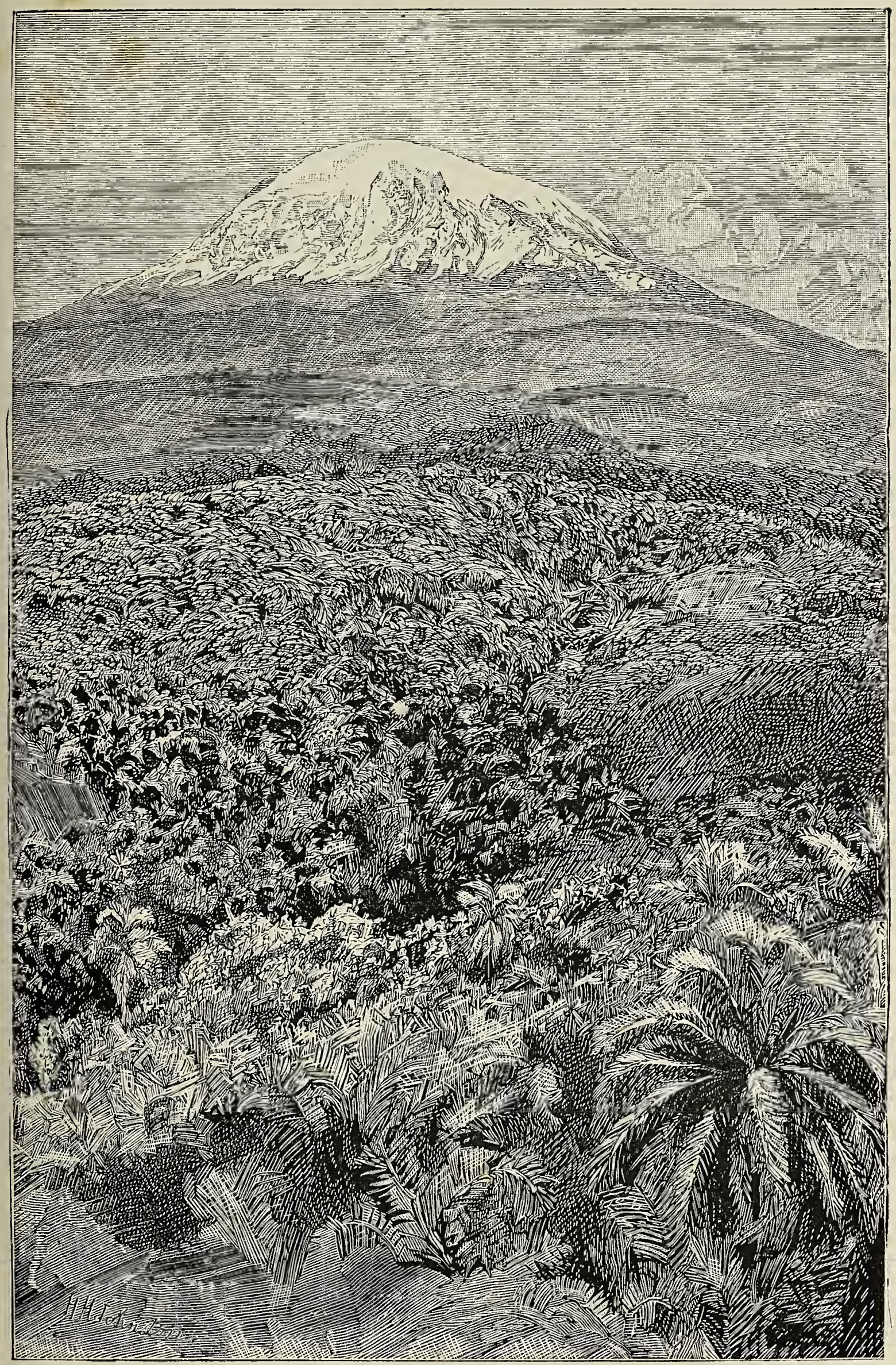

IILIMA-NJARO SEEN FROM ABOVE MOŠ ("PALMS AND SNOW").

To face page 152 . 

is like rich green velvet pile. Here and there, but rarely, on the hill-sides there are open patches of land, covered with short turf or bracken. These offer, by the side of the darker forest, tracts of Iovely grass-green colour, almost unrepresentable in pigment, from the fact that in water-colours or oil there is no plain tint, or combination of tints, that will exactly give it, or in which any permanency can be hoped for. From the matrix of one or two of the nearer hills springs gush forth and flow through ever deepening ravines with musical clamour, though their course and their birthplace can only be conjectured at a distance from the greater luxuriance of the forest which they provoke.

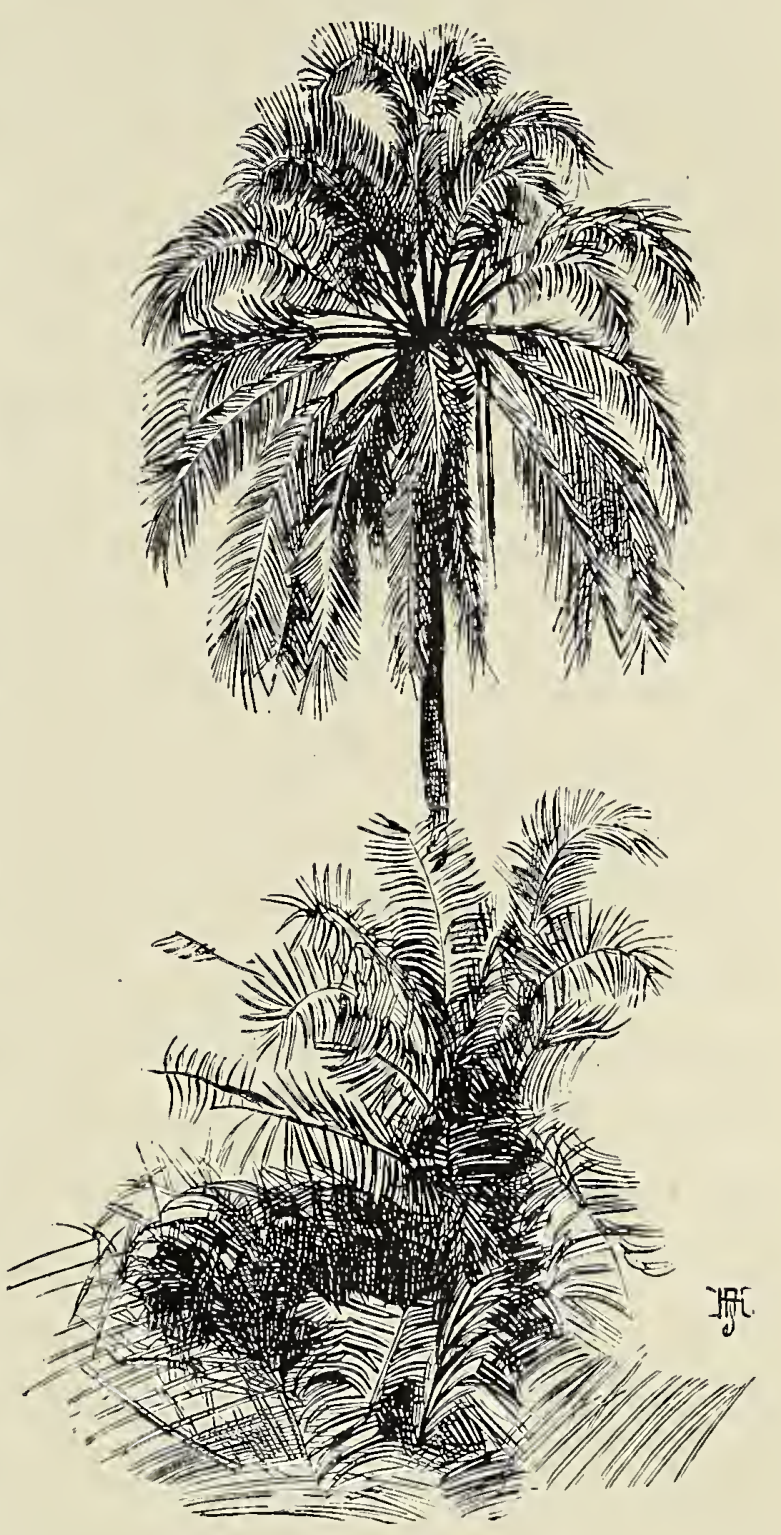

Fig. 40.-Mkindu Palm.

In the foreground I look upon the descending northern slope of the great hill from whose summit this unexampled view is obtained, and here there is an intricate mass of low forest, principally composed of the Mkindu palm (belonging to the genus Phoenix, a kind of wild date), mixed with indiscriminate shrubs, many of them overgrown with parasitic cucurbits and 
loranthus. This palm is the only member of the order I have ever found growing on the slopes of Kilimanjaro. In the plains below there are several others, the Hyphone thebaïca, or branching palm; the "Mwale" (Raphia vinifera), and the Borassus flabelliformis, but I have never seen any of these on the mountain.

Having worked industriously at my sketch, and shot three sun-birds which were hovering round the teazle-like flowers of a labiate plant in my vicinity, I now begin to think of returning homeward, for lunchtime is approaching, and, besides, the monarch of mountains has begun to weary of his condescension; he thinks I have stared at him enough, and he is wreathing light fleecy clouds round his august features as a signal that the interview is at an end. So I gather up my sketching materials, pop the sun-birds into a roll of wadding in my carnassière, and stroll homeward through the red lanes bordered with dracœnas, aloes, strychnia, and bramble, the latter covered with delicious blackberries, and the strychnia, which is semi-cultivated by the natives, with tiny yellow fruit exactly resembling miniature oranges, though scarcely larger than big peas. These are good to the taste, and, according to the natives, wholesome to eat, though in some way I connect them with ideas of poisons, and never largely indulge in their consumption. As I near my settlement I hear a great clamour of tongues, and find a market is going on in the vicinity of the Zanzibaris' quarters. About thirty Wa-čaga are there busy chaffering their goods for cloth and blue beads. The men are all naked, excepting for a tiny cloak or mantle of dressed fur round their shoulders. The women are principally clothed 
with thick bands of beads, but they generally have a short leathern apron or petticoat. The wares of these people consist principally of Indian corn, in the ripe grain, and also green cobs; two or three kinds of beans and peas; flour made from millet seed; tobacco in the leaf; honey; bananas, ripe and unripe; calabashes of sour milk or rancid butter, and numbers of live fowls. Perhaps on such a day as this I have purchased as many as eighty fowls for one "hand" (about an ell) of cloth each (approximate value $2 d$. an ell). Or there may by chance be a goat or sheep for sale; but this not often, as Mandara is supposed to own all the live-stock of the country as personal property, although he gives many goats, sheep, and cows to his subjects as presents, conditionally on their not being parted with, so he himself is almost the exclusive dealer in live-stock. I amuse myself by a little friendly chaffering before lunch, but leave all serious purchases to my servants, for the natives invariably deceive me when I wish to buy, either palming off old scraggy fowls, bad eggs, and adulterated honey on my inexperience, or else charging me extravagant prices.

One little item may be noticed in this market which will show how observant and practical the people are, and how they seize any lawful means of making money. I have only resided here, let us suppose, some few weeks, and yet the natives have noticed my fondness for eating blackberries, a thing they never do themselves for some reason or other. Consequently, without any hint from me, children have been sent by their parents to collect industriously all the berries to be got, and here they are, wrapped in bananaleaves, on sale for a trifle in cloth or beads. Also 
many women have brought bundles of firewood, so neatly done up and chopped into such handy logs that, although it seems superfluous to buy it, when one man's mission in the station is to collect nothing else in the woods all day long, yet it is sold so cheaply, and is so conveniently ready for use, that I often purchase it, and feel by so doing that I am encouraging the enterprise and spirit of my black neighbours.

After lunch I sit for an hour or two skinning birds; then, when the afternoon sun is declining, I set out for another ramble. Perhaps before starting I sip a welcome cup of tea in the natural arbour behind my house. Then taking my sketch-book, I wander forth in delicious aimlessness, now stopping to sketch a distant view of Mandara's village, seen from the head of our ravine, now scrambling up a bracken-covered hill-side in almost wild exuberance of spirits. " $\mathrm{How}$ happy life seems here," I stop and reflect to myself, as, my face all aglow with the flush of exercise, I rest awhile, seated on some grassy mound at the summit of the hill, and looking down on my busy settlement beneath, where the men at work are so many ants creeping two and fro, my gardens are green patches, and my houses might be the tiny habitations of leaves and twigs which some species of ants are wont to construct. Whilst I am gazing over this most varied prospect-over the tiny beginnings of a colony on the hill below, over the many ridges of banana-covered hills beyond, and further away the illimitable plains marked and patterned like a carpet with patches of purple forest, streaks of yellow sand, red hillocks, and pale green savannahs - a slight noise behind me attracts my attention, and I look round to find a 
Čaga man regarding me with a friendly grin, which exposes a row of filed and villainous teeth. It is my milkman, he who supplies me every morning with an extra quantity of milk which is needed for buttermaking. A conversation ensues, wherein neither understands the other to any extent, for I am as yet ignorant of Ki-čaga, and my interlocutor knows no Swahili. However, he evidently wants me to do something, for like a dog he will not leave me alone, but keeps going on a little way along the path, and then looking back. So I gather that he wishes me to accompany him. We soon arrive at the hedge round a native compound, and, passing through the narrow triangular doorway, girt about with living tree-trunks, and blocked, if need be, by a roughhewn massive plank, we enter a small yard

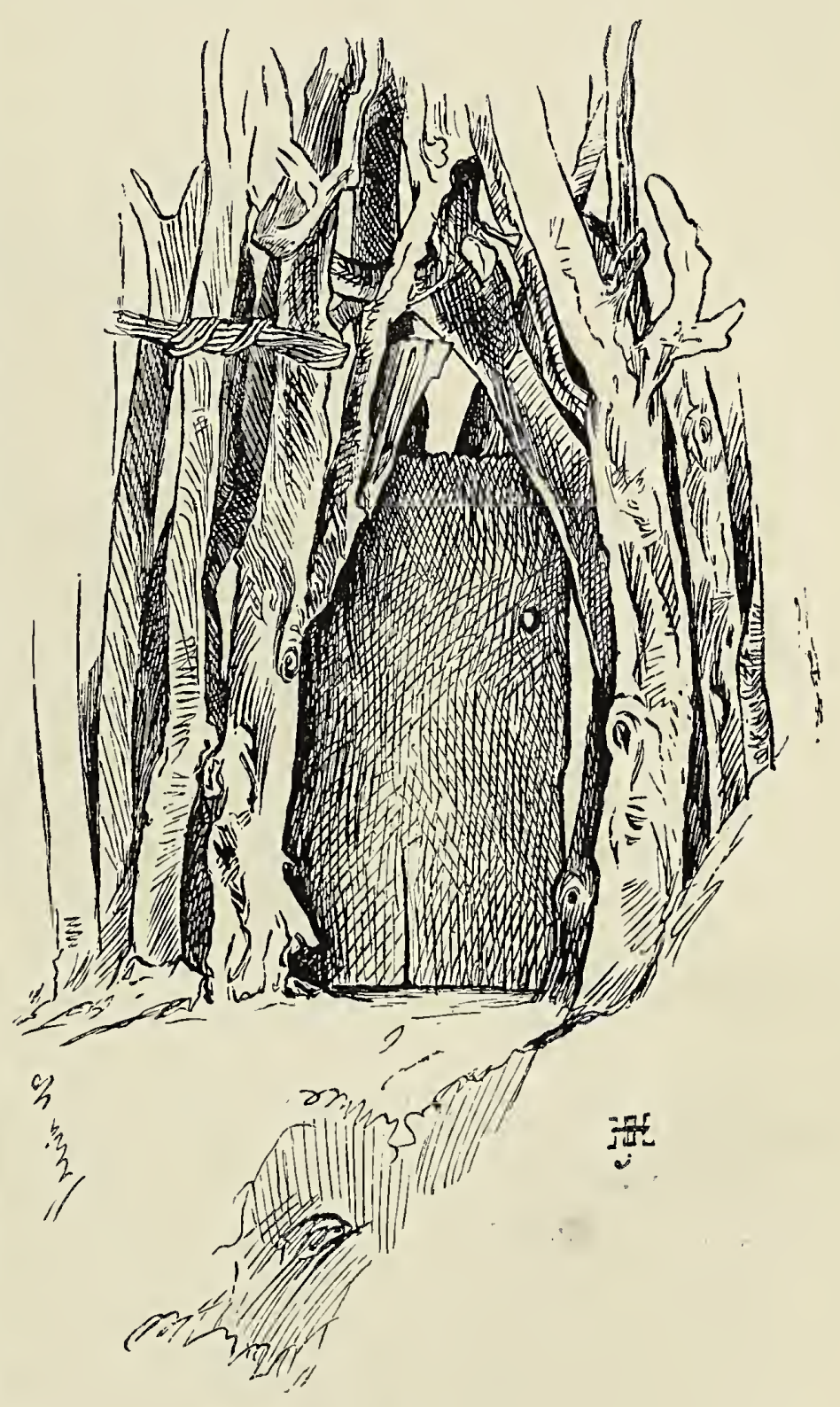

Fig. 41.-Č́aga Doorway.

wherein stand three buildings. One is a neatly- 
built storehouse, raised on piles (as may be seen in the illustration), and the other two beehive huts, surmounted with peaks like hay-cocks; goats and fat-tailed sheep are feeding on the pea-shucks which a woman, who is shelling peas, casts from time to time on the ground; and fowls are busy picking in the several rubbish-heaps, or kitchenmiddens, which stand outside the doorway. Little

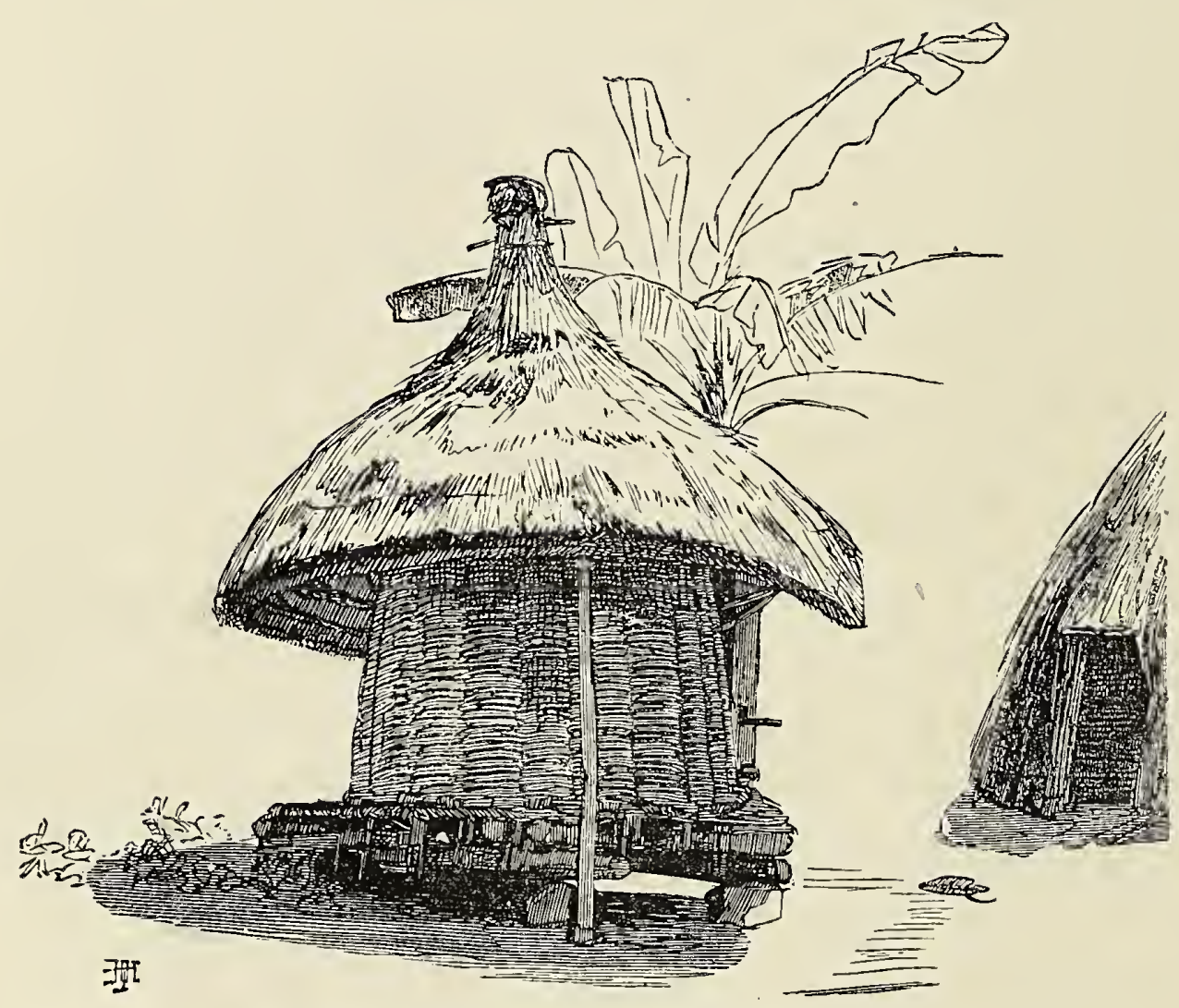

Fig. 42.-Caga Storehoùse and Dwelling.

surprise is manifested at my entrance. Another woman comes out from the smaller house, and stares for a short time at the unexpected arrival, but the woman shelling peas scarcely looks up from her work. Invited by my Caga friend to make myself at home I sit on the only available seat, a rough-hewn log cast on the ground, and commence a sketch of the scene before me. The storehouse is rapidly drawn in, the 
bearing several live monkeys for sale. The poor creatures are tightly tied to forked sticks, and are so bound with withes and strips of bast that they can only grind their teeth in impotent rage. I do not really want them, as they are of a very common species, but to encourage the people to search for and bring me live thing's, I buy them for a small amount of cloth. Then the canines of the savage males are docked, and the monkeys are tied round the hips with leathern thongs fastened to tree-trunks, and then relieved of their fetters and released. Whereon, of course, they career about at the length of their tether, vainly hoping to escape. Strange to say, they will all pause in their wild gyrations to eat bananas or other food that is thrown to them. (In the night, however, all escape, by gnawing resolutely through the leather bands which keep them in captivity.)

When the monkeys are disposed of there is still half an hour or so before sunset, so I induce the natives to sit at my feet and instruct me in their language. Ah! If my readers knew how difficult it is to collect an accurate vocabulary they would be little disposed to blame travellers from șavage regions who return without linguistic information. Think how you have to deal with people who have not the faintest conception of what you are about, except that it somehow has to do with magic, and is therefore not altogether lawful. You are without an interpreter, and can only hold up objects at first, and imply, half by gesture, that you want to know their names. Then as to more intricate questions, what weary work it is to elicit information, and how delighted one feels when some important doubt is solved, or a new explanation is unconsciously offered of some puzzling phenomena. The language 
of Kilima-njaro (Ki-čaga) is one of the Bantu group, which includes nearly all the African tongues south of the Equator. It is one of the prefix-governed tongues, and the forms of its various classes of prefixes are varying, but always show a common ancestral origin. The utmost number of known prefixes is by some computed at sixteen-by Bleek at eighteen, as he includes two pre-positions, "ko" and "mo" ("to" and "in") with the regular prefixes. (See for further information, "Bantu Languages," Chapter XX.)

Now in the language under consideration all the sixteen classes of prefix (except the twelfth) are represented, but some of them are much altered from the typical form. My object is to obtain examples of them all; but I want particularly to ascertain the form of the eighth prefix (a plural one). Unfortunately I cannot ask any of my friends, "What is your eighth prefix?" I should never be understood if I explained for a hundred years. I have to get at it in some other way. "What is this?" I ask, holding up a knife. "Ki-ošo," they reply. " Just so," I reflect, " "ki' is the seventh prefix, and the plural must give the form of the eighth." "How do Jou say "many knives'?" I continue; "ki-ošo" is one, what is for many?" "Śingi" (many), they reply. "No, but many knives?" "Šngi" is again repeated. Then I ask, "See, this is one knife-ki-ošo limo (holding up one finger). What is for two knives?" (holding up two fingers). "Two fingers," they reply, looking up very much puzzled. Then in despair I send for another knife, and placing it beside the original one again, ply them with a question. This only elicits the word for " another ;" but, at lengtb, after many disappointments, they are induced to say " "Ši-ošo šivi" (two 
linives), which gives me "Si-ošo" as the plural of "ki-ošo," and consequently "ši" is the form of the eighth prefix, and so on. But half an hour soon exhausts their mental energies, and they are sent away with a present, while I go to my dinner.

My little table has been laid with a snowy cloth, and the lamp placed on it spreads abroad its soft effulgence. My muddy boots are taken off, and my servant slips my feet into a pair of red morocco slippers that nestle into the skin rug just in front of my camp-chair. A pleasant book is placed at my side, and the gloom of the night and its weird childrenthe bats and the hawkmoths-are shut out by a heavy curtain, and I feel how pleasant and easy it is, even in Africa, to create an atmosphere of home. Here in three or four days my servants can build me a dwelling, and I can furnish it so that when my door is closed and my thoughts abstracted it needs an effort to realize that the wilderness lies outside.

When my dinner, a meal of three courses-soup, meat, and honey dumplings-is finished, the cloth is cleared, the lamp trimmed, and the door closed for the night. Then for two hours I sit and write my diary, much in fact of what I am rewriting now. But at length my eyelids grow heavy, I find my head nodding over the book, so I relax from my labours, undress, and creep thankfully into my snug little bed. I feel as safe and as much at home as in a well-appointed English inn. Only the occasional wild laugh of a prowling hyena, slinking round our settlement, or the distant booming roar of the hungry lion, recall to me almost pleasantly, that I am lodging in the wilds of Africa. But slumber soon intervenes, and thus ends, 
as far as consciousness is concerned, what my diary has characterized as a "thoroughly happy day."

So passed with little variation my first few weeks in Moši; in planting, building, scheming, sketching landscapes, skinning birds, and drying wild flowers. No troubles as yet overcast my horizon, and if afterwards I was harassed with anxious fears, and worried with intolerable suspense, the memory of those darker days is overborne by the vivid impression I retain of the first and brightest period of my sojourn on Kilima. njaro. This I shall always remember as the most enjoyable time I ever spent in Africa. 


\section{CHAPTER VIII.}

\section{"TROUBLOUS TIMES."}

Hither'to I had lived like Robinson Crusoe, in happy ignorance of savage and hostile neighbours. The only possible things of harm that I could have anticipated in my lonely rambles would have been a crafty leopard, pouncing on me from an overhanging bough, or the sudden onrush of a solitary buffalo. But now I was metaphorically and actually to see the footprints of my human foes imprinted in my favourite haunts. Whereas before my rambles on the mountains had been merely bounded by the short leisure time at my disposal, they were now to be circumscribed by the ring of warlike enemies that surrounded us. I have already explained to you the reason I selected Mandara's kingdom as my base of operations on Kilima-njaro. It was usually supposed, before my journey took place, that he was the paramount ruler of the mountain states, and it was thought that if I placed myself under Mandara's protection I might range free and undisturbed over the whole of this African Switzerland. In this, however, a great mistake was made, because Mandara ruled over a relatively small tract of land, and only up to 6000 feet in altitude. He did not command the shortest or any route to the higher regions near the snow-peaks; and being at constant war with his 
neighbours, and his little kingdom in a continued state of blockade, his protection, as far as it influenced a peaceful residence on the upper slopes of the mountain, was worse than useless. Unfortunately, too, Mandara had made immediate use of the two or three barrels of gunpowder I had innocently given him, and had further availed himself of the moral support which my presence at his court afforded to wage a rash and unprovoked war on his neighbours, and to rob them in various well-planned raids of their wives and cattle, adding the latter to his herds and the former to his harem, and checking their enraged pursuits with the lofty threats that, if they dared to infringe the territory of Moši, "his" white man would pickle them alive. Consequently, while I was so tranquilly and innocently pursuing my quiet avocations, skinning birds, drying plants, building houses, and cutting roads amid the ferny glades around my growing settlement, far from the turmoil of war, and unconscious of the perpetration of ill deeds, the unhappy people of Kirua, Kibôšo, and Maraniu were connecting the loss of their womankind and cows with my advent in Čaga, and naturally vowing me a life-long hatred. In the meantime my porters were returning from Taita with the rest of my goods, and in due time approached the base of the mountain. As they journeyed tranquilly one afternoon towards the frontier of Moši, and were congratulating themselves that a short march the next day would bring them to my settlement, their leader descried in the distance a body of men moving cautiously amongst the brushwood. Fearing lest they were Masai, he immediately made a forward rush for a camping-place close at hand-in fact, the very same site, a little peninsula nearly surrounded by a rivulet, 
where on the former journey lions had besieged us, as described in Chapter IV. The noise of their quick movement attracted the notice of the band of savages, who were evidently watching for the passage of my men, and they ran hastily towards the river to intercept the latter, thinking they were going to cross; but on arriving there they found the twenty Zanzibaris drawn up on the "almost-island" with their" guns cocked and ready. The savages hesitated, and stopped to parley. Seeing this my head-man, Kiongwe, resolved to delay their action with conversation as far as possible till darkness should supervene and put a temporary stoppage on warlike deeds, for, as no doubt all well know, most Africans dread to fight at night. After a short silence the leader of the enemy asked, in a hesitating way, "Who are you?" "We are the servants of the white man who lives at Mandara's," proudly replied Kiong'we. "Then you are bad men," shrieked his interpellator with sudden fury. "Your master has helped Makindara (Mandara) to attack us, and he has given him strong medicine to make him conquer. Makindara has robbed us of many things; now you shall pay. Give us all those goods you are carrying, and return to Taveita; you shan't pass by here." Kiongwe was a cunning man. He saw that it was well-nigh impossible for twenty heavily-burdened men to force their way through an armed band of fifty, so he prudently replied in conciliatory terms, "My master is not a bad man; he has fought nobody, and knows nothing of Mandara's wars. See, it is now getting dark. Let us sleep here till dawn, then we will speak again about this matter." Whereupon he told the porters to cut boughs from the surrounding trees and roughly hedge in the encampment, and to 
gather firewood from around to make blazing watchfires. The savages meanwhile disposed themselves sullenly in a circle round the little camp. Darkness fell. One by one the simple-minded enemy sank to sleep, confident that their prey feared the night as they themselves did, and would neither attack nor attempt to flee before the dawn. But Kiongwe kept all his men awake, made the watch-fires blaze, then at midnight, when his foes were snoring with sweet unanimity, he gave a stealthy word of command, the men rose silently, hoisted their burthens on their heads, clutched their guns, and one by one leaving the encampment, picked their way like cautious cats amid the sleeping forms of the besiegers. So, whether observed or not, they walked out into the darkness unopposed, and if any of the enemy slept not, and saw them go, his tongue was tied, and he dared not give the warning to his comrades, for-who could tell? -perhaps, after all, they were not men but ghosts, and none may fight with spirits in the enshrouding night.

Kiongwe and his men stumbled along perseveringly for several hours, and then, having put a good distance between themselves and their possible pursuers, lay down to rest and wait for the dawn, for the last part of their journey offered many obstacles in the darkness to burdened men. I should have told you, in proper sequence, that soon after nightfall Kiongwe had detached from the camp two lithe, active men, relieved them of their burdens, and enjoined them to elude the enemy and make their way speedily to my settlement, warn me of the state of affairs, and ask for advice and assistance. Accordingly, as I was leisurely undressing: that night, at about eleven o'clock, having sat up un- 
usually late to write my diary, I heard knocks at the door, and men saying, "Hodi, hodi ?" ("Hodi" is a polite Swahili term, somewhat equivalent to "May I come in?") Virapan, my servant, opened and admitted Mabruki Majera and Ali Masi, Kiongwe's two messengers. They told me the news in hurried gasps and with a little natural exaggeration. Amazed and indignant that my men should be in danger from savages whom I had never knowingly harmed, I hurried on my things, and, in my impetuosity, was about to dash off with a few men to Kiongwe's assistance. But the more prudent of my followers counselled a wiser course. They represented that in the dark night I might either lose my way or break my leg in some unseen pitfall, or else tumble unprepared on the hidden enemy, who might despatch me in the darkness without even the chance of knowing I was white, and superior to the common run of men. At any rate, they advised that we should first apprise Mandara of our predicament, and seek counsel and assistance from him. Accordingly I immediately started for Mandara's, and had quite enough experience on the way of the difficulties and dangers of a mountain track on a dark night to be thankful I had followed my men's advice, and not sought the foe under these disadvantageous conditions.

We found Mandara-I had sent a messenger on ahead - seated with a company of his warriors under the large open shed in which he ordinarily received visitors or transacted business. He looked rather blinky, having but recently left his slumbers, but on my entry checked a huge yawn, and beckoned me, with a wan smile, to take a seat by his side. His warriors were squatting round blazing fires, stretching their hands 
to the blaze, for it was a chilly night, and their shoulders twitched and trembled with convulsive shivering. I stated the case to Mandara in, perhaps, rather a theatrical manner, and informed him I intended to go and seek my men at once and bring them back, whether the enemy objected or not. "Who," I concluded, "would dare to fight a white man ?" Mandara heard me with a quiet smile, and then, interrupting, said to my men, "Your master is talking nonsense (upumbafu). How does he suppose he can find his way to these men at night? Perhaps he will lose the road, and a lion will kill him, or he may fall into the hands of the Wa-kibôšo, and they won't be afraid to cut his throat. No, this is but a little matter, and not worth the risking of a white man's life. When the time comes for your master to fight, he and I shall go to war side by. side. Now I will tell you what shall be done. I will send sixty of my soldiers at once, and they shall take two of you with them to speak the Swahili tongue to Kiongwe, otherwise he may mistake them for his enemies and shoot. You shall go there with my men and bring the white man's carriers safely back." There was so much good sense in what Mandara said that I resolved to acquiesce, at any rate for the present, so I bade him good-bye, left two of my men behind, and crept back along the uncertain path to my demesne. As we went we saw the war-fires gleam out from hill to hill, we heard the war-cry reechoing from gorge to gorge, and on the road we, from time to time, encountered swarthy naked forms hurrying to the rendezvous. Some had started from their sleep and merely seized their spears and shields, without waiting to don their martial costume, and wives and chilaren were running after them with plumes 
of Colobus skin and carapace of kite's feathers. All greeted us with hysteric friendliness as they passed, and when I met band after band of warriors, I could not help feeling thankful that they were friends, not foes.

I returned home and slept till dawn; then, being awakened with the first streaks of returning light, and finding that none of my men had arrived, I hesitated no longer, armed myself and my few followers, and took the road to the plains. After walking for some two hours I, who was in front, saw the bushes in the distance moving and heard the low voices of men. I was just preparing for a grim emergency and standing in the path, revolver in hand, imagining it was the enemy I had to confront, when a familiar face emerged from the scrub, I saw a burthen carried on the head, and $I$ at once knew it was my missing caravan approaching. I greeted the foremost men affectionately, and passed on to the rear of the little column, bidding the others hurry forward. There I found Kiongwe, and he gave me a hasty account of his adventures. After reposing a short time in a dry river-bed, they had arisen with the dawn, and once more continued their march. Whilst we were talking, loud voices were heard behind, and there appeared my two men, who had accompanied Mandara's soldiers, and who were now scurrying along with a few Moši men following in a disorderly crowd. Directly they saw me they shrieked, "Oh, master, run for your life; the Wa-šenzi (savages) are coming." However, I preserved, fortunately, a little presence of mind, otherwise these injudicious men would have caused a regular panic, as my porters were preparing to cast down their loads and flee. But with a few peremptory words I rallied them, and we beat 
an orderly retreat just in time. Soon after we had reached our little eyrie, wherein I felt so suug and secure, we could hear the distant cries of the baffled and pursuing enemy. It appeared that the sixty soldiers of Mandara, who had gone to relieve my men, passed them on the road, and went on professing their longing to exterminate the presumptuous foe; but no sooner did they come within gunshot of the enemy, who had just awakened and begun to follow the spoor of the fugitives, than the hardy warriors of Mandara took to flight, and under these conditions my two men accompanying them wisely followed their example. A hot pursuit ensued, from which we just escaped, and the enemy, following Mandara's flying men, was diverted from our track and dashed along the road to Mandara's capital. In the vicinity, however, of their chief's residence, inspired no doubt to fight pro aris et focis, the men of Moši made a stand; they were reinforced, and a desperate battle took place, in which the enemy was ultimately worsted. But in the meantime Mandara's neighbours on his western and northern frontier, seeing his guards removed to combat the invaders on the southern side, took advantage of the unprotected state of this part of his kingdom, crossed the border, laid waste with fire and sword, captured cattle and women, and indulged in sweet revenge for many a former raid on their own homesteads. When we saw from our high ridge the smoke rising from the burning villages of Western Moši, and simultaneously heard the din of battle coming from the southern frontier, we felt it was time to take a definite part in the conflict. Should Mandara be crushed between two forces, and vanquished, we might expect scant mercy from the victorious enemy. Accordingly, the 
chief of Moši having sent a messenger asking for advice and ammunition, I immediately armed twenty of my own men with Sniders and muzzle-loading guns, took a barrel of powder, a box of cartridges, and a bag of buckshot; and, further, in view of an eventuality which Ihad often anticipated even in England, I packed a mysterious box with some of the contents of a watertight case, and gave it to one of my men with the strictest injunctions as to its careful porterage.

As we wound along the hill-side towards Mandara's we found the narrow path choked with lowing kine and bleating goats. At the approach of war and invasion the inhabitants of Moši were driving all their cattle to Mandara's fortress. Thither we also went our way. Ordinarily the chief would pass his days in a circle of four or five bee-hive huts and open sheds, surrounded by a low hedge of dracœenas and exposed to view from the village green; but in troublous times he withdrew to an extraordinary fastness which merits a word or two of description. To the south of these visible huts, which to an unsuspecting passer-by constituted the entirety of Mandara's town, rose a dense grove of unusually fine bananas. The initiated who wished to approach the hidden citadel wound through their cool green shade by circuitous paths, patent to all at this time by the press of cattle that thronged them, and then arrived at a stockade of living forest. The chief of Moši had girt about his stronghold with a compact band of trees, dug up by the roots as sapling's and planted alive, so that with a year or two's growth their trunks had thickened and left no space between. Further, they were planted in the outer works four deep, and, being alive and green, their network of foliage masked the fortress with a living grove which 
would not be set fire to with the same ease as a stockade of dead timber. One small opening alone appeared, through which cattle could just be pushed, and which, during a siege, was closed with heavy wooden doors and guarded with the two small cannon Mandara possessed. We made our way through the lowing herds of cattle, passed many minor bulwarks and hedges, and at length arrived before a large building of wattle and clay, shaped almost like a European house. Herein Mandara was sitting with his wives and children, and, in strange contrast to his usual majestic demeanour, seemed quite tremulous with fear. His western borders were being devastated unopposed, and all his soldiers were engaged in fierce battle on the southern side. I sat some while with him, and assured him of my earnest co-operation and of our ultimate invincibility. Then loud shouts began to sound nearer and nearer to the tree-girt walls, and while his attendants rushed to inspect the on-comers, Mandara clutched my hand and implored me not to leave him. But he had no cause for further alarm. The shouting came from his own victorious soldiers, who, after a desperate battle of several hours' duration, had succeeded in beating back the enemy's invasion on the southern frontier, and were now prepared, after quenching their thirst, to go and avenge their slaughtered brethren on the west. This news made Mandara a new man. He shook me by both hands, he laughed aloud, skipped about, and then seizing his huge broadbladed spear, he struck the ground with its shaft, drew up his fine figure to its full height, and strode about the compound with haughty mien and gleaming eye, the very embodiment of a warrior chief, and very different, to the almost lubberly creature who a few 
minutes before had been well-nigh whimpering with fear.

Some of his soldiers who had just arrived wore the most extraordinary war costumes, evidently designed to strike terror into their foes. Most of them had, as a good foundation, plastered their skins with red ochre and mutton fat, and on this had drawn, especially about the face, most ludicrous designs in white-white rings round the eyes, or white spots on their cheeks. This gave them a look like an English clown, with a dash of the typical bogey that haunts the dream of every childhood. On their heads were crescents made of ostrich feathers, or caps of the Colobus monkey skin. This last-mentioned animal (Colobus Gueresa, var.nov. Caudatus) also supplied them with mantles of long black and white fur, and contributed the heavily plumed tails which these Čaga soldiers fixed on to that portion of their body where tails should rightly appear if man had not dispensed with such appendages. Some of the men wore thick capes of kites' feathers round the shoulders, and not a few had tied round the head masks of ghastly ugliness, with a double face, looking behind and before. They were all very excited about their exploits, and many screamed out hysterically in high falsetto voices. One unusually quiet man was pointed out to me as a great hero. It was said that, being surprised collecting firewood in the forest, and attacked by three of the enemy with spears and swords, he had succeeded in parrying their blows with a wooden stake, had disarmed them, and killed them all three.

Whilst we stood listening to this clamour two soldiers staggered in, a ghastly sight, streaming with blood, though their wounds were not serious, and they. 
brought the news that Mandara's brother, who was defending the western frontier, was hard pressed by the enemy, and had begun to retreat. At these serious tidings a silence fell on the assembly. I then proposed to Mandara that I should start at once, and try to give a decisive turn to the conflict against the Wa-Kibôso. Moreover, I had a certain plan in my mind that I was very anxious to carry out. After a little deliberation our mode of procedure was settled, and Mandara's remaining soldiers, having quenched their thirst with liberal draughts of banana-beer, which the women were constantly brewing, now prepared to start once more for the fray. One body of about a hundred started off under the command of Mandara's chief captain, and marched towards the north-west, hoping to take the enemy in flank, while my little force, accompanied by some native guides and a few of Mandara's Swahilis, directed itself due west towards the smoking villages. A very little experience showed me that I could not fight like a Čaga man. When I had descended my seventh ravine and was preparing to mount the eight escarpment along our route under a blazing sun, I devoutly hoped the enemy might not be waiting for us at the top, otherwise all that I could do would be to throw myself breathless and perspiring at his feet, and let him do his worst. But although the enemy was there when we reached the summit, he was harmless; that is to say, we found nothing but dead bodies around us when we had scaled the height, for by another turn in the fortune of war the Wa-Kibošso were once more retreating before Mandara's forces. Stopping here to rest and regain breath, I looked for the first time on the bodies of men slain in war, and the sight was quite sufficiently 
bloody to appal the most callous nature. The weapons which had effected the greatest slaughter in the skirmish had been the great shovel-bladed spears made after the fashion of the Masai. Though Mandara boasted so much of his guns, yet in the hands of these untrained savages, who have no idea of aim, they were almost innocuous weapons, whereas the spears used hand to hand inflicted horrible wounds. Here were corpses disembowelled by a lunge and a twist of the spear. Others had their backs literally carved open down the spine. Most of the severed heads had probably been chopped off by the short Roman swords which the Čaga soldiers carry. Hereabouts was quite a typical field of carnage. In many places the ground was pappy with oozing blood. In others little pools of gore were coagulating and caking under the fierce sunlight. The tall blades of the trampled grass were flecked and splashed with brown drops of the dried fluid. The place looked and smelt like a shambles. Already the many hideous creatures that make their living out of scenes of slaughter were swarming forth, emboldened with the scent of blood. Great green flies buzzed over the stark bodies of the slain, ants swarmed in myriads round the flakes of gore, while, strange contrast! lovely butterflies, blue and black, gold and black, metallic green and saffron yellow, paused intoxicated on the blood-soaked ground, greedily sucking up the thickening, frothy liquid with the enjoyment of ghouls. The neighbouring trees and bushes were dotted with vultures and crows, only waiting our departure to fling themselves on the feast. With a saddened and disgusted feeling I left this scene, almost loathing friends and foes alike. Why, in the midst of such superb scenery, with smiling 
plenty exhibited on every hand, could these silly savages think of nothing but mutual extermination? It was curious to look from the bloody field of battle to the great dazzling snowy dome which rose above us to the north, immaculate, pure, and freezing in its isolation, and then think that it, after all, was the cause of all this trouble. If Kilima-njaro had not drawn me hither on this quest, the people of Moši and Kibôso would not have come to blows on my behalf, and these poor mutilated corpses might still have been live men in the prime of life, eating, drinking, laughing with their wives and children. Must it be that I should walk through blood to reach the snow?

Once more the din of battle reached our ears. The enemy was again engaged with the forefront of Mandara's forces. We could see them fighting amid the banana groves covering a distant slope, or at least we could see the little puffs of white smoke which rose continually from amongst the green maze of fronds, and hear the popping of guns and the faint shouts and battle-cries. Over their heads soared grimly a flight of vultures waiting for their coming repast. As we were seen marching to the field of action, guns firing and flags flying, Mandara's men pressed on their enemies with renewed valour, encouraged by our approach, and the disheartened Wa-kibôšo yielded and fled up the hill-side till they reached the summit, where they turned and halted, met by reinforcements. The men of Moši were too exhausted to follow, and when I had arrived on the scene I found them crouching down at the foot of the hill, watching their foes. Had the Wa-kibôšo now charged down the slope on us, whom they greatly outnumbered, the consequences for our 
side might have been disastrous; for Mandara's weary men began to waver, and seemed to think of going home and leaving me to settle the conflict, and my own men were not only worn out with their previous night's walk, but were further tired by our long tramp to the field of battle. We should therefore have been unfitted to withstand the impetuous rush of two or three hundred men. However, the Wa-kibôšo were content to stand on the defensive. They were curious and anxious to see what tactics the white man would follow, with what new kind of sorcery he would war against them. The white man was proposing meanwhile to a dissentient group of followers a grand charge up the hill, which should carry the enemy's positions, and drive them off in headlong flight. Had he been backed up by the hundred and twenty.one men around him, this plan would doubtless have ended in a signal victory; but as no one except his Indian servant acceded to it, he felt that under those circumstances a grand charge of two would lack sufficient moral effect. During these deliberations the sun was sinking below the purple mass of Mount Méru, and I resolved to fall back on a rather fantastical method $I$ had preconceived of scattering my enemies, and striking effectual terror into their foolish hearts. I moved my men on to the crown of a small hillock which faced the hill-top whereon the ranks of Wa-kibôšo stood in savage array. Before darkness fell my men had planted several stout poles on the summit of our hillock, and had further erected a kind of rough platform of boughs, on which a few of the leather capes of Mandara's men were spread, to make a smooth surface. Then I called for the mysterious case I had packed and brought with me from my settlement. Only my servant, Virapan, 
understood the nature of its contents, and as he drew forth white tubes and blue tubes, and queer little tins, not only the men of Mandara believed that I was about to practise sorcery of the first water, but even my own matter-of-fact Zanzibaris fancied that something uncanny was about to take place. As for the Wa-kibôso I was just near enough to their hill-top to catch every now and then the murmurs of their wonderment at our actions. Quietly and expeditiously Virapan and Cephas cut a few thin rods, and handed them to me to insert into the little extinguishers attached to some of the larger tubes, which were then hung up through staples to the upright posts. I laid out open tins of dusky powder on the platform of boughs, I lighted in readiness my bull's-eye lantern; in short, not to weary the expectant reader longer, I made all the necessary preparations for a grand display of fireworks. No sooner had darkness set in than I blazed forth upon the astonished natives with Bengal lights, red fire, Roman candles, serpent squibs, and lastly a magnificent flight of rockets. The terrified Wa-kibôšo scarcely waited to see the last of these. When the first rocket rose with a flaming shower and a shrieking rush into the air, and then broke well over their heads into a mass of blue and crimson falling meteors, our astounded foes fled in dismay, and we found ourselves alone on the field, whence we journeyed peacefully home by the light of a late rising moon.

The next day we were all utterly prostrate with fatigue, and not in the best of humours, although Mandara had sent us a fat ox wherewith to feast and make merry. The fact was, he had accompanied his gift with congratulations on my tour de force of the day before, and a cool request that I would proceed to 
follow up the advantage gained by an invasion of the enemies' territory, which I was to utterly harry and devastate, and then hand over to Mandara's keeping. In fact he would have liked me to conquer all the states of Čaga for him on my own responsibility. This I peremptorily declined to do. I explained to him that I had only joined in the fight of the day before because my own men and goods had been threatened, but that I had come to Kilima-njaro not to make war on any one, but to go my own way in peace and confine myself to the slaughter of the beasts of the field if I must kill anything. I also let him know with unusual outspokenness that to an English mind his policy of continually harrying the states of his neighbours in order to supply the Arab caravans with slaves, was excessively distasteful, and one which would inevitably lose him Sir John Kirk's friendship.

This reply rather took him by surprise, and for some days there was a coolness between us. Then he sent for me and delivered a long speech, which was certainly one of the cleverest and most casuistic I have ever heard from the mouth of an African slave-dealer as an argument in favour of selling men into slavery. The gist of it was:- "Here are people who make war on me. I defend myself, and carry the war into their country, as we did the other day. Very well, a number of prisoners are made. What would you have me do with them? Slaughter them? No; that would be displeasing to Erua (God). Return them to my enemies? Then they would only take that as a sign of weakness, and attack me once more. Distribute them among my own people on my own land? But my subjects would themselves protest, and say, 'If 
strangers are to occupy the soil, where is the room for our children to cultivate?" Then what can I do but sell them to the Arabs?" I answered this by first describing to Mandara (who probably was unaware of this other aspect) what the Arabs did with the unhappy Wa-Čaga whom they purchased; how they made them labour in the sugar-plantations on the coast; how they exported them to regions across the sea, the nameless outrages inflicted on the youths and maidens, and as I warmed to the subject his face grew sombre, and he hung his head. Then I drew another picture. " See," I said, "how silly is war; who profits but the Arabs?" Yes," I exclaimed, getting furious as I thought of it, "it is you, you vile wretches," pointing to his Swahili parasites who sat sulkily by, "who are the curse of the country. May God punish you in this world and the next! I, at any rate, warn you, I will do my best to thwart your dealings; I will write to the Consul on the coast and give your names, and stop your slaveconvoys. So you had, better decamp and try fields where no white man is." Then I turned to Mandara and said, "Take my advice for once. Cast these men from your country, and turn all your attention to legitimate trade. Make your slaves cultivate your own plantations instead of the Arabs'. Supply the caravans going and returning to and from Masai-land with food. You know how gladly they will pay for it in goods and money (rupees). Thus you will grow rich and still retain the Consul's friendship. Above all, let there be peace on the mountain. Make friends with Ki-bôšo, Ki-rua, and Marañu, and then the white man

1 By Arabs I do not mean pure-blooded Arabs of Arabia, but the halfbreeds, or Mohammedan mongrels, of the Zanzibar coast, who always announce themselves to natives as "Wa-Arabu." 
as your friend may wander everywhere in peace." When I had finished, Mandara took me by both hands and said, "Indeed you are speaking truth; I know it. Why do you not always come to me and counsel me? If I have only these Swahili people to advise me, how can I avoid doing wrong?" In this Mandara was right. I believe, as I wrote to Sir John Kirk at the time, that I might have acquired a very powerful and useful influence over Mandara's mind had I made the endeavour. It was such an advantage being able to talk with him direct, and dispense with the nullifying influence of an interpreter. But at the same time it was not my mission to meddle with the politics of Kilima-njaro; I had been sent there to superintend the collecting of scientific information and the necessary material for investigating the fauna and flora of the snow-mountain, and not to redress the wrongs of the suffering inhabitants. Only so far as they hindered or otherwise affected my proper work could I exert any influence over local chieftains. My employers had not placed funds at my disposal to suppress slave-trading, or weld the states of Kilima-njaro into a confederation against the Swahili traffickers in human flesh. I had, as it was, quite sufficient difficulty in doing any natural history collecting at all, for I had found my two collecters very idle and inefficient, and the entire work, even in its most menial details, was soon to be thrown on my hands without any outside help; consequently I was disinclined to waste many hours of daylight in conversation with the chief of Moši, interesting as he was to talk to. I therefore neglected to follow up the decided advantage I had gained over Mandara's conscience, and employed the few peaceful days which followed the warlike movements I have 
just described exclusively in skinning birds and drying plants. Unfortunately, while thus engaged the Swahili courtiers, who now hated me virulently, made every effort to regain their baneful influence over Mandara's vacillating mind. 


\section{CHAPTER IX.}

AN ANXIOUS PERIOD.

Believing myself to be secure for the present in Mandara's friendship, I resolved without further delay to send eighteen of my thirty Zanzibaris to Sir John Kirk at Zanzibar, whither they could carry my first collections of the fauna and flora of Kilima-njaro, and my despatches laying before him the then existing state of affairs. Moreover, inasmuch as I found my paucity of men a great obstacle in pursuing my investigations and an altogether false economy, I desired Kiongwe, my head-man, who went in charge of this caravan, to recruit for me thirty or forty stout fellows in Zanzibar and bring them back with him, together with a further supply of necessary goods.

Eighteen was a small number of men to send along the Pangani route to Zanzibar, but fortunately, just as they were setting out on the journey, Thomson's friend, Jumba Kimemeta, arrived at Mandara's (I am sorry to say to purchase slaves ${ }^{1}$ ), and offered to escort them all the way to the town of Pangani. I gladly accepted, but as the men were ready I did not like to keep them hanging about idle in my settlement, so I sent them on by themselves to Taveita to join Kimemeta there.

1 He was, however, a good fellow and a good friend to me, and only acted after his own lights. 
Most fortunate was it that I did so. Jumba Kimemeta started from Moši a day or two afterwards, with the slaves purchased from Mandara. The Masai, knowing this, lay in wait for him, attacked his caravan, routed it, and Jumba only escaped by the skin of his teeth, losing slaves, oxen, and goods. Had my men been with him, they would certainly have abandoned the collections, and then nobody in England would have believed me when I explained their loss.

Kiongwe was supposed to occupy a fortnight in journeying to the coast, the same time in returning, while his work in Zanzibar would hardly oblige him to remain there longer than a week or ten days; consequently in six weeks at the most I might expect his arrival in Moši with the reinforcement of men and goods.

Nevertheless it was with some presentiment of coming difficulties that I bade him farewell on the morning of July 11th, and watched his little band slowly wending their way out of my sight into the distant plain. Yet he must be sent some time or other, and the present mornent seemed the most propitious.

After he had gone and my band of men was reduced to twelve, including all hands, trouble was not long in coming. My chief collector, Mabruki, had begun to grow very exacting. He received nearly double the wages of my invaluable Indian servant and considerably more than the other Swahili porters. His food allowance was also specially increased, and he might have had anything in reason for the asking: not that he was a good collector-far from it-but then he was better than nobody and, moreover, was a very fair shot with the rifle. He enjoyed, indeed, sallying out into 
the lower country near the base of the mountain and stalking antelopes, but this was not what I wanted him to do. I preferred that he should go up the mountain and collect there. He soon began to grow dissatisfied and became a continual grumbler. When Kiongwe was preparing to go to the coast he asked leave to accompany him, pleading business of his own to settle. I thought this utterly unreasonable, and knew the excuse of private business was only meant to cover some other purpose. At any rate, I reminded him of his contract and held him to it. This only increased his sulkiness, and he began to listen to the suggestions of Mandara's Swahilis, who were trying actively to ruin me by causing the desertion of my men. They persuaded Mabruki that if he left me and entered Mandara's service, he might become a great man. 'l'hey pointed out how lucrative the slave-trading business was, and how Mandara needed a man like him to transact his business on the coast. Mabruki was won over and only sought an excuse for breaking with me. It was not long in coming. I found him one morning returning from Mandara's town, when I had sent him to a particular valley to collect. He had not a bird or a flower to offer as an excuse. Nor did he try to excuse himself. When I began to scold him, he said quietly, "That is encugh; I don't care for this work, I have found something better to do: give me my food allowance and let me return to the coast." Like a simpleton, I believed he intended to join Kiongwe, who had not long started, so I gave him goods to buy food for a fortnight, lent him a gun and ammunition, paid him the balance of his wages and let him go. The other collector, Athmani, who was his slave, accompanied him. Having got out of me all he could, 
he then turned his steps, not coastwards, but to Mandara's court. Here the Swahilis at once led him to the chief and said "Now, you wouldn't believe us when we told you this white man was bad; listen then to what his own servants say." Accordingly Mabruki and Athmani sat down and told Mandara - not a string of falsehoods-but a number of inconvenient truths so coloured with malicious interpretation as to be in Mandara's eyes the most damning of accusations. They revealed to him that I had a beautiful elephantgun (which had certainly been kept from Mandara's covetous gaze), and detailed, in fact, the entire contents of my armoury-so many sporting guns, so many Sniders, cases of cartridges, kegs of powder, bags of shot. They did not explain that these were brought with a view to the slaughter of birds and beasts and for purposes of just defence, but hinted that these weapons were intended to overawe the chief of Moši and take possession of his country. "Well, but," interposed Mandara, " how could he do that when I have 1000 soldiers and he only ten?" "Don't you understand?" the traitors replied; " he has sent Kiongwe to Zanzibar to bring back many soldiers-" "Forty," interposed Mandara. "Ah, he says forty to you, but how do you know what he may not have written in the letters? No, now is the time to crush him, before his reinforcements come." "But the Baloza, what will he say?" "How do you know whether the Baloza really sent him?" "Why, he brought letters—" "Yes, and read them himself-none of your men can read." Mandara here produced the two epistles, and remarked that the seal of the Consulate was on them. This

2 It was from him that I afterwards heard an account of this conversation. 
rather baffled Mabruki, but Athmani took another tone. " What does it matter if you do take away all his goods -he has broken faith with you, he has concealed from you many of his possessions." "Well, but if he fights for them and is killed, what will the Baloza say then, when he sends to ask for his news?" "Why, you will just answer that he has gone away to the Masai country and you know no more of him. Who can contradict you?" "And the Aruša-ruša (fireworks)?" "All harmless, children's playthings."

Poor Mandara was racked with indecision. On the one hand the Swahili courtiers had been poisoning his mind for days past by representing that my views as to slavery and my displays of fireworks and other potent magic had powerfully impressed the minds of the common people and had seriously impaired Mandara's authority; on the other hand, a remnant of the friendly feeling I had once inspired still lingered in his mind. He coveted my goods with all the intensity of his savage desires - think what the possession of an elephantgun would do to raise his prestige in the eyes of the neighbouring chiefs ! - and the European bed, so smart and clean - and the silver forks and spoons-but no! I was his guest, I was the sacred " mgeni," the strangerfriend from whom nothing must be taken by force, or God would be enraged. Still, why did I keep so many guns and so much ammunition? Was it for peaceful ends, or was the plea of sport a hollow pretext? Was this white man black at heart after all? Did he really intend to send for soldiers to Zanzibar that he might seize the land and be master of it. Clearly it were better to get rid of him quietly while he was weak and without supporters. No wrong should be done, but the white man must go. 
Accordingly, his deliberations not having been sweetened by the frequent cups of tembo thrust on him by his insidious courtiers, he dictated a preremptory message to me, which one of his soldiers was sent to deliver.

I was sitting, working tranquilly, in my little house that afternoon, when the messenger of evil arrived. I had been going through some of Mabruki's recent work, and derived a melancholy satisfaction in finding it so bad as to be useless. I reflected pleasantly that, though I should have henceforth the sole charge of collecting, at least I should save some forty rupees a month, and do the work better myself. Just then I looked up, and saw Mandara's man. "What does he want, Abdallah?" I asked my servitor who ushered him in. "Oh, very bad news," he replied in a low tone, and then proceeded to interpret the message, for my men had made greater progress in Ki-čaga than I at that time.

"Mandara sends to the white man, who calls himself Child of the Baloza, and says, 'Now I know your' heart is black, and you have deceived me. You have shown me only a part of your possessions, and you kept concealed from me many guns, and powder, and engines of war (mi-tambo). This you did that you might take my country by surprise and kill me, and make yourself chief in my stead. And they tell me you have sent to Unguja (Zanzibar), not for forty men, but for an army. Now, therefore, I say to you, you are a guest and I may not take anything from you by force; but give me all your guns, and the big one for elephants, all your powder, and all your bullets, and I will buy them at a fair price. Then I shall know, if this is done, that you do not wish to fight me, and 
you may remain. But if not, then I say, pack up all your goods and go, for I know you are my enemy." " This curious message was written down by Abdallah in Swahili, in order that I might confront Mandara with lis own words, and ask if he acknowledged them. In the meantime I dismissed the soldier, saying I would reply later on. Then, side by side with the message of Mandara's, I wrote an answer to the effect that the "Sultan" of Moši was deceived by bad and designing men, that time would right me in his opinion, and that meanwhile I would neither sell him a gun nor an ounce of powder, nor would I leave his country until Kiongwe should return. (How, indeed, could I do so, when I had ten porters and fifty-eight loads?) In the evening, Virapan, Cephas, and Abdallah repaired to Mandara's court to communicate this reply. As usual he had begun to vacillate, and now let himself be convinced that I had no sinister intentions affecting his rule, but complained that the real fault he found with me was my mean disposition. He took Cephas to his stronghold, and showed him the clothes, guns, pistols, and patent medicines he had received from Thomson; even curious relics-the gifts that Baron Von der Decken had made to Mandara's mother, and the articles which had been wrung from poor Charles New. "Now," he said, "what has your white man given me to compare with these? Fine words, good advice (šauri), tales about hens laying golden eggs. I don't want always talk and nothing else; I want him to show his friendship by gifts, as a white man should. And as he is so fond of fables (hadiai), remind him of the one I told him when he first came here-say to him, 'the tree is now well-rooted and mature, and if it does not soon begin to bear fruit, I shall cut it 
down." "There was some amount of truth in Mandara's complaints. From his point of view I had not been generous. I had paid scrupulously for everything, I had always sent Mandara the equivalent of bis presents of cattle or sheep in various trade goods, or bright, shining, silver rupees. Ihad supplied him with many useful European seeds, and had frittered away nearly all my stock of medicines on his soldiers and wives, and on arriving I had given him the articles mentioned in Chapter V.; but I could not lavish cloth and beads on him continually, as I had only enough to last me till Kiongwe's return, and must pay for my daily food in these commodities; and I would not supply him with guns and powder, now that I knew the use to which he put them, viz. to procure the Arabs slaves. However, although he had no claim on my generosity, I thought it well spent if a little money would secure his friendship, so I offered to pay 11. a month (an immense sum in this part of the world, especially when it is represented by twelve rupees) in the form of rent, for the land which he had given me as a plantation. At first he was beside himself with joy when I conveyed this proposal to him in person, and patted my back with affection; but no sooner had I left him, rejoiced at his change of manner, than Mabruki entered on the scene, sneered at the chief's delight, and said the white man had bags upon bags of rupees-he had seen them-and that it was as easy for him to pay 100 monthly as 12 .

Mandara therefore sent word to me that he had consulted with his advisers, and that he thought 100 rupees a month a reasonable rent for the plantation (this plantation, be it noted, was a piece of wild, 
uncultivated land given to me- by Mandara on my arrival). To this preposterous demand I returned the curt reply that he was talking nonsense (upumbafu), and the matter dropped for a time. However, shortly afterwards when I was out botanizing, a soldier of Mandara's came up and told me civilly but firmly, that I was not to pick any flowers. I asked him what he meant, and he said those were the "Mange's" orders (Mange is the title given to Mandara), that I was to be followed wherever I went, and prevented from collecting plants. I packed up the specimens I had gathered and returned home, meaning to ask Mandara what this meant. On my way I shot a little bird. The soldier at once ran forward, picked it up, and took it, saying, "This is the Mange's." I went to Mandara's town, and desired to know what this hindrance meant. He declined to see me, saying his heart was bitter that day, but sent word to this effect - All this land is mine, therefore all the flowers, birds, butterflies, everything on it are mine also. If you can't afford the rent I ask, never mind, I have nothing more to say; but don't rob me of my property. If you want flowers, birds, or beasts, my slaves shall collect them and sell them to you at a fair price; but if you go and take any more without my leave, I will seize your goods." Here was a nice dilemma! I could not collect on Mandara's territory without paying an enormous tax, and I could not collect outside it without risking death at the hands of his enemies. This was a difficulty in obtaining specimens which would hardly have occurred to the consideration of the scientific societies who sent me out to Kilimanjaro. Having provided the funds, there seemed nothing simpler than to despatch some one to the 
mountain to collect, and here I was, settled on Kilimanjaro, and yet unable to touch a plant or an insect of those interesting regions around me-at least unable in theory, and much thwarted in the practice, although I still went stealthily to collect.

One day soon after this fresh aggravation, Mandara (in whose utmost naughtiness there was always a spice of fun) sent me a dirty old basket full of vegetable refuse, with a message to the effect that I might add this to my collections on the payment of a few ells of cloth. I kicked the basket from one end of the settlement to the other, and said, "that was the only answer," at which rash act my men were appalled, but when Mandara heard of it, he gave a hearty laugh. However, matters did not improve. Failing to extort anything from me by force, Mandara tried starvation and ordered all his people to abstain from selling me any article of food. One or two men who were detected smuggling food into my settlement at night were sold as slaves. Another man who was heard to call me "Mangé Muzungu," "White Chief," was severely beaten as conferring on me a title equal to Mandara's. Nevertheless, I offered no sign of yielding, for I knew that would be fatal-it would mean that little by little everything would be taken from me, and I should be left to return as New did, under similar circumstances, broken-hearted with the thought of failure. Accordingly, though my milkman politely intimated he would be unable to continue sending his daily supply, and though chiliken left off coming to me with blackberries, and the women ceased to bring me ripe bananas, I cheerfully dispensed with butter, cream, fruit puddings, and banana fritters, and when Mandara, curious as to my 
state of mind, set spies to sound me, I expressed myself perfectly happy and self-contained. Indeed, thanks to a little foresight, I had so developed my plantations and my live-stock that I produced enough to sustain us on the premises. But at heart I was miserable. The feeling of utter impotence and of letting day by day slip by without anything accomplished towards the fulfilment of my mission, nearly made me ill, and if the climate had not been such a peculiarly fine one, I should have worried myself into a fever. What I felt most cruelly was the complete want of a sympathizer, of any one to whom I might unbend. All through my difficulties I had to assume a nonchalant air and light-hearted manner I was far from feeling, in order that my men should not be unduly alarmed at Mandara's threats. In the last days of July, matters began to come to a crisis. Mandara had sent to me to say he was about to make war again on Kibôšo, and desired me to furnish him with ten men, well armed, and several kegs of powder. I answered that my men had other. work to do, that Mandara's quarrels were his own business, and, that I had no powder to give or sell. No immediate notice was taken of this refusal, but a day or two afterwards it was brought to my tyrant's knowledge, first, that I was secretly purchasing stores of food, and secondly, that I had been seen catching butterflies and gathering plants in contravention of his orders. Accordingly he resolved on a decided stroke to crush my resistance and frighten me into compliance with his requests.

One morning, the 30th of July, I was sitting at work in my house, when a naked gentleman, with a broad-bladed shining spear and a monkey-skin head- 
dress, strutted into our settlement with an easy nonchalance of manner which made an evident impression on the Zanzibaris, for they did not attempt to oppose his passage into my private compound, but allowed him to enter unchallenged, and plant his spear into the ground with an emphasis that made it quiver, and stand at ease in a conqueror's pose.

My temper had been already ruffled that morn-. ing. We had lost our favourite milch goat in the

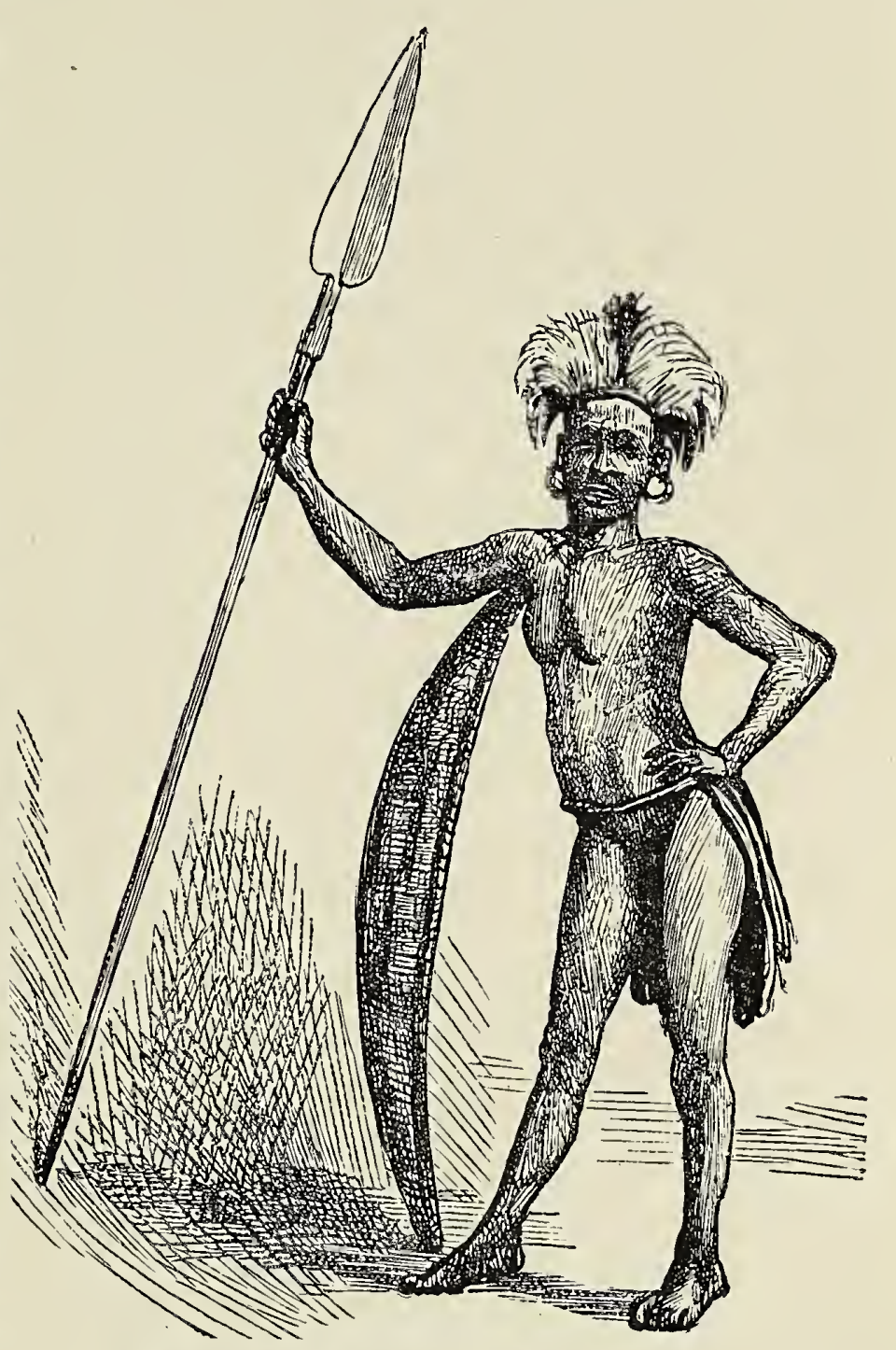

Fig. 44.-A Soldier of Mandara's. night, carried off by hyenas; and I had suddenly learned that the natives refused to sell milk, fowls, or other provisions, in obedience to secret orders from their chief. Also-for misfortunes never come singly-my servant had fallen sick, and my cook had cut off his finger chopping wood. So when I looked up from my work, skinning birds, that lent themselves badly to my taxidermist skill, and saw the swarthy figure planted in front of my house, I wrathfully cried out to 
my attendants, "What does this man want here, and why do you let him in without telling me?" Abdallah came forward, and mildly questioned the Čaga warrior as to his purpose. "Words from Mandara," he laconically replied, and then, tlie interpreter being summoned, proceeded to detail the ultimatum of the chief-so many guns, barrels of powder, bags of shot, tables, chairs, cups and saucers, knives, forks, and spoons to be handed over at once, together with the greater part of my trade goods, or-and then followed Mandara's terrible threats of slaughter and rapine. The purport of this speech I somewhat understood from the occasional words and phrases of Ki-čaga that were familiar to me, and any doubt as to the import of the threats which closed the message was set aside by the man's expressive gesture. When he came to talk of killing, he drew the edge of his dexter finger across his throat, severing in fancy his jugular vein. At the close of his speech the Zanzibari interpreter repeated all that had been said, striving to exaggerate as much as possible the gruesome nature of the threats and the advisability of conceding everything asked for. But I had long since decided that to yield to the "Sultan's" demands would entail the loss of all means of defence, of livelihood, and would be the ruin of the expedition. Even if I succeeded in reaching the coast, it would mean that I had failed in my attempt, and all this would be far worse than the risk of assassination at Mandara's hands, for I knew his moods varied with his potations. So, affecting a calm manner which I did not feel, I refused Mandara's demands in toto. "Hatta sindano" ("Not even a needle"), I added, taking one from my coat lappet and showing" it. This reply having been explained to the envoy, he 
withdrew stolidly to repeat it to his master, and I was left alone with my men to discuss the further proceedings to be taken. Of course only the leading men of the caravan were consulted; the rank and file were supposed to be left in ignorance of our danger, lest panic should seize them. They knew well enough, however, having questioned the Čaga soldier, and now sat in a melancholy group discussing the probability of having their throats cut, and rueing openly the day that their ill fortune brought them to such a country. However, I had finished my confabulations, and therefore ordered the men to be about their work as if nothing had happened, or was going to happen. One man was told to go and get firewood. He took an axe, and reluctantly left the timorous group of gossipers, but behold! he had scarcely got a hundred yards from the cleared ground of the settlement, when we saw him turning about and hastily retracing his steps, while from the brushwood and fern rose the glinting spears and white head-dresses of Mandara's soldiers. It was then, on going to investigate, that I found we were regularly invested by an irregular ring of armed warriors, who were squatted in the grass and fern, without, however, any attempt at concealment. They had formed a cordon which they intimated must not be broken until the demands of the "Mangé" were satisfied. Though firm in their language they were not uncivil, and were evidently only performing their duty. They were even respectful to me personally, evidently assuming that a quarrel between the white man and their chief was not their affair. We learned from them that Mandara meant to try and starve us into submission, that he intended to place these soldiers here to cut us off from all further food 
supplies. I laughed at this. "What!" I asked, "does Mandara know I have eighty fowls, a cow, a calf, four goats, and two sheep, beside a store-house crammed with grain and a garden full of vegetables? Say, how long can we not live on those supplies, and does your chief intend to keep you here for months?" They only shrugged their shoulders indifferently. "Theirs not to reason why, Theirs but to do or die." One man, however, suggested that perhaps if my water supply were cut off at the river-head I might not feel so comfortable. I' then asked what the other Čaga people would say, whom my little canal also supplied with water? Meanwhile my message, with its decided refusal, had reached Mandara, and we could from our height conjecture somewhat the effect produced. How anxiously our gaze wandered over the intervening valley, and rested on the little cluster of yellow beehive huts which masks Mandara's capital! We had seen the messenger enter the town, and after more than a quarter of an hour's interval he emerged alone, and once more took the winding hill-path to our settlement. I was affecting to continue my work in my hut, for it would not do to let either my own men or the natives perceive that I was alarmed at the critical state of affairs, but as I stooped over my bird-skins again $I$ heard the clang of a spear-shaft, striking the hard ground, and again Mandara's emissary stood before me.

"The Mangé wants to see two of your men," he said.

"I will go myself," I replied, getting my hat and stick.

"No," answered the envoy, "Mandara does not want to see the white man. His heart is bitter. Send two of your servants." 
After considerable parleying, for my men naturally felt that it was like entering the lion's den, Abdallah and another Zanzibari volunteered to go on this dangerous errand. Accordingly they set out, secretly armed with revolvers, and accompanied the soldier to Mandara's town. Following their progress with my opera-glass, I saw them enter the native compound, and then ensued an anxious wait before they re-issued and made their way alone back to Kitimbiriu. When they entered the settlement I saw bad news painted on their lineaments, so I hurried them into my house before they could communicate it to my quaking men. When they were seated in the doorway of my dwelling, their dark bodies like silhouettes against the flaming evening sky, they unfolded their ominous tale.

When they had reached Mandara's place, it seemed, they found him seated among his councillors and captains in a quivering rage. His one eye gleamed with anger, and his whole frame trembled with convulsive wrath. Speaking slowly and distinctly, evidently trying to keep control over himself, he told them that there was but one ruler in the country, and that one he. It sufficed for him to send an order to the white man and it must be instantly obeyed, or the throat of every man in the settlement should be cut. "What," he exclaimed, "do I care for his Consul or his Queeny? Have I not a thousand soldiers? Go and tell him !" The men crept away from the precincts of the irate monarch thoroughly cowed, but they were not gone far before he sent to recall them. On again entering his presence, Mandara assailed them with imprecations and horrible threats, and dismissed them a second time, summoned them back again, hurled at them hoarsely more vituperation, and finally bade them 
hurry to my presence and inform me what they had heard.

This they were in no way loth to do, fearing, indeed, for their lives in this assemblage of warriors armed to the teeth, whom a word from their chief would precipitate on any victim of his wrath. I suspected, even when I heard their terrified account, that this scene was a good bit of clever acting on Mandara's part, meant to have its due effect on me by the panic it should produce among my men.

At any rate, as we sat in the gloom of the early night still discussing our situation, my dinner untouched on the table, and, to judge from the gleam of their watch-fires in the bush, the soldiers of Mandara still encircling us, the prospect seemed a sufficiently sombre one. Nor did the night bring a temporary truce to my anxieties. I found it difficult to compose myself to sleep, for my brain was continually forming. projects for escaping secretly from Mandara's country, and yet carrying away somehow my fifty-eight loads of goods; a well-nigh impossible feat to accomplish with ten men. Every sudden noise from the bush, the anxious whispers from my watching men, the distant biowing of a horn, or firing of a gun made me start from bed wide-awake and expecting a midnight attack from the savages. And when towards dawn I found a short forgetfulness in fitful dozing, it was but to awake on a morrow of similar anxiety.

However, the tension was fortunately relieved by an unexpected and unintentional ally. The Wa-kibôso, whom Mandara had been recently raiding, had routed his armies with considerable slaughter-he confessed to the loss of 100 men, about ten per cent. of his entire force-and had further sent a bombastic mes- 
sage to the effect that they were about to arrive in Moši, with the intention of burning, harrying, robbing, slaying everything in their way. Mandara therefore desired in such contingency the moral support of the white man's friendship and co-operation. All the soldiers were naturally withdrawn from the blockade of my settlement, I was once more at liberty to go forth and botanize, and no restrictions were placed in the way of my purchasing food. However, I was too angry with Mandara for what he had made me suffer to respond very cordially to his advances. I refused to co-operate in the defence of Moši, and said I would keep all my powder and ammunition for the safeguarding of my own settlement. Of course the Wakibôso stopped short at the frontier on this occasion. I premised they would from the fact that they had sent to say they were coming. But, nevertheless, they had evidently inflicted a severe blow on Mandara's strength, and one which for a long time kept him quiet. Gradually my relations with him began to improve. His people were so decidedly my friends, that he was forced, despotic monarch though he was, to come over to their opinion. They declared my coming had brought wealth to them all. I bought all their products and paid for them honestly. No man could ever accuse me of an unjust or unfriendly act. When they were sick, they came for medicine, and were never denied. ${ }^{3}$ In short Mandara was compelled by popular opinion to own he had treated me badly, and as a sign

3 A curious incident in my quarrel with Mandara was, that even when our relations were at the worst, he would calmly send to me for medicine for himself, his wives, and children. One of his Swahilis cautioned him that perhaps I might take advantage of this to poison him, but Mandara said quietly, "A black man might do so, but a white man never would." 
of this, he resumed friendly relations by paying me a state visit in my "town." Here he gossiped to his heart's content, and peered like an inquisitive child into all the recesses of my house. It was the first time he had visited me since I had begun building, and he was amazed at the progress made. Then he asked to see all my "wonderful things," and on the whole behaved very well, asking for nothing. At length, after uneasily fidgeting on his chair, he said hurriedly, "And now bring out your elephant-gun ; I must see it." All my men looked scared; now I was going to be fleeced. "Must you see it, Mandara?" I asked, gravely looking in his face. "No," said the poor savage, with a sudden effort to control his covetousness, "I will not see it. Do not show it to me, lest I should desire it."

Really, why I made such a fuss about this elephant-gun seems hard to understand, for it turned out a useless and burdensome weapon, unreliable for greater distances than twenty yards, but in those days it seemed to us to sum up all the question of our resistance to Mandara's encroachments. We felt if we yielded the elephant-gun we should never be able to make a stand on anything else, and then everything would go, and we might be stripped as New was. However, on the occasion of this visit, I did miy best to be gracious, and opened a bottle of champagne-with some trepidation, imagining Mandara would insist on the rest of the dozen-and a tin of cocoanut biscuits. However, the champagne created but a poor impression-I think it was too dry for his palate-while on the other hand, he simply tucked the tin of biscuits under his arm and walked off with it, enraptured with the first one he had 
scrunched. After this day, although we sometimes disputed about commercial transactions (which were always unprofitable to me, and only a disguised form of tribute to Mandara), we never had another quarrel, and I had complete liberty of action in Moši. Alas! this was after all but an extended durance-a prison, though a spacious and lovely one. In vain I yearned for some means of crossing the barrier of foes which intervened between me and my goal, the snow-peaks of Kilima-njaro! 


\section{CHAPTER X.}

\section{A TRIP TO TAVEITA.}

Throughout this period of anxiety, so monotonously related in the last chapter, I had held to one fixed resolve, to quit Moši when Kiongwe returned. Mandara's hostility had nothing to do with it. I never looked upon that as any real obstacle in my path. It was rather that Mandara, whether friendly or otherwise, was comparatively powerless to aid me in my ascent of the higher regions of Kilima-njaro, just as he would have been powerless to prevent it had I established myself with his enemies. The upper road to the snow-peaks lay in the hands of the hostile league of Kibôšo, Kirua, and Maraniu, who blockaded the western, northern, and eastern frontiers of Moši. All Mandara's power lay to the south. He was intimately allied with the Masai of Kisongo and Aruša, and they aided him in keeping open his southern border. This very fact, however, had to enter into my calculations. Mandara was very potent with the Masai; they paid him constant consultative visits. On one occasion, when he was in a good humour, he sent for me and introduced me to his robber allies, telling them he wished that they should see my face, and know it as one of his greatest friends, who must never be assaulted.

In all my rambles to and fro between Moši and 
Taveita, though I might be unaccompanied by more than half a dozen men, I was never interfered with by the Masai, whereas I used constantly to hear of their attacking other caravans; and whenever they did so, Mandara was generally in collusion. Consequently I knew that if $I$ attempted to quit his kingdom against his will or without his leave, he had but to signal to the Masai, and they would effectually bring me to ruin.

Another difficulty I had to deal with was the question of my baggage. I had fifty-eight loads stored at Moši, and ten porters. Kiongwe would be coming from the coast with some sixty carriers, but they would nearly all of them bring burthens; consequently on their arrival in Moši I should be unable to carry off the loads already stored there. The only solution would be to stop the new caravan at Taveita, leave ten men there with the fresh supply of goods, and let the rest come on emptyhanded to Moši. Then I could take leave of Mandara somehow, and carry off all my loads, whereas, if I departed from Moši leaving property behind, and then made friends with Mandara's enemies, he would probably seize my belongings in revenge for this act of faithlessness.

How could we let Kiongwe know of my change of intentions? If I sent a messenger to Taveita, Mandara's spies would be sure to report what was taking place, and set him on the scent of my little plot. The only plan was to go myself to Taveita, because then I could more easily explain my intentions to Kiongwe. According to our calculations he should be due there about the 22nd of August at the latest; so I determined to leave Kitimbiriu on the 18th. Mandara's consent was obtained, and besides sending two of his 
soldiers with me, he accorded his protection to my settlement during my absence. Here, though I only left one man in charge, I felt perfectly confident in Mandara's rectitude. Strange combination of qualities, both good and bad, was the nature of Moši's sovereign! While he could see no harm in bullying, frightening, worrying his guest into yielding up his goods, yet he would never take anything by force, although he had merely to stretch out his hand to do so.

I looked forward to my Taveita trip as the prisoner does to his quitting gaol, or as a pent-up toiler in towns must to his annual holiday in the country. Every effort I had recently made to wander beyond the borders of Moši up the mountain had been resolutely prevented by the Wa-Kibôšo; in fact, on the 11th of August we nearly lost our lives in an ambush. Every flower I gathered in the debatable ground was snatched with trepidation and a wary look all round, and I feared to fire my gun at any bird lest it should attract the attention of my hidden foes. Consequently the idea of leaving Moši on the south and going for a holiday trip to Taveita was full of pleasant possibilities, and proved as interesting in reality as in anticipation. Leaving Kitimbiriu on the 18th, my eight porters and I walked gaily down the path up which we had toiled, some nine or ten weeks before, on our entry into Moši. By noon we had reached the pretty little Mkuyuni river, associated with several of our adventures. Here the lions had besieged us, and here Kiongwe had taken refuge from the savages. Now I found its banks peaceful and deserted, although we had just missed a large troop of elephants, who must have crossed in the morning. Many bristles from their tails still hung in the bushes, dragged out, I suppose, 
as they switched them to and fro. As we were to lunch here I left the part of the stream where the elephants had trampled the banks and sullied the water, and crept through the bushes to a charming secluded bend of the rivulet, where, seated in deepest shade, I could gaze at a vista of sunlit vegetation beyond.

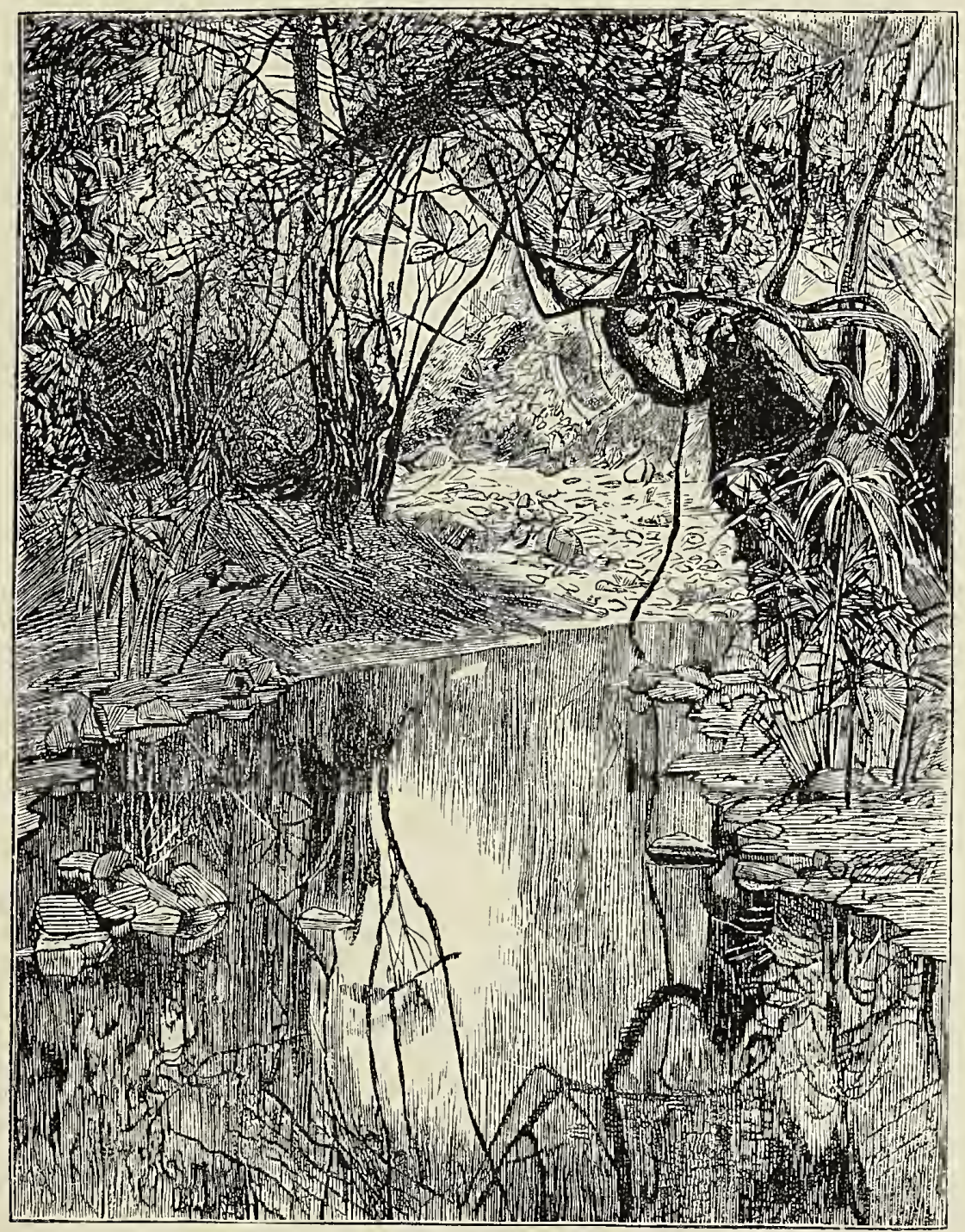

Fig. 45.-The Mkuyuni Stream.

Having rested here, we marched on to the Mto wa Habari, another old camping-place (see Chapter IV.), and the next morning entered the glorious forests of Taveita. Here we found the Swahili town a mere waste and open place strewn with ashes. The Wa- 
taveita had burnt it down, according to their habit, when the caravan season was over and the traders had gone. This is their invariable custom, for which they give various reasons, the real one being probably that they do not wish the coast people to gain a permanent footing there. As far as I was concerned, they welcomed me with enthusiastic delight, and reminded me of my promise to build a house in their midst. I told them I had on the present occasion only come for a few days, to await my caravan, but that I wanted a large piece of ground in a secluded part of their territory where I might ultimately make a "town," in which to store my goods. They led me to a beautiful site, close to where Thomson had built when he sojourned there on his way to Masai-land. Not a vestige of his habitation remained other than the oral tradition of its situation. Possibly, of the fine little colony I started there may be little to see now, for although I bought the land I could not promise to occupy it, and the absentee system is not in favour at Taveita.

This place, from the day of my first arrival up to the time of my final departure, seemed to me one of the loveliest spots on the earth's surface. Imagine first a charming river of crystal clearness winding in curves and loops through tropical forest of such an imposing grandeur that it rather recalls to one's imagination the vegetation of some more lusty epoch of the earth's youth than the present degenerate days of less exuberant growth. The river flows sometimes between high banks-little cliffs of red soil-crested with gigantic trees, whose enormous roots, detached from the crumbling earth, stretch out like grey, sprawling fingers high in air above the rushing water; sometimes curls itself wantonly in loops, cutting out sweet little penin- 
sulas of forest-clad mounds and hillocks, on which one longs to go and build a little hut and live for ever; sometimes flows solemnly and slowly with glassy look amid winding arenues of palms, acacias, albizzias, sterculias, parinariums, sycamores, and wild bananas, through the stately architecture of a vegetable Venice.

Here are places where the river broadens out into shallows, and the banks slope down in turfy lawns or stretches of sparkling sand to the water's edge ; there you may emerge from your bath on natural quays of smooth and polished stone, most grateful to the naked feet that shrink from gritty pebbles or thorny, prickly, tangled weeds.

The River Lumi, which flows through Taveita and creates all its luxuriant forest, is uninhabited by noxious creatures, such as crocodiles or leeches, and only harbours harmless fish, that are good to eat, or great timid raranus lizards, who never interfere with one's bathing. Its water is exquisitely cool, clear, and sweet, and comes from the snows of Kilima-njaro.

Here and there amid the lofty aisles of the Taveitan forest are little clearings, pretty homesteads of yellow beehive huts, neat plots of cultivated ground, groves of emerald-green bananas, which are the habitations of the happy Arcadians who have made this tropical paradise their home. They were once miserable refugees who sought asylum and concealment in the impenetrable forest which even now girds their colony with a belt of closely growing trunks and thickly interknitted mesh of creeping stems. In this leafy labyrinth they were screened from the outside world they dreaded-from the cruel pursuits of the raiding Masai. On the few occasions when these robbers have tried to penetrate the maze of forest, the Taveitans, knowing 
its turns and windings better than the dwellers in the open, have gained a fierce victory over their assailants. Now they dwell in safety, and their little republic is the favourite resort of not only the coast traders, who leave their wives here when they enter the dangerous Masai country, but of all the hunted, homeless fugitives from Čaga, from Taita, and from Ukambani. Though there is thus great intermixture of race, the original language of the Wa-taveita holds its ground and is the general tongue of the community. Swahili is known to most of the inhabitants, who mix a great deal with the coast traders, and Masai is also spoken and understood, because the Masai who once harried the Wa-taveita so cruelly, now come peacefully to trade, exchanging their ivory, oxen, and asses for vegetable food, for trade goods, and for honey-of which the Taveita people obtain great quantities from their bees. Moreover, there is a fairly large colony of about two or three thousand agricultural Masai (called Wa-kwavi by the coast people) settled at Kikoro, a southern extension of Taveita. This is a most interesting locality for a student of African races to settle in. It resembles Stanley Pool on the Congo, Dondo on the Quanza, Khartūm on the Nile, and such like emporiums of trade; a rendezvous of tribes, tongues, peoples, and nations. You may sit here in the porch of your comfortable thatched house, which may be built in a few days from the materials at hand, and receive visits from representatives of most of the nations found in East Central Africa. Arabs, Gallas, Masai, A-kamba, Wa-čaga, Wa-pare, Wa-taita, Wagweno, Wa-swahili, Wa-sambara; the people of Kavisondo on the Victoria Nyanza, of Bu-ganda, and Bunyoro; of Njemps, and Samburu, all find their way 
to Taveita somehow, whether as slaves, traders, tramps, criminals, or refugees. You may hear about twenty African languages talked around you, and, by searching among the slave caravans which stop here for repose, a list of hundreds of East African tongues might be composed.

Yet, though it is so hospitable to all comers, there is no lack of law and order. 'Taveita is ruled over by a senate of notables called the "Wazēe," or elders. These functionaries, though usually in the background, generally come forward when there is any dispute to be settled either between their fellowcitizens or foreign traders, and their authority is upheld by all the able-bodied male population of Taveita. It was from them that I obtained my cession of land, and after the fee was handed over and the agreement ratified, I had no more bother and no more asking for presents. At all times their gentle behaviour and kindly manners were charming.

Although the settlement of Taveita contains in all perhaps some 6000 of every nationality, they are scattered so widely over the domain that one lot of huts is scarcely in view of another. Each family lives apart. At night, strange to say, lions, leopards, and hyenas parade the forest alleys, without check or hindrance. The hyenas dig up the newly-buried corpses and discuss them with horrid laughs, just outside the doors of the surviving relatives, who never intervene. The natives shut up their live-stock in houses similar to their own, and consequently do not lose many by the leopards; but I, being ignorant of the rapacity of these brutes, lost at one time several sheep and goats, for the leopards would leap high palisades and jump back again, carrying away their victim. I set a trap, 
and killed one in the act, and another was shot by the men. Night after night lions would roar and bellow, seemingly just a few yards from our enclosure. Yet, though I have heard of losses in live-stock, I never was told that any human being fell a victim to these carnivora, though from the number of slaves tied together and allowed to sleep in the bush, outside the camps, I should think such a disaster not uncommon.

Taveita is full of monkeys. They are to be seen in nearly every big tree, and chatter and mow at you from the branches. Great baboons are plentiful a little farther from the dwellings, on the borders of the forest. Many big varanus lizards, sometimes reaching six feet in length, frequent the forest near the river.

Food in Taveita is moderately plentiful and reasonable in price, though not so very cheap as in Čaga. Fish, both from the River Lumi and from Lake Jipé, is good and plentiful. Bananas are of fine quality, but dear. Corn and vegetables are also relatively expensive and scarce.

One great treat for the visitor to Taveita during the months of June, July, and August are the ostrich eggs which are brought in from the outside country, where ostriches abound. In September and October these are over, and the natives bring you instead young ostriches which they have captured-bristly little creatures with scale-tipped plumes-and sell them for an ell of cloth each (about twopence in value).

Finding Kiongwe did not arrive, after five or six days' waiting, I returned once more to Moši. Both my departure from Taveita and my arrival at Kitimbiriu were signalized by many kind acts on the part of my black friends. As we wound our way through the tortuous paths of the Taveitan forest, our acquaint- 
ances rushed from their homesteads to inquire the cause of our departure. "You are not going to leave us, Muzungu?" they cried; "promise you will return." "Yes, I promise," was my reply; then they pressed on my acceptance fowls, goats, bananas, and gourds of new milk for the journey. Again, when we arrived at Kitimbiriu, Mandara sent a messenger with many "salaams" and congratulations, and a little "kitowéo" or "relish" for my breakfast, in the shape of two big goats. The Čaga people of the vicinity all came to shake hands, although I had only been absent a week. One man was so delighted to see me (it was my milkman, and I daresay he had missed my custom), that he spat ${ }^{1}$ repeatedly at the sun to thank the Almighty for my safe return. However, rather to Mandara's disappointment-for now that we were friends he wanted me to sit and gossip all day-I returned, to Taveita again on the 28th of August, as much in the interests of natural history as anything, because failing an ascent of the mountain, there was no better bunting-ground than the 'Taveitan forests, especially for birds.

The pleasure of returning to this most interesting place was a little clcuded by finding Kiongwe still not arrived, although he was nearly a fortnight overdue ; but knowing that nothing comes in Africa from useless worrying, I settled down to pleasant work, resolved to resign myself to the inevitable dilatoriness of a Swahili caravan. As soon as it was known that we had returned, many friends came with offerings of milk, fowls, bananas, and fish. One man, a great

1 Spitting, among these people, is a sign of respect and honour. The most reverent way of returning thanks to the Ruler of the universe is to spit in the direction of His visible embodiment, the sun. 
stately savage, innocently naked, and a type of perfect physical development, wanted me to visit him at his house, so I went thither with my Indian servant. Round his little compound was a kind of fence formed of the long mid-ribs of the Mwale palm laid lengthways. There were three houses inside, one for the women, one for the goats and sheep, and one for the man. His dwelling, though small, was far from uncomfortable, and the interior was remarkable for the neatness that characterizes the domestic arrangements of most Africans. There was a raised daïs for the bed, on which skins were laid; a little three-cornered stool to sit on ; a fire burning in the centre of the floor ; spears, knives, horns of animals, and many other articles ranged to dry round the walls. At the man's earnest request we partook of sour milk and sugar-cane. $\mathrm{He}$ also wished us to try some rather dirty half-fried fish, but this I was obliged to decline. Whilst I sat talking to him, his wife, a motherly-looking soul, appeared, leading a small, rather unhealthy child, and was further followed by a genial old hag, my friend's mother. This latter was a merry, social old body, though very monkey-like as she sat and chewed sugarcane, holding it before her with both hands, and gnawing it laterally with her teeth, while the farther end of the cane was clutched between her lean thighs. My host caught his child to him with unmistakable parental affection. He carefully pinched and pressed the great protruded stomach, as if divining this to be an unhealthy symptom. Seeing he was anxious and wishing to say something kind, I offered to send medicine, which in the Swahili tongue is expressed by an Arab word "dawa." But he only replied, "Dawa, what do we know of dawa?" Then he looked up 
to the sky in quite a simple way and said, "Perhaps Muungu will cure him? who knows?-the other one died." "Then you had another child?" I asked. "Yes," he said, "but Muungu took it." He looked again at his child, and seeing its eyes were flecked with mucus he cleaned them with great sucking kisses. At length I rose, and said in a roundabout way I had better be going. He put the child from him with a sigh, and rose and followed me to my camp, carrying a present of bananas.

About this time numbers of Wa-taita from the districts of Bura were flocking to the vicinity of Taveita in search of subsistence. A terrible famine raged throughout the countries bordering on the Zanzibar littoral in the year 1884. Many-far more than we can calculate-died of starvation, multitudes sold themselves and their children into willing slavery, not caring where they went or how they worked, provided only they were fed. This scarcity of food had not affected those happy regions lying within the beneficent influence of the great Snow Mountain. Here the gentle showers condensed around the lofty peaks never failed, and consequently the fruitful soil pro. duced its due supply of crops. Food could scarcely have been cheaper anywhere in the world than in C̆aga, where a man might live comfortably on the expenditure of twopence-worth of cloth a day. But in Taveita, where only sufficient land was cultivated to supply the wants of the residents, provisions were already becoming relatively dear, owing to the unprecedented demand from the influx of coast people, who were afraid of penetrating the mysterious wilds of Čaga. The Wa-taita who had arrived in Taveita, seeking food, were consequently hard put to it at first 
to find a subsistence, and many of them had taken to hunting the big game in the vicinity of the forest country. They went out all night and concealed themselves in the branches of trees overhanging the well-known drinking-places of the animals. Thence they discharged their arrows and lances into the body of a buffalo or rhinoceros. The wounded animal was long in dying, and sometimes lions intervened and carried him off. Sometimes the Wa-taita kept up a running fight, as it were, till the late morning, harassing the wounded quarry with their dog-like pursuit until it fell exhausted with loss of blood and fatigue. Then they threw themselves on its dead body, skinned it, cut it up, had a glorious feast on the half-cooked flesh, which they grilled on hot stones in hastily made fires, and brought the remainder into Taveita to sell or exchange for vegetable food.

Some of these gentry offered to take me one day to a good place in which to shoot game. Soon after dawn I went, under their guidance, first through the belt of magnificent forest which engirdles Taveita, and then emerged on a tract of country similar in aspect to all the dry, bushy plains in Africa. Footprints of game began to show themselves, nearly always, however, in beaten tracks and runs converging towards the distant river. The spoor of rhinoceros, buffalo, zebra, giraffe, warthog, lion, and many antelopes was distinctly visible, and on the leafless trees great vultures perched in somnolent satiety. So heavy were they with their recent meal, and so evidently unused to man, that I was able to approach as close as I pleased to them, and very much disgusted the Taita guides by taking out my sketch-book to draw some of their attitudes, which I did with as much ease as if I had. 
been studying them in a cage at Regent's Park. Unfortunately, I am more of an artist than a sportsman. In many a spot the fragments of bones and the trodden herbage, together with the surrounding footprints, showed that a lion had recently feasted off his prey. In one such place I saw, to my great surprise, a human being slinking away as I approached. I

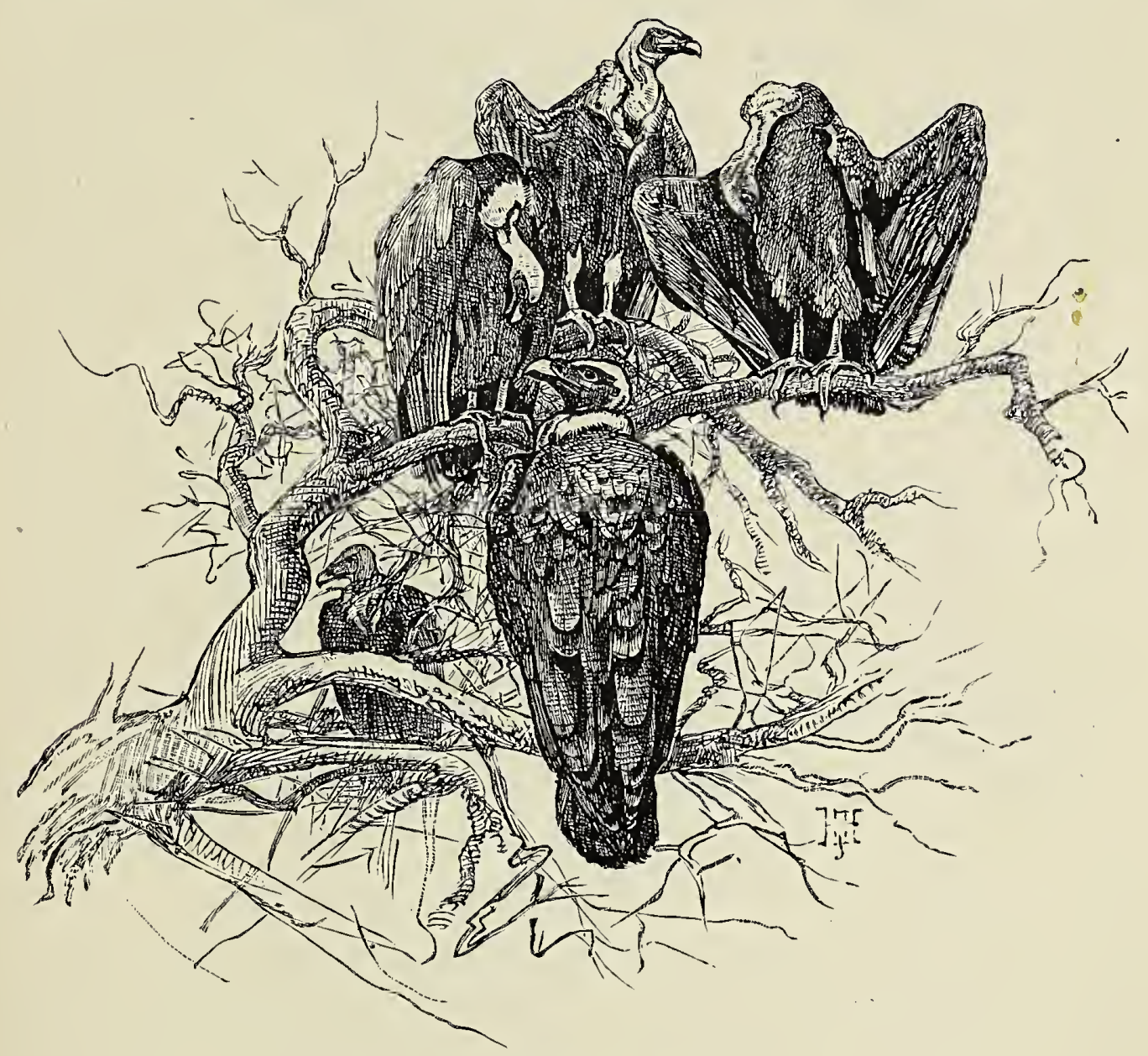

Fig. 46.-Vulturine attitudes.

called out to my guides to know who that was, and they explained to me that certain hungry creatureshuman hyenas - unable to procure the death of any wild animals for themselves, followed the lions wherever they went; and when the king of beasts had killed his prey, slaked his appetite, and walked off to drink, they intervened and carried off the remains of 
his bloody repast. "And does the lion never return and kill them?" I asked. "Will a gorged vulture fly, or a full lion attack a man?" they replied contemptuously. In spite of all this evidence as to the abundance of big game, I actually saw but little, for the morning was now advanced, and the animals had retreated from the hot sun into dense cover. I might, perhaps, have had better sport had I béhaved more like a sportsman; but I would tramp along unconcernedly and chatter to my guides, consequently I often heard a warning whistle and snort from the antelopes we were tracking, and they were off before I could fire. I managed, however, to bring down a Mpala ${ }^{2}$ antelope, and I wounded a warthog, but he got away in the dense bush. I killed some francolin and pigeon with my shot-gun, and at any rate the commissariat did not suffer from my morning's outing. I found the meat of the Mpala very dry and unpalatable, but it was enjoyed by my men and the Wa-taita.

Hearing so constantly from these people of the fine sport to be got at night (we had a moon about this time) and at earliest dawn, I resolved to go and live for a day or two in the wilderness outside Taveita, so that I might be on the spot, and not fatigue myself with a long preliminary tramp to the scene of operations.

We followed the course of the River Lumi-our river as we affectionately called it-in a northerly direction, for about three miles. We had quitted the great forest in which Taveita is built, and except for the band of noble trees through which the river flowed,

2 Apyceros Melampus. I use here the common South African name. The Wa-taveita call it "Kulungu" and the Wa-taita "Nosi." 


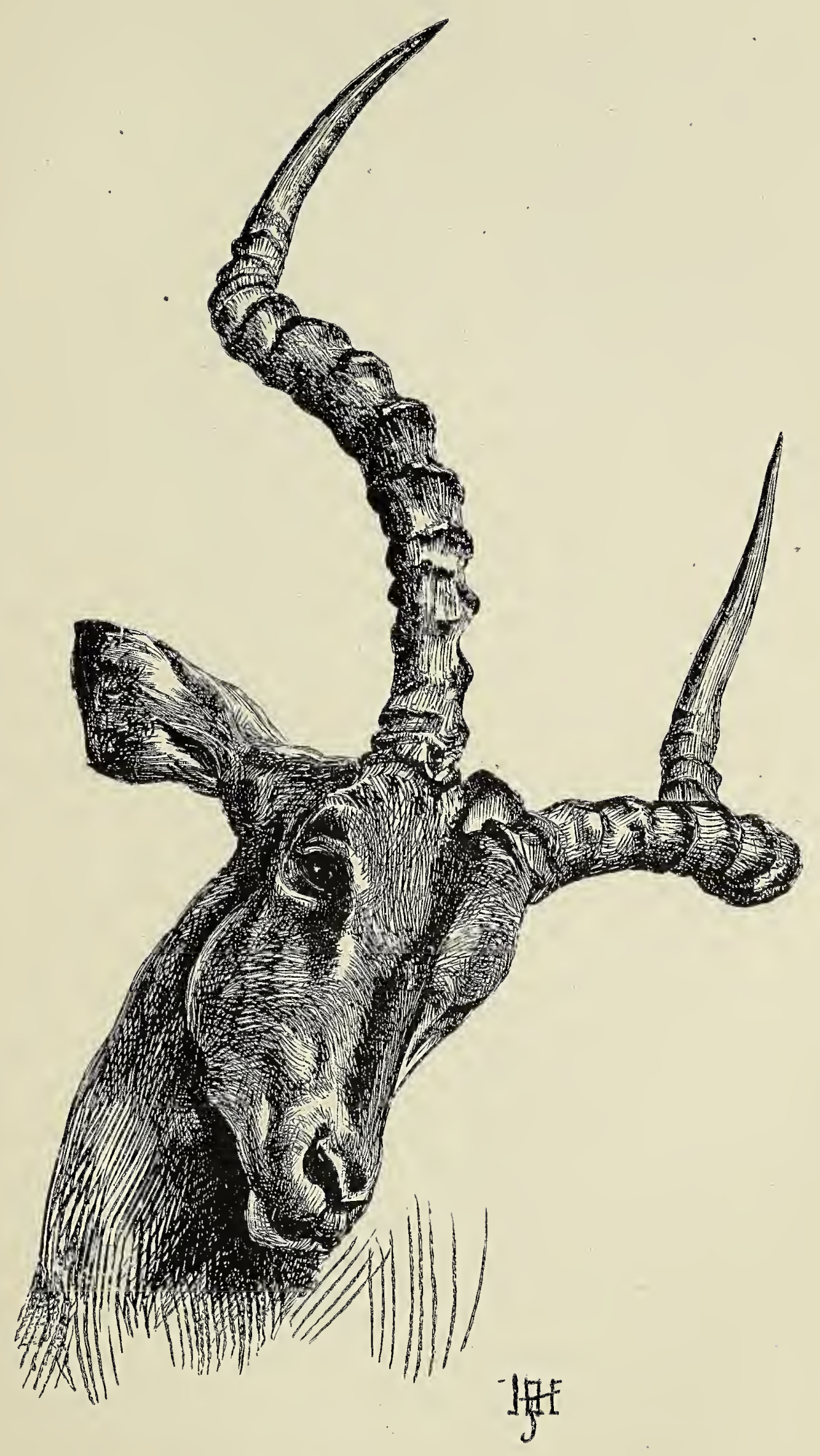

Fig. 47.- The Mpala Antelope (F.pyceros Melampus). 
there were only low scattered bushes covering the plain. This was emphatically the game country of Africa, and wherever you find this kind of landscape, no matter in what part of the tropical continent, you may be sure it is inhabited by the big African herbivora. We pitched the tent in a snug little corner by the river-side, a kind of peninsula surrounded on three sides by the water, and secured from outward view by bushes and trees. I spent most of the day roaming about with a gun, but only killed a zebra (Equns Chapmani), which had, however, a very handsome hide. A great deal of game was visible from the summit of the little cone, rising on the left bank of the river, but it was evidently very wary, owing to the recent inroads of Taita and Kamba hunters.

It was at night, however, that I hoped to bring down a good bag, by concealing myself at the riverside, and shooting the animals as they came to drink. The banks of the Lumi were, as already mentioned, clothed with a narrow band of dense forest. Here and there gaps had been formed in the dense array of trees, and through these the thirsty animals had made a broad way down to the water. The ground would be pounded into red dust, all turf or vegetation destroyed, and even the tree-trunks on either side of the tunnel-for such it was through the dense woodpolished up to a certain height by the passage of crowds of great hustling beasts. Such a place as this, there was no mistaking. That it had been recently frequented we could tell by the abundance of fresh exuviæ strewing the entrance; moreover, here were bones, skulls, horns, and other fragments of the lions' repasts, which, however thoroughly they might have been picked by hyenas, vultures, and ants, still to the practised 


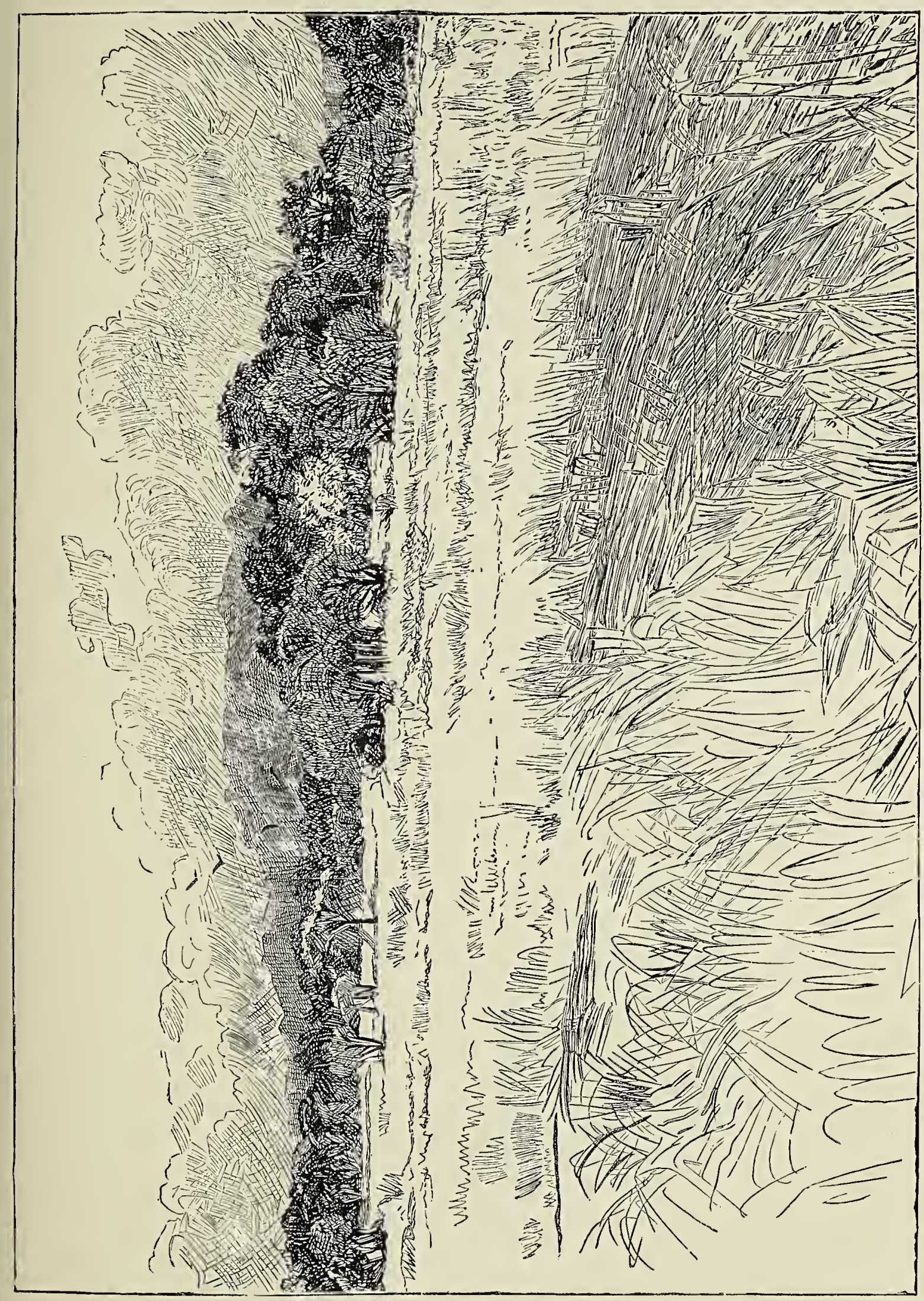



eyes of our guides showed by their condition that some few hours ago they formed part of living individuals.

Here I resolved, therefore, to conceal myself after dark, with my gun and plenty of ammunition, and my imagination pictured with delight scenes after the fashion of Gordon Cumming's tales. The best mode of lying in ambush was much disputed. I at first was in favour of making a kind of "skarm," a low pit just deep enough to hold my body, with a fringe of thorny branches round it as a cover. But this, for various reasons, did not meet with the approval of my men. Firstly, we found, on digging just below the soil, that water filtered into the pit, which would render it disagreeable to stand or sit in ; and, secondly, it was my guide's opinion that wounded or angry beasts might just walk in on top of me. Consequently we adopted the notion of the Wa-taita, which on the whole was best, namely, to construct a platform between the branches of the trees overhanging the "run," about ten feet above it.

This was carried out toward the end of the afternoon, and in the evening, having comfortably dined and taken my coffee in camp, I took leave of my men, and was hoisted up on to the platform, together with an 8-bore elephant-gun, a bag of ammunition, a rug, matches, a bull's-eye lantern, and a flask of cold coffee. Two Wa-taita mounted neighbouring trees, settled down in the forked branches, and we were left to commence our night vigil. My camp was only a quarter of a mile distant, and I was quite safe from any wild beasts except leopards or snakes, neither of which were likely to attack me.

Surely, I thought to myself, there could be no pleasanter way of shooting big game than this. Instead 
of tramping miles and miles through thorns and over sharp rocks, under a blazing sun, in search of a vigilant quarry, here you await him in numbers, seated at your ease, in the cool night air, able to take careful aim, and safe from any nasty display of spite on the part of your wounded victims. Undoubtedly my opinion was the right one from an epicurean point of view, provided that all the elements of the combination were present; but just as the best place in a theatre would be worthless in front of an empty stage, so all my elaborate preparations for a grand battue of big game were of little use when the expected animals did not arrive.

Slowly the night wore on. The moon, just past her prime, rose late, and changed gradually from a coppery red to a yellow white as she mounted higher and higher, bringing by degrees a lesser day to bear upon the scene. Gazing out from under the branches to the open plain, I could distinguish ghostly forms, devoid of colour and substantiality, flitting here and there, objectless and restless-hyenas, probably, seeking stray fragments of carrion. Now and then the singing, monotonous chorus of the cicadas and tree-frogs was momentarily interrupted and again resumed, or varied by the shrill chanting of a soloist, or temporarily overborne by the faint, distant booming of a lion's roar ; otherwise nothing interrupted the solemn quietude of the night.

Half sitting, half reclining on my tree-perch, my limbs soon stiffened with the unchanged posture, and I grew chilly with inaction. The night breeze blowing over the snows of Kilima-njaro sent tremors of cold through my body; I sought a more comfortable position, and a better arrangement of my rug. In doing so a slight creaking and rustling of the boughs was caused, and I was startled to hear from the other side of the water a sudden outbreak of strange, half-human 
cries-screams, barks, and guttural murmurs. Looking in that direction I was able to make out a small party of baboons, who had come down to drink, and evidently mistook the stealthy noises I had made for the approach of their relentless enemy, the leopard. Though they peered uneasily into the gloom, and did not turn at once to run, I would not shoot, because I did not wish to frighten more important game that might be approaching; and, moreover, because, except for scientific purposes, I think it is so sad to kill a monkey. To see a baboon in its death-throes causes me almost as much pain as if he were a member of my own species.

However, my forbearance was not duly rewarded. A few small things, probably civets, cats, or jackals, crept noiselessly to the water-side and drank uneasily, but I held my hand, deeming it mockery to blow them to fragments with an elephant's vullet. Here and there in the open a large form seemed to hesitate about passing through the tunnel where I was concealed, and I always waited, unwilling to risk an uncertain aim and a distant shot for the hope of certain slaughter when they should defile past my lair. But they came not, and disappeared into the outer gloom. What was the reason? I asked myself. They could not see me behind my screen of boughs, and I sat long in noiseless immobility. The fact that they divined the presence of a human being by scent never entered my head, and I forgot that the wind blew from me towards them, and carried to their powers of smell sufficient evidence to deter them from approaching any nearer a suspicious spot. Yet I knew that this drinking-place had been much frequented the previous night, and I could now hear a mingled chorus of animal cries from distant bends of the river, showing that the thirsty creatures of the wilds had come to satisfy their thirst. I 
consulted in a whisper witb the Taita hunters as to the advisability of leaving our perch and seeking game on foot, but they were strongly averse to this procedure, and persisted in saying, "Wait, and they will surely coine." But they surely did not, and as soon as the first promise of dawn irradiated the sky I indignantly

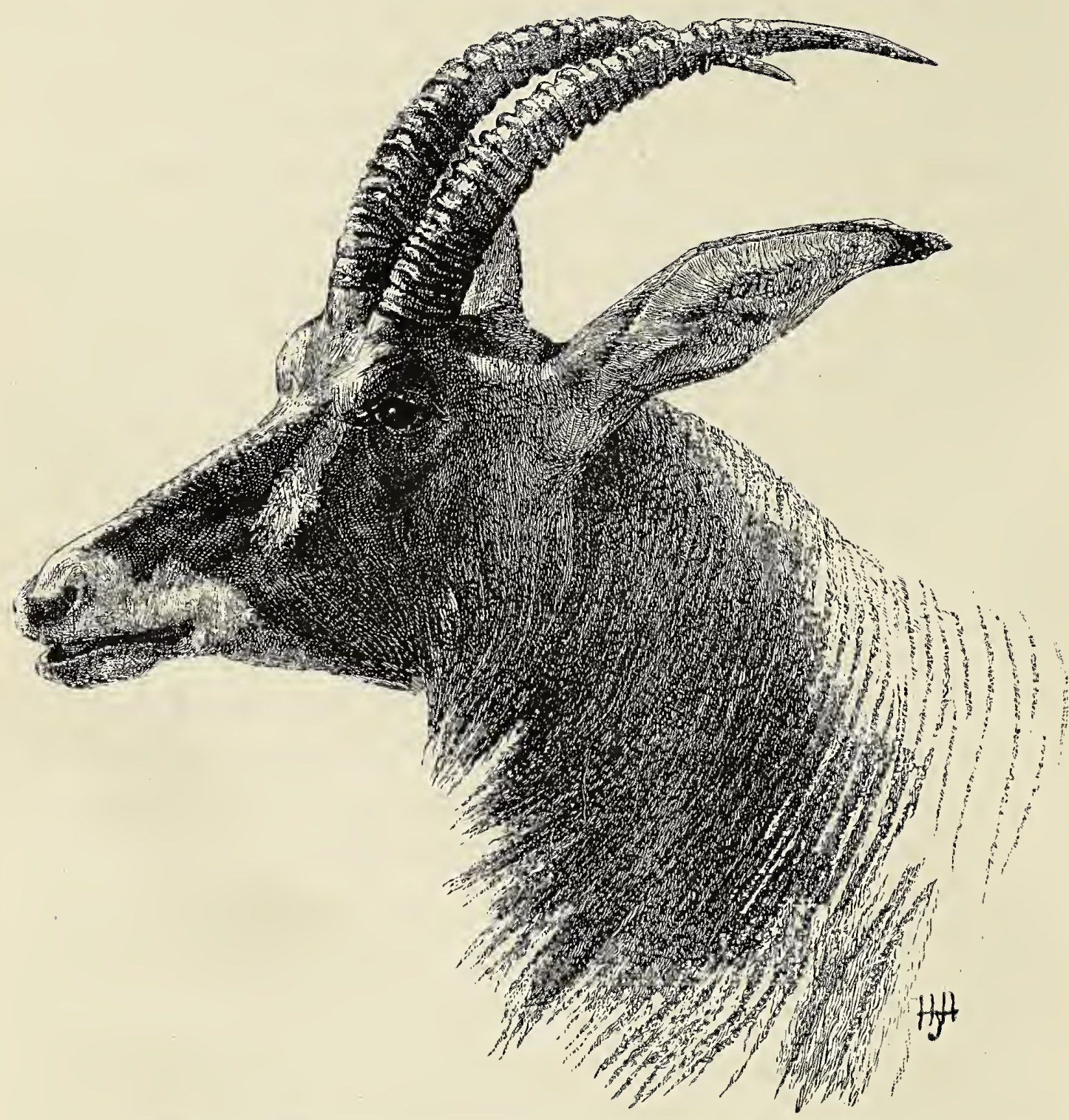

Fig. 49.-Female Roan Antelope (Hippotragus Equinus, of).

left my platform and wandered out into the dewy plains, seeking a victim. A giddy zebra, browsing on the sodden turf, stopped behind his friends to stare at me, and received a bullet from the mighty 8-bore, which soon laid him low. I also killed a female roan. antelope, and so returned less discontented to my camp 
than I might otherwise have felt at my uneventful night, for at any rate here was abundant meat for the men.

At the end of the succeeding day my sporting picnic was interrupted by the arrival of messengers from Mandara, who bore a strongly worded communication in writing, to the effect that I was to return at once to Moši, as Mandara had some important news to communicate. Wondering who among the chief's followers had suddenly attained epistolary skill, ana grumbling at the somewhat dictatorial tone of the command, I nevertheless deemed it advisable to comply, the more so as Kiongwe's inexplicable absence made me averse to risking a loss of Mandara's friendship. I left behind two trusted followers, Abdallah and Kadu Stanley, in my Taveita settlement, with the fullest instructions as to their procedure in case Kiongwe came during my absence, and then once more quitting my favourite place of sojourn, I turned my steps towards Moši with an anxious heart.

Arrived at Mandara's court, however, an unexpectedly pleasant reception awaited me. It appeared that a large Swahili caravan had reached Moši during my absence in Taveita, and its leader happened to be a trader of some position on the coast. He had seen me in Zanzibar the day I went to visit the Sultan with Sir John Kirk, and consequently conceived an exaggerated, but useful opinion as to my relative importance in the scale of humanity. He questioned Mandara as to my welfare and whereabouts with an empressement and evidert interest which did much to endue that chieftain with a loftier opinion as to the social position of his guest. Finding his Swahili friend was a scholar, he resolved to set at 
rest his last doubts in the authenticity of my statements, and accordingly brought out the two letters of Sir John Kirk which I had presented as an introduction, and asked to have them read. When their contents were made known to him he was seized with compunction and apprehension at the way in which he had previously thwarted my mission. A passage in Sir John Kirk's long communication to the effect that he hoped Mandara would aid me to the utmost in ascending Kilima-njaro awoke the chief to a sense of his neglected duty.

Without further delay I must be recalled from Taveita and sent up the mountain before the failure of my mission could be reported to the Baloza. Accordingly, messengers were despatched at once to Taveita, and as soon as I had obeyed their summons and presented myself at my tyrant's court, Mandara hastened to describe the elucidation of his doubts which had taken place, and assured me now of his sincere wish to render me help and counsel. "Did I wish to ascend the great mountain? I should go to-morrow, that very next day, and climb as far as I chose, even to the white 'salt' which covered the top. $\mathrm{He}$ would send guides and soldiers to accompany me." I was at first too surprised at this change of demeanour to realize the happy change in my prospects, but when Mandara kept repeating, as he patted my hand encouragingly, "To-morrow, you shall go to-morrow," it began to dawn on me that it was a serious proposal, and I accepted eagerly and began to discuss the details of the expedition. Nine of my own men would be taken and six soldiers of Mandara's to act as guides. "You had better not defer your journey," said the chief, "lest the Wa-kibôšo get wind of it and inter- 
cept you." It was arranged I should not be absent more than a week, and that the guides should receive four yards of cloth each, to buy food for their sojourn

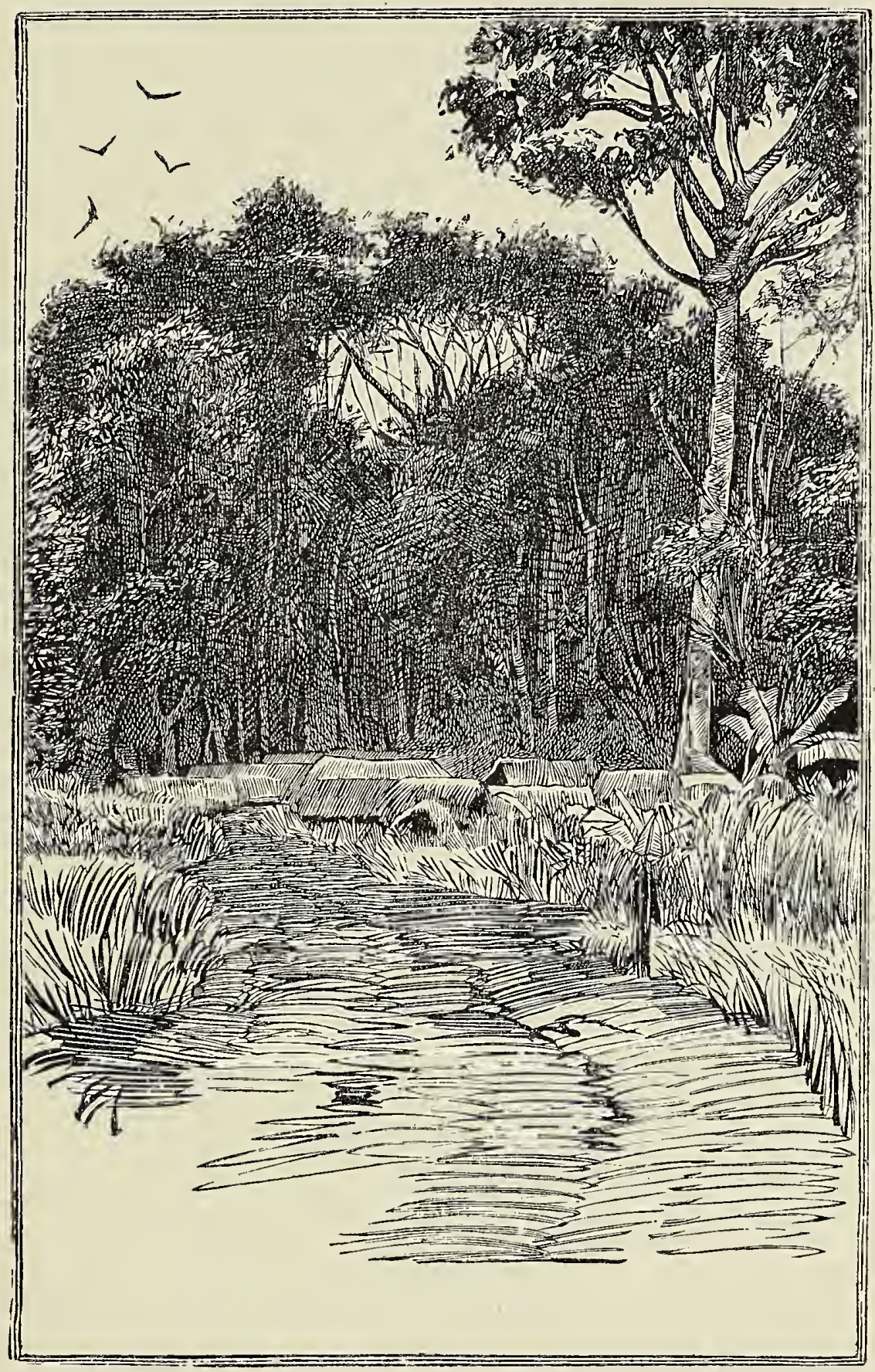

Fig. 50.-My Settlement at Taveita.

on the chilly heights. Mandara presented me with a couple of goats as a contribution towards our commissariat, and took leave of me with continued wishes Q 2 
for my success and a sincere hope of my safe return. I repaired to my settlement, full of joyful anticipation, commenced packing, and slaughtered a bullock, so that every one might have a good preliminary feast before entering on the anxious journey of the morrow. Mandara's six men, one of whom was Kilaki, an old friend and constant frequenter of my "town," came to receive their "cloth" and their instructions. I adjured them not to keep me waiting on the morrow, and then sent them off that they might have time to bid their families farewell and make their investments in food. When preparation had been made, and every. thing packed save the necessaries of our civilized existence, which might be thrust into the bags before starting, I retired to rest, but slept little, so feverishly anxious was I to commence my first ascent of Kilimanjaro. 


\section{CHAPTER XI.}

\section{A FIRST ASCENT.}

Faitheul to their promise, Mandara's five soldiers, led by Kilaki, arrived in our settlement at sunrise. They brought with them bags of provisions, and three fat sheep, which were to constitute a further supply of food, and one which would obligingly transport itself to the desired goal.

Leaving Faraji, the cook, alone in charge of Kitimbiriu, we commenced our ascent by following the upper road skirting the crest of our long hill. We walked first between tall hedges of glossy-leaved dracœnas and gorgeous scarlet-flowered aloes, which grew from tall stems in arborescent form. As we passed the wooden doorways of the different congeries of huts which border these Čaga lanes the inhabitants rushed out mirthfully to greet us. "Utonga ako, Mange Muzungu?" (Where are you going, white chief ?) they cried. "Ngatonga Kibô" (I am going to Kibô) I joyfully answered. (Kibô is the giant summit of the mass.) From each little tidy compound of Wa-čaga, from their trim fields and luxuriant plantations, came merry girls, their arms linked together affectionately, and accompanied by their brothers, fathers, and husbands, all in perfect nudity and all in smiling good-humour. They would range themselves 
along the sides of the narrow lane, backing, with much giggling, into the fern-fronds and brambles as I approached, and saluting my followers with many outspoken remarks as to their personal appearance and the errand on which they were bound. In the rear of the small company came the six soldiers of Mandara, wearing conspicuously the white cloths I had given them, and loaded with their shields, arms, and water-gourds. They urged along the upward path the three docile and unsuspecting sheep, which were to serve as their stock of provisions during our residence above the clouds. At about 5400 feet we quitted the last signs of cultivation, and consequently missed the familiar runnels of water which in the inhabited country intersect the land every few yards. The surrounding scenery was now charmingly soft and pretty, so exactly like Devonshire hills and coombes in general aspect that I need not give it a more detailed description. At 6000 feet we halted for a brief. rest. The ascent had been very gradual. Here, where we first rested, there were grassy downs of short springy turf scattered over with magnificent clumps of forest; but higher up the woodland scenery, though very pretty and "English" in. look, did not offer remarkably fine timber, the trees being short and twisted with dense undergrowth. The wild flowers were beautiful. Parasitic begonias trailed their lovely pink bells in long festoons; magenta-coloured balsams gleamed from among the fern-fronds, and every now and then we would come across clumps of crimson and salmon-tinted gladioli that provoked expressions of admiration even from my followers, whose eyes were caught with the rich displays of colour. The tree-trunks, even to the minor branches, were densely 
hung with moss, orchilla-lichen, or delicate epiphytic ferns. Other species of ferns grew luxuriantly at the side of the path, some of them actually British in their extended range. There were polypodies, holly ferns, bracken, maidenhair, identical apparently-I have since found at Kew they were actually the same-

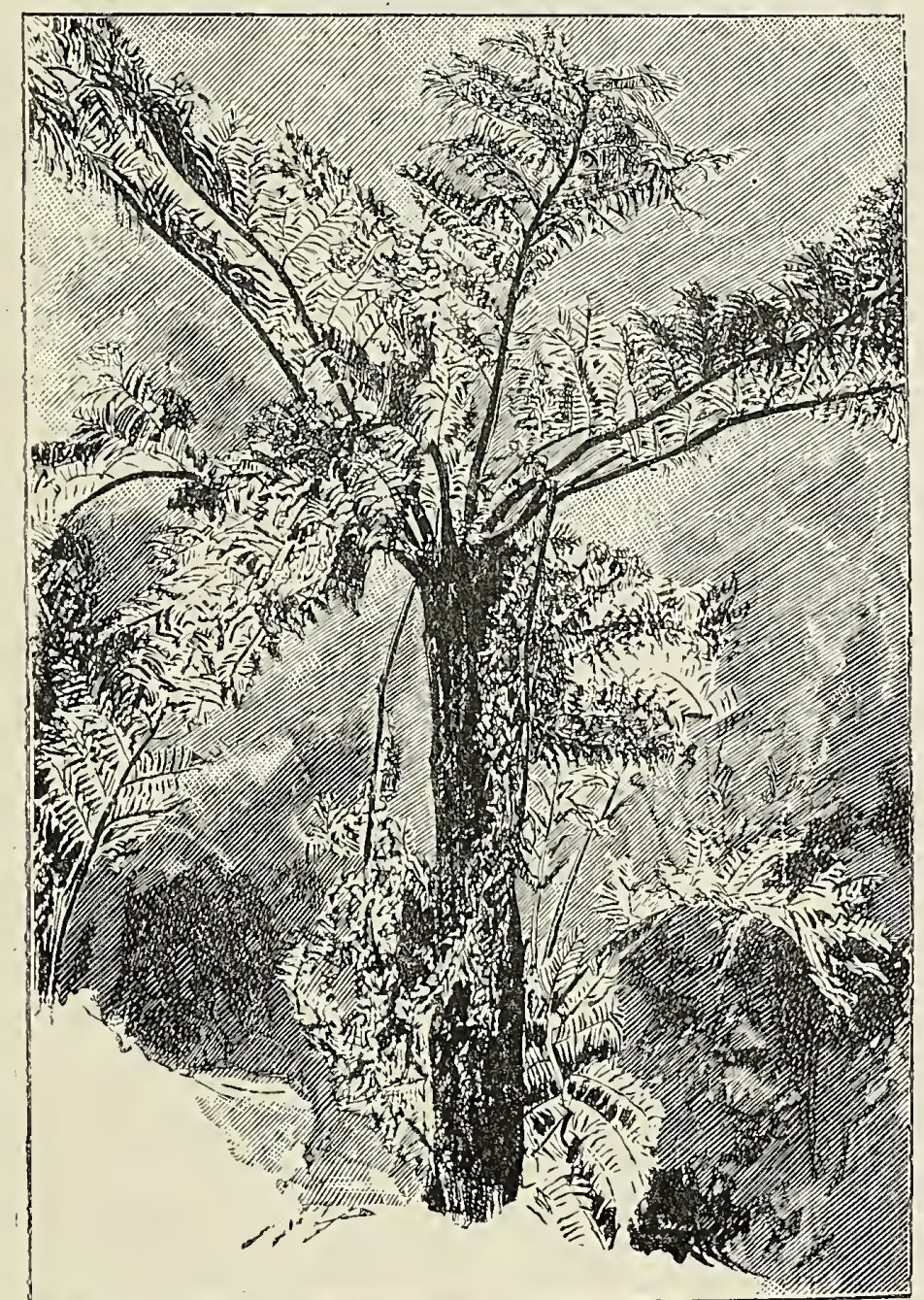

Fig. 51.-Tree Fern (Lonchitis pubescens).

with those we know in England. Unfamiliar, though, to our English scenes were the magnificent tree-ferns (of the species Lonchitis pubescens), which rose grandly above the dense undergrowth, with fronds of a shiny bluish-green, whenever the pale green light of the forest fell athwart their downy leaflets or silky stems. 
At a greater altitude than 8000 feet these tree-ferns were rarely met with; indeed, they were mostly confined to a zone round the mountain between 7000 feet and 8000 feet above sea-level.

Our path was very wet with the moisture that dripped from the forest, and often obstructed with huge tree-trunks that lay across it. It was one of a series of tracks which converge from the different little kingdoms on the mountain up to a height of about 9000 feet odd, where they join a path running nearly due east and west from Sira to Useri. As the inhabitants of the Kilima-njaro States are nearly always at war with one another, and, consequently, have not free transit through the hostile territory of their neighbours, they all resort, by means of the upward road, to the neutral ground above, and at varying heights above the inhabited district pursue their journey round the mountain. They do not always do so peacefully, however, as it is the disagreeable custom of the mountaineers to post themselves occasionally in ambush at the cross-roads and leap out on any passing travellers too weak to resist them, in which case the men are killed and the women are carried off in triumph as slaves. As we were few in number, though presumably stout of heart, our guides were very nervous during this ascent, and often paused to listen anxiously to the murmurs of the forest, fearing to detect the voices of their foes. Our conversation was held in a low tone, and my servant, Virapan, who incautiously gave way to a peal of laughter when amused by some incident on the route, was angrily checked by Kilaki, Mandara's captain, and told that he was risking the lives of the party. However, throughout this day's journey we heard 
nothing more alarming than the occasional trumpeting of elephants or the mocking cry of the blue-green touraco.

Owing to the absence of any drinking-water on our road ever since the last streamlet we had crossed in Moši, we scarcely stopped anywhere to rest until reaching our camping-place, at a height of 8600 feet. Here we found a little rivulet flowing silently over mossy rocks, and forming clear, deep pools every few yards. The water was icy cold. Above the stream the path led us to a slight clearing in the forest, where we saw a few rotting huts and wind shelters. "These," said Mandara's men, "we made when we came to fight against Useri. We slept here, half-way." My men were enjoined by the Wa-čaga not to make any noise that might attract the attention of enemies in the vicinity; they even objected to our lighting big fires, in case the curling smoke might betray our presence; but at this I became impatient, preferring to risk the chance of a scuffle with the Wa-kibôso to suffering from cold. Already, as the sun was setting, the temperature rapidly sank, and the air became very chilly, while a white rime settled on the grass. The forest and the surrounding vegetation were weirdly strange. Giant heaths of the familiar genus Erica grew unfamiliarly as tallish trees. An extraordinary composite plant (since named from my specimens Senecio Johnstoni) flourished in the marshy ground near the rivulet and rose to twenty feet in height. From a distance it appeared something like a banana, with huge broad leaves at the summit of a slim, bare, black trunk, but with yellow flowers like a groundsel -a humble plant, to which indeed, it is not distantly allied. "Everlasting flowers," of tender rosy pink or 
yellow-white, grew in clusters where the forest was less dense, and pretty star-like anemones, blush-colour with yellow centres, sprang up like pale stars amid the dusky herbage. Things that resembled chervil and hemlock grew in rank abundance, and the crimson gladioli gleamed out vividly on all sides. There were also pretty irises and ground orchids of a rich mauve-pink. Altogether, although the flora was different from that at lower levels, it lost nothing in brilliancy of colours. The men rapidly constructed wind shelters of branches, lit roaring fires, and wrapped themselves in their scanty garments to resist the increasing cold. The Čaga soldiers killed two of their sheep recklessly, thinking nothing of economizing their food, and distributed some of the meat among my men, offering me a really choice leg of mutton., All through the night the tree-hyraxes kept us awake with their ringing plaintive cry. After a long discussion the next morning, I decided to move our permanent camp higher up the mountain, so that I might be nearer the field of my researches, and also for the reason that the men of Mandara continually dreaded an attack from their enemies, and would not allow us to fire our guns at any bird or beast, fearing lest the shots might reveal our existence. On reaching a height of 9000 feet the continuous forest came to an end, and we emerged on tracts of tussocky grass, interspersed here and there in parklike fashion with clumps of trees. We were now on a kind of level table or shelf, which stretched away round the southern slope of the mountain, and from which the great central mass (the ridge culminating in the two peaks of Kibô and Kimawenzi) arose with a somewhat abrupt ascent. In the hollows of this further range there 


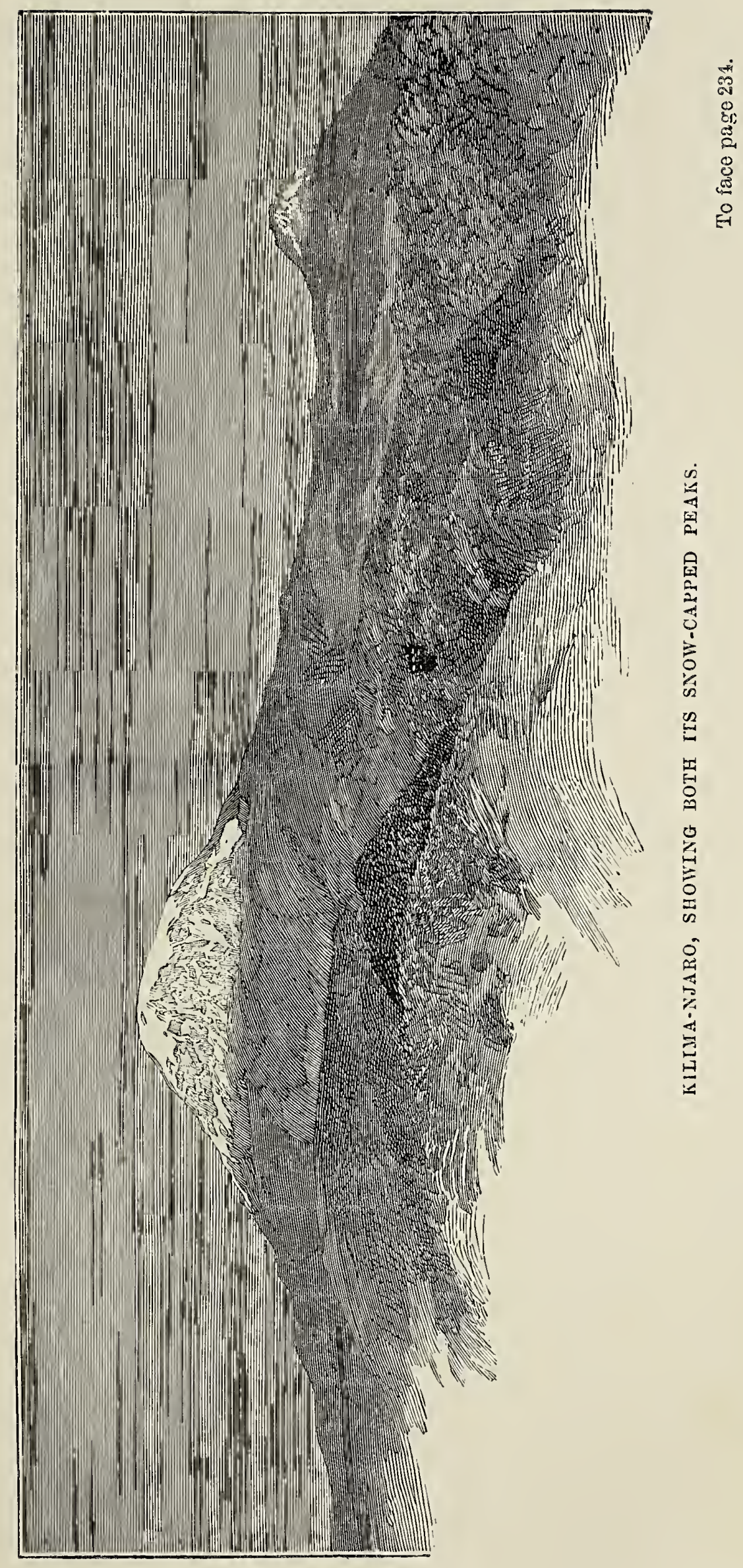



were clumps of forest up to 10,000 feet. Many brightcoloured flowers grew up to this altitude, notably a vivid blue cynoglossum (houndstongue), mauve and blue irises, and pirk, waxy-white, and yellow " everlastings." Tufts of artemisia (southernwood) grew in sheltered places. There were many heaths, a small kind of geranium, huge proteas, and divers ferns and mosses. The foliage of the trees was rather a dull grey-green, and their boughs and trunks were rendered almost shapeless by the thick tapestry of moss and orchilla-lichen. A black and white raven was frequently seen sailing overhead, two or three white butterflies flitted about, and a small grey moth hovered

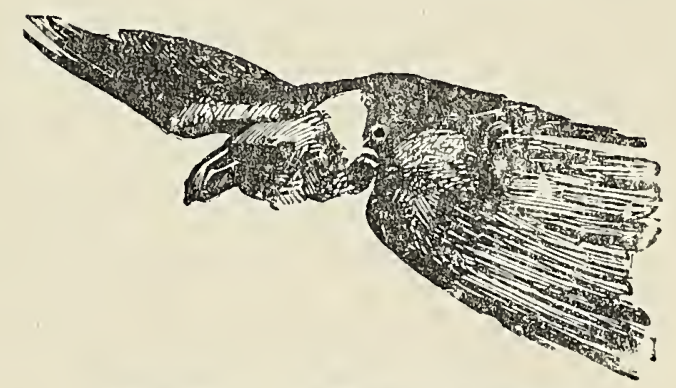

Fig. 53.-A Raven soaring. over the grass. A little lizard, nearly dull uniform black, with faint markings, darted to and fro in the herbage, pursuing the drowsy-looking files that settled on the grass-blades in the sun.

Whilst my men were preparing lunch under the shade of a stunted tree $I$ made a rapid excursion upwards to collect some plants, and then returned to my followers about noon. I had just got out my theodolite to take some observations of the different peaks in sight, and had finished "screwing up" the levels, when a cry from my men behind caused me to look up. In the distance, coming from the west, a large band of Wa-kibôšo-our most bitter foes-were to be seen approaching at a round trot, covering themselves with their shields and waving their spears in the air. I had just time to form my little force of sixteen men into a square, and awaited with anxious heart the 
onset. Fortunately, in the middle of their charge the Wa-kibôšo stopped short. There, between us and them, unheeded by me, stood my theodolite, poised on its tripod stand, with its levels, doubtless, as well adjusted as when I had previously left it. This harmless instrument had filled the Wa-kibôšo with sudden dread. It was, no doubt, considered some engine of sorcery so powerful that I needed but to place it between myself and my foes, and I could then await their onslaught with equanimity. The Wa-kibôšo, therefore, paused, their war-cry ceased, they gazed uneasily at the theodolite, and, to my intense relief, slowly withdrew to a neighbouring hillock, from the top of which they watched our proceedings. After a quarter of an hour of immobility on either side the Wa-kibôšo suddenly left their post of observation at a gentle run, and disappeared into the forest below. I had a short deliberation with my men, who insisted on at once returning to Mandara's country, alleging that the Wakibôšo would return in greater numbers and cut off our communications below, thus sevcring us from our food supplies. I then suggested that, instead of returning direct to Moši, we should continue our exploration of the mountain and then descend through Useri on the plains below, and thus reach Taveita. This also was overruled, and, perhaps, wisely, as the people of Useri were equally hostile to Mandara with the Wakibôšo, and would possibly have massacred our little band of sixteen men had we tried to pass through their country. Finally, I resolved to take the advice of Mandara's soldiers, and return to our settlement at once, without further delay. We therefore re-entered the forest, and passed our old camping-place of the night before, where we saw the print of many feet, 
from which we concluded that the Wa-kibôso must have come here just after our departure, have discovered our route, and followed our tracks up the mountain. We were discussing this question and leisurely continuing the descent, when one of our guides stopped, commanded silence, and listened intently. I naturally did the same, and heard a faint ringing cry behind us. We looked at one another with serious faces and said "The Wa-kibôšo!" Evidently they had re-discovered our track, and were announcing it to their more distant comrades. An unreasoning panic seized my people. They started off in a headlong flight down the mountain, and for some time I feared the men might cast away their loads and lose my collections, but fortunately they clung to their burthens as Swahili porters do even "in extremis." At length I felt I could no longer keep up such a rapid descent over slippery tree-trunks and glissades of mud. I had already nearly broken my leg and effectually barked my shins, so I called repeatedily on the foremost men of our party to stop, and we journeyed for a little while at a more reasonable pace. Soon, however, we had another fright. Those who were in front came to a sudden halt, cried out, and fell back in confusion. "What is it?" I asked, panting. "The Wa-kibôšo," gasped my men, and sure enough, up the steep descent of the narrow path we could descry white head-dresses and gleaming spears approaching. This time we no longer made the least stand. The cook, Cephas, attempted to $\mathrm{fly}$, slipped, and fell into a ditch; others crept into the bush ard hid; and I myself, too utterly sick and exhausted to offer any resistance, sat down by the way-side and awaited my fate. There was a hush, a whisper rising into a shout, and then a sudden glad cry from my reassured followers, 
"Watu wa Mandara! Watu wa Mandara" (Mandara's people). I rose to my feet and greeted the captain of the force with the usual Caga salutation, "Mbuia" (friend). He informed me that Mandara had feared a difficulty with the people of Kibôšo, and had sent 200 soldiers to escort us back. After this last scare nothing further happened to cause us further anxiety. Mandara's soldiers went along their course behind us, and had a skirmish with the Wa-kibôšo to cover our retreat, and we eventually reached our settlement of Kitimbiriu thoroughly exhausted with our day's adventures, but feeling quite happy at once more coming "home."

Mandara sent the next day his congratulations on my safe return, and a fine goat wherewith to make merry. As I had almost given up the hope of ever seeing my caravan from the coast-they were six weeks overdue, and I imagined them annihilated by the Masai-I felt very uncertain as to my chances of withdrawing from Mandara's country, and consequently congratulated myself on the improved relations subsisting between myself and that chief. I now devoted myself entirely to natural history studies and researches into the habits and customs of the Wa-čaga, and the peculiarities of their interesting dialect. The days slipped by most pleasantly, I ate and drank of the best, for my kitchen-garden yielded me almost every well-known kind of vegetable in abundance, and the native markets supplied such cheap and varied provisions that I scarcely had cause to regret the exhaustion of my European stores. In short, I was now resigned apparently to a long isolation on Kilima-njaro, without any present hope of reopening communication with the coast, when, one 
day-in fact on the 22nd of September-while I was working at my collections of plants in the late afternoon, and preparing to clear the table for dinner to be laid, two men, breathless and speechless, emerged from the steep ascent on the eastern flank of our hill and stood before me. I immediately recognized Abdallah and Kadu Stanley, whom I had left behind at Taveita, to report the arrival of the caravan, but their silence seemed so ominous that I could merely stare in suspended apprehension. However, they were only speechless from their steep and exhausting climb, and as soon as they had recovered their wind they ambled forward with beaming faces, kissed my hands, and said, "Oh, Bwana, nothing but good news! good news! Kiongwe has returned, and all is well." With these words: they threw at my feet a bag of letters, and squatted down in my doorway to pant at their ease. The revulsion of feeling within me was wonderful. I now lost my calm, contented resignation of heretofore, and yearned to do great things. No longer need I cajole Mandara and elude the bloodthirsty Wakibôšo. With the reinforcements that were now arriving, I should have at my disposal a force of over sixty men, with which I could disregard the goodwill of the natives of Kilima-njaro, and quietly pursue my mission without fear of hindrance.

However, I was not yet free from difficulties, though the termination of my trials seemed at hand. Mandara, hitherto, especially after his recent amiable behaviour, had cherished the notion that my residence in his country would be perpetual, and would probably become very angry if he found out I was entertaining a project of withdrawing from Moši and transferring my expedition to the country of his enemies. Conse- 
quently it behoved me to act discreetly so that I might carry away all my property from Kitimbiriu without provoking any inimical action on his part. Probably he would not actively intervene to prevent my departure, or to rob me of my goods; but he had only to convey a hint to the Masai in the plains below, and my caravan would have little chance of ever reaching Taveita intact. To Taveita, as a neutral ground, I determined to go before again attempting the ascent of Kilima-njaro from another point in Ćaga. Accordingly I had directed that the porters should leave their new loads there before proceeding to Muši, so that they might come nearly empty-handed, and be ready to transport my goods from Kitimbiriu.

Abdallah had carried out my secret orders very well. Kiongwe stayed behind at Taveita with the sick and halting, and watched over the new supplies which were there stowed away, while Abdallah and Kadu came on to me with thirty porters, and carried nothing but the bag of letters and some selected presents for Mandara.

The morning after the arrival of my reinforcements I went to Mandara's court to announce ceremoniously the safe coming of my long-looked-for men, and to read to him some letters I had received from Sir John Kirk. Dressed in my best clothes, and accompanied by several followers gaily decked, and bearing presents - for I had fortunately received some gaudy uniforms and other gifts for Mandara from Zanzibar-I made my way to his little square of beehive huts, wherein he passes the hours of daylight. As I crossed the village-green the groups of soldiers there stationed preserved a sullen demeanour, evidently reflected from the present disposition of their chief. But I was not 
abashed, and passed blithely on into the very midst of Mandara's circle. The chief was seated in gloomy silence, surrounded by his usual Swahili courtiers. When I saluted him cheerily he turned away his head and scowled. His parasites did the same, in a somewhat exaggerated fashion. But I was determined to force my good-humour on him. Laying a brilliant scarlet gold-braided vestment on his lap, I shook his unwilling hand, and said, "Khabari njema! (Good news !). Khabari njema, Mandara. Khabari za Baloza, sikiliza (News of the Consul, listen)." Mandara grunted and turned his head half round. Then I seated myself on one of the low stools near him and began to rather freely interpret a letter I drew from my pocket. In this supposed communication from Sir John Kirk I affected to find stringent orcers to leave Mandara's country, and return to the coast without delay. "I don't believe a word of it," said the Prince of Moši when I had finished, " not one word! If the Baloza wants you to return, why does he send your men back loaded with goods when, if what you say is true, you don't need them? No, you want to quit me and go to live with some other chief on the mountain, and that is why you have left your goods behind at Taveita, and your porters come here empty-handed." I protested, however, that his suspicions were unjust, and vowed that although now obliged to leave him, I would some day return; but for a little while Mandara was obdurate. He even muttered threats about impeding my departure, although after uttering them he looked ashamed and contradicted himself. At length when I had half forcibly thrown the scarlet coat round his shoulders and laid out the other presents in tempting array his set features relaxed into a 
regretful smile. "Well, child of the Baloza!" he said, with a sigh, "if you must go, you must, and I cannot prevent you. But you will promise to return, will you not? And then, see what we will do together" -and he warmed to the theme as he talked; - "We will rnake a big shamba (plantation) and grow all the vegetables of Europe; we will trade for ivory with the Masai; we will get rich together, eh?" Four months of Mandara's society had taught me how illusory all his offers of partnership were. However, I soothed him with assurances that sooner or later I would reappear in Moši and our relations should be renewed in a satisfactory manner. "And you won't forget to bring me an iron bedstead and an iron chair, like yours, and a European dog, will you?" I assented to all these requests, and ultimately our meeting broke up with much mutual friendliness.

The next morning I bought some sheep and goats of Mandara, and bade him an affectionate farewell. 'i'hen, having made all due preparations, and taken a heartbreaking leave of my thriving plantations, where the beds of potatoes and trailing cucumbers looked so prosperous, I gazed for the last time at the country of Moši, where I had made my home during four months, and then turned my back on Mandara and his kingdom, and set my face once more towards Taveita. 


\section{CHAP'TER XII.}

\section{A MOVE TO MARANंU.}

The people of Taveita were glad to welcome me once more to their midst, and after the first few days, spent in rapidly building houses to store my goods, and huts for my followers-from which efforts a small town ultimately arose-I prepared to smooth the way by negotiations for a peaceful ascent of Kilima-njaro. The chief of Maranu, a largish state (a little bigger than Middlesex) on the south-eastern flank of the great mountain, had latterly sent emissaries to Taveita, to question the people of the forest sanctuary as to my real character and disposition. News of my disputes with Mandara had reached him, and he thought, perhaps, he might oust that chief in my good graces, and get me all to himself with my (supposed) illimitable wealth, and my wonderful powers of sorcery. I met his advances enthusiastically-perhaps too enthusiastically, because it at first roused suspicion as to my real motives in entering Maraniu-and sent to say, by Taveitan intermediaries, that I should be very happy to make peace. I invited, moreover, all the different chieftains of Kilima-njaro to send delegates to Taveita,

1 As this word often recurs it may be well to note that in accordance with the system of spelling employed it would be pronounced "Marang'u." 
where we might discuss our differences on neutral ground. The hope was in me that now being duly supported by a well-equipped band of followers, and residing on my own land, I might act as the peaceful arbiter of Kilima-njaro, might show its foolish people that their quarrels were only to the advantage of the Arab slave-traders, and induce them to band together in a friendly confederation to resist the common enemy. My proposal for a conference was well received. Representatives from Kibôšo, Mamba, Mwika, Kirua, Useri, came to Taveita. I had also sent a letter to Mandara, explaining my object and inviting him to co-operate, but no immediate answer was given, nor did he send any delegate to attend our conference. The naked ambassadors of the different states $I$ have mentioned were all of one opinion. "Make friends with Maranu, and you are friends with all of us. As to forming a league with Mandara against the coast people, perhaps we will see-later; but it is Mandara who must first make amends; it is he who has for years past robbed, enslaved, and harried us. Did Maranu ever fight with Kibôšo, or Useri with Mamba and Mwika? Never! There would be peace on the mountain were it not for Mandara. He began the war-let him make proposals of peace. Where is his delegate to-day?"

I confess that having done my utmost I was not going to waste any more time in trying to restore peace in troubled Čaga. Politics I only meddled with inasmuch as they were contingent on the prosecution of my scientific missicn. As Mandara abstained from following my pacific suggestions, all that remained to me was to make friends as speedily as possible with Maraniu-not for the pleasure of its chief's acquaintance, or for interest in its welfare, but in order to 
reside in the upper regions in peace and quiet-and then proceed at once to the borders of the snow, and make up for lost time by collecting as busily as possible. Had the mission of pacifying and regenerating the states of Kilima-njaro been confided to me I would have thrown my whole heart ințo it, and might perhaps have done some real good, but it was not for that end that I had received my grants from the Royal Society and the British Association. They wanted plants and birds and beetles, not assurances that certain obscure communities of savages in Central Africa had been induced to abstain for a few months from killing and enslaving one another. What would they say, when my six months' residence on Kilima-njaro was over, and I presented myself to their committee, and said, " Oh, I am sorry to inform you I found the state of affairs in the Čaga commonwealth so disorganized, that I set myself to work to restore peace and prosperity, and this took up so much time that I wasn't able to collect"?

No, so anxious was I to effect the purpose for which I had come to Eastern Africa, that I often, when worried by all these intrigues, could find nothing more fitting to exclaim than "Bother your quarrels and your wrongs, let me get to the snow." Sometimes I longed for giant bombs containing carbonic acid gas, that I might explode them on the mountain, and painlessly asphyxiate its troublesome inhabitants. But as this was out of the question, the only plan I could think of was to make friends with Mandara's enemies, whether Mandara liked it or not. Accordingly, after the little conference referred to, I despatched a mission to Maraniu with handsome presents for its chief, and a warm acceptance of his peaceful overtures. Kiongwe, 
who had a pleasant manner and knew a little Ki-čaga, undertook this rather risky errand. Arrived in the vicinity of the king's residence he was long kept waiting outside, because the timid young sovereign was afraid of being bewitched by the white man's emissary. The people of Maraniu, no less than their chief, still feared treachery on my part. They dreaded lest all these peaceful overtures might not be a cunning means of penetrating the country and then attacking it unawares, in league with the dreaded Mandara. So as they still hesitated between accepting or rejecting my proposals they resolved to ascertain the true character of my mission by a potent test. A goat was brought before the young chief, and made to swallow a poisonous drug. "Now," said the Sultan of Maranu to the smiling but secretly uneasy Kiongwe, "if the goat dies I shall know that your heart is black and your mission deceitful, and I will kill you, that your master may see how I hate a lie; but if the goat lives, good; I shall then be convinced you have spoken the truth, and your master really wishes to be my friend." After a short period of suspense the goat began to retch violently, and finally vomited the noxious dose, then it shivered a little, shook itself, bleated, and began to browse. A loud burst of delighted acclamation greeted this favourable outcome of the ordeal, and Kiongwe was relatively safe. His moral sifting was not altogether finished, however; he must submit to a further trial. The queen-dowager, who was reputed a regular witch or wizard-finder, took him by both hands and gazed earnestly into his eyes. If his look should flinch or turn aside, then was his heart black and treacherous. So far from flinching, however, he glared at the queenmother for his very life, and it was she who first 
blinked; consequently, this last épreuve had terminated in his favour, and further whoops and yells of hysterical joy rent the air. Then sending for the fattest ram in his dominions, the chief of Maranu dismissed Kiongwe with this characteristic present, and bade him assure me that he and his subjects anxiously awaited the happy day when I and my people would enter and build in their country.

On the day following Kiongwe's return a curious occurrence, savouring of poetical justice, took place. One of my men informed me, early in the morning, that in another part of Taveita the renegades of our expedition, Mabruki and Athmani, had passed the night on their way to the coast, whither they were convoying a band of slaves. (The reader may remember that these two men had deserted from me during my first trials in Moši, and had gone to live with Mandara to organize his slave-trade.) At first I concluded that the information was of little value, as they would be certain to rise with the dawn and pursue their road, and I regretted bitterly that the news had reached me too late to cause an effective intervention. But further reflection showed the possibility that Mabruki and his confederate might still be within reach. The body of the caravan would have quitted Taveita at dawn, but the two ex-collectors, occupying now the position of independent traders, and being no longer subservient, to commands, might possibly linger behind for an extra hour of sleep or to buy provisions for the day. At any rate $I$ resolved to see if $I$ could catch them and release any of their unfortunate slaves. Accordingly, assembling my followers round me, in case there should be an appeal to force, we marched swiftly and silently down to the camping-place indicated by my 
informer, and there had the great joy to catch Mabruki and Athmani lying on the turf, half dozing, with four slaves-three women and a boy-fastened round the trunk of a tree, in whose grateful shade the renegades reposed. As I told my men in a loud voice to cut the ropes which bound the slaves (the poor creatures had their heads inserted in a kind of wooden pillory, which was tied to the tree-trunk), Mabruki and Athmani started up in amazed anger, and the former seized his gun as if meaning to shoot me, but I suppose a glance at my well-armed followers made him refrain, so he broke out into angry abuse instead. "Look here, Mabruki," I said, "if you talk like that I will have you tied to this tree and soundly thrashed. You are subjects of the Sayyid of Zanzibar, and as such forbidden to trade in slaves. I have a perfect right to free these people, and, what is more, if I carried out my duty I should put you in irons, and hand you over to justice when I reach Zanzibar; but as I am going back to Kilima-njaro that is not convenient, so I let you go free for once, knowing that sooner or later punishment will overtake you." He changed his tone, and fawned on me, and assured me that the slaves were not his, but Mandara's, and in taking them I should make Mandara my bitter enemy; but I paid no attention, and carried off the slaves to my town. When we had reached this place I questioned them, and found they were people of Maranu captured by Mandara in war, and sold cheap to Mabruki, who was taking them to the coast to sell on his own account, together with a large number of other slaves which he was to dispose of for Mandara. These latter had left Taveita, under the charge of one of Mandara's Swahilis, by early dawn, and Mabruki, who was the 
leader of the caravan, was to have rejoined them by midday. Having learnt this, I ordered the fetters of the slaves to be struck off, and told them they were now free to go whithersoever they willed, but that if they feared to fall again into the hands of their captors they might wait till the morrow, and accompany my caravan to Maranu. This proposal they gladly accepted, and when the fact was fully realized that their liberty was given back to them and that they would soon be restored to their mountain home-for these Čaga people are like the Swiss of old, passionately attached to their native peaks and valleys-they burst into exclamations of delight, calling me "Ndofu"-elephant-and "Great Chief," and "Father," and, what was less agreeable, crawling to my feet after the manner of their people and spitting on me continually, to manifest the esteem in which I was held. Mabruki and Athmani returned to Mandara's, vowing they would come back with a big army to avenge their loss. But I knew it was a vain threat, so I left my little town with but a small garrison, and started for Kilima-njaro with a band of over forty men, some carrying loads and others acting as guards, for we were not too sure that enemies might not rise up somewhere to contest our progress, and I was resolved this time to attain my end by force if necessary.

The country of Maranu was reached after one day's long walk. Its southern frontier was a very remarkable one, and formed a barrier seemingly impossible to cross in the teeth of armed opposition. An impetuous stream flowing between precipitous walls of rock separated Maraniu from the outer wilderness. When we arrived on the brink of this ravine and looked across to the opposite side, transit seemed a feat 
for birds alone; but under the guidance and with the help of the Wa-maranu, who had come to meet us, we managed to cross this strange gulf. We were first of all let down a sheer wall of rock twenty feet in height, clinging to the stout ropes of creepers, and then received in the arms of stalwart natives, who were standing thigh-deep in the rushing water at the base of the cliff. Two men carried me over to the opposite shore, oppressed, not with my weight, but by the force of the current, which threatened to make them lose their footing and wash us ail away. Fortunately on the further side the cliff was not so precipitous, and afforded a few feet of landing. Here I paused to watch the safe descent of my men and goods down the opposite wall of cliff into the water, and, when all were fairly over their difficulties, I began to scale the bank behind me, and was able to reach its summit unaided otherwise than by the friendly branches which the cresting woodland stretched towards me. Then, when the climb was over, I found myself surrounded by silent natives, well armed, but quite friendly, and by their directions I continued my upward journey along a narrow slippery path until I arrived at the gate of the town.

This perhaps is an incorrect phrase. It is rather the gate of the country than of the town. Throughout C̆aga, by which is meant the inhabited district of Kilima-njaro, there is no such thing as a congeries of habitations forming a town or village in our sense of the word. Each family lives apart with its own two or three houses for men, women, and beasts, surrounded by its plantations and gardens, with plenty of room for expansion all round. In another sense, however, each separate state of Čaga may be looked 
upon as a huge straggling city, one vast capital of huts and gardens, equally inhabited and cultivated throughout its extent. This little territory is more or less completely surrounded by natural defences-indeed the girdle of ravines and cliffs has formed the state by giving security to its inhabitants-but there is almost always one easy means of approach which has been left open by Nature, and that is, therefore, strongly fortified by man. Consequently nearly all these tiny Čaga kingdoms have their "door" of entry, which is at all times strongly guarded, and often serves as a pretext for toll. In my case, however, as an honoured guest of the chief, I was not asked for any "gate-money," and the guards on the farther side of the barrier invited me cordially to enter freely. This, in spite of goodwill on their part, was not easy of accomplishment. The opening through which I was experted to pass was a narrow delta-like slit or tunnel about three feet high, three feet broad, and six feet long. Through this I had to wriggle awkwardly, and consequently entered Maranu in the attitude of the Enemy of our race when punished for the fall of man. However, as this entailed no humiliation in the natives' eyes, and as prince and peasant quitted and entered their precincts in the same manner, I took it very good-humouredly, picked myself up, dusted my habiliments and smiled beamingly on all around. The smile was returned with many a broad grin, but as yet no word of greeting passed their lips. They simply sat on their haunches and stared at me. None of them, except two or three who had acted as my guides, had ever seen a white man before, and they wanted to examine the marvel visually before expending their energies in talk. However, I was not 
so taciturn, but addressed a few friendly words in Ki-čaga to the foremost men. A shout of surprise went up, "Amanya mateta haru!" (He knows our language!) they cried, and we were friends at once. I could not help feeling how satisfactory this was. Here there were perhaps 400 savages assembled, all of them armed - in short, most of the fighting-men of the country were present, and about 200 of them provided-strange incongruity !-with Government Sniders. These had recently been obtained from a Swahili trader who had bought rifles from Thomson's men and other discharged expeditions on the coast, and had exchanged them in Maraniu for ivory. Bravely as my forty followers might have fought, we should inevitably have been massacred to a man in these rocky defiles had the natives chosen to revenge on us their old quarrels with Mandara, in which, until recently, I had been thought to bear an active part. Fortunately they had no such evil intentions, and I felt such confidence in the naïve wonder and awe with which I was regarded that I walked about unarmed, and allowed my men to disperse in all directions. I inquired for the Sultan, but I was told that he had gone on a visit to his uncle of Kibôso, and would not return until the next day. His brother, however, a proud-looking, handsome boy, with an ancient Egyptian cast of features and light complexion, was pointed out to me, and I asked him to show me a place wherein we might camp, as night was approaching. He set a soldier to lead the way, and we walked upwards for about half an hour, finally settling on a village-green-a smooth expanse of turf, intersected by a stream of running water. The Sultan's mother, a woman of middle age, came to greet us, and brought 
the welcome present of a large fat goat, which was immediately killed, cut up and distributed among my hungry followers, a nice loin-chop and kidneys being cooked for me.

The next morning the worthy mother of the reigning chief sent me a bowl of delicious fresh milk, and I received also many visits on the part of the local notables, but had to dismiss them while my toilet was being performed, though this brought little privacy, as many shoved their heads under the skirting of the tent and watched me take my bath with intense interest. As soon as I had dressed I set the men to work to cut branches and make a necessary fence round the tent and kitchen-otherwise the crowd of natives would have invaded every corner. Then I went on my walks abroad to see Maranu in the fresh morning air, and pay various visits of ceremony. First, I repaired to the Sultan's mother to thank her heartily for sending gifts of meat and milk. This lady received me in a spacious compound under a kind of open shed, with seats placed all round, and a handsome white ox-hide neatly stretched over the floor within. The Sultan's mother took me by both hands, and looked hard into my eyes. This ordeal I was instructed (solto voce by Kiongwe) to bear without flinching, and on no account to avoid the Sultana's gaze. Consequently I glared at her so fixedly that she was forced to lower her eyes, upon which she turned to her attendants and declared she approved of me thoroughly. Then I was desired to seat myself by her side on the white ox-skin. I did so. A brief and embarrassed silence followed, broken by the queen-mother, who expressed to Kiongwe somewhat hesitatingly that she greatly desired to see the colour of my legs. On 
hearing the request I had first thought to dissuade her by explaining what a tedious process it would be to unlace and take off my long shooting-boots, but, seeing she was seriously disappointed, I consented so far as to pull up my knee-breeches and disclose the upper part of my shin. Loud were the cries from the many lookers-on, and deep the admiration of the Sultan's mother at the sight of flesh so white. "It looks like cloth which has been washed with soap from the coast," she said, and then added, with considerable acumen, "I know why his skin is so pale; he always keeps it covered. We show everything to the sun," which was strictly true, for not only the queen-mother, but most of the ladies of this African court were really as devoid of apparel as could well be, the only attempt at a covering being collars of beads and iron bracelets. After this we went in a long procession to the Sultan's residence, the owner being temporarily absent. Here there was much more constructive art displayed than at Moši. First a solid wall or enceinte of stones; then the divisions of the minor spaces formed by neatextremely neat-hedges of well-trimmed dracœna, and, lastly, stout fences of large planks, constructed to divide and shut off the various compartments of the Sultan's rather al fresco residence. These planks had not been sawn, but simply split first and then planed by gentle chopping with a small axe until the thickness was about equal. The boards were fastened together by holes drilled in the side and stout bands of leather cord passed through and through.

I extracted the following information from the queenmother as to the hereditary laws in this part of Čaga. It is not the eldest son who succeeds his father as the ruling chief, nor the youngest, but usually the 
second or third, because this fortunately placed individual generally, for reasons too complicated to be here explained, acquires the greater portion of his sire's wealth, and is chosen to succeed him by the elders of the nation as one likely to be munificent. Somiriali, the present Sultan of Maranu, is quite a young man, and has fifty wives.

On the third day of my stay in his country the Sultan returned from his expedition, and I went to see him early in the morning. After waiting some minutes in a crowd of soldiers and women, a thin, mean-looking youth at length appeared, and advanced somewhat timidly towards me. He took my hand, and I shook his vigorously. Then there was an awkward pause, and after smiling vaguely at one another, Mauki, one of the Sultan's men, calied to me from the crowd that I had better withdraw and see the Sultan afterwards in his house. Accordingly later on I repaired to the chief's residence, and there saw him sitting in a close, pokey little compartment, his sleeping-chamber, in fidgety expectation of his presents. He looked on restlessly while the tin box was opened, and, as each fresh thing appeared, he asked, "What else? What else?" The musical-box he somewhat appreciated, and turned its handle by jerks. The cloth and beads were hardly looked at, and the coloured pictures which had so delighted the æsthetic Mandara were received with suspicion and distrust, as savouring somewhat of magic. After many words and fine promises, all of which had little effect on the dissipated youth, who was more concerned about the parasites that infested his person than about the advantages to be derived from the white man's friendship, we withdrew and took our leave; but, shortly afterwards, the Sultan 
followed on my footsteps, and appeared in the camp just as I was sitting down to a quiet breakfast. I began to hate him, especially as he entered my tidy tent and sat down in his greasy paint and dirt on my clean bed. Now commenced my difficulties. I wanted, in reality, merely to pass through this man's country and obtain guides for the higher regions, and wished his people to accompany me for the further reason that they would be able to explain to the warlike Wakibôšo, with whom they were allied, the change in my position, and how I had made friends with their chief of Maraniu, who was one of the principal leaders in the coalition against Mandara.

The chief, however, looked on my arrival in his country as an excellent opportunity for extortion; and, moreover, wanted me to live permanently at his court, so that my stream of wealth might flow into his coffers rather than his neighbours'. So it was I had to intrigue a little with the Sultan of Maranu as to my ultimate intention of returning to Taveita, and promise anything so that he should remain in good-humour, and give me guides, and let me go to the snow-peaks. Therefore I was obliged to control my repugnance at his filthy presence, and smile sweetly at his inquisitive pryings into my private boxes. At one time he suddenly seized my loaded revolver, hanging up from the tent-post, and, before I could stop him, fired off every cartridge in it at random, fortunately hitting nobody, but only missing my own person by a fluke. Then he would take my greatcoat and try it on, and indeed endeavoured to walk off with it, until forcibly detained. At length he calmed down, and proceeded to formulate his demands, which he desired me to forward by special messenger to Sir John Kirk, at Zanzibar, 
hinting that I should be held a hostage until the goods arrived. I stipulated that meanwhile he should send me up the mountain. He consented, and then I allowed him to give the wildest scope to his covetous imagination. "See," he said, "I want you to give me this bed" (patting my tidy, clean white couch). "Very well," I replied, "when I come back from the mountain." "And this chair?" "Yes, and the chair, too." "Very well, now take karatassi (paper), and write down all the things I want the Baloza (Sir John Kirk) to send me from the coast." (I got out a sheet of note-paper and a pencil, and affected to write.) "First, I want thirty barrels of powder." "Yes," I answered with sweet compliance, and wrote busily. "Next, 100 bunduki Sna-ider (Snider rifles), and 100 bunduki za fataki (muzzle-loading guns), and 1000 viassi (cartridges), for the bunduki Sna-ider, and a big ' kinanda' (concertina) like the Arabs have, and a little box like this (my desk), and a table and a house of cloth (tent), and thirty loads of big red beads, and thirty loads of fine blue beads, and fifty loads of Merikani, and soruali (trousers-a palpable want), \&c." Here he paused to think of some fresh item, and Kiongwe, enraged at his rapacity, could no longer restrain his feelings, so he said to me, in broken English, "This man plenty devilly." The Sultan pricked up his ears, and asked suspiciously, "Eh, what? Kitu gani devilly?" (What sort of thing is " devilly" ?) "Oh," I replied, with much presence of mind, "a sort of coat like this," pointing to my jacket. "Very well, then," he answered, "write down two devilly." I affected to do so, and then once more besought the Sultan that guides might be given me the next morning. As his greed was now appeased 
by these lavish promises he assented, and to my great relief, wrapped his unpleasant garment round him and left my tent.

Accordingly it was decided that the following day we should commence our second ascent of Kilimanjaro.

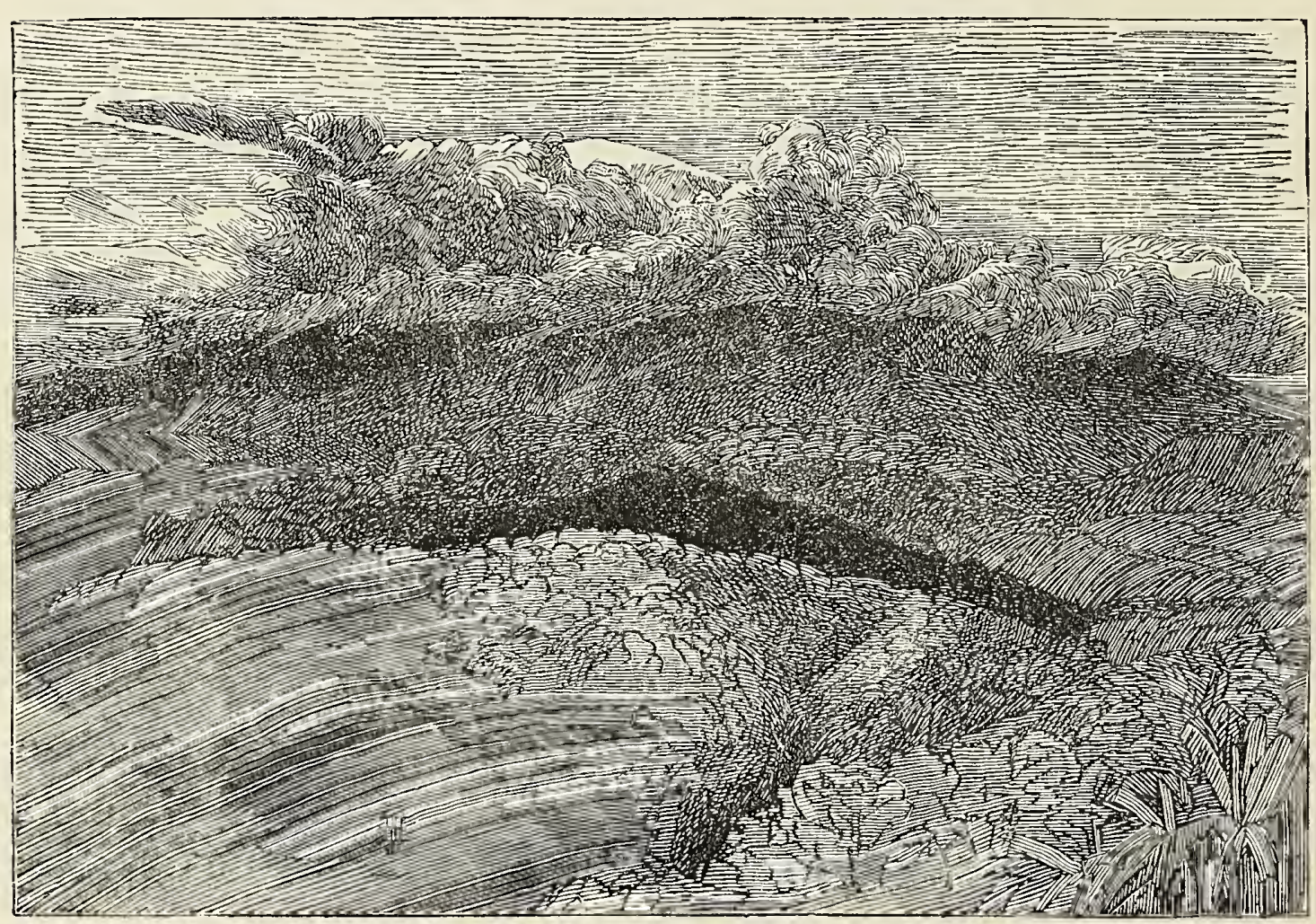

Fig. 54.-Kibô Cloud-capped. 


\section{CHAPTER XIII.}

\section{A SECOND ASCENT.}

After a most disturbed night, owing to the howling of the natives, who were celebrating their chief's return by vigorous dancing, I set to work early to pack and prepare for my second ascent of the mountain. It was very hot that morning, and what with the fatigue and worry of distributing the loads and serving out "posho" (food allowance), I felt quite knocked up. The Sultan made many difficulties about furnishing me with guides, but as I showed resolutely that I intended to go either with or without them, he gave in, and sent me four men, clamorous ravens that they were. These latter shrieked and disputed about the amount of cloth due to them, and at length I abruptly turned two away. About halfpast one we started, and left the precincts of the Sultan's "court" with little regret. After crossing one fine river and walking through a smiling and fertile country, we began to ascend some thousand feet above the level of Maranu, and passed along intricate lanes of dracoena and by banana groves flourishing at a height of about 5500 feet. After a further ascent of a few hundred feet, cultivation came to an end, and we entered a heathy district, with pleasant grassy knolls and many streams of running 
water, finally encamping for the night beside a lovely fern-choked brook at 6500 feet, the whole ascent having proved very gradual.

The following day we quitted our camping-place at about half-past seven, and walked on, with occasional rests, for about two hours, when we found ourselves in dense forest, at an elevation of 7000 feet. Here we stopped and breakfasted. The scenery was pretty much the same as on the Moši road, which was described in Chapter XI. Short, gnarled trees, uplands thickly covered with moss and ferns, and teeming with parasitic begonias, bearing sweet-scented white flowers; many tree-ferns and few signs of animal life, save occasional tracks of elephants or the scattered feathers of a touraco-dark blue with red pinions. At half-past eleven we started again, and journeyed on till nearly three. We had then reached an elevation of 9000 feet, and had passed for some distance through a region clear of forest, and merely covered with open grass. At our campingplace, however, we entered the woodland again, and here, fortunately, found a little stream of water. Indeed, on the road between the mountain and Maranu water was much more abundant than on the Moši track. I caught a small chameleon and soveral beetles in this place. The next day we left this camp at eight o'clock, and journeyed eastward for about two hours, searching for a good site whereon to make my settlement, which must be close to water, and not too high up, so that my shivering followers might not suffer unreasonably from cold. I selected an admirable spot on a grassy knoll rising above the river of Kilema, which takes its source near the east of Kimawenzi. The altitude of this site was nearly 
10,000 feet. It was about four miles in a direct line from Kimawenzi, and about seven from Kibô.

Directly my choice was made, so that no time might be lost, the men set to work at once cutting down the giant ericas (heaths), and using their trunks for building-poles and their dry heather for thatch, while the coarse grass that here covered the ground was reaped, and also employed for roofing the huts and making snug beds on the ground. With such rapidity did the men work that before nightfall on the day of our arrival some fifteen cosy huts had been nearly completed, and a rough kind of kitchen had been made for my behoof. For my own lodging the tent had to serve, as I was not yet confident as to the rain-proof character of the heather huts. That night they were to be roughly tried.

I had taken to my bed early in the afternoon, having severely hurt my knee, falling over sharp rocks in the stream-valley; but I could see through the tent door clouds of fearful portent rolling up over the upper slopes of the hidden mountain. In the early night growls of thunder began to be heard, together with lurid quiverings of lightning, which shimmered through the awful complete darkness. Big drops fell one by one with thuds like pellets on the tightlystretched covering of the tent. Then, suddenly, a bellow of thunder, so deafeningly loud that one's ears were stunned for a moment, burst from the storm right over our heads, seemingly, and echoed from all the ravines and hollows of the mountain side. Flash after flash of lightning revealed the whole scene in momentary brilliancy, and then the few desultory drops of rain changed into a soaking downpour. I called my two personal servants and my cook into the 
tent, which, happily, was water-tight, and they gratefully huddled together on the floor till the tempest ceased.

The next morning, however, by a happy contrast the scene was fair and smiling. The sky was cloudless and serene, the two snow-peaks were in full view, and mild as the heat of the sun was at this elevation, it was nevertheless of some service in drying the soaked garments of the men. All through this day succeeding the storm the men worked unremittingly at their houses, especially thatching their roofs with increased care, and when another downpour took place we observed with pleasure that no wet had penetrated the interior of the dwellings.

When these were completed, the whole settlement was further surrounded by a stout fence or "boma" as a wise precaution against possible assault. The rushing river flowed along one side of our little village, and the only gate of entrance and exit was so constructed that it might easily be blocked and rendered impassable.

My own portion of the settlement was strongly railed off from the rest, and would serve in case of attack as a citadel and last refuge from besiegers. You see we were still doubtful as to the manner in which our old foes of Kibôso would behave, and thought it best to anticipate the worst. We had scarcely finished these preparations before, one morning early, my men came running in to announce the approach of a troop of suspicious-looking savages. It was the Wa-kibôšo, we felt sure, and all made silently ready to defend the settlement if these people intended to fight. Soon their foremost men appeared on the rising slope to the west of the settlement, 
planted their spears in the ground and sat down to parley. Taking Kiongwe and one of the Maraniu guides, I hobbled out (for my wounded knee still pained me) to within ten yards of the Wa-kibôšo. "Do you come as friends or foes?" I asked. "Mbuïa, mbuïa!" (Friends, friends !), they quickly replied, and then came running down the slope to shake hands. After this they informed us that hearing the white man, who had lived in Moši, had now left Mandara and had come to live peacefully high up on Kilimanjaro, the people of Kibôšo were anxious to be friends with him and come to trade, but that, fearing he might still be bitter in heart against them, they had sent their soldiers on in advance to sound the white man's feelings. I hastened to reply cordially to this statement and begged the Kibôšo soldiers to go and tell their fellow-citizens who were waiting in the bush that they might come and trade fearlessly with me and receive good measure for what they sold. The soldiers and I then exchanged presents, after which they went off to call their countrymen on the scene. The trading Wa-kibôšo came by midday, bringing provisions for sale, both good in quality and cheap in price, so that now, all anxiety about provisioning my party was at an end.

I could not but admire the enterprise which these people showed in carrying their wares a distance of some eight or nine miles to trade with one whom but a few days before they had considered a dangerous magician. I soon got on excellent terms with these Wa-kibôšo whom in past days I had looked upon as my bitterest foes, and who had been in turns amazed and mystified by my fireworks and my theodolite. Now that we were friends I had many a pleasant 
chat with them, and offered to visit their country and chief (who is the uncle of the Prince of Maranu), but this last proposal they hesitated to accept. Their Sultan had given them permission to trade with me, and he wished to remain at peace with the white man, but as to seeing him! - "No, he was much too undoubted a sorcerer!" The chief of Kibôso was an old man, and it would be easy to bewitch him. So, on the whole, it would be better for both parties that we should remain apart. I did not insist, as I only cared now to collect in the chilly regions near the snow, and wished for no more native complications after my delays and difficulties in Moši and Marañu. Every day during my stay at this high elevation the Wa-kibôšo came to trade, bringing bleating goats, magnificent clusters of ripening bananas, sweet potatoes, honey, and tobacco ; and, moreover, as soon as they were made aware of my wishes, they captured animals for my collections, and would bring me squeaking, wriggling hyraxes tied securely to forked sticks. Many of these little beasts proved utterly untamable, though I kept several young ones alive until I returned to Taveita, but on reaching the lowlands they sickened and died.

The accident to my knee-cap compelled me to spend several days in enforced idleness, but as soon as I was able to go about I began my rambles up the mountain. My first excursion was to the base of Kimawenzi, the lesser of the two peaks. The terrible hurricane of wind, however, that raged round this jagged series of lava spurs prevented me from continuing the ascent, although I doubt if it be possible for any one to reach the summit, owing to the want of foothold. The snow varies very much in quantity on 
Kimawenzi. Sometimes the whole peak will be covered down to the parent ridge, with only the precipitous rocks peeping blackly through the mantle of white. At other periods the snow will be reduced to an insignificant patch, and the reddish sand which fills the crevices and glissades between the lava rocks

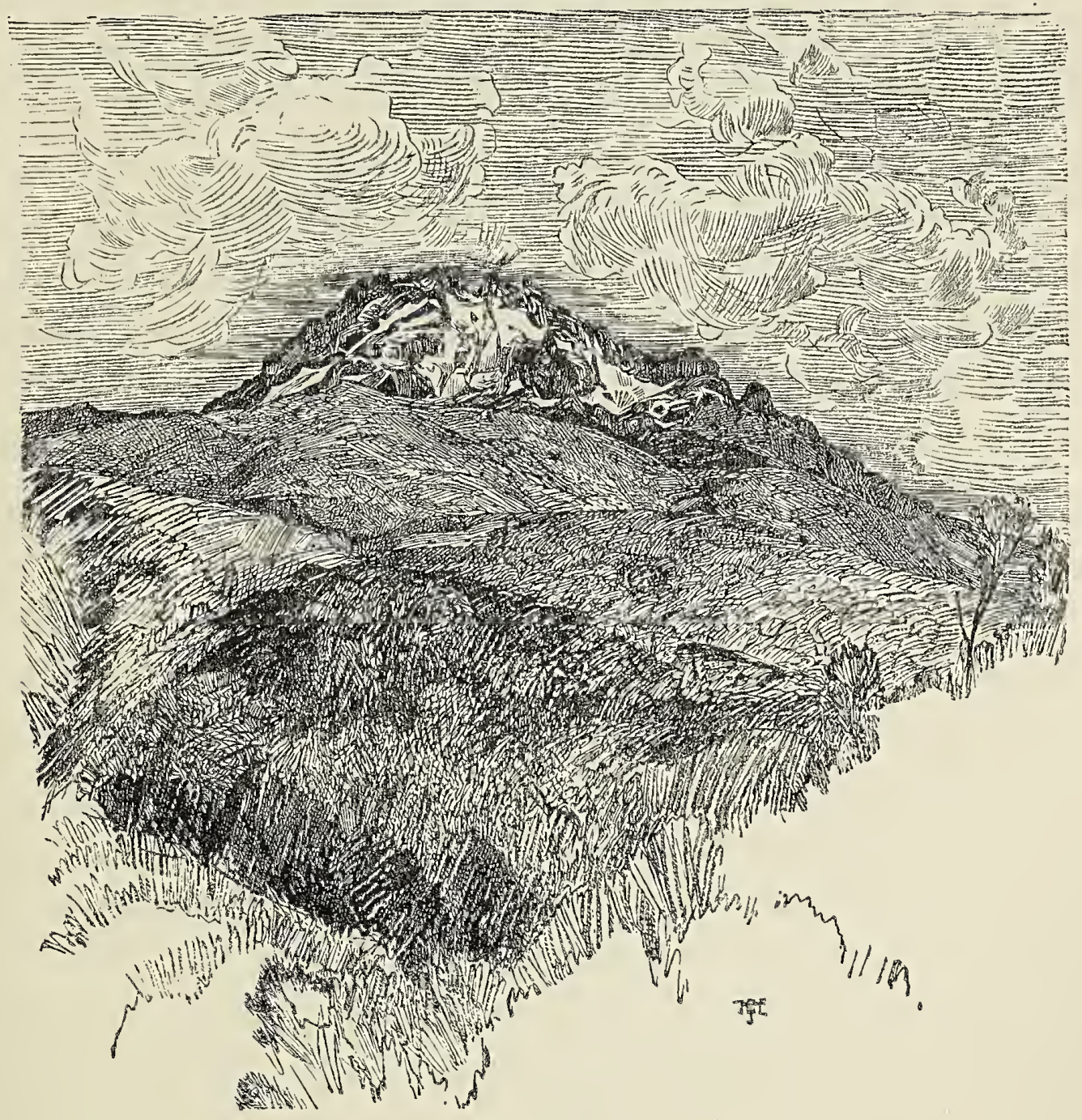

Fig. 55.-Kimawenzi.

will be left exposed to view. This change from an almost complete snow-cap to nearly no snow at all may be effected in twelve hours.

During the whole of our stay in these regions, which included the greater part of October, we were subjected constantly to the most violent thunderstorms, 
and indeed the weather generally was abominable, and its effect on my men most depressing. Although the roofs of their hastily-built huts were fairly watertight, yet the constantly dripping rain made the ground swampy, and the driving mist swept into every opening and rendered everything uncomfortably damp. For hours together we would be enveloped in dense fog, which had such a gloomy appearance that my men often begged me to abandon my intentions of ascending any further, and return to sunny Taveita. But, until I had made a further attempt to reach the snows and possibly the apex of Kibô I could not accede to their wishes. Therefore, I began to make arrangements for a lengthened climb of the huge domed summit which marks the climax of Kilima-njaro. To do this successfully it would be necessary, owing to the time occupied in the ascent, to sleep on the way. Accordingly, I could not go alone, but must induce a few followers to accompany me to carry my necessary impedimenta. My Indian servant, Virapan, of course volunteered; but I had to leave him behind, as he was not only disabled with severe ulcers on the leg's, but I was afraid to quit the settlement without putting some responsible person in charge. So I selected three of my followers who looked agile and strong, and were not more cowardly than the majority-by cowardly I mean afraid of the unknown and the unseen: they were brave enough in the presence of ordinary African dangers-and providing each man with a warm blanket, and loading them with my own coverings, and with food, and implements for collecting and observing, I waited until the morning mists had somewhat cleared, and then, taking an affectionate leave of the rest of my caravan, who looked upon my 
companions and myself as rash men courting death, I turned my face to that quarter of the sky where the heavy concentration of cloud masses indicated the presence of the great Kibô.

Starting at nine, I walked upwards, with few stoppages, until 1.30. At first we crossed grassy, undulating hillocks, the road being fairly easy. Then we entered a heathy tract, scorched and burnt with recent bush fires, but higher up, where the blaze had not reached, the vegetation was fairly abundant and green. Small pink irises ${ }^{1}$ studded the ground in numbers, an occasional gladiolus ${ }^{2}$ of a vivid crimson gleamed brightly out from the tufted grass. About 12,600 feet we struck a pretty little stream, flowing S.S.W., and lower down carving its way through a tremendous ravine, the sides of which were clothed with thick vegetation and gaily lit up with the brilliant red-leaf shoots of the protea (Protea Abyssinica) shrub. At the place where we crossed the stream the banks were shelving, and above the little ford the water fell in pretty cascades through a rift in the higher ridge of rock. About this spot the surrounding scenery had lost much of its accustomed asperity. On the further side of the stream was a patch of level green sward, somewhat spoilt by the buffaloes who came thither to drink and sport, and who had rucked up and befouled much of this little natural lawn. Strange sessile thistles grew here, nearly five feet in circumference, belonging to the genus Carduus, also an extraordinary lobelia (Lobelia Deckeni), three to four feet in height, with a teazle-like crown of silvery green bracts and bright blue blossoms. Other remarkable plants were the lovely Cynoglossum amplifolium,

1 Dierama pendula.

2 Gladiolus Watsonioides. 
with rich ultramarine flowers, and an extraordinary arborescent plant, since named Senecio Johnstoni, looking somewhat like a banana in the distance, but in reality consisting of a tall, black, smooth trunk, twenty to thirty feet in height, and surmounted by a huge crown of broad leaves interspersed or headed up with bunches of yellow blossom. This strange composite

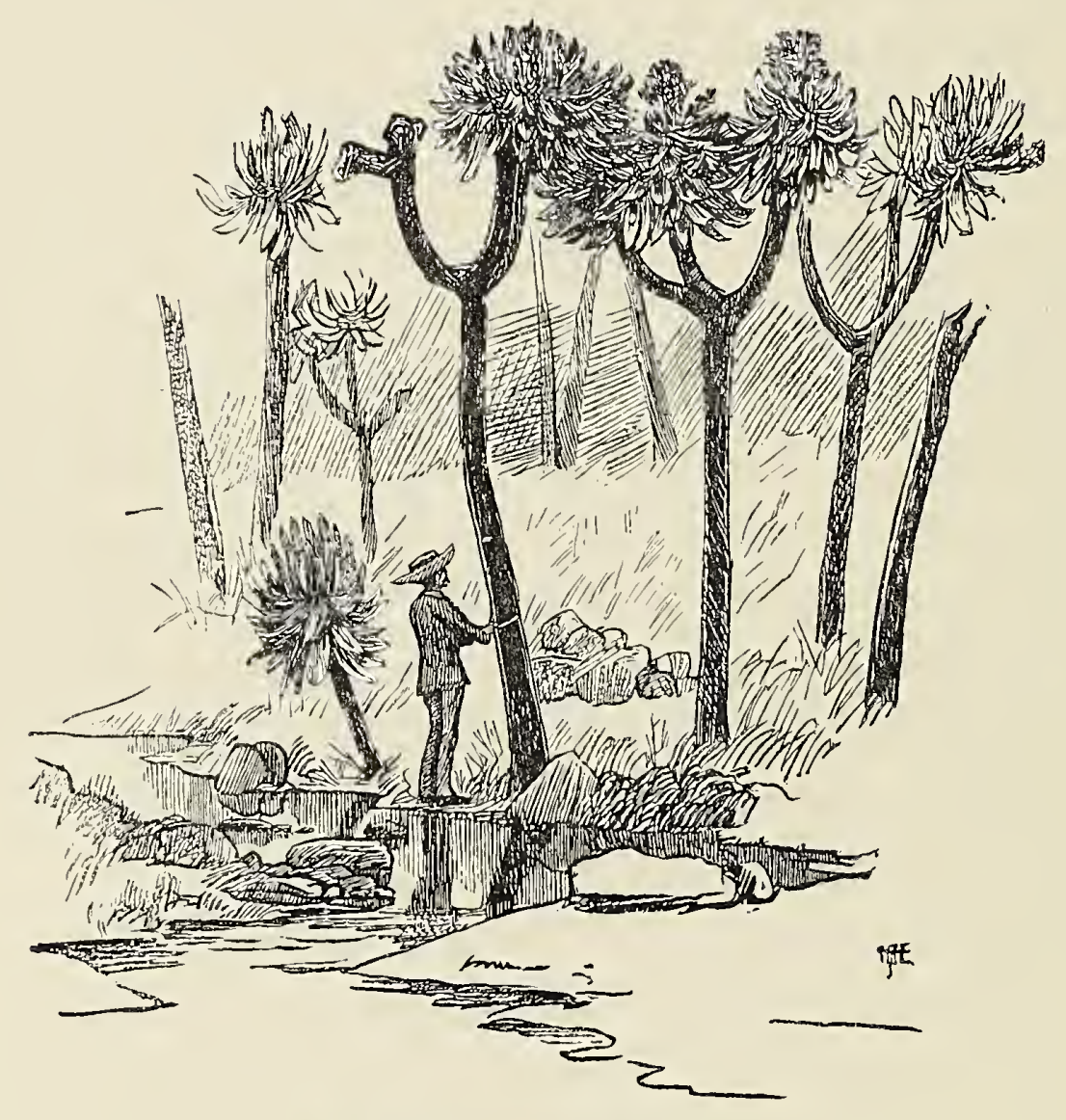

Fig. 56.-Senecio Johnstoni.

grew abundantly in the streamlet's bed, and its trunk was so superficially rooted and so rotten that, in spite of its height and girth, I could pull it down with one hand.

Tufts of chervil and other tall Umbelliferce, with patches of vivid green moss, overhung the water, which itself was lovely in its absolute clearness and in the bright wavelets and streaks of foam which marked 
its hurried descent. At this altitude of nearly 13,000 feet bees and wasps were still to be seen-their very presence, too, seemed to account for the vivid colours of the flora-and bright little sunbirds darted from bush to bush, gleaning their repast of honey. ${ }^{3}$

As we ascended on the further side of the streamvalley we came to some strange boulders or smoothed masses of rock. They had been eaten away underneath into small caverns, large enough for a man to creep into. I went inside several, but detected nothing whatever resembling either past or present animal occupation. The last fern I saw on Kilimanjaro, ${ }^{4}$ as I went upwards, I picked from under a sheltered shelf of one of these caverus. Beyond and about these huge slabs of rock the ground became pappy and boggy with water, in fact some three or four small springs issued from about the rocks, and seemed to have done their work in carving the cavelike hollows within. Putting down my hand to gather a small plant by the roots, I was surprised to find the water warm. At first I fancied it an illusion, and called to one of the men to try, when he also exclaimed at the unexpected warmth. Then getting out my thermometer I found the temperature of the trickling mud-for it was little else in this bog-to be $91^{\circ}$ Fahr.

Mounting high above the rivulet the scenery became much harsher. Vegetation only grew in dwarfed patches as we passed the altitude of 13,000 feet, and the ground was covered with boulders, more or less big, apparently lying in utter confusion, and

3 These were of two new species: Nectarinia Johnstoni and Cinnysis mediocris. Vide Chapter XVIII., "Birds."

* Aspidium aculeatum. 
without any definite direction. These slabs of rock were singularly shaped, and marked like huge tortoise-shells (vide illustration), being divided by lines and seams into a tesselated surface. They were not very difficult to climb over, and even seemed to act as irregular stone steps upwards. In their interstices heaths of the size of large shrubs grew with a certain luxuriance, and bright yellow euryops flowers studded

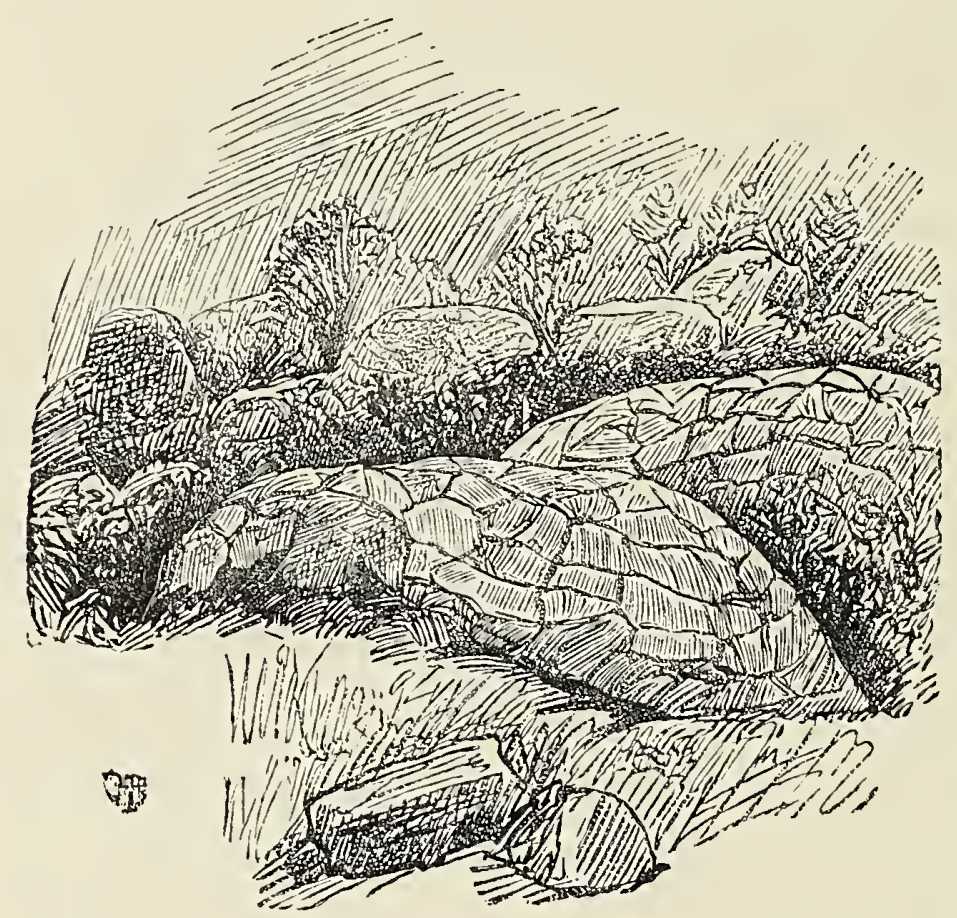

Fig. 57.-Curious Rocks, marked like a Tortoise-shell.

the occasional patches of bare earth, while every now and then my eye alighted with pleasure on lovely clusters of pink everlasting flowers growing, where they did grow, so thickly that they presented a blushing sheet of rosy bloom. About 13,700 feet I saw the last resident bird, a kind of stonechat. ${ }^{5}$ It went in little cheery flocks, and showed such absence of fear that I had to walk away from it before shooting, to avoid shattering my specimen. After this, with the excep-

5 Pinarochroa hypospodia. Vide Chapter XVIII. 
tion of an occasional high-soaring kite or great-billed raven, I saw no other bird.

On reaching a height a little above 14,000 feet, I stopped again to boil the thermometer and refresh myself with a little lunch. The result of my observations gave this altitude as 14,117 feet. Throughout this ascent, which was easy to climb, I suffered absolutely nothing from want of health or mountain-sickness, although my three Zanzibari followers lagged behind, panting and exhausted, and complained much of their lungs and head. Moreover, every gust of

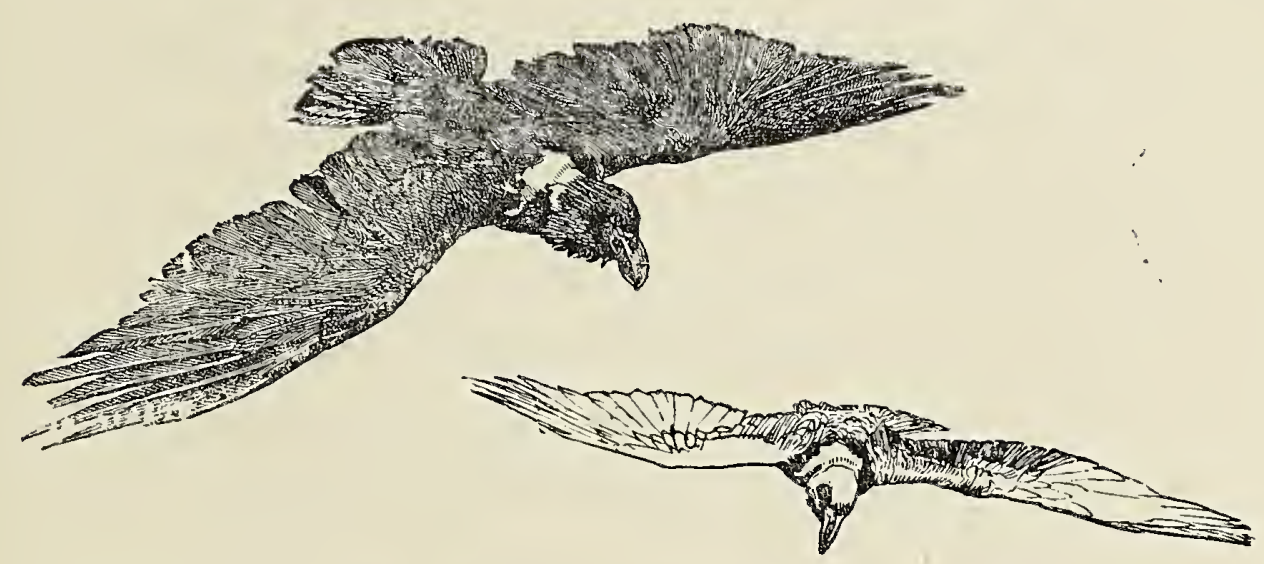

Fig. 58.-Great-billed Ravens.

wind breaking the silence of the mountain made them look round with ashy countenances, convinced that the Bogy of Kilima-njaro was upon them, coming in propria personâ to chastise our presumption. I often dreaded that their panic would overcome them, and that they would turn and flee, carrying with them my collecting things, instruments, and provisions. Moreover, about this time we occasionally heard distant rumblings of thunder echoing among unseen cliffs and valleys; and although these weird sounds might be only referable to that cause, still I confess they did resemble somewhat the rising murmurs of an angry 
spirit-or, at least, they did to my men's imaginations, for I myself, never having heard an angry spirit murmur, was not in a position to discriminate. However, I resolved not to try their powers of endurance much longer, so; on arriving at the place where I stopped to lunch-a protected hollow surrounded by huge flattened boulders-I determined to fix on this as our sleeping-place for the night, and accordingly directed the men to collect the dry roots of the heaths and other fair-sized shrubs as firewood. They were further instructed to proceed to the small stream which rose hard by and fill our gourds there with water, and afterwards to stretch out a macintosh in guise "of a tent, so that we might have some shelter against possible rain and wind. Other directions for rendering our instalment as comfortable as the unfavourable circumstances would permit were also given; and having left the men in seemingly better spirits, I hastened to continue my ascent while the weather would permit.

Climbing up a few hundred feet higher than the last stopping-place, and rounding an unsuspected and deep ravine, I arrived close to the base of a small peak which had been a continual and useful point to aim at during the whole journey from my station. I was now at an elevation of 15,150 feet, and on the central connecting ridge of Kilima-njaro, and could see a little on both sides, though the misty state of the atmosphere prevented my getting any good view of the country. This ridge, which from below looks so simple and straight, is in reality dotted with several small monticules and cut up into many minor ridges, the general direction of which is, on the southern side, from north-east to south-west. To the eastward I 
could see the greater part of Kimawenzi rising grandly with its jagged peaks and smooth glissades of golden sand. Westward I still looked vainly in the piled-up clouds, for the monarch of the chain still remained obstinately hidden, and I was at a loss how to best approach his awful crown of snow. At length, and it was so sudden and so fleeting that I had no time to fully take in the majesty of the snowy dome of Kibô, the clouds parted and I looked on a blaze of snow so blinding white under the brief flicker of sunlight that I could see little detail. Since sunrise that morning I had caught no glimpse of Kibô, and now it was suddenly presented to me with unusual and startling nearness. But before I could get out my sketch-book and sharpen my chalk-pencil the clouds had once more hidden everything, indeed had enclosed me in a kind of London fog, very depressing in character, for the decrease in light was rather alarming to one who felt himself alone and cut off at a point nearly as high as the summit of Mont Blanc. However, knowing now the direction of my goal, I rose from the clammy stones, and clutching up my sketch-book with benumbed hands, began once more to ascend westwards. Seeing but a few yards in front of me, choked with mist, I made but slow progress; nevertheless, I continually mounted along a gently sloping, hummocky ridge where the spaces in between the masses of rock were filled with fine yellowish sand. There were also fragments of stone strewn about, and some of these I put into my knapsack. The slabs of rock were so slippery with the drizzling mist that I very often nearly lost my footing, and I thought with a shudder what a sprained ankle would mean here. However, though reflection told me it would be better to return 
to my followers and recommence the climb to-morrow, I still struggled on with stupid persistency, and at length, after a rather steeper ascent than usual up the now smoother and sharper ridge, I suddenly encountered snow lying at my very feet, and nearly plunged headlong into a great rift filled with snow that here seemed to cut across the ridge and interrupt it. The dense mist cleared a little in a partial manner, and I then saw to my left the black rock sloping gently to an awful gulf of snow so vast and deep that its limits were concealed by fog. Above me a line of snow was just discernible, and altogether the prospect was such a gloomy one with its all-surrounding curtain of sombre cloud and its uninhabited wastes of snow and rock, that my heart sank within me at my loneliness. Nevertheless, I thought "only a little farther and perhaps I may ascend above the clouds and stand gazing down into the crater of Kilima-njaro from its snowy rim." So turning momentarily northwards I rounded the rift of snow, and once more dragged myself, now breathless and panting, and with aching limbs, along the slippery ridge of bare rock which went ever mounting upwards. I continued this for nearly an hour, and then dropped exhausted on the ground, overcome with what I suppose was an ordinary attack of mountain-sickness.

It is not necessary to dilate on my sensations at this moment. Possibly there are some among my readers who have scaled the giant peaks of South America, India, and Armenia, and who would laugh at the puny difficulties that Kilima-njaro presents-a mountain that can be climbed without even the aid of a walking-stick, and where the most serious obstacles arise from mist and cold which would scarcely deter a 
cockney from ascending Snowdon. But the feeling that overcame me when I sat and gasped for breath on the wet and slippery rocks at this great height was one of overwhelming isolation. I felt as if I should never more regain the force to move, and must remain and die amid this horrid solitude of stones and snow. Then I took some brandy-and-water from my flask, and a little courage came back to me. I was miserably cold, the driving mist having wetted me to the skin. Yet the temperature recorded here was above freezingpoint, being $35^{\circ}$ Fahr. I boiled my thermometer, and the agreeable warmth of the spirit-lamp put life into my benumbed hands. The mercury rose to $183 \cdot 8$. This observation when properly computed, and with the correction added for the temperature of the intermediate air, gives a height of 15,315 feet as the highest point I attained on Kilima-njaro. I thus came within a little more than 2000 feet of the summit, which is usually estimated to reach an altitude of 18,800 feet.

Having looked at my watch, I found it was now nearly half-past four, so I resolved to hasten back as quickly as possible to my improvised shelter, for the clouds were thickening, and thin showers of sleety snow were falling. A high wind arose and whipped my face with the icy rain, and made it very difficult to keep my footing on the slippery ridge. At length I reached the boulders and the sand, then descending with greater ease entered once more, at about an altitude of 15,000 feet, the region of regetation. Keeping in view the small hillock I have already mentioned as such a useful landmark, I ultimately found my way back to the spot where I had left the men. What was my agonized surprise to find on 
searching the sheltered hollow, that it was deserted and abandoned! I hesitated but little. Sooner than remain there without blankets, food, or fire, I would endeavour to regain my station, even though $I$ had to wander all night on the lonely flanks of the mountain; so starting off in the waning daylight, I hurried over the now easy descent at a pace that soon quickened into an irregular run. I crossed the stream at the well-remembered ford; and cheered with the sight of old landmarks, and warmed with the violent exercise, I marched straight on in the direction of my little village. The mists dispersed, the moon shone out brightly, I could clearly distinguish familiar hill-tops, and on reaching once more the banks of my own river, I then had an unfailing guide to follow until the glimmering watch-fires of my settlement glanced out from our bushy stockade, and the loud voices of men broke the still and frosty air. As I stepped in through. the palisade, and appeared before my almost terrorstricken men, I saw I was at first taken for my own ghost, but when I had spoken a few sentences in a very real and energetic tone to the three culprits who had deserted me, the other men crowded round me in an ecstasy of joy, kissing my hands, patting me all over to assure themselves that I was back in the flesh, and assuring me that if I had taken them, they would never have left me to perish in the snowy solitudes above-no! not if the Demon of the Mountain had appeared visibly in all his terrors to confront them. It appeared that my three followers had remained for about an hour in the place I had left them, and then seeing I did not return, had been seized with an irresistible panic, had caught up their loads, and had returned helter-skelter to the station. Fortunately 
they had not lost the collections, so after a short rebuke I was disposed to condone their fault; the more so, as I felt so thankful to return to warmth and shelter and familiar faces, that I little cared to pass the night in unprofitable scolding.

'I'he next day I was so worn out with fatigue that I could not go far beyond the settlement, and therefore spent my time chaffering with the men of Uru and Kibôšo, who had arrived to hold another market. On the morrow, I once again made an attempt, this time alone, to reach the snows of Kibô, and just managed to do so, but the weather was again atrocious, and the bitter cold compelled me to return at an early hour, to avoid being benighted far from camp. The rain cleared about five o'clock, and on my homeward tramp I had one magnificent view of the dome of Kibô, thickly and freshly powdered with snow and roseate under the rays of the declining sun. I was struck by the numbers of great-billed ravens which together with one hawk circled and soared high up, near the snows of the mountain. Perhaps some adventurous buffalo had come to grief and they were watching from the heights above his struggles in a native's pitfall. I saw the dung and footprints of these buffaloes up to 14,000 feet, and it is possible that they pass backwards and forwards over the central ridge between the northern and southern slopes of Kilimanjaro. I also saw the footmarks of a large antelope, possibly a koodoo, to judge from the natives' description. I might here remark that in spite of a month's residence in these high altitudes, not to mention previous visits at other times, I never succeeded in seeing a specimen of the buffalo or big antelope who penetrate in their wanderings up to the very snow, 
although of their existence I have not the smallest doubt from the distinctness and freshness of the footmarks so frequently met with, and from the presence

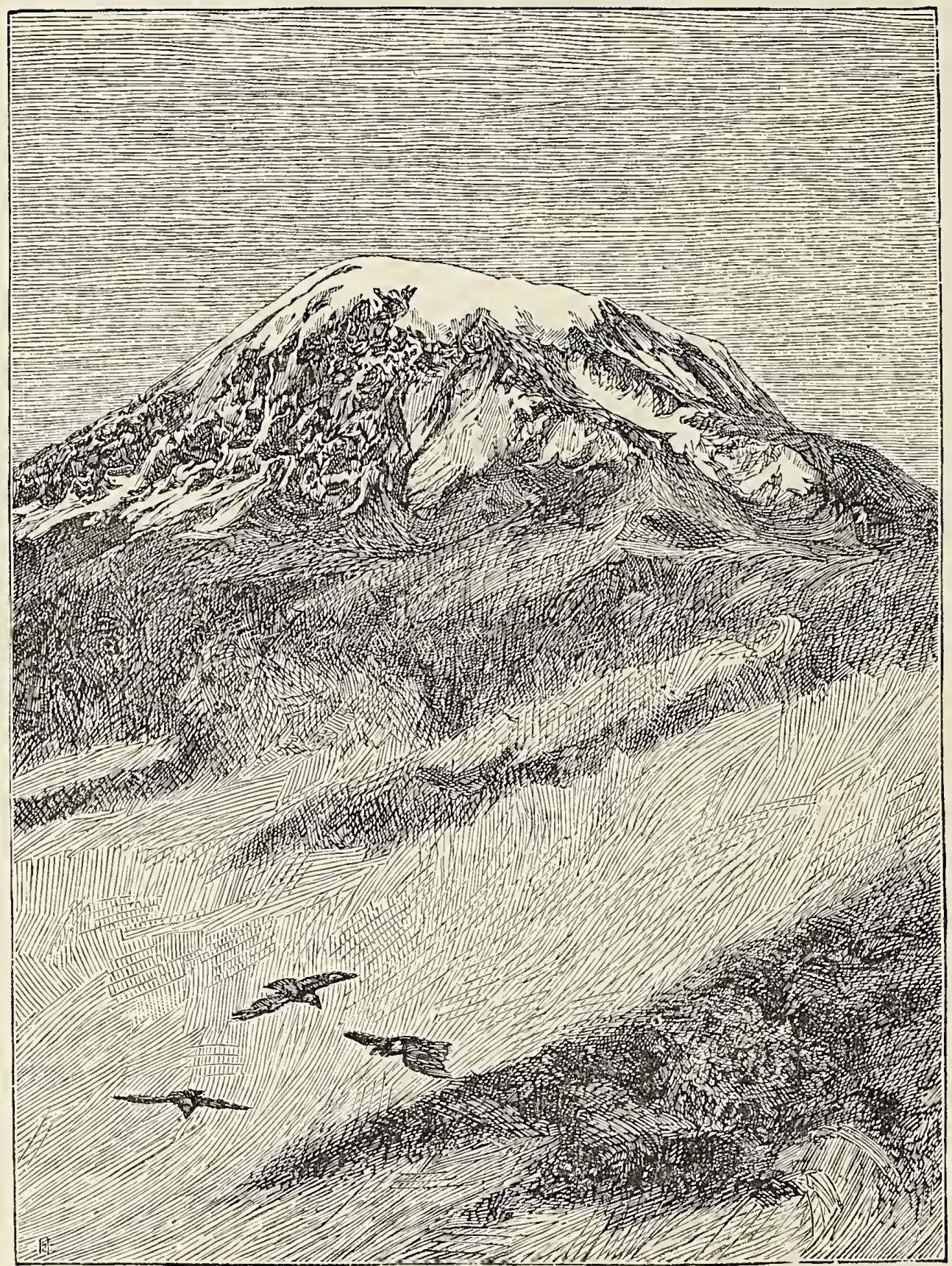

Fig. 59. - The Dome of Kibô from an altitude of 11,000 feet.

of droppings only a few hours old. The natives, also, ascend the mountain to heights of 12,000 and 13,000 feet, solely for the purpose of digging pitfalls to entrap 
these creatures. I have questioned them many times and exhaustively, and they assured me the buffalo and koodoo were identical with those inhabiting the plain below. 'The natives' shields were often made of untanned buffalo-hide, and the horns were turned into powder-flasks. I should further mention here that the elephant, at all times an excellent mountaineer (I have seen him on the Chella mountains in Angola at 8000 feet), wanders up Kilima-njaro to as great a height as the buffalo. I have not only seen his recent traces, but at a height of 13,000 feet I actually saw three of these animals crossing nimbly a stream-valley, and mounting with agility the steep slopes that rose above the water. At night, too, round our settlement we would frequently hear their loud shrill trumpeting. A species of hyrax ${ }^{6}$ inhabits the slopes of Kilima-njaro up to 11,000 feet. It affects always the neighbourhood of trees. During the night, in the forest, these creatures call loudly to one another. The young hyraxes, even in captivity, exhibit great power of modulation in their voices, and their loud cries are almost human in tone.

During the greater part of October I remained in this lofty settlement, and spent nearly every hour of daylight rambling about the mountain with my collecting-portfolio and bird-gun. But in only two of my trips, as already recorded, did I reach the snow. Owing to the length of time involved in a climb to the snow-line (for the slope of the mountain was very gradual) I was never able to accomplish the entire ascent of either peak, going and returning in one day; and as I found it impossible to induce my shivering

6 Hyrax Brucei, an Abyssinian form. Vide Chapter XVIII. "Mammals of Kilima-njaro." 
men to follow me into the mists and hailstorms, and could not unaided carry tent, instruments, and food, I had reluctantly to resign my long-meditated feat, and leave the actual summit of Kilima-njaro still virgin.

Moreover, my time for collecting at these high levels was coming to an end. Although I had soon got inured to the climate myself, and felt invigorated by the frosty nights, my poor followers, accustomed to the greenhouse-atmosphere of Zanzibar, were suffering: cruelly from the cold. To clothe forty men in warm blankets was beyond my resources, and to induce them to live for a long period lightly clad in garments of cotton, in a temperature which was often below the freezing-point, required, to say the least, considerable persuasion; but my chief anxiety arose, not so much from their unwillingness to remain a few weeks longer at an altitude of 10,000 feet, as from their unfitness to do so. Several of the men were suffering severely from bronchial affections; one or two had had touches of pleurisy; of chilblains and rheumatism all complained; so that I began to fear that, unless I moved to lower levels, I should have no men left to carry my loads. 'Therefore, after deliberating with the headmen of the caravan, I prepared to evacuate my highest station on Kilima-njaro at the end of October, and following a new route through unexplored country, return to my settlement at Taveita. 


\section{CHAPTER XIV.}

THROUGH THE FORESTS OF KIMAWENZI AND IHE COUNTRY OF ROMBO.

To have retraced my steps to Maranu, now that my residence near the snow was at an end, would have been simply madness. I had made use of the Sultan as far as he could aid my mission, and now to re-enter his dominions and place myself voluntarily in his power would be nothing less than walking into a trap from which an exit could only be obtained by an enormous ransom. According to Čaga fashion I should simply be kept as a hostage till I had made good my promises and induced Sir John Kirk to satisfy the utmost demand of my greedy captor. Consequently I cared little for the unknown risks of a new road, provided I fell not again into the cul-de-sac from which I had issued safely to ascend the mountain. Moreover, I wished to see something of the eastern flank of Kilima-njaro; so after much consultation of my map and discussion with my head-men I fixed on a track running round the base of Kimawenzi and descending to the plain through Rombo, past the crater-lake, Čala, and along the banks of the Lumi river, which flows through Taveita.

During the whole time of our stay on the upper slopes of Kilima-njaro our native guides from Maraniu 
had remained with us, of course receiving pay for their employment. They always believed that we should return with them to their grasping Sultan, and I kept them in ignorance of my real plans, intending quietly to part company with them where our two roads diverged, and not forewarn them of my determination to avail myself of another route back to Taveita. Together we started, therefore, when all had been made ready; and leaving our alpine settlement with its grassy slopes and forests of arboreal heaths, we took the path running eastwards round the upper slopes of the mountain. Descending a few hundred feet we found ourselves in comparatively dense and luxuriant forest, with a rich undergrowth, contrasting strongly with the bleak, grassy steppes only a trifle higher in altitude. Further on we arrived at the old camping-place of our former upward journey, at a height of 9000 feet. Here we remained to rest and eat our midday meal, gathering up our energies for the rather critical task that lay before us ; for, having resolved on no account to return to Maranu, we must now part company with the men who had hitherto led us, and, relying in future on our own powers of pathfinding, strike out an independent route to the desired goal. As my head-men were somewhat diffident of their own qualities in "fore-louping" (as the Boers call it in the south), I undertook to lead the caravan back to Taveita by compass and map. Accordingly, little heeding the cries and mocking laughter of our guides, we started confidently along a faintlymarked path running eastward. At first all went well, but soon the path died away, and not daring to stop or hesitate, I plunged boldly into the trackless bush. The men followed meekly, but the absence of 
any road rendered their progress very trying. After about an hour of struggling through the rank forest undergrowth, during which I keenly felt my responsibility, we emerged on a little open grassy patch. Here all, uninvited, put down their loads, and very free criticism on our mode of travel was uttered. To add to our disagreeables, incessant rain had been falling since two o'clock. Whilst stopping here to rest and hold a consultation, like a despotic monarch who feels his power threatened and seeks to appease his subjects by granting them a constitution, I invited all the men to take part in our deliberations, and suggest the best course to be followed. At this juncture the native guides arrived, having followed in our footsteps, anxious to see the result of our self-guianance. Wishing to transfer my responsibility to other shoulders, I offered them a present of cloth if they would lead us through the trackless forest to the precincts of Rombo ; whence I knew we could find our way unaided to Taveita. They consented, and once more we entered the dusky woods, following a zigzag course by means of the rough paths which elephants had just made. Often the long-stemmed flowers, and crushed, stained grass would be slowly rising up again erect from the prostrate position into which they had been trampled by the feet of the cumbrous proboscidians, and their smoking dung would bestrew the track, showing how recently these lords of the forest had preceded us. Indeed, from time to time they would make their presence known by sonorous trumpeting, but as they were quite aware of our proximity they took good care to conceal their huge bodies. The undergrowth was so dense that you might have touched an elephant in your gropings before you saw him; but above this 
dense tangle of six or seven feet in height rose the straight smooth trunks of superb trees; indeed, the timber I saw here was exceptionally fine.

The gloom of the forest was intensified by the enormous masses of orchilla-weed which grew thickly on the upper branches of the trees, in such a manner as to suggest a grey-green cloth being thrown over the foliage. The density of the woodland growth was almost appalling; we felt like insects creeping and twining through the interstices of the mighty trunks. As we preferred to go whither the elephants had forced a way, our course was naturally an erratic one, and several times the men lay down in despair to pant and rest, declaring that night would still find us groping in the forest maze-nay, that should the guides maliciously desert us, we might wander for ever in this leafy labyrinth till we either perished at the hands of skulking robbers or fell an easy prey to angry elephants or hungry leopards. In vain I pointed to my compass and said that should the guides fail us, that was an unerring pathfinder; the men shook their heads despondently and said it might be in "Ulaya "$m y$ country--but in the land of the savages_- Ušenzi" -it availed nothing. I must confess the dull green gloom of the forest was very oppressive. The mists of the mountain permeated the foliage and a continual moisture dripped down on us. We were all wetted through every covering. Our clothes were ponderous with absorbed water-it was fatiguing to stagger under their weight. Disagreeable noises-all very easy to account for, but full of vague terror to my superstitious following-broke the stillness of the rank depths of vegetation wherein we stumbled and crept along. The hyraxes uttered their thrilling, half-human, wailing 
cry. Unseen birds sounded their sonorous notes like a tolling bell. Ear-piercing shrieks came from some hunted monkey, pursued, maybe, by a leopard. Elephants sent their discordant nasal trumpeting vibrating harshly through the glades. Each porter, as he clutched his load with one hand and with the other pushed aside the interwoven boughs, turned his head uneasily from side to side, dreading the sudden rising from the bush of some terrible unimagined foe.

Strangers to this tremulous suspense, the Maraniu guides hacked away a bush here, pushed aside a branch there, leapt over fallen tree-trunks, slid down glissades of sodden earth, glided through thorny groves, and paying no heed to our sighs and groans, our pleadings for repose, our cruel stumbles and headlong falls, passed imperturbably through the trackless woods, and cared seemingly little whether we followed them or not. N'evertheless at whatever cost we kept them in sight, and at length to our universal relief quitted this gloomy region of dense, dank forest at about half-past five in the afternoon, and emerged quite suddenly and unexpectedly upon a beautiful parklike country of grassy hillocks, undulating plains, running streams, ferny hollows, and tidy copses. Hereabouts we camped out, and I, ravished with the beauty of the scenery and with the magnificence of the view (for I was still at an altitude of 8500 feet, and could see far and wide round the mountain), set myself to work to create in imagination a fair city of civilization which should rise on these grassy slopes and dominate the cultivable lands below. Here, on these two hillocks, I would build my twin forts, and here should be my terraced vineyards, there cornfields and. gardens, and there a handsome stone house, my pre- 
liminary palace. As I mused thus, the sinking sun emerged from a curtain of cloud, and shed a wonderful rosy radiance over the beautiful scene. The distant valley of the Ruvu, with its sinuous lines of green forest, the mountain mass of Ugweno, with hills and hillocks in all directions, the nearer forests, the natural lawns sloping downwards towards the cultivated zone; and, lastly, the awful, jagged, snowstreaked and spotted Kimawenzi rising to the northall were irradiated with a tender, smiling light, the very shadows of which were attenuated and softened. Then, until purple darkness fell upon the scene, I stood on one of the seven hills of my African Rome, and pondered on the possibilities of its existence.

On the succeeding day we discovered early in the morning that our guides had really and actually deserted us, so we were left entirely to our own resources for finding the way to 'Taveita. However, I was confident, and the men scarcely less so, for no matter how distant our goal might be, we at least could see it in the valley before us. Nevertheless, not wishing to pursue a course which would lead us through Mamba, Mwika, or the inhabited regions on the south-western flank of Kimawenzi, I was obliged to direct myself more to the northward, and consequently out of the shortest route to Taveita. We travelled for hours through a delightful country made by Nature for a European settlement, and singularly English in look, with open grassy spaces, which seemed in the distance like ruddy cornfields, and shady woods and copses full of fine timber. Plenty of running streams of clear water intersected this gently sloping, almost level plateau, which, although such a tempting 
Arcadia, was entirely uninhabited, save by buffaloes and elephants. The average elevation of this country was between 8000 feet and 9000 feet, and the temperature, consequently, almost cool, ranging from fortythree degrees at night to seventy degrees in the midday warmth. After some four hours' walking from our camp, we crossed the long ridge that marks the southern flank of Kimawenzi, and began to descend the eastern slope of the mountain. Soon we emerged on a kind of heathlike country, and then looked forth on a splenaid view stretching from Mwika to the mountains of Bura and Ukambani (the Kiulu range), with Lake J̌ipé on one hand and the River Tzavo on the other. At our feet lay the banana groves of the inhabited belt of Useri and Rombo.

To the latter we directed our descending steps, and soon encountered in the bush some of its stray inhabitants, a savage-looking set, probably posted there to give notice of attack from the dreaded Mandara, who has occasionally visited the country on his slaveraiding expeditions. These men fled precipitately at our approach, and raised a cry of warning to the inhabitants below, the result being that on entering their territory we found them armed to the teeth, and resolved to resist our further approach. After a little parleying-which was conducted under difficulties, for they clearly spoke a very different dialect to the ordinary Ki-čaga tongue-we gave a small present in cloth, and requested to be shown the road to Taveita. They accepted my gift somewhat sullenly, and made no move to guide us through their country. However, holding the men well in hand, I quietly pursued our downward journey, always keeping in view the distant green streaks in the valley below, which 
marked the windings of the River Lumi. Our progress was repeatedly hindered and occasionally stopped by the ever-increasing and turbulent force of savages who pressed upon our flanks, clamouring for a division of our goods. "Ngubo! Ngubo!" was their sole cry, and an archaic one, for "Ngubo" is the oldest known form of a widespread Bantu word for cloth or covering. In Zulu it is "Ngubo" as the Wa-rombo have it, but in most other East African tongues it is " Nguo". and "Nguwo."

I flung them a few yards of red cloth as a present to their sultan. This acted like the articles which are thrown to pursuing wolves from the inmates of a hunted sledge-it served for a moment to delay their oncoming, and $I$ had time to form my somewhat scattered men into line and press resolutely on towards the plain. The natives followed with increased hostility, mistaking our resolute retreat for a cowardly flight. As a matter of fact I did not much fear them in spite of their numbers, as they carried no guns and were but armed with ill-made spears, so that in case of hostilities I could doubtless have slaughtered many; but my anxiety the whole time I lived on Kilima-njaio was to avoid war and bloodshed. Although in a pitched. battle you may easily gain the advantage, yet the news that you have resorted to violent methods to attain your end spreads through a district like wildfire, and everywhere you are received with deep distrust or open enmity. I am of the opinion of $\mathrm{Mr}$. Thomson that it is preferable to suffer many indignities sooner than be the first to shed blood. I also agree with him that it is insanity to travel about Africa unarmed. Never anywhere was that saying truer, "Si vis pacem para bellum." So we held on our way resolutely and 
quietly, paying no heed to the verbal provocations of the Wa-rombo. When at length we emerged on the open country, I turned and saluted them with some very vigorous terms in Ki-čaga, and they for a while dispersed; afterwards for some distance hanging on our heels like hyenas ready to snap up any loiterer or lag-behind.

The country of Rombo, from what I could see of it, is not very attractive in its natural features. Indeed, I was informed afterwards that its unhappy people, harried on all sides by Wa-čaga and Masai, were only allowed to live there because the land was not worth taking possession of. The rainfall, so abundant and constant on other parts of the mountain, is here strangely and partially deficient. The perennial watercourses flowing from the base of Kimawenzi either turn to the south-east or north-east, thus neglecting the due-eastern slope of the mountain, on which Rombo is situated. True, the land is deeply scored and intersected by a few profound ravines, but these are but the beds of occasional torrents which flow only after heavy rains in the uplands. The River Lumi, even, dries up where it nears Rombo, and its flow, apparently, reissues farther on from an underground channel. The aspect of the country is very dismal. Poor little withered plantations of parched cereals or groves of stumpy, dwarfed bananas mark the few attempts at cultivation; and outside these, there is little but stony gorges scattered with thorny vegetation in their dry depths, and stony hills and rolling plateaux sparsely clothed with long, dry, yellow grass. Yet, unprepossessing though this land may be, it is likely to be an important district in the opening up of Kilima-njaro. Not only is it nearest to the approach from the coast, 
but it offers the shortest cut to the magnificent uninhabited regions lying all round the mountain between 6000 feet and 11,000 feet, which present the most favourable conditions for European settlements. In all other parts of the lower slopes of Kilima-njaro you meet with populous and arrogant little states, which at any rate need much subsidizing before they consent to your passage through their territories; whereas in Rombo the population is sparse, and the natives are poor savages unarmed with anything more formidable than ill-made spears, and unable to seriously oppose the march of a small and resolute force. A little kindness would soon win them over, especially if they were protected against the raids of slave-hunters.

All through this somewhat trying day we had never paused in our descent to eat or drink. We were agreed that no halt would be satisfactory till we reached the banks of the River Lumi- "our river," as we affectionately called it-and camped by its running waters. As we slowly wound our way over stony hillocks and grassy downs, followed by the waspish Wa-rombo, our gaze concentrated itself on the distant line of dark green forest which curved across the yellow plain like a narrow ribbon, ending in the great blot of verdure which marked the site of Taveita.

On our way we had an interesting view of Čala, a little lake filling up one of the minor craters on the mountain-side.

About seven in the evening we reached the banks of the Lumi only to find, to our cruel disappointment, it was absolutely devoid of water. In dumb despair we gazed on itis grey boulders and parched sand. Then a little reflection convinced me that we were needlessly despondent. I had, in my previous rambles, 
followed the Lumi to within a few miles of where we had just arrived, and left it still a flowing river; consequently a little further on. water must be found. So again we took up our burthens and limped wearily along the banks of the stream. After an hour's tramp, one of my men gave a cry of delight and pointed to a stagnant pool of green water in the river-bed. All but myself rushed down and drank greedily, but I preferred restraining my thirst till we

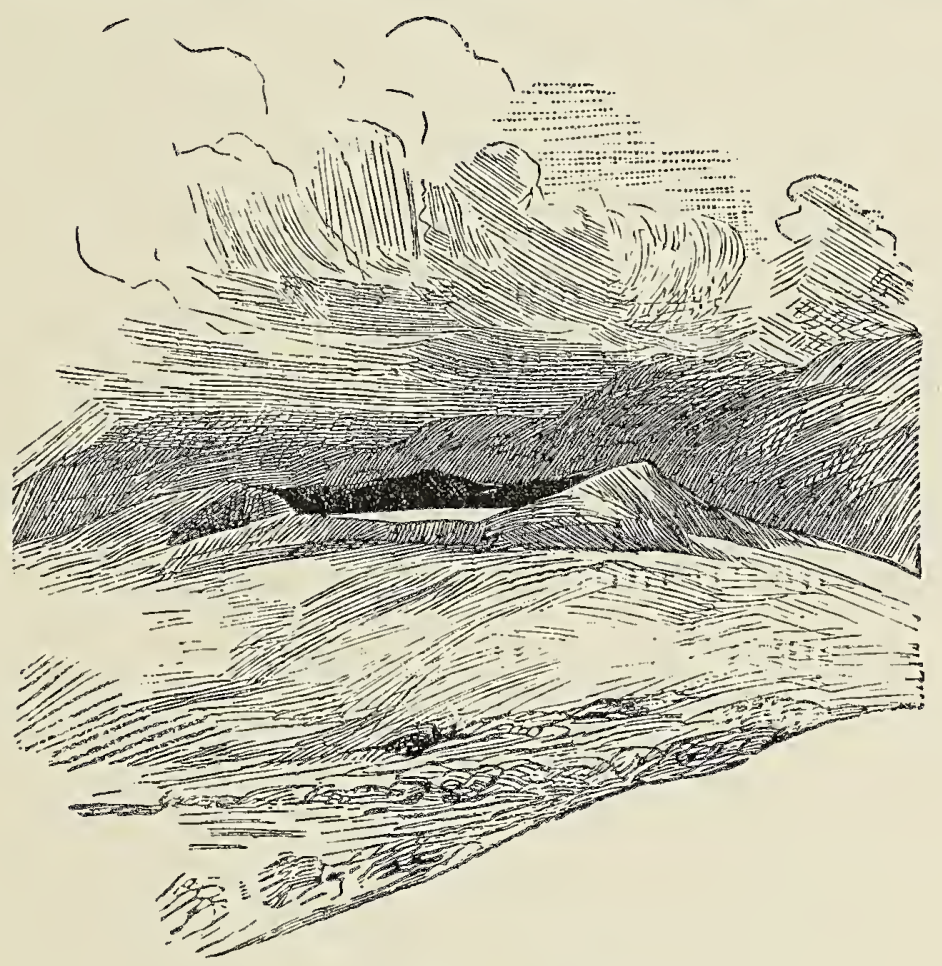

Fig. 60. - Lake Čala.

obtained a purer fluid. Soon the pools in the dry stream-course became more frequent, then a tiny thread of water began to flow, and at length the whole river, as it were, issued ready-made from the earth. Evidently during the dry season the Lumi filters underground for part of its course and is only a visible river after the rains.

Finding another of those charming peninsulas so often described in these experiences - a lovely glade उ 2 
with spreading trees and smooth turf, nearly surrounded by a loop of the stream-we resolved to make our camp here. Fortunately a brilliant moon dispelled the darkness and materially aided our work. The neck of dry land connecting us with the outer plain was carefully cut off with a formidable hedge of thorns, and secure in our isolated camp, we might disregard the prowling Wa-rombo who still skulked without. A guard was set, but no attack disturbed our heavy slumbers. However, the next day we had no sooner started than bands of savages began to form on the rising slopes of the mountain and came running towards us at a half-trot. This time matters looked serious. There were men armed with guns as well as Wa-rombo with spears and shields. The history of it was this (as I afterwards learned). When our guides had deserted us halfway to Rombo they had hastened back to Maraniu to inform their master of my breach of faith. Resolved now to strip me of all my goods and avenge ancient grudges, the young chief despatched an army of a hundred men armed with Sniders to intercept me and crush my little force. They never imagined I could find my way alone, and expected to encounter me still wandering hopelessly in the forests of Kimawenzi. However, on arriving at my former sleeping-place it was ascertained that I had taken the direction of Rombo. To Rombo, therefore, they came, and angrily questioned its inhabitants. These savages informed the Maranu soldiers that $I$ had forced my way through their country that very day and was now camped by the Lumi. At earliest dawn the Maraiu and Rombo hordes came in search of us, hoping to catch the caravan on the march and surprise it when the porters should be scattered singly 
along the track. We were, however, already prepared for a possible attack, and walked forward across the plain in a compact body of forty resolute men. As soon as it was seen that the enemy was gaining on us I sent all the porters carrying burthens to the front, and assembled in their rear those who were well armed and acted as guards. In this order we continued our march. When within a hundred yards the foremost men of Maraniu called on me to stop and parley. I bade the porters who were loaded to walk on slowly along the track whilst I and my guards halted to hear what the enemy had to say. The parleying, however, was but a ruse to gain time. No sooner had I turned towards the foe, to question them, than they started up from their recumbent position and fired a volley at us with their guns. Although the bullets went harm. lessly whistling over our heads, I was enraged at this treachery and saw now it was high time that I taught them a lesson. Too much forbearance would seem to them timidity. So I gave the word and we took careful aim and fired. The savages had already thrown themselves flat to await our return fire; nevertheless two of them were wounded. Then as we advanced for a further discharge, the entire force rose to its feet and fled precipitately, and we naturally did not trouble to pursue. The entire result of this encounter was that one of my men had been slightly wounded by a Rombo lance and (as we afterwards ascertained) one Maranu soldier received a scalp wound and another had his arm broken by a bullet. Then we resumed our march and ultimately reached Taveita without any further incident.

Here I rejoiced to find all well and thriving. Abdallah had purchased five young ostriches, which, $\mathfrak{i}$. 
gether with my Muscovy ducks, pigeons, fowls, goats, and sheep, made up a curious farmyard. A large space had been cleared and sown with crops, and a tall fence surrounded my domain. The day following my arrival I purchased seven more ostriches at an ell of cloth apiece; thus hoping to lay the foundation of an ostrich farm. After three days of rest I set out on a trip which I had meant to extend to the northern side of Kilima-njaro, but owing to the smallness of my band of followers I was not able to succeed, as the Masai were prepared to give trouble, and I had not goods enough to satisfy their demands. I penetrated first to Useri, a Čaga state on the north-eastern slope of Kimawenzi, but the Sultan of that place refused resolutely to see me, alleging that I was a powerful magician (teste those never-to-be-forgotten fireworks!), and would certainly bewitch him if we came in visual contact. Nevertheless, he did not wish to quarrel with me, and gave his subjects permission to trade. I remained here three days, and bought provisions, skins, rhinoceros horns, and two tusks of ivory. Had I had the goods with me for barter I might have traded advantageously in the last commodity, for the Wa-seri not only obtain many tusks from the elephant pitfalls which they make in their country, but also buy it from the Endorobo, ${ }^{1}$ or helot tribes of the Masai, who camp in the vicinity of Useri at certain seasons of the year. I proceeded about four miles further in the direction of Kimangélia, but received the news from a retreating Swahili caravan that the Masai in the vicinity of that place had quarrelled with the traders and refused to allow any caravan to pass

1 From $-d o r o b=$ short, stumpy, inferior. The En-preceding it is the feminine article used in a depreciatory sense. 
them. As I was not strong enough to force my way, I returned once more to Taveita and busied myself with collecting in the vicinity.

I also received a deputation of Maraniu and Rombo people, who came to make peace after our skirmish of the week before. They declared it had arisen through a misapprehension of my intentions. They now feared that having offended me I might bewitch their land from a distance, and wished to exchange presents, because I was a powerful magician, who turned aside the bullets and spears of his enemies. I laughed at all pretensions to supernatural power, but tried to explain that it was always silly to quarrel with white men, who must get the better of any struggle, not because they practised witchcraft, but because they had better guns than black men and knew how to use them. I was glad to hear that no lives were lost, and would willingly make friends. Accordingly I accepted a small bullock they had brought and gave them in return gay cloths and bags of beads with which they retreated joyfully, extolling the power and generosity of the white man, who never made slaves. 


\section{CHAPTER XV.}

LAKE J̆IPÉ AND THE ROAD TO GONJ้A.

The time was now approaching when I should be obliged to leave Taveita and return to the coast.

My six months on Kilima-njaro were coming to an end, and the funds for the expedition also. Unless more money were granted me I should have to discharge my porters, pay their wages, wind up my affairs, and return to England, for living in Central Africa is no more possible without money or money's worth than it is elsewhere. Nevertheless, I could not bear to think I was quitting the country, and felt so hopeful and convinced that help in some shape or form would await me in Zanzibar, and that in a few weeks I should be back in Taveita with renewed zeal for my work, that $\mathbf{I}$ did not like to abandon my comfortable and well-ordered settlement to the wild beasts and white ants, especially as the ground it was built on was my own, purchased from the natives of Taveita. Therefore, after a little deliberation, finding, moreover, that I had many goods and implements of husbandry which I could neither carry to the coast, for want of porters, nor bring myself to throw away; and disliking also to abandon my goats, fowls, ducks, pigeons, and tame ostriches, I finally decided to leave four men in charge of the settlement, who should 

await my return during three months, and if I did not then arrive, pack up as many of the things as they could carry, and accompany one of the Swahili caravans returning to the coast.

These and other preparations made, I took a most reluctant farewell of my pretty town, and also of the affectionate and friendly Wa-taveita, who entreated me to return very soon and dwell amongst them. I then made a short march of four hours to the northern corner of Lake J̌ipé, and camped out there, remaining a few days in the vicinity of this piece of water in order to observe the denizens of its banks. Lake Jipé is in reality a shallow backwater of the Lumi river, which afterwards becomes the Ruvu, and enters the Indian Ocean at Pangani. It is, in short, a tiny edition of the Albert Nyanza, about twelve miles long by three to four broad. On the southern bank the mountains of Ugweno rise grandly to heights of 6000 and 7000 feet, contrasting markedly with the opposite shore, whereon we were encamped, which is a flat plain, but little raised above the lake.

Ugweno is a continuation of the long chain of high mountains which border the northern aspect of the Ruvu valley, starting with Usambara on the coast and continuing through the Pare and Ugweno range to the base of Kilima-njaro. The countries of Ugweno and Usanga (a district lying towards Pare) are rich in iron ore, which is smelted by the Bantu inhabitants -Wa-gweno and Wa-sanga-and sold to the Čaga smiths in the shape of pig-iron. The Wa-gweno seem anciently a division of the Caga tribes, and their language is much the same. The country they live in, being healthy and well supplied with water and very 
sparsely inhabited, is well fitted for European settlements.

The vicinity of Lake Jipé is much frequented by herds of game and its waters are teeming with big fish, principally siluroids and cyprinoids. Hippopotami and crocodiles are plentiful. Numbers of water-birds haunt the reedy shores-storks, egrets, pelicans, spur-winged plovers, ducks, and Egyptian geese. The country round this lake is a first-rate district for sport, but hunters should camp near the River Lumi, for the water of Jipé is disgusting, and only drinkable after it has been well boiled and skimmed. As there is no current through the lake-for the river that flows in, turns round and flows out againand as this stagnant pond lies exposed to the continual rays of an ardent sun, and harbours, moreover, large numbers of hippopotami, who make the lake like their tank at the Zoological Gardens, the water drawn from it is a filthy fluid, warm, green, and slimy. My men drank of it in large quantities, nevertheless, without harm, but for myself I had it boiled and boiled for hours, and the green scum or froth taken off. I was obliged to avail myself of this liquid, as after leaving the lake we should be obliged to travel for thirty-five miles without water.

From the southern borders of J̌ipé we obtained our last view of Kilima-njaro. The craterous shape of the larger peak, Kibô, was very apparent. It was towards the close of a peaceful afternoon, just as I was turning to quit the lake, that I had my farewell glimpse of this king of African mountains. The sky had become a very pale blue with the descending sun. The whole upper part of Kilima-njaro, with its double peaks, was on view. Soft grey clouds slept on the 


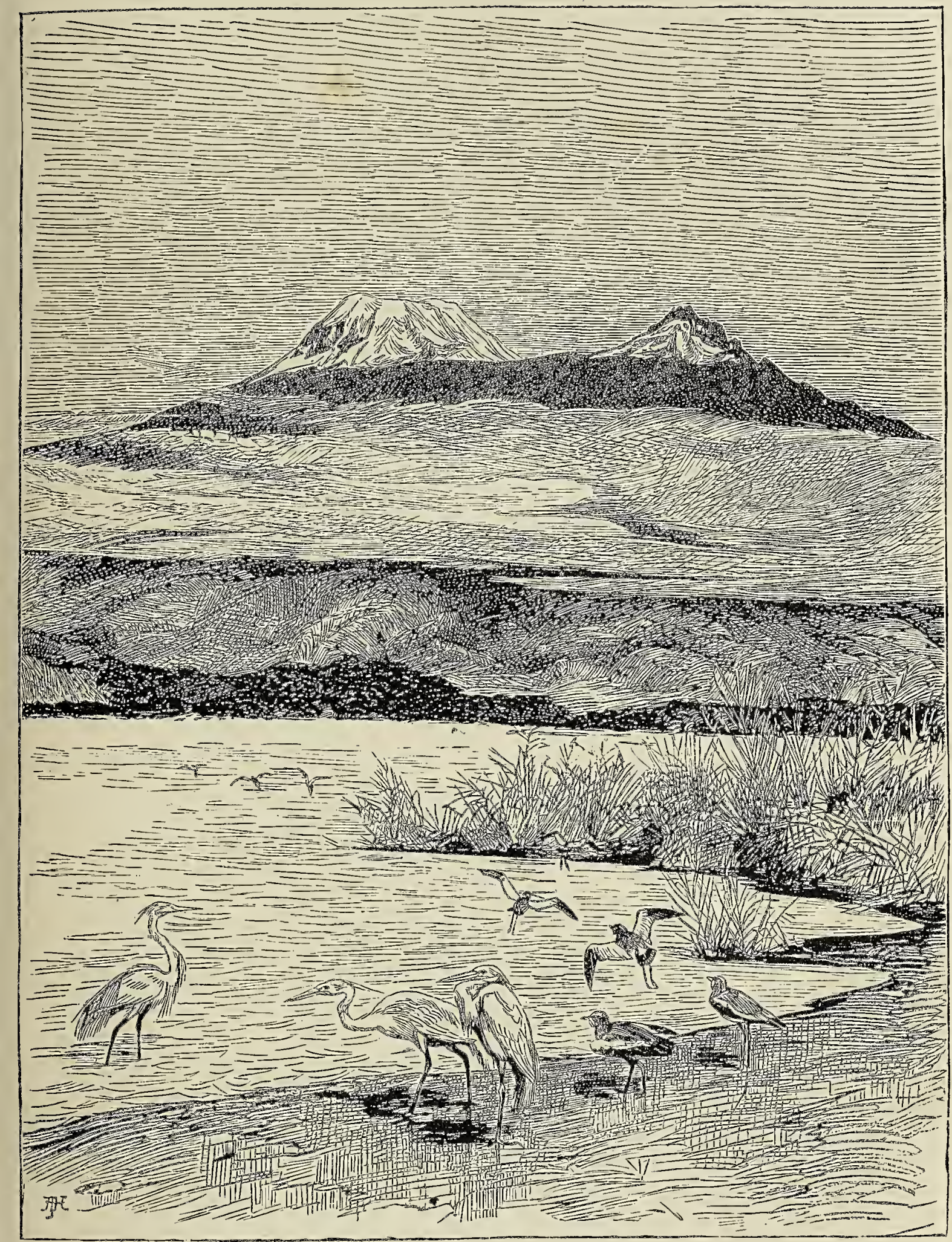

KILIMA-NJARO SEEN FROM LARE JURE

To face page 298. 

middle slopes, and at the base of the vast mountain lay the numberless hills and hillocks of cultivated Caga. Then came the dense forests of the Ruvu and the Lumi, the silver breeze-swept waters of Jipé, a low promontory covered with spear-grass, and in the foreground a muddy, oozy shore dotted with egrets and plovers. Before turning away to commence a long stage in our journey to the coast I hastily sketched in this picture on my sketch-block.

The sudden change from the bracing climate of Kilima-njaro to the heat of the plains had at first affected my health, much as a rapid transition from the temperate regions to the tropics might do, and I had a slight touch of fever at J̌ipé, which laid me up. As this was, however, an unpleasant locality in which to remain, my men proposed to carry me in a hammock until I should have regained my strength. To that I consented, and as the walk before us to the next camping-place was long and waterless, it had been also determined that we should defer our departure from the further extremity of the lake until five o'clock in the afternoon, and take advantage of the brilliant moon to pursue our course in the cool hours of the night. Accordingly an hour before sunset, when I had finished my hasty sketch of Kilimanjaro, I got into my hammock, which was carried by Faraji, the head-cook (an old Congo man) and Hamis Hadi, a stalwart porter of the Yao tribe, and for a short time went over the ground at a swinging pace, all the caravan keeping up with me, for it was fine "going" country. We were directing our course S.S.E. over a plain of great extent, absolutely level, without a rut, and covered with fine turf, like a vast lawn. Here and there a bushy tree broke the mono- 
tony. We saw a troop of young ostriches walking quietly about like well-behaved children, unaccompanied by any parental guardian, while herds of buffaloes and many beautiful antelopes were grazing on the sweet short turf in this brief hour of waning sunlight. Towards nightfall it began to rain, and the rising moon was hidden. I had to leave my hammock and struggle along on foot, wading desperately through slush and water, falling into ant-bear burrows, and weighed down with my heavy, rain-soaked greatcoat, which I wisely wore to avoid a wetting nearer the skin. We could not stop to rest until the rain should cease, for the drenching was best undergone in motion; nevertheless, it was dreary work pounding along up to our ankles in liquid mud, unable to see more than a few yards ahead, and only knowing the path from what was not path by its having become the bed of a torrent. The rain descended in a terrific downpour, which nearly beat us to the earth, but amid all my dreariness I felt thankful at reflecting that my baggage was safely packed in air-tight cases which water could not penetrate. About eight o'clock the worst of the storm seemed over, and though it drizzled a little while longer, the clouds were rapidly dispersing and giving way to the brilliant moon. We sought refuge under a low tree and camped out. The men, although soaked and wearied, behaved very well, and tried to cheer each other with small witticisms. All crowded anxiously round Cephas, our clever second cook, who could make a fire when no one else could, and who now had obtained a little dry wood by breaking in pieces the various dead branches lying about and extracting the dry pith from the centre. With this as a commencement he soon lit a fire, and 
when the joyous flames leapt up from the crackling, spitting wood, exclamations of glad relief burst from every one's lips, and we all extended our cold wet hands to the blaze. Soon my servant, Virapan, brought me a bowl of hot and savoury soup, and after swallowing this I crept into my nice dry bed and slept a delicious dreamless sleep until two in the morning, when Kiongwe aroused me to go on. Then, with many a dismal yawn and sigh, we struggled along towards a dome-shaped hill, principally of limestone, and partially covered with forest. Reaching its base at about daybreak, we then turned southward and walked over a low plateau, which shut out Kilimanjaro and Jipé for ever from our view, while, on the other hand, we looked towards the hills of Ngurun. gani and the fine mountains of Pare. The country on the northern slope and on the summit of the tableland was exceedingly desolate and barren, but on the descent towards the south, and in the basin-like hollow below, the soil was rich, black, and alluvial, and green grass grew luxuriantly, together with some lovely lilies, whose white blossoms starred the prairie in all directions. Here I saw more game at once than I have ever seen in Africa. It was a sportsman's paradise-a delicious dream of happy hunting-grounds hardly to be realized in this life. Hundreds and hundreds of giraffes scudded before us; herds of elands (the bulls a deep dun colour with glossy hides that looked like satin in the noonday sun) sauntered along, now nibbling the sweet grass, now trotting off as we advanced. Myriads of red hartebeests, sable antelopes, mpalas, and zebras studded the undulating plain, while a small group of ostriches might be observed on our left-hand side, and a rhinoceros stood 
under the shade of a mimosa to the right of the path, flicking his short tail from side to side, and watching the movements of our caravan with suspicion. Alas! they had no reason to fear me. Waterless, deadbeat, and sun-stricken, it needed all my resolution painfully to plod along the path, and I was quite incapable of stalking big game when I doubted if I should have sufficient force left to carry me to our camping-place.

About two o'clock we crossed the Ngurungani ridge, and arrived at a stony river-bed, in which a little rainwater still remained. The men drank greedily of it. Here in the middle of the road we saw a sheep freshly killed, skinned, and cut up, all the gory remains being neatly tied up in the skin. Various meanings were assigned to this unwonted apparition; but as I once more took the road and saw the sandy path marked with many footsteps, and with the impressions of oxen's feet, I said to myself, "The Masai!" The men also were of this opinion, but thought they had passed early in the morning. Nearing our camping-place, however, we saw smoke and heard voices, so we cautiously stopped and waited for all the caravan to assemble. Then, united, we pressed boldly on, although the hearts of many quaked at the thought of encountering the most dreaded savages of Eastern Africa. Abdallah walked beside me, and Virapan in front, and I heard the former gabbling prayers to Allah and his Prophet as he shouldered his rifle and marched along. Virapan and I were the first to see the Masai. We arrived at the bed of a broad torrent, now dried up, save for occasional rock-pools, and there, in a large basin-like hollow below the rocks on which we stood, were perhaps a thousand men, some of whom were 
sitting gnawing half-cooked beef round smouldering fires. As we emerged from the bush and our boots clattered on the stones, they looked up, but without exhibiting any surprise or even offering to move. I called out in lusty amiability, "Subai ?" (their form of greeting, to which the proper answer is "Iba!"), but no reply came. The nearest among them motioned us back in a not discourteous manner, and intimated they would come and talk to us anon. We marched into a small enclosure of thorns and stones, overlooking the stony hollow wherein the Masai were seated, and putting down the burthens, got ready our twenty-eight guns for a desperate fight if necessary. Then the Masai came, perhaps forty at once, with a leader. The leader called out to us imperiously, "Tōtŏna!" ("Sit down!"), which we did. Then they conferred among themselves. Some said, "Endara Elajomba!" ("Fight the coast people"). Others said, "No, wait first." Then they again withdrew, and afterwards the captain and a few elder men returned bearing branches in their hands (a sign of peace). They called on two or three of our men to advance and confer with them, so Kiongwe, Ibrahim, and Bakari went. After asking various questions as to who I was, where I came from, and whither I was going, the Masai leader inquired "Had we any sickness?" This query aroused a happy, but sadly unveracious, thought in my mind. "Tell him," I said to Kiongwe, in Swahili, a language the Masai did not understand, "Tell him we have small-pox." Kiongwe grasped the idea, and said to the Masai captain, with well-feigned vexation, "Yes; we have got a man suffering from the white disease" (the Masai name for small-pox). "Show him," the leader replied, at the same time moving several yards 
off. I immediately dragged forward an Albino, who was a porter in my caravan-a wretched pink-andwhite creature, with tow-coloured hair and a mottled skin. The Masai at once exclaimed, "Oh, this is a bad disease-look, it has turned the man white!" Then he shouted out they had no wish to interfere with us, nor would they take anything from our infected goods. One concession alone they asked, and this we readily granted, which was that we would not follow too closely on their footsteps lest they might get our "wind" and catch the disease. And with this they turned round, rejoined their fellows, called up their herd of cows and their donkeys, and slowly wended their way up the hilly path. In half an hour's time the last Masai had disappeared, and, relieved from our anxieties, we rushed to the water and drank.

The camp that these warriors had been occupying offered a most curious aspect. The great baobab-trees, just coming into pale green leaf, were crowded with birds of prey-or rather of carrion-vultures, crows, and marabu storks. Under the sparse shade of this rather leafless forest of grey boughs the Masai had made their camp, near the stones of the dry torrent's bed. They had killed many cattle, and cast the refuse and offal into the low bushes. On this the vultures and storks had glutted themselves to repletion, and now perched heavily and stupidly on the tree-tops. The smoke of the cooking-fires rose still in white columns into the air, and brought to our nostrils acrid odours of burnt fat. Behind all was the blue wall of the Pare hills rising high against the western heavens, which in the approaching sunset had turned to a clear citron yellow.

Strange to say, soon after the last of the Masai had 
disappeared from the scene, all these heavy carrionbirds roused themselves and flapped away to follow the retiring army of bandits. My men informed me that whenever the Masai are on the march they are

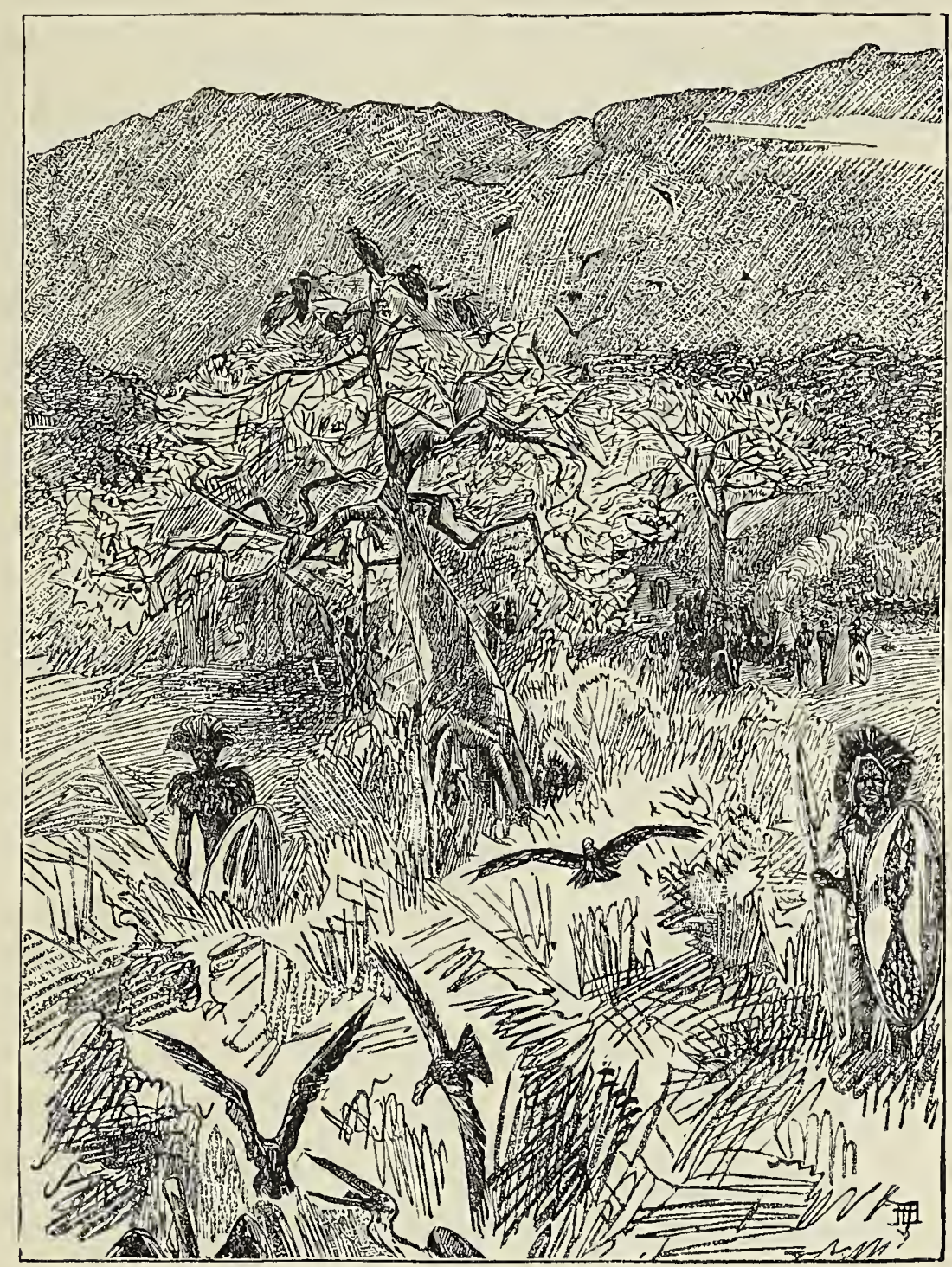

Fig. 62.-Masai Camp.

accompanied from place to place by a flight of vultures, storks, and crows, whom they religiously protect, for the services they render in removing offal from their camps. Whenever in this country you approach a shady spot, and see the branches of the trees loaded with vultures, be sure within that grove a party of Masai are eating roast beef or sucking the blood from 
a slaughtered ox, and if you are unprepared to encounter these gentry take warning and turn away.

The next day three hours' walking over a very heavy black soil-washed down by the rains from the hills -brought us to Kisiwani, a. dry river-bed at the foot of the Pare hills. Here I was so utterly exhausted and faint with the exertions and anxieties of the last few days, following my touch of fever, that I had to spend half the day in complete repose in order to recruit my strength. It was a charming spot in which to do so. Magnificent forest trees towered high into the air; but higher still, and cutting off half the heavens, as it were, rose the noble Pare mountains. A soothing atmosphere of peace pervaded our camp. Hither came no Masai, for they wisely kept aloof from the indignant attacks of the Pare mountaineers, who had more than once given these freebooters a sound thrashing. Nevertheless to honest men like us they were kind and friendly. They brought us gourds full of ice-cold water from their mountain streams, and ripe bananas, and funny little black sheep. Their chief sent me a present and an invitation to come and see him in his mountain home. I would have gladly done so, but I felt no confidence in my walking powers, and I dreaded to bring on another attack of fever by over-exertion. So I sent him several choice gifts and complimentary messages, and said when I next came that way I would remember his kindness to a passing stranger.

The Wa-pare, from what I have seen of them, seem a very amiable people, like the Wa-taveita. I take a great interest in their country, because I regard it as one of the links of healthy land uniting Kilima-njaro - the future sanatorium of Eastern Africa-with the 
coast. Twenty miles beyond Kisiwani we came to the pleasing and fruitful district of Gonja, a settlement of Wa-zeguha, ruled by sons of Semboja, the chief of Usambara, a vassal of the Sayyid of Zanzibar. Here signs of coast influence were quite apparent, and for the first time since leaving Mombasa at the commencement of the expedition, I knew I was not among savages.

Gonja, with its clear, swift river, its splendid groves of forest trees, its luxuriant plantations, reminded us of our favourite Taveita, and we felt a keen sympathy with this place, which was the first inhabited spot we had encountered in seventy miles of wilderness. At the back of Gonja, in the Pare hills, the scenery was enchantingly lovely - wooded crags, rich valleys, emerald-green banana groves, rippling streams, and splendid waterfalls, one of which, another Staubbach, gave rise to the river which encircles the town. We could see its grey-white shoot of descending water in the distance, too far off to show the changing light of motion, and apparently as unvarying and immobile as the blue hill-side, just like a photographed waterfall. On a little peninsula backed by hills, and nearly surrounded by a loop of the river, the rambling village of Gonja is built, the whole congeries of houses being encircled with a tall fence of euphorbias and other prickly shrubs. The dwellings are fashioned much after the style of the native houses on the coaststructures of wattle and clay, generally divided into several apartments.

We found the chief and notables dressed like respectable Arabs, and they greeted us with Arab salutations. I ascertained that not only they but the people they governed were great linguists. They spoke Ki-zeguha, 
Ki-pare, Ki-swahili, a little Arabic, and Masai. The latter language they were quite versed in, and for some hours I sat down with my note-book adding considerably to the information I had already amassed.

The upper classes in Gonja, and especially those connected with the family of the chief Semboja, look like Arabs in their complexion and physiognomy. They have, however, woolly hair. I questioned them as to their origin, but they did not acknowledge Arab intermixture; nevertheless, they are evidently a cross breed, though the intermixture may be and probably is ancient. They are the outpost of-may I call it civilization?-and Mohammedanism in this part of Africa. Here one's life is quite safe ; here no presents are asked for, and here money is taken and understood. How curious is the spread of the influence of a strong government! Since the days that India has been well governed under British rule, her commerce and her currency have begun to extend themselves widely over Eastern Africa, from Somali-land to Natal, and here in the market-place of Gonja, nearly a hundred miles from the coast, you will find the people talking of pice, annas, and rupees, and see the image and superscription of her Majesty the Empress of India circulating freely among the various tribes who come hither to trade. 


\title{
CHAPTER XVI.
}

\author{
GONJA TO LONDON.
}

Leaving this settlement of Gonja we walked through a beautiful and well-forested plain, brimming over with fertility, although little cultivated. We camped at Kihungwe's, another Zegūha chief of Semboja's family, who has made a settlement on the banks of the Mkomazi river, and attracted to his precincts vagabouds and fugitives from all adjacent countries. We were now at the northern entrance of a broad and level plain which stretches between the mountains of Pare and Usambara and slopes very gently to the River Ruvu. It is perhaps forty miles in width, uninhabited save by a few harmless bands of Masai, whose spirit has been broken by repeated defeats received from the Wa-sambara and the Wa-pare, and who are now too meek to demand tribute from passing caravans. I met some of these people on the road, and stopped to chat with them and glean some more notes about their language. We also encountered some of the Wa-mbugu, a curious race of cattle-keepers dwelling at the foot of the Usambara hills.

This plain is covered with thin shrubs and stunted trees, with occasional patches of emerald-green grass. It is the resort of immense quantities of game, which 
here finds cover, sustenance, and water, for the Mkomazi flows through the centre.

We found the recent spoor of elephants, and saw at different times giraffes, elands, gnus, and cobus antelopes. I shot a cow eland, but she managed to get away into the dense bush, and we had not time to follow her trail. Baboons were singularly abundant in the big trees, and as for the guinea-fowls!-I never saw the like in any part of Africa. Altogether this Mkomazi valley teemed with life, and would doubtless prove as fine a hunting-ground as $\dot{N}$ gurungani, or the vicinity of Lake J̌ipé.

As we approached Mazindi, the capital of King Semboja, the forest trees grew loftier and richer in foliage, and the ground began to change from the flat plain to a succession of ridges and low hills. We were, indeed, approaching the verge of Usambara; in fact a kind of " undercliff," lying at the foot of those extraordinary mountains which towered from 4000 to 7000 feet above the plain. In all my varied African experiences, in the Atlas Mountains of Algeria, in the Chella range of Southern Angola, on Kilima-njaro, or elsewhere, I have never seen anything so unique and strangely imposing as the western aspect of Usambara. Imagine giant cliffs of granite and limestone rising nearly like a sheer wall 4000 feet and more from the plain. The ascent looks impossible, and one imagines a descent might only be performed by lowering oneself from the top with several thousand feet of rope. At the back of this giant barrier of granite there lies a lovely land of forests, streams, and mountain meadows, wherein reside-strange as it seems to us who wander in this savage wilderness!-Englishmen, labouring hard to spread all that is best in religion and civilization among 
the docile inhabitants. Scarcely more than forty miles in a direct line from where we are gazing over Usambara, are European houses, churches, schools, dispensaries, and, I daresay, tennis-courts and cricket-grounds.

The thought that civilization was so near us rendered me impatient with the wilderness which, for a wonder, began to lose its potent charm. I hurried along the red track, and gazed so fixedly towards our goal, a distant clump of huts and stone walls, which is called Mazindi, that I bestowed but little observation on the surrounding landscape. Nevertheless I could not but notice the numbers and numbers of handsome hyphœne ${ }^{1}$ palms that lined the way. We walked through a stately grove, which, but for the different species of palm, reminded me of Elche in SouthEastern Spain. My men could not resist stopping to gnaw the gingerbread-like fruit of the hyphœne, and so I got far ahead of them and arrived alone at the gate of Mazindi.

Women were returning from the river with their filled pitchers gracefully poised on the head. Their faces were pleasing, and their complexions a clear olive-I was just going to write "evidently from Arab intermixture," but I hesitate. The subject of the origin of these Usambara people is rather a complicated one, and their lightness of complexion seems to be due to some other cause than a strain of Arab blood. I cited this as the reason why the Wa-zegūha of Gonja were so different to the negro type, but I did so in despair of any other solution, and because I knew that the Wa-zegūha on the coast had for centuries come into contact with the Arabs; but with the Wa-sambara, whom I first met here in Mazindi it

1 Hyphone Thebaïca. 
is different. The Arabs had penetrated very little into the hills and valleys of Usambara, so difficult of entry in the opposition of a sturdy people, and therefore a theoretical cross with them would not satisfactorily account for the yellow skins and fine features of some of the Wa-sambara. Possibly the aboriginal mountaineers, who preceded the Bantu invasion, were allied to the Galla or Masai in race, and have largely transmitted their characteristics to the modern inhabitants.

There are, as it were, two towns of Mazindi: one, built on the steep rise of the undercliff, and simply the residence and court of Semboja, the chief; and the other a regular rambling African village in the plain below, surrounded by banana groves and a dense euphorbia hedge. There are besides many gipsy-like encampments of Masai, and even temporary "towns" of those cattle-keeping rovers, who have, after years of border warfare, made friends with Semboja, and are gradually changing in character from restless thievish nomads to honest settled agriculturists-in short, here you may see Masai in the process of becoming "Wa-kwavi," as the Swahili traders call them. Far too much has been made of this slight distinction. One man has written a vocabulary of "Kwavi," and another of "Masai," and each ignored the fact that they were independently treating one identical tongue. Of course other grammarians and generalizers followed suit like parrots, and so you see the Masai family of languages solemnly divided into two main branches:-

(a) Masai,

(b) Kwavi;

which would be as silly as announcing that the English "languages" offered two distinct groups- 
(a) Cockney,

(b) Provincial.

Though the nomad Masai and the agricultural Masai (Wa-kwavi) differ so much in habits they do not differ at all in language, other than where they may border on Bantu settlements and borrow a few Bantu words. If you ask the "Wa-kwavi" of Mazindi what they are, they will reply at once, "Masai." And if you ask a nomad Masai of the Ruvu, or elsewhere, what he calls his congeners of Mazindi-who, perhaps, a generation ago were fighting in the same clanhe will answer contemptuously, "Em-barawuio," a feminine word of not very pleasant signification. ${ }^{2}$ "Kwavi" is supposed to be a corrupted version of "El-oigob," "the people of the soil." This is a term used in common by Masai and Kwavi, but is more especially affected by the latter, as it implies a settled residence.

Though the Masai of Mazindi and the Mkomazi valley speak their language with purity, whether agriculturists or rovers, yet in race they certainly alike betray a mingling with alien people. In their midst are still residing helot tribes, of undecided relationships, who may represent the remnant of conquered and partially absorbed races, previously owners of the land.

High above Semboja's citadel waves the bloodred Arab-flag of Zanzibar. Semboja is eager to own himself a vassal of Sayyid Barghash. When I went to see him on the morning of my arrival I found myself ushered into an African imitation of the

2 He feels for his honest, plodding relative the same contempt that a Highland rover who was called Gow would evince for his cousin who settled as a merchant in the lowlands and translated his name into Smith. 
Oriental "divan," a low-pitched, thatched building, in the interior of which a low wooden seat bordered three sides of the oblong room, the fourth side being a half-open verandah. Many Swahili and Arab traders and courtiers were seated there, squatting on their haunches, and imperturbably smoking. A few lazy greetings were muttered, but I thought their tone rather insolent, and very coldly replied. At the end of the bench, near the verandah, was a gorgeous silk cushion and a Persian carpet. I was about to seat myself thereon, imagining it was the guest's place, when the Sultan, Semboja, suddenly entered and shouldered me out, taking me by the arm and forcing me down beside him. I was rather hurt at this cavalier proceeding, but soon recovered my good humour when I found no offence was intended. Semboja was a little Arab-like, wizen old man, with a very quizzical expression. Two bright eyes sparkled amid his erow's feet and wrinkles. He had villainous teeth, stumpy, and red with much chewing of betel-nut. His costume was quite Arab in style, and in perfect taste. His well-trimmed, elegant feet were shod in inlaid sandals. On a finger of his right hand was a fine signet ring, which he turned round and round as he spoke. The most elegant Swahili came from his lips, intermingled with Arab terms and phrases, much as, some years ago, English people had the questionable taste to interlard their conversation with scraps of French. Semboja was evidently quite a cultured man-a more civilized Mandara. At the time I visited him he was much concerned about German aggression, rumours of which had just begun to get abroad. He therefore repeatedly announced himself a faithful vassal of Sayyid Barghash. When 
I presented to him the letter of recommendation which the Sultan of Zanzibar had kindly given me at the outset of my journey, he kissed the seal reverentially, and listened attentively while it was read aloud by his scribe. At the conclusion he turned to me and said, "All my possessions are yours. Take what you will. What do you want?" I replied, laughing, "Nothing but your good will, and a little fresh milk." But Kiongwe, who was more practical, said to Semboja, with a deprecatory cough and a grin, "The white man is very fond of the flesh of sheep and oxen." "Good," exclaimed Semboja; " in the things of Europe I am a poor man, but of cattle, sheep, and milk I have plenty, and will not let my guest go lacking." Accordingly, soon after we returned to camp, some soldiers of Semboja arrived with a fine fat bullock, two goats, and a sheep, and the women of his household sent us gourds of both fresh and fermented milk, the latter being most esteemed by Africans. As a return for this hospitality I gave Semboja a 12-bore fowling-piece and 100 cartridges, some coloured pictures which he much desired, a suit of pyjamas, and quantities of gaudy handkerchiefs and clothes for his wives.

Mutually pleased, we parted with many effusive compliments, and, refreshed by my short rest at Mazindi, I pursued my course to the borders of the Ruvu. On reaching this turbulent stream we walked along its banks with little incident as far as a point about fifteen miles from the coast, called the "Mašamba," or "plantations" of Pangani. Here, with a few of my men, I took to a canoe and descended the river to its mouth. After rather a dangerous voyage in this rickety "dug-out," we fortunately reached the 
beach of Pangani without a catastrophe. It was a pitch-dark night when I landed on this unfamiliar shore, and I felt more strange and friendless than I had ever done in the wilderness. Where should I find a decent shelter for the night in this dirty Arab town? As I wandered up into the bazaar I sought in vain for the face of some one to assist me. At length I entered a better street and paused before the stately dwelling of a rich Hindu. I entered the hall and inquired for the master. A portly, yellow-faced man, in richly embroidered garments, came forward. "Can you tell me," I asked him, "where I can obtain houseroom for the night? I have just come from the interior." "I suppose you had better go to the Mission," he said curtly, and turned away. "What Mission?" I inquired of my men. I did not know there was an English Mission in Pangani. I knew the Universities' Mission had stations on other parts of the coast and in Usambara, but I had never heard of one in Pangani. As a matter of fact they really only possessed a house there as a pied à terre used in passing to and fro between Usambara and Zanzibar.

I went back into the dark, dirty street, and clutched the first boy I saw. "Now," I said, "I will give you a rupee if you will lead me to the English Mission." "Orright," he replied delightedly in broken English, "cum 'long!" A few turns and twists in the labyrinth of sordid streets brought us to a more open space, and we were suddenly conducted into the courtyard of a large house. Here our guide pulled a loud, clanging bell, screamed out something in Swahili, and left us. Immediately a pleasant-looking man and woman came out of a side door opening on to the yard, and giving a respectful salutation, invited us 
to ascend a broad ladder which led to a terrace and some upper apartments. The woman carried a lamp, and the man a bunch of keys. Without another word the man opened the door of a spacious, well-lit room, and the woman placed the lamp on the table within. "What shall I get you?" she asked. "Will you have some chai (tea)?" I said gratefully I would, and secretly wondered all the time where were the white occupants of the house. Why were they not made aware of my coming? Presently the woman returned, and began to make the bed. Then she pointed to a large chest, and said, "You must open that; only white men know how." I looked at the box, and saw a word in Greek letters printed on it. It was a letter lock, and I comprehended the woman's meaning. The key-word was printed in Greek, so that the mission servants, I suppose, who could read English, should not understand the mode of opening the lock, and make too free with the contents of the chest, which, on opening, I ascertained to be all the necessaries for the table-cruets, knives, forks, cloths, napkins, glasses, and plates. I opened another box, and found therein well-chosen books, reviews, and newspapers, food for the mind. And yet no host to greet me! Really, this was like some fairy tale, where you enter an enchanted castle whose owner has been turned into a cat, or a monkey, or a marble statue, and find no responsible master to bid you welcome, but yet a mute hospitality on every hand, and all your wants forestalled and provided for.

"Where are the Wa-zungu (white men) who live in this house?" I asked the housekeeper as she brought my supper. "They left in the steamer two days ago." "Did you expect me?" I continued. "No." 
"Then perhaps I am taking someone else's room." "No," she said, "there are other chambers if others come, and all white men who come to Pangani lodge here."

In the best sense of the word the Universities' Mission keeps open house at Pangani. I did not need much pressing to make this residence my headquarters during my short stay in the town.

The proud Hindu whom I had met on first landing cashed my note of hand for a large amount of rupees, and I was thus enabled to pay off my caravan men at Pangani. They nearly all of them received presents on account of their good conduct and fidelity. It was with some display of feeling on both sides that I parted with my Zanzibari servitors, especially with those who had borne all the anxieties and dangers of our stay in Čaga, and we could only console ourselves by supposing that our journeyings and companionship would soon be renewed. Indeed I trusted to be back in Pangani in another fortnight, ready to return to Kilima-njaro.

Hiring a dirty, evil-smelling Arab dau (all were dirty and evil-smelling, so I had little choice, except as to the particular kind of dirt and variety of odour), I set out with a few followers and my luggage for Zanzibar. The vessel was so leaky and old, that I am sure we should have gone to the bottom in the least bit of a gale. Fortunately the sea was like oil, or glass, or a millpond, or whatever simile best produces to your imagination absolute unruffled stillness. Yet this safe extreme of calm had its disadvantages. In vain our Swahili captain whistled, and cried " $\mathrm{N}$ jōò Kazkazi!" (Come, north wind!); not a breeze would fill our drooping sail. The men rowed with long oars, and I 
suppose that had some effect; at any rate, whether it was current, wind, or oars, we must have had some motive-power, because at four o'clock we were off the island of Zanzibar, and by seven in the evening we had reached the town and harbour of that name. I left my servants on board to guard the luggage, and went alone into the lamp-lit streets. I could hardly walk soberly, nor keep my lips from parting in exultant smiles when I thought how I was going to take Sir John Kirk by surprise. Here he was, if he thought about me at all, imagining that I must be still living with Mandara on Kilima-njaro, and yet I was within but a few strides of his house. I pictured my entry-I would hastily explain to the servant, and run upstairs unannounced, and knock at Sir John's door as he was dressing for dinner. What astonishment, what laughing explanations there would be! How we would sit and talk half the night over our coffee and grog in the pretty drawing-room, hung with Oriental porcelain! Thus musing, I reached the Consulate and knocked at the outer door, which I was surprised to see closed. After a long delay, bolts and bars were withdrawn, and a sleepy janitor looked out. "Don't you remember me?" I asked anxiously, "the Bwana mdogo that went to Kilima-njaro?" "Ah, yes," he replied, his face growing friendly with recognition, "to be sure! but," shaking his head sadly, "the Bwana mkubwa (the great master) is not here." "Not here?" I exclaimed, sick with disappointment, "then where is he?" "Gone to Kilwa in the steamer -won't return till steamer does." I turned away sadly, and thought I might just as well have slept the night on board the smelly dau. Then I remembered the Judge of the Consular Court lived hard by. I went 
to him, and he gave me a capital dinner, told me all the news, and alleviated my disappointment. The doctor, ${ }^{3}$ who was dining with him, offered me a bed, and so I was spared the fleaey quarters of a Zanzibar hotel. The next day, whether it was the disappointment of missing Sir John Kirk, or the sudden change to the relaxing climate of Zanzibar, I fell ill with a feverish languor, and lost interest and appetite. I could not even stir myself to read my letters, except so far as to ascertain that there were no fresh funds forthcoming with which to continue the expedition. My collections were already packed, and I had nothing to do but to await the arrival of the homeward-bound steamer. Fortunately, in this despondent condition, Captain Dowding, of H.M.S. Osprey, then stationed at Zanzibar, ran across me and carried me off to his pretty ship. Here, in the soothing cleanliness and comfort of a man-of-war, I recovered my health and spirits, and waited resignedly the steamer's coming. Sir John Kirk just returned in time to welcome me back and see me off, and then, regretfully, I put away Kilima-njaro, Taveita, Kitimbiriu from my memory, and tried to look forward with pleasure to a return to Europe.

Our voyage from Zanzibar to Aden was a slow agony of nearly a fortnight's duration. The monsoon was dead against us, and the ship was-well, not worthy of the company that owned her. The days dragged by like continual repetition of an uneasy dream. It was too rough to write, I had nothing to read, and even the last resource of the weary voyager

3 Dr. Williams, the kindest of hosts and best of good fellows, who is since unhappily dead, to the universal regret of the English colony in Zanzibar. 
-an interest in his meals-failed me. From what. I remember of the bill of fare, tinned salmon and currant buns were the standing dishes at every repast. I was so far fortunate in having fellow-sufferers of an agreeable disposition, and in mutual sympathy we derived the means of alleviating our discomforts and awaited patiently our release at Aden.

After a few days at this unjustly vilified spot, where, perhaps, the kind hospitality of General and Mrs. Blair caused me to view everything too much-not couleur de rose, that would be out of place in Aden, where a hot red tint preponderates-but couleur de verdure, I set out for Suez, and had an exceedingly rapid passage, in the British India S.S. Dacca, of under five days. Owing to the quarantine, however, this advantage was neutralized, as I just missed the overland mail, and had to resign myself to a week in Egypt, which was not unpleasantly spent in looking up old friends and revisiting old haunts.

Then travelling vi $\hat{a}$ Brindisi and Calais, I reached London on the 31st of December, 1884; in spite of all delays, not much more than six weeks after I last saw the snow-peaks of Kilima-njaro from the reedy shores of Lake J̌ipé.

Thus ends the history of my expedition to the snow. mountain of Eastern Equatorial Africa.

A sketch of the results of my researches and observations in Natural History, Anthropology, Languages, \&c., will be given in the following chapters. 


\section{CHAPTER XVII.}

CLIMATE, GEOLOGY, BOTANY, FTC.

ELSEWHERE in this work I have briefly pointed out the main features in the physical geography of the Kilimanjaro region, the dry, almost uninhabited plains, covered with coarse yellow grass and stunted trees, save where perennial streams induce rich vegetation; the misty snow-capped mountains, where the damp climate causes a verdure and a freshness reminding us of the fairest portions of our own island; the majestic forests that clothe certain districts like Taveita, or, not far distant, the broad flats white with natron-salt, the beds of dried-up lakes. With a country offering such very diverse features there are naturally wide ranges of temperature and an infinite variety of climate. Two days' climb on Kilima-njaro will transfer you from equatorial heat to Arctic cold. You may change your surroundings in this short period from the tropical vegetation of Taveita to a lifeless wilderness of ice, rocks, and snow. Midway up the mountain there are lovely regions, mild, equable, and moist, with a climate resembling a Devonshire summer. Here the intense verdure and the luxuriance of fern life testify to the constant showers of gentle rain. A few thousand feet below, in the salt plains, you may be parched and scorched by the hot desert winds, recalling-though 
in a much modified degree-the sirocco or khamsin of Northern Africa. In the forests of Taveita the (to me, not disagreeable) unvarying, moist, greenhouse warmth of the tropical lowlands awaits you. Here, perhaps, the utmost range of the thermometer during the twenty-four hours will be ten or twelve degrees. In the outer plains it may vary from $91^{\circ}$ in the early afternoon to $58^{\circ}$ before dawn.

During the four months (June-September) of my stay in Moši, at an altitude of 5000 feet, the average readings in the shade of the thermometer were as follows: At noon, $71^{\circ}$; at 8 p.m., $60^{\circ}$; at 6 a.m., $58^{\circ}$. The lowest reading at noon was $68^{\circ}$ (August 12th); the highest $80^{\circ}$ (July 3rd and June 12th). The lowest reading at night (from 10 to 12 p.m.) was $54^{\circ}$; the highest 62 . In my more elevated collecting stations, at 10,000 and 11,000 feet, the lowest night temperature (recorded) was $29^{\circ}$; the highest at 3 p.m., $65^{\circ}$. At Taveita the highest registered was $90^{\circ}$ at 3 p.m.; the lowest at 4 a.m., $60^{\circ}$. The highest temperature ever recorded in the plains between Kilima-njaro and the coast was $91^{\circ}$.

From these observations the reader will perceive that, for at least six months of the year, the temperature of this portion of Eastern Africa is quite bearable, if not in some places delightful. Nowhere is there extreme heat, and the nights are always so far cool, that bedclothes are supportable and sleep is refreshing. What it is for the other half of the year I cannot personally say, as I have had no experience, but travellers and missionaries who know the adjacent countries assure me that the temperature is but little higher during the other months when the wet season prevails; it is rather that the climate becomes every- 
where more equable, and the thermometer does not descend so relatively low at night.

The seasons that prevail over this district are also influenced by local surroundings. Close to the coast the rains commence in October, intermit from December to March, and return in all their force during April and May. The true "dry season" is from June till October, during which not a drop of rain falls, though the sky is often clouded. Between the coast country and the elevated plateau about 100 miles inland there is a district which is much stinted in its rainfall, except where unusually high mountains arrest the moisture-laden winds from the Indian Ocean. There we arrive at the most general type of African scenery-wide, rolling savannahs, covered with grass and scattered clumps of trees. These extend, here and there broken by mountain ranges, to the shores of the Victoria Nyanza, and over all this district the rainfall is generally limited to the months of November, December, March, April, and May. On the western shores of the Nyanza Lake rain falls during ten months of the year, a contrast to the regions lying in the same latitudes between the Victoria Nyanza and the Indian Ocean. In all lofty plateaux or high mountain ranges the rainfall is very different to what it is in the plains below. Thus in Kilima-njaro it rains more or less throughout the year. My residence there was during the dry season, yet, nevertheless, in the month of June I had to record six days of rain; in July, 8; in August, 9 ; in September, 7 ; in October, 8; and in the first half of November, 5. The real rainy season is from November to May, but the Wa-čaga inform me that there is seldom at any season a continuous heavy down- 
pour, but rather a greater or less frequency of showers.

In the plains, however, near the mountain, the fall of rain is torrential, and is equal in violence to what one usually meets with in the tropics.

While snow is never absent from either of the twin summits of Kilima-njaro, and, indeed, at all times covers the upper part of the dome of Kibô with a mantle of unvarying white, yet the quantity and downward extent of the snows vary almost daily, even in the dry season. After a rainy night in the lowlands, the snow on the following morning may be seen on Kibô down to a level of 14,000 feet, and even a little lower on the western slope, while the whole of craggy Kimawenzi is a pinnacle of scintillating whiteness, like-to use a very hackneyed simile-a sugarloaf. Yet if the succeeding day be warm and sunny, the snow on Kimawenzi may shrink in twenty-four hours to a tiny patch and a streak in between the jagged walls of black rock, while on Kibô it will withdraw its inroads 1000 feet above the level of the day before. On the whole, the least snow observable is during the months of July and August. In October there is a great deal. I should think the most snow fell, from what I hear by native report, during February and March, but at this time, nevertheless, the natives maintain that an ascent of the mountain is easiest, as the mists are not so frequent. Neither is the cold so great, curiously enough.

Snow is reported occasionally to fall on the summit of Mount Meru, the pyramidal peak lying to the southwest of Kilima-njaro, and on its western slope to lie for some months. The western slopes of Kibô and Kimawenzi are much more snow-covered 
than the eastern, and the snow extends to lower levels.

Doubtless the perpetually melting snow is the cause of the many streams. which issue from the sides and base of Kilima-njaro. Nevertheless, it is curious, considering that the snow-clad peaks slope to all the quarters of the compass, that the streams flowing from the mountain should be principally confined to its southern aspect. From the north of Kilima-njaro not a stream descends, although some thirty miles from its summits, in the plains of N giri, there is an extensive marsh, sometimes, in the rainy season, almost becoming a lake. To the west of the mountain, one stream, the Engare Nairobi (cold water), flows to an unknown bourn, possibly ending in the great salt marsh or swamp of Engaruka. On the eastern versant, start the various rivulets of Useri, Kimangelia, and others which go to form the Tzavo, a river entering the Indian Ocean at Malindi. The River Lumi, flowing through Taveita and into Lake J̌ipé, also rises on the eastern side of Kilima-njaro; but none of these streams, already mentioned, start from the higher levels of the mountain. They either issue at once, or only well forth in full volume at its base. Thus the Lumi is generally represented as rising some distance up the mountain in the country of Rombo. In a measure this is correct, for the dry bed of the stream is there, and this occasionally in the wet season is filled by a torrent, but at most times it does not show a drop of water, and it is only when one has quite descended the mountain and reached a level of 2000 odd feet-the level of the surrounding plain - that the Lumi suddenly issues full-grown from its dry bed. A mile from where it first appears in a series of 
puddles, it is scarcely fordable. On the southern side of Kilima-njaro, however, it is very different. Here two large streams commence to flow close to the snowline, one rising near the base of Kibô, and the other near the base of Kimawenzi. Myriads of other rivulets intersect this hilly region of C̈aga, which between 6000 feet and 3000 feet is well populated and under considerable cultivation. The most perfectly-watered and most fertile country is, strangely enough, without inhabitants, namely, the districts lying to the southeast of Kimawenzi, described in Chapter XIV. All these streams flowing from the south and south-east of Kilima-njaro form the River Ruvu (Luvu of the Wa-taveita, and Ruvu of the Wa-zeguha), which enters the Indian Ocean at Pangani.

The greatest extent of the elevated mass of Kilimanjaro is about sixty miles, from north-west to southeast.

That this huge mountain-mass is nothing but the result of past volcanic activity has been well shown by Mr. Thomson. He conjectures that Kimawenzi was the original outlet of the volcano, but that when, in course of time, its peak had been raised higher and higher by the accumulation of lava-flow and ashes, and the subterranean forces sought another and easier outlet, the mightier crater of Kibô was formed, which ultimately towered above its older rival, and in its turn grew too high for the escape of the imprisoned matter, which found fresh vents in the many minor craters on the mountain-side. Now, though there are still traditions of slight earthquake shocks having occurred within the last two or three generations of inhabitants, there has been no further manifestation of volcanic activity, and the great snow- 
crowned volcano has probably entered a peaceful old age.

NOTE BY PROFESSOR T. G. BONNEY, DR.Sc., LL.D., F.R.S., President of the Geographical Society,

On a Small Collection of Rocks brought from the Higher Regions of Kilima-njaro by Mr. H. H. Johnston.

No. 1.-Subangular fragment of smooth, compact, nearly black rock; appears as if somewhat waterworn; fracture rather conchoidal. A glass-basalt, or possibly one of the more basic anyite-anderite. 14,000 feet. Central ridge of Kilima-njaro.

No. 2.-Subangular fragment, somewhat rounded in outline; appearance like No. 1; colour rather light; and a few small scattered erystals of whitish felspar visible; more probably an augite-anderite. 14,000 feet. Central ridge of Kilima-njaro.

Nos. 3-5.-Flattened fragments, with a rather platy, more or less scoriaceous structure; fragments of a lava flow; probably augiteanderite. 14,000 feet. Central ridge of Kilima-njaro.

No. 6.-A dull, dark-grey roek, with numerous small scattered crystals of either hornblende or augite. I believe the former. Probably a hornblende-anderite; at any rate, it is almost certainly an anderite of some kind, and one of those which are near the basalts. The specimen is a large slab. 14,700 feet. Base of Kimawenzi.

Nos. 7-14.--Fragments of rock and mineral. The rocks, which are rather decomposed, appear to be of volcanic origin, and most contain rather large crystals of the mineral sent with them. This is a rather peculiar form of felspar, the sort probably anderite. 14,000 feet. Base of Kibô.

Nos. 15, 16.-Decomposed, scoriaceous in part, with generally. compact shapes. Dark in colour. Contain rather large crystals of the above-named felspar, which is probably a variety of anderite. 14,000 feet. Central ridge.

No. 17.-A crystal, fairly well-preserved, about $1 \frac{1}{2}$ inch long. Apparently it is a felspar, but the form is certainly an exceptional one. From its form I should suppose it to belong to the monoclinic system, and was bounded by basal clinopinacoidal and prismatic planes; but I do not remember to have seen a sanidine (or indeed any other felspar) crystal of this form, and suspect it will prove to be a plagio-clastic felspar. 14,000 feet. Central ridge.

No. 18.-Rolled pebble of dark scoria, with crystals sometimes 
nearly an inch long and $\frac{1}{8}$ inch thick, of a glassy mineral, probably felspar, perhaps sanidine. 13,000 feet. . Stream-valley on southern slope of Kilima-njaro.

Nos. 19, 20. - Fragments less rounded, of a similar sort, perhaps less scoriaceous. From same place as above.

No. 21.-A similar fragment, but rather more glassy-looking, with a "ropey" structure, and containing smaller crystals. 13,000 feet.

No. 22.--Rounded pebble, dark scoria. 13,000 feet.

Nos. 23-33.-Fragments. Varieties of a dark, more or less vitreous lava, which I think in chemical composition is likely to agree rather with an augite-anderite than a basalt. 13,000 feet. Stream-valley.

No. 34.-A pebble, dark lava, with small grey felspar crystals. 13,000 feet. Stream-valley.

Nos. 35-37.-A dark compact lava, containing elongated felspar crystals as above. 14,000 feet.

Nos. 38, 39.-Rather decomposed. A dark subvitreous lava, with crystals of felspar, similar to those from base of Kibô. 15,000 feet. Rocks from base of Kimawenzi.

No. 40.-Similar to preceding specimens, but rather paler in colour softer, and more decomposed. Same locality.

Nos. 41-43.--Stones from Kimawenzi. Similar to last-named. 14,800 feet.

The flora of Kilima-njaro is naturally interesting, as may be imagined from the extraordinary range of climate between the eternal snows of the summits and the hot tropical plains at the base. The regetation on the coast is fairly rich and luxuriant, and typical of the tropics. There are fine forest trees-acacias, figs, baobabs, bombaxes, calophyllums, and others, while the mango has been introduced from India, and become wild. The pandanus grows in marshy places; cycads are occasionally seen, and among palms the Cocoa-nut, the Borassus, the Hyphone thebaïca (branching palm), several kinds of Raphia, Elais, and wild Date. At the commencement and close of the rainy season the ground is covered with vividlycoloured wild flowers. Blue clitoreas, blue commely- 
nas, crimson, white, yellow, purple, and pink hibiscuses, lovely epiphytic orchids, white, spotted, and green, and ground-orchids of the genus Lissochilus-crimsonmauve and sulphur-yellow. Altogether, as I have often declared, Tropical Africa differs apparently from the other parts of the tropics in displaying splendid shows of bright-coloured flowers which really surpass anything we meet with in the temperate zone.

Inland, however, a short distance from the coast this wealth of vegetation ceases as we cross the somewhat dreary "Nyika," or wilderness, a country poorly provided with water, and uncertain in its rainfall. But as soon as the beneficent influence of the giant mountains makes itself felt in moisture-laden breezes and dew-dropping mists, then Flora revives, and puts forth all her strength. In such places like Taveita the wealth of vegetation and the grandeur of the forest trees is inspiring. You feel carried back from our age of mean development to some past epoch, when vegetable life was on a scale with the strange, huge animal forms which marked the lusty earth's creative prime.

The lower slopes of Kilima-njaro are exquisitely green, and scarcely a patch of earth remains uncovered, but the general aspect of vegetation recalls our English Devonshire and not the tropics. Bushy trees crown the hill-tops, or choke the narrow valleys. The grassy downs are covered with patches of bracken and scented with a low-growing mint. The native lanes are bordered with brambles and magnificent ferns, some of which belong to common European genera. There are besides other things more properly African which do not mind the colder climate of the uplands, such as draconas, aloes, strychnias, balsams, and groundorchids. In some of the stream-valleys the Musa 
Ensete, a wild banana, grows luxuriantly up to about

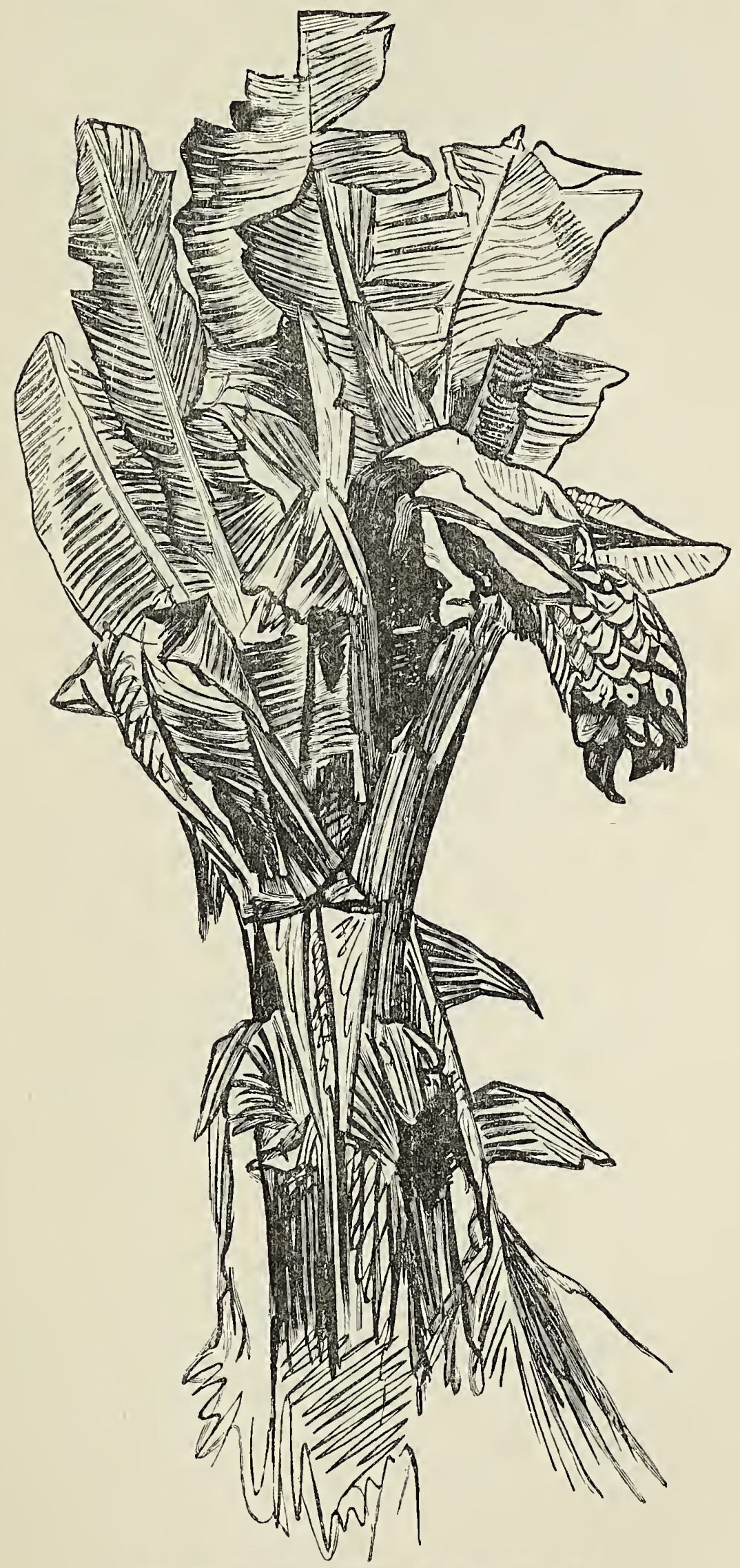

Fig. 63.-Musa Ensete, a wild Banana.

6000 feet and down to 3000 feet, or a little lower if 
there is water. It is also met with in the Taveitan forest at the base of Kilima-njaro. It seems to be in fruit at all seasons of the year, but the bunch here illustrated was cut in September. The colour of the ripe fruit is a pale orange. The length about $3 \frac{1}{2}$ inches. Inside there are varying rows of seeds, from two to five or more, and in each row there may be either two, three, four, five, six, or seven seeds. Each seed is irregularly shaped, about $\frac{1}{2}$ inch in diameter, and very black. The pulp which surrounds and closely adheres to the seeds is orange in colour, when fresh, and somewhat pithy in texture, although very glutinous. The inside of the seeds is a friable white pith, easily rubbed into a white powder by the natives. When in this state it is used for divinations and augury. Blown from the palm of the hand into the air, its capricious wafting by the breeze is supposed to indicate the direction of an expected attack during war, or the most favourable quarter in which to travel for commerce. The thin pulp of this fruit is just eatable; faintly sweet, but leaving a somewhat acrid taste in the mouth like an unripe banana of the cultivated species. Its structure is somewhat curious, for it is composed of long veins at wide intervals, and in between are thin delicate lines running at right angles. It is supposed by the natives that children grow up fine and tall if they eat the pulp of Musa Ensete. ${ }^{1}$ The natives recognize its relationship to the cultivated banana.

At a height of 7000 to 8000 feet tree-ferns may be met with, belonging to the species Lonchitis pubescens (illustrated on p.231). Then above that the arborescent heaths begin to appear, and the orchilla lichen covers nearly all the forest with a grey-green veil. Between

' This belief also prevails in the Nyassa region. 
8000 and 9000 feet the giant Senecios are met with (a new species, illustrated in Chapter XIII.), and continue upwards till near the borders of the snow. Gorgeous crimson gladioli, pale pink and mauve and cerulean blue irises, grow to great altitudes; indeed, some of the flowers of the grassy uplands between

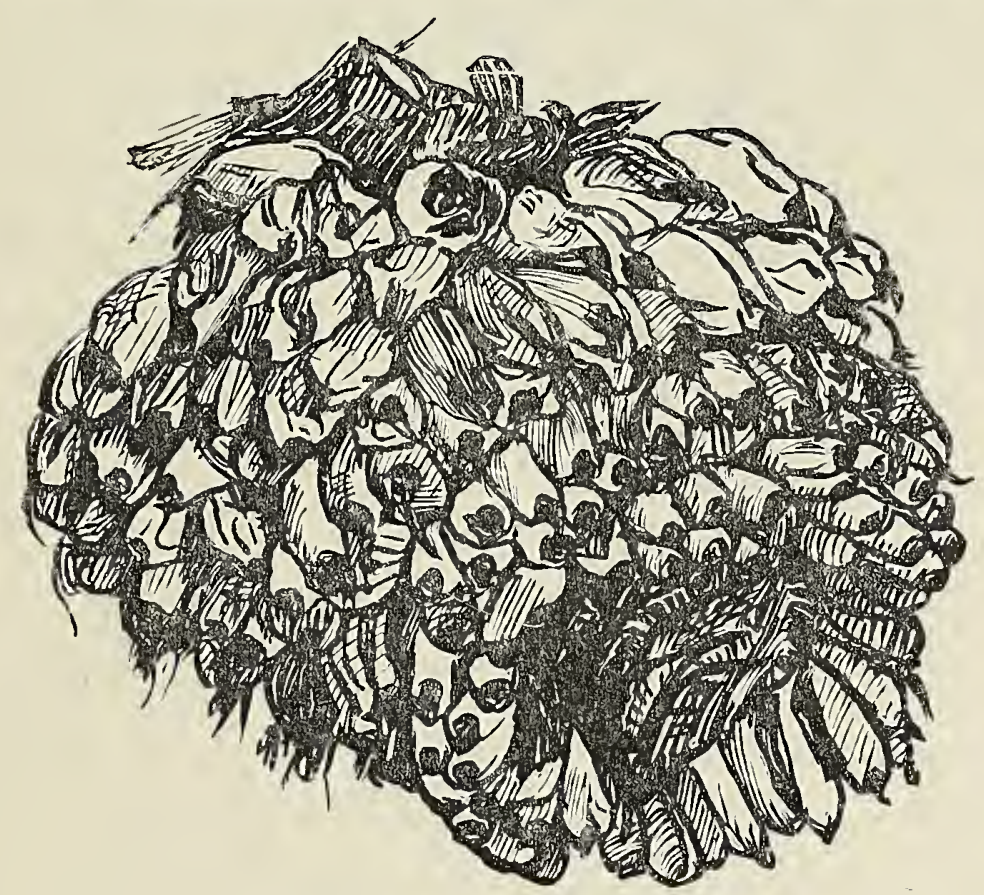

Bunch of Fruit of $M$. Ensete.

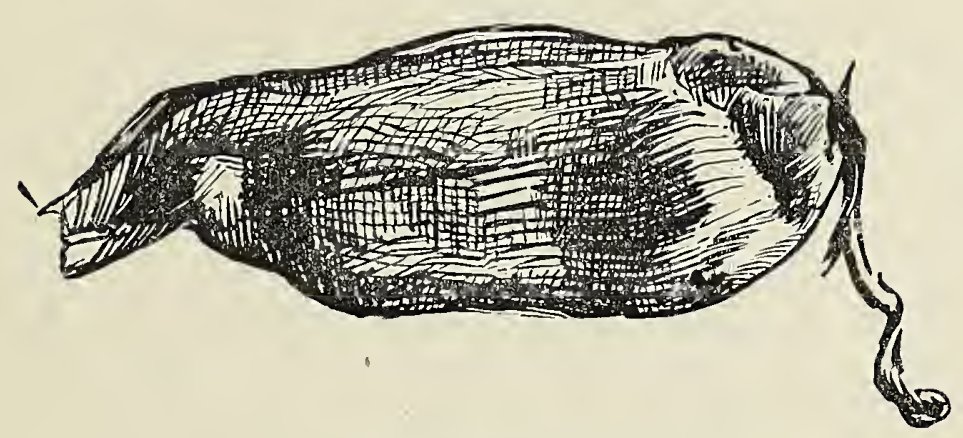

Fig. 64 .

Single Fruit. Half natural size.

10,000 and 14,000 feet, are particularly brilliant in colour. There are vivid blue cynoglossums, the blushpink everlastings, the yellow euryops, the strange straw-coloured proteas, with red bracts and red-leaf shoots, the smalt-coloured lobelias (L. Deckeni), and many others which it would be tedious to catalogue. 
Ferns cease to be found at a greater altitude than 13,000 odd feet. The giant heaths above that altitude give place to smaller species, the vegetation generally becomes more and more stunted, and therefore the strange Senecios look the stranger from their towering in solitary grandeur above the lowly herbs. But after an altitude of 14,000 feet is passed they are also absent from the scene; then one is left with a few artemisias (southernwood), heaths, and everlasting flowers, until at length they too disappear, and there remain little red and greenish lichens, expanses of yellow sand, leadcoloured rocks, black boulders, and snow.

Taking into consideration the fact that the region of Kilima-njaro is volcanic, and therefore probably geologically modern, it must be evident that the main features of its vegetation are of no great antiquity. It is therefore an interesting problem as to which of the two floras-the South African or the Abyssinian -was the first to reach the chilly regions round its snow-clad peaks. It is also as yet an undecided question as to which flora is the advancing one; whether the Cape forms are slowly penetrating northward, some of them reaching Abyssinia, some of them arrested on the heights of Kilima-njaro, and marking a return flow of the vegetation (and possibly of the fauna also) of Southern Africa, or whether the great invasion of Northern forms which have so largely contributed in later epochs to the modern fauna and flora of Tropical Africa is still going on. Whilst Cape genera and species of plants penetrate to Abyssinia, Abyssinian forms have reached the Zambesi highlands and the Drakensberg Mountains.

The flora of the higher regions of Kilima-njaro is almost equally divided in its affinities between Abyssinia 
and Cape Colony. There are besides, in the collections I have brought back, two new genera offering no near allies; types of other genera only known hitherto in Arabia or India; and some new species of East African genera that have apparently modified themselves for life at high altitudes. It is interesting to note that while some of the species whose generic home is in the hot tropical plains have strayed up the great mountain and got used to the cold, so others, which come from temperate regions, have ventured down the mountain and got used to the heat. A curious instance of this is Artemisia afra, which I have found at 14,000 feet near the snow, and at 3000 feet, in close proximity to the hot plains. If plants of temperate or cold climates could occasionally stray so far as this from the regions and the temperature they most affect, it would materially aid in their distribution, for the seeds of the Artemisia (this plant will be familiar to my non-scientific readers as "southernwood," or "old man") might easily be borne from the jungle at the base of Kilima-njaro to the precincts of Mount Meru, some thirty miles distant, and find on the chilly slopes of that mountain another congenial home and starting-place for a further colonization of unknown peaks beyond. Thus, taking into consideration the fact that more or less high ground connects the mountains of the Kilima-njaro district with the Cape Colony in the south and the Cameroons in the west, it is possible to account for the presence of many hardy genera belonging to temperate zones on the heights of Tropical Africa without always invoking special climatic changes and revolutions in the past.

To the ordinary mind even of an unreflecting tra- 
veller there is something very wonderful and imposing in the aspect presented by such a region as Kilimanjaro. The summits clothed with virgin snow, the upper regions bearing the humble plants of temperate climes, the heaths, the hounds'-tongues (to call them by their familiar names), the forget-me-nots, the buttercups, clematises, anemones, violets, and geraniums; the bracken, polypodies, and male fern that are always associated with the flora of our chilly lands; and then, descending. through rich forests of tree-ferns, dracœnas, and moss-hung mimosas to the vegetable wealth of the equatorial zone, to the wild bananas, the palms, the orchids, the india-rubber creepers, the aloes, and the baobabs that are among the better-known of the myriad forms of vegetation clothing the lower spurs and ramparts of Kilimanjaro.

Zone above zone

The climates of Earth are displayed as an index, Giving the scope of the Book of Creation, There in the gorges that widen, descending, From cloud and from cloud into summer eternal, Gather the threads of the ice-gendered fountains, Gather to riotous torrents of crystal, And, giving each shelvy recess where they dally The blooms of the north and its ever-green turfage, Leap to the land of the lion and lotus! 


\section{APPENDIX.}

ENUMERATION OF THE PLANTS COLLECTED BY MR. H. H. JOHNSTON ON THE KILIMA-NJARO EXPEDITION, 1884 .

(By Professor Oliver, F.R.S., and Mr. J. G. Baker, of the Royal Gardens, Kew.)

WiтH three exceptions the new species here described belong to genera already known from Tropical Africa. These exceptions are Hormolntus Johnstoni, Oliv. (Leguminosæ), and Astephania africana, Oliv. (Compositæ), both monotypic genera here first described, and Anisotes parvifolius, Oliv. (Acanthaceæ), belonging to a genus known previously only from Arabia and Socotra.

The genus Valeriana is here recorded for the first time from Tropical Africa, I believe; but the single specimen brought home I have not ventured to describe. A species of the genus occurs at the Cape. A single specimen also of an Anthoxanthum was gathered at $13,200 \mathrm{ft}$. on Kilima-njaro-possibly a robust form of A. odoratuma second genus here first noted from E. Tropical Africa.

Clematis Thunbergii, Steud. var. hirta (foliis C. Wightianæ) 3-5000 ft Thalictrum rhynchocarpum, D. \& R. . . . . $7000 \mathrm{ft}$. Ranunculus oreophytus, Del. • . • . $8000: 11,000 \mathrm{ft}$. pinnatus, Poiv. $\quad . \quad$. $\quad . \quad$. $8500 \mathrm{ft}$. Anemone Thomsoni, Oliv. . $\quad$. $\quad$. $\quad$. $\quad 9-13,000 \mathrm{ft}$. Uvaria leptoclada, Oliv. sp. n. . . . . Taita, $2000 \mathrm{ft}$. Stephania abyssinica, Rich. var. tomentella Kilima-njaro, $5000 \mathrm{ft}$. Arabis alpina, L. . . . . . $8000: 10-11,000 \mathrm{ft}$.

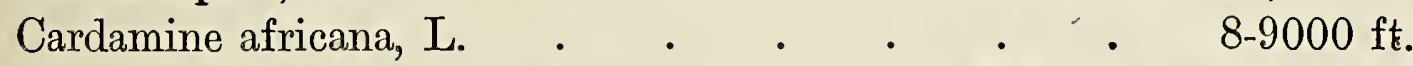
" Johnstoni, Oliv. sp. n. . Kilima-njaro, $8000 \mathrm{ft}$. Farsetia stenoptera, Hochst. forma . . . . . Taita Cleome monophylla, L. . . . . Kilima-njaro, $6000 \mathrm{ft}$. Courbonia decumbens, Brongn. var. parvifolia " $\quad 5000 \mathrm{ft}$. Caylusea abyssinica, F. \& M. . . . $\quad$ " $5000 \mathrm{ft}$. Viola abyssinica, Steud. forma-foliis cordato-rotundatis . $\quad 8-10,500 \mathrm{ft}$. Pittosporum abyssinicum, Hochst. . Kilima-njaro, 5-6000 ft

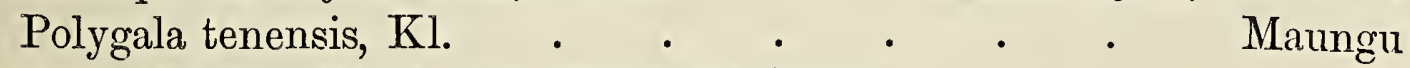
Silene Biafræ, Hk. f. v. S. Burchelli (imperfect single specimen). . . . . Kilima-njaro, 11,000 ft. Cerastium vulgatum, L. forma . . . . $\quad$. $7000 \mathrm{ft}$. 
Cerastium africanum, Oliv.

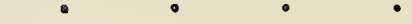
Drymaria cordata, W. $\quad$. $\quad . \quad$. . . $6000 \mathrm{ft}$.

Hypericum lanceolatum, Lam. • . . . . 6-7000 ft.

" kiboense, Oliv. sp. n. . . Kilima-njaro, 13,000 ft.

" Schimperi, Hochst. (approaching

H. Quartiniananum, Rich., which may be only a form of it) .

Sida grewioides, G. \& P.

"Schimperiana, Hochst. (Dictyocarpus truncatus, Wight).

Abutilon asiaticum, L. ? v. A. indicum, Don Pavonia Schimperiana, Hochst. . . . Kosteletzkya adoensis, Hochst. var. hirsuta . Hibiscus vitifolius, L.

" Ludwigii, E. \& Z. (of M. T. M. in Fl. Trop.

Afr. i. 203)

" gossypinus, Thbg.

" schizopetalus, Hk. f.

, platycalyx, M. T. M.

Waltheria americana, $\mathrm{L}$

$$
\begin{array}{r}
5-6000 \mathrm{ft} . \\
4400 \mathrm{ft} .
\end{array}
$$

Kilima-njaro, $5000 \mathrm{ft}$. $4300 \mathrm{ft}$.

$6000 \mathrm{ft}$. and upwards. $6000 \mathrm{ft}$. $6000 \mathrm{ft}$.

Mahernia exappendiculata, M. T. M. var. tomentosa?

an sp. distincta affinis? . . . . Taveita. exappendiculata, M. T. M. var.?. Kilima-njaro, $5000 \mathrm{ft}$. Grewia salviæfolia, Heyne forma

Taveita. forma foliis obtusioribus Kilima-njaro, $5000 \mathrm{ft}$. Triumfetta an. T. pilosa?. (Fl. Trop. Afr. i. 257) $6700 \mathrm{ft}$. Sparmannia abyssinica, Hochst. var. hirsuta . . $7000 \mathrm{ft}$. Triaspis auriculata, Racll. .. Maungu; and 40-60 miles from coast. Monsonia biflora, DC. (M. angustifolia, Roxb.) . . Taveita.

\begin{tabular}{|c|c|c|c|c|c|c|}
\hline , & $" \quad$ forma $p$ & arvifolia & . & & - & $7000 \mathrm{ft}$. \\
\hline & simense, Hochst. & . $\quad$. & . & & . & $6000 \mathrm{ft}$. \\
\hline & „ ? forma & & & . & . & $11,000 \mathrm{ft}$. \\
\hline " & (inadequate) & & & . & & $10,000 \mathrm{ft}$. \\
\hline & ocellatum, Camb. var & & & & $\circ$ & $6000 \mathrm{ft}$. \\
\hline is $\mathrm{co}$ & niculata, L. var. . & & & & & $4400 \mathrm{ft}$. \\
\hline atiens & Walleriana, Hk. f. & & & Kilir & ma-njar & $0,5000 \mathrm{ft}$. \\
\hline$"$ & kilima-njari, Oliv. & . $8500:$ & 7000 & and " & 'up to 1 & 10,200 ft." \\
\hline & sp. . . . . & . 8500 & (and? & No. & 25,800 & $0 \mathrm{ft}$.$) , also$ \\
\hline & sp. . & • & . & · & . & $7-8000 \mathrm{ft}$. \\
\hline & sp. . & $\cdot$ & . & . & - & $7000 \mathrm{ft}$. \\
\hline
\end{tabular}
Geranium aculeolatum, Oliv。 . . . . . $6000 \mathrm{ft}$.

Toddalia sp.? aff. T. aculẹatæ, Pers. ? (no frct.) . . Lanjora. " sp. (no frct.) . . . . Kilima-njaro, 4-5000 ft. 
Toddalia dub. (no fret.)

Harrisonia abyssinica, Oliv.

Odina (in fruit) an O. leptoclada, Oliv. ? .

Turræa floribunda, Hochst. var. macrantha . nilotica, Kotschy \& Peyr. var. robusta

Rhamnus prinoides, L'Her.

Zizyphus Jujuba, Lam. var. obtusifolia pubescens, Oliv. sp. nov.

Vitis rotundifolia, F.? (imperfect)

, arguta, Hook. f. var.?

" cyphopetala, Fres. forma

, erythrodes, Fres.

Deinbollia insignis, Hook. f. ?

Schmidelia rubifolia, Hochst.

Cupania (too young).

Rhus villosa, L. f. forma parvifolia glutinosa, Hochst. .
40-60 miles from coast. Kilima-njaro, $5000 \mathrm{ft}$. $" \quad 5000 \mathrm{ft}$. " $5000 \mathrm{ft}$. - Maungu, $2000 \mathrm{ft}$. Kilima-njaro, $5000 \mathrm{ft}$

Taita.

Kilima-njaro, 2-3000 ft. $" \quad 5000 \mathrm{ft}$. " $\quad 5-6000 \mathrm{ft}$ plains, 2-6000 ft. Kilima-njaro, $6000 \mathrm{ft}$. » $5000 \mathrm{ft}$.

Taita.

Kilima-njaro, 2-3000 ft. ,$\quad 2-3000 \mathrm{ft}$. , $6000 \mathrm{ft}$. glaucescens, Rich. var. $40-60 \mathrm{miles}$ from coast $\& 5000 \mathrm{ft}$ Agelæa Lamarckii, Pl. ? (in fruit) Adenocarpus Mannii, Hk. f. Parochetus communis, Hance Trifolium subrotundum, S. \& H. " Johnstoni, Oliv. sp. nov. " polystachyum, Fres.

Indigofera an I.macrophylla, S. \& T. var.? an

sp. n. (no legumes) arrecta, Hochst.

, pentaphylla, L. .

Tephrosia Vogelii, Hook. f.

Hormolotus Johnstoni, Oliv. gen. nov. Eschynomene cristata, Vatke? . Ormocarpum Kirkii, S. Moore Desmodium Scalpc, DC. lains up to $6-7000 \mathrm{ft}$. $6-9000 \mathrm{ft}$. $9000 \mathrm{ft}$. $5000 \mathrm{ft}$. Kilima-njaro, 10,000 ft. ,$\quad 5000 \mathrm{ft}$. $\begin{array}{ll}" & 5-6000 \mathrm{ft} . \\ , & 4-5000 \mathrm{ft} .\end{array}$ 40-60 miles inland. Kilima-njaro, $6000 \mathrm{ft}$. . 40-60 miles inland. Kilima-njaro, $5000 \mathrm{ft}$. . 5000 and $6000 \mathrm{ft}$. oxybracteatum, DC. (D. paleaceum G. \& P.) $5-6000 \mathrm{ft}$. Alysicarpus rugosus, DC.

Lathyrus an. L. sativus, L. ? (no fruit) Clitoria Ternatea, L. (forma minora) . Glycine javanica, L. forma?

$7000 \mathrm{ft}$

Kilima-njaro, $5000 \mathrm{ft}$. $7000 \mathrm{ft}$

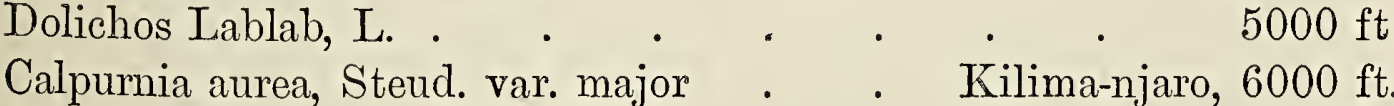
Cæsalpinia sp. n. ? . . . . . . 40-60 miles inland. Pterolobium lacerans, R. Br. (P. abyssinicum, Rich.) . $\quad 6000 \mathrm{ft}$. Cassia didymobotrya, Fres. 
Cassia goratensis, Fres.

. 40-60 miles inland. \# zambesiaca, Oliv. . . . . . . 40-60 miles inland. " mimosoides, L. . $\quad$. $\quad$. $\quad$. $\quad$. $\quad$. $6000 \mathrm{ft}$.

Bauhinia tomentosa, L. var. parvifolia-hirtella Kilima-njaro, 2-3000 ft. var. glabra .

Maungu. $" \quad$ reticulata, DC. (imperfect) . . Kilima-njaro, $5000 \mathrm{ft}$. Acacia pennata, W.

Rubus dictyophyllus, Oliv. sp. n. . " 4-10,000 ft. Brayera anthelmintica, Kth. var. villosa . . . 7-10,000 ft. Alchemilla argyrophylla, Oliv. sp. n. . . Kilima-njaro, 8-10,000 ft. Johnstoni, Oliv. sp. n.

$13,000 \mathrm{ft}$. Terminalia Brownii, Fres. ? (no fret.) . . . . 2-3000 ft. Combretum paniculatum, V. forma . . . . $\quad 4-5000 \mathrm{ft}$. „ sp. (foliis hirtellis) (no fret.) . . 40-60 miles inland. " sp. (foliis lepidotis) (no fret.) .

Dissotis eximia, Hk. f. 40-60 miles inland. Kilima-njaro, $5000 \mathrm{ft}$. sp. aff. D. grandifloræ, Benth.

Epilobium hirsutum, L. . . . . . . $6000 \mathrm{ft}$. Wormskioldia (Streptopetalum Hildebrandtii, Vatke) . Taita. Tryphostemma Hanningtoniana, Mast. . Maungu, $2000 \mathrm{ft}$. Momordica cardiospermoides, Kl. . . . . 40-60 miles inland. " cucullata, Hk. f. an var. Morkorra? Kilima-njaro, 4-5000 ft. Cephalandra quinqueloba, Sch. forma? . " $\quad 5000 \mathrm{ft}$. Zehneria scabra, Sond. var.? . . . " " $6000 \mathrm{ft}$. Begonia sp." (fragment).

„Johnstoni, Oliv. sp. n. . Kilima-njaro, 5-6000 ft. Mollugo nudicaulis, Lam. . . . . . 40-60 miles inland. Sanicula europæa, L. . $\quad . \quad$. $\quad$. $\quad$ • $\quad .10,000 \mathrm{ft}$. Trachydium abyssinicum, Bth. \& Hk. f. . . . $\quad 12,000 \mathrm{ft}$. Peucedanum? aff. P. Petitiano, Rich. . . . . $7000 \mathrm{ft}$. " sp. (no fruit)

Caucalis infesta, Curb.? (no fruit) Kilima-njaro, $5000 \mathrm{ft}$. , $5300: 6000 \mathrm{ft}$. melanantha, Bth. \& Hk. f. . . . . $6000 \mathrm{ft}$. Umbellifer-fragment worthless . . . . $5300 \mathrm{ft}$. " dub. (too young for determination) . . $11,000 \mathrm{ft}$. ", Anthriscus? . . . . $8500: 13,200 \mathrm{ft}$. Dirichletia nr. glaucescens, Hn. (in fruit only) . . $\quad 2-3000 \mathrm{ft}$. Pentanisia ouranogyne, S. Moore • • . . 2-3000 ft. Pentas mombassana, Hn. (var. hirtella) . . Maungu. " carnea, Bth. . . . . . Kilima-njaro, $5000 \mathrm{ft}$. " purpurea, Oliv. $\quad . \quad \cdot \quad . \quad . \quad . \quad$ Kilima-njaro, $5000 \mathrm{ft}$. 
Pentas purpurea, Oliv. var.? longiflora longiflora, Oliv. sp. n. . .

Oldenlandia an O. Bojeri, Hn. var.? .
$4,400 \mathrm{ft}$.

Kilima-njaro, $5000 \mathrm{ft}$. Maungu.

Schimperi, T. A. forma . Taveita, \& 40-60 miles inland. obtusiloba, Hn. . . . Kilima-njaro, $5000 \mathrm{ft}$. Heynei, W. \& A. . . . . . $4400 \mathrm{ft}$. Hedyotis Johnstoni, Oliv. .

Empogona Kirkii, Hk. f. var.? glabrata Pavetta Oliveriana, Hiern.

$" \quad$ (fruit) nr. P. gracilis, Kl. \& Caffra, Thbg.

Kilima-njaro, $6000 \mathrm{ft}$. . 40-60 miles inland.

Kilima-njaro, $6000 \mathrm{ft}$.

. 40-60 miles inland.

Vangueria edulis, Vahl var.?

Kilima-njaro, 4-5000 ft. euonymoides, Schw. .

Oxyanthus Gerrardi, Sond. var.

Polysphæria multiflora, Hiern. .

Psychotria aff. P. (Grumilea) capensi, Sond.? hirtella, Oliv. sp. n. .

Spermacoce Ruelliæ, DC.?

Galium Aparine, L.

Dipsacus pinnatifidus, Steud.

Scabiosa Columbaria, L. var.

Valeriana sp. nov. (Genus new to Trop. Africa.) Only a single flowering specimen . . . $10,000 \mathrm{ft}$.

Vernonia Wakefieldii, Oliv. sp. n. Kilima-njaro, 2-3000 ft. " stenolepis, Oliv. sp. n. . " marginata, O. \& $\mathrm{H}$. ", aff. V. paucifloræ, Less. ? an var. sp.

Adenostemma viscosum, Forst. . Mikania scandens, W.

Dichrocephala chrysanthemifolia, DC. Felicia abyssinica, Sch. Bip. Conyza stricta, W. " xgyptiaca, Ait.

\section{" Hochstetteri, Sch. forma}

Pluchea Dioscoridis, DC. var. glabra . Psiadia sp. n. ? . Achyrocline Hochstetteri, Sch. . . Gnaphalium luteo alburn, L. Helichrysum Newii, O. \& H. " "up to $8000 \mathrm{ft}$." $6000 \mathrm{ft}$. Taita, $6000 \mathrm{ft}$. Kilima-njaro, $6000 \mathrm{ft}$. $6000 \mathrm{ft}$. $12,000 \mathrm{ft}$. Taita ; Maungu. Kilima-njaro, $5000 \mathrm{ft}$. $\begin{array}{rr}" & 5000 \mathrm{ft} . \\ " & 5000 \mathrm{ft} . \\ " & 5000 \mathrm{ft} . \\ . \quad 6000 \mathrm{ft} . \\ \text { Kilima-njaro, } & 6000 \mathrm{ft} . \\ . \quad & 6000 \mathrm{ft} . \\ 13,200: 14,200 \mathrm{ft} .\end{array}$ elegantissimum, DC. var.? (H. formosissinum Sch. Bip. var. angustifolia) - 9-11,000 ft. formosissimum Sch. Bip. var. . var. capitula alba

$10,000 \mathrm{ft}$. 
Helichrysum kilima-njari, Oliv. sp. n. Kilima-njaro, $8300 \mathrm{ft}$. " globosum, Sch. Bip. forma? . . . 10,000 ft. " fruticosum, Vatke. var. . . 13,000:13,200 ft. " abyssinicum, Sch. Bip. forma. $11-13-13,200 \mathrm{ft}$. Sch. Bip. . . . . 9-11,000 ft. $"$ setosum, Harv. (H. fœetidum, Cass. var.?

Kilima-njaro, $6000 \mathrm{ft}$. Astephania africana, Oliv. Gen. nov. . .

Melananthera Brownii, Sch. forma . .

Aspilia? or Wedelia nr. W. Menotriche \&

mossambicensis (sp. n.?) . . . $\Longrightarrow \quad 5000 \mathrm{ft}$. Artemisia Afra, Jacq. forma. $\quad$ 9900-13,200 ft.; also at $3000 \mathrm{ft}$. Coreopsis sp. n.? (inadequate) . . . . . $4300 \mathrm{ft}$. Bidens pilosa, L. . . . . . . $4000: 6000 \mathrm{ft}$. Tripteris Vaillantii, Dcne. ? . . . . . $4000 \mathrm{ft}$. " sp. too young . . . . $\quad 8500 \mathrm{ft}$. (Thrown away. Fragmentary composite) . . . 12,000 ft. Gynura cernua, Bth. . $6000 \mathrm{ft}$. " vitellina, Bth. . . . . Kilima-njaro, $6000 \mathrm{ft}$. Cineraria abyssinica; Sch. Bip. forma . 7-10,000 : barren 13,200 ft. Senecio discifolius, Oliv.

- Kilima-njaro, $5000 \mathrm{ft}$. deltoideus, Less.? var. . . . . $6000 \mathrm{ft}$.

" Valeriana, Oliv. sp. n. . . . Kilima-njaro, $5000 \mathrm{ft}$. " Johnstoni, Oliv. sp. n. . Kilima-njaro, 8-500-14,5000 ft. Notonia abyssinica, A. R. . . . . 40-60 miles inland. Euryops dacrydioides, Oliv. sp. n. . . Kilima-njaro, 10-14,00 ft. Gazania diffusa, Oliv. sp. n.

Erythrocephalum minus, Oliv. . . . 40-60 miles inland. Carduus leptacanthus, Fres. . . . Kilima-njaro, $6000 \mathrm{ft}$. " allied to C. chamæcephalus, O. \& H . . $\quad 13,200 \mathrm{ft}$. Gerbera piloselloides, Cass. . . Kilima-njaro, 4-5000 ft. Sonchus sp.

Lobelia Deckenii, Hemsl. (Tupa Deckenii, Asch.)

Lightfootia abyssinica, Hochst. forma .

$6000 \mathrm{ft}$. Wahlenbergia sp. n.? Without fruit: allied to W. capilacea A. DC. of the Cape . . . . $11.000 \mathrm{ft}$. Erica arborea, L. forma. - . . . . . 10,000 ft. Blæria spicata, Hochst. . . . $8-11,000 \mathrm{ft}$. Ericinella Mannii, Hk. f. . . . . . . 7-10,000 ft. Plumbago zeylanica, $\mathrm{L}$.

Lysimachia an L. Richmerianæ, Vatke var. Euclea fruticosa, Hiern. ? $\vec{\sigma}$ 40-60 miles inland. Landolphia florida? (Inflorescence only.) Kilima-njaro, $6000 \mathrm{ft}$. Country at base of $2000 \mathrm{ft}$. 
Landolphia Petersiana, Dyer.

Adenium speciosum, Fenzl. forma? .

40-60 miles inland. Gomphocarpus bisacculatus, Oliv. sp. n. Kilima-njaro, $5000 \mathrm{ft}$. " stenophylla, Oliv.

Lanjora, $2000 \mathrm{ft}$.

" aff. G. lanato and G. stenophyllo

$2300 \mathrm{ft}$.

Schizoglossum (Lagarinthus) sp. . . Maungu, $2000 \mathrm{ft}$.

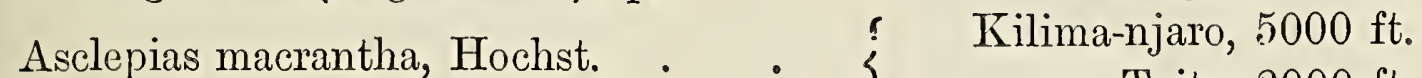
Aargaretta rosea, Oliv. $\mathcal{L}$. Margaretta rosea, Oliv. . . . . Kilima-njare, $5000 \mathrm{ft}$. Cynanchum abyssinicum, Dene. var.? tomentosum . $7000 \mathrm{ft}$. Ceropegia sp. n. aff. C. Meyeri . . . Kilima-njaro, $6000 \mathrm{ft.}$ Gymnema parvifolium, Oliv. sp. n. . . $\quad$ " $5000 \mathrm{ft}$. Swertia Schimperi, Griseb. . . $\quad 8-11,000 \mathrm{ft}$. " pumila, Hochst. ? . . . . . 11,000 ft. Ehretia amœna, Kl. . $\quad$. $\quad$. . . . 40-60 miles inland.

Heliotropium sp. nov.? aff. H. longifloro and Steudneri

Cynoglossum micranthum, Desf. (C. lanceolatum, F.) . . . .

Cynoglossum amplifoliun, Hochs t. (C. lancifolium, H. f. ?) . . . . . . . 9900-1100 ft. Myosotis stricta, Link (the plant of Abyssinia and the

Camernons) : var. nucibus nigres centibus . . 13,200 ft. Scrap of Boraginacea (Heliotropium ?) . . . $13,000 \mathrm{ft}$. Ipomœa bullata, Oliv. sp. n. . . 40-60 miles inland. " pinnata, Hochst: . . . . Kilima-njaro, $5000 \mathrm{ft}$. " sp.? (too imperfect) . . . . . $6000 \mathrm{ft}$. Cuscuta (§ Grammica) kilima-njari, Oliv. sp. n. . . $\quad 6000 \mathrm{ft}$. Solonum nigrum, L. var. . . . . . . $4400 \mathrm{ft}$. " sp. apparently identical with a Natal sp.

" Renschii, Vatke . . . . . Taveita. Buttonia natalensis McKen . . . Kilima-njaro, $5000 \mathrm{ft}$. Veronica Anagallis, L. . . . . . . $6000 \mathrm{ft}$. " myrsinoides, Oliv. sp. n. . . . . 11,000 ft. Rhamphicarpa (sp. n. ?) . . . . . . $4400 \mathrm{ft}$. Bartsia decura, Hoclist, var.? · • • 40-60 miles inland. Orobanche sp. . . . . . Kilima-njaro, $6000 \mathrm{ft}$. Streptocarpus sp. aff. S. caulescenti, Vatke . . $\quad 6000 \mathrm{ft}$. " montanus, Oliv. sp. n. . . Kilima-njaro, 7-9000 ft. Hebenstreitia dentata, L. . . . . . . 9-12,000 ft. Selago Thomsoni, Rolfe . . . . . . 11,000 ft. "Johnstoni, Rolfe . . . . Kilima-njaro, 11,000 ft. 
Sesamum indicum, L.

Thunbergia affinis, var. pulvinata, S. M. . . . . Maungu.

" fuscata, T. And. ? . . . . . $6000 \mathrm{ft}$.

, sp. ?

Blepharis bœrhaavifolia, Juss.

$" \quad$ an var. B. Hildebrandtii, S. M.? .

Maungu.

" $"$. Kilima-njaro, 2-3000 ft. Phaylopsis longifolia, Sims.? (Antheilemaimbricatum, R.Br.) $5000 \mathrm{ft}$. " $"$. . . . . $6000 \mathrm{ft}$. Mimulopsis sp. v. Strobilanthes . . . . . . $7000 \mathrm{ft}$. Barleria sp.

\# nr. Brepens, Nees. . . . . 40-60 miles inland. Strobilanthes? sp. n.? . . . . . . 6-7000 ft.

Crossandra nilotica, Oliv. var. acuminata, Moore . . Lanjora. " " $"$ " Kilima-njaro, 2-3000 ft. Asystasia Schimperi, T. And. var. minor . . - 4-5000 ft. Justicia (Adhatoda) Schimperiana, T. And. . . Maungu. $" \quad$ (Rostellaria) palustris, T. And.? " plicata, Nees var.? . . . " matamensis, Schf. . • . $\quad$. $6000 \mathrm{ft}$. $" \quad$. . . . . $\quad " \quad 5000 \mathrm{ft}$. $" \quad$ foliis angustioribus . . 40-60 miles inland. " aff. J. neglectæ, T. And. . . Kilima-njaro, $6000 \mathrm{ft}$. ". debilis, V. . . . . . . . . . Maungu. " sp. near $J$. insulario and neglecta, with species gathered from 4400 to $6500 \mathrm{ft}$.

sp. (inadequate) . . . . . . $7000 \mathrm{ft}$. Isoglossa laxa, Oliv. sp. 11. . . . . Kilima-njaro, $7000 \mathrm{ft}$. Brachystephanus sp.? . . . . . . $7000 \mathrm{ft}$. Anisotes parvifolius, Oliv. . . . . . . 40-60 miles inland. Rhinacanthus communis, Nees . . . . 40-60 miles inland. Hypoestes aristata, Sol. . • • • . . Maungu. $" \quad "$ forma . . . . Kilima-njaro, 2-3000 ft. " antennifera, Moore . • . . . $6000 \mathrm{ft}$. Lantana viburnoides, V. . . . . . . $4400 \mathrm{ft}$. „, Petitiana, Rich. ? an L. salvifolia forma? . $\quad 6000 \mathrm{ft}$.

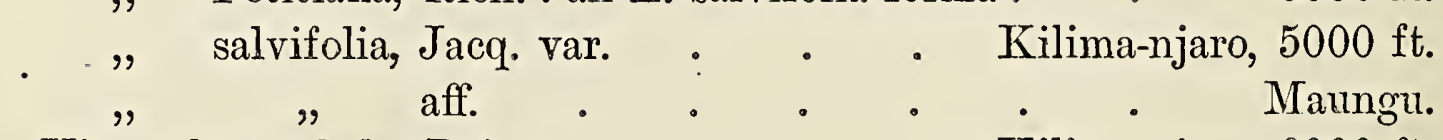
Vitex chrysoclada, Boj. . . . . Kilima-njaro, $6000 \mathrm{ft}$. " aff.V. mombassæ, Vatke, and lanigeræ, Schr. $\quad$ " $5000 \mathrm{ft}$. Clerodendron Johnstoni, Oliv. sp. n. . . $\quad$ " $5000 \mathrm{ft}$. " (Cyclonema), sp. n.? • • . . Taita. ",$\quad$ myricoides, Hochst. var. ? "Very common, reaches $7000 \mathrm{ft.}$." 
Ocimum canum, Sims var. .

Kilima-njaro, 2-3000 ft.

" graveolens, A. Br.?

,

$6000 \mathrm{ft}$.

sp.

$6000 \mathrm{ft}$.

Orthosiphon? aff. O. glabrato, Benth.? @ . 40-60 miles inland.

Plectranthus parvus, Oliv. sp. $n$

Kilima-njaro, $5000 \mathrm{ft}$. aff. P. glanduloso, Hk. f.

$6000 \mathrm{ft}$.

Coleus umbrosus, Vatke

Taita.

Platystoma africanum, Beauv.

Moschosma, M. multiflori v. M. riparii var.?

AEolanthus zanzibaricus, S. Moore

Hyptis pectinata, Poit.

Salvia nilotica, V. var.?

Meromeria punctata, Bth.

an M. punctatæ forma

abyssinica, Bth. forma

Tinnæa æthiopica, K. \& P. var. .

" sp. may be distinct .

Anjuga remota, Benth.

Leonotis-L. rugosæ, Benth. var.

Leucas glabrata, Benth.

. Maungu and

„ Neuflizeana, Courb.

" glabratæ var.

Labiata (§ Ocymoideæ) sp.

,$\quad$ ? imperfect

Plantago palmata, Hk. f. .

Digera arvensis, $\mathrm{F}$.

Psilotrichum africanum, Oliv. sp. n.

Phytolacca abyssinica, Hoff.

Chenopodum murale, $\mathrm{L}$

Oxygonum (Ceratogonum atriplicifolium, Meiss.)

Polygonum barbatum, L.

,

9

" ? L.

senegalense, Meiss. serrulatum, Log.

Rumnex Steudelio, Hochst. .

$" \quad, \quad$ ? (in fl.)

Protea abyssinica, W.

Arthrosolen latifolius, Oliv. sp. n.

Loranthus curviflorus, Benth.

Loranthus sp.

Thesium an T. radicans, Hochst. ?
Kilima-njaro, 5-6000 ft. $6000 \mathrm{ft}$. . 40-60 miles inland.

Kilima-njaro, 4-5000 ft.

" $6000 \mathrm{ft}$. $4000 \mathrm{ft}$. $6000 \mathrm{ft}$. $4-6000 \mathrm{ft}$.

Kilima-njaro, $5000 \mathrm{ft}$. $5000 \mathrm{ft}$. $3000 \mathrm{ft}$. $" \quad 3000 \mathrm{ft}$ ", $4-5000 \mathrm{ft}$. , 2-3000 ft. - Maungu, $2000 \mathrm{ft}$. . 40-60 miles inland.

Taita; Maungu. $8000 \mathrm{ft}$. $10,000 \mathrm{ft}$. $7000 \mathrm{ft}$.

40-60 miles inland, and Maungu. Kilima-njaro, $5000 \mathrm{ft}$. ,$\quad 6000 \mathrm{ft}$. " $5000 \mathrm{ft}$. $" \quad 5000 \mathrm{ft}$. $6000 \mathrm{ft}$. , $6000 \mathrm{ft}$. " $6000 \mathrm{ft}$. " $5000 \mathrm{ft}$ " $\quad 6000 \mathrm{ft}$. $13,000 \cdot \mathrm{ft}$

Kilima-njaro, $6000 \mathrm{ft}$. 9-13,000 ft. Kilima-njaro, $5000 \mathrm{ft}$. . 40-60 miles inland. $4500 \mathrm{ft}$. $10,000 \mathrm{ft}$. $13,000 \mathrm{ft}$. 
Euphorbia (§ Tithymalus) sp. . . . . . $10,000 \mathrm{ft}$. " sp. . . . . . . . . $7000 \mathrm{ft}$. Bridelia melanthesoides, Kl. forma . Kilima-njaro, $5000 \mathrm{ft}$. Phyllanthus maderaspatensis, L. . . $\quad$ "2-3000 ft. Nirari, L. forma? . . $\quad$ " $5000 \mathrm{ft}$. Antidesma, A. venosum, Tul. var. ? . . . 40-60 miles inland. Gelonum zanzibarense, M. Arg. . . . . 40-60 miles inland. Jatropha sp. n. ? . . . . . . 40-60 miles inland. Croton pulchellus, Baill. ? . . . . . 40-60 miles inland. " macrostachys, Hochst. . . . Kilima-njaro, 5-6000 ft.

Acalypha ornata, Rich var. (A. Livingston-

iana M. Arg.?.
cf. A. adenotricha, Rich. $\quad \cdot \quad$ ·

" paniculata, Miq. . . • •

Tragia an T. mitis var.? (fret.) .

Sponia bracteolata, Hochst.? .

Morus indica, W.? . .

Pilea Johnstoni, Oliv. sp. n.

Myrica an M. salicifoliæ, var.

Polystachya kilima-njari, Reichb. fil. .

Vanilla sp.? (fragment)

Angræcum eburneum, Th.?

Eulophia sp.

Lissochilus sp. .

" sp. .

Disperis Johnstoni, Reichb. fil. sp. n. .

" Kersteni, Reichb. fil.

Habenaria aff. macranthæ, Hochst.

" stylites, Reichb. fil. \& S. Moore

" pleistadenia, Reichb. fil. . .

$" \quad$ ranicolorata, Reichb. fil. sp. n. .

Satyrium chlorocorys, Reichb. fil. sp. n.

Disa Deckenii, Reichb. fil. .

Orchidacea dub. (foliis radicalibus 1-spec.)

Acidanthera laxiflora, Baker sp. n.

$\begin{array}{lr}" & 6000 \mathrm{ft} . \\ " & 6000 \mathrm{ft} . \\ . \quad & \text { Maungu. } \\ . \quad & 5000 \mathrm{ft} .\end{array}$

Kilima-njaro, 4-5000 ft.

Lanjora.

. 40-60 miles inland.

Kilima-njaro, $5000 \mathrm{ft}$. " $4-5000 \mathrm{ft}$. . 40-60 miles inland.

. 40-60 miles inland.

Kilima-njaro, $6000 \mathrm{ft}$.

Maungu.

. 40-60 miles inland.

. 40-60 miles inland.

Kilima-njaro, 5-6000 ft.

$\begin{array}{lr}" & 7500 \mathrm{ft} . \\ " & 6000 \mathrm{ft} . \\ " & 2-3000 \mathrm{ft} . \\ " & 8-10,000 \mathrm{ft} . \\ " & 7000 \mathrm{ft} . \\ " & 7000 \mathrm{ft} . \\ " & 6-8000 \mathrm{ft} . \\ " & 6000 \mathrm{ft} .\end{array}$

Gladiolus (Eugladiolus) pauciflorus, Baker sp.n. Kilima-njaro, 2-5000 ft.

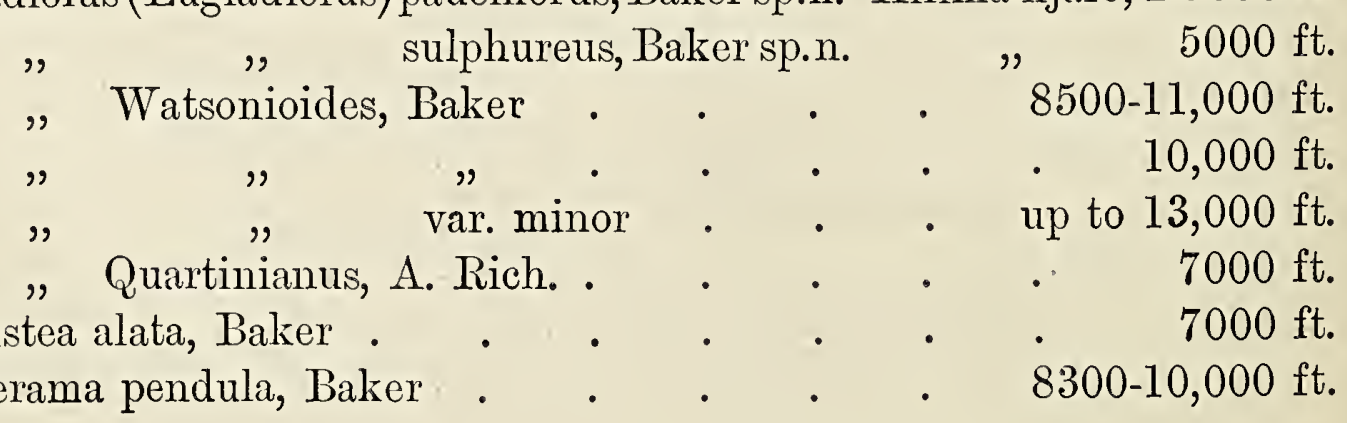


Hiemanthus abyssinicus, Herb. (= H. tenuiflorus, Herb.) . Dioscorea aff. D. crinitæ, Hk. f. . . Kilima-njaro, $6000 \mathrm{ft}$. Asparagus falcatus, L.

" sp. n.? an aff. A. plumoso .

$" \quad$ aff. A. plumoso, Baker (no. fls.) .

Gloriosa virescens, Lindl. .

Scilla (Ledebouria) Johnstoni, Baker sp. n.

Walleria natans, Kirk

Bulbine asphodelioides, R.\& S. . . . 40-60 miles inland.

Ornithogalum (Osmyne) Melleri, J. G. Baker 40-60 niles inland. Kniphofia Thomsoni, Baker . _ . $8000: 11,000 \mathrm{ft}$. Aloe, perhaps A. commutata, Tod. (material inadequate) $\quad 3-6000 \mathrm{ft}$. „ (Eualoe) Johnstoni, Baker . Kilima-njaro, 2-5000 ft. Dracœila sp. n. . . . . . . " $\quad 6-9000 \mathrm{ft}$. Anthericum (Phalangium) venulosum, Baker sp. n. , , 2-5000 ft. :" " rubellum, Baker sp. n. " " $5000 \mathrm{ft}$. Dasystachys Grantii, Benth. . . $\quad " \quad 5000 \mathrm{ft}$. " ? (inadequate) . . . $\quad " \quad 5000 \mathrm{ft}$. Commelyna, near C. latifolia, H. . $\quad$ " $\quad 5000 \mathrm{ft}$. Aneilema sinicum, Lindl. . . . . $\quad$ " $5000 \mathrm{ft}$. " xquinoctiale, Kth. $\quad$. $\quad$. . Maungu, 5-6000 ft. " cf. lanceolatum .

" pedunculosum, C. B. Clarke? . . . . up to $9000 \mathrm{ft}$. Phœnix sp. spadices only. "Mkindo" palm. . nearly to $6000 \mathrm{ft}$. Luzula Forsteri, DC. forma . . . $8-9000 \mathrm{ft}$. Cyperus dichrostachys, Hochst. . . . Kilima-njaro, $6000 \mathrm{ft}$.

" rotundus, L. forma (C. adoensis ?) . $\quad$ " $\quad 4-5000 \mathrm{ft}$.

" paniceus, Bkler. ? . . . $\quad " \quad 5000 \mathrm{ft}$.

". leptocladus, Kth. . . . . . . . . $\quad$. $6000 \mathrm{ft}$. Kyllinga cylindrica, N. ? . $\quad$. $\quad . \quad$. $\quad$. $\quad$. $6000 \mathrm{ft}$. Fimbristylis an F. hispidula (glabrata)?

" (Abildgaardia bilosa, Nees) 40-60 miles inland. " (Oneostylis)(Scirpus(Oneostylis) atrosanguineus, Bœckl).

Carex an C. Wahlenbergiana, Boott? with specn. from 6-10,000 ft. " triquetrifolia, Bœckl. . . . . . . 12,000 ft. "Johnstoni, Bockl. . . . . $6-10,000 \mathrm{ft}$. Isachne mauritiani, Kth.? . . . . . . $7000 \mathrm{ft}$. Panicum excurrens Trin. (P. plicatum var. ?) . . $7000 \mathrm{ft}$. " (Tricholæna) an P. longisetæ, Hochst. var. . $4400 \mathrm{ft}$. " (Tricholæna ?) fragment . . . . $6000 \mathrm{ft}$. Oplismenus compositus, Beauv.? fragment . . . $5300 \mathrm{ft}$. Andropogon (Cymbopogon) cymbarius, L. forma . $6000 \mathrm{ft}$. 
Andropogon (Cymbopogon) hirtum, L. var. Anthistiria an A. abyssinica, Hochst. . . Elionurus argenteus, Nees : $.8300: 10-11,000 \mathrm{ft}$. Aristida adoensis, Hochst. . Kilima-njaro, $5000 \mathrm{ft}$. Sporobolus indicus, Br. (S. elongatus, Br.) . Anthoxanthum odoratum, L. var.? Kohleria cristata, Pers. var. (Airochloa convoluta, Hochst.) Eragrostis Schimperi, Benth. (Harpachne,
Hochst.) Eragrostis Schimperi, Benth. (Harpachne,
Hochst.) $5000 \mathrm{ft}$. $5000 \mathrm{ft}$. $13,200 \mathrm{ft}$. $7000 \mathrm{ft}$.

Kilima-njaro, $6000 \mathrm{ft}$. sp.

Festuca macrophylla, Hochst. var.? aff. F. Schimperianæ Rich. Hymenophyllum polyanthos, Sm. Cystopteris fragilis, Bernh. Adiantum caudatum, L.

" $\quad$ thiopicum, I. .

" Capillus-veneris, L.

Cheilanthes multifida, Sw. Pellæa geraniæfolia, Fée.

$$
\begin{aligned}
& 6000 \mathrm{ft} \text {. } \\
& 13,000 \mathrm{ft} \text {. } \\
& 8000 \mathrm{ft} \text {. } \\
& 13,000 \mathrm{ft} \text {. } \\
& 4300 \mathrm{ft} \text {. } \\
& 4-6000 \mathrm{ft} \text {. } \\
& 5-6000 \mathrm{ft} \text {. } \\
& \text { 4-7000 ft. } \\
& 4-7000 \mathrm{ft} \text {. } \\
& \text { 4-7000 ft. } \\
& 6-8000 \mathrm{ft} \text {. }
\end{aligned}
$$

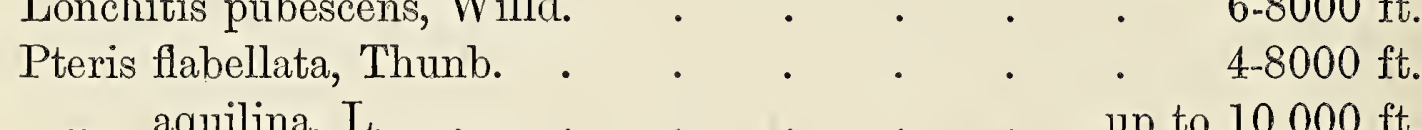

$$
\begin{aligned}
& \text { Asplenium monanthemum, L. . . . . . } 10,000 \mathrm{ft} \text {. } \\
& " \quad \text { lunulatum, Sw. . . . . . . } 4-8000 \mathrm{ft} \text {. }
\end{aligned}
$$

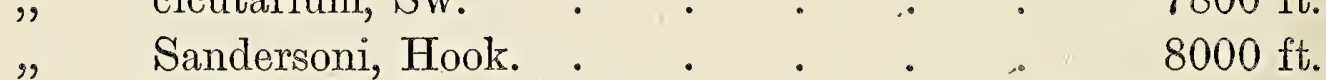

$$
\begin{aligned}
& \text { " sertularioides, Baker sp. n. . . . . . } 9-13,000 \mathrm{ft} \text {. } \\
& \text { Aspidium aculeatum, Sw. . } \quad . \quad \text {. } \quad . \quad \text {. } \quad . \quad 4-8000 \mathrm{ft} \text {. } \\
& \text { " cicutarium, var. gemmiferum, Fée. . . 4-8000 ft. } \\
& \text { Acrostichum hybridum, Brg. . . . . . } 8000 \mathrm{ft} \text {. } \\
& \text { Mohria vestita, Baker sp. n. . . . . . } 6000 \mathrm{ft} \text {. } \\
& \text { Selaginella rupestris, Spring. . . . . 40-60 miles inland. }
\end{aligned}
$$$$
\text { "quadriaurita, Retz. . . . . . . . 4-7000 ft. }
$$$$
\text { " furcatum, Thunb. . . . . . } 4-8000 \mathrm{ft} \text {. }
$$$$
\text { " cicutarium, Sw. . . . . . } 7800 \mathrm{ft} \text {. }
$$$$
\text { " loxoscaphoides, Baker sp. n. .. . . . } 8000 \mathrm{ft} \text {. }
$$$$
\text { „ Thunbergii, Kunze. . . . . . . . } \quad . \quad 5000 \mathrm{ft} \text {. }
$$

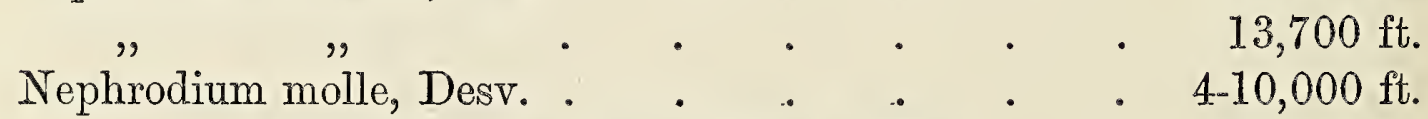$$
\text { Polypodium Phymatodes, L. . . . . . } 5000 \mathrm{ft} \text {. }
$$$$
\text { Aubertii, Desv. . . . . . } 8000 \mathrm{ft} \text {. }
$$$$
\text { Lycopodium clavatum, L. . . . . . . . . . . . . }
$$$$
" \text { molliceps, Spring. . . . . . } 5000 \mathrm{ft} \text {. }
$$ 
Marchantia (no fruit).

Grimmia . . . . . . . . . $12,000 \mathrm{ft}$.

Dicranum. . . . . . . . . $10,000 \mathrm{ft}$.

Thuidium . . . . . . . 10,000 ft.

Physcia flavicans (Sw.)

" speciosa (Wulf.).

Parmelia perlata (L.).

Usnea sp. (The " orchilla-weed" of commerce).

Most abundant, from 5000 to $12,000 \mathrm{ft}$.

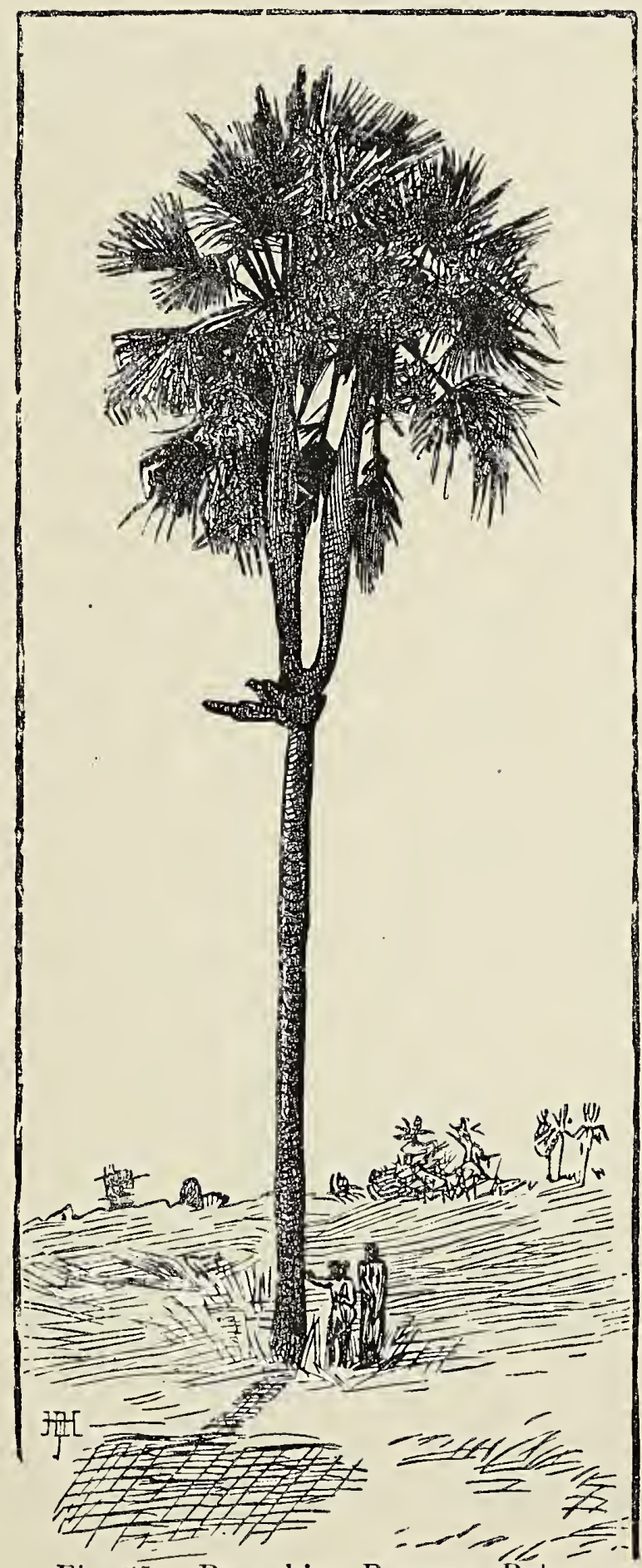

Fig. 65. -- Branching Borassus Palm. 


\section{CHAPTER XVIII.}

\section{ZOOLOGY.}

I wiLl precede the enumeration of my zoological collections by a short sketch of the main features of the Kilima-njaro fauna.

To begin with our near kinsfolk, the monkeys. I found these creatures much more abundantly present in East Central Africa than during my journeys on the West Coast. Although Western Africa is probably better provided with species of quadrumana than any other division of the continent, the monkeys are much scarcer in numbers and harder to see, possibly owing to the greater density of the forests.

During eight months on the Congo I only saw monkeys twice in a wild state, and that in one place only; and throughout my entire stay of sixteen months in West Africa I can only remember six occasions on which I actually beheld these animals in a state of nature. On the other hand, I had scarcely left the East Coast, to journey towards Kilima-njaro, when monkeys showed themselves abundantly in the wilds.

The first to attract my attention were the baboons, probably the species known as Cynocephalus hamadryas, C. Sphinx, and C. babouin. They were generally found on the outskirts of native plantations, where they almost subsisted on the maize and other 
food-stuffs stolen from the gardens of their more highly-developed fellow-primates. In the inhabited region of Kilima-njaro, generally known as the country of Čaga, baboons were strangely abundant. They were generally in flocks of fourteen to twenty, of all ages, and both sexes. They were so little molested by the natives that they showed small fear of man, and, instead of running away, would often stop to look at me about twenty yards off, and the old males would show their teeth and grunt. I have frequently seen the natives driving them from the plantations, as they might a troop of naughty boys, and the baboons retreating with swollen cheek-pouches, often dragging after them a portion of the spoil. On one occasion, in a river-bed at the foot of Kilima-njaro, my Indian servant, ordinarily a very plucky boy, met a troop of baboons, who, instead of fleeing up into the trees, came running towards him in a very menacing manner, and he was so frightened at their aspect that he took to his heels. The baboons followed, and, but that the boy forded the shallow stream, and put the water between him and his pursuers, he might have had an awkward contest. I killed a baboon once in Čaga, one of a troop who were rifling a maize plantation, and its companions, instead of running away, surrounded the corpse and snarled at me. As I had fired off both barrels of my gun, and had no more ammunition, I went back to my settlement to fetch some of my followers, and upon the approach of several men the baboons ran off. We picked up the dead one and carried it back. It was a female, and apparently young and tender. Out of curiosity I had its flesh cooked the next day and ate it, ${ }^{1}$ hoping in this lawful

1 The natives of many parts of Africa greatly esteem the baboon as 
way to form some idea of the practice of cannibalism; I can only say that the succulence and quality of this creature's flesh were quite unexceptionable. I have noticed this with most of the species of Old-World monkey I have as yet tasted. During my four months' stay in Mandara's country I ate the common Cercopithè. cus pygerythrus constantly, and found it made a very toothsome stew. The most remarkable monkey in all this region is probably the Colobus, which apparently offers a new variety or sub-species in the country round Kilima-njaro, remarkable for having an entirely white heavily-plumed tail. The common species, with a black tail tipped with white, I have shot in the forested plains near the coast. The Colobus monkey is almost the only one that quite avoids the neighbourhood of man; the other genera frequent the vicinity of native plantations, and doubtless profit by the abundance of cultivated food. I never observed any Galago (a lemuroid animal) in this district, nor do the natives speak of one, although it is a genus well represented in other parts of Africa.

Bats are by no means common or often seen. I saw some fruit-bats once in the forest hanging to a sycamore fig-tree. No member of the group of Insectivora came under my notice. The Carnivora in this country of big game are, of course, well represented. The lion is very abundant and very bold; but the leopard is more feared by the natives than his larger ally. While stopping in Mandara's country, two of that chief's subjects were killed by leopards, one of them

an article of food. Vide the paper on the Cameroons, by the Rev. George Grenfell, in the "Proceedings of the Royal Geographical Society," October, 1882, p. 590. Doubtless the great resemblance to human flesh is not held as a drawback. 
close to the frequented village-green. The leopard ascends the mountain up to about 8000 feet, scarcely higher. I shot one of these creatures in the valley of a stream in broad daylight. I think it had been sleeping by the water, and was suddenly awakened by my near approach, and too dazed to fly immediately. The most common dog is the side-striped jackal. There is a wild dog found on Kilima-njaro which barks loudly. It is quite nocturnal, and $\mathrm{I}$ have never been able to shoot it; but from its appearance in bright moonlight it looks somewhat like the Abyssinian dog (Canis Simensis). The natives know it by a different name from that applied to the jackal-viz. Nzudu.

Hyenas are very common, and both species, striped and spotted, are present; but the striped hyena more affects the hills, while the spotted kind inhabits the plains. The spotted hyena is a much more predatory animal here than one generally imagines. Not only does it steal sheep and calves from the herds, but it even carries off children, and will often attack wounded or weakly men. I once sent a sick man back to the coast a short distance by himself, and he was severely bitten at night by the hyenas. He succeeded, however, in beating them off, and recovered from his wounds.

Civets and genets are very abundant; so also are one or two specimens of ichneumon. I noticed no kind of weasel, ratel, or badger.

The Orycteropus Athiopicus, or Ant-bear, is common on the plains, to judge by his many huge burrows; but I have never seen him, and only identify him from natives' descriptions.

Among the Rodentia there were few that came under 
my notice. A species of Graphiurus ${ }^{2}$ (probably $G$. capensis) is found in the forests of Kilima-njaro. The porcupine is fairly common, and a small black rat infests the natives' houses.

A hyrax is found on Kilima-njaro (H. Brucei) between 7000 and 11,000 feet. It lives entirely in the trees, which it climbs with the facility of a squirrel. It is much sought after by the Wa-čaga for its warm, furry skin, which is made into cloaks.

The elephant inhabits Kilima-njaro up to a great height. I have seen two females and a young one at an altitude of 13,000 feet, crossing a stream-valley, and mounting the opposite bank with the agility of goats. As I have also met with this creature in the Chella Mountains of Angola, where he climbs to 8000 feet, in fact, as high as he can go, I am convinced he can easily adapt himself to a mountain life.

Round the base of Kilima-njaro the rhinoceros is very abundant; and in Lake Jipé hippopotami are found. The zebra (Equus Chapmani) is present in incredible quantities in the plains round Kilima-njaro. In fact, the vast herds of varied game which pasture on the level country between the snow mountains and the coast remind one of the tales of Gordon Cumming.

Among the more noticeable Ruminantia are the buffalo (Bubalus Caffer), the giraffe (very abundant), the eland, the kudu, the bush-buck (Tragelaphus sylvaticus), the sable antelope (Hippotragus niger), the pallah, one or two gazelles, gnus, hartebeests, blessboks, and many small species of Neotragus and Cephalophus, The kudu penetrates up the mountain to a height of 14,000 feet, in company with the buffalo,

2 For illustration vide p. 392. 
attracted possibly by the sweet perennial pasture. A Neotragus and a Cephalophus are also found at high altitudes. I give here a drawing of a head of the

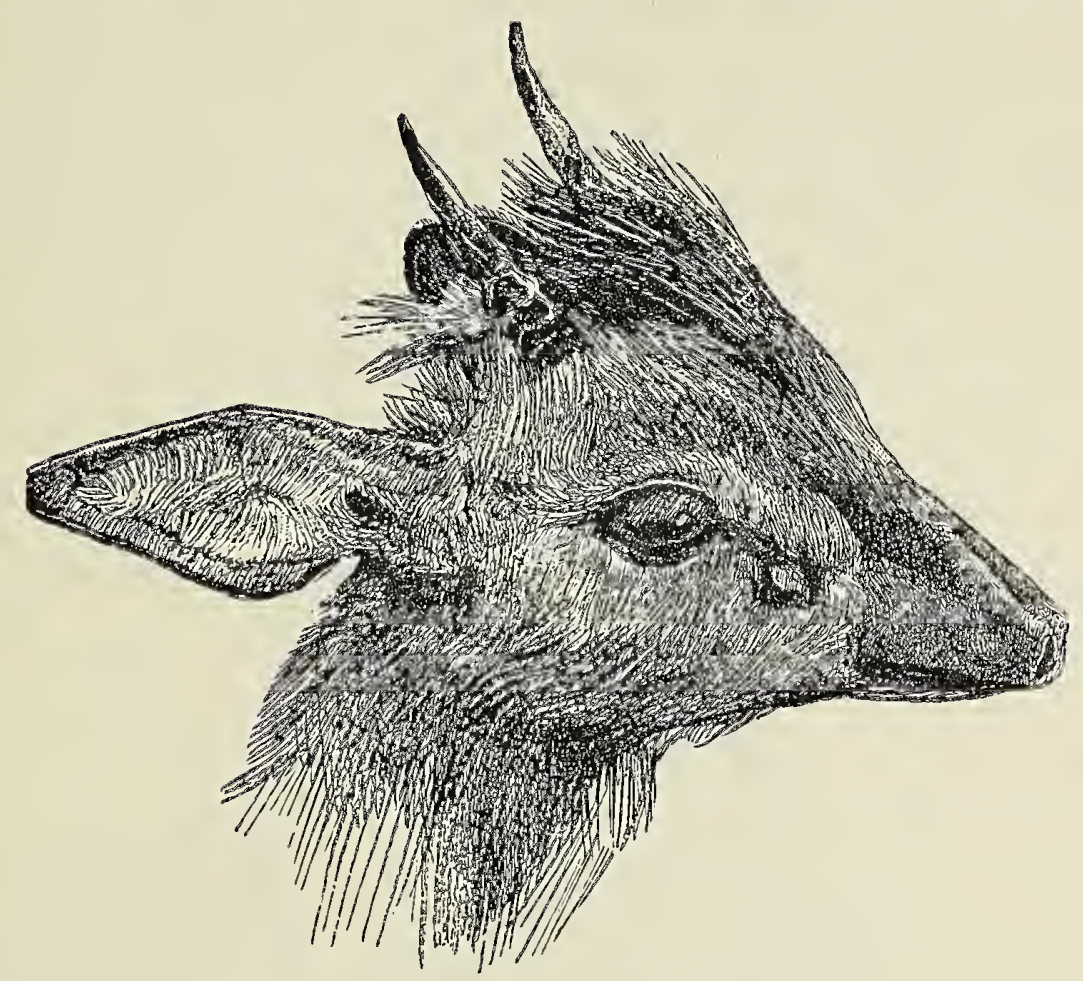

Fig. 66.-Neotragus Kirti.

little Neotragus antelope (possibly $N$. Kirki) found on Kilima-njaro. As you may see, it has the nose nearly developed into a trunk, a tendency which is very common, after all, among mammals, and which reaches its utmost development with the elephant.

In the plains round Kilima-njaro the red hartebeest (Alcephatus Cokei) is found in myriads. This creature by the colour of its coat and its strange shape assimilates marvellously with the huge red ant. hills (habitations of the white termites) which abound in the districts favoured by the hartebeests. When you are out stalking it is really most difficult and. puzzling sometimes to know which is hartebeest and ant-hill; for the long grass hiding the antelope's legs leaves merely a red humped mass which, until it

A a 2 
moves, may well be a mound of red earth. The unconscious mimicry is rendered the more ludicrously exact sometimes by the sharply-pointed flag-like leaves of a kind of lily which frequently crown the summit of the ant-hill or grow at its base, thus suggesting the horns of an antelope, either with the head erect, or browsing low down. Vide Chapter IV.

Among the passerine birds of Kilima-njaro I have brought back six that are new to science. Three of these are sun-birds, one is a flycatcher, and the remaining two are chats. The sun-birds are found very high

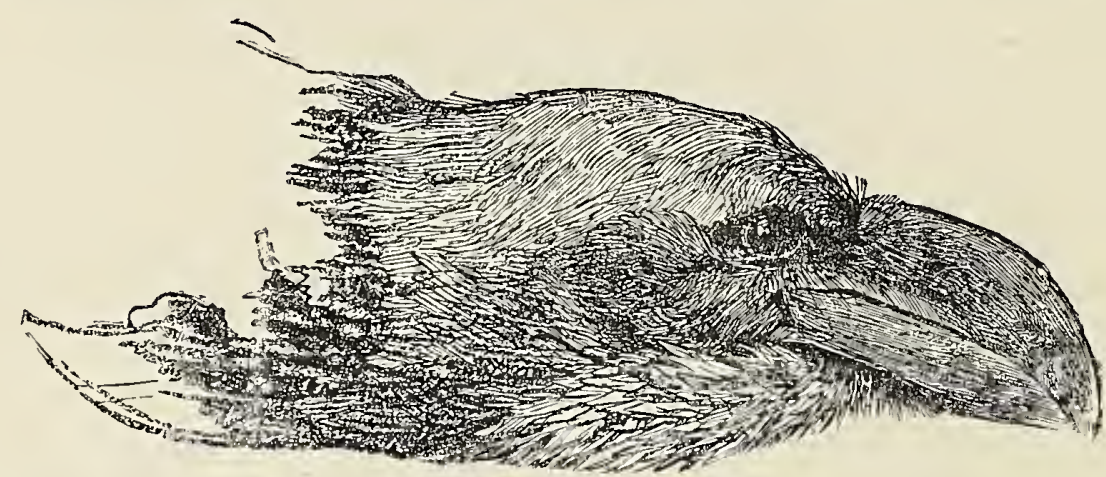

Fig. 67.-Head of Great-billed Raven (Corvultur albicollis).

up the mountain, in that resembling the hummingbirds which frequent the Andes near to the snow-line. They hover round the long tubular flowers of certain labiate plants, and on being captured it will be noticed that the feathers of the brow are thickly covered with pollen, so that in these regions sun-birds share with insects the means of fertilizing flowers.

The bird mentioned in Chapter XIII. as being found at a height of 14,000 feet, the highest dweller, except the occasional passing ravens or kites, is Pinarochroa hypospodia, a kind of stone-chat.

Other passerine birds of a note are a lovely oriole (Oriolus notatus), which frequents the forests of the 
lower slopes, and the great white-necked raven, alluded to and illustrated in Chapter XIII.

The great crested hornbill (Buceros cristatus) is generally distributed over the mountain up to 6000 feet, especially near habitations. They show no fear of man, being generally protected by the natives, who look upon them with superstitious awe, arising possibly from their being useful scavengers, as well as from their peculiar loud cry, which resembles at times

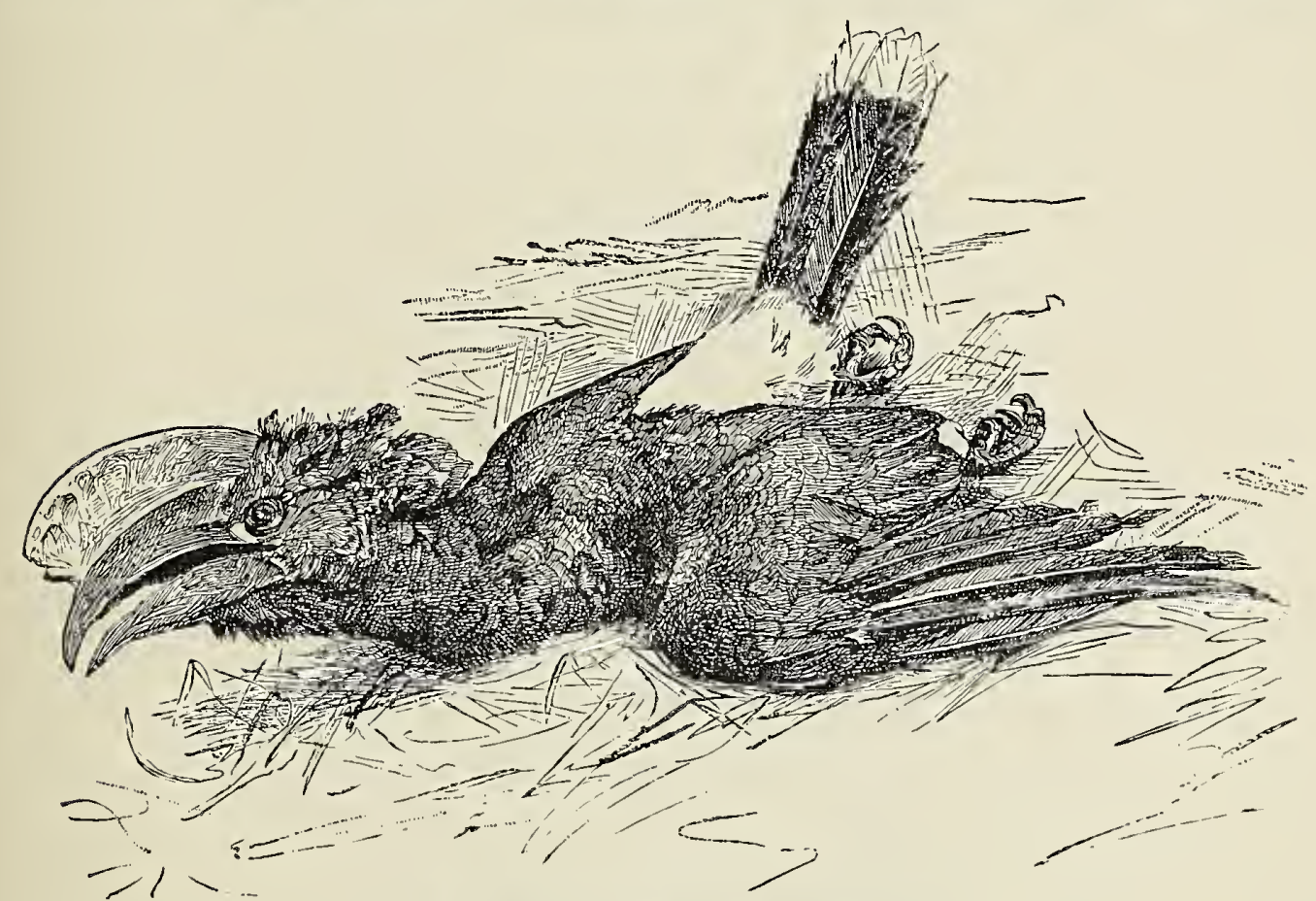

Fig. 68.-The dying Hornbill.

that of the wailing of a woman in distress, at others that of the braying of an ass. In August and September they are generally breeding, and occasionally the head of the female may be seen peering out from a hole in a tree, some thirty or forty feet high, where she has been plastered in by her affectionate husband. By the chips lying about it would appear that these holes are excavated by the birds to the required size. They are monogamous, and show great affection for each other, which is fortunate, as the female during 
incubation has entirely to rely on her mate for daily sustenance. I shot a fine male hornbill once, at Taveita, and he fell to the ground mortally wounded. His dying struggles were quite touching to behold, and I felt almost criminal in having caused his death. His breath came and went in great gasps, and his snowy stomach was streaked with red blood. His large eye with long lashes gazed at me with calm wonder and vague reproach, as if to say, "What ill have I done that you should kill me?" He disdained to snap at the stick with which I gently poked his opened beak, and still kept his eye fixed on me, regarding my impertinent investigations of his person as unnecessary insults. So he lay during sorne minutes, with long shuddering breathings raising and lowering the feathers of his breast and back. Then another hornbill, evidently his mate, came and perched on the bough of a neighbouring tree and uttered a low cry. The dying bird started up to life again, raised his head high, flapped his wide-spread, glossy wings, dragged himself painfully along the ground, and gave vent to one sonorous bellow; then his great head dropped on one side, and his wide-open eye glazed with an expression of eager hope hardened in it even in death.

A beautiful turaco inhabits the forests in Kilimanjaro. It is bluish-green-purple, with a white-lined crest and scarlet skin round the eyes. Its wings, like most other turacos, have intense crimson pinions, and therefore it is a gorgeous object as it flaps its loose flight through the forest aisles.

Several species of pigeon are found on the mountain, notably one very fine bird, Palumbus arquatrix, which inhabits the upper regions. 
Francolin and guinea-fowl are most abundant, but the latter bird I have never met with at any great altitude above the plains.

Numbers of water-birds frequent the shallow lakes and swamps in the vicinity of Kilima-njaro. Lake J̌ipé is a great resort of pelicans, geese, ègrets, and saddle-billed storks. I have only noticed one waterbird on the mountain at any altitude, and this was a species of duck, I think Anas xanthorhyncus, which was found inhabiting ice-cold streams at an elevation of 11,000 feet.

The abundance of vultures has already been remarked, and is in marked contrast to what may be observed in West Africa, where these vultires are absent, and their place is filled by another Accipitrine scavenger (Gypohierax), who apparently finds so little offal to sustain him, that he has in many places to turn his attention to fishing. ${ }^{3}$

The ostrich which is so numerous in the vicinity of Kilima-njaro, is a recently determined species-Struthius Danaoides, Shelley-apparently differing from S. camelus in the colour of the soft parts and naked skin, and the size and markings of the egg. I kept many of the young ostriches alive during my residence at Taveita. As most of my readers know, young ostriches for the first few months of their life are covered with curious scale-like plumes, but, unless they are scientific ornithologists, they may not be also aware that the hand (wing) of the ostrich exhibits three fingers, instead of the two that most other birds possess. The third finger is without a claw. This is but one of the many details which make the ostrich more reptilian than other living birds. The ostriches

${ }^{3}$ Vide "The River Congo," p. 356. 
breed during the months of June, July, and August in the vicinity of Kilima-njaro. The hatched young appear about the month of October, or a little earlier. I am told by the Wa-taveita that for the first few days after emerging from the egg they remain under

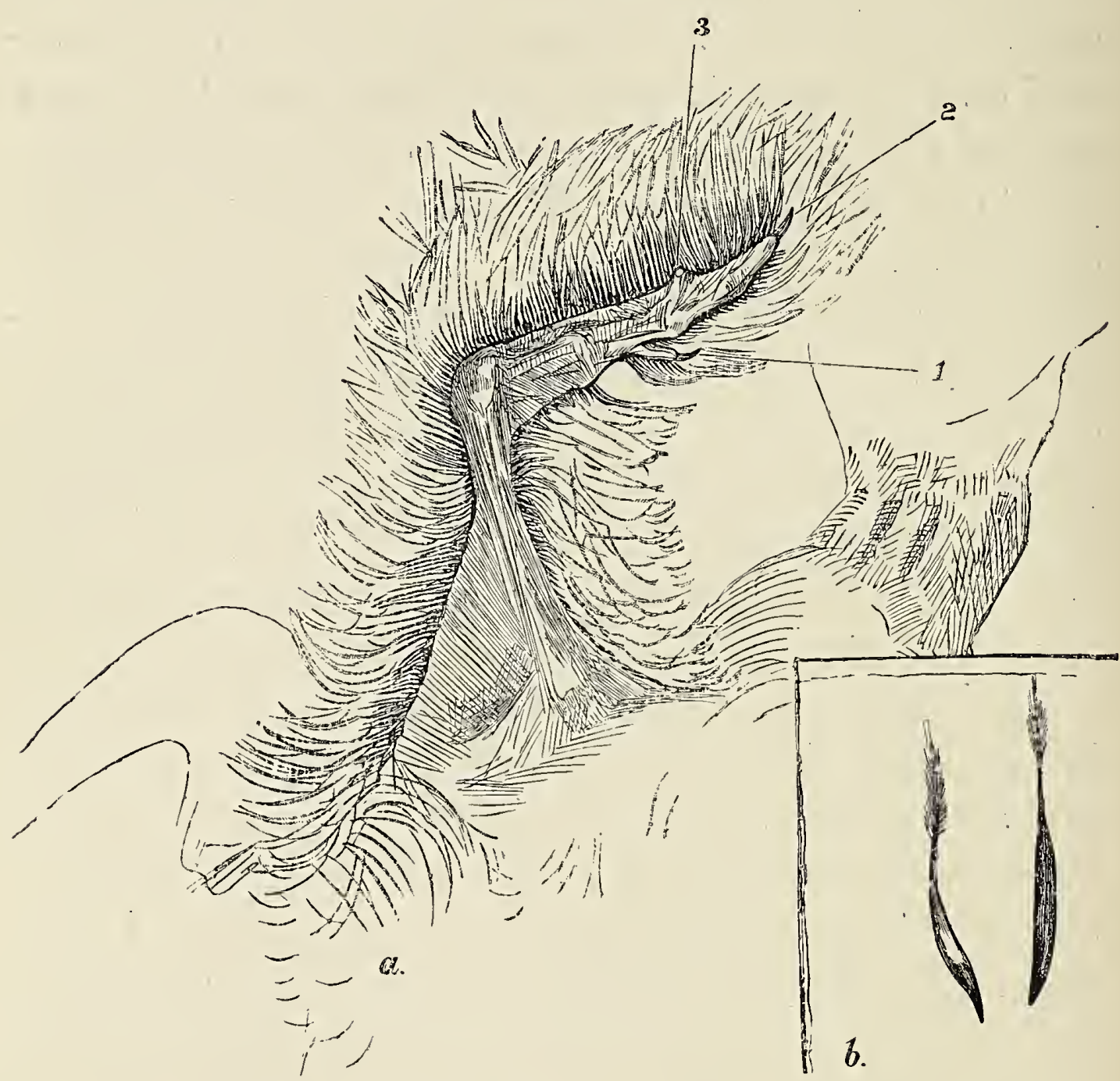

Fig. 69.-(a) The right Manus or Wing of young Ostrich. (b) Scale Feathers of young Ostrich.

the guardianship of the mother, but I must own that whenever I have myself seen them, they were, no matter if young enough to be run down and easily captured, unaccompanied by any parent. Nevertheless the natives persist in their statement, and they further averred, without any questioning from me, that 
the male ostrich simulates lameness (like the peewit and the wild duck), in order to distract the pursuit of his children by would-be captors.

Among reptiles, crocodiles are found in Lake Jipé and in the River Ruvu. Large varanus lizards (Monitor niloticus) are frequently found in the forests of Taveita. They share the water and the trees as their habitat, generally plunging into the stream when frightened or disturbed. They seem to me to feed largely on fish, and no doubt often capture and eat small squirrels and birds. When extended full length along a tree-trunk, immobile, and exactly matching the colour of the bark with their grey-green mottled skin, these creatures are very hard to distinguish from their surroundings, and doubtless often in consequence deceive the sharp eyes even of a squirrel. From what I know of these creatures, and from what the natives tell me, they use their long, heavy, whip-like tail as a powerful weapon. When driven into a corner they will slash right and left, and if the tail strikes your shins they will certainly be barked. A blow with the tail will kill a dog, and I believe many an unwary bird, squirrel, and possibly small monkey, is flicked from a tree overhanging the stream into the water, and plunged after by the agile lizard. The teeth of this creature are weak and blunt, and only sufficient for mastication.

There are some five species of snakes, mostly nonvenomous. The common python is present.

Chameleons are not only very common on Kilimanjaro, but are found up to an altitude of 13,000 feet. The natives consider them venomous and hurtful, and scream with fear if one is pushed near them. They regarded me as a sorcerer when I handled these crea- 
tures with impunity. Of course the poor little chameleons, like the "effets" that our nurses always warned us against, are entirely innocuous, and make, moreover, interesting pets, being a source of amuse-

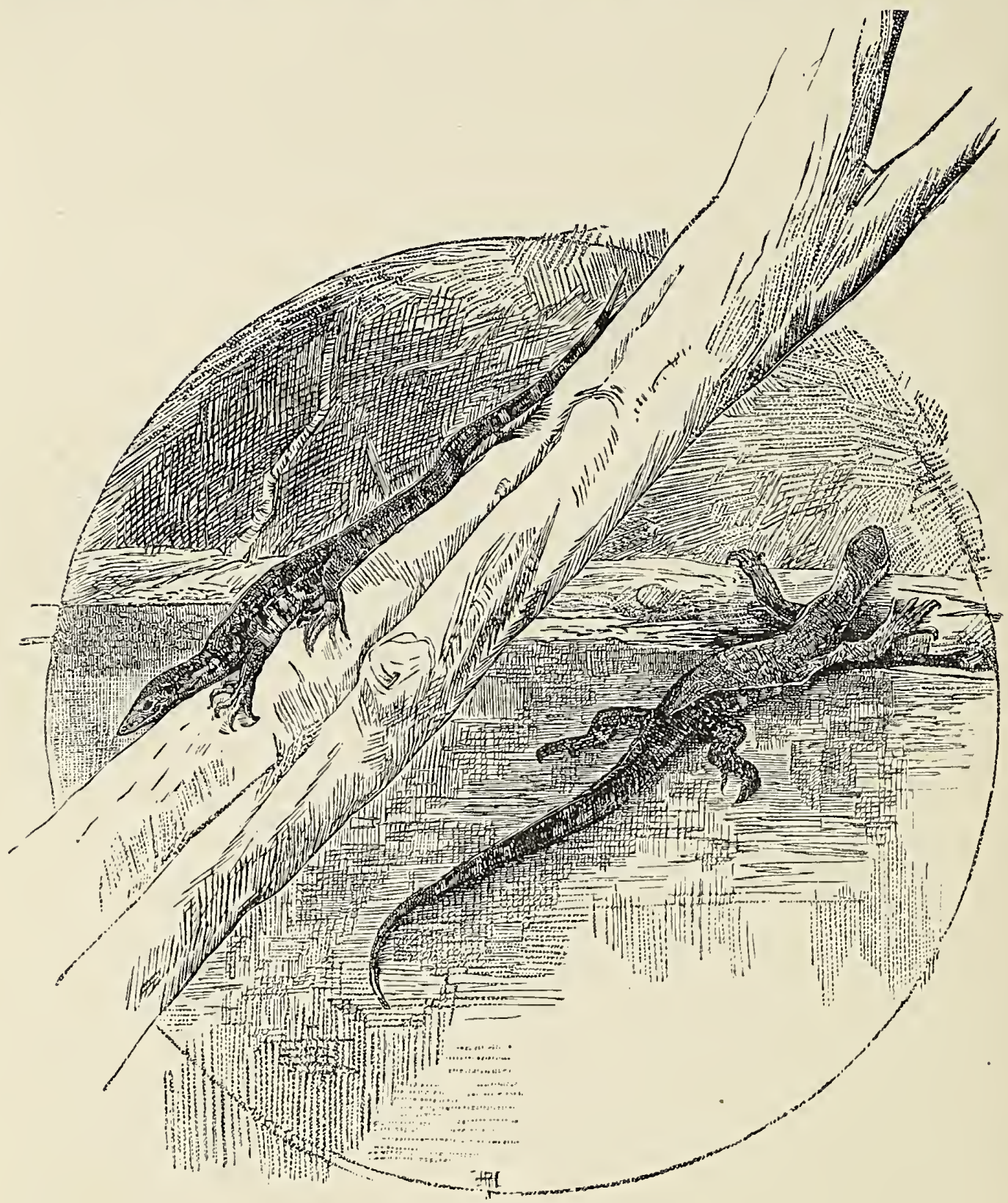

Fig. 70.-Varanus Lizards.

ment with their goblinish ways and strange appearance. Frogs are found in the ice-cold strearns as high up as 13,0()0 feet. Tree-frogs of many kinds haunt the forest, and chirp perseveringly. 
Fish are nowhere found in the rivers of Kilima-njaro, save in the River Lumi, which flows into Lake Jipé. I give a drawing of the only kind caught in the Lumi,

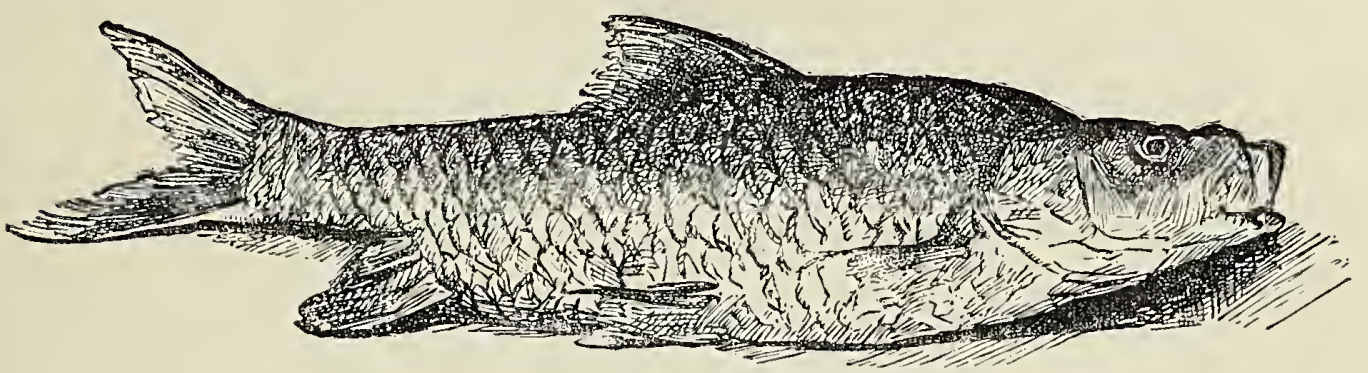

Fig. 71.-A Fish from the River Lumi.

which is the river of Taveita. It is probably a species of Barbel or Labio, of the family Cyprinida. In Lake J̌ipé a silurus is very common, and there are many other kinds of fish also present, but the shores of the lake are deserted, nobody fishes there, and the fish would not rise to ordinary bait; and therefore as my time at J̌ipé was short, and my health bad, I had no opportunity of investigating its piscine forms. Freshwater crabs of the genus Thelphusa ( $T$. depressa, var. Johnstoni) are present in most of the mountain streams. They appear to be most closely related to the rivercrabs of Natal and South Africa.

Throughout this region butterflies are few and scarce. They do not penetrate much higher than 8000 or 9000 feet. The common clouded yellow is often seen on Kilima-njaro.

Bees and wasps penetrate to a height of 14,000 feet. They belong principally to the genus Xyloropus. Most of the beetles are allied to, or identical with, South-east African forms. One new species has no allies nearer than India. Others are related to Abyssinian species, and some to the beetles of Somaliland. 


\section{APPENDICES ${ }^{1}$}

1. Note on a Nematoid Worm (Gordius verrucosus) obtained by Mr. H. H. Johnston on Kilima-njaro. By F. Jeffrey BeLL, M.A., F.Z.S.

THe single specimen of Gordius which was obtained by Mr. Johnston belongs to a well-known and widely-distributed species, but yet presents points of interest such as are almost always absent from socalled new species.

So far as my knowledge extends (and on this particular point it is in advance of that of Dr. Linstow, who, in his valuable "Compendium der Helminthologie," does not mention the parasite now under consideration), Gordius verrucosus is in earlier life parasitic on a species of the genus Mantis; and there is in the British Museum a specimen of "Mantis, sp.," which, as Mr. Waterhouse has been good enough to point out to me, is really $M$. membranacea, accompanying a Gordius. The whole of the abdomen of this Orthopteron is completely emptied of its contents. A similarly excavated Mantis, the appearance of which had excited Mr. Waterhouse's wonder, is to be found among the insects collected by Mr. Johnston between 3000 and 5000 feet.

A specimen, belonging apparently to the same species, is to be found half-in and half-out of the abdomen of Hierodula bioculata, a Mantid collected on the west coast of Africa, and lately presented to the trustees by Dr. Günther, F.R.S.

With regard to the geographical distribution of the species, it is to be noted that it is sufficiently wide to include South Africa and Ceylon; while there are in the British Museum specimens named respectively by Dr. Baird, the author of the species, and by Dr. Örley, who in 1881 went carefully through the collection in the Museum; these specimens are reported as coming from Vera Paz, Guatemala (presented by O. Salvin, Esq.), and the "neighbourhood of Irazu, Costa Rica" (presented by Messrs. Godman and Salvin). The fact that the same parasite is to be found in hosts of different species is well

${ }^{1}$ Mostly reprinted (by permission) from the "Proceedings of the Zoological Society, 1884-5" -in some cases with a few additions on my owll part. 
known. The present case, in which Mantis membranacea from Ceylon, Idoleum diabolicum from Kilima-njaro, and Hierodula bioculata from West Africa, are infested by a common form, is almost exactly paralleled by the case of the Tcenia described by Peters from a rhinoceros from the Mozambique, and by Murie and Garrod in rhinoceri from India.

As to the second point which has arisen, the presence of $G$. verrucosus in Central America, I note differences in the form of the integumentary papillæ, which are sufficient to induce me to suggest that no stress should be at present laid on this point, though they are not enough, when taken in conjunction with my own want of experience in the degrees of possible variations, to lead me to put myself into more decided opposition to the views or determinations of such workers as Dr. Baird or Dr. Örley.

\section{Description of a new Variety of River-Crab of the Genus Thelphusa, from Kilima-njaro. By E. J. Miers, F.L.S., F.Z.S.}

The species of Thelphusa, or River-Crabs, are extremely numerous, and their discrimination is often very difficult, on account of the changes which the species undergo as they increase in age and size.

In the collection brought by Mr. H. H. Johnston from Kilima-njaro are two specimens of this genus, which I assign, though not without some hesitation, to the Thelphusa depressa, Krauss, described from types taken near Pietermaritzburg, Natal. They agree with the description and figure in their depressed carapace, which is considerably dilated at the branchial regions, in the non-development of the lateral epibranchial tooth, and in other essential characters; but differ in the more strongly defined cervical suture of the carapace, and the more strongly denticulated merus, and much less strongly arcuated dactylus of the chelipedes. As regards this latter character, I may observe that in a series of Thelphusce (perhaps T. difformis) in the Museum collection, the dactyli of the chelipes are in some males arcuated, and in others nearly straight.

I append a detailed description of the specimens from Kilima-njaro, which I propose to designate $T$. depressa, Krauss, var. Johnstoni, but which may prove to belong to a distinct species.

Thelphusa Depressa, Krauss, var. Johnstoni.

Cf. Thelphusa depressa, Krauss, Sudafrik. Crustaceen, p. 38, pl. 11. fig. 4 (1843).

Carapace transverse, widest in its post-frontal region, depressed, with the dorsal surface nearly smooth, and divided into two nearly 
equal portions by the zigzag cervical suture, which extends transversely across the carapace to the postero-lateral margins; behind this a second transverse depression (not a suture) crosses the carapace behind the cardiac region. The postfrontal crest extends to the antero-lateral margins of the carapace, and is interrupted only by the meso-gastric suture, which bifurcates posteriorly (as usual in the genus); this crest is granulated near to the antero-lateral margins, which are defined by a distinctly granulated line; the lateral epibranchial teeth are not developed. On the hepatic and branchial regions are several faintly indicated lines, which extend inward for a short distance over the dorsal surface of the carapace from the lateral margins. The front is about one-third the width of the carapace, punctulated above, with its anterior margin sinuated, its antero-lateral angles obtuse and not prominent. The orbital margins are entire, and defined by a raised line, which is granulated except near to the front; the inferior orbital margin is regularly arcuate, not (as in $T$. perlata) angulated near to the interior subocular lobe, which is not at all prominent; the tooth, also, at the exterior orbital angle is very little developed; the parts of the carapace adjoining the antero-lateral angles of the buccal cavity are very distinctly granulated. The eye-peduncles are slender (for a species of this genus), and the eyes do not attain the exterior angle of the orbit. The exterior maxillipedes are formed as in T. perlata, having the ischium and merus of the endognath distally truncated, the merus rounded at its antero-external angle, and scarcely emarginate at its antero-internal angle. The chelipedes in the adult male are unequal, the right the larger; in both the merus is armed with a series of spinules on the anterior margin, and with a somewhat longer spine near the distal extrenity; the carpus with a spine followed by a smaller spinule on the inner margin; the palm is somewhat compressed and nearly smooth, rounded above; the dactyl and pollex are denticulated on the inner margins, and have between them, when closed, a rather narrow interspace; the dactyl is slightly arcuated and as long as, or rather shorter than, the palm. The ambulatory legs are of moderate length, with the fourth to sixth joints compressed, and with the superior margins acute; the margins of the penultimate joints near to the distal extremity and the dactyli are armed with small spinuliform teeth, which on the dactyli are disposed in four longitudinal series.

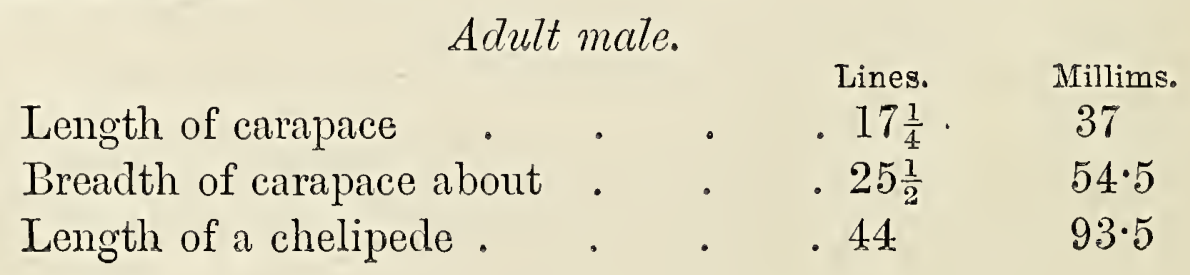


This form may be distinguished from other African species in which the postfrontal crest is distinctly developed, by the following characters :- From T. perlata, M. Edw., which is found at the Cape and Port Natal, by the wider transverse carapace, which is more dilated at the branchial regions, and not dorsally granulated near the anterolateral margins, and by the form of the orbit, whose inferior margin is regularly concave (not as in specimens referred to T. perlata in the Museum collection), abruptly angulated near the interior subocular lobe. From T. inflata, M. Edw., by the less convex carapace, straight postfrontal crest, and the granulated line which borders the anterolateral margins of the carapace. T. aubryi, M. E., T. africana, A. M. E., and T.emarginata, Kingsley, from the Gaboon, West Africa, and Port Natal, have an additional tooth between the exterior angle of the orbit and the postfrontal crest. In T. goudoti, M. E., from Madagascar, the postfrontal crest is less developed, and the immobile finger of the chelipedes forms more or less of an angle with the inferior margin of the palm. Another species from Madagascar, T. madagascariensis, A. M. E., which has not, I believe, been figured, is distinguished by the lesser development of the postfrontal crest and the straighter fingers of the chelipedes, which meet along their inner margins. In the West African T. bayoniana, T. anchietce, and T. dubia, Brito Capello, the lateral epibranchial tooth is more developed. In T. limulc Hilgendorf, from Senegambia, the postfrontal crest is less distinctly developed near the lateral epibranchial teeth, behind which, in the males, are indications of two other teeth.

\section{A List of the Lepidoptera collected by Mr. H. H. Johnston DURing his ReCent Expedition to Kilima-njaro. By F. D. Godman, F.R.S., \&c.}

Mr. Johnston's collection of Lepidoptera contains 61 specimens, including 27 species ; of the latter there are 21 species of Rhopalocera and 6 of Heterocera. Of the Rhopalocera I have described three species as new, and a fourth, a Chrysophanus, of which only one specimen of a female is in the collection, remains unnamed, though it too is probably.new. This small collection therefore contains nearly twenty per cent. of novelties, which must be considered a high proportion.

But so small is the series that I do not think any comparison of the Lepidopterous fauna of this region with that of the rest of Africa can be entered upon with advantage. Suffice it to say that by far the majority of the species are widely distributed African ones; that there is a northern element, as shown in Colias edusa, 
and perhaps the Chrysophanus; and that there is barely a trace of the Abyssinian fauna in the materials before me. But these suggestions may all be set aside whenever a representative collection is made. Of the 27 species no less than 19 are represented by single specimens.

\section{RHOPALOCERA.}

\section{Danais dorippus.}

Eupleaa dorippus, Klug, Symb. Phys., Insecta, t. 48. f. 1-5.

Kilima-njaro, rocky, wooded, and cultivated country and grassy downs, at 4000-5000 feet, July.

Four examples (2 $\hat{\delta}, 2$ q).

None of these specimens have any white on the secondaries, and agree best with Fig. 5 of Klug's plate. D. dorippus is a common East African species.

2. Acrea Johnstoni, sp. nov.

Alis anticis rufis, apicibus et marginibus externis (introrsum valde sinuatis; nigro-fuscis) posticis ad basin et marginibus externis late nigrescentibus, area discali albida venis fuscis divisa; subtus anticis fere omnino rufis ad marginem externum canescentibus, venis nigris et inter eas striolis fuscescentibus; posticis ut supra limbo externo canescente venis et striolis inter eas diviso; maculis quibusdam ad basin nigris; palpis, femoribus iuterne, abdomine infra, et maculis costalibus, rufis ; capite et thorace maculis albis notatis.

Kilima-njaro, clearing in forest at 5500 feet, September.

A single male specimen of this apparently very distinct species.

3. Acrea insignis.

Acrcea insignis, Distant, P. Z. S. 1880, p. 184, t. xix. f. 6 .

Acrcea Buxtoni, Hew. Ent. Month. Mag. xiv. p. 154.

Kilima-njaro, wooded hills at 5000 feet, August.

This insect was first described by Hewitson from examples procured by Buxton in the neighibourhood of Zanzibar, and was named by him after its discoverer. Mr. Distant pointed out that the name $A$. Buxtoni had been already applied to another species by Mr. Butler, and hence renamed it as above. Our collection contains a good series of this insect, chiefly taken by Mr. Last at Mamboia in Eastern Central Africa. These exhibit considerable variation in the amount of black at the base of the secondaries, for while some specimens have only four or five isolated spots, others have a large confluent patch occupying the basal third of these wings, and between these two extremes we have every intermediate, all captured in the same locality and at the same time. 
Mr. Johnston procured but a single example, which has the confluent black patch, and agrees in this respect with some of our own specimens from Mamboia.

4. ACræa BResta, sp. nov.

Alis anticis semihyalinis ad basin rosaceo suffusis macula in cellula altera ad finem ejus quinque in serie fere recta ultra eam, una inter ramos medianos, duabus inter ramum medianum primum et venam submedianano nigris, margine externo fusco nigro maculis lunulatis submarginalibus rufs, posticis rosaceis ad basin obscurioribus margine externo nigro area discali plus minusve maculata; subtus anticis fere ut supra posticis flavidis nigro distincte maculatis, ad basin et marginem internum rosaceo notatis, margine externo nigro lunulis septem flavidis includente; fronte, palpis et pedibus fulvis; abdomine subtus flavido, lateribus albo maculatis; capite, prothorace et thorace albido distincte maculatis.

Kilima-njaro, in wooded country at 5000 feet, August.

A single male specimen allied to $A$. onccea, differing in its diaphanous primaries and its more rosy secondaries.

5. Acrea natalica.

Acrcea natalica, Boisd. Voy. Deleg. ii. p. 590 ; Hopff. Pet. Reise, Zool. v. p. 371, t. 23. f. 12, 13.

Kilima-njaro, grassy downs at 6000 feet, June.

One example ( $q$ ).

Agrees best with specimens of this species, but the disk of the secondaries is whiter and the spots in general are larger.

6. Pyrameis cardui.

Papilio cardui, Linn. Syst. Nat. i. p. 276.

Kilima-njaro, in thin forest country at 7000 feet, July.

One much worn male.

7. Junonia clelia.

Papitio cletia, Cram. Pap. Exot. t. 21. f. E, F.

Kilima-njaro, rocky country at 4000 and 5000 feet, wooded country and grassy downs at 5000 feet, June and July.

8. Junonia minone.

Papitio cenone, Linn. Mus. Ulr. pp. 274, 275.

Kilima-njaro, in rocky, grassy, and wooded country at 5000 feet, wooded country at 6000 feet, June and July.

Six specimens, all males, of this widely ranging species.

9. Precis sesamus.

Precis sesamus, Trimen, Trans. Ent. Soc. 1883, p. 347.

Kilima-njaro, forest country at 7000 feet, July.

One example $(\hat{\sigma})$. 


\section{Lycena gaika.}

Lyccena gaika, Trimen, Trans. Ent. Soc. 3rd ser. i. p. 403.

Kilima-njaro, grassy downs at 5000 feet, June.

One male.

The single specimen agrees with Trimen's description and with our series of this species. It appears to us to be distinct from L. lysamon, with which Mr. Trimen united his L. gaika in the "Rhopalocera Africæ Australis." Both species occur in South Africa, but L. lysamon may always be distinguished by the presence of a black spot within the cell of the primaries.

11. Chrysophanus, sp.?

Kilima-njaro, grassy downs at 5000 feet, June.

A single female example of a true Chrysophanus, which we are unable to recognize and which we hesitate to describe without specimens of the other sex.

\section{Terias Rahel ?}

Papilio rahel, Fabr. Ent. Syst. iii. p. 204 (apud Trimen).

Kilima-njaro, wooded country at 5000 feet, August.

A single female specimen, which we cannot undertake to determine with certainty without examples of the other sex. It may possibly be a female of $T$. candace, Feld., from Abyssinia.

13. Pieris severina.

Papilio severina, Cram. Pap. Exot. t. 338 , f. G, H.

Kilima-njaro, wooded country at 5000 to 6000 feet, July and August. Taveita, dense forest at 2300 feet, September.

One male and three females.

14. Pieris hellica.

Papilio hellica, Linn. Syst. Nat. i. p. 760.

Kilima-njaro, wooded, rocky, and cultivated ground, grassy downs, at 4000 to 5500 feet, July and August.

Thirteen males and one female.

All the specimens have the primaries rather more pointed, with a slightly blacker apex, and the colouring of the underside is brighter than in the examples in our collection.

15. Eronia Cleodora.

Eronia cleodora, Hübn. Samml. exot. Schmett. ii. t. 130.

Tavieta, in dense forest at 2300 feet.

16. Callidriyas pyrene.

Colias pyrene, Swains. Zool. Ill. i. t. 51.

Kilima-njaro, in wooded country at 5000 feet.

Two females only.

17. Callidryas florella.

Papilio florella, Fabr. Syst. Ent. p. 479. 
Kilima-njaro, in wooded country at 6000 feet

A single female specimen.

18. Colias edusa.

Papilio edusa, Fabr. Mant. Ins. ii. p. 23.

Kiliman-njaro, wooded and grassy countryat 4000 and 5000 feet, July. Four males and one female.

19. Teracolus auriginius.

Teracolus auriginius, Butl. Ann. Mag. Nat. Hist. ser. 5, vol. xii. p. 103.

Kilima-njaro, in wooded and grassy country, 5000 and 6000 feet.

Two examples agreeing with specimens in the British Museum thus named by Mr. Butler.

20. Papidio Demoleus.

Papilio demoleus, Linn. Syst. Nat. i. p. 753.

Kilima-njaro, in wooded country at 5000 feet, August.

A single specimen of this common African species.

21. Papilio brontes, sp. nov.

Alis nigris fascia lata communi, ad costam anticarum disjuncta, metallico-cceruleo, macula parva ad anticarum apicem et posticis serie submarginali ejusdem coloris, subtus fusco-nigris anticis ad apicem et posticis omnino, brunnescentioribus, his venis et striis tribus in cellula longitudinalibus nigris, fascia communi sub. marginali a vena mediana anticarum ad angulum posticarum analem transeunte, venis nigris divisa, in anticis quoque inter venas bisecta lactescente-alba, margine posticarum interno maculis parvis duabus ejusdem coloris, posticis subcaudatis, vena mediana producta.

Kilima-njaro, in forest country at 5000 feet, August.

Allied to Papilio bromius, but the transverse band is of a deeper blue, both wings are less elongated, the secondaries are more acutely produced at the anal angle. Beneath, the light coloured submarginal band is straighter on the secondaries and less broken up, moreover it is extended on the primaries as far as the median nervure beyond the cell, the apex of primaries and the secondaries are browner and though the latter have three radiating streaks in the cell as in $P$. bromius, there are no intervenal streaks beyond it.

A single male specimen is the only one Mr. Johnston obtained.

\section{Heterocera.}

Mr. Johnston's collection contains six specimens of as many species of Heterocera, and for these Mr. Butler has kindly given us the following names. 
22. Acherontia atropos.

Kilima-njaro, forest at 3000 feet, September.

23. Mecyna polygonalis.

Kilima-njaro, wooded country at 5000 feet, August.

24. Hrpina, sp. ?

Kilima-njaro, wooded country at 5000 feet, July.

25. STERRHA OACRARIA.

Kilima-njaro, scrubby heath at 8000 feet, July.

26. Prodenia?

Kilima-njaro, wooded country at 5000 feet, September.

27. Amrna, sp.?

Kilima-njaro, wooded country at 5500 feet, August.

4. ON the Insects collected on Kilima-njaro by Mr. H. H Johnston. By Chas. O. Waterhouse.

\section{COLEOPTERA. ${ }^{2}$}

The series of Coleoptera collected by Mr. Johnston comprises examples of fifty-six species. Many of them belong to widely distributed genera and are not of special interest.

Of the nine species taken at an elevation of 10,000 to 14,000 feet, the following are worthy of note:-Two male examples of Carabus Deckieni, Gerstaecker, which was described from a single female example found in this mountain. The species, however, proves to be a Calosoma, and not a Carabus, and is nearly allied to a species found in Abyssinia.

There is a single specimen of one of the Trichiidæ, which I have provisionally placed in the genus Calometopus, although the clypeus not being emarginate it is possible that a new genus may have to be made for its reception. I have named the species Calometopus planatus. There are only two species of this genus known, $C$. senegalensis and $C$. nyassa.

The third species which I would mention is one of the Heteromera of the family Moluridæ. I have named it Melanolophus ater; it appears to be most nearly allied to $M$. septemcostatus, described by Fairmaire in Revoil's "Faune et Flore des Pays Çomalis," but which, if I have correctly determined it, occurs also in Abyssinia.

Of the species found at lower elevations the majority, so far as I have identified them, are only known from South-east Africa (e.g.

2 A plate illustrating the new and rare species in this collection is given in the "Proceedings of the Zoological Society," p. 231. 1885. 
Melyris parvula, Gerst., Himatismus buprestoides, Gerst., Amiantus castanopterus, Haag, Sepidium muscorum, Gerst., Anomalipus heraldicus, Gerst., Mylabris kersteni, Gerst., Epicauta dichrocera, Gerst., Rhopalizus sansibaricus, Gerst., Phrissoma giganteum, Guérin); others are found in most parts of Africa (e.g. Calosoma senegalensis, Dej., Oryctes boas, Fabr.).

Of the new species which I describe, Scarabreus cribricollis has its nearest ally, so far as I know, in an Indian species S. sanctus, Fabr.; Amblysterna Johnstoni is nearest to A. natalensis, Fabr.

\section{Carabide.}

Carabus Deckeni, Gerst.

This interesting species was described by Dr. Gerstaecker (Wiegm. Arch. f. Naturg., 1867, p. 10 ; Von der Decken's Reise in Ost-Africa, iii. p. 56, pl. iv. f. 2) from a single female example found by Dr. Kersten on Kilima-njaro at an elevation of 8000 feet.

The two examples male and female found by Mr. Johnston differ from the female described by Dr. Gerstaecker in being rather smaller (only 13 millim. long), and, so far as one can judge from description, in having the elytra smoother with less impressed striæ.

Dr. Gerstaecker remarks on the fact of a species of Carabus being found in this locality, none ever having been found before in South Africa. The species, however, is not a Carabus, but a Calosoma, as is indicated by the compressed third joint of the antennæ; a character which Dr. Gerstaecker overlooked when he stated that the separate joints of the antennæ are formed as in Carabus pumilio.

\section{SCARABeide.}

SCARABAUS CRIBRICOLLIS, n. sp.

Black, somewhat dull. Head closely and very strongly punctured, the punctures longitudinally confluent on the front of the clypeus, the anterior teeth of which are rather acute and moderately reflexed. Thorax nearly twice as broad as long, moderately convex, with a transverse impression in the middle of the base. In the middle of the disk is a shining (but finely punctured) line, which does not extend much beyond the middle; all the rest of the surface is strongly punctured; the punctures near the shining line are a little separated from each other, but at the sides and on the fore part they are crowded together and asperate; the sides are strongly rounded, finely serrate, and fringed with black hair. The elytra are a little narrower than the thorax, very slightly narrowed posteriorly, dull, but with the suture shining; the striæ are fine, the interstices flat and finely coriaceous (except the sutural interstices and the scutellar 
region), with numerous dull shallow punctiform impressions placed very irregularly. Femora and tibiæ fringed with black hair. Sternum smooth and shining, with a well-marked broad impression between the intermediate legs.

Length 22 millim.

This species most nearly resembles the Indian Scarabceus sanctus, Fabr. The sides of the thorax are, however, more regularly rounded, much less sinuate before the posterior angles; the shining discoidal line is broader, and there are no smooth spots on each side of this line. The elytra have the striæ finer and neater, the interstices are flatter, coriaceous, with the punctiform impressions smaller and nore separated from each other.

Onthophagus Johnstoni, n. sp.

Entirely black, except the apex of the antennæ, which is rustyyellow. Head as long as broad, obliquely narrowed in front of the middle, rounded at the apex, closely and coarsely rugose, except near the eyes. There is a slightly raised straight ridge between the eyes, and a second, longer one halfway between this and the front of the clypeus. The thorax is smooth, shining at the sides and in front, slightly dull above; the fore part is perpendicularly truncate; the truncature bounded above by a slightly prominent ridge; viewed from the front there are three shallow impressions : on each side there is a line of small tubercles bounding the discoidal area; the surface of the disk is moderately closely but extremely delicately punctured, and appears impunctate to the naked eye; the sides are more distinctly punctured: the base is oblique on each side, and is angularly produced in the middle. The elytra are convex, shining, not quite twice as wide as the length at the suture, rounded at the sides and apex, very delicately striated, the striæ delicately punctured; the interstices flat, sparingly punctured; near the suture the punctures are extremely delicate but become more distinct towards the sides. The pygidium is rather sparingly but distinctly punctured. The sides of the sterna, the margins of the fenora, and the posterior tibiæ are fringed with long black hair.

Length 21-25 millim.

I know of no species which much resembles this. Its most near ally is a species which I have seen named O. noctis, Th., in Mr. Bates's collection. The species has somewhat the general build of 0 . marsyas, Ol.; the head is longer, the clypeus not sinuous at the sides; the thorax rather flatter above, with a prominent, nearly straight ridge in front above the anterior perpendicular truncature; the anterior angles are as if truncated; the base is more angularly produced in the middle of the base ; the elytra are scarcely narrowed at the base, \&c. 


\section{TRICHIID五.}

Calometopus? planatus, n. sp.

Nearly black; the elytra dark testaceous, with the suture, margins, and a lunate spot near the scutellum smoky black. Antennæ and tibiæ reddish yellow, the margins of the abdominal segments pale yellow. Head very closely and rather strongly punctured; the clypeus more finely punctured, a little broader than long, not emarginate at the apex, but slightly arcuate, the angles obtuse; all the margins reflexed. Thorax a very little broader than long, moderately convex, very strongly and rather closely punctured, parallel at the sides to considerably in front of the middle, where it is obliquely narrowed; the anterior angles nearly right-angles, very slightly prominent; the posterior angles obtusely rounded; the base gently arcuate and margined : on the disk there is a slight impression a little in front of the middle: the sides have the lateral ridge only behind the middle and at the anterior angle; the slightly swollen under flank is thus not separated from the upper surface of the thorax in front of the middle. Scutellum elongate, triangular, strongly punctured. Elytra twice as broad as the thorax, a little longer than broad; flat, with the sides nearly perpendicularly deflexed; dull, the suture and sublateral ridge shining : each elytron with six somewhat irregular dorsal lines of dark punctures; the apex closely rugulose. Pygidium closely vermiculatestrigose. Club of the antennæ a little longer than all the previous joints taken together. Body beneath and the legs sparingly clothed with yellow hair. Anterior tibiæ obtusely tridentate. The posterior tibiæ with a triangular tooth a little below the middle; the edge above this tooth with four or five small teeth. Tarsi long and slender; claws red. Abdomen shining, not very closely but strongly punctured; the basal segment yellow in the middle, margined with yellow at the sides.

\section{Length 12 millim.}

A single example was met with. It is probable that this species may have to be separated from Calometopus on account of the form of the clypeus, which is not emarginate. Never having seen the type of the genus (C. senegalensis), I am unable at present to say in what other way it differs.

\section{BUPRESTIDE.}

Amblysterna Johnstoni, n. sp.

Size and general form of $A$. natalensis, Fabr. Golden green, shining, the underside and legs coppery, the sides of the abdomen violet. Thorax more convex than in A. natalensis, more closely and much more strongly punctured; the sides more regularly arcuate, with 
only a very small lateral impression; the dorsal median channel wellmarked. Elytra very strongly and irregularly punctured, with small punctures interspersed; the punctures near the shoulders are somewhat transverse, and the interspaces being very narrow become transverse rugæ. All the large punctures are finely punctured and filled with pale pubescence, which gives the elytra a speckled appearance. The lateral and apical costæ are as in $A$. natalensis, but not so strongly marked, and there is no lateral stripe above the lateral costa. Antennæ black, with the opaque portions smoky. Underside of the body somewhat violet, the abdominal segments margined with green. Legs coppery.

Length 25 millim.

Psiloptera Leta, n. sp. (Illustrated P. Z. S. 1885, p. 235.)

Rather parallel, depressed, bluish green above, brassy green below. Head very rugose. Thorax nearly one-third broader than long, a little broader across the middle than at the base, and then obliquely narrowed in front," with a shallow median impression and one on each side; the surface rather strongly but very irregularly punctured, coarsely rugulose-punctate at the sides; the irregular space on each side of the median impression sparingly punctured, shining coppery; and a little more removed from the niddle there is an irregular-shaped coppery spot a little in front of the middle. Scutellum black. Elytra nearly parallel for two-thirds their length, then narrowed to the apex, not very convex, with lines of somewhat strong punctures; the alternate interstices flat, the others in parts very slightly convex; the flat interstices are strongly and not very closely punctured; the others have each about eight ovate finely punctured impressions; the raised parts smooth and slightly brassy. At the sides there is a submarginal, closely, and finely punctured impressed line, extending from under the shoulder to near the apex; in this stripe there is some very fine whitish pubescence, which is only visible in certain lights. Prosternum with a triangular projection on each side of the front margin. Abdomen irregularly and strongly punctured, and finely pubescent.

Length 30 millim.

\section{MoluRIDe.}

Melanolophus ater, n. sp. (Illustrated P. Z. S. 1885, p. 235.)

Dull black. Head closely and strongly punctured, with a slight impression on the forehead. Antennæ with the third joint nearly as long as the fourth and fifth taken together; the fourth joint a little longer than broad, the following joints very similar; the tenth joint the same length as the ninth, but broader than long; the eleventh as broad as the tenth, but short, truncate at the apex. Thorax as long as broad, or even a trifle longer, very convex (densely and strongly punctured, the intervals irregular, shining, rugæ or granules), 
moderately narrowed at the base and apex; arcuate at the sides, with no lateral ridge; the front margin nearly straight, the anterior angles not prominent, the base slightly bowed. Elytra not quite twice as broad as the thorax, oblong-ovate, moderately convex; each elytron with three zigzag shining costæ (two dorsal, one lateral), the interstices plicate and rugulose; the suture not costiform. The sides of the elytra shining, the surface uneven and sparingly punctured. Prosternal process closely and rather strongly punctured; the mesoand metasterna less so. Abdomen dull, very finely punctured, the punctuation of the apical segment rather stronger. Legs rugose, not clothed with paler tomentum:

Length 14-15 millim.

The females are rather broader than the males, especially in the elytra, which are more oblong and somewhat flattened dorsally. The males have two very small shining spots on the disk of the thorax in front of the middle, and there is an indication of a fine median line.

I have been in doubt whether to place this species in the genus Amiantus or the more recent genus Melanolophus, Fairm. (Faun. et Fl. des Pays Çomalis, 1882, p. 69). The general form is, however, more that of Melanolophus, but the suture of the elytra is not costiform. The anterior angles of the thorax are not produced forward as in Amiantus. The antennæ are rather shorter than in either of these genera.

HYMENOPTERA, ORTHOPTERA, \&c.

The other Insects collected by Mr. Johnston do not present anything remarkable. There is, however, a very fine specimen of Mantis (Idolum diabolicum, Saussure), of which a male example in the British Museum is from the White Nile.

\section{IIST OF BTRDS COLLECTED OR OBSERVED ON KILIMA-NJARO AND ITS VICINITY. ${ }^{3}$}

By Captain G. E. Shelley, F.Z.S., and Mr. H. H. Johnston, F.Z.S. ** Those birds which were only observed by the author, and the skins of which were not obtained, have their numbers inserted in brackets.

1. Arseonax minima (Heugl.).

Muscicapa minima, Heugl. Orn. N. O.-Afr. p. 435, pl. 18. f. 1. ô, 4000 feet; ठ, 6000 feet; $\delta, 7000$ feet.

3 The collection contains examples of fifty species, including the following six considered to be new to science :-Muscicapa Johnstoni, Pinarochroa hypospodia, Pratincola axillaris, Nectarinia Johnstoni, N. Kilimensis, and Cynniris mediocris. 
2. Muscicapa Johnstoni.

Muscicapa Johnstoni, Shelley, P. Z. S. 1884, p. 558.

ㅇ, 6000 feet.

Found on the southern slope of the mountain just above Mosi, on the borders of the cultivated district.

3. Lanius caudatus, Cab.

Lanius caudatus, Gadow, Cat. B. Brit. Mus. viii. p. 254 ; Fischer, Zeitschr. ges. Orn. (Madaraz), 1884, p. 344.

§, 3000 feet. In immature plumage.

This species affects the desert and waterless districts at the foot of the mountain, where it perches upon the low shrubs, and pounces upon the grasshoppers, which are very abundant in these districts, and form its principal fool.

4. Lanius collaris, Linn.

Lanius collaris, Gadow, Cat. B. Brit. Mus. viii. 1883, p. 255.

Lanius humeralis, Fischer, Zeitschr. ges. Orn. (Madaraz), 1884, p. 344.

ऽ, 4000 feet; $\delta$ क, 5000 feet; $\delta, 6000$ feet; 2, 7000 feet.

One of the commonest birds on the mountain, and very bold.

5. Dryoscopus sublacteus, Cass.

Dryoscopus sublacteus, Gadow, Cat. B. Brit. Mus. viii. 1883, p. 140 ; Fischer, Zeitschr. ges. Orn. (Madaraz), 1884, p. 348.

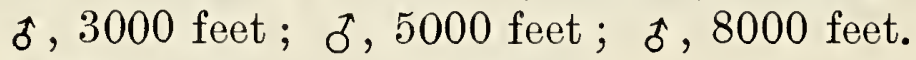

6. Dryoscopus cubla (Shaw).

Dryoscopus cubla, Gadow, Cat. B. Brit. Mus. viii. p. 148 ; Fischer, Zeitschr. ges. Orn. (Madaraz), 1884, p. 345.

of o , 3000 feet; \& , 5000 feet; of, not labelled. The female had the irides scarlet.

7. Crateropus Kirki, Sharpe.

Crateropus Kirki, Fischer, Zeitschr. ges. Orn. (Madaraz), 1884, p. 316.

๙ , 5000 feet.

Very common and bold.

8. Pycnonotus Layardi, Gurney.

Pycnonotus Layardi, Sharpe, Cat. B. Rrit. Mus. vi. 1881, p. 132 ; Fischer, Zeitschr. ges. Orn. (Madaraz), 1884, p. 341.

q, 3000 feet; 2 o, 5000 feet.

9. Turdus cabanisi, Bp.

Turdus cabanisi, Seebohm, Cat. B. Brit. Mus. v. 1881, p. 229.

of, 5000 feet; of, 6000 feet.

The most northern locality of this species, whence it ranges southward on the east coast to the Transvaal.

Almost confined to inhabited districts. 
10. Pinarochroa hypospodia, sp. $n .^{4}$

Kilima-njaro, 오 , 14,000 feet.

Close to P. sordida (Rüpp.), which is the type of the genus Pinarochroa; but the present bird is slightly larger, paler and less isabelline beneath, and has the white on the tail more limited, each feather having broad blackish-brown ends.

Upper parts brown, slightly darker on the crown and quills; tail-the four outer pairs of feathers white with broad blackish-brown ends; this colour extends somewhat down their shafts, and covers about one-third of the end-portion of the outer web of the exterior feather, and nearly the entire inner web of the third feather from the centre; the centre two pairs entirely black. The wing-coverts and inner secondaries are broadly edged with sandy brown, and the remainder of the quills have almost obsolete similarly coloured edges. Sides of the head in front of the eye and the cheeks slightly washed with ashy brown. Underparts ashy buff, slightly darker on the lower throat and front and sides of the chest, and passing into rufous-shaded brown on the flanks, thighs, and under tail-coverts; under surface of the wings dark brown with the coverts rufous-brown; the axillaries and inner margins of the quills ashy buff. Total length 5-7 inches, culmen $0 \cdot 55$, wing 3 , tail $2 \cdot 2$, tarsus $1 \cdot 25$.

Found only at great altitudes, affecting the grassy and boulder regions, where they are to be seen in family parties of from three to five. Here they enliven the desert scenery by flitting before the traveller with a constantly repeated pleasing chirp, and perched upon the boulders flit their tails up and down after the manner of Chats.

11. Pratincolia axillaris.

Pratincola axillaris, Shelley, P. Z. S. 1884, p. 556.

$\widehat{\phi}$ o, 5000 feet; 3 $\hat{\phi}, 6000$ feet; $q, 7000$ feet; $\hat{\delta}, 8000$ feet; ¿, 10,000 feet. Breeds in September.

Very abundant but not met with below 5000 feet. They are bold, and frequent the native villages in their lower range.

12. Prinia mystacea, Rüpp.

Prinia mystacea, Sharpe, Cat. B. Brit. Mus. vii. p. 191.

Drymoca tenella, Fischer, Zeitschr. ges. Orn. (Madaraz), 1884, p. 312.

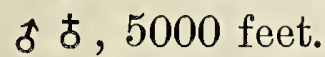

13. Cisticola subruficapilla (Smith).

Cisticola subruficapilla, Sharpe, Cat. B. Brit. Mus. vii. p. 283.

§, 5500 feet; + , 8000 feet.

14. Nectarinia famosa (Linn.).

Nectarinia famosa, Shelley, Monogr. Nect. p. 13, pl. 5.

${ }^{4}$ Illustrated in "Proceedings of the Zoological Society," pp. 222, 223. 1885 . 
$\delta$ in partial moult, $2 \%, 5000$ feet; $q, 6000$ feet; $\delta$ in moult, 7000 feet.

Very abundant.

15. NeCTARinia Johnstoni, sp. n. ${ }^{5}$

ठ, Kilima-njaro, 11,000 feet.

Very similar in size, form, and colour to $N$. famosa, but readily distinguished by the pectoral tufts being bright scarlet.

Entire head, neck, back, least and median wing-coverts, and chest metallic green, with the base of the feathers black; a small black patch from the gape to the eye. The head, neck, and back have a slight golden shade, not so strong as is generally the case in $N$. famosa, while the rump and upper tail-coverts have a bluish lustre; remainder of the wings brownish black with a slight purple gloss; the greater wing-coverts are partially edged with metallic green, shaded with bronzy violet on a few of the outer feathers ; the primarycoverts and the greater secondaries show, in certain lights, faint indieations of similar metallic edges. Tail purplish black, the feathers towards the centre being narrowly and partially edged with bluish green. Axillary tufts bright scarlet; abdomen, thighs, and under surface of the wings blackish brown; under tail-coverts purplish black, with slight traces of metallic bluish-green margins to a few of the feathers. The under wing-coverts towards the bend of the wing are tipped with metallic green. Bill and legs black. Total length $10 \cdot 6$ inches, culmen $1 \cdot 25$, wing $3 \cdot 3$, tail $6 \cdot 6$, tarsus $0 \cdot 7$.

Very abundant. Not seen lower than 5000 or 6000 feet, but reaches higher up the mountain than any other bird with the exception of Corvultur albicollis and Pinarochroa hypospodia. Found very much round a curious teazle-like lobelia ( $L$. Deckeni). Also at lower levels it affects the tall aloe flower-shoots.

16. Nectarinia kilimensis, Shelley.

Nectarinia kilimensis, Shelley, P. Z. S. 1884, p: 555 .

Two of, 3000 feet; $\hat{\delta}$ o, 4000 feet; 4 d, 5000 feet; + , 5600 feet; $\delta$, not labelled.

Found mostly near base of mountain, very common. Rarely if ever seen above 5600 feet.

17. Nectarinia Reichenowi (Fischer). ${ }^{6}$

Nectarinia Reichenowi, Shelley, P. Z. S. 1884, p. 556, pl. 51.

Drepanorhynchus Reichenowi, Fiseher, Zeitschr. ges. Orn. (Madaraz), 1884, p. 338.

§, 4000 feet; 2 q, 5000 feet. Never seen above 5000 feet.

5 Illustrated in "Proceedings of the Zoological Society," pp. 222, 223. 1885 .

${ }^{6}$ Ibid., p. 556.1884. 
They abound in the native plantations, being, in common with most of the other Sun-birds, attracted there by the flowers of the sweet potato and of various beans and peas.

18. Cinnyris AfFinis, Rüpp.

Cinnyris affinis, Shelley, Monogr. Nect. p. 239, pl. 74. fig. 2.

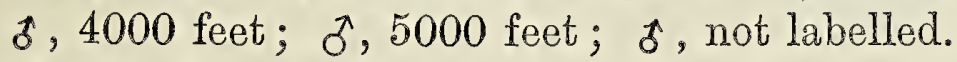

Very abundant at low levels.

19. Cinnyris mediocris, sp. n.

đ, Kilima-njaro, 12,000 feet.

Intermediate between $C$. chalybeus and C. chloropygius, but with the bills lightly more curved than in either. It resembles C. chalybeus in the colouring of the metallic parts, having the blue terminal collar to the throat and blue upper tail-coverts; but differs from that species and resembles $C$. chloropygius in the colouring of the abdomen, thighs, under tail-coverts, and wings, which are darker and more olive than in C. chalybeus.

Entire head, neck, back, least and median wing-coverts uniform metallic golden green; upper tail-coverts steel-blue; remainder of the wings dark brown, with the margins of the feathers shaded with olive; the green of the throat terminates in a narrow steel-blue collar, followed by a broad scarlet collar; pectoral tufts yellow; remainder of the underparts brownish olive, slightly washed with olive-yellow; thighs dark-brown; bill and legs black. Total length $4 \cdot 6$ inches, culmen 0.7 , wing $2 \cdot 1$, tail 2 , tarsus $0 \cdot 7$.

Fairly abundant. Only remarked in upper regions.

20. Cinnyris Kirki, Shelley.

Cinnyris Kirki, Shelley, Monogr. Nect. p. 273, pl. 85 ; Fischer, Zeitschr. ges. Orn. (Madaraz), 1885, p. 339.

$\delta$ in moult, 3000 feet; $\delta$ q, 5000 feet ; $q, 7000$ feet.

21. Motacilla tongtoauda, Rüpp.

Motacilla longicauda, Rüpp, Neue Wirb. pl. 29. fig. 2.

Two of, 6000 feet.

22. Poliospiza tristriata, Rüpp.

Poliospiza tristriata, Heugl. Orn. N.O.-Afr. p. 642.

q, 8000 feet. Found in small flocks.

23. Citrinella chtrinelioides, Rüpp.

Citrinella citrinelloides, Heugl. Orn. N.O.-Afr. p. 644.

\&, 6000 feet; $o^{\pi}, 7000$ feet.

24. VIDUA PRINCIPALIS (Linn.).

Vidua principalis, Fischer,Zeitschr.ges. Om.(Madaraz), 1884,p. 325.

Two \&, 5000 feet.

25. ? Penthetria eques, Hartl.

Penthetria eques, Fischnr, Zeitschr. ges. Orn. (Madaraz), 1884, p. 326. 
f, 5000 feet; $\circ, 7000$ feet.

These are immature specimens or in the brown winter plumage, and can therefore only be doubtfully referred to this species.

26. Hyphantornis ocularius ( Smith).

Hyphantornis ocularius, Fischer, Zeitschr. ges. Orn. (Madaraz), 1884, p. 331 .

$\delta, 2300$ feet; $\delta, 6000$ feet.

27. Sycobrotus Reichenowi, Fischer.

Sycobrotus Reichenowi, Shelley, P. Z. S. 1884, p. 557.

Hyphanturgus Reichenowi, Fischer, Zeitschr. ges. Orn. (Madaraz), 1884, p: 331.

$2 \delta, 3$ q, 5000 feet; $\delta, 6000$ feet.

Breeds in colonies, especially affecting palm-trees.

28. Oriolus notatus, Peters.

Oriolus notatus, Sharpe, Cat. B. Brit. Mus. iii. p. 196 ; Fischer, Zeitschr. ges. Orn. (Madaraz), 1884, p. 334.

ऽ, 2500 feet. Irides carmine.

29. Amydrus Morio (Linn.).

$\widehat{\delta}, 7000$ feet.

This is a full adult male, agreeing perfectly in its measurements with Natal specimens.

Met with in small flocks of five or six. They utter a low pleasing cry or soft whistle and frequent small thickets.

30. Corvultur adbicollis (Lath.).

Corvultur albicollis, Sharpe, Cat. B. Brit. Mus. iii. p. 24.

Archicorax albicollis, Fischer, Zeitschr. ges. Orn. (Madaraz), 1884, p. 336 .

๙, 5000 feet.

Inhabits the whole mountain up to the snow, and breeds in August in crevices in the most inaccessible rocks.

31. Corvus Scapulatus, Daud.

Corvus scapulatus, Sharpe, Cat. B. Brit. Mus. iii. 1877, p. 22 ; Fischer, Zeitschr. ges. Orn. (Madaraz), 1884, p. 337.

o, 5000 feet.

More a bird of the plains than the mountainous region, where its place is taken by Corvultur.

32. Barbatula leucotis, Sundev.

Barbatula leucotis, Marshalls, Monogr. Capitonidæ, p. 131, pl. 52.

Megalcema leucotis, Fischer, Zeitschr. ges. Orn. (Madaraz), 1884, p. 371.

o, 3000 feet; o , 6000 feet.

It inhabits the dense forest, where its presence is often proclaimed by its harsh strident note, which it repeats at intervals, and being a 
bold bird is easily killed. The first pair were met with at Taveita, perched on the bough of a mimosa, and others were seen on the southern flank of the mountain up to 6000 feet.

[33.] Dendropicus sp.

Shot in country of Taita, alt. 3000 feet. Skin lost.

34. Hapaloderma narina (Vieill.).

Hapaloderma narina, Fischer, Zeitschr. ges. Orn. (Madaraz), 1884, p. 368.

ô, 3000 feet.

This specimen agrees better with the Natal birds, with which we have compared it, than with the equatorial race, $H$. constantia, Sharpe.

Only one specimen seen at Taveita, in the forest, and must be scarce, as the natives appear to have no name for it.

35. Eurystomus afer (Lath.).

Eurystomus afer, Sharpe, Ibis, 1871, p. 274.

Two \& , 4000 feet.

Often mob birds of prey.

36. Halcyon orientalis, Peters.

Halcyon orientalis, Sharpe, Monogr. Alcedinidæ, p. 181, pl. 66 ;

Fischer, Zeitschr. ges. Orn. (Madaraz), l884, p. 361.

s, 5000 feet.

Feeds principally upon the small crabs which inhabit the mountainstreams.

37. Buceros cristatus, Rüpp.

Bycanistes cristatus, Elliot, Monogr. Bucerotidæ, pl. 26.

Buceros cristatus, Fischer, Zeitschr. ges. Orn. (Madaraz), 1884, p. 361 .

$\delta, 4000$ feet; $q, 5000$ feet; $q, 6000$ feet.

Generally distributed over the mountain up to 6000 feet, especially near habitations. They show no fear of man, being generally protected by the natives, who look upon them with superstitious awe, arising possibly from their being useful scavengers, as well as from their peculiar loud cry, which resembles at times that of the wailing of a woman in distress, at others that of the braying of an ass. In August and September they were breeding, and occasionally the head of the female might be seen peering out from a hole in a tree some thirty or forty feet high, where she had been plastered in by her affectionate husband. By the chips lying about, it would appear that these holes are excavated by the birds to the required size. They are monogamous, and show great affection for each other, which is fortunate, as the female during incubation has entirely to rely on her mate for daily subsistence. 
38. Buceros melanoleucus, Licht.

Tockus melanoleucus, Elliot, Monogr. Bucerotidæ, pl. 49.

$\delta$ o, 5000 feet.

[39.] Bucorvus abyssinicus.

The ground hornbill, very frequently seen on Kilima-njaro and elsewhere in vicinity of native villages, not higher than 5000 feet. Never noticed in open country away from human habitations. Rigorously protected by natives, on account of its scavenging habits.

40. Turacus Hartlaubi (Fischer and Reichenow).

Corythaix Hartlaubi,Fischer, Zeitschr. ges.Orn.(Madaraz),1884, p.363.

of \&, 10,000 feet. Bill red and green. Skin round the eyes scarlet. Sexes similar.

It frequents the forest, and is most abundant at about 9000 feet. Its loud cry may be frequently heard, but it is difficult to see amongst the thick foliage, and still more difficuilt to approach, being very shy.

41. Colius leucotis, Rüpp.

Colius leucotis, Fischer, Zeitschr. ges. Orn. (Madaraz), 1884, p. 363.

§, 5000 feet; 2 ๙, 6000 feet.

[42.] Perocephalus Rüppeliti.

Observed in the country of Taita.

Not met with on Kilima-njaro.

43. Francolinus Schuetti, Cab.

Francolinus (Scleroptera) Schuetti, Cab. J. f. O. 1880, p. 351 ; 1881, pl. 2.

Francolinus Schuetti, Fischer, Zeitschr. ges. Orn. (Madaraz), 1884, p. 382 .

ऽ, 6000 feet.

Frequents the rocks and was very abundant at 5000 feet. It was not met with in the plains.

44. Francolinus Altumi, Fischer and Reichen.

Francolinus Altumi, Fischer and Reichen. J. f. O. 1884, p. 179, pl. 2 ; Fischer, Zeitschr. ges. Orn. (Madaraz), 1884, p. 383.

万, 6000 feet.

This species frequents the plains more than the mountains.

[45.] Numida cristata.

The crested guinea-fowl. Often killed in plains and ravines at the base of the mountain.

[46.] Numida cornuta.

Very common in low country.

[47.] Coturinix histrionica.

Common in plains.

[48.] Oтіs sp.

Frequently met with in plains at base of the mountain. 
[49.] Lobivanellus aLbiceps.

On Lake Jipé.

[50.] STERna CASPIA.

On Lake Jipé.

51. Treron Wakefieldi, Sharpe.

Treron Wakefieldi, Shelley, Ibis, 1883, p. 269.

Two $f$, 5000 feet; $q, 6000$ feet.

Seen generally in pairs, eats the sycamore-figs.

Proc. Zool. Soc. -1885 , No. XVI.

52. Palumbus arquatrix (Temm.).

Palumbus arquatrix, Shelley, Ibis, 1883, p. 283.

ô, 10,000 feet.

Bare skin round eyes, bill, and feet saffron-yellow. This specimen agrees perfectly with others from Natal. Only noticed at great altitudes from 8500 feet to 10,300 feet. Seen in pairs in the dense forests, sometimes in company with Turacus Hartlaubi.

53. Tympanistria tympanistria (Temm.).

Tympanistria tympanistria, Shelley, Ibis, 1883, p. 326.

Peristera tympanistria, Fischer, Zeitschr. ges. Orn. (Madaraz), 1884 p. 278.

q, $5000 \mathrm{ft}$.

[54]. Turtur vinaceus.

Everywhere at base of mountain.

[55.] Turtur semitorquatus.

Common in plains, near water.

[56.] Chalcopelia afra.

In low country.

[57.] Balearica pavonina.

In numbers near Lake J゙ipé.

[58.] Porphyrio, sp.

In the vicinity of Lake Jipé and the River Ruvu.

[59.] Chenalopex mygyptiaca.

Lake J̌ipé.

[60.] Anas xanthorhyncus?

Streams at high altitudes, 8000 feet to 11,000 feet.

[61.] Pelicanus onocrotalus.

Lake Jipé.

[62.] NycticoraX, sp.?

Lake J̌ipé and R. Lumi.

[63.] ARdea PURPURea.

Lake J̌ipé and R. Lumi.

[64.] Ardea goliath.

Lake J̌ipé. 
[65.] ARdea ALBA.

Lake Jipé.

[66.] Ardea bubulcus.

Lake Jipé and most rivers. This bird often follows the cattle of natives to pick off the ticks that infest them.

[67.] SCOPUS UMBRETTA.

Lake Jipé and R. Lumi. Very common.

[68.] XENORHYNCUS SENEGALENSIS.

Lake J̌ipé.

[69.] Leptoptilus CRUMeniferus.

Very common in plains. Follows the Masai armies in their raids, and frequents Masai settlements. Rarely seen away from the society of man.

70. IBIS HAGEDASH (Lath.).

Ibis hagedasch, Fischer, Zeitschr. ges. Orn. (Madaraz), 1884, p. 386.

o, 3000 feet. Irides scarlet.

Shot in a marsh near Taveita out of a small flock of ten or twèlve.

[71.] Serpentarius SeCretarius.

The "Secretary Bird." Very common in the plains.

72. Polyboroides typicus, Smith.

Polyboroides typicus, Sharpe, Cat. B. Brit. Mus. i. p. 48.

o, 5000 feet.

Only met with in the neighbourhood of villages. Their feathers and those of the kite are much prized by the natives for the ornamentation of their capes.

[73.] NeOPHRON PERCNOPterus.

The Egyptian vulture. Common up to an alt. of 5000 feet.

74. Neophron monachus (Temm.).

Neophron monachus, Sharpe, Cat. B. Brit. Mus. i. p. 19.

Neophronpiteatus,Fischer, Zeitschr. ges. Orn.(Madaraz), 1884, p. 376.

o, 5000 feet.

Not observed higher up the mountain, as it frequents the more thickly inhabited parts; often in flocks associated with the ground hornbills and the white-necked ravens.

[75.] Vultur CINEREUS ?

Plains round Kilima-njaro.

[76.] GyPS RüPPELLII.

[77.] ОтоGугs?

Plains round Kilima-njaro.

[78.] Spizaetus, sp.

Found on Kilima-njaro up to 8000 feet alt.

[79.] Haliætus vocifer.

Lake J̌ipé and Ruvu R. 
[80.] Heliotarsus ecaudatus.

Plains round Kilima-njaro.

81. Buteo aUgur, Rüpp.

Buteo augur, Sharpe, Cat. B. Brit. Mus. i. p. 175 ; Fischer, Zeitschr. ges. Orn. (Madaraz), 1884, p. 374.

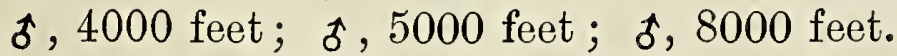

82. Buteo desertorum (Daud).

Buteo desertorum, Sharpe, Cat. B. Brit. Mus. i. p. 179 ; Fischer, Zeitschr. ges. Orn. (Madaraz), 1884, p. 374.

$\delta, 5000$ feet.

83. Asturinula monogrammica (Temm.).

Asturinula monogrammica, Sharpe, Cat. B. Brit. Mus. i. p. 275 ; Fischer, Zeitschr. ges. Orn. (Madaraz), 1884, p. 374.

\$, 5000 feet.

84. Struthio danaoides, Shelley.

The ostrich of E. Equatorial Africa. Eggs brought back ; collected in vicinity of Taveita. Young ostriches kept in captivity by me in that place.

This ostrich, I am informed by the natives, lives a good deal on insects and small reptiles, as well as on leaves and herbage. The young ostriches I kept at Taveita ate raw meat in preference to anything else, though they would also swallow leaves and chopped grass.

\section{LIST OF MAMMALS OBTAINED AND OBSERVED ON MOUNT KILIMA-NJARO AND ITS VICINITY.}

By Ordfield Thomas, F.Z.S. With a few additional notes by the Author.

** The species which have their numbers bracketed were those of which skins or horns were not brought home, and which were either identified by the Author in their particular habitat, or approximately named by Mr. Oldfield Thomas from the Author's drawings. It is needless to say these drawings, wherever made, were carefully executed from specimens living or dead, and their fidelity may be relied on.

[1.] Cynocephalus hamadryas.

Country of Taita and vicinity of River Lumị.

[2.] Cynocemphalus sphinx.

Kilima-njaro up to 6000 feet, especially in vicinity of native villages. Also in adjacent plains and along the River Lumi. Especially abundant near Taveita. 
[3.] Crnocephalus babouin.

On Kilima-njaro up to 5000 feet, and in and near Taveita.

[4.] Cercopithēcus albicularis.

In and near Taveita.

[5.] Cercopithēcus Lalandir.

In and near Taveita and along River Lumi.

[6.] Cercopitheiecus Griseo-viridis.

On Kilima-njaro up to 7000 or 8000 feet, and everywhere near water in the plains below. Naturally the commonest monkey to be seen.

7. Cercopithēcus pygerithirus, Geoffr.

$a, b$. Mosi, on the south side of the mountain, 5000 feet, June to August.

Very common in the cultivated gardens round the village, and in the forests lower down at Taveita. These monkeys are exceedingly familiar and mischievous, coming into the gardens to steal fruit, \&c., and are entirely without any fear of man.

8. Colobus guereza, Rüpp., var. caudatus, var. nov.

a. Useri, N.E. flank of mountain, 3000 feet, end of October.

Very common all round the base of Kilima-njaro.

The specimen brought, like two or three beautiful skins obtained by Mr. Thomson in the same neighbourhood, belongs to a peculiar race or variety apparently restricted to this region, and characterized by having the white brush of the tail very much larger and finer than is the case in the true Abyssinian C. guereza. In the latter animal the proximal 12 to 16 inches of the tail is short-haired and quite black, only the terminal 8 to 12 inches being white and tufted, and the white mantle hanging down from the body hides only about one-third of the black part of the tail. In the Kilima-njaro race, however, only some 3 or 4 inches of the base of the tail are black, and the remainder (with the hairs about 20 or 21 inches) is developed into a magnificent white brush, of which individual hairs are from 7 to 9 inches in length. The hairs of the white body-mantle, moreover, entirely cover the black at the base of the tail, the white of the latter and of the mantle being quite continuous.

In addition to this race, however, the true Guereza is also found in the neighbourhood of Kilima-njaro, as the mantle of the lowland Masai warrior, of whom a drawing is given in Chapter XIX., is made of the skin of this animal, but this is, of course, a rather vague indication of the original locality of the specimen. Mr. Johnston tells me that the natives clearly distinguish the two races, and that the white-tailed form is, at least in the Kilima-njaro district, a more strictly mountain animal than the other. 
Taking now into consideration the extreme constancy of the markings of the Colobi, the very different appearance that the present animal has from the usual type, its restriction to a small district round Kilima-

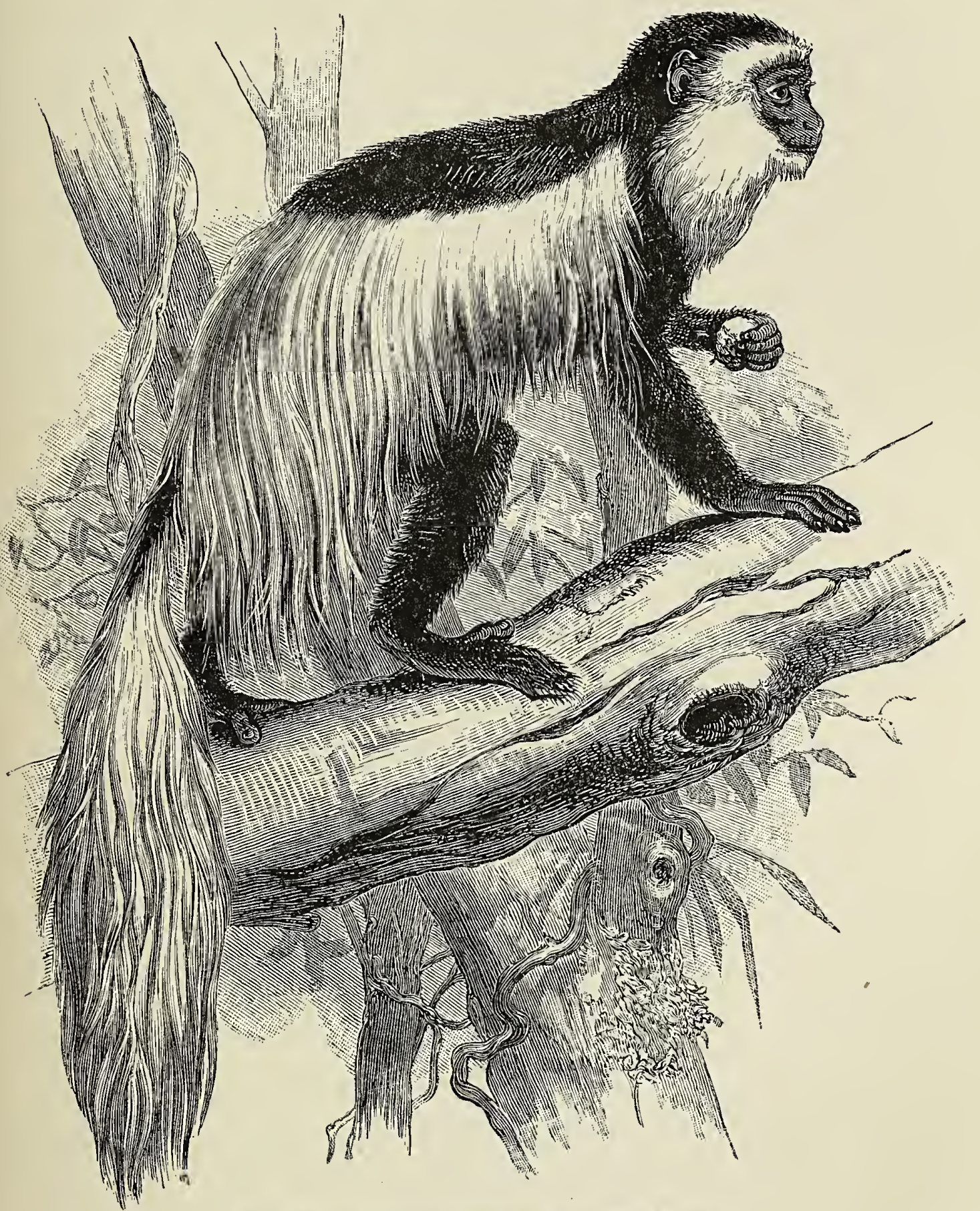

Fig. 72.-Colobus Guereza, var. Caudatus.

njaro, and the distinction by the natives of the two forms, $I$ think it will be necessary to distinguish Mr. Johnston's animal as a separate variety or sub-species, to which the name of C. guereza caudatus might be applied.

[9.] Galago crassicaudata?

Found in Taita and near the coast, but not on the mountain. 
[10.] CyNONYCTERIS COLLARIS.

Taveita forests.

11. Vesperugo nanus, Peters.

Moši, 5000 feet, September 12. Found hanging to a tree in daytime.

[12.] Felis Leo, L.

The lion is abundant in the neighbourhood, but never ascends higher than about 3000 feet.

13. Felis pardus, L.

a. Near foot of mountain, 3000 feet.

The leopard is very common up to about 7500 feet.

[14.] Felis serval.

Skin obtained in Taita. Common in country at base of Kilima-njaro.

[15.] Felis Caffra.

Kilima-njaro up to 5000 or 6000 feet, and forest of Taveita.

[16.] Felis caracal.

A skin seen near Useri, in possession of natives. According to their report common in the plains.

[17.] Cynelurus venator.

The cheetah appears to be very frequently met with to the north and north-east of Kilima-njaro. The Masai and Endurobo often bring skins for sale. One was purchased at Useri, but subsequently lost.

[18.] Viverra civetta.

Very common near base of mountain.

19. Genetta tigrina, Schr.

a. Moši, 5000 feet, October.

$b$. Taveita, 2300 feet, August.

Very common; occurs up to 7000 feet. A female specimen, caught by Mr. Johnston, gave birth to three young at about the end of October.

20. Herpestes caffer, Gm. (?).

a. Moši, 5000 feet, August.

Is not properly a mountain animal, but occurs round the village for the sake of the fowls and other prey which it can manage to steal there.

Without the skull it is impossible to determine with certainty whether this is $H$. ichneumon, L., or H. caffer, Gm. ; but the skin has, on the whole, rather more the appearance of $H$. caffer, and it is, therefore, provisionally referred to the southern form.

[21.] Hxena croudta.

Very abundant in vicinity of Kilima-njaro, but scarcely ascends higher than 3000 feet. 
[22.] Hyena striata.

Found on the mountain from 3000 to 6000 feet. Prowls round native villages. Also met with in Taveita and Taita.

23. Canis lateralis, Scl.

a. Moši, כ̌000 feet, August.

Very common round the village, to which it is attracted by the chance of stealing refuse, \&c.; not otherwise found much above 3000 feet.

[24.] Canis, sp.

Mr. Johnston several times saw and heard a species of dog or fox, which he was not able to obtain, but which looked rather like a large fox, and emitted a distinct bark, similar to that of a domestic dog. It is just possible that this was the rare Abyssinian Canis simensis, Rüpp., no other animal appearing at all to agree with Mr. Johnston's description. Native name, Nzudu.

[25.] SCIURUS mRYTHROPUS?

On Kilima-njaro, between 3000 and 7.000 feet.

[26] Xerus, sp.

Taveita forest.

[27.] Graphiurus Capensis.

Kilima-njaro, 6000 feet. Nocturnal habits. Vide illustration, p. 392. [28.] Mus, sp.?

A small black rat infesting native houses.

[29.] Aulacodus swindernianus?

Reported by natives near Taveita. Native name, Mbulku.

[30.] Hystrix cRistata.

Very common in plains.

[31.] Lepus Capensis.

Killed near Taveita in plains.

32. Hyrax Brucei, Gray (?).

$a, b$. $\delta$ and $q, 10,000$ feet, on the south side of the mountain, 26th October.

Native name in Ki-čaga, Kimburu.

Fairly common in the mountain-forests, where they live entirely in the trees, and not among the rocks. They do not descend below about 7000 feet and range up to 11,000 feet. These two specimens were brought alive to Mr. Johnston; but the female, after giving birth to three young, died almost at once, and the male, refusing to eat, also died in three or four days.

The specimens agree exactly, so far as can be made out from skins only, with the type of Gray's H. irrorata (Ann. Mag. N. H. 1869, p. 242), a species, however, which Mr. Blanford (Geol. Zool. Abyss. p. 252,1870 ) has shown to be probably not specifically separable 
from the same author's H. Brucei. Mr. Blanford obtained his Abyssinian conies at elevations varying from 2000 to 8000 feet, and it was only to be expected that specimens inhabiting a locality so much

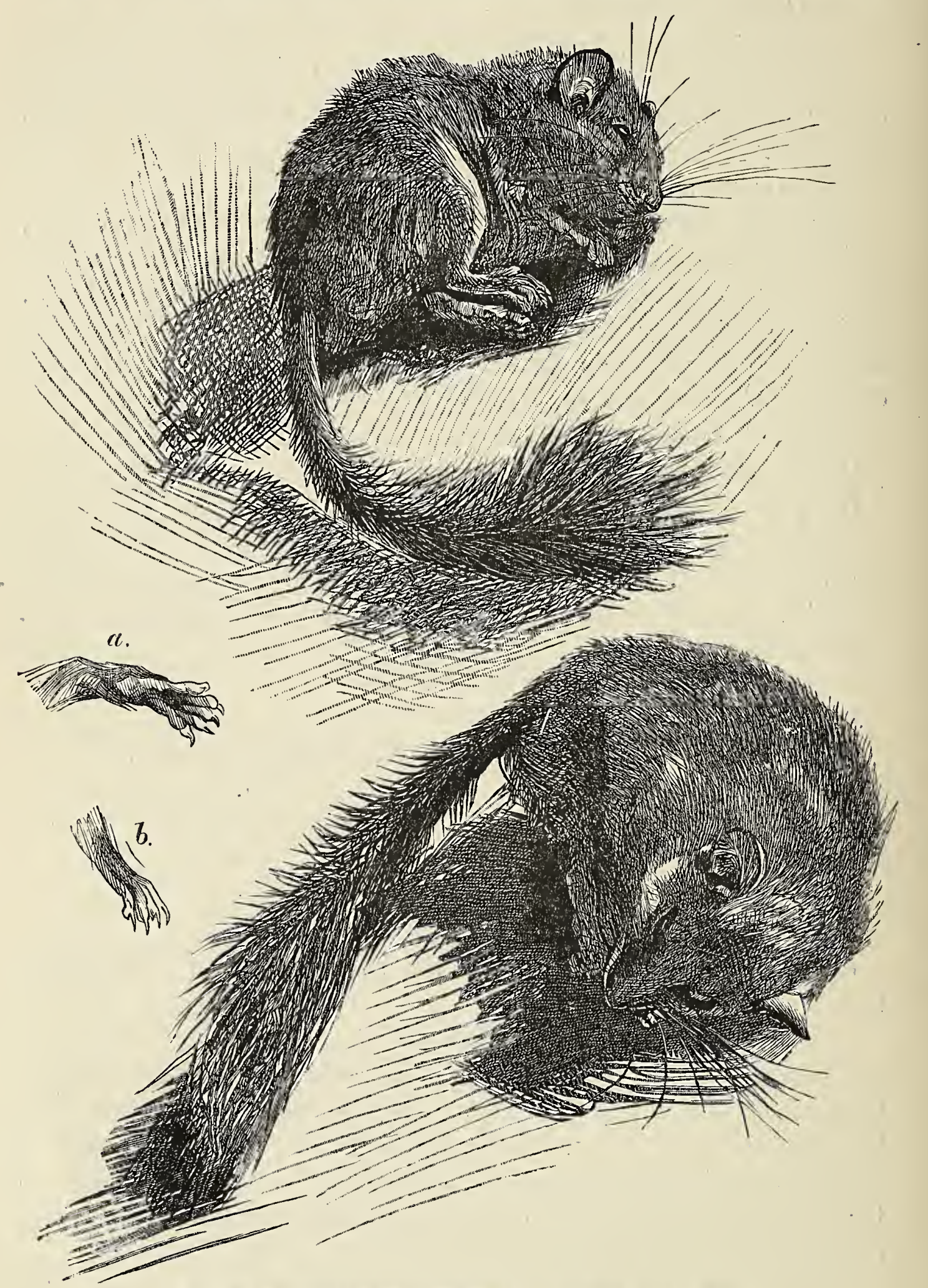

Fig. 73.-Graphiurus Capensis. (a) foot. (b) hand.

further south as Kilima-njaro should have been found ranging as high as 11,000 feet above the sea. 


\section{[33.] Elmethas africanus, L.}

Mr. Johnston states that he himself saw and shot at elephants at an altitude of no less than 13,000 feet.

34. RHINOCERos BICORNis, $\mathrm{L}$.

$a, b, c$. Horns ; Taveita, 2300 feet, end of October.

Very common on the elevated plains at the base of Kilima-njaro, but not ascending the mountain itself. Is not found in the true forest, but only in the bush.

These horns were brought in to Mr. Johnston by the A-kamba people, who obtain them by killing the animals with poisoned arrows.

35. Equus Burchelit, var. Chapmani. Thomas.

a. Taveita, 2300 feet, 25 th August.

Very common, in herds of about twenty, on the open plains round the mountain, never ascending above about 2400 feet.

This specimen, like all those I have seen or heard of from localities on or north of the Zambezi, belongs to the so-called Equis Chapmani, Layard, 6 in which the dark stripes extend on the limbs right down to the hoof.

That this form, however, cannot be distinguished specifically from the true $\boldsymbol{E}$. Burchell $i$ is sufficiently proved by the following sentence, extracted from Mr. T. E. Buckley's useful paper on the distribution of South African mammals : ${ }^{7}$ - "Out of five of these animals shot in one herd, there were individuals showing every variation of colour and marking; from the yellow and chocolate stripes to the pure black and white, the stripes in some ceasing above the hock, and in others being continued distinctly down to the hoof." On the whole, the somewhat ugly trinomial "Equus Burchelli Chapmani" seems to express fairly correctly the degree of distinctness to which this northern race has attained.

I am told by Mr. Thomson also that throughout his travels in Eastern Equatorial Africa he has never seen any but this leg-striped race of Burchell's zebra.

[36.] Hrppopotamus amphibius.

Common in Lake Jipé.

[37.] Phacochorus, sp.

Wart-hogs are found on Kilima-njaro up to an elevation of 8000 feet. [38.] Bubalus cafeer, Sparrm. (?).

According to Mr. Johnston, buffaloes occur commonly in the forests up to 14,000 feet. Whether these are $B$. caffer or $B$. opquinoctialis, Blyth ( $B$. centralis, Gray), is doubtful, but a magnificent pair of horns brought by Mr. Thomson from the same region belong undoubtedly to 
B. caffer; and I therefore provisionally refer those seen by Mr. Johnston to the same species.

[39.] Giraffa camelopardalis.

Very abundant near Taveita, and along Ruvu valley. For native name, see Vocabulary of Ki-čaga, \&c.

[40.] Oreas canna.

The eland is everywhere most abundant in the plains.

[41.] Strepsiceros.KudU, Gray.

Mr. Johnston states that the kudu ranges up to no less than 14,000 feet, at which height it is by no means rare. ${ }^{8}$

[42.] Tragelaphus sylvaticus.

Common in plains, especially near Tàveita.

[43.] Oryx BeIsa?

A species of Oryx, apparently O.. Beisa seen at Ngurungani.

[44.] Hippotragus niger.

Frequently seen in vicinity of Taveita.

[45.] Hippotragus equinus..

$q$ shot near Taveita. Vide illustration, Chapter X.

[46.] Alcelaphus Cokei.

Most parts of the plains. Vide Chapter IV.

[47.] Connochetes GnU.

Common in plains:

[48.] Aepyceros melampus.

The beautiful pallah is everywhere common in the plains. Shot near Taveita. Vide illustration, Chapter X.

[49.] Gazella Granti?

A Taita hunter showed the author a pair of horns which he had procured from the scene of a lion's repast near Taveita, which seemed to belong to this graceful antelope:

[50.] Cervicapra bohor.

Common in plains, and. apparently inhabiting mountains up to 10,000 feet.

[51.] Neotragus Kirki?

Vide illustration, ante.

This Neotragus: here illustrated was killed.in Kilima-njaro at an altitude of over 11,000 feet. It apparently ranges up to 14,000 feet altitude in the dry season.

[52.] Cephalopus mergens.

Met with in the grassy plains and!near rivers:

[53.] ORYCTERopus athiopicus.

Common in the plains.

8 The same fact has been noticed by Captain R. F. Burton on the Cameroon Mountains. Vide "Abeokuta and the Cameroons," vol. ii. 


\title{
CHAPTER XIX.
}

\author{
ANTHROPOLOGY.
}

THE races of man which $I$ am about to enumerate at the commencement in this chapter, extend over a region of Eastern A'frica lying between the first degree north of the Equator and five degrees to the south, and bounded on the west by the Victoria Nyanza and the thirty-fourth degree of east longitude, and on the east by the Indian Ocean. I wish, for the sake of comparison, to review all the known races inhabiting this wide stretch of country; but I shall more especially describe those dwelling in the vicinity of Mount Kilima-njaro, with whom I have come into personal contact during my recent stay in that district.

The country which lies: between the Victoria Nyanza and the coast, and is circumscribed by the limits I have just cited, offers certain peculiarities of conformation worthy of recapitulation, inasmuch as they doubtless influence the races of men inhabiting those regions. Beyond the fertile cultivated coast-belt, which is rarely more than ten miles broad, begins the Nyika, a strange "wilderness," as its name imports, covered with harsh repellant vegetation, and almost unprovided with running water. Here the rainfall is scanty, and the country bears a parched look all the year round. This semi-desert, except where it is 
broken by mountainous districts or intersected by great rivers, extends uninterruptedly to within a short distance of the eastern shores of the Victoria Nyanzais indeed the prevailing type of scenery throughout Africa, for the Dark Continent is on the whole less forested than any other part of the tropics. But, as a happy contrast to this dreary "veldt," as it is called in the south, rise the magnificent mountain systems of Usambara, Taita, Pare, Ugweno, Kilima-njaro, Kiulu; not to mention other mighty ranges which Thomson has made known to us, and which offer from his description the same characteristics as those I have myself explored. Another break in the Nyika is made by the courses of perennial rivers flowing to the Indian Ocean, such as the Ruvu or Luvu, the Tzavo or Sabaki, the Tana, and a few minor streams of less importance. The marked distinction between the outward aspects of the well-watered forest country on the banks of rivers, lakes, or amid high mountains, and the great rolling plains sparsely covered with stunted trees or thorny scrub which I call the Nyika, is carried out further in the races of man inhabiting either. The forest country on the hills or along the rivers is occupied by resident agriculturists, belonging principally to the Bantu family, ethnologically and linguistically, and the forbidding wilderness in the plains is ranged over by the semi-nomad, cattle-keeping Masai, who for the present must be regarded as forming an independent group in African anthropology.

The Masai, who occupy a large portion of this district, are divided into many classes, tribes, and even independent nations. Some are settled agriculturists (called by the coast people Wa-kwavi), others are still 
fierce semi-nomads, spreading far and wide in their raids, though retaining a certain tribal district in which they make a more or less permanent abode. There are the Wa-kwavi of En-jemsi and the district of Lake Baringo; of Laikipia; Kosova and Lumbwa, near Kavirondo. There are also the Wa-kwavi of Aruša and Méru, near Kilima-njaro, and of the Ruvu river, and $\dot{N}$ guru in the south. The principal Masai clans are those of Sigirari, Kisongo, Sogonoi, Nंgiri, and Laitokitok, in the vicinity of Kilima-njaro, and of Matumbato, Kaputei, Kinangop, Dogilani, En-guaso En-gišu-(Cattle-river)-districts stretching to the north and west of the great snow-mountain. Thomson ${ }^{1}$ considers the Masai of Kilima-njaro to be the purest in blood, and the most free from foreign admixture.

To the extreme north of the district under review certain peoples have been made known to us by 'Thomson's explorations, such as the Nandi, Sük, and Kamasia tribes, which, according to this distinguished traveller's observations, would seem to be related in language and race with the Masai, and help to fill up the blank between the southern members of that family and their distant relatives, the Latuka and Bari, in the valley of the White Nile.

The principal Bantu tribes in this region are the Wa-tutwa, Wa-kara, and Wa-rori on the southeastern shores of the Victoria Nyanza, and the Basamia and Ba-nyara to the north of Kavirondo; the

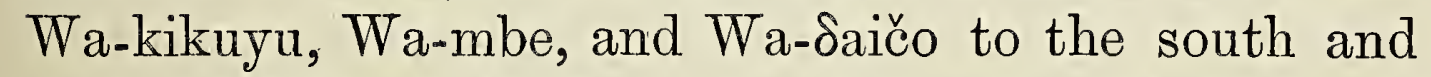
west of Mount Kenia; the A-kamba, inhabiting a large district known as Ukambani, between the rivers Amboni and Tzavo; the Wa-pokomo on the Tana, which flows from the base of Kenia to the Indian

1 "Through Masai Land," pp. 412-414. 
Ocean ; the A-nyika, A-digo, Wa-bondei, and the Arabized Wa-swahili on the coast between Lamu and the mouth of the Ruvu at Pangani; the Wa-sambara and Wa-zeguha that inhabit Usambara and the adjacent plains; the Wa-taita of the Taita mountains, mid-way between Kilima-njaro and the coast; the Wa-pare and Wa-gweno, and, lastly, the Wa-taveita, dwelling to the south-east of Kilima-njaro; the Wa-kahe of the Upper Ruvu, and the Wa-čaga, who inhabit all but the northern flanks of the great snow-mountain.

The north-eastern portion of this district, which I term Eastern Equatorial Africa, is mainly populated by the Galla and Somali peoples, two races bitterlv opposed to one another, although closely related in blood and language. They form a remarkably distinct variety of man apparently midway between the Negro on the one hand and the Arab on the other. Their languages belong to the Ethiopic branch of the Hamitic family according to some, and according to others constitute (with their congeners) a separate and independent group, with certain undeniable approaches to the Semitic and Hamitic tongues.

The region over which the Galla race exists is a curiously extended one, and yet often strangely restricted in width. They occupy, roughly speaking, a long, narrow strip of Eastern Africa scarcely exceeding, at the utmost, 200 miles in breadth, in fact more or less confined between the thirty-seventh and fortieth degree of east longitude, but nevertheless stretching in a southerly direction from the twelfth parallel north of the Equator to the fourth parallel south, over a distance of some 1100 miles. The Gallas have largely mingled with the population of Abyssinia in North-Eastern Africa, and now they are every year 
advancing farther and farther southward down the Zangian coast, pushed on by their remorseless foes the Somali. At present the Gallas are nearing Mombasa, and the Somali have begun to approach the banks of the Tana river. Inland the southern boundary of the Galla extension is at present the Sabaki river. On the west they border on Ukambani, the country of the A-kamba, a Bantu race, and farther north they march with the Masai district till about $4^{\circ}$ or $5^{\circ} \mathrm{N}$. of the Equator, when, as far as we know, tribes of Nilotic negroes become their western neighbours. Apparently, as time goes on, they will come betwixt hammer and anvil. The Somali will push them farther and farther west, 'while the Masai will force them to recoil eastwards to avoid his savage raids. Thus their future is rather gloomy. Perhaps the best thing they ean do is to advance towards the Nile and Abyssinia.

There is a curious colony of Nilotic negroes settled in the district of Kavirondo on the eastern bank of the Victoria Nyanza, surrounded on all sides by tribes of Bantu and Masai race. From what we know of their language, philologically, at any rate, they are closely related to the Siluk people of the White Nile, and must represent a curious and isolated colony of Nile negroes, the remnant of some former invasion now surrounded on all sides by people of alien origin. They are only known as yet from the descriptions of Swahili traders, and no European has yet visited their country save the hasty coasting trip along their shores which Stanley made when circumnavigating the Victoria Nyanza.

Thomson has explored the country to the north of Kavirondo, and we learn from him that there the people are Bantu, speaking apparently a language closely 
related to Lu-ganda and Ki-nyoro. The nearest kinsmen, therefore, of this Siluk colony on the Victoria Nyanza, would seem to be the Lur people who inhabit the north-western bank of the Albert Nyanza, in $4^{\circ}$ N. latitude. I think it very probable that, at any rate in language, the Siluk race is a distant relative of the Masai. The Bari tongue, one of the most northern members of the Masai group, betrays in its vocabulary a resemblance to certain languages of the Siluk family which can hardly be accidental or be accounted for by a theory of loan-words. The same thing occurs also with the Dinka, as Lepsius pointed out in the preface to his "Nuba Grammar." 2

Much yet remains to be ascertained about the relationships and affinities of the reported dwarf races

2 The following comparison of a few words in Šuli (a Šiluk dialect) and Bari may be interesting to the reader:-

\begin{tabular}{|c|c|c|}
\hline English. & $\begin{array}{l}\stackrel{\text { Suli. }}{\text { (Kavirondo \& Lur.) }} \\
\text { \& }\end{array}$ & Bari. \\
\hline Goat & Mindiel & Metyo. \\
\hline Cow & Dian & Kiten். \\
\hline Leopard & Kuač & Koka. \\
\hline Crocodile & Nyan & Ki-nyon. \\
\hline Rain & Kot & Kudu. \\
\hline Water & $\mathrm{Pi}$ & Piom. \\
\hline Blood & Remo & Rema. \\
\hline Honey & Kič & Ci. \\
\hline House & $\overline{\mathrm{A}} \mathrm{t}$ & Kadi (Masai, Aji). \\
\hline Cloth & Obono & Bano. \\
\hline Knife & Pala & Wale (Masai, Alem). \\
\hline Ashes & Vurr & Kuren (Kö-puröt; smoke). \\
\hline Wood & $\operatorname{Tim}$ & Mudim (Masai, Dim). \\
\hline Brook & Kulu & Kolotok. \\
\hline Man & Netyo & Nuto. \\
\hline Nose & Ume & Kume. \\
\hline Evening & Otieno & Kotian. \\
\hline Sand & Kuoyo & Kuј̆ö. \\
\hline A little & Tidi & Ko-dik (Masai, Ku-titi). \\
\hline To count & Ken & Ken (Masai, Iken), \\
\hline
\end{tabular}

Vide "Comparative Vocabulary of Masai," chap. xx. 
lying between Kilima-njaro and the Nyanza, who may turn out possibly to resemble the Doko who inhabit a portion of the almost unknown regions stretching between Abyssinia and Masai-land: There are also curious helot tribes living in serfdom with the Masai and the Galla, and speaking the languages of their masters, though they are said to retain independent tongues of their own. Such are the Wa-boni (also known as the Wa-sania, Wa-dahalo, Wa-ta, Juwano, Alanggulo, \&c.) who live in the vicinity of the Sabaki, Tana, and Ozi rivers, also on various parts of the coast between Malindi and the River Jub. Then, also, there are the Endorobo (a Masai term, probably En-dorobo, "the short, stumpy, inferior"), the Elkonono, a tribe of blacksmiths. The Wa-boni (their very. name is foreign, as may be seen by the Swahili prefix Wa-) live among or near the southern Galla tribes, and are often plundered by these tyrants. They are chiefly hunters, practise no agriculture, and keep few domestic animals but dogs. In physical type, judging by the fer specimens $I$ have seen in the vicinity of Lamu, I should call them very unlike the Galla. They are sooty black, undersized, and very negroid in their features, with woolly hair. M. Greffulhe, a French merchant who had come in contact with them while living and trading in their country, was kind enough to furnish me with a few words of their language, which I insert in a foot-note. ${ }^{3}$ The reader will see

3 English.
1.
2.
3.
4.
5.
6.
7.

Koi Wa-boni.
Lamā
Sadi
Afūr
Šan
Li (Masai, Ile)
Toïba

Toko. Galla.
Lama.
Zadi.
Afūr.
Šan.
Dya.
Torba.

1 d 
that it is principally the same as Galla, except that in the numerals it makes a slight approach to Masai which is not so evident in the former tongue.

The Endorobo and Elkonono whom I encountered to the north-east of Kilima-njaro, were living near the Masai encampments as a helot race of hunters and smiths. I was informed that they manufactured all the spears, shields, and swords of the Masai. They were an ugly lot, very different in appearance from the Masai, short in stature, black, and with their legs often bowed and exhibiting a negro's shin. I could not elicit any words of their own language-if they possessed a peculiar speech-and in my hearing they only spoke Masai.

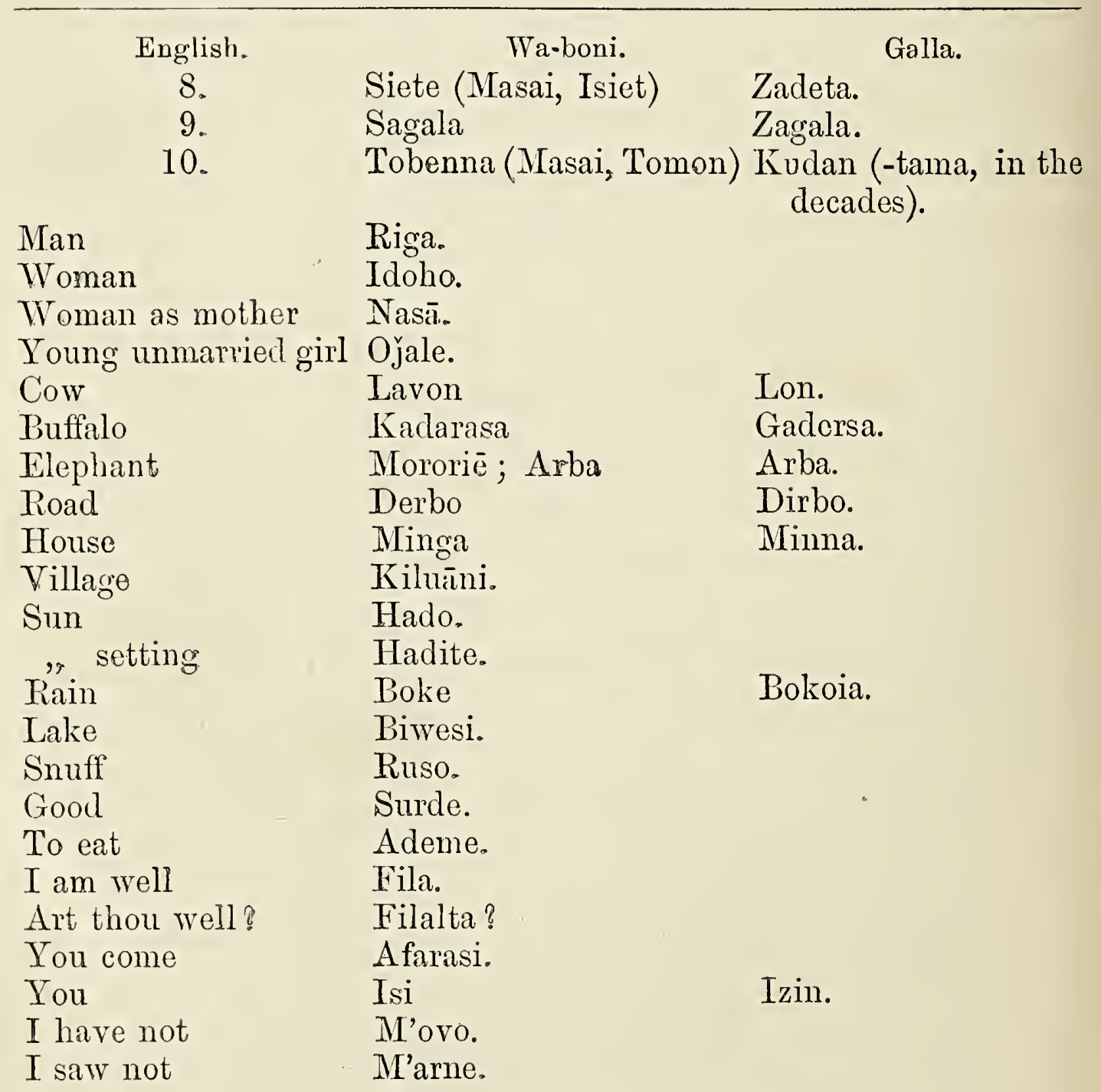


In the country to the west and north-west of Usambara, below the mountains, are the remnants of a curious tribe of cattle-keepers, the Wa-mbugu, as their Usambara neighbours call them. They are sometimes known as the Ala. In appearance they are pleasing, with thin lips, well-shaped noses, rather narrow eyes, and not unlike the Masai. Their colour is a deep brownblack, and their hair does not apparently differ from the frizzly chevelure of the Bantu negro. The language they speak (which has recently been brought to light by Archdeacon Farler of Magila ${ }^{4}$ ), is a thorough enigma. While possessing Bantu prefixes, and using them as they are used in Bantu languages, its word-roots, with one or two exceptions, are utterly unlike anything we have yet met with. The exceptions are a few terms taken from Masai, Ki-kamba, and Ki-sambara.

On the coast, especially between Lamu and Pangani, ancient Arab settlements were planted a thousand years ago, and though their pristine glory has long since departed, some of the descendants of these early colonists still remain, and together with the more recently arrived 'Omani and Hadramauti Arabs represent the Semitic family in this congeries of nations. The intermixture of Arab and Bantu has formed the curious mongrel race known as the Wa-swahili, or "people of the coast" (from the Arabic Sahel, coast), and these enterprising traders have, especially in late years, played a most important rôle, for good and for bad, in the opening-up of Eastern and Western Africa.

I will now proceed to describe more in detail such of those tribes and races with whom I came into personal contact during my expedition to Kilima-njaro.

4 Vide Appendix to "A Pocket Vocabulary of East African Languages." By the Rev. A. Downes Shaw. S.P.C.K. 
They fall naturally into two groups-the Masai and the Bantu.

Until I had safely reached Kilima-njaro with all my goods, I was not at all anxious to encounter any of the former race, great as was the interest I felt in their strange customs and the structure of their euphonious language. Nevertheless, when Mandara sent to me one day the message that a party of Masai had come to visit him and trade, and that I might run over and interview them, I hastened to do so; and, tucking my note-book under my arm, I made off to Moši, where the good-natured chieftain, who was a fluent speaker in Masai, served as my interpreter, and wrung from his solemn, stately guests some of the information which I here impart. At that time Thomson had only just returned to Zanzibar from his wonderful journey through Masai-land, and the result of his observations had not been given to the world: so that the Masai were to me nearly a new subject, and I was eager for enlightenment as to their idiosyncrasies. To many of my readers who have perused Mr. Thomson's interesting work, much of what I here write may seem a twice-told tale, but as a matter of fact it is rather the filling in the details of the picture Mr. Thomson has so vividly and faithfully drawn.

The Masai of whom I write belong mainly to the clans of Kisongo, ${ }^{5}$ Sigirari, and Laitokitok. I have come in contact with them both on the march and when I have been living at Taveita or Moši, whither their women and elders would come to purchase honey and vegetables. I have also traded with

${ }_{5}^{5}$ The people of this district are considered by Thomson to be the finest examples of their race. 
the Wa-kwavi (agricultural Masai) of Taveita, Aruša, and the Ruvu valley.

The distinction made between the Wa-kwavi and Masai has been already commented on, and I would only refer to it again to repeat it is little more than one based on mode of life. In speech these two divisions of the race are identical, and the Wa-kwavi only differ from the Masai in appearance in those districts where they have made slaves among the neighbouring Bantu tribes and taken the females as concubines, a thing which has occurred considerably-as I am informed by Swahili traders-in those vague districts lying between Kilima-njaro and Unyamwezi. But as the Masai of neighbouring districts do the same, with the same result, namely, that the colour of the skin becomes black, and the features lose all fineness of moulding-this negroid mingling is not to be taken as a characteristic of the Wa-kwavi section.

The previous history of the Masai people has been a common incident in the unwritten race-struggles which surge among savage humanity. It has been that of most rising and invading populations, like the Huns and Turks and Goths of Europe. First, some tribe, or division of a tribe, has been forced into war in self-defence, and has won a victory over its assailants. Then it acquires a taste for fighting, and from being persecuted becomes the persecutor. It spreads its conquests and ravages far and wide, the fighting qualities descend from father to son in increasing intensity. Soon, however, there are no weaker peoples left to subdue or to harry. The land is a wilderness, cultivation has ceased. The fighting tribe suffers from hunger. Then a section of them turns to the soil and commences a rude agriculture. 
This pursuit in time prospers, and the improved condition of the agriculturist attracts the envy and greed of their nomadic brothers. A civil war ensues, which, no matter what vicissitudes may happen, ends in the triumph of the tillers of the soil, for to defend their crops and granaries they construct fortifications and walled towns. Then with the victory of the settled authorities comes an opening for commerce. The lives of traders are safer among a hardworking colony of agriculturists than amid lawless rovers and cutthroats. So, in time, civilization finds an opening into what was once a terra incognita on account of the fierceness of its inhabitants. So it has been, and is, with the Masai. The last few decades a perceptible alteration in their condition of life has begun to appear. That section of them known as the Wakwavi has taken to a settled mode of life. No longer do they rove about seeking whom they may rob and slay, but they dwell within fixed limits, cultivate the soil, and encourage traders to settle in their midst. A bitter civil war has raged between them and their still nomadic cousins, at times a war of mutual extermination, but somehow or other the settlements of the Wa-kwavi continue to increase and prosper, while not a few of the tribes of Masai who retain their pastoral habits and still scorn to till the soil are being confronted by a disagreeable alternative that they themselves can recognize. They must either turn their spears into spades and their swords into reaping-hooks -or starve. The cattle disease which has lately raged among them throughout the length and breadth of the land, has played havoc with the herds on which their main sustenance depends. As to renewing their livestock by raids on the tribes of the coast or the far 
interior, that will soon be-is already-an impossibility. Where their victims were too weak to resist they have simply given up cattle-keeping for fear of attracting the ruthless plundering of the Masai, and now subsist meekly on vegetables and fowls; where they were already strong, they have become stronger, either by settled government or by occupying unassailable positions. Soon there will be no cattle left to raid, and the Masai will range the wide deserted plains in all their splendid insolent bravery and die of inanition. The inhabitants of the walled cities or the lofty hills will dwell secure from attack, and the wretched remnants of vanquished tribes still lingering in unprotected haunts will not be worth robbing. Then the proud Masai must turn to and wring from the soil that sustenance which only comes as the reward of honest labour. A dear old warrior of Kisongo, with the manners of a well-bred Arab, and the physique of an aged Hercules (supposing that hero to have recovered his attack of blood-poisoning and to have attained the condition of a magnificent ruin), said to me a little more than a year ago, "Ah, when you next return to Taveita in twelve months' time, you will find us all Embarawuio (Wa-kwavi), like these people of Kikoro, ${ }^{6}$ whom we used to rob and kill when $I$ was a youth. And now, see! All our cattle are dying, though we have sent them to the pastures of Jipé, and I have to come here to buy food from these Es-singa (slaves), who are fat and strong, and lack not good things to eat." The old gentleman had,in fact, come with a troop of wives and many asses to buy grain and honey and dried bananas. In time these more civilized Wa-kwavi will prevail in numbers and power over the fierce pas6 Kikoro is the Kwavi settlement in Taveita. 
toral Masai, and thus Eastern Equatorial Africa -will be opened up to safe and profitable trade. At the very worst, however, the Masai are neither so dangerous nor so bloodthirsty as the Soudanese Arabs or the fanatical Tuaregs of the Sahara. If you are content to pay their tribute, you need not fight, and if you are forced to defend yourself, these people are powerless in front of a stockade, as they have no guns, and never throw their spears, being only accustomed to a hand-to-hand fight. We may be thankful that Mohammedanism has not yet reached them to turn them into mad fanatics or faithless cut-throats like their neighbours to the north and east. It is, indeed, a curious subject.for reflection that this powerful religion, which in a short time swept like an epidemic over all Somaliland and the entire Soudan from Red Sea to Atlantic, should have halted on the borders of Masai-land, powerless in its appeals.

The physical appearance of the unregenerate robber Masai is splendid. It is a treat to the anthropological student to gaze on such magnificent examples of the fighting man. It is an example of one side of our multiform nature pushed to an exclusive and supreme development. The Masai warrior is the result of the development of Man into a beautiful Animal. To call him God-like, as we do the Greek ideals, would be silly and inappropriate - as much so as seeing divinity in a well-bred race-horse or an Alderney cow. To compare him with the statues of Apollo with which we are most of us familiar in foreign galleries or as plaster casts in English palaces of entertainment, is unfair to the one and the other. If you could find Apollo represented with huge-lobed ears, fang-like teeth, high cheek-bones, and a woolly crop, not to 
mention other peculiar and, to our, or perhaps I may say your notions-for I am personally without prejudices-ungraceful developments, then you might aptly compare his ideal representation with the living Masai; or if you could discover specimens of these people who possessed the fleshy effeminate contours, the sexless countenance of vacuous beauty attributed to the god of poetry, music, and prophecy, you might more. fittingly describe them as dark statues of Apollo. As it is, the physical perfection of these East African beef-eating, bloodthirsty warriors is of the prize-fighter's or the rowing-man's ideal, rather than the æsthete's.

The full-grown Masai of pure blood generally attains six feet in height by the age of seventeen, though at that time he is often spindly and cumbersome, an ungraceful hobbledehoy. Three years, however, of an exclusive diet of milk, blood, and half-raw beef-steaks, combined with a rigorous training in warlike and athletic exercises, have developed him into a sinewy, muscular man of admirable proportions, broad of chest, with a smallish head, a graceful neck, and limbs whose muscles seem hard as iron. There is no fat on his body. I cannot say that his hands and feet are always well-shaped. Though the instep is high, the foot spreads out rather broadly and squarely at the toes; the minor ones advancing nearly in a line with the big toe.

Their faces are somewhat Mongoloid in look, at first sight. The rather narrow, slanting eyes, the prominent cheek-bones, and the pointed chin suggest that impression. On the other hand, the nose is often beautifully shaped, with high bridge and delicatelycarved nostrils, which obey sensitively the passing feelings of their owner, quivering and dilating with 
pride and rage, or widening and relaxing with good humour. Their heads are often singularly round and broad for Africans, though at the same time I have not failed to see the most dolichocephalic skulls among the true Masai. The hair is certainly longer and less frizzly than among the true negroes, though at the same time this may be only due to the careful and continual combing-out it undergoes and its straightening with a thick paste of clay and fat. It is, after all, a negro's wool, and is not longer or more abundant, certainly, than the regular Papuan crops of hair which the Bantu. people of the Upper Congo have been found to possess.

The ears of the Masai are naturally large, and, inasmuch as big ears are admired, this may be an inherited and perpetuated peculiarity; but, apart from what Nature has done for the race, Art steps in and effects greater changes still in the individual. When quite young the Masai children drill holes through the lobes of their ears. Through these small twigs are pushed, beginning at the size of lucifer-matches and gradually increasing as the aperture is extended until a huge wedge of ivory, four or five inches in diameter, can be passed easily through the lobe of the ear, which is changed to a thin loop of skin drooping to the shoulder. Sometimes a kind of wooden stretcher is employed, like a cotton-reel with a groove at both ends, and this is inserted lengthwise, to extend the ear. Usually, when it is considered sufficiently large, a row of fine iron chains, made by the skilful Caga forgers, will be hung to the distended loop, or there may be a circular wooden or ivory ring like Mandara's, which is illustrated on page 107. Married people change all these ornaments for discs of copper-wire, coiled round and round and looking just like small 
Catherine-wheels in shape. These are hung on to the ear, and it is de rigueur to do so on entering the marriage state.

The eyes, in these people, as already noted, are long and slanting. The sclerotic is clearer and whiter than in the typical negro, though in most of the men it becomes very bloodshot and enhances their fierce, wicked look. The eyebrows are prominent and generally hairless-I think the hairs are pulled out purposely with tweezers. Whether there is much sign of beard or moustache I cannot say. The men I have seen are always rigidly smooth-faced. They use razors (El-morūnya) of iron, made by the El-konono, a helot tribe of blacksmiths. I fancy the place of shavingsoap is taken by a thin layer of wet clay. "To shave," -barn-, also means " to scrape," in their language. I do not think, however, there is much growth of beard in these people, or that they need to shave very frequently. The shape and size of the mouth varies exceedingly in the Masai, doubtless according to the greater or less purity of the race. This feature is always large, but frequently the lips are thin, and the upper one rather inverted than everted. The teeth are generally very ugly. They are often carious, but even when sound they project at an angle from the purple-red, discoloured gum, and appear like isolated fangs. The wide space which is often seen between the two middle incisors of the upper jaw is doubtless due to artificial filing, and is supposed to aid them in the projecting of their saliva, which is such an important ceremony with these people. Instances of marked prognathism I have never seen among the Masai.

7 To spit on any one is a sign of respect and friendship. To wipe off the saliva is a great insult to the spitter. 
As regards their limbs, I have generally noticed that the forearm is long, as it often is in Africans, and that the tip of the middle finger nearly reaches the knee when the arm is dropped by the side. The forearm is generally thin and rather straight all the way down, but although the muscles do not much project they are hard as iron. These few lines of vague description are of little use to anthropologists, and I regret very much that $I$ have not a series of body-measurements to give you, but such a thing was impossible with the Masai. They angrily rejected the proposal. when I advanced with my measuringtape.

The colour of their skin is a dull chocolate-brown, ordinarily, varying between the Nos. 28 and 42 of Broca's colour types. Occasionally among the women lighter shades may be seen, but this is generally in the vicinity of the Wa-gogo people, who are very lightcomplexioned negroes. Some Masai-more especially Wa-kwavi-are a dull black, but this tone always accompanies coarse features and indicates a mixture with captives from the black tribes east, south, and west. Hair on the body seems tolerably abundant in the usual parts, if allowed to grow-at least, so I am informed-but it is always rigorously, pulled out, and all the Masai I ever saw were carefully depilated.

Circumcision is generally performed on the male at the age of fourteen, as far as I can ascertain-that is to say, it is done as one of the preparatory rites that celebrate the attainment of manhood. The manner of operation and the result are, I believe, quite peculiar to the Masai. ${ }^{8}$

${ }^{8}$ Præputio e superiore parte diviso, duæ quasi lingulæ sub glandem 
After birth, the Masai baby (who is generally quite yellow when first born), is carried in a roll of leather attached to its mother's shoulders. Female infants are considered a disappointmennt, and are often termed contemptuously "pans," or "empty, hollow vessels" (E-modi). The more boys a wife bears, the more she is esteemed. Up to the age of three both sexes alike are term "En-gera" or "children"- -a word meaning "the sheep sort," or "the little sheep," Then the males are distinguished as "En-aiok" (sing. En-aion), and later as "El-aiok," while the girls continue to be called En-gera until they attain puberty, when they are known as En-doye (sing. En-dito). Young men after circumcision, when they leave the family home and consort with the warriors, are called "El-barnodi," from the roots barn, to shave, and odi, or godi, a calabash. It means that they shave or scrape the milk-calabashes (which are never cleaned with water, but by scraping and rubbing with wood-ashes) for the young warriors, and make themselves otherwise generally useful. At about the age of seventeen they become fighting-men, and join the army, which includes practically the entire manhood of the nation between the ages of seventeen and twenty-four. The young men are known as El-moran. Their dress is picturesque but scanty. In ordinary, every-day life they wear nothing, and walk about in all their splendid, shameless nudity; or if they wish to make a little toilet, or are about to leave the camp, they sling a

truduntur, ubi quum coaluerunt, fit molle et rotundum tuber glandi. subjectum, ita ut paullo longius conspiciente videtur penis duplicem terminum habere. Hoc membrum apud Masaios enorme est: quod celare turpe existimatur, honestum expromere, atque etiam ostentare. Apud feminas clitoris ante matrimonium abscinditur quo facilius fiat conceptio. 
leathern cape about the shoulders or over one shoulder, tie a narrow leather girdle round the waist, in which to stick a knife or wooden club, and don their leather sandals, of which, by-the-bye, they are continually cutting out fresh pairs from new ox-hides, this being almost the only form of work they do not consider menial. When going to war, however, these simple adornments above described are considerably added to. The leather cape is removed, and its place is takenfirstly, by a long piece of cloth, sewn down the middle with a coloured stripe; and secondly, by a thick carapace made of kite's feathers, or, as in my sketch, by a cape made of the skins of the Colobus monkey. A cap of Colobus skin may also be worn on the head, or a striking head-dress made of ostrich feathers, and shaped roughly like an ellipse. The leather cape which ordinarily is worn round the shoulders will now be twisted round the waist like a belt, and in the folds of this are secured the knobkerry (Ol-oikuma) and the Ol-alem or sword. Sometimes a ring of goatskin, with the fur outside, or a strip of Colobus skin, will be worn round the ankles, and then, with a longbladed spear and shield four feet high, the equipment of a Masai warrior is complete.

The hair of the men is combed out into long frizzles, artificially lengthened with strips of bark, and stiffened with clay and fat. Sometimes it is worn in long locks like rats'-tails, or more frequently it is drawn into a couple of pig-tails both over the forehead and at the nape of the neck. The women usually shave their heads, wholly or in part, and bestow little care on that part of their person. On the other hand, they are much more extensively clothed than the men, being enwrapped generally from head to feet in ample garments of dressed leather. Their necks, wrists, 
and ankles are covered with massive coils of iron or

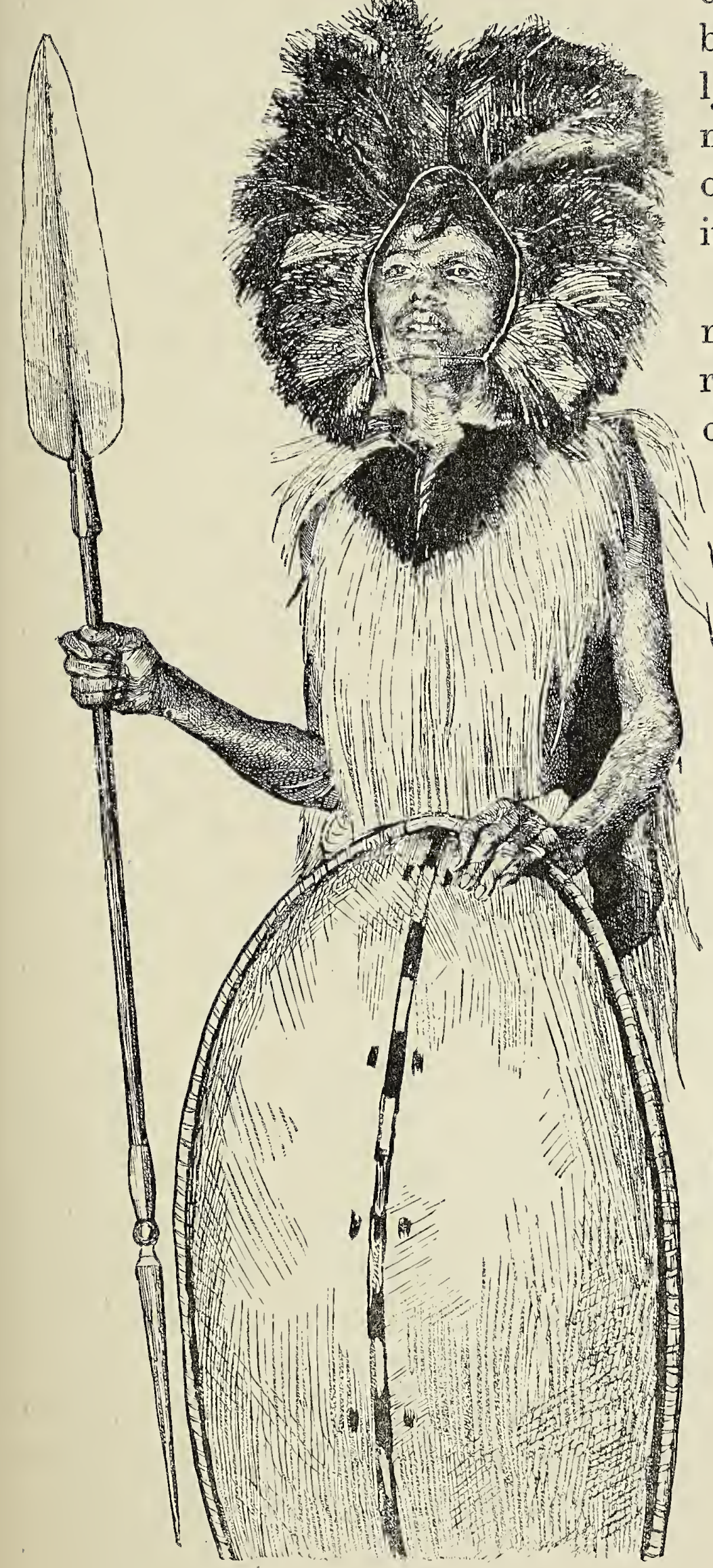
copperwire, and beads are largely used to ornament the fringe of their clothing.

The Masai men rarely marry until they are over twenty-

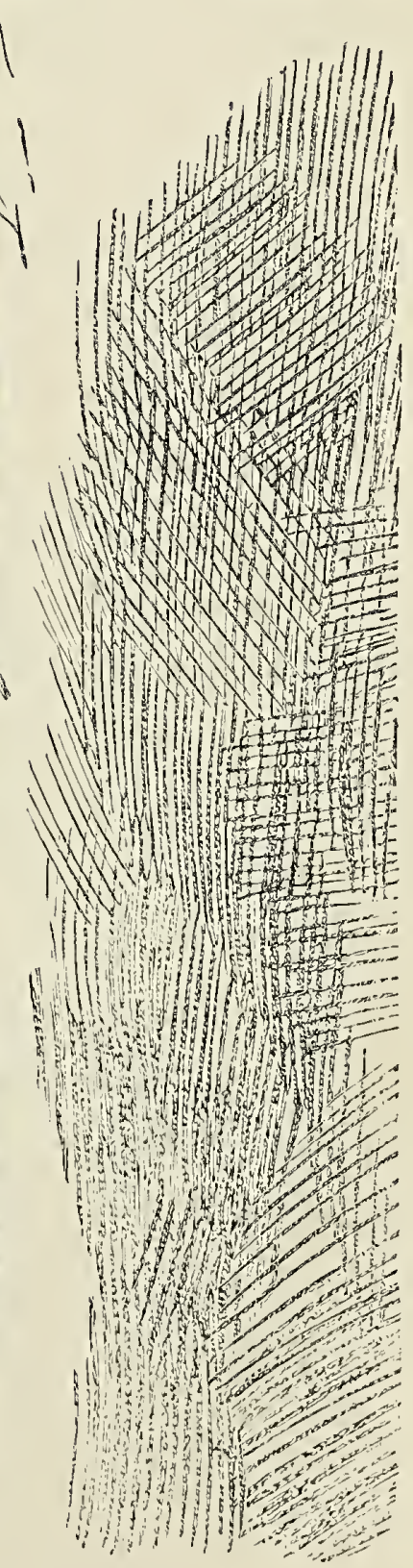

Fig. 74.-A Masai Warrior. 
five, nor the women until twenty. But both sexes, avant de se ranger, lead a very dissolute life before marriage, the young warriors and unmarried girls living together in free love. The married Masai is a changed being. From a lustful, bloodthirsty fiend he becomes a staid, courteous, and reasonable man, anxious to obtain and impart information, and as desirous of healing a breach and preventing bloodshed as before he loved to foment a quarrel and take part in a massacre. Whilst still an unmarried man and a warrior he abjures all vegetable food, and strictly confines himself to a diet of milk and meat. Moreover, he must not mix these two things, but, before changing from one to another, must take a powerful purgative, so that, for instance, if he has. been living on milk, and wishes to eat or drink blood, he must thoroughly clear his system before changing from one to the other. But after marriage, when he is no longer looked upon as a fighting-man, his diet is unrestricted. He now seeks to obtain vegetable food from the humble races of cultivators who dwell in the vicinity of his settlement, or eagerly purchases honey with tusks of ivory.

Marriage is little more than a question of purchase, and the amount of cows to be paid varies with the comparative wealth of the bridegroom and the bride's father. This question also regulates the number of wives. They seldom, however, espouse less than two. Married people are generally called "El-kieko," and the husband is termed "El-moruo."

When little children die, they are often buried within the village enclosure, or even beneath the floor of the mother's dwelling. Grown-up persons are generally placed under a tree in a sitting posture with the knees 
touching the chin. A calabash supposed to contain milk, but generally empty, is placed by the side. A slight excavation in the ground is either chosen or made, in which to put the body. Stones are then heaped around it and over it, and grass is thrown on the top, so that a kind of cairn is generally formed. Nevertheless, the hyenas scarcely ever fail to pull down this mound and drag out the corpse, which is then devoured without any interposition on the part of the surviving relatives. When any person dies within an inhabited village, the settlement has to be purified by the medicine-man with a liquor made from the halfdigested food (E-mojok) in the stomach of an ox, which is killed for the occasion. After death the name of a deceased person is never mentioned, lest his spirit should obey the call and return. Notwithstanding this impression, these people have almost no fear of or belief in ghosts or demons, and mock at the Bantu people in their vicinity for their elaborate propitiation of the shades.

The Masai worship a vague Supreme Being, whom they call "En-gai," a feminine word also meaning the "heavens" and "rain." En-gai is sometimes supposed to dwell on the summit of Kilima-njaro, which is therefore called "Engaji-Engai," or the House of God. This Great Spirit with whom rain and grass ${ }^{9}$ are peculiarly associated-as being the chief sign and result of his beneficence-is propitiated with loud singing and dancing (Isilil). They also sacrifice sheep, and tie all the bloody remains in the skin and leave it on isolated mountains, or at a place where

${ }^{9}$ Grass (gujita) is regarded as peculiarly sacred. It is a sign of peace and good-will. To throw grass at any one is to display goodwill and favour. 
many paths converge. The Masai mention another and weaker divinity, whom they also designate by a female appellation - "En-naiterkob." En-naiterkob seems to be a kind of earth-spirit (En-kob, the earth, the world), in contradistinction to En-gai, the heavens, the over-arching sky. The Masai often call on Naiterkob to mediate with En-gai and obtain the granting of their prayers for rain, success in war, or many male children. They regard with peculiar veneration the snowy summits of both Kilima-njaro (Ol-doinyo oibor, the white mountain) and Kenia (En-durkenia, or Ol-doinyo oigeri, the spotted mountain), imagining that these are at once the chosen residence of Naiterkob and the places on which En-gai reposes, and that they are therefore the most fitting sites for mediation with the Most High.

The political constitution of the Masai tribes is mainly patriarchal, but the rule is sometimes a dual one. The father of the tribe, the supreme chief, is generally a man chosen for his wealth, his wisdom, or his martial renown; or it may be that he is a mighty medicine-man skilled in the arts of divination and prophecy, and able to compound powerful drugs from the roots and bark of certain trees. If the former he is called Ol-beijani, and holds his place as long as he can keep it, but if his power is sacerdotal-if he is an Ôleibon, then he is probably supreme till death. The office is not hereditary. Sometimes the Beijani and the Eibon are found ruling side by side-the temporal and spiritual chieftains. In other cases it may be the Eibon who wields exclusive power or unites the temporal and spiritual functions in his own person. The Wa-kwavi states are usually little republics ruled by an oligarchy of all the wealthier or more powerful 
elders. Here the Eibon, or medicine-man, plays a less important part.

The Masai are very respectful in disposition to their elders, and the younger members of the community will seldom sit in the presence of the old men. At the same time they exhibit little grief at the death of their comrades, whether in battle or in village squabbles. As to remorse, that outcome of civilization does not exist among them. A Masai will murder his friend or neighbour either in a free fight over a herd of captured cattle, or in pursuance of private revenge, and live not a whit the less merrily afterwards. Nevertheless, while it is thought an honourable distinction to kill a fellow-citizen in fair fight, to murder any one secretly or by surprise is punished by a heavy fine. This is for the good of the community, not because it is thought wicked. The Masai, in fact, have scarcely any conceptions of good and bad like those of Europeans. Torono, which we translated "bad," really means "broken, useless, inferior, spoilt ;" Mangadi is not "wicked," but "cruel;" Sidai is not "good," but "loose-mannered, easy-going, wanton, unchaste." Certain actions are recognized as injurious to the community and the commonwealth, and as such they are punished and repressed; but they do not, as do many races of men, connect different good or bad deeds with the pleasure or displeasure of the gods. Were the Masai given to enunciating moral maxims they would probably say, "To be good is to be silly," and "Be cunning and you will prosper;" "Happy is the man who has smashed many skulls and stolen many cows: his children shall honour him," and so on.

The agricultural Wa-kwavi build their houses generally after the method of the Bantu or other foreign 
races in whose vicinity they settle; besides copying them in many other particulars. The semi-nomad Masai do not make much pretence at architecture. As they roam about over certain districts, they often inhabit different portions at different times of the year. In the rainy season they may take to the open plains where the grazing is now good for the cattle, but in the winter or rainless period they will change to hilly ground where the mists create perennial verdure, or to the vicinity of great lakes and rivers for the same reason. Their quickly-constructed towns or villages, of which the women are generally the architects and builders, consist of a huge circle of low mud huts, surrounded by a thorn fence. In the middle of this enclosure the cattle are kept at night. Their huts are generally built as follows: first making a rough framework of pliant boughs, which are bent over and stuck in the ground at both ends, they plaster on this a mixture of mud and ox-dung, and, for further resistance to heavy rain, hides are thrown over the top, outside. The height of the dwellings barely exceeds four feet. There is a low, porch-like door. The only attempt at furniture is a hide laid across a row of sticks to serve as a couch at night.

The length of the house may be from nine to ten feet, and the breadth five. The top is generally rounded from the nature of the framework. They often, especialiy when built in a row, look like little more than inhabited mud walls.

The principal utensils of the Masai are calabashes, made from gourds and the huge fruit of the baobabtree, leather bags, pots and spoons hollowed out of soft wood, or made of clay for cooking purposes. Snuff-bozes and pipe-bowls are made from the hard 
shells of certain fruits, or from ivory or rhinoceros horn. Their spears, knives, razors, and all metal instruments are made by the curious El-konono tribe, who dwell among them as vassals and serfs. Some of the poor Masai make a subsistence by neatly sowing leathern garments and disposing of them to women or old men in exchange for food.

The domestic animals of the Masai are oxen, goats, sheep, donkeys, and dogs. Fowls they despise and do not keep. Their cattle absorb all their thoughts. For their possession and retention wars are waged. The gift of an ox is a sign of solemn peacemaking, and is generally accompanied by much spitting right and left of the men who lead it. Nearly all their rites and superstitions are connected with cattle. They believe that they are the lawful heritage of the Masai race, whose primal ancestor received from Naiterkob the power to tame the wild oxen of the woods; and under this impression they "lift" the cattle of all weaker nations, maintaining that they have no right to their possession. Nevertheless, they probably got their kine from their northern home, somewhere on the White Nile, for the generic word they use for cow and cattle is identical with that of the Bari people round Gondokoro, and related to similar terms in the Siluk and Dinka tongues (vide Vocabulary). The only type of ox which I have seen in their possession is that humped Asiatic breed (the zebu), so common in Tropical Africa, and which probably owes its introduction to the ancient Egyptians. But I am informed that farther in the interior to the eastward of Kilima-njaro, there is another breed of cattle in the possession of these people-a breed like the oxen of the Cape and Southwest Africa, with large bodies, no hump, and immense 
wide-spread horns. On the Kunene river (South-west Africa, latitude $17^{\circ} \mathrm{S}$.) I have met with the two breeds side by side-the big, long-horned and the small, humped cattle. In Angola there is a mingling of the two. On the Gold Coast and the Oil rivers I have only seen the small, humped variety, though I am told farther inland the other appears. Whence this longhorned, straight-backed, large-sized ox (which is normally a dun-brown) came from, I am at a loss to say. Of course it was not African in its origin, as in Africa there is not, nor, as far as we know, has there been, a wild ox of the genus Bos. Yet this last breed-which much resembles the Hungarian and South European (Spanish) cattle, was evidently an early introduction into Africa, for in many districts it appears to have preceded the humped kind. It was the only breed the Hottentots possessed. It seems to be very much kept by the populous nations in the interior of South Central Africa, between the Congo and Zambezi.

The Masai have a word for the pig which is also common to their distant relatives on the Nile (vide Vocabulary), but they do not keep it in a domestic condition. The term for pig is used to indicate the wild wart-hog (Phacochcerus).

Their goats are those of East Africa generally, a small, plump variety. They possess two breeds of sheep, only one of which I have seen. This is the hairy, fat-tailed sheep, with short horns. The other I judge from report to resemble the tall, big-horned, chest-maned, domestic sheep of Central and Western Africa (vide illustration, p. 428 of my book, "The River Congo"). The common fat-tailed sheep is called En-gera, and the long-horned kind El-mērekeš, or El-kirieš. 
The Masai donkeys are generally splendid beasts, and are simply and solely the wild Ethiopian ass (Equus homiopus) domesticated. Where they have been free from mixture with coast breeds, they are, as I saw them, literally undistinguishable in size, colour, and markings from the wild ass of Abyssinia and North-east Africa. They have none of the stripes on the legs which appear in the wild ass of Somaliland. The Masai must have got them from the far north. Their word for ass agrees with that in the Latuka language spoken in $5^{\circ}$ north latitude, to the east of the Nile (vide Vocabulary).

The Masai are much attached to their dogs. Generally each child is followed about by one, its own exclusive pet. They are-those that I have seendisappointing mongrels, all colours, and of no marked breed. Generally the ears are erect and pointed. The colour may be fawn, fawn and white, black and tan, all black, or black, tan, and white. They are about the size of large terriers. They never bark.

The marabou storks (Leptoptilus), vultures, and hyenas (H. crocuta) which frequent the Masai encampments are strangely tame, and are protected for the useful scavenging they perform. Strangers cause grave offence by killing them. The spotted hyena is often called by the Masai "Ol-uwaru onyojine, "the limping leopard." The striped hyena, which is rarer and shyer, and keeps more to the open, is called "Otonu."

Whenever the warrior Masai are on a journey they are positively accompanied by flights of vultures and a few marabou storks. Wherever they stop to slaughter cattle, these scavengers descend and feast on the offal till they are so gorged that you may see a Masai push- 
ing them away with his foot. The hyenas that haunt the vicinity of their burial-places root up and devour the dead soon after their relatives have laid them in the soil, without in any way being checked or molested.

The Masai rarely kill or eat any of the game around them-zebras, giraffes, buffaloes, and antelopes, so that their country from long preserving has become a hunter's paradise. Unfortunately, the Masai are incensed at any guns being fired in their vicinity, lest the report should stampede their cattle; consequently a sportsman would often find himself cruelly hampered.

The ivory in which these people trade is secured for them by the helot tribes of hunters-En-dorobo, El-mau, and others, who actively pursue the elephants with spears and poisoned lances. The Wa-kwavi, who are agricultural Masai, cultivate, of course, most of the East African vegetables-sugar-cane, maize, bananas, millet, tobacco, sweet potatoes, and the collocasia root. The names of all these things are derived from Bantu languages, and are not related to terms employed by the other members of the Masai family in the Nile basin. Tobacco is not smoked by the Masai, but mixed with natron (magad) and chewed. It is also powdered and taken as snuff most extensively. Tobacco is always called by a corruption of the coast name, which again is only a variant of "tobacco." It is wonderful, considering how recent is the introduction, that tobacco has so quickly spread among these wild people that they already forget its foreign origin.

The Masai are very fond of honey, which they not only purchase from their agricultural, bee-keeping neighbours, but also obtain from the stores of wild bees in wart-hog or ant-bear burrows. To these they are often guided by the honey-bird (Indicator), a crea- 
ture they naturally regard with kindness. From the honey, mixed with water, they make an intoxicating mead called "ol-marūa." This and sour milk are their chief beverages. Milk is regarded as a sacred fluid. They will never give or sell it to strangers of other nations, and were it not that the women are less rigid in their views than the men, and that they may occasionally be bribed with beads to bring milk clandestinely to the strangers, this grateful fluid would otherwise be unprocurable in Masai-land. Moreover, although they will readily give or sell castrated bullocks, they will never willingly part with a cow. The most heinous act a stranger can commit in their land is to boil milk. This, they think, will so enrage the cows that they will at once run dry. Any one caught doing so can only atone for the sin with a fearfully heavy fine, or, failing that, the insult to the holy cattle will be wiped out in his blood. Talking of blood, this is one of the Masai warrior's chief and favourite forms of nutriment. The ox is generally stunned with a blow on the back of the head, and then a vein is opened in the throat. To this the Masai applies his lips, and sucks and sucks until he can hold no more or until his impatient comrades tear him from the spurting vein. Doubtless the salts in the warm blood supply a need in his diet, for in no other form does salt mix with his food, the warriors being compelled to refrain from the salted tobacco their elders so enjoy.

Commerce and the cattle disease will do much to open up Masai-land, which is the finest country in Africa. The one will soften and the other will tame these fierce people. The increasing love of trade goods impels them to encourage the arrival of coast caravans, and the loss of their cattle, as before explained, will 
force them to till the soil. Then, as my old Masai friend prophesied, they will all become Wa-kwavi, and if the original nomad Masai be a fierce, intractable, insolent bully, he no sooner becomes a settled agriculturist than he changes into the nicest, quietest, honestest, mildest inhabitant in Africa. Therefore, although they may fail to see it, the greatest boon En-gai can confer upon them is to sweep their cattle off the land.

Almost exclusively the Masai inhabit the plains round the Kilima-njaro district, while the uplands still retain the older population of the country. This consists of people belonging linguistically and racially to the great Bantu family, which occupies nearly all Africa south of the Equator. From a linguistic point of view the Bantu are absolutely homogeneous-there is no mistaking a Bantu tongue for a member of any other family. But ethnologically the distinction is much disputed. Some good authorities maintain that the Bantu races (Kaffirs, Congo, Swahili people, and the inhabitants of the great lakes) do not agree amongst themselves in any particular type, nor differ markedly from other negroes on the Nile or the west coast. This is a question of such intricacy, and needing so much careful argument, that I am not prepared to enter into it here, nor am I ready or anxious to prove the racial homogeneity of the Bantu-speaking people. While I recognize that there is certainly a great physical similarity between the Ovampo, Ovaherero (Damaras), the inbabitants of the Upper Congo, the Ba-ganda of the Victoria Nyanza, and the Zulus, I admit at the same time that there are many other tribes and races speaking Bantu languages who differ markedly from the fine types above cited. I have seen natives from the borders of Lake Nyassa, from the Lower Congo, 
from East Central Africa, who presented all the most hideous and exaggerated features of the Gold Coast negro, although the yellow faces in some of them might suggest an ancient strain of Hottentot or Bushman. Of course the Bantu is a negro-so is the Masai, the Wolof, the Mandingo, or the pale-faced Berta of Abyssinia; so also, in my opinion, are the Hottentots and Bushmen. All African races with frizzly hair I would call negroes, whether their noses varied (as they do in the same tribe) from the patulous, wide nostrilled, bridgeless form of the Bushman to the fine, aquiline, delicately-shaped organ which you encounter among the Masai or the Wolof. There is no feature constant like the hair. You may meet some tribes of Bushmen who are dwarfs, and others (such as those found near the Kunéné and Upper Zambezi) who attain the average size. The colour of all negroes may vary in the same district from jet-black to tawny-yellow, but still their hair, though it may be long or short, is frizzly. Nevertheless, among the negro races there are wide differences that separate them into certain fairly well marked groups, the members of which evince more affinity for one another than for other sections of the sub-species or variety. Thus the low types of Masai resemble, not the Bantu, but the negro races of the Nile-the SilukDinka people-from whom they perhaps originally sprang. The finest physical type of the Bantu, whether he be found in Damara-land, on the Victoria Nyanza, or in Natal, offers much the same characteristics in common, and does not at all resemble the Masai, who may be the highest development of the Nile negro, or the Wolof, who is among the handsomest samples of the races of Northern Guinea. Therefore, inasmuch as the mountaineers of the Kilima-njaro district and 
elsewhere, who speak languages of the Bantu family, differ from the Masai in speech and in physical features, and resemble rather in both these points the majority of the inhabitants of the southern half of Africa (who also belong linguistically to the same group), and further, as I cannot call one negro and the other negroid (since both are negro), I prefer to use the term Bantu in a physical as well as in a linguistic sense, and to speak of the Bantu peoples in contradistinction to the Masai. The principal Bantu tribes in the district I am describing are the Wa-taveita on the River Lumi, at the base of Kilima-njaro, the Wa-čaga, who, under many chieftains and political divisions, inhabit the great mountain, the Wa-gweno and Wa-kahe to the south, and the A-kamba and Wataita to the north-east and east. When I started for Kilima-njaro from Mombasa I encountered no inhabitants until we reached the hills of Maungu, on the borders of Taita. Here some people came and sold us honey and spoke to us in the Ki-taita dialect. At Ndara and Bura we subsequently saw more of the Wa-taita, and many of them afterwards emigrated to Taveita and Čaga, and even entered my service as hunters and scouts, so that I was enabled to see a good deal of them from first to last, and take down vocabularies of their dialect.

In outward appearance the Wa-taita are unprepossessing. They are about the medium height, the men varying generally from five feet three inches to five feet nine inches, and the women from four feet eleven inches to five feet four inches. They have fairly good figures, the limbs, especially the legs, are well formed, but the men are somewhat effeminate and slight-looking. In facial aspect there is much 
variation. While many have little pug noses with no perceptible bridge, and a much-rounded, projecting forehead, others exhibit an almost Red Indian physiognomy, with aquiline noses, high cheek-bones, and retreating foreheads. The teeth are artificially filed and sharp pointed, but are naturally set somewhat wide apart in the jaw. The whites of the eyes are much clouded. The ears are so tortured and misshapen by prevailing fashion, that it is hard to guess their original shape. The body is disposed to be hairy, but is carefully depilated all over, even to the plucking out of eyebrows, eyelashes, beard and moustache. The colour of the skin is generally dull, sooty-black, but this is often disguised by the coating of soot or red earth and fat or castor-oil, which is rubbed over the skin. The hair is generally shaved all round the head, and only allowed to grow on the occiput. Here it is much cultivated and pulled out into long strings, which are stiffened with grease and threaded with beads. Beads, indeed, are the adoration of the Wataita. The women wear massive collars of them, sometimes six inches broad and three inches deep, which are placed round the neck, and sometimes so lift up the chin as to compel the wearer to keep the head well thrown back. Several hundred strings of beads are bound round the waist, smaller bands cross and recross the back and breasts, they are banded round the shaven part of the head, they hang in scattered strings from the temple downwards, they decorate the tiny tablier or leather apron which is worn for purposes of decency, and the borders of the two-tailed leathern garment which hangs on the back and legs are also edged with beads of various colours. In both sexes the lobes of the ears are pierced, and 
the hole is widened until the distended flap of skin nearly reaches the shoulder. When this result has been attained, many rings of beads are inserted, and continue to weigh down the distorted ear, the outer auricle of which is further pierced and hung with beads of a larger kind. This hanging the ears with beads is peculiar to the Wa-taita, the other mountain races in the vicinity employing for the like purpose fine iron chains, bolts of wood, or rings of wood or ivory. There are but slight traces of religion among them. They are afraid of spirits, who are supposed to dwell in large forest trees, and perhaps for the reason that their dead are always buried in the forest. The country is but slightly wooded, but on the hilltops clumps of high trees are religiously conserved. The baobabs among these people, as among other East African races, are looked upon as particularly the abode of spirits. The word for God in their language is Mulungu, but I more than suspect it is a borrowed term from the coast tribes, and that Eruwa, "sun," is their true conception of an over-ruling deity. Among the Wa-pare, the Wa-gweno, the Wa-taveita, and the Wa-caga the word for "sun" and "God" is identical. Mulungu is in use among the A-nika and the A-kamba, and Muīngu and Mungo among the Wa-swahili and the Wa-pokomo. All these variants descend from an original form, $M u-n-7 u t u-n-k u l u$, which is most closely preserved in the modern Zulu U-nToluntulu. The adjective -kulu in nearly all Bantu tongues has the meaning of "great" or "old." To this was added the $n$ prefix, then the personal prefix $m u$, so that finally the combination meant the "old, old one," for great and old in this sense are almost synonymous, and Bleek conjectures the term to have been a relic of 
ancestor worship, or the deification of some tribefounder.

One other incident may be mentioned about the Wa-taita before I leave them. Their marriages are arranged first by purchase, the intended husband paying the father of the girl the three or more cows fixed as the price. When these preliminaries are settled the girl runs away and affects to hide. She is sought out by the bridegroom and three or four of his friends. When she is found, the men seize her and carry her off to the hut of her future husband, generally each man holding a limb, so that she is supported by four men including the bridegroom. On arriving at their destination, being accompanied on the way by bands of laughing girls and women, she enters the hut with her four captors, and each in turn is allowed to exercise a peculiarly marital privilege. Then having been in this strange manner repaid for their services, they leave her to the exclusive possession of her husband. She remains with him for three days, then is escorted back to her father's house by another procession, and finally returns to her future home to take up the cares and duties of domestic life.

The language of the Wa-taita is about intermediate between the dialects of the coast and those of Caga.

The A-kamba, who live on a broad stretch of country to the north of Taita nearly to the base of Kenia, are the neighbours of the Gallas on the coast. They are very roving, colonizing people, and great hunters. I have seen many of them at Taveita, whither they would bring rhinoceros horns and dried rhinoceros flesh for sale. These are on the whole a good-looking race, and I was surprised to find in many that the hair, though short, is straight, which together 
with a light skin shows an intermixture of Galla blood. They are slightly clothed in leathern coverings with a certain regard for decency. Originally, according to their traditions, inhabitants of plains and mountains to the south-east of Kilima-njaro, they were driven farther north by the inroads of the Masai, and eventually settled in that long strip of country which separates the latter race from the Galla. Here they have taken pretty firm root, together with their close

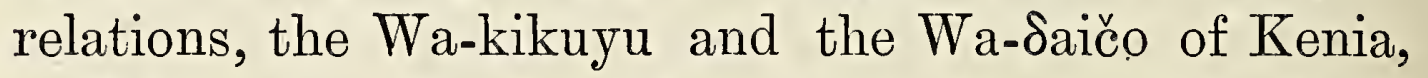
and however they may have been harassed by both Masai and Galla, they have increased and multiplied. Indeed of late years they have become too numerous in their own land for the limited supply of food, and so are compelled to wander to the coast and to Taveita in search of subsistence. They are a quiet, industrious, manly race, very different to the wretched A-nyika of Mombasa (teste Krapf), and will doubtless, when their country comes to be opened up, play the same important rôle of carriers and workmen as the Wa-swahili of Zanzibar.

The beautiful forest district of Taveita is inhabited by two different colonies. One a Kwavi people of Masai origin, and the other and more primitive a most interesting Bantu tribe, the Wa-taveita, who exhibit marked peculiarities in their language and ideas. Let me begin by saying that they are one of the pleasantest people I have ever encountered in Africa. They are of fair height, some of the men being both tall and robust, and attaining occasionally six feet in height. Their figures are often models of symmetry and grace. They anoint the body with oil and ochre, as do the neighbouring people already described. The hair is dressed in many fashions, more often divided 
with fat into separate strips, and the whole united in a pigtail at the back, or else allowed to hang in long locks about the face and shoulders. They frequently let the beard and moustache grow, and generally abstain from plucking out eyelashes and eyebrows, as is done elsewhere, though this is also occasionally practised at Taveita. Circumcision is general. Marriage is of course a matter of purchase, but no sign of imitating capture seems to be practised here. If the young man cannot afford to pay for his wife at once, he gives over to the father a certain portion of the price, and his intended bride is betrothed to him and carefully prevented from communicating with other males until the rest of the purchase is paid. Then she becomes a wife, and directly signs of pregnancy are manifest she is dressed with much display of beads, and over her eyes a deep fringe of tiny iron chains is hung, which hides her and also prevents her from seeing clearly. She is generally accompanied by an old woman, who is deputed to screen her from all excitement and danger until the expected event has taken place; after which little further fuss is made, and other succeeding children are born without any extra precautions being taken.

After marriage the greatest laxity of manners is allowed among the women, who often court their lovers under the husband's gaze; provided the lover pays, no objection is raised to his addresses. Both sexes have little notion or conception of decency, the men especially seeming to be unconscious of any impropriety in nakedness. What clothing they have is worn as an adornment or for warmth at night and early morning. These people are affectionate and kindly in their family relations, as may be instanced by such an 
episode as the one recorded on page 214 of this work. Nevertheless they display strange callousness sometimes where death is concerned. The body of a muchloved wife or child is hastily buried in a shallow trench outside the circle of huts, and covered with stones and grass. The hyenas at night proceed to exhume and devour the corpse without provoking any interference from the sorrowing relatives, who the next morning will kick aside the osseous fragments of their loved ones without exhibiting the slightest sign of emotion or tenderness. They have a vague belief in life after death, but it is the disembodied spirits on whom they concentrate their thoughts, and not the lifeless clay, which is to them of no account. This is not as most of their congeners thinkit is rather the effect of Masai influence; for among the majority of Bantu negroes very considerable attention is paid to the corpse, under the idea that the spirit of the dead person is still much affected by the condition and disposal of its previous tenement.

The people of Taveita subsist mainly on vegetable food, of which they rear a great variety in their beautiful gardens. They also eat fish and meat. The fish are caught in the River Lumi, which runs through the settlement, by means of skilfully-made wickerwork traps and weirs. They also construct from the midribs of a Raphia palm most clever rods and lines, the whole material coming from the palm, with a native-made iron hook superadded.

The Wa-taveita proper number about 2000. They bear an excellent reputation among the coast traders for honesty and friendliness. They speak Ki-swahili almost universally, and speak it with singular correctness; but of course among themselves Ki-taveita is the only language used. This very interesting Bantu 
dialect offers many curious features and retains a

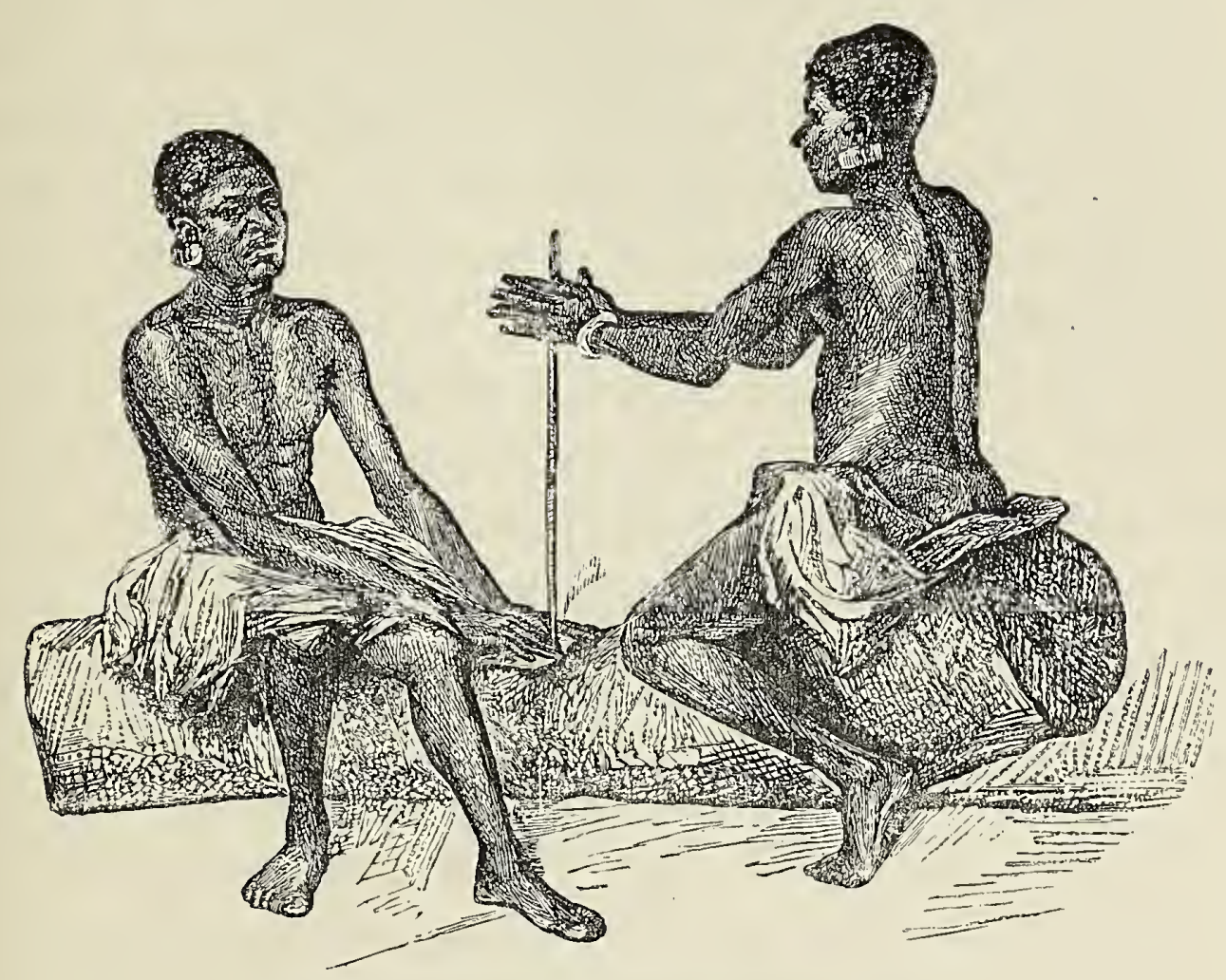

Fig. 75.-Men of Taveita making fire.

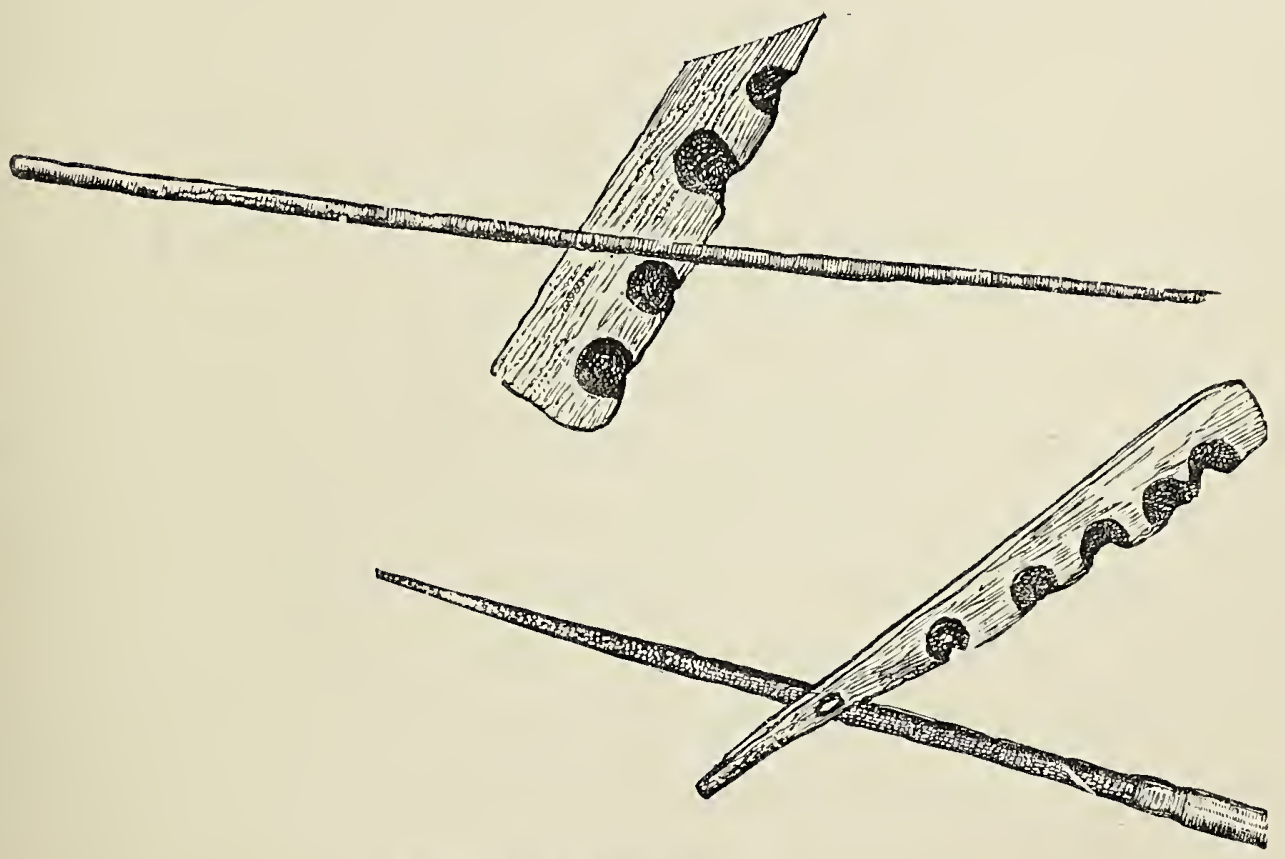

Drills and Fire-sticks.

number of archaic words in its vocabulary. It is somewhat midway between Ki-kamba and Ki-čaga F $f 2$ 
but offers independent features of its own. So much intercourse with traders from the coast seems to have slightly robbed them of originality, and in their modes of life and forms of belief they somewhat ape the Waswahili. Many of them are almost Mohammedans. I noticed one little detail as regards fire-making which is worth recording. To produce fire, which is done in the common African way by rapidly drilling a hard pointed stick into a small hole in a flat piece of wood, is the exclusive privilege of the men, and the secret is handed down from father to son, and never, under any conditions-so they say-revealed to women. I asked one man why tbat was. "Oh," he said, "if women knew how to make fire they would become our masters." Nevertheless, without this drawback, the fair sex in Taveita have pretty much their own way. I have known one or two leading matrons who have always insisted on having their voice in the deliberations of the Wazēe, or elders, who govern Taveita. I have referred to their laxity of conduct after marriage, but it springs so much from amiability of disposition that it can hardly be called vice. In short, a more kindly, sensible, considerate set of beings, I have never met than the Wa-taveita.

The Wa-čaga of Kilima-njaro do not altogether resemble them. Theyare neither so pleasing in appearance nor in disposition. Sometimes they attain a fine stature, as in the case of Mandara, the chief of Moši, but generally they are short men. The women, however, are at times good-looking, and have well-proportioned figures. In fact, the ordinary rule amongst Africans is here reversed, and the women are handsomer than the men. Amongst these people we again meet signs of marriage by capture, but in their case it does not seem to be as I have described in the Wa-taita, for the bridegroom 
is quite equal single-handed to the capture of his wife, and certainly not disposed to reward his friends in the same manner as the less exclusive M-taita husband. On several occasions when I observed a marriage ceremony during my residence in Čaga, I found it consisted (after the purchase of the woman had been privately arranged) in the husband carrying off his wife pig-aback, while the relatives and friends pursued with shrieks of laughter, affecting to try and rescue the screaming girl ; but, of course, all this was simulated, and a survival of past customs, for nowadays a man only gets his bride when he has settled the bargain previously with his future father-in-law. In such states as Moši, where there is a relatively large standing army, the chief will generally distribute the female slaves captured in war among his soldiers, and dower them himself with cattle. Thus his soldiers become indebted to him for their domestic happiness, and are consequently very much attached to the person of their monarch, who is, to them, the sole dispenser of benefits.

Real immorality hardly exists among the Wa-čaga; Mohammedan influence not having as yet initiated them into vicious thoughts and ways. We should be apt to call, from our point of view, their nakedness and almost animal unconsciousness of shame indelicate, but it is rather, when one gets used to it, a pleasing survival of the old innocent days when prurient thoughts were absent from the mind of man. The Wa-čaga cannot be accused of indecency, for they make no effort to be decent, but walk about as Nature made them, except when it is chilly, or if they wish to look unusually smart, in which cases they throw cloth or skins around their shoulders.

There are, as far as I can ascertain, no initiatory 
ceremonies among the Wa-čaga, such as are so constantly met with in other tribes of Bantu negroes in connection with the entrance into a state of puberty of young people of either sex. Circumcision, if performed on the male, which it is not universally, is generally done after the age of puberty.

The Wa-čaga share with the Masai, whom they may have copied, a curious habit of spitting on things or people as a compliment or sign of gratitude. I remember one man, after I returned to my settlement in Čaga from a short trip to Taveita, was so pleased at my safe return that he took my hand in his and spat repeatedly at the sky, saying constantly "Eruwa iča!" ("God is good!"). They have but a vague idea of the deity. Indeed, one never knows whether or not he is identical with the sun, for that luminary bears just the same name, "Eruwa." It is interesting to notice, in contradistinction to the derivation of the name of God I recently gave as coming from ancestor worship, that among other African nations the deity is identified with the sky or the sun. Thus there is the term "Eruwa" already referred to, which indicates "God" in Ki-čaga. Among the Wamtaveita it is "Zuwa," also "Sun," although the Swahili have lately introduced their word, Muungu. The form "Eruwa," "Zuwa," is identical in origin with the Swahili "Jua," the Luganda "Njuba," the Congo "Ntuva," all meaning sun, and all remounting to an archaic form "Nduba." On the Upper Congo the Ba-yanzi have but one word for God and sky"Ikuru," or "Likulu." Even among the Gallas "Waka" means indifferently God and sky, and in the Masai language "Engai" (a feminine word) means both God, sky, and rain. 
However, to return to the subject of the Wa-čaga. Though having little religious belief, they are very superstitious, and have great dread of sorcery. Large trees are supposed to be much affected by ghosts, and for this reason are spared by the axe. Their dead

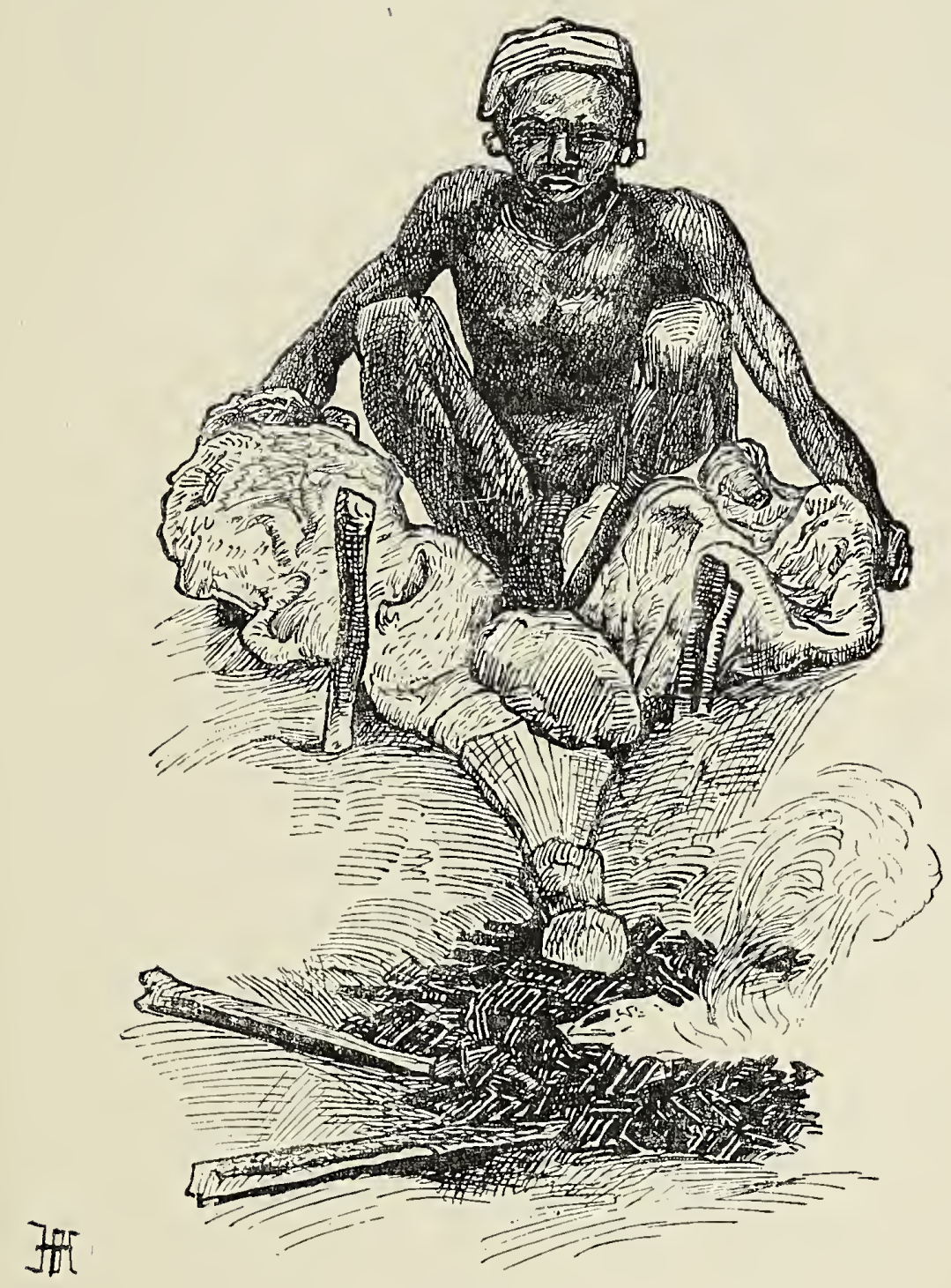

Fig. 76.-A Čaga Forge.

are buried in these isolated forests, sometimes in hollow trees, sometimes in the ground. Hyenas generally dig them up and eat them - this being little cared for by the survivors, as is the case among the Masai and the Wa-taveita.

The Wa-čaga are clever smiths, and forge all kinds 
of utensils, weapons, and ornaments from the pig-iron they receive from the country of Usanga, near Lake J̌ipé. The forge is but a pair of goat-skin bellows converging into a hollow cone of wood, to which is added two more segments of stone pierced through the centre and ending in a stone nozzle which is thrust into the furnace of charcoal. The bellows are kept steady by several pegs thrust into the ground, and a huge stone is often placed on the pipe to keep it firm. After the iron has been heated white hot in the charcoal it is taken out by the iron pincers and beaten on a stone anvil. The Čaga smiths make not only spear-blades and knives of apparently tempered steel, but they can fabricate the finest and most delicate. Out of a rhinoceros horn they will make a beautifully turned and polished club, carved by hand, for they have no turning lathe. Pottery is almost absent. Basket-work is carried to great perfection, and they can weave it so tightly that milk may be held in these utensils of woven grass or banana-fibre. The wooden platters that they make show no little skill in shaping, as they are cut out of solid blocks of wood, and not joined in any way.

But it is in their husbandry that the Wa-čaga mostly excel. The wonderful skill with which they irrigate their terraced hill-sides by tiny tunnels of water diverted from the main stream shows a considerable advancement in agriculture. Their time is constantly spent in tilling the soil, manuring it with ashes, raking it, and hoeing it with wooden hoes. All their agricultural implements, except the choppers, adzes, and sickles, are of wood-wooden hoes, wooden stakes, and so on. They have a very clever mode of irrigating equally a given surface. As the little canals 
of water are always elevated above the cultivated plots, they will tap it at a convenient spot above the bed to be watered, and then turn the stream in to a rough conduit made of the hollow stems of bananas cut in half, the end of each stem overlapping the next. Then as the water enters the last joint it is freely turned right and left, dispersing the vivifying stream in all directions.

The food of the 1. Wooden Hoe.-2. Leather Honey Case. -3. Gourd.4. Wooden Tray or Dish. -5 . Clab made from Rhinoceros Horn. -6. Knife. Wa-čaga is mostly vegetable. Fish are

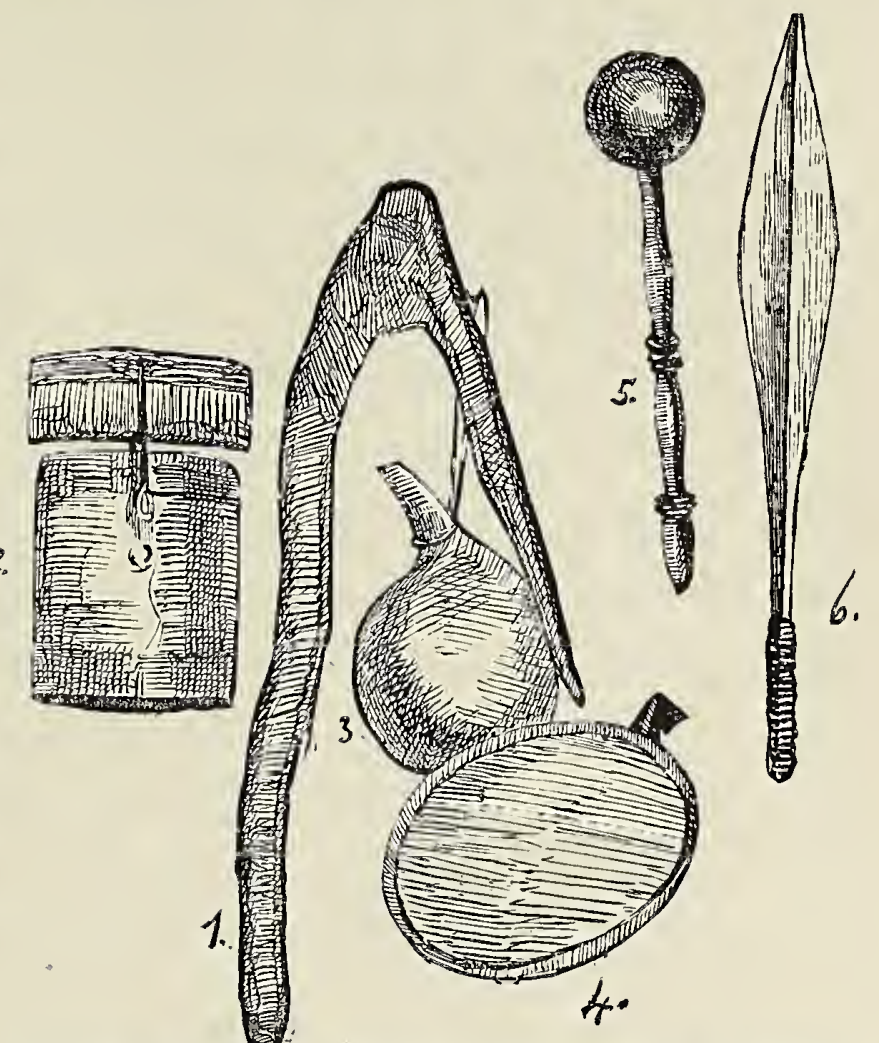
Fig. 77.-Č́aga Utensils. absent from the streams of their country; but, morever, like the Wa-taita, they think them unfit to eat, and of the same nature as serpents. They breed fowls in large numbers, but merely to sell to the pass. ing caravans of traders from the coast, for they them. selves abjure poultry as food, thinking it unwholesome and unmanly. Their other domestic animals are the ox, the goat, the sheep, and the dog, though the latter animal is rarely seen. The oxen are much valued. They belong to the humpedZebu breed prevalent throughout East Africa from the days of the ancient Egyptians. The goats are small and handsome, with poorly developed horns, drooping ears, and often two small appendages of skin in place of the ordinary 
beard. The sheep are of large size, hairy, with fine dewlaps and drooping ears. The male has an enormously fat tail, developed to such an extent as to really impede his movements. A fine sheep may be bought for from four to eight yards of cloth, a fat goat for about the same cost, and a milch goat a trifle dearer.

Milk enters largely into the diet of the Wa-čaga, and they are also passionately fond of warm blood fresh from the throat of a newly-slaughtered animal. Whenever I killed an ox for my men-who being Mohammedans insisting on cutting its throat and letting it bleed to death-the Wa-čaga would assemble with their little wooden bowls, and as the animal lay in its death throes on the ground, the hot purple blood spurting at high pressure from the severed veins, the eager natives filled one after the other their wooden vessels and then stepped apart from the crowd to drink the coagulating gore with utter satisfaction and a gourmet's joy. They are great flesh-eaters when they can afford it, but, as I have already said, their main diet is vegetable. Among the plants grown for food are maize, sweet potatoes, yams, arums (Colocasia antiquorum), beans, peas, red millet, and the banana. Tobacco is also largely cultivated, and the natives chew it and consume it as snuff mixed with natron-salt. Honey is produced in immense quantities by the semiwild bees which make their hives in the wooden cases put up by the natives among the forest trees. A large barrelful may be bought for two yards of cloth.

The Wa-čaga inhabit the western, southern, and eastern slopes of Kilima-njaro. The northern side of the mountain is without any other inhabitants than roving bands of Masai. The principal Čaga states, 
beginning on the west, are Šira, Kibonoto, Mačame, Uru, Kibošo, Mpokomo, Moši, Kirua, Kilema, Maraniu, Mamba, Mwika, Msai, Rombo, Useri, and Kimangelia. Although these little states are perpetually quarrelling among themselves, they are nevertheless closely united by ties of blood and possess a common language, Ki-čaga, unless, indeed, the Warombo, as I have sometimes thought, speak a dialect of their own.

The inhabitants of Kahe (the country lying due south of Kilima-njaro in the plains of the Upper Ruvu), of Ugweno, and also, I am told, of Mount Méru, seem to resemble closely the $\mathrm{W}$ a-čaga in language and in physical features. They were doubtless the same race not long since, but the invasion of the Masai split them up into different sections, and they became isolated in their coigns of refuge, some on the mountains, some in the marshy swamps. The Wa-gweno are a very timid set, and greatly afraid of witcheraft. Everything at all strange or incomprehensible is "usawi" (sorcery). They not only dread the Masai with all their hearts, but they also invest the little Lake Jipé, which lies at the foot of their mountains, with imaginary terrors, declaring they dare not fish on its banks or cross its waters in canoes, on account of an awful kelpy-like monster which dwells in the lake and sallies out to devour all who may approach the waterside. In vain do the Wa-taveita go and fish there fearlessly under the eyes of the Wa-gweno; these timorous folk nevertheless continue to avoid the lake wherein are present such boundless stores of food. I have no doubt that the legend of the water-monster arose from either the voracious crocodiles or the obstreperous hippopotami which inhabit the waters of J̌ipé. 
My readers may possibly have been disappointed to find in this chapter so little information as to peculiar customs or beliefs exhibited by the people it described. I can only say this. want is not owing to any lack of probing or questioning on my part. I have come to the conclusion that whatever religious notions, mystic ceremonies, initiatory practices which the inhabitants of Kilima-njaro may have retained originally from

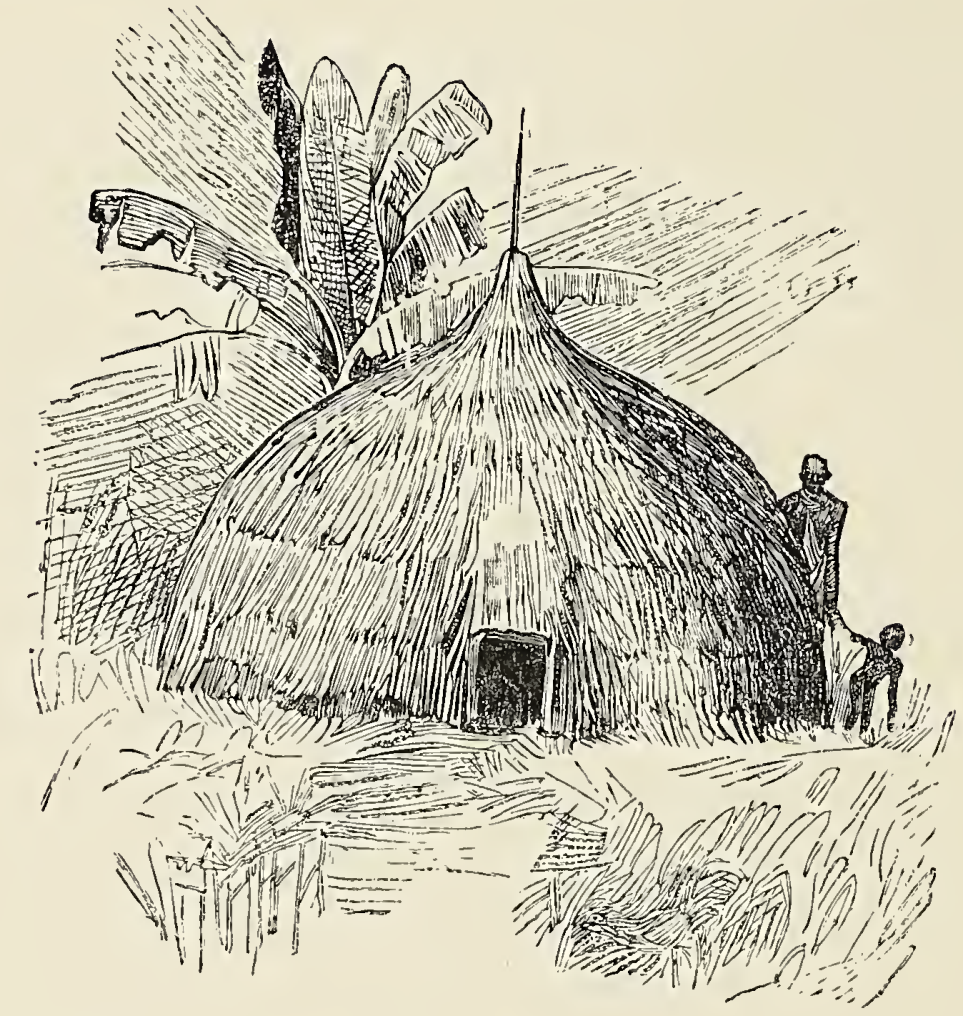

Fig. 78.-A Č́aga House.

their ancestors and shared with their other existing relatives, have at the present time disappeared, or have been worn away by constant changes of abode, massacres, flights, and all the incidents of an anxious struggle for existence, which the fluctuating peoples of Eastern Equatorial Africa have, for the last few centuries, undergone. Those who may have read what I have previously written respecting African races on the Congo, in Angola, and elsewhere, will perceive that 
I have often had to remark curious initiatory ceremonies, elaborate animistic belief displayed in burial customs, various modes of phallic worship, and obscure superstitions connected with eating or drinking. Scarcely any of these phases of savage religion, fancy, or folk-lore, have I encountered in the peoples who inhabit Kilima-njaro and its vicinity. I do not say they are non-existent, I merely mention that they have not come under my personal recognition, and if succeeding travellers are more fortunate than $I$ in this particular, I shall conclude that in spite of my constant investigation these peculiarities have failed to display themselves to my perception. 


\section{CHAPTER XX.}

THE IANGUAGES OF THE KILIMA-NJARO DISTRIGT.

(a) Masai.

(b) Ki-čaga, Ki-taveita, \&c. (Bantu Languages).

THE interest taken in African languages is a newly awakened but a growing one. The work of Bleek, Lepsius, Müller, Steere, and Schön ; of Barth, Koelle, Krapf, and Reinisch-not to mention many other earnest workers in this freshly opened field, who each contribute their quota to our present sum of knowledge - has at length begun to meet with due appreciation, and though many of these patient grammarians and students of unrecognized forms of speech have passed away; yet in almost every case their work has begun to acquire a notoriety and a value that neither they nor their publishers hoped for when the grammars or vocabularies or handbooks were first issued to an unheeding public.

Those who are beginning or prosecuting their African linguistic researches owe a debt of gratitude to Mr. Robert Needham Cust ${ }^{1}$ for his painstaking bibliographical work, which tabulates every known source of information on the subject, and where some form of order is introduced into what, from very paucity of knowledge, has long been a hopeless maze

1 "The Modern Languages of Africa," 2 vols., Trübner and Co. 


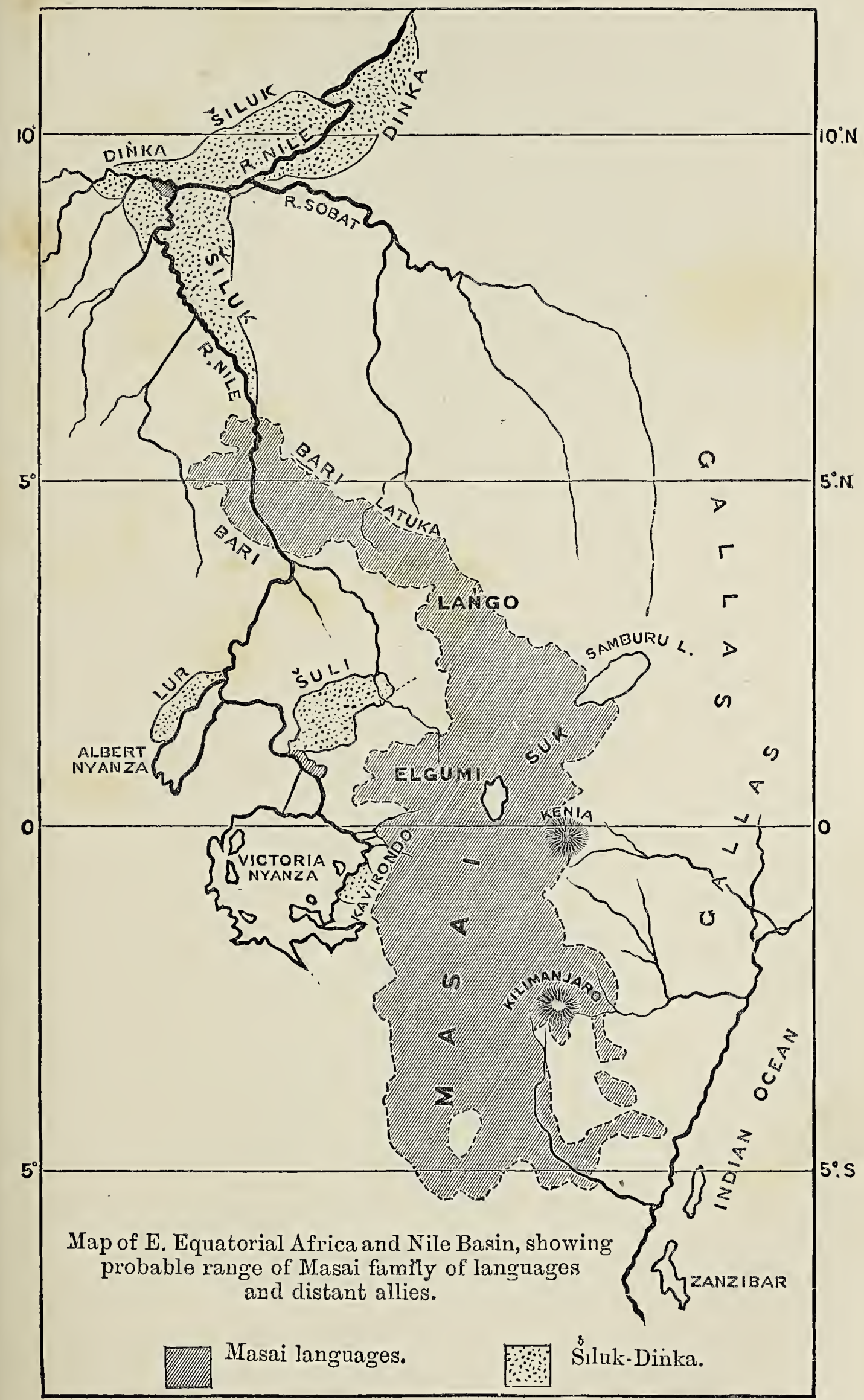

To face page 446. 

of conflicting theories. Imperfect as our grasp of the subject is, we are able now at least to rise from its contemplation with certain definite ideas as to the grouping or classifying of African tongues. We know there is the great Bantu family in the southern half of the continent; the common origin and relationships of the Hamitic languages becomes apparent; the tongues appertaining to the Semitic group in the north and north-east are relegated to their place; and if more general classifications of the vast number of Negro and negroid forms of speech are found to be at present illusory, we can at least recognize several very distinct and natural families, lacking, it may be, any appreciable relationships with extraneous linguistic groups outside their own area, but possessing evident signs of a common structural plan and a common origin. Such are the Nuba tongues, the Fula group, the Hausa, Kanuri, Wolof, Kru, Mande, Bagirmi, Śiluk, and Dinka language-clusters of Central and Western Africa. Distinct also, and offering only a slight indication of possible affinities, is the language spoken with but little dialectal variation by the wellmarked race known as the Masai, whose ethnological features have been treated of in the preceding chapter.

In the south, south-west, and south-central districts of Africa, enclaves of the Bushman and Hottentot tongues are found--the "Click" languages, as they are often called, and the subject of their mutual relations is still much disputed by authorities. But Theophilus Hahn ${ }^{2}$ shows that there is decided resemblance in many words of common use, and in the

2 "Tsuñi-|goam ; the Supreme Being of the Khoi-khoi." T. Hahn, Ph.D.; Trübner and Co. 
first three numerals, and even Bleek is constrained to admit that the difference between the speech of Hottentot and Bushman scarcely exceeds that between English and Latin or English and Sanscrit, languages derived from a common Aryan stock, though widely separated by time and manner of development.

(a) Masai.

As far as is known, the neighbourhood of Kilimanjaro offers languages belonging to only two of the African families which I have mentioned-the Masai and the Bantu. As has been already stated, helot tribes of En-durobo are often found in the vicinity of Useri, Kimangelia, and the north-eastern slopes of Kilima-njaro, but those few with whom I came into personal contact only spoke Masai, and could not be induced to utter any words or phrases of their own speech if they still possessed any special dialect peculiar to them. My materials for a superficial study of the Masai language were principally derived from individuals, both Masai proper and the so-called "Wakwavi," or agricultural Masai, who visited the chief Mandara for trade during my residence in Moši; from the Wa-kwavi of Kikoro, near Taveita; from the few Masai whom I met near Useri, and from the roving Masai who visited Gonja, at the foot of the Pare hills, and Semboja's town, Mazindi, on the western flank of Usambara. I find my vocabularies agree pretty closely with those of Krapf and Erhardt, and the chief differences arise from what I believe to be the more exact orthography I have employed. Erhardt gives in general the form of the word more correctly than Krapf. Both their vocabularies, however, are deserving of the highest credit as having 
been compiled with wonderful accuracy under circumstances of much difficulty.

Krapf called his work "A Vocabulary of the Wakwavi Tongue," and Erhardt entitled his, more justly, "A Vocabulary of the Masai Language." Neither seemed to be aware that they were studying the same form of speech, although practically the only difference in their vocabularies comes from the employment of diverse modes of orthography. The language they illustrated seems to be a tolerably pure form of Masai which is spoken in the vicinity of Kilima-njaro.

I find some discrepancy between my linguistic notes and those of Mr. Last, who visited the southern Masai, or Wa-kwavi dwelling in Northern Nguru. I believe that gentleman has in hand a voluminous MS. vocabulary which will, doubtless, exhibit an interesting study of the language; but the sentences and words given by him in the Royal Geographical Society's “Proceedings" for September, 1883, seem to show that the dialect is either a very corrupt one or has been imperfectly understood. Some words are evidently borrowed from neighbouring Bantu dialects, and the possessive pronouns and persons of the verb are sometimes not in accord with the English translation.

About Northern Masai we know but very little. It was a great disappointment to me that Mr. Joseph Thomson, who is the sole European who has yet visited those regions where the Masai impinge on other races to the north, should have had no opportunities of making linguistic notes. He would otherwise have been able to throw some light on the affinities and origin of the Masai language. He mentions the people of Sūk who dwell somewhere to the north of Lake 
Baringo, and observes that their language resembles Masai to a certain extent, with, however, distinct differences. What these differences are he does not tell us, and therefore we cannot conjecture, in the absence of information, what affinities the Sūk language may display.

The researches of Dr. Emin-Bey (the governor of the Egyptian Equatorial provinces, whose fate is still uncertain) throw a certain amount of light on the northern members of the Masai family of languages. He gives us a vocabulary of the Latuka language (of which a few words were also gathered by Sir Samuel Baker), and places the position of the Latuka people in about $5^{\circ} \mathrm{N}$. of the Equator, where they are nearly surrounded by the negro tribes (and languages) of Madi, Šuli, and others. Dr. Emin-Bey says the Latuka belongs to the Lango cluster, farther south, calls the Lango a Galla language, and remarks that the Latuka also evinces Galla affinities. In these suppositions I am disposed to disagree with him. The Latuka language has absolutely less relationship with the Galla than the few slight and doubtful signs exhibited by the Masai: and the probability is that, as the Latuka is said to be closely related to the Lango, this latter language is also of the Masai group. Though the Latuka tongue differs considerably from Masai proper, perhaps to the extent of fifty per cent., in the small vocabulary collected by Dr. Emin-Bey, there is, however, no doubt whatever that it is a language of the same family, and I shall endeavour to show in the appended vocabulary that it agrees in many test-words and essential points with Masai. The only other known tongue which can at present be said to form an independent member of this family is the Bari, a 
language spoken over a fairly large district on both banks of the White Nile between $4^{\circ}$ and $6^{\circ} \mathrm{N}$. latitude. The fact of its evident relationship to Masai was pointed out by Lepsius in the preface to his Nubian grammar, but this interesting discovery has been completely ignored by other authorities on African languages, who have grouped the Masai with Nuba, ${ }^{3}$ Fula, and many other utterly dissimilar tongues.

At the present time, from the information we possess, we are able to constitute a separate family of African languages called the Masai, of which the undermentioned forms of speech are probably members. (I append a query to those of doubtful existence or affinities.)

\author{
Bari. \\ Latuka. \\ Laingo? \\ Sūk? \\ Samburu? \\ Masai.
}

The only possible affinities that the Masai group displays for other independent families of African languages are, on the one hand, with the Dinka and the Siluk tongues, and on the other, with the Galla branch of the Hamitic family.

With the Dinka and Šiluk (Šli, Lur, Šiluk, \&c.), the resemblances are confined to a certain undoubted correspondence in the vocabularies, numerals, and pronouns; while in grammar there is scarcely any affinity.

Masai proper, more than the northern members of the family, approaches the Galla somewhat in grammatical construction, and there are, besides, a few cases of correspondence in the numerals and pronouns.

3 This, I must confess, is a conclusion so difficult of explanation that I fail to understand how it was arrived at. 
There is absolutely no distinction between the Masai proper and the agricultural Masai, or "Wa-kwavi," as regards their language. The vocabularies given by Krapf of the Wa-kwavi, and Erhardt of the Masai, only differ slightly in orthography, and are independent versions of one and the same form of speech. As I have already remarked, the Masai tongue, wherever spoken by Masai people, offers, as far as we yet know, little dialectal variation, though it is used over a district stretching between $5^{\circ} 30^{\prime} \mathrm{S}$. and the Equator. In this uniformity it resembles the Galla language, which exhibits but trifling differences in the dialects spoken on the confines of Abyssinia $\left(12^{\circ} \mathrm{N}\right.$. latitude), and on the coast of the Indian Ocean, near Mombasa. Doubtless the fact is due to the roving habits of the race, for, as has been already mentioned, the Masai warriors range in their raids over nearly the entire district that bears their name, and thus are kept in constant communication with the outlying tribes of their race.

Before describing in a superficial manner the grammatical construction of the Masai tongue, I feel bound to remark that for beauty and simplicity of expression it stands almost unrivalled among the languages of Africa. Compared with such dreadfully complicated forms of speech as the Fulde (spoken by the Fulbe or "Fulahs" in Central and West Africa), where there are some nineteen ${ }^{4}$ ways of forming the plural, and the verbs with their many tenses and moods are worse than in Greek, the Masai language offers the grammatical simplicity of English. It has, moreover, a very copious vocabulary, and its combinations of sounds are harmonious, simple, and easily pronounced ${ }^{4}$ To say nothing of irregularities. 
by Europeans. Another pleasant feature about it is that every syliable is so clearly enunciated by the people who speak it that a stranger may much more easily distinguish each word and realize its meaning than is ordinarily possible with a barbarian tongue.

The leading features of the Masai language are these. It distinguishes three genders or classes of nouns, answering approximately to masculine, feminine, and neuter (or common). These genders are indicated by the form of the demonstrative article, demonstrative pronoun, nominal, adjectival, and participial prefix, but only the last-the neuter, or common-is represented in the personal pronouns and in the persons of the verb.

There are two numbers, singular and plural. The plural is formed by an addition to or a change in the termination of the noun in the singular, sometimes by a change of article, ${ }^{5}$ and in certain parts of speech (pronouns, a few adjectives, \&c.) by prefixing or affixing $K u$ or $K$ to the root. ${ }^{6}$

There are no cases or declensions of the noun expressed by inflection or change in termination. The substantive in the genitive case follows the governing word, with a particle interposed between the nominative and genitive. This particle seems to be either masculine, feminine, or neuter, according to the gender of the noun in the nominative case.

The adjectives are either independent substantives assuming an adjectival position, or else they are participles from a verbal root, preceded by the masculine, feminine, and neuter (or general, or collective) prefixes.

${ }^{5}$ As in the masculine nouns, which in the plural take the neuter article.

${ }^{6}$ This is a very common prefix in Bari, where it becomes Ko generally : not always there used in a plural sense, but rather an intensitive. 
The personal pronouns precede the verb. The possessive pronouns follow the noun. The demonstrative pronouns may either be placed before or after the substantive. The interrogative pronoun precedes the verb, so also does the relative particle, and the interrogative particle precedes the noun.

The stem or root of the verb remains unaltered, but the tenses and modifications of the sense (such as a passive, a reciprocal, a causative meaning, \&c.) are formed by adding both prefixes and suffixes. Many of these are traceable to abbreviated forms of independent verbs.

The negative particle is always prefixed to the verb. It is generally expressed by the particle $m e$ ( $m$ - before a vowel); but in certain tenses negation is indicated by the use of a separate prefix formed from an auxiliary verb.

The prepositions in Masai, as their name indicates, precede the word they govern. The only postpositions are certain enclitic adverbs.

The accent in Masai falls occasionally (especially in derivatives) on the first syllable of the word (generally the root), most frequently on the penultimate, and rarely on the last.

Having briefly noted the leading characteristics of the language, I will now proceed to examine its important features in a somewhat more detailed manner.

As regards the phonology of Masai it may be remarked that the vowels have mostly their Italian value. There are no obscure or modified sounds, and in this the Masai language resembles most of the Bantu forms of speech, wherein, also, there are no vowels that are not clearly and distinctly sounded as in Italian. In Masai words may end in a consonant (unlike the opposite rule in Bantu), but two consonants never 
come together, unless one of them be a nasal or a liquid. The sounds represented in the language are these :-

Vowels.-a, e, i, o, o, u. (U is sometimes pronounced as a semidiphthong, like " $u$ " in the word "sure.")

Diphthongs.-ai, ae, ao, au; ea, ei, eo, eu; ia, ie, io, iu ; oa, oe, oi, ou ; ua, ue, ui, uo.

Consonants.-(No aspirates; neither $\mathrm{h}, \mathrm{h}^{\prime}$, nor $\chi(\mathrm{kh})$ are represented). Gutturals.-k, g. Palatals.-y, j (sounding both as French " $j$ " and " $d j "), d^{\prime}$ (" $d y^{\prime} "$ an intermediate sound between " $d$ " and " $\mathrm{j}$ "). $\quad \mathrm{C}$ (ch in church) is not present in Masai. Dentals.-d, t, s (no z), š (sh), ž. $\quad$ Liquids.—l, r. Nasals.—n, $\dot{\mathrm{n}}\left(\mathrm{ng}^{\prime}\right)$, ny. Labials.$\mathrm{m}, \mathrm{b}, \mathrm{p}, \mathrm{w}, \mathrm{v} . \quad$ (F and $\mathrm{v}$ are absent in Southern Masai.)

It may be noted here that in Masai the hard and soft forms of the gutturals, dentals, and labials are easily interchangeable. It is difficult to know sometimes whether to write $\mathrm{D}$ or $\mathrm{T}, \mathrm{K}$ or $\mathrm{G}, \mathrm{B}$ or $\mathrm{P}$. In

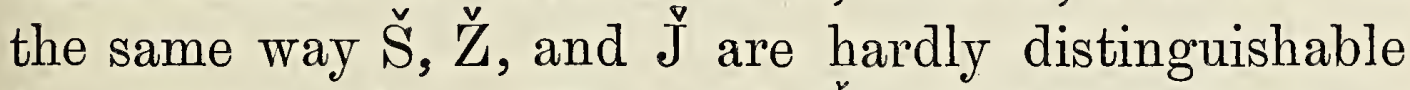
from one another. The word Žore, "friend," is pronounced sometimes Šre, J̌ore, and even Dyore. Gudut, " mouth," may be Kutuk, Gutuk, or Kuduk.

The article in $\mathrm{Masai}^{7}$ seems to be of three forms, viz. $\hat{o} l$, el, and en. The first may be taken as meaning "strong, big, masculine," and is probably related to ole, olewa, "strong, male, manly." Or it may be a compound between this sexual adjective and the second article $e l$, which latter seems to be common in

${ }^{7}$ In Latuka the article is apparently $O$ or $o l, n a$, and $e l$.

In Bari the article is almost identical with the third personal pronouns, the demonstrative, and the gender prefix. It is as follows :-

$$
\begin{array}{ccc}
\text { Masc. sing. } & \text { Fem. sing. } & \text { Common plur. } \\
L o, l u & N a, n u & t i, c ̌ c i, k u .
\end{array}
$$

As a demonstrative pronoun it is-

$$
\begin{array}{cc}
\text { Masc. sing. } & \text { Fem. } \text { sing. } \\
\text { Lo } & \text { Na. } \\
\text { Masc. plur. } & \text { Fem. plur. } \\
\text { Ci-lo, kulo } & C i-n e, \text { ku-ne. }
\end{array}
$$


gender and collective in number, serving as plural to $\hat{o} l$, and sometimes preceding nouns of a collective character that have no singular. El most probably is a demonstrative pronoun of common gender, and the same as ele, he, she, it, this (plur. liulo, they, these).

Both $\hat{o l}$ and $e l$ drop their liquid consonant before the letter "s" beginning a word; as in Arabic, a double sound of that consonant is heard, as-ossesin (=ol-sessin, "the body"), ossoit (=ol-soit, "the stone"), es-soit (=el-soit), \&c.

The last of the three articles, en, assumes the forms $e$, es, en (sometimes erig), and em, according as it precedes nouns commencing with an $n$ or $m$, an $s$, a vowel, or a labial ; as- $E$-modi, "a pan," or "pot;" e-nanga, "cloth;" es-siangiki, "a wife;" ein-olon, or en-golon the sun;" en-guduk, "the mouth ;" embere, "the spear."

The article $e n$ is mainly feminine in its significance, but it also gives a diminutive, depreciatory, weakened, playful, or affectionate character to the word it precedes. Thus en-kier is "a female sheep" (ố-ker, "a ram"), ex-doinyo, " a hill" (ól-dvinyo, "a mountain"), em-barawui, "the Wa-kwavi, or agricultural Masai," a contemptuous name used in the feminine sense by the nomad Masai to imply cowardice; en-gujita, "tender grass" (ôl-gujita, "strong, rough grass"), and so on.

The article en (with its variants, $e, e \dot{n}, e \dot{n} g, e m, \& c$. seems to be more immediately derived from ena, the feminine demonstrative pronoun answering to ele in the masculine, before described. It is possible that ena may be a compound of $e l$, the common article, directive, or demonstrative, and na the feminine particlei.e. el-na, e-na, ena, en. Just as I already hinted 
that $\hat{o l}$ may be compounded of o (ole, "male") and el.

This consideration leads us to the discussion of the masculine, feminine, and neuter (or common) particles which are often prefixed to nouns and adjectives.

$O, o i, l i, l e$, indicate masculinity or strength when prefixed to a root. These forms are evidently derived from ole (plur. olewa), "male," a term which is possibly allied to the verbal stem gol, "to be strong," and iôlo, yôlo, "to know," "to be able," and even olon, golon, "sun." Placed before a root word, ole has by contraction or abbreviation become $o$, oi (ole, o-e, o-i), $l e$, \&c. This prefix is used at present to give a masculine character to the word it precedes: as oigob (oikob; kob, "land"), "men of the land ;"8 o-irok, "black," masc.; o-ibor, "white," masc. (ol-doinyo oibor, "the white mountain"); o-irosi, "heavy," masc.; li-kai, " another," masc.; l-ino, "thy," masc.; and so on.

The traces of the common or neuter prefix, e, ei, or el (ele), are not so frequent as either the masculine or feminine particles; still there are several words in which it is indisputably present, as ei-bardani, "bride or bridegroom ;" ei-gulo, "breast-bone;" ei-bangi, "a moderate-sized hill;" e-jon, "fresh, green;" e-irok, "black;" e-ado, "long;" e-muaja, "how much ?" all adjectives in the common gender: and abstract nouns, as eweji, "place;" eiso (Latuka, eido), "heaven;" e-duwa, "bitterness ;" e-gogo, "old age," \&c.

The feminine prefix is $n a$, and appears to be connected with the root, nana, "weak, soft, tender," even in a depreciatory sense, "worthless, rotten." It is united to all stems to which a special

8 This term oigob (with the article, el-oigob) is supposed to be the origin of the Swahili term "Kwavi" for the agricultural Masai. 
feminine sense is to be given. Thus, na-ido " sister," a term of address to women (oido, "brother," masc.; eido, "the brotherhood," common; na-dangile, "dear one, darling" - a term applied to women; na-do, "long," fem. (enainga nado, "the long cloth"); nagai, "good, well," adv. from -gai, "good" (En-gai, fem., "God, rain," lit. " the good"); na-jon, "green," fem., \&c.

Examples of the above prefixes applied to the same root :-

Masculine.

Ôl-doinyo ojon, "the green mountain."

$$
\begin{aligned}
& \text {-jon, "fresh, green." } \\
& \text { Common. }
\end{aligned}
$$

El-ata éjon,

"fresh oil."
Feminine.

Em-benek najon, "the green leaf."

There would appear at times traces as of all these particles-o, na, and $e$-forming or having formed themselves into pronouns for the classes they represent, especially in juxtaposition with the verb. At the present moment this only appears in participial adjectives formed from verbs, and not in the tenses, where only the common prefix,$e$, is represented. Whether anciently all three forms were used as pronouns-he, she, and it-or whether such a development is approaching, I cannot say. At present, he, she, it, they, are represented by a common verbal pronoun or particle-e or ei. Thus we say-

$$
\begin{array}{ll}
\begin{array}{l}
\text { Ôl-dunani } \\
\text { En-dangile } \\
\text { El-eduwa } \\
\text { El-dana }
\end{array} & \text { \} e-mud (-mud = the root of the verb). } \\
\left.\left.\begin{array}{l}
\text { The man } \\
\text { The woman } \\
\text { The bitterness } \\
\text { The people }
\end{array}\right\} \begin{array}{l}
\text { he } \\
\text { she } \\
\text { it }
\end{array}\right\} \text { disappears. } \\
\text { they disappear. }
\end{array}
$$

Also ele, the demonstrative pronoun, is generally 
accepted as a personal pronoun, meaning "he," "she," and "it." "They" is ordinarily expressed by the plural form of this word, viz. kulo. Of course, for strictly demonstrative purposes, this pronoun has a feminine form, which will be treated of afterwards.

To summarize what I have been saying, it would seem as if originally there had been in Masai three genders or classes of nouns-masculine or strong, common or general, feminine or diminutive-and that these three classes were provided with certain particles which were prefixed to word-stems to indicate the class or gender of the governing noun. This somewhat reminds one of the concord in Bantu languages, but the resemblance is not effectually carried out; if it were, you would be able to say in Masai-

$O l$-dunani o-gol o-šam; ; ki-šam-ole ;

The man strong he loves; we love him;

$=$ The strong man loves; we love hin.;

or,

En-dangile na-lulunga na-kweni ; ki-nin̈-na:

The woman healthy she laughs; we hear her.

$=$ The healthy woman laughs; we hear her.

As it is you say-

Ôl-dunani o-gol $\quad$-šam.; ki-šam-ele, and. En-dan̈gile na-lulunga e-kweni ; ki-nin-ele.

In the Bantu tongues; where there is a large (in all sixteen) number of noun-classes, the governing prefix of the subject follows throughout. Thus in Swahili they say-

$W a$-tu wa-zuri wa-ja; na-wa-ona;

The men handsome they come; I them see;

$=$ The handsome men are coming; I see them;

or-

Ki-tu ki-dogo ki-mo; Tu-ki-pate.

The thing little it is within; That we it may get.

$=$ The little thing is inside; let us get it. 
In the sex-denoting Hamitic, Semitic, and Aryan tongues this concord, imperfectly as it is now represented, once existed, though the sex-denoting particles were generally added to the termination of the word instead of preceding it.

Thus in Galla (Hamitic) they say-

\section{Niti hieti oboleti-ši ilalti iši wamte. \\ Woman poor sister her saw (and) her called. $=$ The poor woman saw her sister and called her.}

In this case the syllable $t i$, which has a feminine signification, and $i s i$, its variant, run through all the words dependent on the governing noun.

In Hottentot ${ }^{9}$ almost the same thing presents itself (I quote from Bleek's Grammar) :-

//Nã-tara-ti, sida !hau-s-di-ti, /ñ̃ !ñ-s-!na //an-hã-ti, hõ-ti-

Those women our tribe's they, another village in dwelling find them da-ra, gare-da-ra goma-n ã-te. we do, praise we do cattle of them.

$=$ The women of our tribe who live in that village, we find them, we praise their cattle.

In Arabic (Semitic) much the same concord is present as in Galla. Thus, to use the same phrase we might say :-

\section{الامراة مسكينة شُفافتس اختها و نادتها}

Al-imrat maskinat šăfat uxt-ha wa nadat-ha.

The poor woman saw her sister and called her.

In many of the Aryan tongues the concord is exhibited by more or less uniform terminations of words according to gender, which are usually constant in their operation. ${ }^{1}$ We most of us can call to mind the

9 The Hottentot is a sex-denoting language, but I do not imply that it is necessarily related to the Hamitic tongues.

1 such as in Latin where the vowel " $a$ " is particularly characteristic of the final terminations of feminine nouns, and reappears in most of 
masculine, feminine, and neuter endings of familiar Aryan languages, which modify the same root in a generic sense, and which are repeated in the dependent adjectives and pronouns. It is as much a concord as what strikes us so particularly in Bantu, only it takes the form of $a$ suffix instead of a prefix.

The personal pronouns in Masai are:-
Sing.
Plur.
1. nanu.
iol.
2. ie, or iye.
endai.
3. ele (he, she, it). Vide demons. pron.
kulo.

The 2nd person singular ie seems to be a somewhat mutilated form. I fancy there are slight indications in the language of its once having had a masculine and feminine form, as in the Semitic tongues; possibly oiye, loiye (loiye is still used as a form of saluting males) for the masculine, and naiye for the feminine. The 2nd person plural seems to be of a feminine character, and to be composed of enda, demons. pron. fem., "that," and ie or iye, "thou" - so that it would originally assume the meaning of "you, there." In Galla, all nouns, whether masculine or feminine, use the feminine pronoun, and are considered to be in the feminine gender when used in a collective senise.

Ele and kulo, the 3rd pers. sing. and plur. are simply demonstrative pronouns, and when not standing with the verb would be common or masculine in gender. The female equivalents are ena and lina. The objective forms of the personal pronouns are the corresponding pronouns and adjectives, as in such a phrase as this :-

"Illa ancilla est bona." Here the concord is as apparent as in the tongues we have been quoting. 
apparently the same as those in the nominative case. In construction they are placed after the verb or predicate.

$$
\begin{aligned}
& \text { "I give you" is Nanu aišo ie. } \\
& \text { "Thou givest me" is Iye išo nanu. } \\
& \text { Thou givest me. }
\end{aligned}
$$

At the same time, it must be remarked that in speaking Masai the pronoun in the objective case is often understood rather than given. Thus "I give" will often stand for "I give him, or you, or them," according to the context.

Reflective pronouns are often simply the ordinary personal forms, but in cases of peculiar emphasis the words os-sesin (body), ôl-dau (heart), are used in conjunction with possessive pronouns. Thus "I, myself," is nanu, os-sesin-lai, lit. "I, my body;" or "I love myself," Nanu ašam ôl-dau-lai, lit. "I love my heart."

For the 3rd person, sing. and plur., a form ninye, or nenye, is sometimes used. This may possibly be an old feminine form of the 3rd person possessive article, enye, and may refer to a feminine noun understood. A reciprocal form of the pronouns is sometimes made by prefixing pa, a preposition meaning " for, by, with," as paiok, paye, \&c. This has often the force of "each other."

Before the verb-root certain particles are used which seem originally to have been abbreviated forms of the personal pronouns.

For the 1st person sing. $a$ -

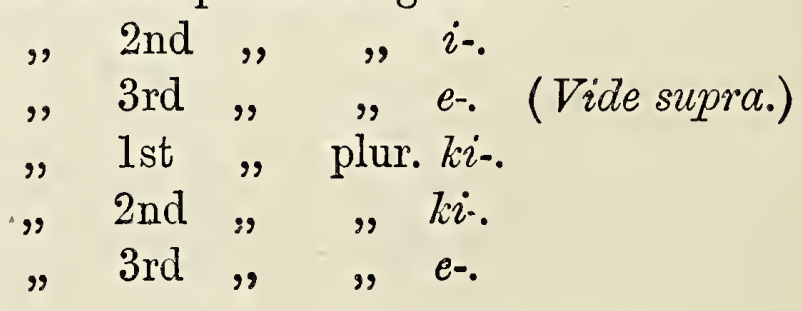


Examples :-

\begin{tabular}{ll}
\multicolumn{2}{c}{- kweni, to laugh. } \\
A-kweni, & I laugh. \\
I-kweni, & Thou laughest. \\
E-kweni, & He, she, it laughs. \\
Ki-kweni, & We laugh. \\
Ki-kweni, & You laugh. \\
E-kweni, & They laugh.
\end{tabular}

It is possible that the form of the 1st pronominal prefix in the verb was $n a,{ }^{2}$ an abbreviation of nanu. There are one or two cases in which it still seems to linger, as in naji, "I am called." The form of the 1st and 2nd persons plural, it will be noticed, are the same. As may be noticed in several African languages, the 2nd person plural has not a very well fixed existence, and seems to borrow forms from the other persons.

The possessive pronouns are used as suffixes, and are:-

Sing.

My, -lai, mase.; $a i$, fem. and common.

Thy, -lino, masc.; -ino or -nono, fem. and common.
Plur.

-lainai, masc.; -ainai, fem. and common. -linono, masc.; -nono, fem. and common.

His, her, its, -lenye, masc. ; -enye, fem. and common (sing. and plur.). Our, -lain, masc.; -ain, fem. and common (sing. and plur.). Your (doubtful; possibly -inye or -enye, the same as his, \&c.). Their, -lēnyє̆na, masc. ; -ènyĕna, fem. (sing. and plur.).

Examples of above:--

$$
\begin{aligned}
& \text { Arabe-lai, my friend (masc.). } \\
& \text { Anasi-ai, my sister (fem.). } \\
& \text { Eiboni-lino, thy chief (masc.). } \\
& \text { Naiu-ino, thy mother (fem.). } \\
& \text { Aji-enye, his house (fem.). } \\
& \text { Tokitin-ainai, my things (fem.). } \\
& \text { \&c. }
\end{aligned}
$$

The relative pronouns in Masai seem to present but

${ }^{2} \mathrm{Na}$ is still the form used in Central Masai-land, according to Dr. Fischer. 
one form, and that is a slight one. It consists of $n$ prefixed to the pronominal particle preceding the verb, as :-

$$
\begin{aligned}
& \text { Ol-dunani nešam (n-e-šam). } \\
& \text { The man who loves. } \\
& \text { En-doki našam nanu. } \\
& \text { The thing which love I. } \\
& =\text { The thing which I love. }
\end{aligned}
$$

The interrogatives are :-

Ariai? "who? which?" Nyo? and Ainyo? "what?" $K$-, $K a ?^{3}$ is often prefixed to nouns, and means "what sort of?" "what-?" Ka-l-kiter ? "what sort of a bullock?" \&c.

All these interrogatives need the relative $n$ - before the verb, as Ainai neno? "Who is coming?" Ken-doti neti? "What thing is here?"

The demonstratives are:-

\begin{tabular}{lcll} 
& Sing. & \multicolumn{2}{c}{ Plur. } \\
Masc. & Fem. & \multicolumn{1}{c}{ Masc. } & \multicolumn{1}{c}{ Fem. } \\
Ele or elo. & Ena, "this." & Kulo or Kule. & Kuna, "these." \\
Elde. & Enda, "that." & Kulde. & Kunda, "those."
\end{tabular}

Sometimes $n$ or $n i$ (a form of the adv. eni, "here,") is prefixed to all the forms, and accentuates their position-nelo means "this, here," When prefixed to the plural, $7 u$ is left out, as nieldo, "those, these." All these demonstratives may take their place as personal pronouns.

Adjectival pronouns are:-

Poki or boki, " all, every."

(Polivare, all two $=$ both.)

-kai, other.

$$
\left.\begin{array}{l}
\text { Likai, masc. sing. } \\
\text { Enkai, } \\
\text { Nakai, } \\
\text { Kulikai, common. }
\end{array}\right\} \text { the other. }
$$

The adjectives in Masai are either independent nouns used in an adjectival sense (like in many of our

\footnotetext{
${ }^{3}$ Sometimes pronounced $g-$, ga.
} 
compound substantives, such as, "dog-collar," "mealworm," \&c.) and unassociated with gender or class; or else verb-roots, which are preceded by the classprefix of the noun they qualify, and which are adjectives in a participial sense.

Of the first description there are words like torono, torok, originally a substantive meaning "destruction, anything broken, spoilt," but now only used as an adjective with the meaning of "bad, very bad," according to termination. Torot is at once the plural and the intensified form. Thus:-
Ôl dunani torono is " the bad man."
$\hat{O} l$ durani torok is " the very bad man."
El dunanak torok is "the bad men."

Adjectives of this description generally agree with their governing substantive in number (unless they are only found in a collective form possessing no plural), but exhibit no prefixes indicative of gender; but those of the second class, which comprise the bulk of the adjectives, and which may possibly be presentparticiples, always prefix to their stem the distinctive particle showing the class of the noun they qualify. Thus, iroši, a verb-root meaning "to be heavy," becomes oiroši, masc., nairoši, fem., eiroši, common, according as it serves as adjective to-
Ôl-alem (masc.), "the knife."
En-dolu (fem.), "the hatchet."
El-ekari (common), "the bread."

These adjectives do not change their termination in the plural. Masculine nouns, which, as I have already explained, go into the common, neutral gender when they become plural, change their adjectival prefix also. Thus you say:- 
but

\section{Ol-doinyo oibor (the white mountain), sing. ;}

El-doinyon eibor (the white mountains), plur.

The adjectives, however, remain the same in both numbers for feminine and common nouns.

In Masai, the adjectives always follow the nouns.

In treating of the prefixes, pronouns, and adjectives, I have said so much about the substantive indirectly that there remains but little to remark respecting this important part of speech.

In Masai, it seems to me that the substantive originates from a verbal-root rather than that it gives birth to the verb, as seems to be the case in the commencement of Aryan speech, I shall treat of this further when discussing the verb.

I have already treated of the three genders, or classes of nouns, in Masai ; I will now briefly explain how the plural is formed. This, in the majority of substantives, is done by adding $k$ or $k i, n$ or $n i^{4}$ to the root, with, unless it ends in a vowel or a liquid, a vowel in between the root and the plural suffix. As a matter of fact, most substantives end in a vowel. ${ }^{5}$

One or two seemingly irregular plurals are formed by adding $a$ to the root, or $\operatorname{tin}^{6}{ }^{6}$ as :-

$$
\begin{aligned}
& \text { Kera, plur. of Ker, "a sheep." } \\
& \text { Ewejitin, " Exeji, " a place." } \\
& \text { Tokitin, " Toki, " a thing." }
\end{aligned}
$$

Many collective nouns, or nouns of neuter gender, form no plural, or occasionally (and this is also noticeable in certain adjectives) form a plural by prefixing lcu. This prefix $k u$ will have been already noticed in

4 Vide passive of verbs.

5 Vide verbs.

$6 O$ is sometimes a plural termination. Compare the plurals in Bari given in Mitterrutzner's Bari Grammar. 
the demonstrative pronouns where it forms the plural (liu-na, luu-lo, luu-lde, \&c.). It is evidently an old plural prefix of neuter gender. There are no "cases" distinguishable in the Masai noun, but when it is used in a "vocative" sense the definite article is dropped and the class prefix substituted. Thus, in addressing children you say "Na-kera!" "Oh, children!" instead of Ein-kera, "the children," "Ô-dunani!" "Oh, man!" "Eiboni!" "Oh, chief!"

It is difficult to treat of the Masai verb without entering somewhat into the question of the construction of the Masai language.

I believe that it is possible to trace most of the fundamental ideas which form the base of this speech to monosyllabic roots. Many of these are still existing in their primitive form, side by side with their polysyllabic variants, and it is not difficult to guess at the agglutinative processes which have built up the structure of the language.

The particles which are used to form the different concepts that are built up from a single root may be placed before or after the stem. Sometimes they consist of independent verbal roots, prefixed or affixed, or they may be simple reduplications of the primitive idea with a view of intensifying it, or adverbial or prepositional prefixes, or affixed particles used in a passive sense, and so on. An example will better illustrate my meaning.

From the root, $u d$, "digging, boring, hollowing," is derived-

eng-ud-uk

("the mouth") (eng. = the art. fem.

$u d=$ the root.

uk = another stem, meaning "shining, glittering;" therefore

eng-ud-uk means the glittering cavity, viz. "the mouth.")

स $\mathrm{h} 2$ 


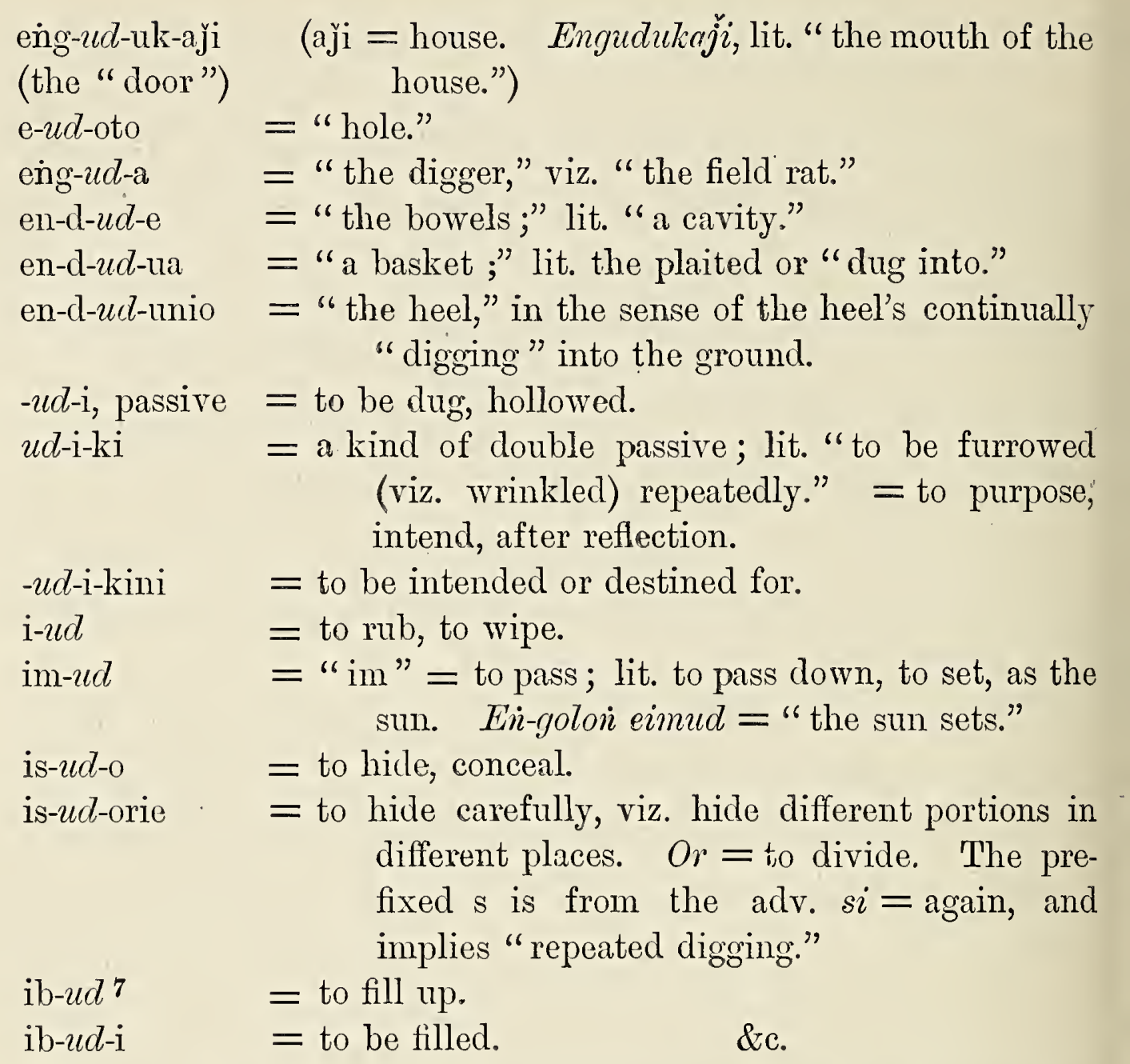

Many of the leading verbal-roots will be found in the Vocabulary.

I will now give a few illustrations of the Masai verb and of its method of conjugation.

Exauple I. -en, to bind together.

Active Voice.

Present Tense.

Affirmative.

\begin{tabular}{|c|c|c|}
\hline 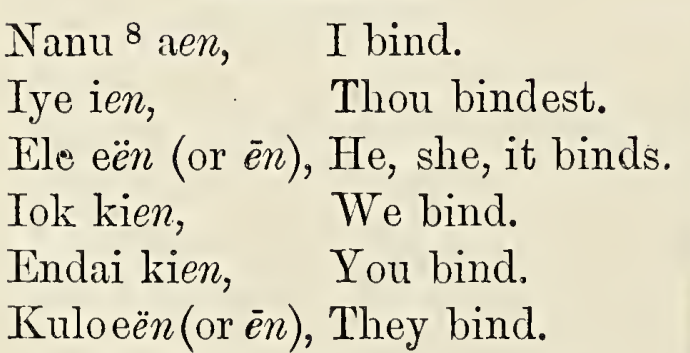 & $\begin{array}{l}\text { Maen, } \\
\text { Mien, } \\
\text { Mèn, } \\
\text { Mekien, } \\
\text { Mekien, } \\
\text { Mēn, }\end{array}$ & $\begin{array}{l}\text { I bind not. } \\
\text { Thou bindest not. } \\
\text { He binds not. } \\
\text { We bind not. } \\
\text { You bind not. } \\
\text { They bind not. }\end{array}$ \\
\hline
\end{tabular}

Negative.

I bind not.

Thou bindest not.

7 Latuka-ivot $=$ "full." Vide Vocabulary.

8 The personal pronouns are placed here for convenience of reference. They are not always used with the verb unless emphasis is required. 
Past Tense.

\begin{tabular}{ll|ll} 
& Affirmative. & Negative. \\
Atena, & I bound. & Ituaen, & I bound not. \\
Itena, & Thou boundedst. & Ituien, & Thou boundedst not. \\
Etena, & He bound. & Etuèn, & He bound not. \\
Kitena, & We bound. & Itukien, & We bound not. \\
Kitena, & You bound. & Itukien, & You bound not. \\
Etena, & They bound. & Etuèn, & They bound not.
\end{tabular}

Future Tense.

(The particles used in forming this tense are evidently relics of the roots -lo, -po, signifying "to go." Vide Vocabulary, verbs.

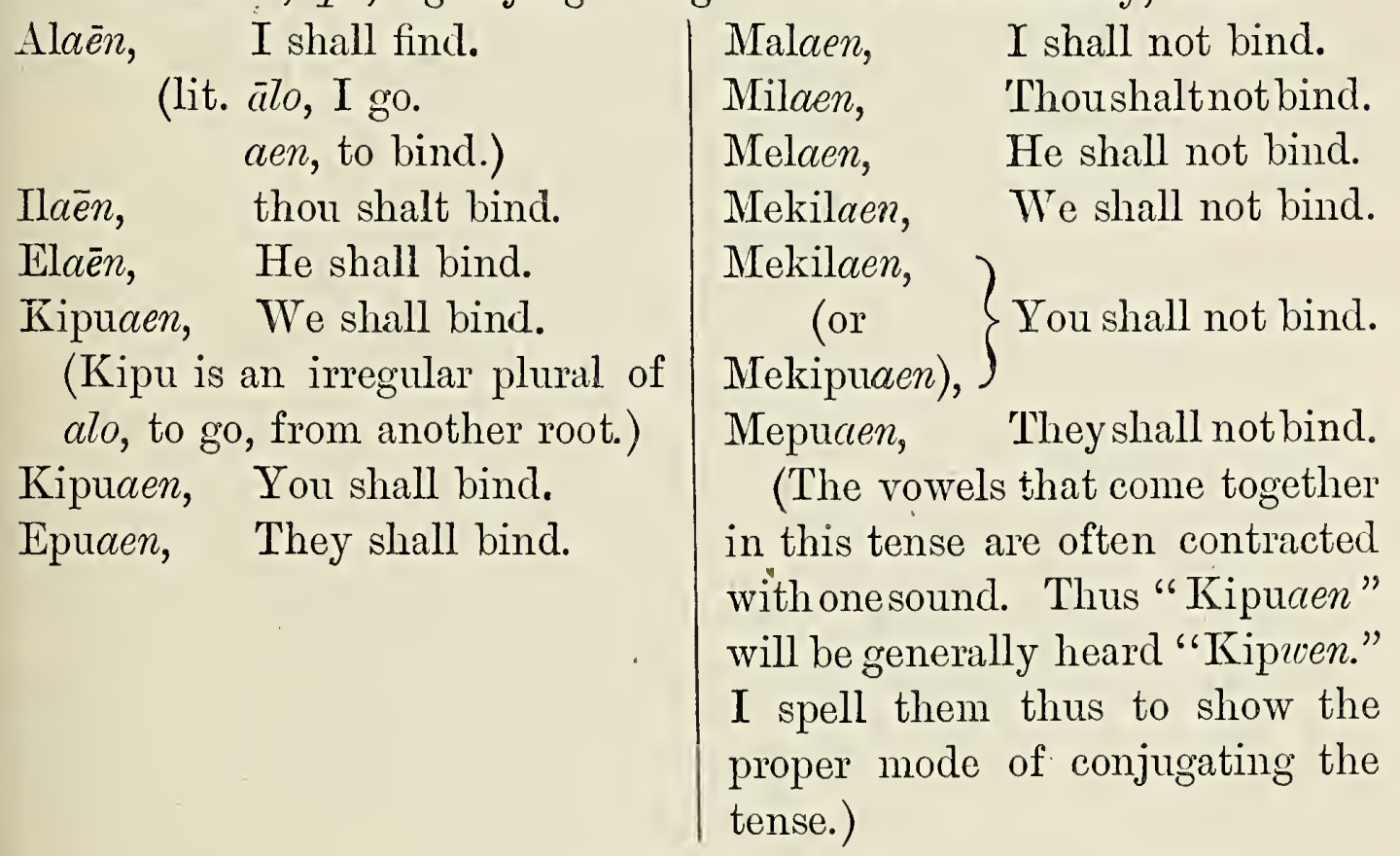

IMPERATIVE Mood.

Maten, let me bind.

Tena, bind thou.

Maten, let us bind.

Endena, bind yè.

Mien, bind not.

Mienieni, bind ye not.

\section{Subunnctive Mood.}

Present Tense.

\begin{tabular}{ll|c} 
Pèn, & $\begin{array}{c}\text { If, when, whilst I } \\
\text { bind. }\end{array}$ & $\begin{array}{c}\text { Pemaen or } \\
\text { pemèn, }\end{array}$ \\
Peien, If I bind not. & $\begin{array}{c}\text { If thou bindest. } \\
\text { \&c. }\end{array}$ & $\begin{array}{c}\text { Pemien, If thou bind not. } \\
\text { \&c. }\end{array}$
\end{tabular}

This tense is made by prefixing the preposition pe, if, when, whilst, \&c., to the present indicative.

Another combination is with the relative particle $n$, $n e$, and expresses, "that I may," \&c. It always 
follows an interrogative pronoun or a preceding verb. This tense is often expressed by an infinitive in English, as :-

Ayau naen, I wish to bind; lit. I wish that I may bind.

After a relative or interrogative pronoun it is prefixed to the verb in the same manner, as :-

Aniai nèn? Who is binding? lit. Who that is binding?

Its manner of uniting with the personal prefixes of the verb is the same as that of pe, me, and other particles already given, viz. :-

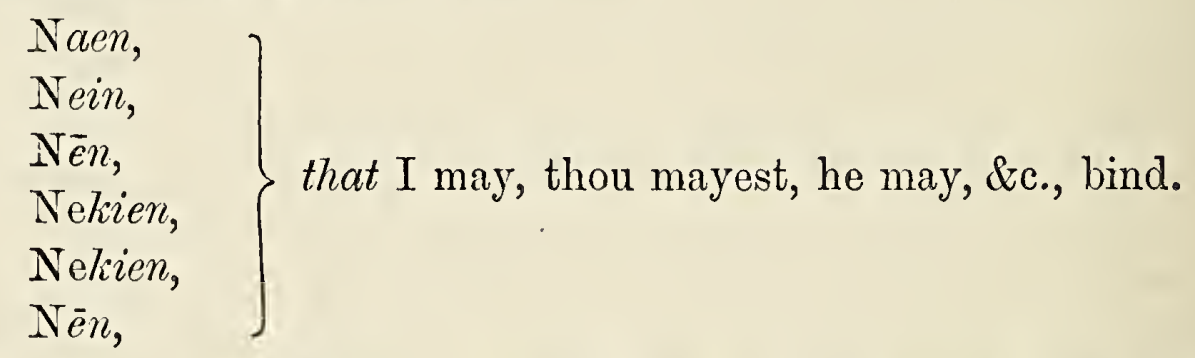

Both these particles, pe and ne or ni, together with others, such as teni, "if," perchance, $K, K a$, "What?" (Kaien? "What art thou binding ?") may be prefixed to all the tenses of the indicative mood in the active and passive voices, thus giving them a subjunctive or potential sense.

Thus you may say:-

Petena, If he bound.

Neitukien, That we bound not.

\&c.

Passive Voice.

-eni, to be bound.

Indicative Mood.

\section{Affirmative. Negative, \\ Present Tense.}

Aeni, I am bound.

Ieni, Thou art bound.

\&c.

Maeni, I am not bound.

Mieni, Thou art not bound. \&c.

Adding for this tense $-i$ to the present indicative, active voice. 


\section{Past Tense.}

Affirmative.

Negative.

Atènaki, I was bound.

Itënaki, Thou wast bound.

And so on.
Ituätenaki, I was not bound.

Ituitenaki, Thou was not bound. $\&$ c.

Adding -ki to termination of past tense, indicative, active voice.

Future Tense.

Alaeni, I shall be bound.

$\& c$.

Imperative Mood.

Tenaki, be thou bound.

Endenaki, be ye bound.

Besides the above-mentioned tenses, others can be formed by the aid of auxiliary verbs, as :-

Aidipa atena, I had bound, I have already bound; lit. I have finished, I have bound.

Ituaidip atena, I had not bound, \&c.

Ayau naen, I would bind; lit. I would, will, desire that I bind.

Many verbs, especially derivatives, and those commencing with $i$, make their past tense differently from the mode already described, viz. by simply affixing a to the root. Thus:-

$$
\begin{array}{ll}
\text { Aidip, } & \text { I finish.- } \\
\text { Aidipa, } & \text { I finished. } \\
\text { Aiken, } & \text { I count. } \\
\text { Aikena, } & \text { I counted. }
\end{array}
$$

The mode of forming the past tense in other verbs is, as in the first example, given by prefixing - ta, -te, $-t i$, -to, or $-t u$, to the root, and adding $a$ to stems ending in a consonant, as :-

$$
\begin{aligned}
& \underset{\text { (properly } a \text {-te-en } a),}{A \text {-ten }}\} I \text { bound. } \\
& \text { A-ta-šama, I loved (from šam, to love). } \\
& A \text {-ti-riša, I equalled (from rišs, to equal). } \\
& \text { A-to-roro, I Itrod (from roro, to tread). } \\
& \text { A-tu-šsıma, I put down (from šum, to put down). }
\end{aligned}
$$


It may be remarked that on the tonic vowel of the root, the vowel of the prefix - $t$ - generally depends.

The elements of construction in the verb may be briefly summarized.

The present affirmative is simply the root with the personal prefixes added. The past affirmative is formed by prefixing - $t a$, -te, - $t i$, -to, or - $t u$, to the root, and affixing $a$, or by doing the latter only in the case of most derivative verbs commencing with $i$.

It is possible that the $-t a, \& c .$, prefixed to the verb to form a past tense is related to the verb-root -ta, "to be, become, have." The origin of the future tense has already been surmised. It is formed by prefixing - $l$ $(a l, i l, e l)$ to the three persons in the singular of the present tense, and -po (kipu, epu) to the three persons in the plural.

The imperative, it will have been remarked, resembles greatly the past tense in the affirmative. In those verbs which form their preterite without prefixing -t-, the imperative also lacks this particle, and resembles the past tense exactly in the 2nd pers. sing. In the 2nd pers. plural, the e, en, em, end, placed before the verb, as in Endašam, "love ye ;" Enden, "bind ye," stands for Endai, "you."

The negative is generally formed by prefixing $m$ or me- to the affirmative. This particle is derived from the adverb emme, "no, not." The exception to this rule lies in the negative past tense of indicative where $i t u$, etu takes the place of $m$. I cannot obtain any clue to the origin of this prefix, unless it is related to -toa, "died, ceased" (Atoa, "I died.")

The passive is usually formed by adding $i$ in the present, and $k i$ in the past tenses to the form of the active voice. In some verbs, $-i$ is replaced by -lii or 
$-n i$, and either of these two may be doubled to intensify or modify the sense.

The meanings of verbal-roots may be altered by various affixes and prefixes. Among the former are-

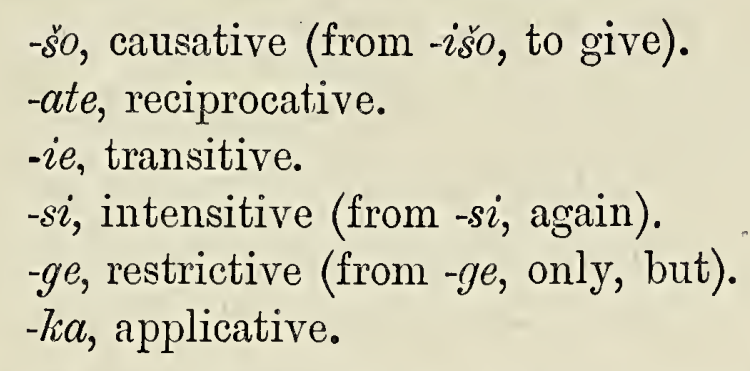

The verb "to be, to have (viz. be with), to become, to exist," is expressed by three forms :-

$$
-r a,-t a \text {, and }-t i \text {. }
$$

-ra applies more to actual existence, and is only used in the present tense. - $t a$ is used in present and past, and with compounds. It is often translated by "to have." - $t i$ applies to locality generally, and is possibly nothing but the preposition $t i$, "in, on" (Ati, "I am here," Iti, "thou art here, or there," \&c.). There are some few defective verbs, and one or two such as "to go," "to come," which are irregular, and made up of several different roots, as happens often in other tongues.

As previously explained, great variety of meaning may be obtained from the original monosyllabic roots, which express simple concepts, by the agglutinative process which tacks on before and behind other particles which enlarge, diminish, or intensify the primitive sense of the verb.

Adverbs in Masai are generally affixed, and prepositions prefixed to the verb-root. Many independent nouns or verbs have the form of adverbs and prepositions. The conjunctions are au, "or, either ;" o and na, "and, with," according to gender.

Having now passed the main features of this lan- 
guage in review, we may be better able to fix its position and relationships among other African linguistic groups.

In the recognition of sexual gender it resembles the Semitic, Hamitic, and Hottentot tongues; but, as I have tried to show, this generic distinction is somewhat hazy and seems to have originated rather in differentiating the strong, big things from the small and weak. The three classes in Masai, viz. strong or masculine, neuter or common, feminine or weak, seem to occupy a somewhat intermediate position between the many arbitrary classes in the Fula and Bantu languages, and the two genders of nouns-male and female-in the Semitic and Hamitic families. The "feminine" consonant in Masai is $n$. In the Hottentot, ${ }^{9}$ Hamitic, and Semitic languages it is generally $t$ $(\curvearrowright(t h), \stackrel{s}{s}, h)$.

In the question of construction the primal roots of the Masai language seem to have been monosyllabicin this differing from the Bantu and Hamitic (wherein they were probably dissyllabic) and the Semitic (in which they were trisyllabic and triliteral). The manner of forming the plural by adding an affix to the root resembles the plan adopted in certain Hamitic or Ethiopic tongues, particularly in Galla, where the few plurals that exist are made by adding $-n,-n i,-d a$ to the singular form of the noun. The secondary and rarer mode of giving a plural signification to a root (chiefly in pronouns and adjectives, and in Bari in certain nouns) by changing the prefix to $k u$ (Bari, $k o$ ), reminds one of the prefix-governed families of African tongues.

The mode of forming derivative verbs by affixing

9 The Hottentot, like the Masai, has three classes, masc., fem., and common. 
various suffixes to the stem, thus imparting a reciprocal, causative, or intensitive meaning to the simple root, recalls the same method in the Galla and Bantu languages.

At the same time, although the Masai group offers certain points of agreement in grammatical features with the Hamitic and Bantu divisions, there is no positive approximation to either. Certain of the numerals bear a slight resemblance to those of the Galla, and there are also a few words alike in the vocabularies of both these groups, but the similarity is possibly accidental, or some of the words may have been borrowed, one from the other. Masai certainly resembles Galla in its recognition of sexual gender, but differs from it by the possession of a third or neuter class of nouns (the Galla, all Hamitic or Semitic tongues beside, only recognizes two genders, masc. and fem.). Judging by certain indisputable resemblances between the vocabularies of Masai and Bari and the Dinka-Šiluk tongues, there is a great probability that the origin of the Masai family of languages is to be traced to the basin of the White Nile. Its affinities with the Galla branch of the Hamitic group raise the same interesting problems as the similarity which exists in certain grammatical features between the Hausa language of the Niger basin and the Berber tongues. On these points depend the solution of many difficult questions respecting the origin of the Hamitic and Semitic languages, and possibly races.

I append the following vocabulary of Masai for purposes of reference rather than with any idea of giving a glossary of the language. This would be out of place in a work of this sort, and therefore the following list of words is only given for the conveni- 
ence of the student of African philology who may happen to take up this book.

I have added to the Masai vocabulary words from other African languages, either belonging to the same group or forming part of separate linguistic families which might seem to be remotely connected with the Masai.

The mode of spelling adopted in these and other vocabularies which follow, and throughout the volume where African names are introduced which have not a generally accepted orthography, is practically the same as that proposed in Lepsius" "Standard Alphabet." The following letters are used :-

Vowels :-

$$
a, \bar{a}, e, \bar{e}, i, \bar{\imath}, o, \bar{o}, \hat{o}, \ddot{o}, u, \bar{u}, \ddot{u} \text {. }
$$

\section{Consonants :-}

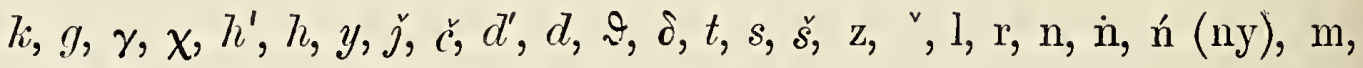
$\mathrm{b}, \mathrm{p}, \mathrm{f}, \mathrm{v}, \mathrm{w}$.

In their pronunciation it may be said roughly that the vowels are sounded as in Italian and the consonants as in English, but for the benefit of those who have not studied Lepsius' system I give a further explanation. Among the vowels

$$
\begin{array}{llll}
a \text { is sounded as in "master." } & \text { "mather." } \\
\bar{a} & , & , & \text { "rmet." } \\
e & , & , & \text { "grey." } \\
\bar{e} & , & , & \text { "bit." } \\
i & , & , & \text { "ravine." } \\
\bar{\imath} & , & , & \text { " } \\
o & , & , & \text { "not." } \\
\bar{o} & , & , & \text { "bone." } \\
\hat{o} & , & , & \text { "store," or a in "all." }
\end{array}
$$

$\ddot{o}$ like the German $\ddot{o}$ in "Böse," or French wu in "cour." 
$u$ is sounded as in "put."

$\bar{u} \quad " \quad$ " "rule" (oo).

$\ddot{u}$ like the French $u$ or German $\ddot{u}$.

The consonants are sounded thus :-

$k$ as in "kitten."

$g$ as in "gate."

$\gamma$ (the Greek gamma) like the Arabic $\dot{\varepsilon}$ ( $\gamma$ ain), a sound resembling the Northumberland "burr" or the French "r grasséyé."

$\chi$ (the Greek chi), like $c h$ in German or $\dot{\tau}$ in Arabic.

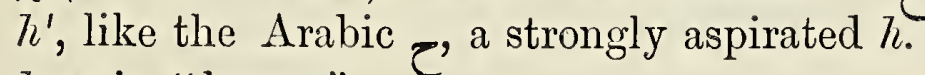

$h$ as in "house."

$y$ as in "year."

$j$ as in "jar" (the English " $\mathrm{j}$ ").

$c$ as $c h$ in English or $c$ before $e$ and $i$ in Italian. $\stackrel{\check{C} a}{a}=$ cha. $d^{\prime}$ a sound like "dy," intermediate between $y$ and $d$.

$d$ as in "day."

$\vartheta$ as th in "think."

$\delta$ as $t h$ in " that."

$t$ as in "tale."

$s$ as in "sail."

$\check{s}$, English sh, as in "shawl."

$z$ as in "zinc."

$z$ as in " azure" " = the French " $\mathrm{j}$."

$l$ as in "lace."

$r$ as in "Rome."

$n$ as in "need."

$\dot{n}$ as in "singing" - a ringing nasal sound like $n g$, but carrying on no sound of the $g$.

$\dot{n}$, sometimes used at the end of words for $n y=$ the Spanish $\tilde{n}$. $m$ as in "maid" and "umpire."

$b$ as in "boat."

$p$ as in "perch."

$f$ as in "fail."

$v$ as in "veil."

$w$ as in "wait" and "nawab" (a consonantal $u$ ).

Where the accent is not marked, it generally falls on the penultimate. 
(b) The Bantu languages of Kilima-njaro.

At the risk of wearying a majority of my readers, I will preface my vocabularies of the Bantu languages of the Kilima-njaro district by a slight sketch of the main features of this most remarkable family of tongues. The word "Bantu" has been so often used in this book that there are some who may be unaware of its meaning, and annoyed at its constant repetition and apparently meaningless character. To these, and not to the advanced in African studies, I tender this little general dissertation.

Any one who glances at a linguistic map of Africa - such an one as Mr. Ravenstein has drawn for Mr. Cust's book on African languages-will hardly fail to perceive how thickly certain districts, such as Abyssinia, the basin of the White Nile, the Lower Niger, or the country round Sierra Leone, are dotted with the names of distinct languages. Nor is it merely a question of numerous dialects of common origin. Many of these tongues-spoken, it may be, by only two or three thousand inhabitants of a single cluster of villages in a circumscribed area-are quite isolated, quite without relationships to other known forms of speech; or again, some of the languages may show faint indications of possible affinities-just a few hints in their grammatical construction or vocabulary, or phonology-sufficient to enable great generalizers in philology to bundle them together in one common group, in a desperate hope of simplifying the arrangement of African languages. Even the well-marked and undoubted natural families that overlie these regions-the Hamitic, the Fula, the Nubian, the Šiluk, the Hausa, the Mandingo-exhibit only sufficient similarity of structure in their different 
branches to enable the philologist to satisfy himself that he is justified in regarding them as forming homogeneous groups. But the various members of any one of these families often differ widely in their vocabularies, and sometimes are unlike in many

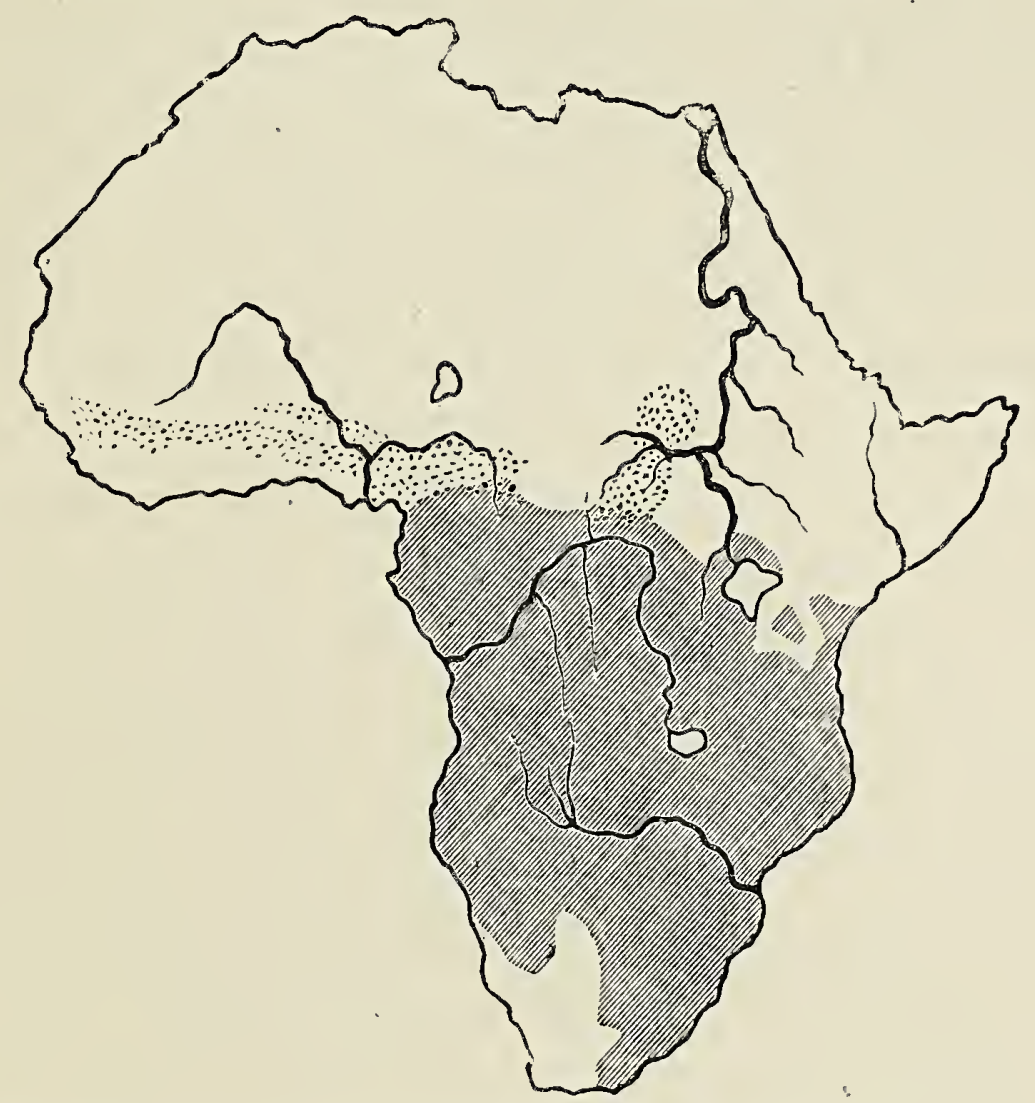

indicates the range of the Bantu family of languages.

indicates the position of languages possibly allied.

Map No. 5.-Map of Africa, showing range of Bantu Languages.

grammatical points. For instance, Galla and Šilha (Shlu) (the language of the Moroccan Berbers) are both members of the Hamitic group, yet, beyond their structural resemblance and their agreement in certain main features of grammar, they scarcely possess a root or test-word in common. ${ }^{1}$ I need not multiply instances

1 Compare with this Lu-ganda and Ö̈i-herrero, languages spoken at 
of this; the fact is already recognized by students of African languages, that in the northern half of the continent there are bewildering multitudes of diverse tongues belonging to many independent families, and apparently irreducible to a common origin. Yet cross the irregular boundary-line which runs over the con. tinent from $6^{\circ} \mathrm{N}$. on the west coast to the Equator on the east coast-viz. the northern limit of the Bantu speech - and what do we find? Why that the whole of the southern half of Africa, with the exception of the Masai and Galla intrusion in the north-east and the Hottentot enclave in the south-west, ${ }^{2}$ is the domain of a single homogeneous family of languages, the Bantu differing perhaps less among themselves than do the many offshoots of the Aryan stock. The only other African tongues which in any way approach the Bantu (as regards similarity of structure) occupy little isolated patches of country in Central and Western Africa, surrounded often by totally dissimilar forms of speech. Originally, there is little doubt, the primal Bantu language was as one of these, a member of a little group of prefix-governed tongues developed somewhere in the heart of Africa. Peculiar circumstances gave the people who spoke it the opportunity of playing a great rôle in unwritten African history; and the Bantu negroes, at one time very likely an obscure and unimportant tribe like the Temne and Bulom of Sierra Leone, the Efik of Old Calabar, or the Tumale of Kordofan, became the ruling and almost

either extremity of the Bantu language-field, separated as widely as are Galla and Šilha, yet differing from each other only as Latin from Greek.

2 I hardly think it worth while to except the languages of the Pigmy races (Obongo and others) from this general statement, as we know too little of them to pronounce as to their affinities. 
the exclusive race of Southern Tropical Africa, swallowing up, obliterating, absorbing the previous inhabitants of the land, and carrying their own form of language triumphantly from the Upper Nile to Natal, and from the River Tana on the east coast to Fernando Po on the west. In the spread of the Masai race and language we may see, on a much smaller scale, a parallel to this extension of the Bantu. It will be remembered that I already have pointed out the relations which the Masai language bears to the Šiluk and other tongues spoken in the basin of the White Nile. Some of these forms of speech resemble Masai about as much as the Non-Bantu prefix-languages resemble Bantu-proper. Most of them are spoken over small and confined areas. Yet the range of the Masai tongue and its various dialects extends almost uninterruptedly from $3^{\circ} \mathrm{N}$. to $5^{\circ} \mathrm{S}$. of the Equator, wherever the Masai race has spread in its warlike raids. Now we know that in many parts of Eastern Equatorial Africa the Masai only arrived, as it were, the other day. In many districts, too, in the centre of their present home the remnant of aboriginal natives still retain the oral tradition that several generations ago the Masai were unknown in the land. Yet, with the exception of a few isolated mountain-ranges where the Bantuspeaking inhabitants still linger, the Masai language is dominant throughout the whole length and breadth of the huge country known as Masai-land. Moreover, it is probable that had this warlike race not encountered natives armed with firearms and dominated by Arabs on the south, they would have overrun a considerably larger district than the one they at present occupy, and their language would have acquired an even greater range, and in course of time have lost its uniformity, 
and become split up into many separate dialects. Yet it is probable that some centuries ago the Masai were only a small section of a Nilotic race which adverse circumstances drove from its original home, and forced farther and farther south, the Masai all the time developing their fighting qualities, first to save themselves from extinction, and then in turn to pursue a successful policy of rapine and dominion. Such, in all likelihood, were the origin and history of the spread of the Bantu race and language. It is quite possible that before their advent the southern half of Africa was sparsely populated, perhaps by a low type of negro in the north and west, and Hottentots, Bushmen, and Pigmies in the south and centre. The invading Bantu carried all before liim in the early days of his invasion, and was probably little but a fightingman, as is the Masai at the present day. In the west, however, he was stopped-choked, one might almost say-by the dense negro population, and in the southwest by the Hottentots, who were probably driven to bay in this corner of the continent. In the centre of Africa the race and language of the Bantu people are purest to this day, probably from the much less intermixture which took place between them and any previous inhabitants. Judged by his purest types-the inhabitants of the great lakes and the Congo basinthe Bantu was probably a red race in its origin. Intermixture with Hottentots has given the Zulus a yellowish tinge, and clicks in their language, and the fusing of Bantu and Negro on the west coast has debased the character of the speech and deepened the colour of the skin.

Taking into consideration the fact that the unwritten languages of a savage people vary with 
extraordinary rapidity, and noting at the same time how great is the uniformity in grammar, construction, and vocabulary between all the Bantu languages, we can hardly believe that they are a very ancient offshoot of the negro race, or that the date of their original dispersion from their centre of development is very far removed. I should think, as far as we may judge, that it is about 2000 to 2500 years since the Bantu people commenced their invasion of Southern Africa; and that before this date-before the dispersal of what was evidently a compact and homogeneous tribe -one common language, the Bantu mother-speech, ${ }^{3}$ was spoken. One of the principal reasons which induces me to hazard this guess as to the recent period at which this family of languages split up into separate branches and spread out over half the continent of Africa, is the interesting fact that in nearly every form of Bantu speech the domestic fowl is indicated by words of one type, all pointing to a common origin. This in its most archaic form is nguku. This is the term used in Ki-nyoro, ${ }^{4}$ in Lu-ganda (the language of Buganda, on the north-west shore of the Victoria Nyanza), in the tongues of the Upper Congo, of Lake Tanganyika, of Kilima-njaro, at the present day, while variants of the same word are found in Kafir (inkuku), Zulu, Mpongwe, and, in short, almost all the known members of the Bantu group. Now this leads us to believe that the domestic fowl must have been known to the original Bantu race before it commenced its migrations from the centre of its development, from

${ }^{3}$ Itself, no doubt, in those early days but a sister-tongue or a lateral branch of many cognate forms of prefix-governed speech descended from an earlier stock.

${ }^{4} \mathrm{Ki}$-nyoro, one of the most northerly forms of Bantu language, is spoken in Bu-nyoro on the Victoria Nile, in lat. $2^{\circ} \mathrm{N}$. 
its primal home. Yet the era of the domestication of Gallus Bantiva is not a very remote one, as far as we can ascertain, even in Malacca and Indo-China, its original habitat. Hindostan seems to have known it as a domesticated bird about 2000 years B.C., China about 1200 B.C., and the Polynesians possibly carried it with them when they started about two thousand years ago to colonize the Pacific Archipelagoes. From India it spread to Persia, and the Persians made it known to the Greeks about 1000 B.c. Aristophanes called it the "Persian bird." It was not known to the Romans till much later, and the Ancient Jews ignored it till long after the Babylonian captivity. It was introduced into Egypt, as far as we can tell, during the early part of the Ptolemic rule. Down the Nile it quickly spread to the negro and negroid inhabitants-as quickly as turkeys, Muscovy ducks, pineapples, manioc, Indian corn, and other American products have penetrated to the heart of Africa during the last two centuries--and thus probably reached the ancestors of the Bantu race not more than some two thousand years ago. Even yet there are many parts of Africa where the fowl is not known, such as in Masai-land and in some parts of South and West Africa. The Bushmen have it not. Moreover, the fact that there is such an absence of special varieties and peculiar breeds seems to suggest that the fowl in Africa has not yet had time to depart in any marked manner from the original stock. ${ }^{5}$

By studying the comparative vocabularies of the

' I fancy some may be inclined to suggest that the fowl may have been introduced at an earlier date into Africa by way of Madagascar, and that the Malay invaders of that island might well have brought it with then from the Indian Archipelago. Apart from the fact that we can discover no introduction of any animal or plant in a domesti- 
Bantu languages, many interesting conjectures may be made as to the original home and primitive condition of this people. Thus the fact that similar words are used in the remotest and most widely separated members of the group to express "leopard," "elephant," "hippopotamus," "buffalo," "pig," "ape," "monkey," "grey parrot," "bee," $\& c .$, leads us to believe that these creatures were familiar to the primitive Bantu race; while we may infer that because the rhinoceros, giraffe, lion, ostrich, and zebra are known by many different and varying terms in the dialects of those tribes acquainted with them, they were unknown to the forefathers of the people in their ancestral home. Now the first-mentioned list of creatures (with many others which might

cated condition from Madagascar into Africa, but rather that most domesticated animals in that island bear Bantu names, and in all likelihood owe their origin to importation from the Mosambique coast, we may further consider, for weighty linguistic reasons, that the region of South-east Africa opposite Madagascar was a very unlikely site for the original home and starting-point of the Bantu people. Again, it might be argued that the fowl may have been introduced from Madagascar to the opposite coast, and that it was thence passed on into all parts of Bantu Africa-the Lake district, Natal, the Cameroons, the Congo-carrying with it everywhere its original name. But in this case how is it, while all the Bantu languages know it by kindred (practically identical) terms, that in neighbouring or intervening forms of speech of alien families it is designated by entirely dissimilar words ? Also it must be noted that all foreign products introduced into Africa, and acclimatized there since the discovery of America, do not carry their original names with them from tribe to tribe as they pass across the dark continent. Things like Indian corn, sweet potatoes, manioc, the Muscovy duck, the pineapple, bear a different designation in almost every separate dialect, and though sometimes their original foreign name may turn up in the centre of Africa, in the intervening lands nearer the coast it has been long since changed and distorted beyond recognition. Lastly, the introduction into Madagascar of the domestic fowl is usually ascribed to the Arabs, about eight or nine hundred years ago. Few writers on Madagascar mention its presence in the island, and it is probably not widely kept even at the present time. 
be cited but for want of space) suggest a wellforested and well-watered country in West Central Africa as the original abode of the Bantu race. The grey parrot, for instance, is found as far east as the Victoria Nyanza, and as far south as Angola, but otherwise is confined to Western Africa. The leopard, elephant, apes, and monkeys mostly affect denselywooded regions. The hippopotamus only inhabits big rivers or lakes. The buffalo is rarely found westward of the Niger. On the other hand the lion, giraffe, rhinoceros, zebra, or ostrich decidedly prefer the sparsely-wooded steppes and savannahs of Eastern and Southern Africa; so that, on the whole, we may conclude that the primitive Bantu being unacquainted with them, and knowing other creatures (such as the grey parrot) confined to the forested districts of Western Central Africa, there had his primæval home, and thence started on his career of conquest and colonization over Western, Southern, and Eastern Africa.

From the fact that there is a common name for "ox" (ingombe, inkombo, inkomo, omo, nombe) throughout nearly all the Bantu languages, we may safely infer that cattle-keeping was a feature of the primitive life of the race, and also that they were agriculturists, because the terms applied to various implements for tilling the soil, to " ploughing," "digging," "sowing," "reaping," are retained, very little altered, by some of their remotest descendants. We may gather from the same reasons that besides the ox they possessed other domestic animals, namely, the goat, possibly the sheep, the dog, the pig, ${ }^{6}$ and the fowl. Of the present

${ }^{6}$ The word for pig is as widespread as that for ox. I have tried to show in my book on the Congo that the pig was domesticated in Africa long before its introduction by the Portuguese. 
cultivated plants, very few were known to them in the days before their dispersal, perhaps only millet, pumpkins, edible arums, the banana, and a few obscure roots and fruits.

They seem to have been acquainted with the use of iron and copper, used smelting-forges of the primitive type still in vogue, and beat out knives, spears, and arrow-heads as they do now. The bow was certainly in common use, and its name is not only well-nigh universal throughout Bantu Africa, but also seems to have sprung from a very old root. Pottery, basketweaving, and some form of clothing, either of plaited grass, banana-fibre, or imported cloth, was in use. Canoes were familiar to the early Bantu people, to judge by the universality of their primitive name. A conception of a Supreme Being or Creator seems to have existed, but a belief in spirits of the dead, in magic, witcheraft, certain vague forms of "fetishism," and phallic worship certainly prevailed, and the "medicine-man," "rain-maker," or magician most undoubtedly exercised as powerful a sway over the primitive Bantu as he does throughout every branch of his widespread descendants.

Apparently in that golden age before their dispersal the Bantu people were neither acquainted with smallpox, syphilis, nor many forms of disease which plague them nowadays. They smoked hemp, possibly, but not tobacco, and they drank one or two kinds of fermented liquors. They anointed themselves with oil, rancid butter, red earth, and the dyes of certain trees. They sang and they danced, and they possessed drums and musical instruments with strings.

Circumcision is not universal among all Bantu nations at the present day, and it is possible that it 
was not originally practised by their common ancestors, though at the same time it may have been partially in use. Initiatory ceremonies for youths on attaining manhood were certainly in vogue. Just as the life of the early Aryans may be conjectured from the examination of word-roots common to most of the forms of speech which are descended from an Aryan mothertongue, or in the same way by a careful study of the modern Bantu languages, we are able not only to reconstruct the primitive Bantu speech, but we can also glean much information as to the relative culture and mode of life existing in the original tribe of negroes from which most of the Bantu races of Africa are descended.

It is just possible that some of my readers may wish to know the meaning and origin of this term "Bantu" which has been so frequently used in this book, and which is generally accepted as the designation of an important family of African languages and a large section of the negro race. "Bantu" (properly $B a-n t u)$ means "men, people, folk." It is the plural of Mu-ntu "a man," "a human being," and is a term which under different variations is present in nearly every one of the languages belonging to this family. It may become Wantu, Wandu, Watu, Vantu, o Vantu, Vatu, Atu, Batu, Wanu, Vanu, Anu, o Manu, but it is always traceable back to the archaic form-Bantu. This with the added article in some languages becornes a Bantu. Such it is in Zulu, in Kaffir, and such it is in Ki-nyoro and Lu-ganda, on the Victoria Nile and the Victoria Nyanza. On account of the universality of this form, and of its being so characteristic of the structure of these languages, it was proposed by Bleek as a fit designation for the great South African family 
of prefix-governed tongues. Many other titles, of course, have been suggested. Krapf proposes, firstly, "Nilotic," which is absurd, as only one or two outlying members of the family touch the Nile; and OrphnoCushitic, which is utterly unmeaning and very cumbersome. Another writer suggests "Kaffr-Congo" as a fit appellation, but how is this term to include the languages of Kilima-njaro and the Cameroons? "Zingian," "Zanjian," are equally silly and inadequate. "The prefixing languages" is not sufficiently restrictive, as several other African groups are governed by prefixes-in short we return to "Bantu" as the only satisfactory designation of this class of languages and of the tolerably homogeneous races who speak them. The leading characteristics of the Bantu languages have been much misinterpreted by various writers on African philology. As a rule one original author takes the question up in a superficial manner, studies one particular language, or at most a small section of the entire group, draws a few hasty conclusions, and those who succeed him in a consideration of the subject copy him like unreasoning parrots, and spend neither time nor trouble in elaborating an opinion of their own. Thus Bleek, who only made a detailed study of Kaffir-Zulu, and was (through no fault of his,) unacquainted with more recently discovered tongues, states that he considers the KaffirZulu to be the most archaic form of existing Bantu speech and the nearest approach to the original mothertongue. Other writers. succeeding him blindly copy the same opinion and parade it as their own, whereas had they taken the trouble to make any independent researches, using recent material to aid them, they would have long since ascertained that Kaffir-Zulu is 
very far from proving to be the Sanskrit of the Bantu. Again, other authors speak of the concord (a feature by no means peculiar to the Bantu, but present in many other radically different languages, as I have pointed out on page 459) as "euphonic alliteration." This is rubbish. Its origin is clearly not euphony, but lies in the laborious reiteration which in so many savage languages is used to obtain certainty of meaning; and as to alliteration, why in most languages it does not exist because the nominal and other prefixes no longer correspond in sound. For instance, in Lu-ganda, one of the most archaic of Bantu languages, we should say-

\section{Muti guli muvundo gutuka; tugisale. Tree that rotten falls; let us it cut down. = That rotten tree is falling; let us cut it down.}

If it were a question purely of euphonic alliteration we should expect to find $m u$ as the concord-prefix applied to "Muti," a noun of the third class. But, as you see, it is sometimes $m u$, sometimes $g u$, and sometimes $g i$. This is explained to the careful student who finds by research that the original form of the third prefix was $\dot{n} g u$, which became changed in some situations to $m u$, and in others to $g u$ or $g i$. This is not only the case in nearly all the Bantu languages, but it applies to many of the prefixes, and shows that anything like alliteration does not often occur.

Another generally enunciated dictum about the Bantu languages was that all their roots were polysyllabic. This is, however, not the case. While some of the simple concepts expressed in words of more than one syllable cannot be dissolved any farther into their component elements, at the same time many most important ideas are expressed by monosyllabic 
roots which are certainly not abbreviations. Such are the widespread forms found in nearly every member of the group : $-f a$, "dying, to die;" -pa, "to give;" -ndi and -ba, "to be ;" -ta, "to slay ;" na (nya) "to evacuate;" ya, za, "to come," \&c., and numberless noun-roots, such as -ti (in mu-ti, "a tree" -anything to do with wood; ka-ti, "a little stick;" - /ca, diminutive prefix), -ntu, "an object" (mu-ntu, "man;" ki-ntu, "thing;" pa-ntu, "place," \&c.), and so on.

We may therefore reduce the real features of the Bantu family of languages to these:-

I. They are agglutinative in their construction.

II. None of their words ever end in a consonant except in rare instances, where the termination through contraction becomes a nasal sound.

III. No two consonants come together without an intervening vowel, except where one of them is a nasal or a labial.

IV. Substantives are divided into many classes or genders, the full number of which is sixteen. These are governed by characteristic prefixes, differing in singular and plural, and observing the "concord" throughout the sentence.

V. No sexual gender is recognized, but two particular classes of prefixes (one singular, and one plural) indicate sentient forms of animal life only, though these may also be expressed by nouns bearing other prefixes as well.

VI. The pronominal-particles (which are really identical in origin with the prefixes) must always precede the verbal-root, except in the imperative mood.

VII. The verbal-root may modify its termination by change of vowel or by suffixing certain particles; or it may even change its radical vowel, either to form a tense or to alter the original meaning of the simple stem, this being actually inflection.

VIII. Adjectives and numerals always follow the noun.

The complete number of prefixes is, as before remarked, sixteen. Bleek has made it eighteen, by adding two prepositions to the list, which in a few of the languages appear to adopt the concord; but they 
are independent prepositions, and not true pronominalprefixes.

In the most archaic forms at present discoverable the sixteen prefixes are as follows :-

Singular.

1. Mŭ.

3. $\left(\mathrm{Mu} \overline{\mathrm{u}}(\dot{\mathrm{N} g u})^{7}\right.$

5. Di or Li (Ndi).

7. Ki (Nंki ?).

9. $\mathrm{N}-(\mathrm{Ni}$ ?).

11. Lu.

13. Ka (often diminutive in sense).

14. $\mathrm{Bu}$ (generally used to form abstract nouns from concrete roots).

15. Ku (a directive; identical with preposition meaning "to."

Used as an.infinitive with verb-roots).

16. $\mathrm{Pa}$ (locative; only applied to nouns or other forms of speech indicating place or position).

There are few instances of the prefixes changing from plural to singular in signification, or vice versî, except that the 14th ( $(\mathrm{Bu})$, which is generally used to form abstract nouns, may occasionally serve as plural to the 13 th $(\mathrm{Ka})$. The 15 th and 16 th $(\mathrm{Ku}$ and $\mathrm{Pa})$ are of no number, being practically prepositions. Ku is used with verbs in the sense of "to," and as an adverb of locality. Pa only serves as concord to nouns of place, and as a preposition generally means "here" and "on." The 9th prefix often adheres to nouns in both numbers.

As regards the correspondence of singular and plural prefixes, it is by no means constant, though the plan set forth above is considered by some the normal

7 Where an alternative rendering is added in brackets, it is meant to indicate what the peculiarities of the concord and other reasons lead us to regard as the older form of the prefix, now no longer in actual use. 
one. The 1 st $(\mathrm{Mu})$ always takes the $2 \mathrm{nd}(\mathrm{Ba})$ as a plural, but the 2nd prefix may occasionally become plural to the 9 th $(\mathrm{N}-)$. The 5 th always takes the 6 th and the 7 th and the 8th as plural, but the 6th prefix (Ma) and the 8th (Bi) sometimes correspond with other singular prefixes. Thus $\mathrm{Ma}$ may often be the plural of $\mathrm{Bu}$, or of $\mathrm{N}$-, or of Lu. Again, the 12th prefix $(\mathrm{Tu})$ is very often the plural of the 13 th $(\mathrm{Ka})$, and the 10th (Tin or 2 in) of the 11 th $(\mathrm{Lu})$. In some languages certain prefixes drop out altogether, and are either represented by a hiatus or replaced by another prefix. Indeed, there are very few Bantu languages in which all the sixteen prefixes are present, and probably none in which they all retain their archaic forms.

In Makonde, a language spoken about Cape Delgado in East Africa, the entire sixteen are present, and possibly this occurs also in Ki-nyoro, the tongue spoken in Bu-nyoro, on the Victoria Nile, Oci-herero, of Damara-land, and probably a few languages of the Congo basin and the Upper Zambezi possess this distinction. On the other hand, there are many Bantu tongues in which the number of classes has become very much diminished, while some of the prefixes have so changed their forms as to become fused into others, and no longer recognizable. Thus, in Mpongewe, the corrupt tongue of the Gaboon, there are only twelve of the original sixteen classes represented, and among these the 1st, $3 \mathrm{rd}$, and 11 th assume the same form, and can only be distinguished by their corresponding plurals or concord. In Swahili, also, the classes are reduced to twelve, and in some other languages to eleven, and even ten.

Again, the forms of the prefixes often vary from the standard already cited. Thus Ba will become Va, Wa, 
A, and even Ma. And Sin or Tin change to Zin, Din, Lin, or Ion.

The Bantu languages have been divided for convenience of description into four main branches, the Western, Southern, Eastern, and Central. These are not altogether natural and homogeneous divisions, as some of the languages though geographically close to one another are in reality widely separated in manner and time of development. However, for the present: this arrangement, being a simple one, may stand.

It is, therefore, in the Eastern division that the Bantu languages of Kilima-njaro are placed, though they' exhibit certain points of resemblance to the tongues spoken on the Victoria Nyanza. On the whole, perhaps, their most decided affinities lie with the languages to the east of them, namely, the Kikamba, Ki-taita, Ki-nyika, and Ki-pokomo.

The language spoken on Kilima-njaro is Ki-čaga. This seems to be the speech of all the Bantu inhabitants of the mountain, unless, indeed, the Wa-rombo are to be excepted. These wild people seemed to me to use a different dialect to the rest of the Wa-čaga. (Vide Chapter XIV.)

To the south-east of the great mountain is the little agricultural colony of Taveita. Ki-taveita is the language used by the Bantu half of the populationMasai being the speech of the remainder. Ki-gweno closely resembles Ki-čaga. It is the dialect of the Ugweno mountains to the south of Lake J̌ipé.

Ki-kamba is spoken by the A-kamba dwelling on the upper waters of the Tzavo river, but as this language has already been described by Krapf, and latterly by the Rev. A. Downes-Shaw, ${ }^{8}$ I do not think it necessary

8 "A Pocket Vocabulary of East African languages," by the Rev. A. Downes-Shaw. S.P.C.K. 
to include it in my vocabularies, otherwise than to point out an occasional correspondence of terms.

For the system of orthography used in spelling these languages, I would refer the reader to the explanation given on page 476 in connection with the Masai vocabulary. In the phonology of these languages several facts require to be noticed.

$K i$-čaga, which has evidently been an isolated tongue for several centuries, surrounded by an ocean of Masai, has developed rather a peculiar pronunciation. Some of the vowels, especially $u$, have acquired a much duller and more indistinct sound than is usual among Bantu languages, where ordinarily the vowels have a clear, open sound, as in Italian. In Ki-caga it is often difficult to distinguish between $a$ and $u(\ddot{u})$ and $i$. In many words where $u$ is the tonic vowel in other forms of Bantu speech, it is changed to $i$ in Ki-čaga.

$G$ often becomes $h$, and sometimes $\gamma$. II may replace several consonants, but generally stands where a $g$ is used in other tongues. $L$ as an initial is very frequently changed to $n,{ }^{9}$ and sometimes $r$, while $r$ is an exceeding common sound, being constantly substituted for $t, d$, and $z$. Sometimes $d$ stands for $t$, and after the former letter a "trilled" sound like an $r$ is often heard, so that the listener hardly knows whether to write such a word as wanda, "place," wanda, or wandra. $F$ before $i$ often becomes $s(s i)$, and $p$ changes to $w$. In Ki-taveita $g$ often becomes $\gamma$, but never $h$. $D$ sometimes replaces $t$, and so does $s$ in a few words, but otherwise $t$ holds its place and does not change to $r$ or $h$, as is so frequently the case in Ki-ćaga or Kinyika. $\quad V$ has a tendency to become $w$, and $p$ does

- Where this occurs in the case of the 5 th prefix $L i$, which I believe is derived from an older form $\mathrm{Ndi}$, it is probably only a case of the $n$ surviving. 
not exist in the language, its place being nearly always taken by $h$, in foreign words by $b$, and in a few cases by $f$. Ki-gweno offers much the same features as Ki-čaga in its phonology, except that $h$ instead of $w$ replaces $p$, and $t$ is not so often changed to $r$. 


\section{A TABLE OF SUBSTANTIVAL PREFIXES IN KI-ČAGA,}

KI-GWENO, AND KI-TAVEITA.

\begin{tabular}{|c|c|c|c|c|c|}
\hline \multicolumn{2}{|c|}{$K I-\check{c}_{\Delta} G_{A}}$. & \multicolumn{2}{|c|}{ KI-GW BNO. } & \multicolumn{2}{|c|}{ Kr-TAVEITA. } \\
\hline \multicolumn{2}{|c|}{ Classes. } & \multicolumn{2}{|c|}{ Classes. } & \multicolumn{2}{|c|}{ Classes. } \\
\hline $\begin{array}{l}\text { Singular. } \\
1 \text { Pers } \\
\text { Mu- } \\
\text { M- } \\
\text { A- }\end{array}$ & $\begin{array}{c}\text { Plural. } \\
\text { onal } 2 \\
\text { Wa- }\end{array}$ & $\begin{array}{l}\text { Singular. } \\
\text { I Pers } \\
\text { M- }\end{array}$ & $\begin{array}{c}\text { Plural. } \\
\text { onal } 2 \\
\text { Wa- }\end{array}$ & $\begin{array}{l}\text { Singular. } \\
1 \text { Pers } \\
\text { Mu- } \\
\text { M. }\end{array}$ & $\begin{array}{c}\text { Plural. } \\
\text { onal } 2 \\
\text { Wa- }\end{array}$ \\
\hline $\begin{array}{l}\begin{array}{l}3 \\
M \bar{u}-\end{array} \\
M-\end{array}$ & $\begin{array}{l}\quad 4 \\
\text { Mu- } \\
\text { Mwi- } \\
\text { M- } \\
\text { Mi- }\end{array}$ & $\begin{array}{l}{ }^{3} \\
\mathrm{Mu}- \\
\mathrm{M}-\end{array}$ & $\mathrm{Mi}^{4}$ & $\begin{array}{l}\text { M } \\
\text { M. } \\
\text { ú- }\end{array}$ & $\stackrel{4}{4}$ \\
\hline $\begin{array}{l}\quad 5 \\
\text { Ni- } \\
\text { Nyi- } \\
\text { Li- } \\
\text { I- } \\
\text { Ri- } \\
(-)\end{array}$ & $\begin{array}{r}6 \\
\mathrm{Ma}^{6}\end{array}$ & $\begin{array}{l}5 \\
\mathrm{Ni}-\end{array}$ & $\begin{array}{r}6 \\
\mathrm{Ma}-\end{array}$ & $\begin{array}{l}5 \\
\mathrm{Ni}- \\
\mathrm{I}- \\
\mathrm{vi}-\end{array}$ & $\begin{array}{r}6 \\
\mathrm{Ma}-\end{array}$ \\
\hline $\begin{array}{l}\quad 7 \\
\text { Nki- } \\
\text { (Ngi-) } \\
\text { Ki- } \\
\text { \&.- } \\
\text { C- }\end{array}$ & $\begin{array}{l}\quad 8 \\
\text { Nši- } \\
\text { v̌i- } \\
\text { Si- } \\
\text { Fi- }\end{array}$ & $\begin{array}{r}7 \\
\mathrm{Ki}-\end{array}$ & ${ }^{8}{ }^{-}$ & $\begin{array}{l}\quad 7 \\
\text { Nki- } \\
\text { Ki- }\end{array}$ & $\begin{array}{l}8 \\
\text { Wi- } \\
\text { Ti- }\end{array}$ \\
\hline $\begin{array}{l}\mathrm{N}_{-} \\
(\mathrm{M}-1)\end{array}$ & $\begin{array}{l}\quad 10 \\
\text { N- (M-) } \\
\text { Ny- } \\
6+10 \\
\text { Ma-n- }\end{array}$ & $\begin{array}{c}9 \\
\text { N- } \\
(\mathrm{M}-)\end{array}$ & $\begin{array}{l}10 \\
N_{-} \\
\left(M_{-}\right)\end{array}$ & $\begin{array}{l}\mathrm{N}^{9}(\mathrm{M}-) \\
\mathrm{Ni}-\end{array}$ & $\begin{array}{l}10 \\
\mathrm{~N}-(\mathrm{M}-) \\
\mathrm{Ni}-\end{array}$ \\
\hline $\begin{array}{l}11 \\
\text { Nu- } \\
\text { Nyu- } \\
\text { Ayo- } \\
(-) \\
U_{-}\end{array}$ & $\begin{array}{l}10 \\
N_{-} \\
\mathrm{NJ}^{\mathrm{j}}- \\
(\mathrm{M}-)\end{array}$ & $\begin{array}{l}11 \\
\text { Lu- } \\
\text { Nu- }\end{array}$ & $\begin{array}{l}6+11 \\
\text { Ma-1u- }\end{array}$ & $\begin{array}{c}11 \\
\text { Lu- }\end{array}$ & $\begin{array}{c}6+11 \\
\text { Ma.lu- } \\
10 \\
N-(\mathrm{M}-)\end{array}$ \\
\hline $\begin{array}{l}13 \text { Dimi } \\
\text { Ka- } \\
(\mathrm{Ki}-?)\end{array}$ & $\begin{array}{c}\text { nutive } 8 \\
\text { si- }\end{array}$ & $\begin{array}{l}13 \text { Dimi } \\
\mathrm{Ka}-\end{array}$ & $\begin{array}{r}\text { nutive } 8 \\
\text { Fi-? }\end{array}$ & $\begin{array}{l}13 \text { Dimi } \\
\text { Ka- }\end{array}$ & $\begin{array}{c}\text { nutive } 12 \\
\text { Tu- } \\
8 \\
\text { Vi- }\end{array}$ \\
\hline $\begin{array}{l}14 \\
\text { Wu- } \\
\text { U- }\end{array}$ & $\begin{array}{l}6+14 \\
\text { Ma-wu- } \\
\text { Ma-u- }\end{array}$ & $\begin{array}{l}14 \\
\text { Wu- } \\
\text { U- }\end{array}$ & $\begin{array}{l}6+14 \\
\text { Ma-wu- } \\
\text { Ma-u- }\end{array}$ & $\begin{array}{r}14 \\
\mathrm{Wu}-\end{array}$ & $\begin{array}{l}6+14 \\
\mathrm{Ma}-\mathrm{wu}-\end{array}$ \\
\hline 15 & $\begin{array}{l}\quad 6 \\
\text { Plural in } \\
\text { nouns. } \\
\text { Ma- }\end{array}$ & $\mathrm{Ka}-$ & Ma- & Ku- & $?$ \\
\hline $\begin{array}{l}16 \text { Loca } \\
\text { Wa- }\end{array}$ & tive & $\begin{array}{l}16 \text { Loca } \\
\text { Ha- }\end{array}$ & tive & $\begin{array}{l}16 \text { Loca } \\
\text { Ha- }\end{array}$ & tive \\
\hline
\end{tabular}

1 M- beforelabials. 


\section{EXAMPLES OF THE ABOVE PREFIXES APPLIED TO NOUNS.}

\begin{tabular}{|c|c|c|}
\hline $\mathrm{KT}$ - ̌̀AGA. & KI-GWENO. & KI-TAVEITA. \\
\hline 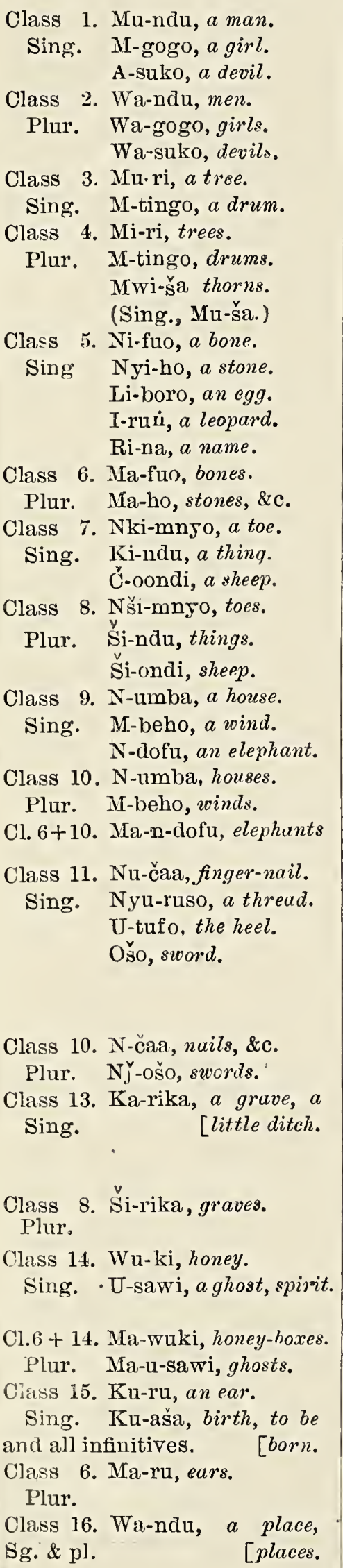 & $\begin{array}{l}\text { Class 13. Ka-mwana, a little } \\
\text { Sing. } \\
\text { [child. } \\
\text { Class 8? Fi-mwana?, little } \\
\text { Plur. } \\
\text { Cchildren. } \\
\text { Class 14. Wu-ra, a bow. } \\
\text { Sing. U-sawi, a ghost, witch- } \\
\text { craft. } \\
\text { Cl.6+ 14. Ma-wu-ra, bows. } \\
\text { Plur. Ma-u-sawi, ghosts. } \\
\text { Class 15. Ku-ru, ear. } \\
\text { Sing., \& in infinitives of verbs. } \\
\text { Class 6. Ma-ru, ears. } \\
\text { Plur. } \\
\text { Class 16. Ha-ndu, a place. } \\
\text { Sg. \& pl. }\end{array}$ & 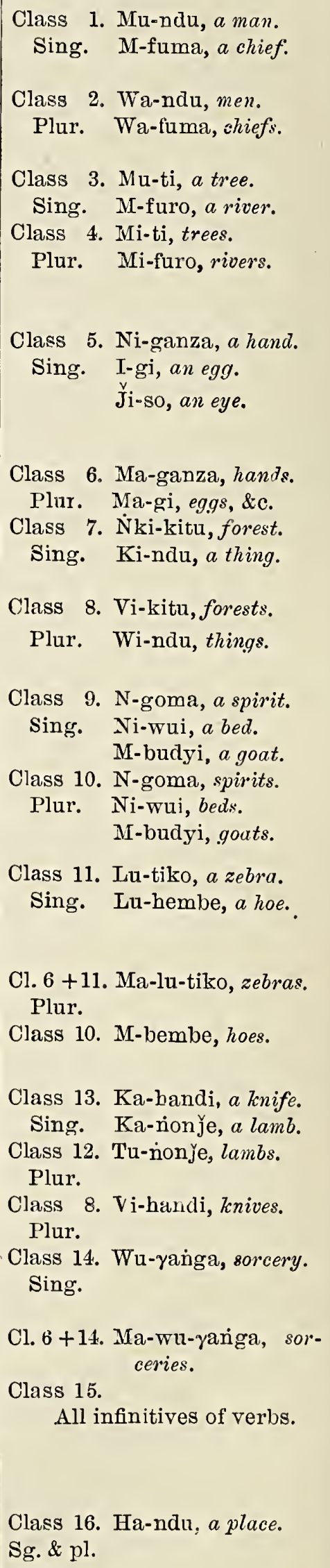 \\
\hline
\end{tabular}




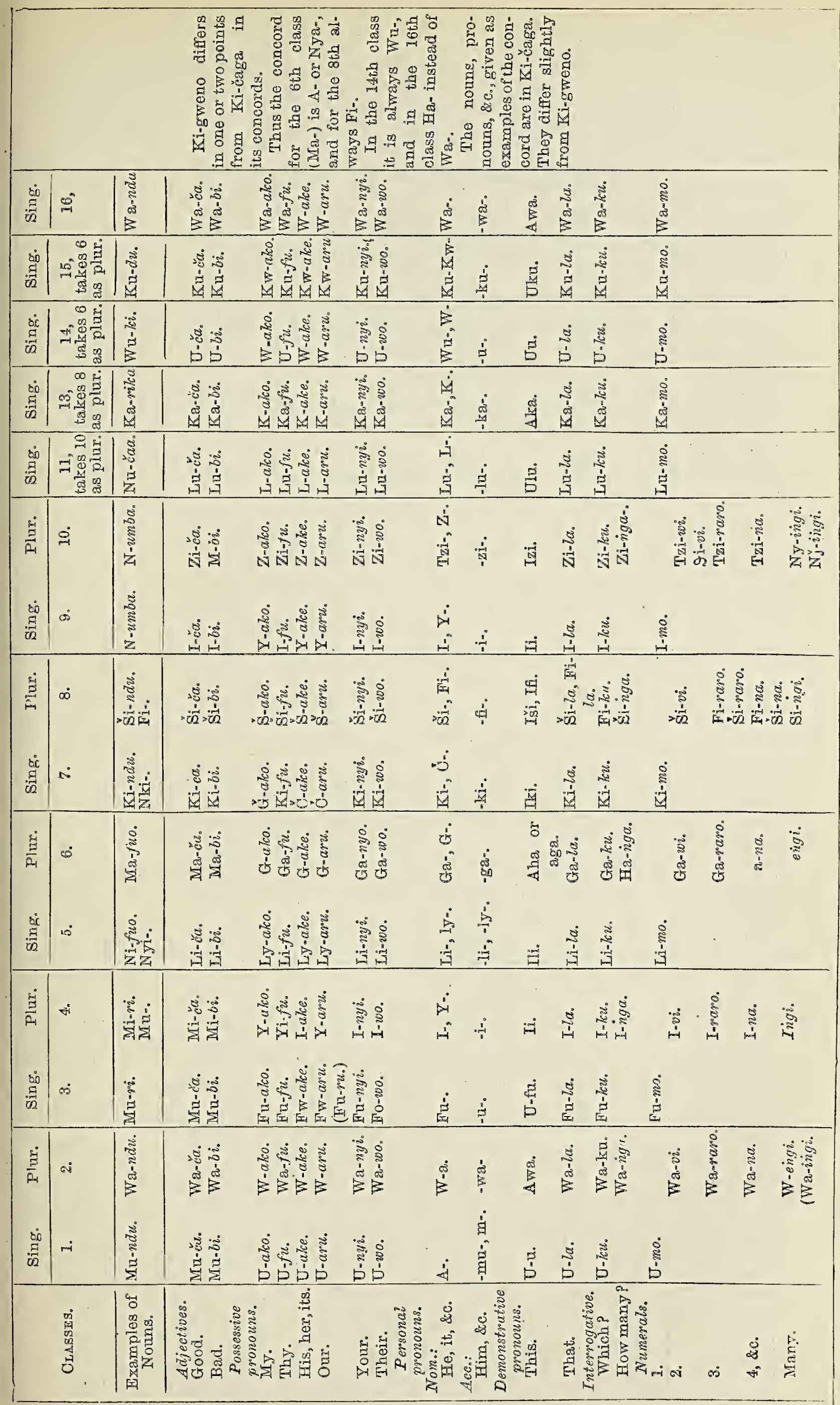




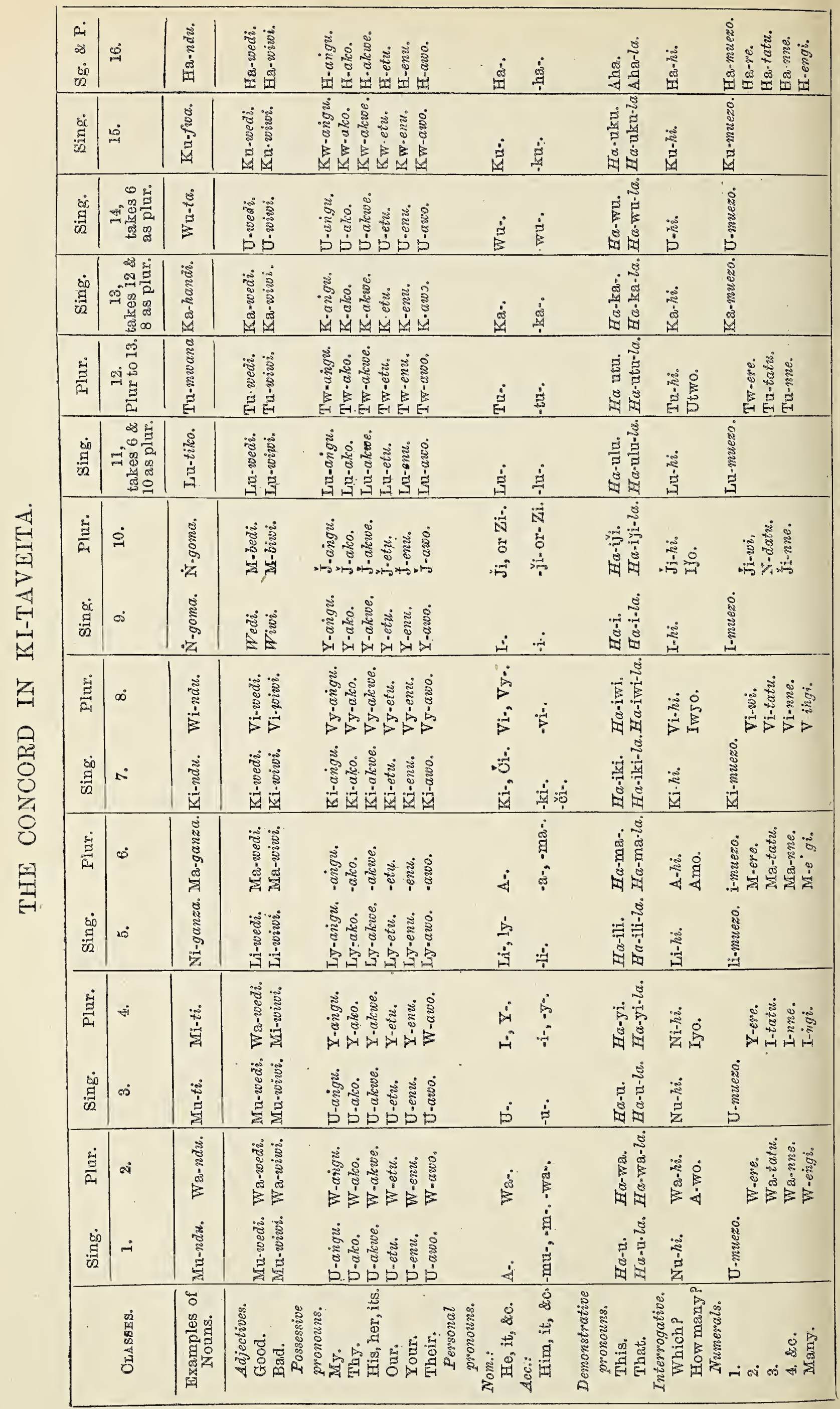




\section{APPENDIX I.}

\section{MASAI-COMPARATIVE VOCABULARY.}

Nouns.

(The particle following the noun is the article, masculine, feminine, or neuter.)

\begin{tabular}{l|l|c}
\hline \multicolumn{1}{c|}{ English. } & \multicolumn{1}{c}{ Masai. } & Latuka, Bari,1 \&c. \\
\hline Air & Giǰabe, en & Lat., Ečon (Game). \\
Animal & Jañito, ol \\
Ant & Oisusu, ol ; pl. Oisusun & \\
Antelope & Guruk, ol & \\
Anus & Galau, en ; pl. Galaun & \\
Kurum, ol & Duli, ol \\
Ape(baboon) & Goroi, ol ; pl. Goroin & \\
\hline
\end{tabular}

1 These are added for the purpose of comparison. The words given of Latuka are copied from Dr. Emin-Bey's vocabularies, published in the Zeitsehrift für Ethnologie, Berlin, 1882. Dr. Friedrich Müller is my chief authority for Bari. The following are among the languages occasionally cited in this vocabulary :-

Latuka and Bari, members of the Masai family.

Dinika.

Situk)

Šuli $\}$ Šiluk family.

Lür

Galla

Somali

Boni

Ethiopic branch of Hamitic family.

Woratta

Latuka is spoken in a somewhat small district nearly $5^{\circ} \mathrm{N}$. latitude, to the east of the White Nile.

Bari is the language of a slightly larger area on both banks of the White Nile round about Gondokoro. It borders on Latuka.

Dinka is the name given to a large group of languages spoken about the junction of the White Nile and the Bahr al Ghazal, from $7^{\circ}$ to $9^{\circ} 30^{\prime} \mathrm{N}$.

Siluk is the tongue of the negroes inhabiting the western bank of the White Nile from latitude $9^{\circ} 30^{\prime}$ to $11^{\circ} \mathrm{N}$. 


\begin{tabular}{|c|c|c|}
\hline English. & Masai. & Latuka, Bari, \&c. \\
\hline $\begin{array}{l}\text { Arm (upper) } \\
\quad \text { (lower) } \\
\text { Arrow } \\
\text { Ass } \\
\text { Axe } \\
\text { Back } \\
\text { Banana } \\
\quad \text { (fruit) } \\
\quad \text { (tree) } \\
\text { Basket } \\
\text { Bat } \\
\text { Beads } \\
\text { Beard } \\
\text { Bed } \\
\text { Bee } \\
\text { Bell } \\
\text { Bellows } \\
\text { Belly } \\
\text { Bird } \\
\text { Blood } \\
\text { Body } \\
\text { Bone }\end{array}$ & $\begin{array}{l}\text { Berangas, em } \\
\text { Dañgule, en } \\
\text { Bai, em ; pl. Ba } \\
\text { Sigiria, os ; pl. -n } \\
\text { Dolu, en; pl. -an } \\
\text { Gorion, en } \\
\text { Marigo, ôl ; pl. -n } \\
\text { Musalala, ôl ; pl. -n } \\
\text { Dam, en ; pl. -i } \\
\text { Sirírim, os ; pl. -i } \\
\text { Miunyei, ôl ; pl. -n } \\
\text { Ruat, er ; pl. -an } \\
\text { Joni, ôl ; pl. -n. } \\
\text { Ótoro, ôl } \\
\text { Piriri, ôl ; pl. -n } \\
\text { Gunei, eí ; pl. -n } \\
\text { Goš́ke, eñ ; pl. Oišua } \\
\text { Kweni, en } \\
\text { Sérige, os } \\
\text { Sesin, os } \\
\text { Oito, ôl ; pl. Oik }\end{array}$ & $\begin{array}{l}\text { Lat., Neina. } \\
\text { Bari, Nyeke } \\
\text { Lat., Avatoro. }\end{array}$ \\
\hline
\end{tabular}

Suli is really only a dialect of Siluk; and is spoken by a small tribe to the south of Latuka, in latitude $4^{\circ} \mathrm{N}$.

Lur is also only a variant of Siluk. It is the language of the north-western bank of the Albert Nyanza, in $3^{\circ} 30^{\prime}$ to $4^{\circ} \mathrm{N}$. lati. tude. (A further extension of the Siluk tongues is the speech of Kavirondo, spoken on the eastern shore of the Victoria Nyanza in $2^{\circ} \mathrm{S}$. latitude, so that this closely-related group of languages-the Siluk-extends its colonies from $11^{\circ} \mathrm{N}$. latitude to $2^{\circ} \mathrm{S}$. of the Equator.)

Galla, an important member of the Ethiopic branch of the Hamitic family of languages, is spoken with relatively little variation over an immense area, stretching from $12^{\circ} \mathrm{N}$, in Abyssinia, to $4^{\circ} \mathrm{S}$, in the vicinity of Mombasa, and up the Sabaki river to within sight of Kilima-njaro.

Somali, the dominant language of the eastern horn of Africa, closely related to Galla.

Boni is a form of Galla spoken by the Boni (Wa-boni, as the Swahilis call them), or San people, a helot race of hunters living on the banks of certain rivers in Southern Galla-land.

Woratta, an independent Ethiopic tongue, distantly a!lied to Galla, and spoken in Central Galla-land. 


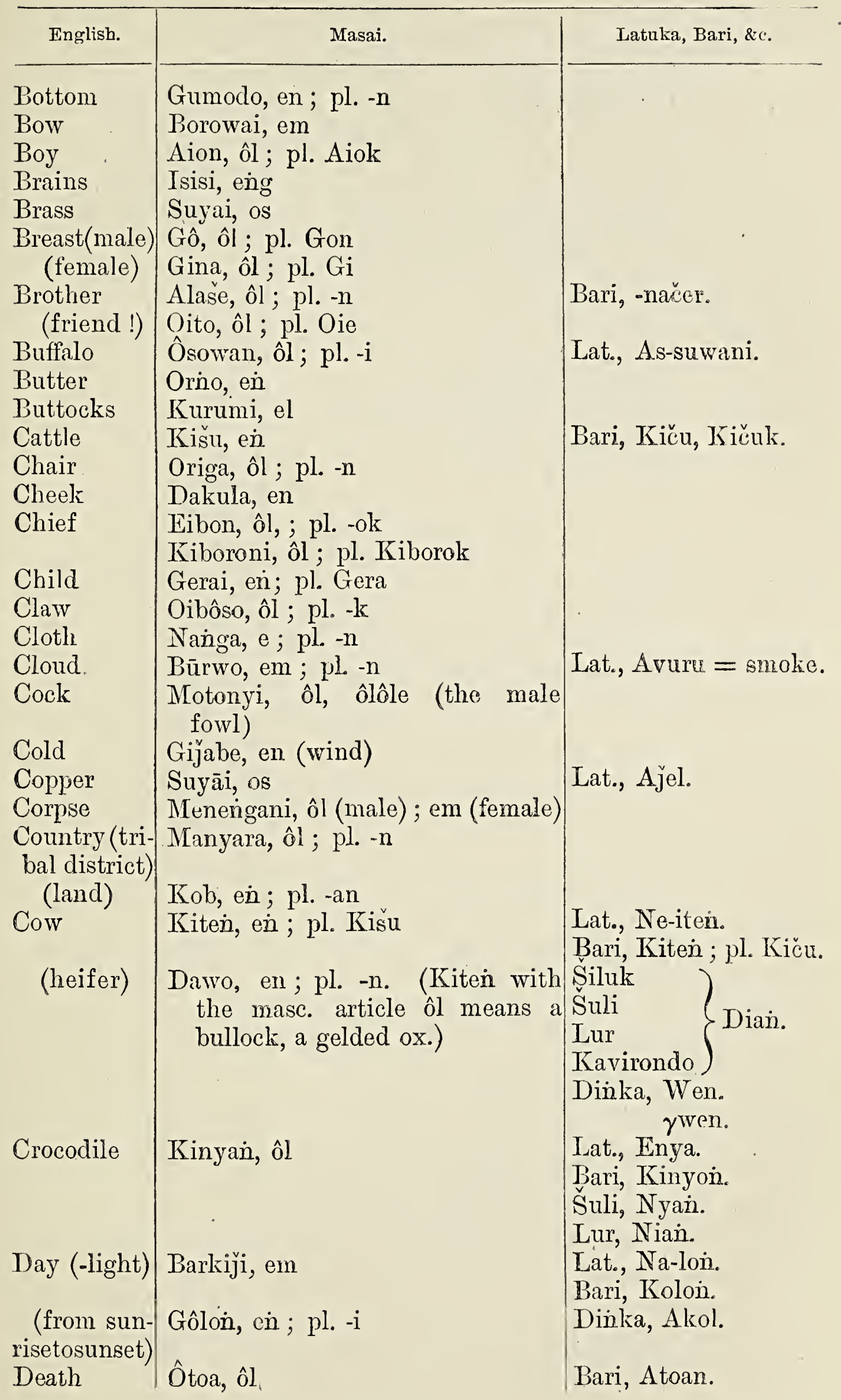




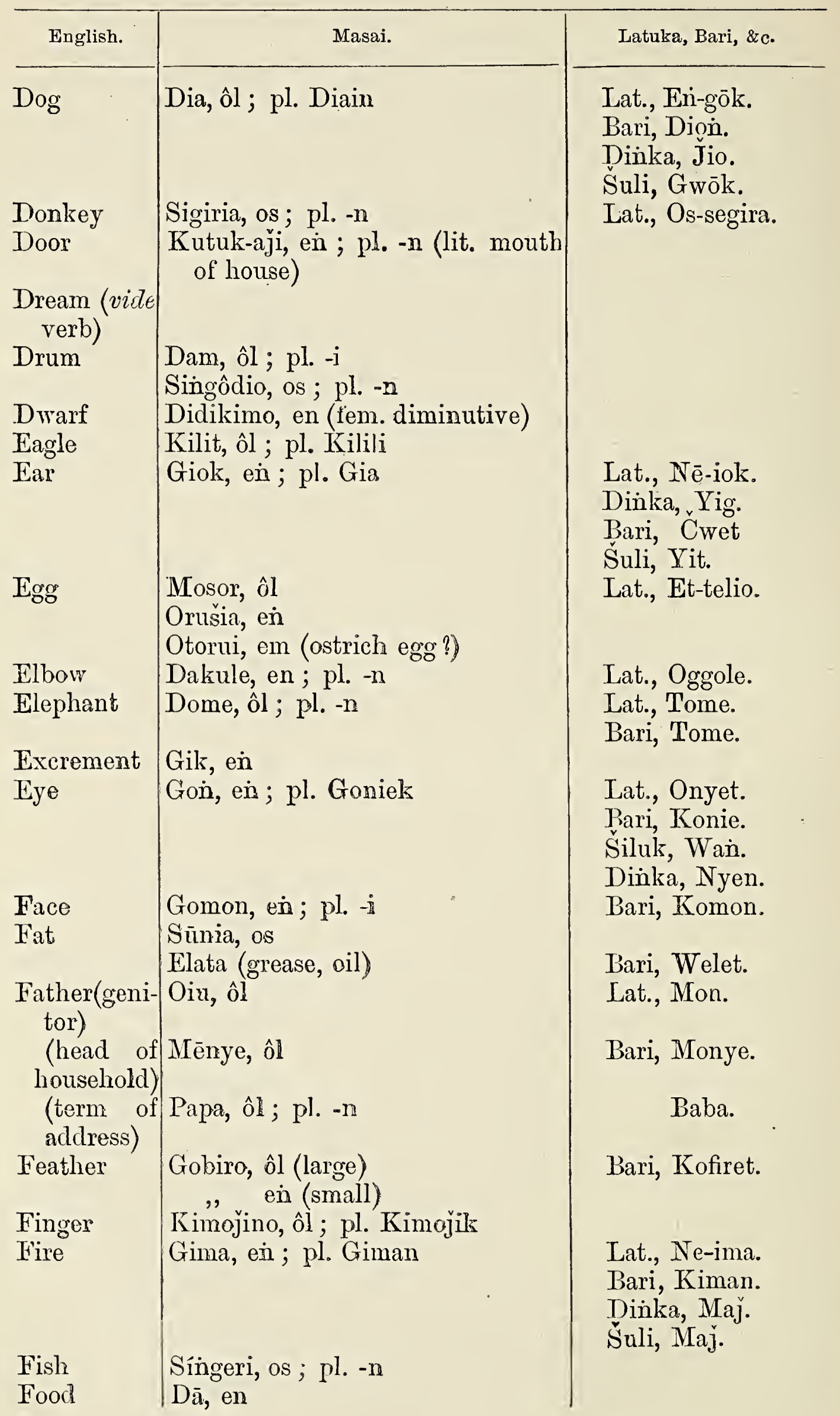




\begin{tabular}{|c|c|c|}
\hline English. & Masai. & Latuka, Bari, \&c. \\
\hline Fool & Dūrwei, ôl ; pl. Durwan & \\
\hline $\begin{array}{l}\text { Foot } \\
\text { (lower nart) }\end{array}$ & Geju, en ; pl. Gejek & \\
\hline $\begin{array}{c}\text { (lower part) } \\
\text { (sole) }\end{array}$ & $\begin{array}{l}\text { Oilēle, ol ; pl. -k } \\
\text { Dap, en }\end{array}$ & Lat., At-tiva. \\
\hline Foreigner & Omoni, ôl (lit. beggar) & \\
\hline Forest & Dim, en & Bari, Mudim. \\
\hline & Guku, en & $\begin{array}{l}\text { from Nguku, a univer- } \\
\text { sal Bantu word. } \\
\text { (Bari. Cukoro : Lat.. }\end{array}$ \\
\hline Friend & Žore, ôl : pl. -n & Nogoro, logoro.) \\
\hline & Dōruet, ôl ; pl. -a & \\
\hline $\begin{array}{l}\text { Frog } \\
\text { Fruit }\end{array}$ & Dua, en & Bari, Doke. \\
\hline $\begin{array}{l}\text { Fruit } \\
\text { Genitor }\end{array}$ & Gululwi, è & Bari, Konie. \\
\hline Genitor & $\begin{array}{l}\text { Oiu, ôl (masc.) } \\
\text { Naiu, e (fem.) (from the root -iu-) } \\
\text { Maūti, ol }\end{array}$ & \\
\hline Girl & $\begin{array}{l}\text { Mautl, ol } \\
\text { Dito, en ; pl. Doiak } \\
\text { Siañgiki, es ; pl. -n }\end{array}$ & Lat., Odueti. \\
\hline Goat & $\begin{array}{l}\text { Dare, en (common plur.) } \\
\text { Kine, ôl (he-goat); pl. Kineji. } \\
\text { Kine, en (female); pl. Kinejin }\end{array}$ & Lat., Ne-ini. \\
\hline God & Gai, en (fem., also rain, sky, \&c.) & \\
\hline $\begin{array}{l}\text { Grass } \\
\text { Grave }\end{array}$ & Kujita, ôl & \\
\hline Grave & $\begin{array}{l}\text { Gurare, en } \\
\text { Gumoto, en }\end{array}$ & Lat., Ume, el. \\
\hline Gum of teeth & Irt, en & \\
\hline & Diol, en ; pl. -n & \\
\hline $\begin{array}{l}\text { Hair (of the } \\
\text { head) } \\
\text { (body) }\end{array}$ & $\begin{array}{l}\text { Babit, ôl } \\
\text { Bon, em }\end{array}$ & \\
\hline Hand & Gaina, en ; pl. Gaik. & $\begin{array}{l}\text { Lat., Na-gas. } \\
\text { Bari, Kanin. } \\
\text { Dinka, Yien. } \\
\text { Siluk, Cinga. }\end{array}$ \\
\hline $\begin{array}{l}\text { Hare } \\
\text { Head }\end{array}$ & $\begin{array}{l}\text { Kitoǰo, ôl } \\
\text { Lugunia, ôl ; pl. -n }\end{array}$ & $\begin{array}{l}\text { Lat., Itojo. } \\
\text { Lat., Na-gu. }\end{array}$ \\
\hline Heart & Dau, ôl; pl. -n & $\begin{array}{l}\text { Bari, Kwe. } \\
\text { Lat., Et-taji. } \\
\text { Bari, Tewili. }\end{array}$ \\
\hline $\begin{array}{l}\text { Heel } \\
\text { Hill }\end{array}$ & $\begin{array}{l}\text { Dudunio, en ; pl. -n } \\
\text { Eibañgi, ôl ; pl. -n }\end{array}$ & Lat., Ebak. \\
\hline $\begin{array}{l}\text { Hippopota- } \\
\text { mus }\end{array}$ & Makau, ôl ; pl. -n & \\
\hline Hoe & J̌erembe, en & A Bantu word. \\
\hline Honey & Neišo, e & Lat., Essio. \\
\hline
\end{tabular}




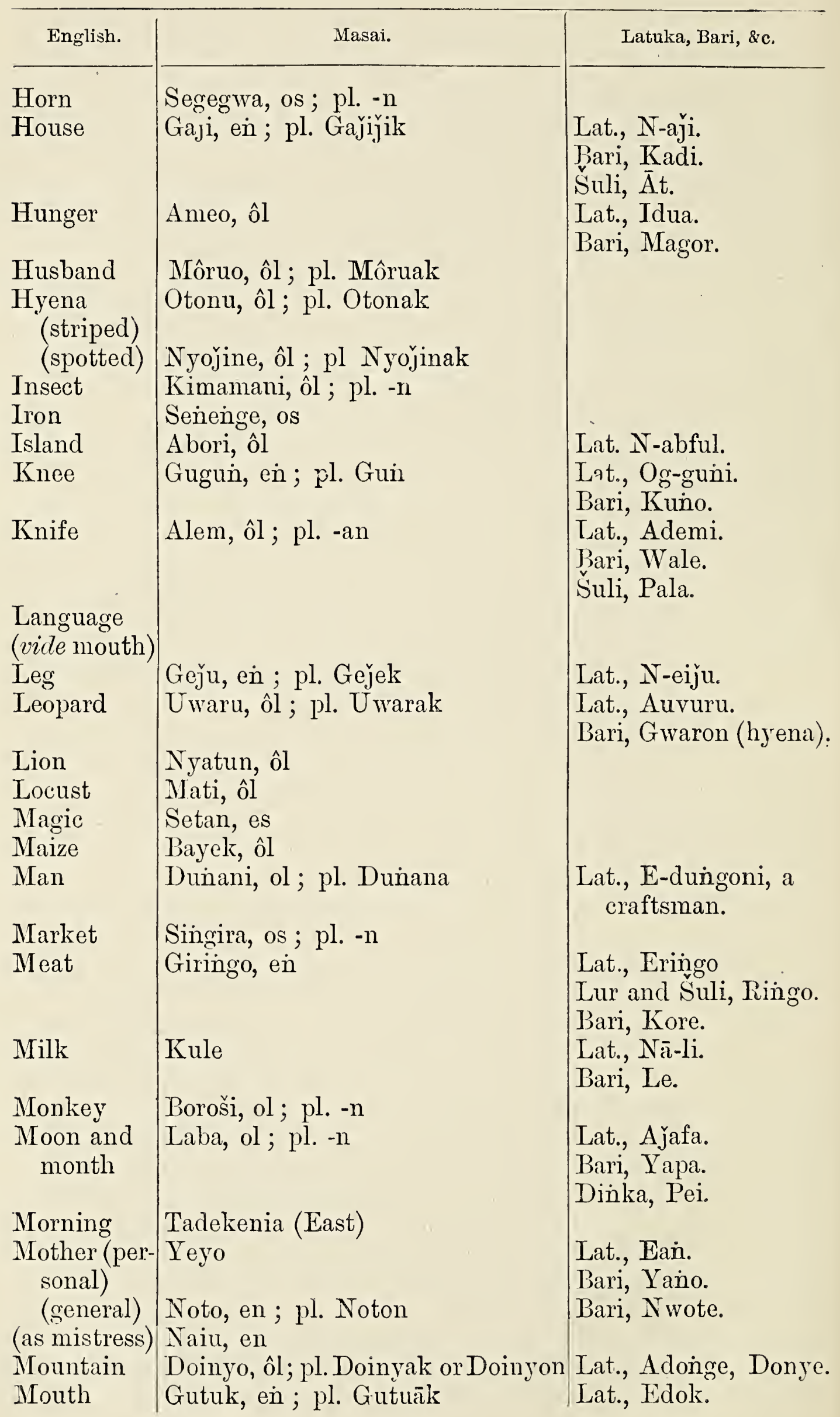




\begin{tabular}{|c|c|c|}
\hline English. & Masai. & Latuka, Bari, \&c. \\
\hline $\begin{array}{r}\text { (language, } \\
\text { door, \&c.) }\end{array}$ & Oibôso, ôl ; pl. Oibôsok & $\begin{array}{l}\text { Bari, Kotok. } \\
\text { Dinka, Vtok. } \\
\text { Šiluk } \\
\text { Suli } \\
\text { Lur Dŏga. } \\
\text { I.at., Aviela. }\end{array}$ \\
\hline Name & Garna, en ; pl. -n & $\begin{array}{l}\text { Lat., Avure. } \\
\text { Bari, Karin. } \\
\text { Dinka, Rin. }\end{array}$ \\
\hline $\begin{array}{l}\text { Navel } \\
\text { N'eck }\end{array}$ & $\begin{array}{l}\text { Surôrwa, os ; pl. -n } \\
\text { Murd, em; pl. -on }\end{array}$ & $\begin{array}{l}\text { Lat., Am-morit. } \\
\text { Bari, Murut. }\end{array}$ \\
\hline $\begin{array}{l}\text { Needle } \\
\text { Night }\end{array}$ & $\begin{array}{l}\text { Ditu, ôl ; pl. -n } \\
\text { Kewarie (darkness) }\end{array}$ & Bari, Kwaje. \\
\hline Nose fall & $\begin{array}{l}\text { Dara, en } \\
\text { Gume, ôl ; pl. -n } \\
\quad, \quad \text { en (diminutive) }\end{array}$ & 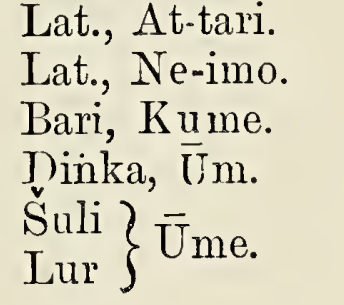 \\
\hline $\begin{array}{l}\text { Ox } \\
\text { Peace }\end{array}$ & $\begin{array}{l}\text { Mongi, ôl ; pl. Kiteni } \\
\text { Serre, es } \\
\text { Sôtwa, os }\end{array}$ & \\
\hline Penis & $\begin{array}{l}\text { Jabo, en ; pl. Jabok (the "wrapped- } \\
\text { up," "concealed," is the mean- } \\
\text { ing of this word, although, as a } \\
\text { matter of fact, the Masai men } \\
\text { are the most shamelessly in- } \\
\text { decent in the world) }\end{array}$ & \\
\hline Pig . & Bitir, ôl ; pl. -on & $\begin{array}{l}\text { Lat., Abūtir. } \\
\text { Bari, Uri. }\end{array}$ \\
\hline $\begin{array}{l}\text { Pipe } \\
\text { Place } \\
\text { Plantation } \\
\text { Pot } \\
\text { Prostitute }\end{array}$ & $\begin{array}{l}\text { Modi, ôl ; pl. -o } \\
\text { Weiji, e ; pl. -tin } \\
\text { Guruma, en ; pl. -ni } \\
\text { Modi, em; pl. -o } \\
\text { Siǰ or Sid', es }\end{array}$ & \\
\hline $\begin{array}{l}\text { Rain } \\
\text { Rat (bur- } \\
\text { rowing) }\end{array}$ & $\begin{array}{l}\text { Gai, en (Engai, in one word) } \\
\text { Uda, eng; pl. -n }\end{array}$ & Lat., Ag-gede. \\
\hline $\begin{array}{c}\text { (house) } \\
\text { Rhinoceros }\end{array}$ & $\begin{array}{l}\text { Deroni, en ; pl. Dero } \\
\text { Mūnyi, ôl }\end{array}$ & $\begin{array}{l}\text { Lat., Emoy'. } \\
\text { Bari, Mui. }\end{array}$ \\
\hline River & $\begin{array}{l}\text { Gare, en (water) } \\
\text { Gwasu, ôl }\end{array}$ & $\begin{array}{l}\text { Lat., Ari. } \\
\text { Bari, Kare. }\end{array}$ \\
\hline
\end{tabular}




\begin{tabular}{|c|c|c|}
\hline English. & Masai. & Latuka, Bari, \&cc. \\
\hline & $\begin{array}{l}\text { Mwipo, ol ; pl. -n } \\
\text { Geju, ôl (small stream) } \\
\quad, \text { en (brook) }\end{array}$ & \\
\hline $\begin{array}{l}\text { Road } \\
\text { Roof }\end{array}$ & Goitoi, en ; pl. -n. & \\
\hline $\begin{array}{l}\text { Roof } \\
\text { Saliva }\end{array}$ & Geberi, en & \\
\hline Salt & Gāmulak, en & $\begin{array}{l}\text { Lat., Amēla. } \\
\text { Bari, Kamolak. }\end{array}$ \\
\hline $\begin{array}{l}\text { Salt } \\
\text { Sand }\end{array}$ & $\begin{array}{l}\text { Munıan, em } \\
\text { Gúlukok, eñ ; pl. Gúlukwa }\end{array}$ & A Bantu word. \\
\hline $\begin{array}{l}\text { Shadow } \\
\text { Sheep }\end{array}$ & Oip, ôl ; pl. -i & \\
\hline $\begin{array}{l}\text { Sheep } \\
\text { Shield }\end{array}$ & $\begin{array}{l}\text { Ger, ôl, en ; pl. Gera } \\
\text { Oño, ôl ; pl. -n }\end{array}$ & Lat., Na-ker (fem.). \\
\hline $\begin{array}{l}\text { Shoe (leath- } \\
\text { ern sandal) }\end{array}$ & Namka, en ; pl. -n & \\
\hline Sickness & $\mathrm{Ea}$, eng (from è, to die) & \\
\hline Sister & $\begin{array}{l}\text { Ganắsi, en ; pl. Ganấsan } \\
\text { Dañgile, en (a. term of salutation) }\end{array}$ & Bari, Kiacer. \\
\hline Skin (hide) & Jôni, ôl ; pl. Jonito & Lat., Na-gon (fem.). \\
\hline $\begin{array}{l}\text { Sky } \\
\text { Slave }\end{array}$ & $\begin{array}{l}\text { Gadamba, è } \\
\text { Singa, os ; pl. -n }\end{array}$ & \\
\hline Sleep & Jô, en (Dyo) & $\begin{array}{l}\text { Lat., Ajôto. } \\
\text { Bari, Doto. }\end{array}$ \\
\hline Small-pox & Eng-ēa naibor (the white sickness) & $\begin{array}{l}\text { Suli, Nenjo. } \\
\text { Lat., Eibora. }\end{array}$ \\
\hline Smoke & Bürwo, em & $\begin{array}{l}\text { Lat., Av-vuru. } \\
\text { Bari, Kofuret, K } \\
\text { puröt. }\end{array}$ \\
\hline Snake & Asurai, ôl ; pl. Asuran & $\begin{array}{l}\text { (Lat. Am-monu. } \\
\text { Bari, Munu.) }\end{array}$ \\
\hline Snow & Seret, es & \\
\hline Snuff & $\begin{array}{l}\text { Kombau, ôl } \\
\text { Gišsuki, en }\end{array}$ & \\
\hline $\begin{array}{l}\text { Son } \\
\text { Song }\end{array}$ & $\begin{array}{l}\text { Aioni, Aiu, ôl or eng ; pl. Aiok } \\
\text { Singolio, os ; pl. -n }\end{array}$ & \\
\hline Soul & Dau, ôl & \\
\hline Spear & Bere, em; pl. -n & $\begin{array}{l}\text { Lat., Aveira. } \\
\text { Bari, Gor. }\end{array}$ \\
\hline Speech & Rorei, or & \\
\hline Spine & $\begin{array}{l}\text { Omon, el (words) } \\
\text { Giji, en }\end{array}$ & \\
\hline Spinster & Gapiak, en & \\
\hline $\begin{array}{l}\text { Star } \\
\text { Stick }\end{array}$ & Okiräi, ôl ; pl. Ôkir & \\
\hline Stick & $\begin{array}{l}\text { Sebua, os } \\
\text { Ošoke, en ; pl. Ošoa }\end{array}$ & Lat, Noke. \\
\hline Stone & Soit, os; pl. -on & $\begin{array}{l}\text { (Lat., Amoru. } \\
\text { Bari, Murufit.) }\end{array}$ \\
\hline
\end{tabular}




\begin{tabular}{|c|c|c|}
\hline English. & Masai. & Latuka, Bari, \&ce. \\
\hline String & Ene, eñg & \\
\hline Sun & Olon̉, eñg, or Goloń, en் & 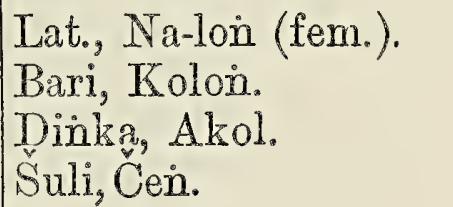 \\
\hline Tail & Kidônoi, ôl ; pl. Kidon̉o & \\
\hline Tale & Bai, ôl & \\
\hline Tear & $\begin{array}{l}\text { Gijo, ol ; pl. -n } \\
\text { Siri, es }\end{array}$ & \\
\hline Testicles & Derege, ôl ; pl. -n & \\
\hline Thief & Aburon, ôl ; pl. Aburok & \\
\hline Thing & Doki, en ; pl. Dokitin & \\
\hline Thorn & Gikwa, ôl; pl.-n & $\begin{array}{l}\text { Lat., Ikoa. } \\
\text { Bari, Kikwoti. }\end{array}$ \\
\hline Throat & $\begin{array}{l}\text { Murut, em } \\
\text { Gos, ôl }\end{array}$ & $\begin{array}{l}\text { Bari, Murut. } \\
\text { Yoåin. }\end{array}$ \\
\hline Thunder & $\begin{array}{l}\text { Gurugur, en } \\
\text { Dara, en }\end{array}$ & Lat., Ed-diri. \\
\hline Tobacco & Kumbau, ol & $\begin{array}{l}\text { (from the word Tum- } \\
\text { bako, through the } \\
\text { corrupt form Kum- } \\
\text { batu.) }\end{array}$ \\
\hline $\begin{array}{l}\text { Toe (vide } \\
\text { finger) }\end{array}$ & Kimojino, ôl & Lat., Abuge. \\
\hline Tongue & Gejep, ôl ; pl. -a & $\begin{array}{l}\text { Lat., Angaji. } \\
\text { Bari, Nedeb. } \\
\text { Dinka, Lyeb. } \\
\text { Šuli, Lieva. } \\
\text { Lur, Levve. }\end{array}$ \\
\hline Tooth & Ala, ôl; pl. $-n$ & $\begin{array}{l}\text { Lat., Ala. } \\
\text { Rari, Kele. } \\
\text { Şuli, Läk. } \\
\text { Dinka, Lēk. }\end{array}$ \\
\hline Town & $\begin{array}{l}\text { Gaì, è̀ ; pl. Ganite } \\
\text { Maniara, ôl; pl -n }\end{array}$ & \\
\hline Tree & $\begin{array}{l}\text { Jani, ol, en; pl. Janito } \\
\text { Jata, en; pl. Gek } \\
\text { Dimi, en (a number of trees, } \\
\text { forest) }\end{array}$ & $\begin{array}{l}\text { Iat., At-tana. } \\
\text { Suli, Jat. } \\
\text { Bari, Kadini. } \\
\text { Dinka, Tim. }\end{array}$ \\
\hline $\begin{array}{c}\text { Tribe (vide } \\
\text { town and } \\
\text { country) }\end{array}$ & Kob, én; Gaí, en & r \\
\hline Truth & Edede & \\
\hline Twins & Mao, el & \\
\hline Udder & Nyawo, en; pl. -n & $\begin{array}{l}\text { Lat., Anyava. } \\
\text { Bari, Panyak. }\end{array}$ \\
\hline
\end{tabular}




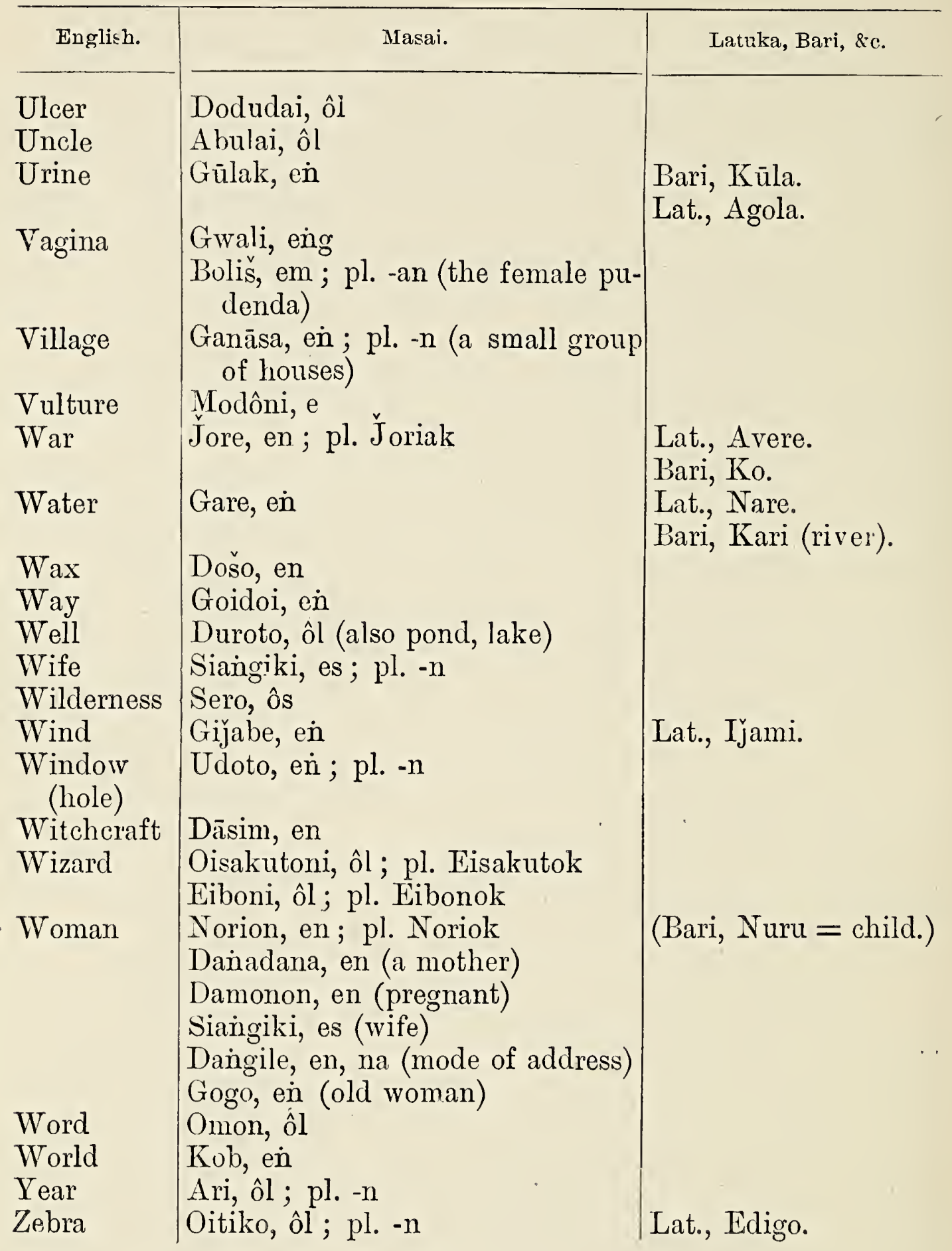

Numerals.

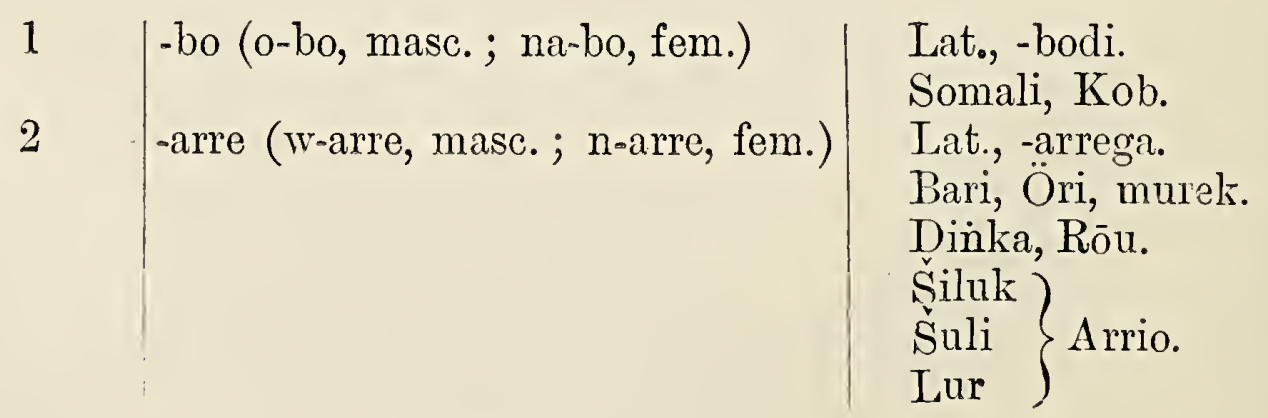




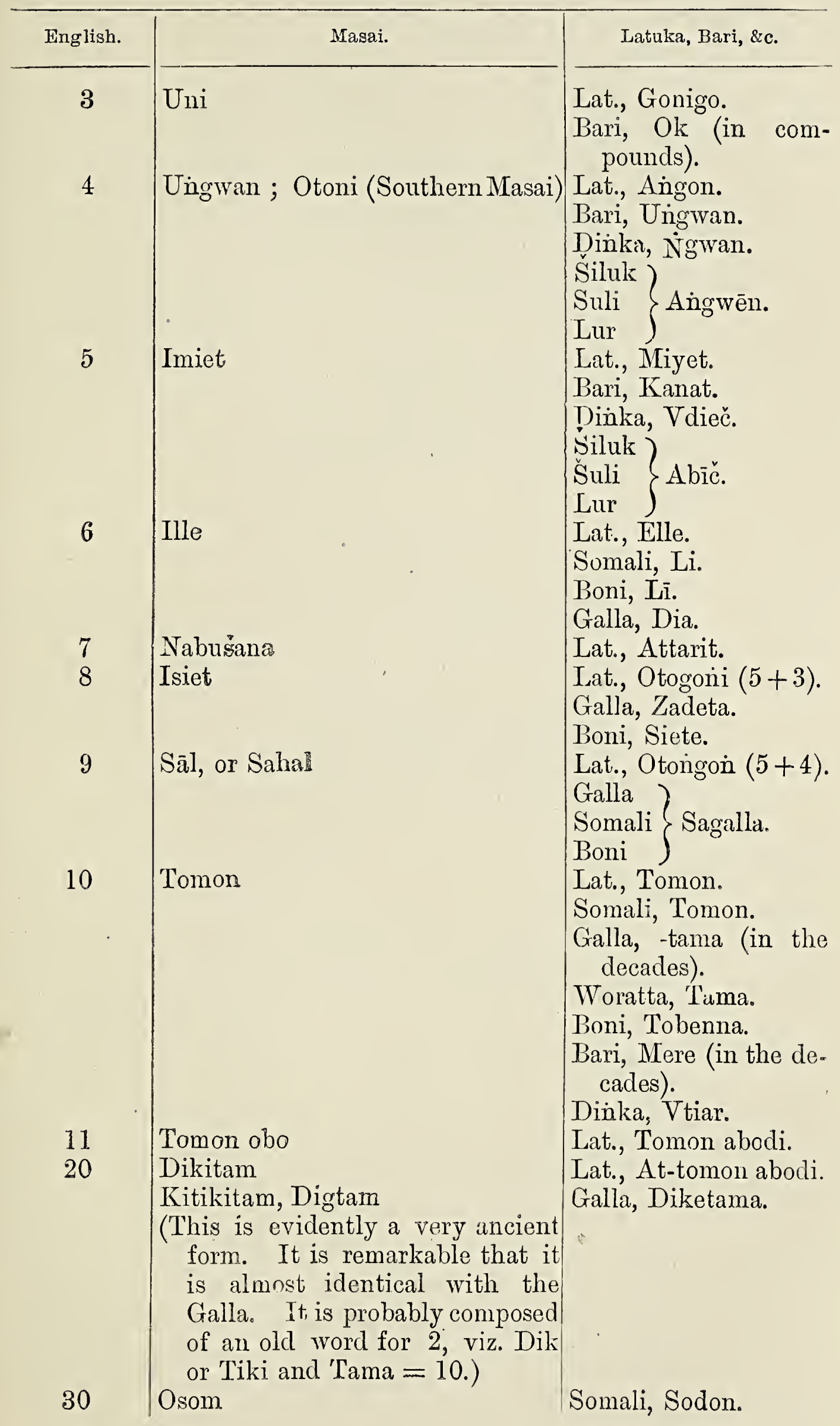




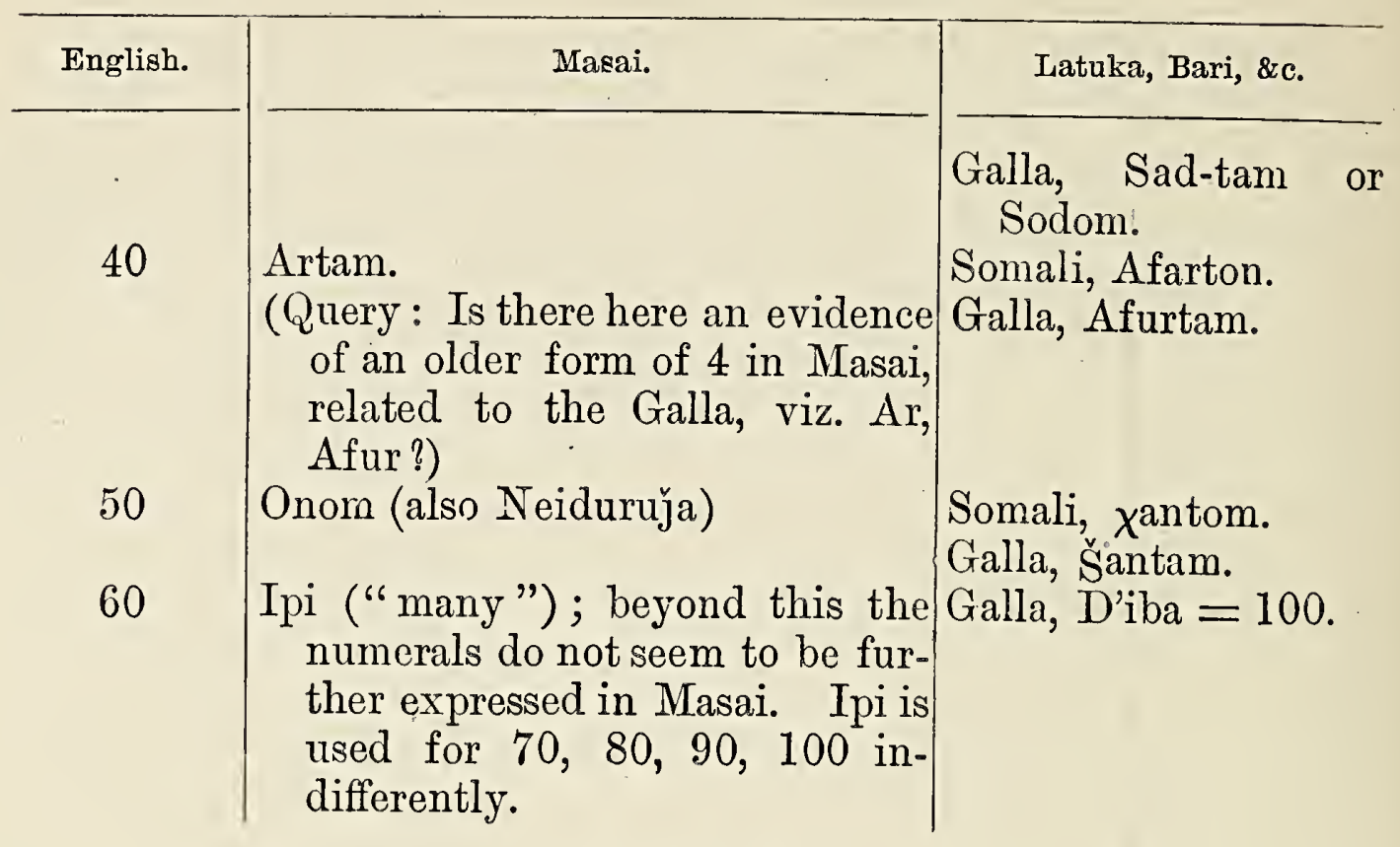

AdJECTIVES.

\begin{tabular}{|c|c|c|}
\hline All & Boki (perhaps -bo, one, pluralized) & \\
\hline Alone & -beñ, ố, na, or ei ${ }^{2}$ & Lat, Abodi (from Bo- \\
\hline Bad & $\begin{array}{l}\text { Torono; pl. Torok. (In Masai } \\
\text { the pl. of adjectives is often } \\
\text { used in the singular as an in- } \\
\text { tensitive ; thus Torok means in } \\
\text { the singular, "very bad.") }\end{array}$ & $\begin{array}{l}\text { Bari. - doro = fallen, } \\
\text { spoilt, damaged. }\end{array}$ \\
\hline $\begin{array}{l}\text { Beautiful } \\
\text { (vide good) }\end{array}$ & Sidai & \\
\hline Bitter & -dua & Lat., -dua $(\hat{o}$, na, e). \\
\hline Black & -rok & Lat., -riok. \\
\hline & Eloitwe & Bari, Elurwe. \\
\hline Bold & Ol-ènoni ; pl. Eñok, el (the manly) & Lat., Ol-le. \\
\hline Broad & Dabaš & \\
\hline $\begin{array}{l}\text { Broken } \\
\quad \text { (spoilt) }\end{array}$ & -derie & Dari, Allagaran. \\
\hline $\begin{array}{l}\text { Clean (vide } \\
\text { white) }\end{array}$ & -ibor & Lat., -ibor. \\
\hline $\begin{array}{l}\text { Clever (cun- } \\
\text { ning) }\end{array}$ & Nyen, or Nen & Bari, Kaña. \\
\hline Cruel & $-\mathrm{man}$ & \\
\hline Dead & -toa & Bari, Atoan. \\
\hline
\end{tabular}

2 Whenever the adjective is given with a hyphen preceding it, the reader must understand that it is merely the root, and that the masc., fem., or neuter particles must be prefixed according to gender. Invariable adjectives commence with a capital letter. 


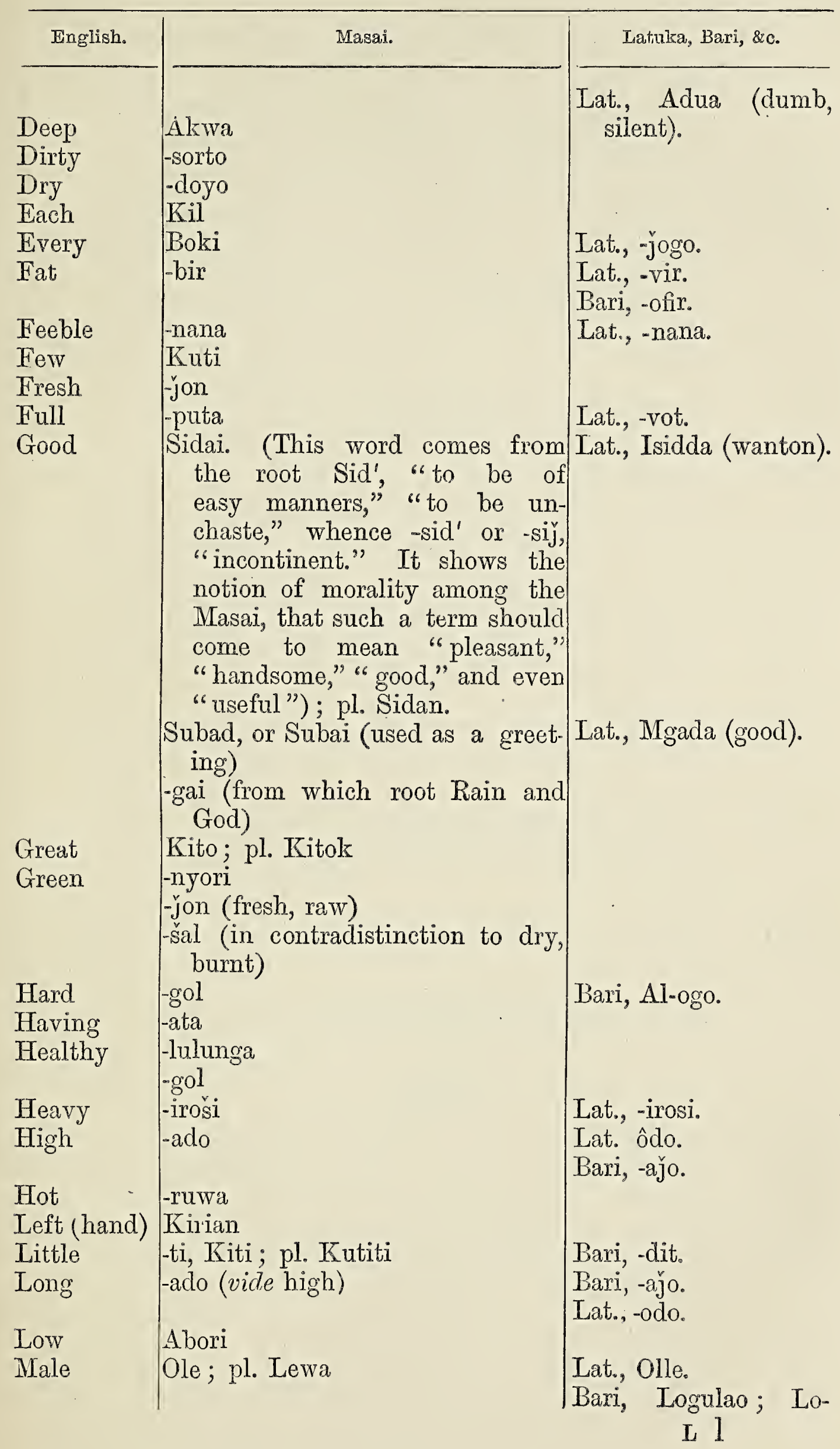




\begin{tabular}{|c|c|c|}
\hline English. & Masai. & Latuka, Bari, \&c. \\
\hline & & $\begin{array}{l}\text { (masc. article and } \\
\text { prefix). }\end{array}$ \\
\hline Many & Kumo, Kumok & \\
\hline Near & Etana & \\
\hline New & Nejuk & $\begin{array}{l}\text { Lat., An்gejuk. } \\
\text { Bari, Ludukotyo. }\end{array}$ \\
\hline Old & $\begin{array}{l}\text { Msana } \\
\text { Gogo (old in years) } \\
\text { Eos }\end{array}$ & $\begin{array}{l}\text { Lat., Meruan. } \\
\text { Bari, Madon. }\end{array}$ \\
\hline Open & Eigenu & $\begin{array}{l}\text { Lat., Ana. } \\
\text { Bari, Aña. }\end{array}$ \\
\hline Other & -kai, ôl, è ; pl. Kulikai & \\
\hline Pregnant & Emena & \\
\hline Red & -nyokie & \\
\hline Right(hand) & Olewa (vide male) & \\
\hline Ripe & Eo, Eoto & $\begin{array}{l}\text { Lat., -dori. } \\
\text { Bari, Toran. }\end{array}$ \\
\hline Short & Torop or Dorob. & Lat., Os-suk. \\
\hline Sick & -mui, Emui & Lat., Ungive. \\
\hline Spotted & -geri & Bari, Mimyen. \\
\hline Strong & - gol & \\
\hline Sweet & -melok & \\
\hline Thick & -pir & $\begin{array}{l}\text { Lat., -vir. } \\
\text { Bari, ofir. }\end{array}$ \\
\hline Thin & Rongai & \\
\hline White & $\begin{array}{l}\text {-nana (evidently connected with } \\
\text { 'Na, the feminine particle) }\end{array}$ & $\begin{array}{l}\text { Lat., Na-, fem. article. } \\
\text { Bari, Na, No, Nu, } \\
\text { fem. article. } \\
\text { Siluk, Nyano = she. } \\
\text { Lat., -ivor ; Ahon. }\end{array}$ \\
\hline
\end{tabular}

For Pronouns see preceding sketch of grammar.

\section{VERBS.}

\begin{tabular}{l|l} 
Able, be & -idim \\
Abound & -bore \\
Agree & -siate \\
Angry, to be & -goro \\
Anoint & -el \\
& \\
Arrive & -pik \\
Ask & -beki \\
Avoid & -bar \\
Avoid & -pal
\end{tabular}

Bari, Jँore = overflow.

Bari, Awaran=angry. Bari, Wel-et $=$ ointment. 


\begin{tabular}{|c|c|c|}
\hline English. & Masai. & Latuka, Bari, \&c. \\
\hline Awake & $\begin{array}{l}\text {-tobiwo } \\
\text {-inyo }\end{array}$ & \\
\hline $\mathrm{Be}$ & -ra; -ta; -ti. & \\
\hline $\begin{array}{l}\text { Bear (to give } \\
\text { birth) }\end{array}$ & -išo & \\
\hline Beat & $-a r$ & \\
\hline Begin & -angas & \\
\hline Bend & -lok & \\
\hline $\begin{array}{l}\text { Benighted, } \\
\text { to be }\end{array}$ & - muta & \\
\hline Bind & $\begin{array}{l}\text {-en, - ren, -igen (all sorts of variants } \\
\text { from the primitive root -en) }\end{array}$ & \\
\hline Bite & -on & \\
\hline Blow & $-\mathrm{yuk} ;-\mathrm{kut}$ & Bari, Kudie. \\
\hline $\begin{array}{l}\text { Boil (act.) } \\
\text { (neut.) }\end{array}$ & $\begin{array}{l}\text {-yir } \\
\text {-tokitok }\end{array}$ & Dar, suche. \\
\hline $\begin{array}{c}\text { Break (act.) } \\
\text { (neut.) }\end{array}$ & $\begin{array}{l}\text {-rek (from this root a number of } \\
\text { terms are derived, such as -derie, } \\
\text { broken, from the past tense of } \\
\text {-er }=- \text { derie, \&c.) }\end{array}$ & \\
\hline $\begin{array}{l}\text { Break open } \\
\quad, \quad \text { off }\end{array}$ & $\begin{array}{l}\text {-bol } \\
\text {-pukus }\end{array}$ & $\begin{array}{l}\text { Bari, Bel, Belen; Fu- } \\
\text { tukö. }\end{array}$ \\
\hline Breathe & -yań & Bari, Yukakin. \\
\hline Bring & - iau & Bari, Jwe. \\
\hline Build & $\begin{array}{l}\text {-itobir (from -ito, make, and -bir, } \\
\text { big, wide, \&c.) }\end{array}$ & \\
\hline Bury & $\begin{array}{l}\text {-nuk } \\
\text {-tur (to excavate) }\end{array}$ & \\
\hline Buy & -inyanu & \\
\hline Call & -ibot. & \\
\hline Carry & -nap (-rab in conjugation) & \\
\hline Catch & -iwōn; -wab & \\
\hline Choose & -ikebu; - silu & \\
\hline Circumcise & -murāt & \\
\hline Clean & -jud & $\mathrm{Bari}_{3}$ Cea. \\
\hline Climb & -jlebaki & \\
\hline Clothe (act.) & - yop & \\
\hline (pass.) & -isop & \\
\hline $\begin{array}{l}\text { Count } \\
\text { (reckon) }\end{array}$ & $\begin{array}{l}\text { an irregular verb conjugated by } \\
\text { the imperfect and independent } \\
\text { forms -lotu, -yuo, -ponu } \\
\text {-iken }\end{array}$ & $\begin{array}{l}\text { Bari, Po, Fo. } \\
\text { Bari, Ken. }\end{array}$ \\
\hline Copulate & -urbono & \\
\hline
\end{tabular}




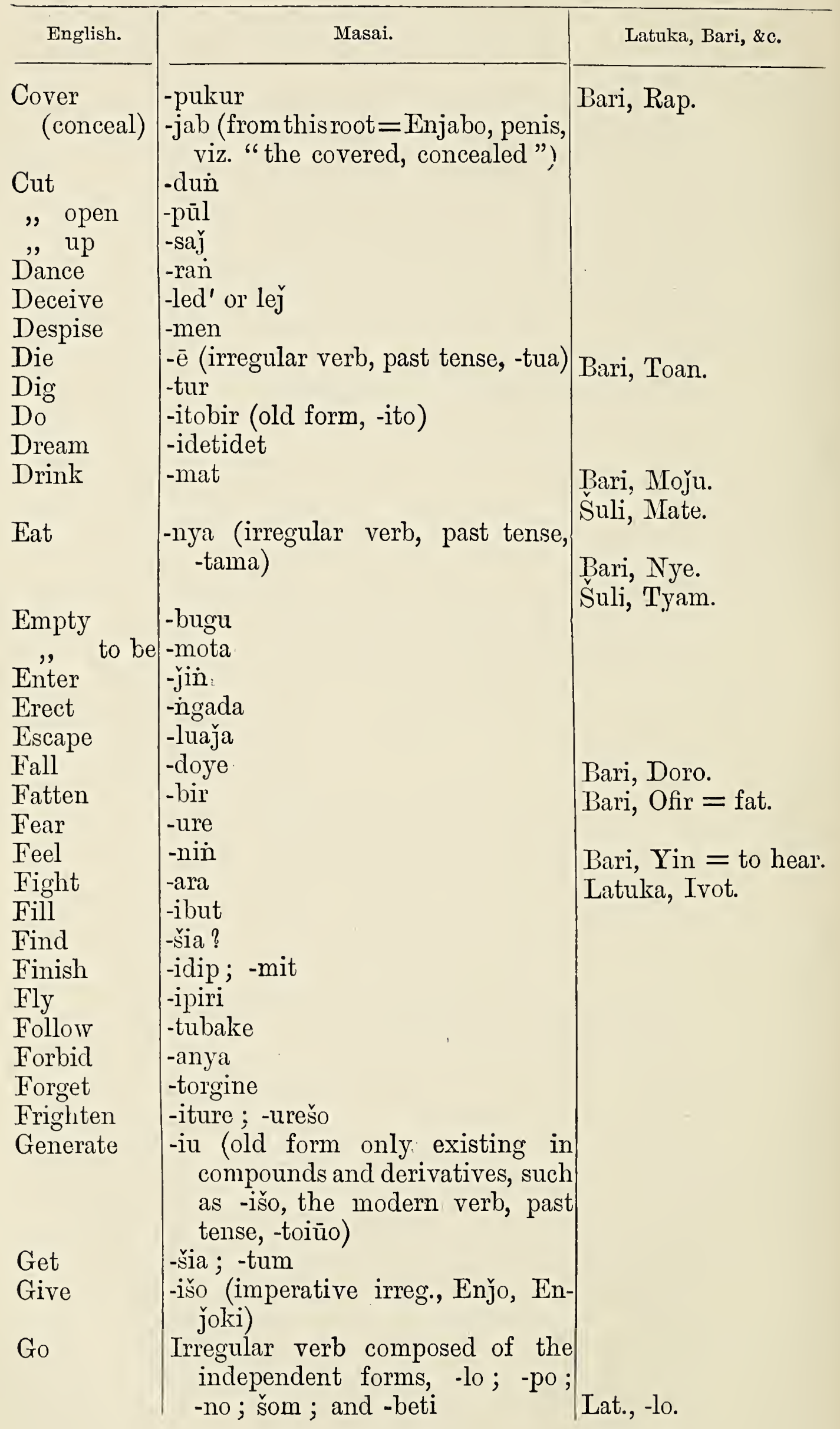




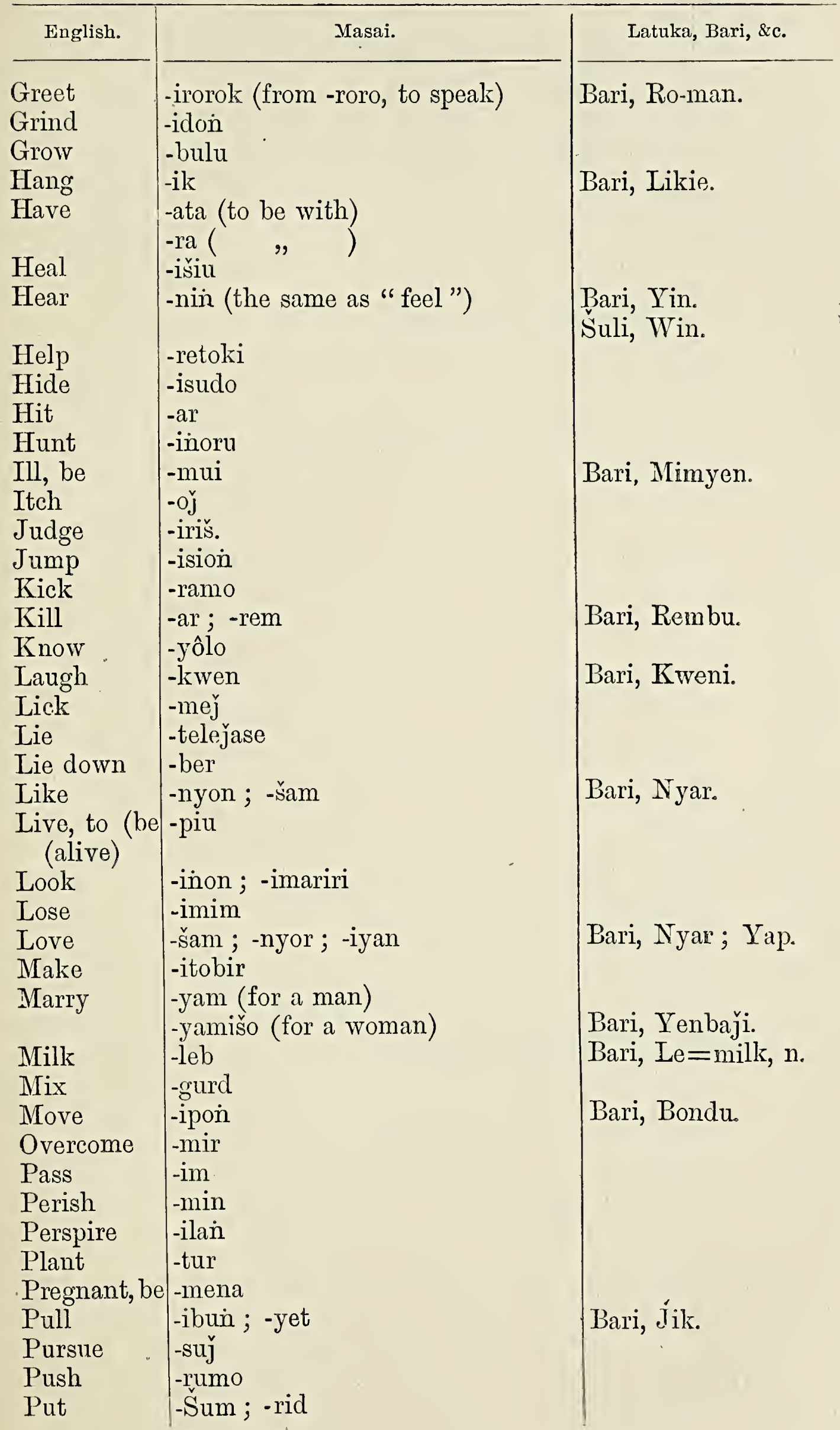




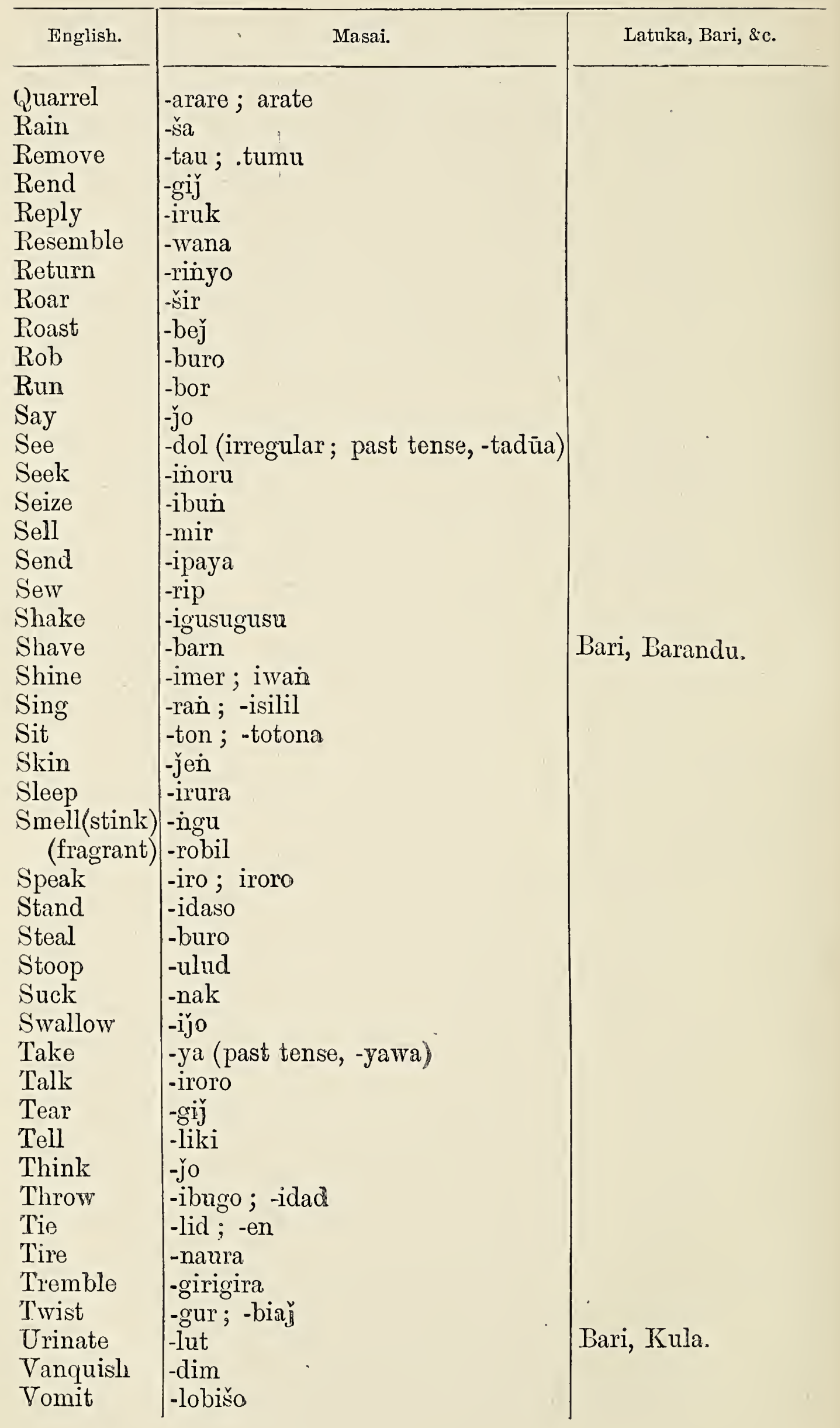




\begin{tabular}{l|l|l}
\hline \multicolumn{1}{c|}{ English. } & \multicolumn{1}{c|}{ Masai. } & Latuka, Bari, \&c. \\
\hline Want & -yau & \\
Wash & -ug; -sul & \\
Watch & -muda & \\
Weep & -išir & \\
Wipe & -yud & \\
Write & -sir & \\
Yawn & -ana &
\end{tabular}

A.dverbs, Prepositions, \&c.

\begin{tabular}{|c|c|c|}
\hline Above & Keber & Bari, Ki. \\
\hline Afterwards & Pei & \\
\hline Agair - & & \\
\hline Ago & Oba, muidi & \\
\hline Although & $\mathrm{Pe}$ & \\
\hline Always & Osake & \\
\hline $\begin{array}{l}\text { And } \\
\text { As, like }\end{array}$ & $\begin{array}{l}\text { O (masculine); na (feminine) } \\
\text { Kam }\end{array}$ & Galla, Kam. \\
\hline At & $\mathrm{Ti} ; \mathrm{T}-$ & \\
\hline Because & Amu & \\
\hline Before & Tengomom ("in the face") & \\
\hline Behind & Tolkurum & \\
\hline $\begin{array}{l}\text { Beyond } \\
\text { But (only) }\end{array}$ & Endalo & \\
\hline $\begin{array}{l}\text { But (only) } \\
\text { Down }\end{array}$ & $\begin{array}{l}\text {-ke (generally enclitic) } \\
\text { Abori }\end{array}$ & \\
\hline Either (or) & $\mathrm{aul}-\mathrm{ao}$ & \\
\hline Entirely & Boki; naleñ & \\
\hline $\begin{array}{l}\text { Far } \\
\text { First }\end{array}$ & $\begin{array}{l}\mathrm{Ba} \\
-\mathrm{bo}\end{array}$ & Bari, Fajo. \\
\hline For & $\mathrm{Ko} ; \mathrm{K}-$ & Bari, Ko. \\
\hline $\begin{array}{l}\text { From } \\
\text { Here }\end{array}$ & Ene ; tene & Bari, Ni. \\
\hline How? & $A^{v i}$ ? & \\
\hline How much? & $\begin{array}{l}\text {-muaja (prefix according to gender } \\
\text { of noun) }\end{array}$ & Bari, Moda? \\
\hline If" & Den or Ten; $\mathrm{Pe}, \mathrm{P}$ & \\
\hline $\begin{array}{l}\text { In } \\
\text { Like }\end{array}$ & $\begin{array}{l}\text {-ti ; T-, Te ; Atwa } \\
\text { Kam }\end{array}$ & Galla, Kam. \\
\hline Much & Kumo, Kumok & \\
\hline No & Emé & Galla, Me, eme. \\
\hline $\begin{array}{l}\text { Not } \\
\text { Now }\end{array}$ & $\begin{array}{l}\text { Me, M- } \\
\text { Tata }\end{array}$ & \\
\hline Of & -a (la, na, ra, according to gender) & \\
\hline $\begin{array}{l}\text { Often } \\
\text { On }\end{array}$ & Enake & \\
\hline On & Keber & Bari, Ki. \\
\hline Only & $\mathrm{Ke}$ & Barı, Gelen. \\
\hline
\end{tabular}




\begin{tabular}{|c|c|c|}
\hline English. & Masai. & Lutaku, Bari, \&c. \\
\hline $\begin{array}{l}\text { Outside } \\
\text { Quickly } \\
\text { Really } \\
\text { Slowly } \\
\text { So } \\
\text { There } \\
\text { To } \\
\text { To-day } \\
\text { To-morrow } \\
\text { Under } \\
\text { Upon } \\
\text { Very } \\
\text { Well } \\
\text { What sort? } \\
\text { What kind } \\
\text { of? } \\
\text { When? } \\
\text { Where? } \\
\text { Why? } \\
\text { With } \\
\text { Yes } \\
\text { Yesterday }\end{array}$ & $\begin{array}{l}\text { Aulo } \\
\text { Sarasara } \\
\text { Edede } \\
\text { Akidi } \\
\text { Neja } \\
\text { Ende, Tende } \\
\text { Ko, K-; Te, T- } \\
\text { Tata; Duo } \\
\text { Teisere } \\
\text { Abori } \\
\text { Keber } \\
\text { Kumo } \\
\text { Subai } \\
\text { Ka, K-? (prefixed to word) } \\
\text { Kaỹi? } \\
\text { Ajji? Akodēē? } \\
\text { Painyo? (For what?) } \\
\text { La, na, e ; ko ; pe } \\
\text { Nejata (It is so); Oi ; iba ; eo ; } \\
\text { iko, \&c. } \\
\text { Nole }\end{array}$ & $\begin{array}{l}\text { Bari, Cona. } \\
\text { Bari, Ni. } \\
\text { Lat., Agana. } \\
\text { Lat., Talelon. }\end{array}$ \\
\hline
\end{tabular}




\section{APPENDIX II.}

\section{VOCABULARIES OF KI-ČAGA, KI-GWENO, AND KI-TAVEITA.}

For explanation of Orthography, see the preceding remarks on pp. 476,477 .

The number affixed to a substantive indicates the prefix class to which it belongs, and shows how its plural may be formed. Unusual or irregular plurals are given.

Nouns.

\begin{tabular}{|c|c|c|c|}
\hline English. & Ki-čaga. & Ki-gweno, \&c. & Ki-taveita. \\
\hline \begin{tabular}{l} 
Air \\
Animal \\
Ant \\
Anus \\
Ape (baboon) \\
Arm \\
Arrow \\
Aunt \\
Axe \\
Back \\
Banaua (fruit) \\
\multicolumn{1}{c}{ (tree) }
\end{tabular} & $\begin{array}{l}\text { Mwera, } 3 \\
\text { Ikoro, } 5 \\
\text { Ṅgerero, } 9 \\
\text { Nčoin, } 9 \\
\text { Njuki, 9 } \\
\text { Kimanga, } 7 \\
\text { Mfo, } 3 \\
\text { Ndeu, } 9 \\
\text { Ndehe, } 9 \\
\text { Msamu, } 3 \\
\text { Nyimbi, mbi, } 9 \\
\text { Nifuo, } 5 \\
\text { Nčole, } 9 \\
\text { Wanda, } 16 \\
\text { Wuda, } 14 \\
\text { Mana, 1 } \\
\text { Orongo, Nyorongo, } 11 \\
\text { Moro, } 3\end{array}$ & $\begin{array}{l}\text { Niru'u, } 5 \\
\text { (Ki - teke, River } \\
\text { Congo;nku, 9) } \\
\\
\text { (Ki-kamba; Kingel- } \\
\text { wa, 7) } \\
\text { (Masai, Ol-joni) } \\
\text { Nzuki, } 9 \\
\\
\text { (Ki-kamba, Ivu, 5) } \\
\text { Ndege, } 9 \\
\text { Mbi, } 9 \\
\text { (Ki-kamba, Iwindi, 5) }\end{array}$ & $\begin{array}{l}\text { Nyama, 9. } \\
\text { Safu, 9; Maciči, } 6 . \\
\text { Itako, 5. } \\
\text { Iregēú, 5. } \\
\text { Mukono, 3. } \\
\text { Mwasa, 3. } \\
\text { Mudnēdu, } 1 . \\
\text { Isoka, 5. } \\
\text { Mwongo, 3. } \\
\text { Idiō, 5. } \\
\text { Nginda, 9. } \\
\text { Mku, 3. } \\
\text { Kitango, 7. } \\
\text { Ngongolo, } 9 . \\
\text { Mukazi, 3. } \\
\text { Kōlo, 9? } \\
\text { Niwai, 9. } \\
\text { Nyoki, 9. } \\
\text { Manga? Kisumanze,7. } \\
\text { Nkumfura, 9. } \\
\text { Kinena, 7. } \\
\text { Ndege, 9. } \\
\text { Sakame, 9. } \\
\text { Mwuri, 3. } \\
\text { Niwindi, 5. } \\
\text { Nisi, 9. } \\
\text { Wuta, 14. } \\
\text { Mwana, Kume, 1. } \\
\text { Wongo, 14. }\end{array}$ \\
\hline
\end{tabular}




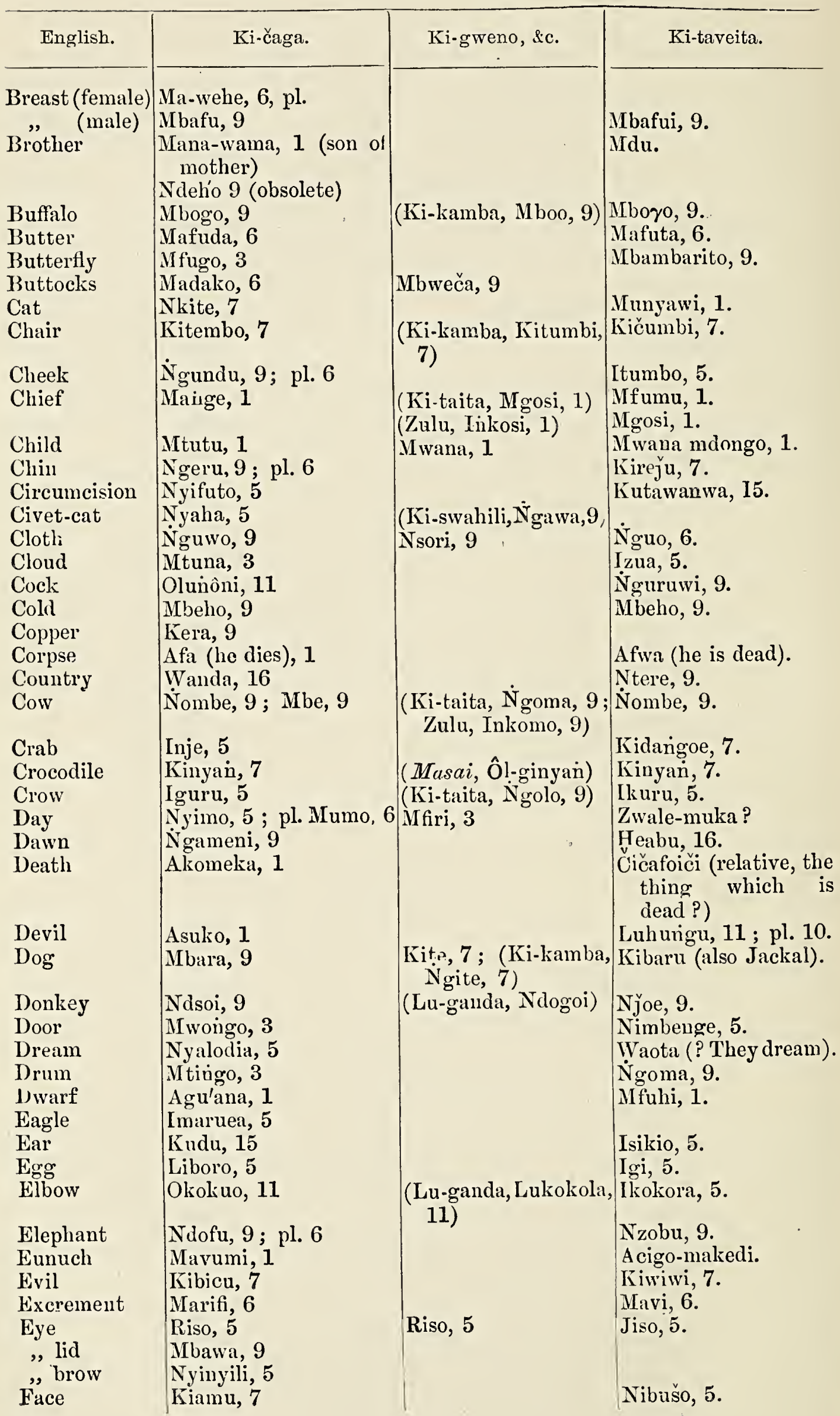




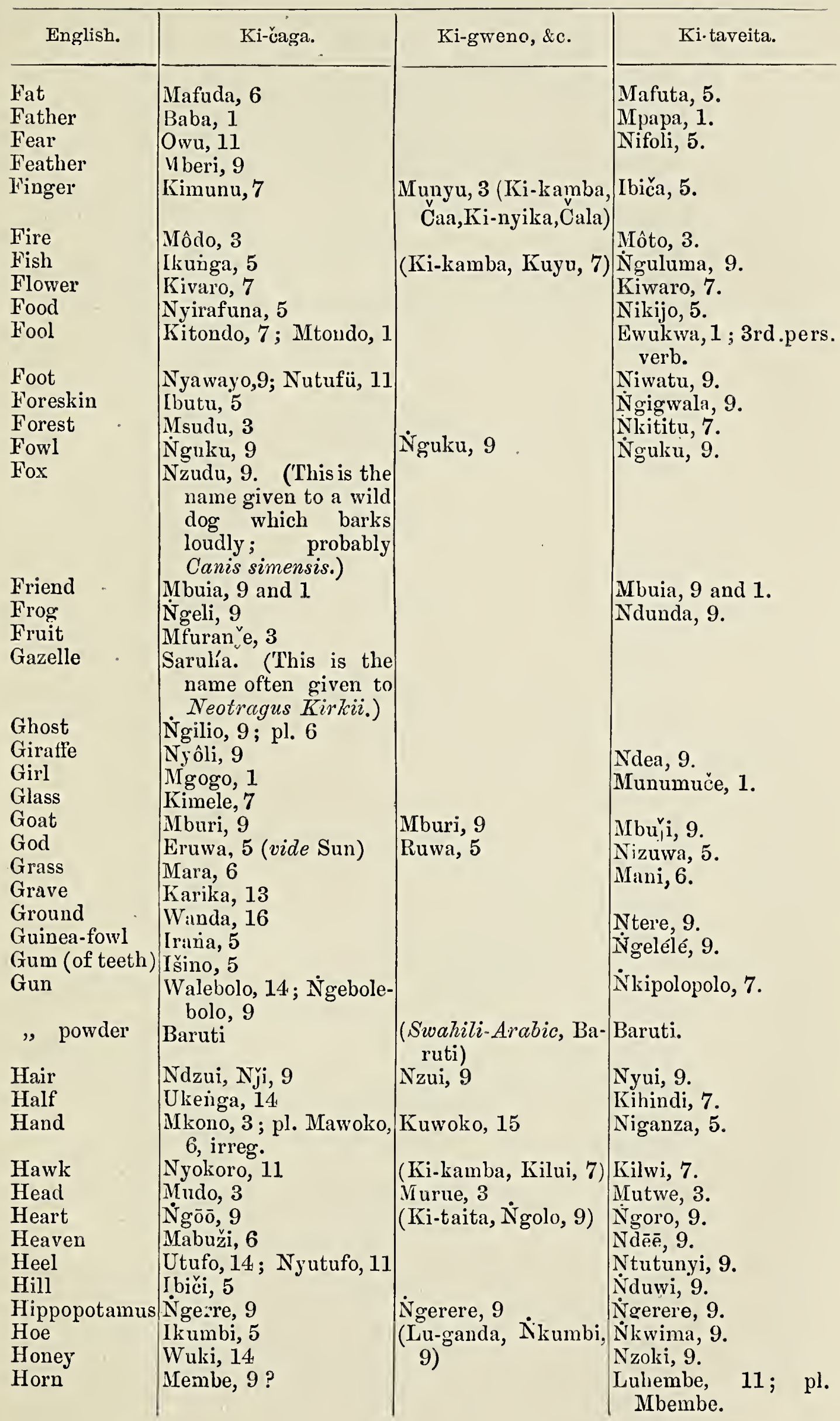




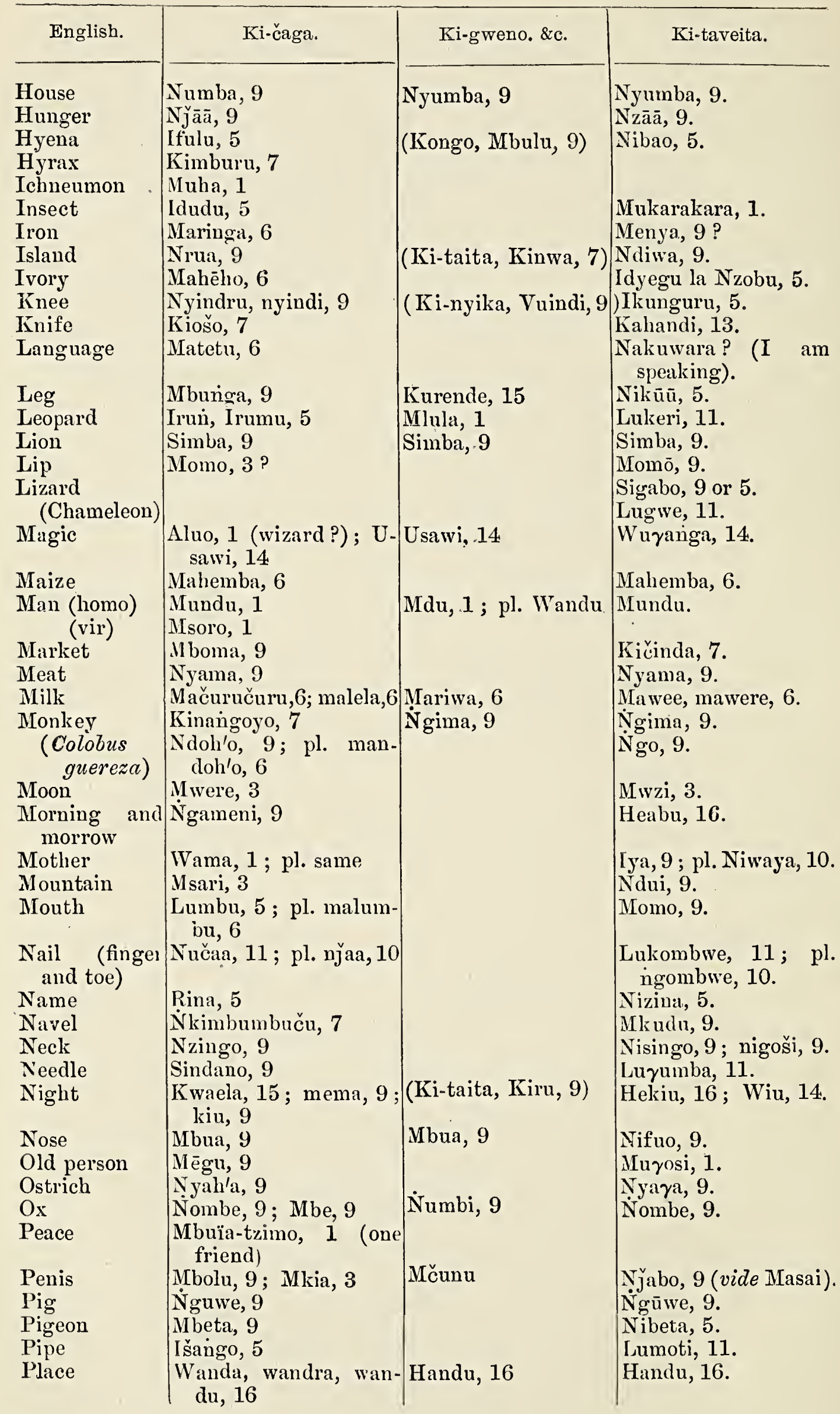




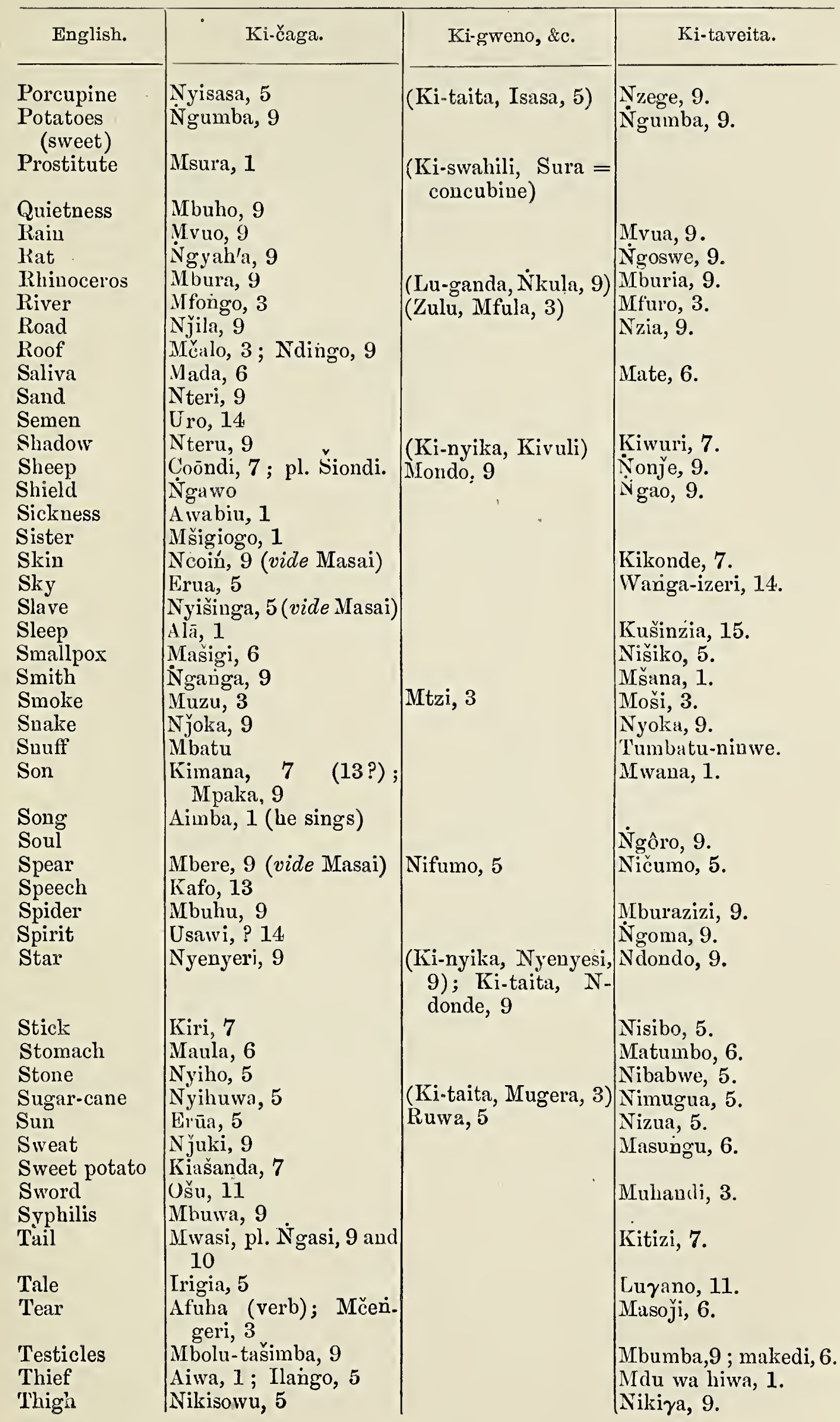




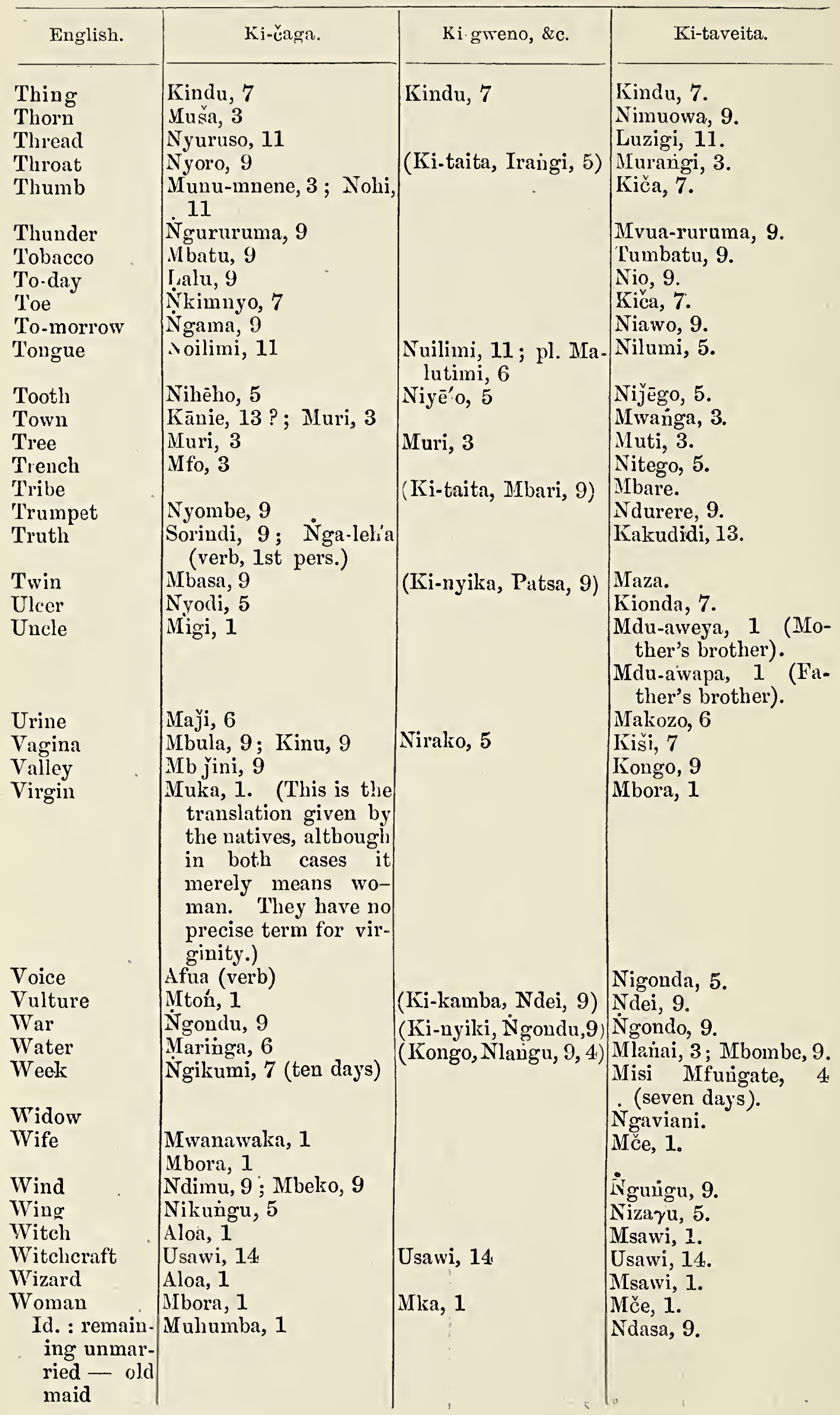




\begin{tabular}{|c|c|c|c|}
\hline English. & Ki-čaga. & Ki-gweno, \&z. & Ki-taveita. \\
\hline $\begin{array}{l}\text { Wood } \\
\text { Word } \\
\text { Year } \\
\text { Yesterday } \\
\text { Zebra }\end{array}$ & $\begin{array}{l}\text { Itteta, } 5 \\
\text { Mwaka, } 3 \\
\text { Alā-kiu (he sleeps at } \\
\text { night) } \\
\text { Nitiko, 5 (vide Masai) }\end{array}$ & Nitiko, 5 & $\begin{array}{l}\text { Lukuni, } 11 . \\
\text { Nakuwara (I speak). } \\
\text { Nisika, } 5 . \\
\text { Niwu, } 9 . \\
\text { Lutiko,11(videMasai). }\end{array}$ \\
\hline
\end{tabular}

\section{Numerals.}

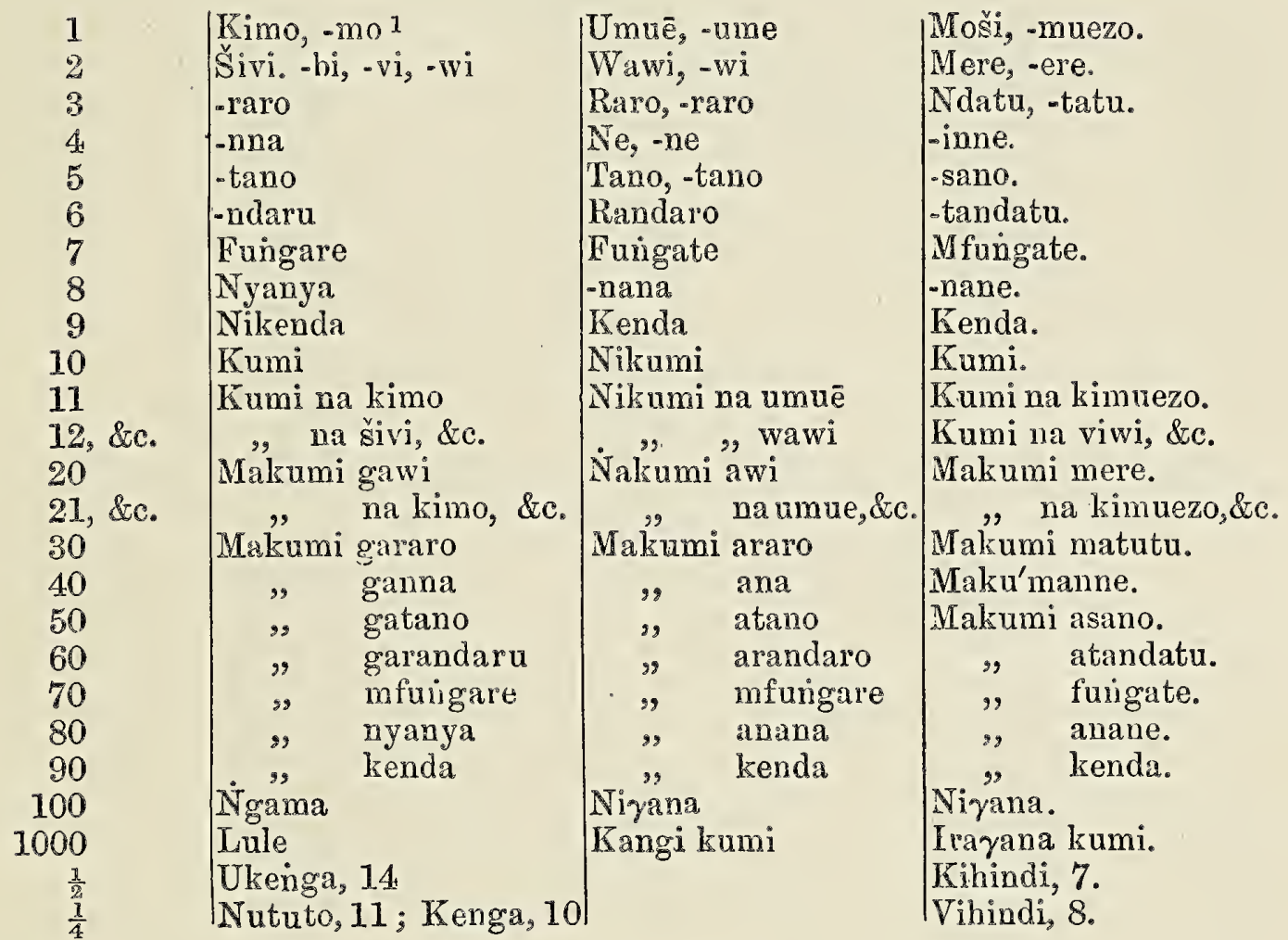

\section{ADJECTIVES.}

All

\section{Bad}

Beautiful

Bitter

Black

Blind

Blue

Bold

Broad

Castrated

$\begin{aligned} & \text {-ose (wose, yose, tzose, } \\ & \text { gose, \&c., ace } \\ & \text { to concord) } \\ & \text {-bi, -biču } \\ & \text {-ča (vide Good) } \\ & \text { Ngawawa } \\ & \text {-rusa } \\ & \text { Meso gafa (lit. eyes } \\ & \text { dead) } \\ & \text { rusa, -rusu } \\ & \text { Auko-marima } \\ & \text { Nigirinji } \\ & \text { Ifutu? }\end{aligned} \mid$ (Ki-nyika, nyiru)

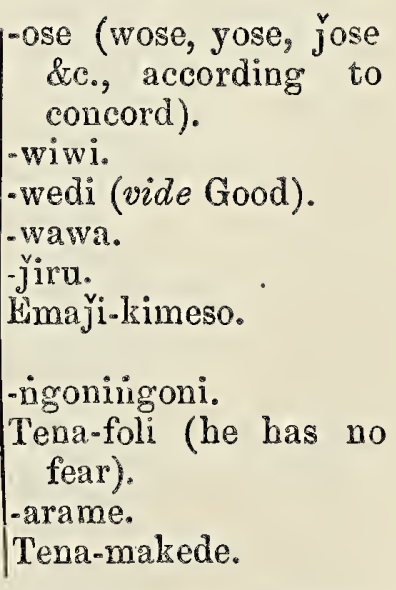

1 The blanks before the root indicate that the concord prefix is to be inserted according to rule. 


\begin{tabular}{|c|c|c|c|}
\hline English. & Ki-čaga. & Ki-gweno, \&c. & Ki-taveita. \\
\hline Cheap & $\underset{\text { him) }}{\text { Nga-m-lemba (I cheat }}$ & & \\
\hline Clean & Yačia & & -azera. \\
\hline Clever,cunning & Nyauiana & & -čēē. \\
\hline Dead & $-f a$ & & -fwa. \\
\hline Deaf & Maru-afa (ears dead) & & \\
\hline Dear & Yabičuo & & \\
\hline Drunken & Anaigo & & Enige; Aengeya. \\
\hline Dry & Nyosa & (Ki-taita, Oma) & $\begin{array}{l}\text { Haoma (refers to } \\
\text { class 16). }\end{array}$ \\
\hline Dumb & Nyaši & & -guguma. \\
\hline Every & Ilibaua (verbal form) & & Killa. \\
\hline Fat & Nyaúana muno & & -ebandi. \\
\hline Female & -ka & & -če. \\
\hline Few & -tutu & & -doligu. \\
\hline Fierce & -senge & & -ekahe. \\
\hline Filthy & -hõyo & & -enaikwe. \\
\hline $\begin{array}{l}\text { Fine (narrow, } \\
\text { (delicate) }\end{array}$ & -suse & & -zexi. \\
\hline Foreign & -wanja & & -geni. \\
\hline Free & & & -huji. \\
\hline Fresh (raw) & -hièvo & & -bise. \\
\hline Gentle & -rigula & & \\
\hline Good & -ca & & -wedi. \\
\hline Great & $\begin{array}{l}\text {-íaneji; anana } \\
\text { Maraula }\end{array}$ & & $\begin{array}{l}\text {-baha. } \\
\text {-bisi }\end{array}$ \\
\hline Green & Maranja & & -bisi. \\
\hline Handsome & -ačia & & -wedi. \\
\hline $\begin{array}{l}\text { Happy } \\
\text { Hard }\end{array}$ & $\begin{array}{l}\text {-huri } \\
\text {-mumu-mumu }\end{array}$ & ' & $\begin{array}{l}\text { Anara. } \\
\text {-šini ; -clindie. }\end{array}$ \\
\hline $\begin{array}{l}\text { Having, pos- } \\
\text { sessing }\end{array}$ & - enye & & -enye. \\
\hline Healthy & Megu ? & & -dindie. \\
\hline Heavy & -gunja & & -eme. \\
\hline High & -sali & & -eza. \\
\hline Hot & Mfoilha & & -nwe; Moto. \\
\hline Idle & -kiwa & & -doko. \\
\hline Jealous & Nya-ena & & \\
\hline Left (hand) & Kumoso & & Kumoso. \\
\hline Little & -boma & & -dongo. \\
\hline Isong & -leše & & -weza. \\
\hline Mad & -suko; nya-suko & & -ewukwa. \\
\hline Male & -soro ; Mbunga & & - ume. \\
\hline Many & -ingi & & -ingi. \\
\hline Mean & -ehē & & -edindie. \\
\hline Naked & Ntondo (simplicity) & & -ehotuho. \\
\hline Narrow & -sari & & -sisiri. \\
\hline New & Nzaru & & -sa. \\
\hline Old & $-\mathrm{k} \overrightarrow{\mathrm{u}}$ & & -asakāā. \\
\hline Open & -ruwo & & \\
\hline Other & Nyumu & & -ngi. \\
\hline Plenty & Ntamu & & \\
\hline Poor & -roko & & -kiwa. \\
\hline Quick & -igula & & \\
\hline Quiet & -rarere; Tzirarere & & -hoye. \\
\hline Raw & -bisi & & -bisi. \\
\hline Red & $\begin{array}{c}\text { Nare-nare ; nya-rera } \\
\text { (copper-coloured) }\end{array} \mid$ & & \\
\hline
\end{tabular}




\begin{tabular}{|c|c|c|c|}
\hline English. & Ki.čaga. & Ki-gweno, \&c. & Ki-taveita. \\
\hline $\begin{array}{l}\text { Rich } \\
\text { Right (hand) } \\
\text { Ripe } \\
\text { Rotten } \\
\text { Same } \\
\text { Short } \\
\text { Sick } \\
\text { Sour } \\
\text { Strong } \\
\text { Sweet } \\
\text { Thick } \\
\text { Thin } \\
\text { Weak } \\
\text { Weary } \\
\text { White } \\
\text { Young }\end{array}$ & $\begin{array}{l}\text { Njamu } \\
\text { Kulyo } \\
\text { Nyenyele; -lali } \\
\text {-biču } \\
\text { - hiana } \\
\text { - simba } \\
\text {-goro } \\
\text { - wawa } \\
\text { - - ana } \\
\text { - cora } \\
\text { - simba } \\
\text { - suse } \\
\text { - ngula } \\
\text { - coka } \\
\text { - bố }{ }^{2} \text {; Pia } \\
\text {-gogo. }\end{array}$ & $\therefore$ & $\begin{array}{l}\text {-fumwa (to be chief), } \\
\text { Kume (lit., "male"). } \\
\text {-wibwa. } \\
\text {-fwanane. } \\
\text {-fuhi. } \\
\text {-ewajua. } \\
\text {-čikie. } \\
\text {-ečêē. } \\
\text {-enona. } \\
\text {-ebandie; Wuruti. } \\
\text {-sisiri. } \\
\text {-remwa. } \\
\text {-dyewa. } \\
\text {-doigo. }\end{array}$ \\
\hline
\end{tabular}

\section{Prionouns.}

I

'Thou

He, she, \&c.

We

You

They

$\mathrm{Me}$

'Thee

$\mathrm{Him}$

Us

You

Them

Mine

Thine

$\mathrm{His}$

Our

Your

Their

Nyinyi ; nji-, ñg-

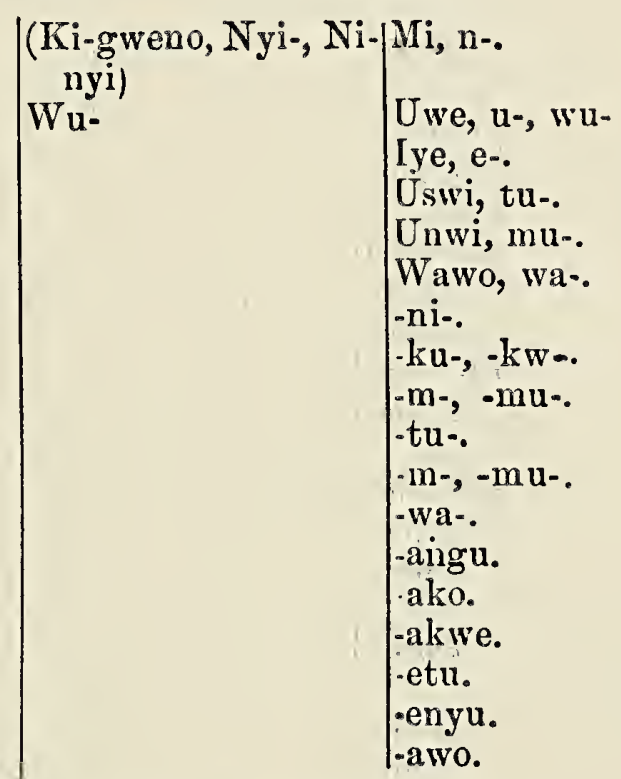

(Fur Demonstratives, \&c., see Tables of Concords.)

\begin{tabular}{l|l} 
Who? & Nkica \\
Whom & -iki-? \\
What? & Kiki? \\
Whose? & -ile?
\end{tabular}

$\mid \begin{aligned} & \text { Niani? } \\ & \text {-ani-? } \\ & \text { Kini? } \\ & \text {-kweni? }\end{aligned}$

(For which, \&c., vide Tables of Concords.)

2 From this root is derived Kibô (whiteness), the name of Kilima-njaro's lighest peak. 
VERBS. ${ }^{3}$

\begin{tabular}{|c|c|c|c|}
\hline English. & Ki-čaga. & Ki-gweno, \&c. & Ki-taveita. \\
\hline $\begin{array}{l}\text { Able (be) } \\
\text { Adorn } \\
\text { Adultery (com- } \\
\text { mit) } \\
\text { Agree (b) } \\
\text { Angry (be) } \\
\text { Answer } \\
\text { Arrive } \\
\text { Ask } \\
\text { Awake } \\
\text { Bake (pottery) } \\
\text { Bark } \\
\text { Bathe } \\
\text { Be } \\
\text { Beat } \\
\text { Begin } \\
\text { Believe } \\
\text { Bewitch } \\
\text { Bite } \\
\text { Blow } \\
\text { Boil } \\
\text { Born (be) } \\
\text { Break } \\
\text { Breatbe } \\
\text { Breed } \\
\text { Bring } \\
\text { Build } \\
\text { Burn } \\
\text { Burst } \\
\text { Bury } \\
\text { Buy } \\
\text { Call } \\
\text { Can } \\
\text { Carry } \\
\text { Carve (sculp- } \\
\text { ture) } \\
\text { Castrate } \\
\text { Catch } \\
\text { Change } \\
\text { Chase } \\
\text { Cheat } \\
\text { Choose } \\
\text { Circumcise } \\
\text { Clean } \\
\text { Clinb } \\
\text { Come } \\
\text { Cook } \\
\text { Copulate } \\
\text { Comb }\end{array}$ & 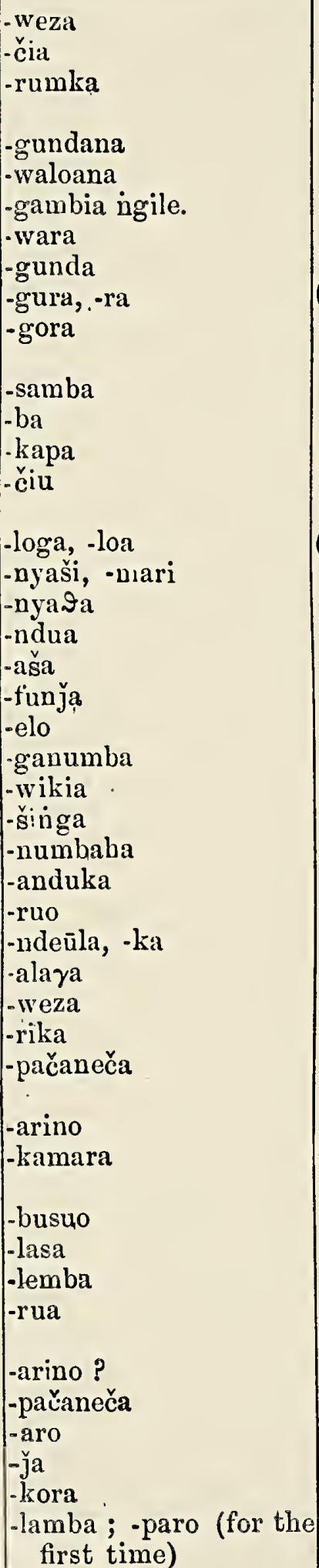 & $\begin{array}{c}\text { (Ki-swahili, -kamata; } \\
\text { Ki-nyika, -kuira) }\end{array}$ & 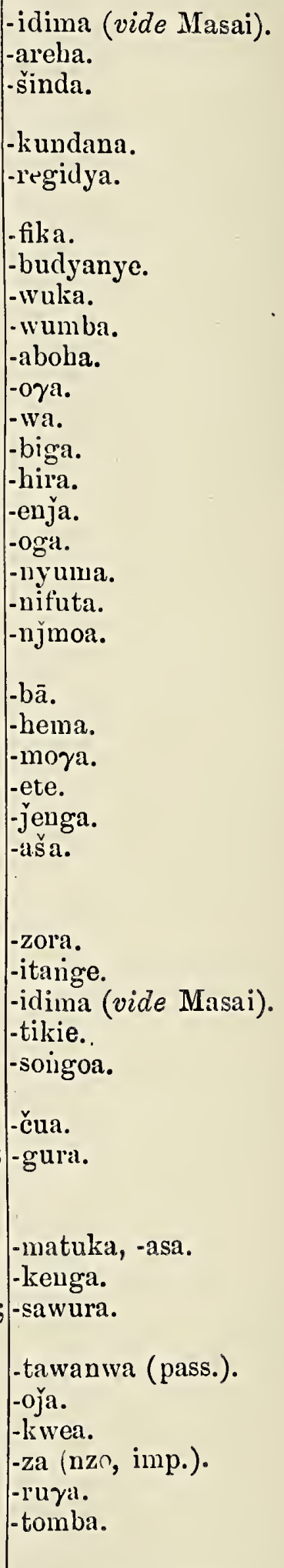 \\
\hline
\end{tabular}

3 Only the root of the verbs is given. The prefrx in the infinitive answering to our "to"" is Ku-, No. 15. 


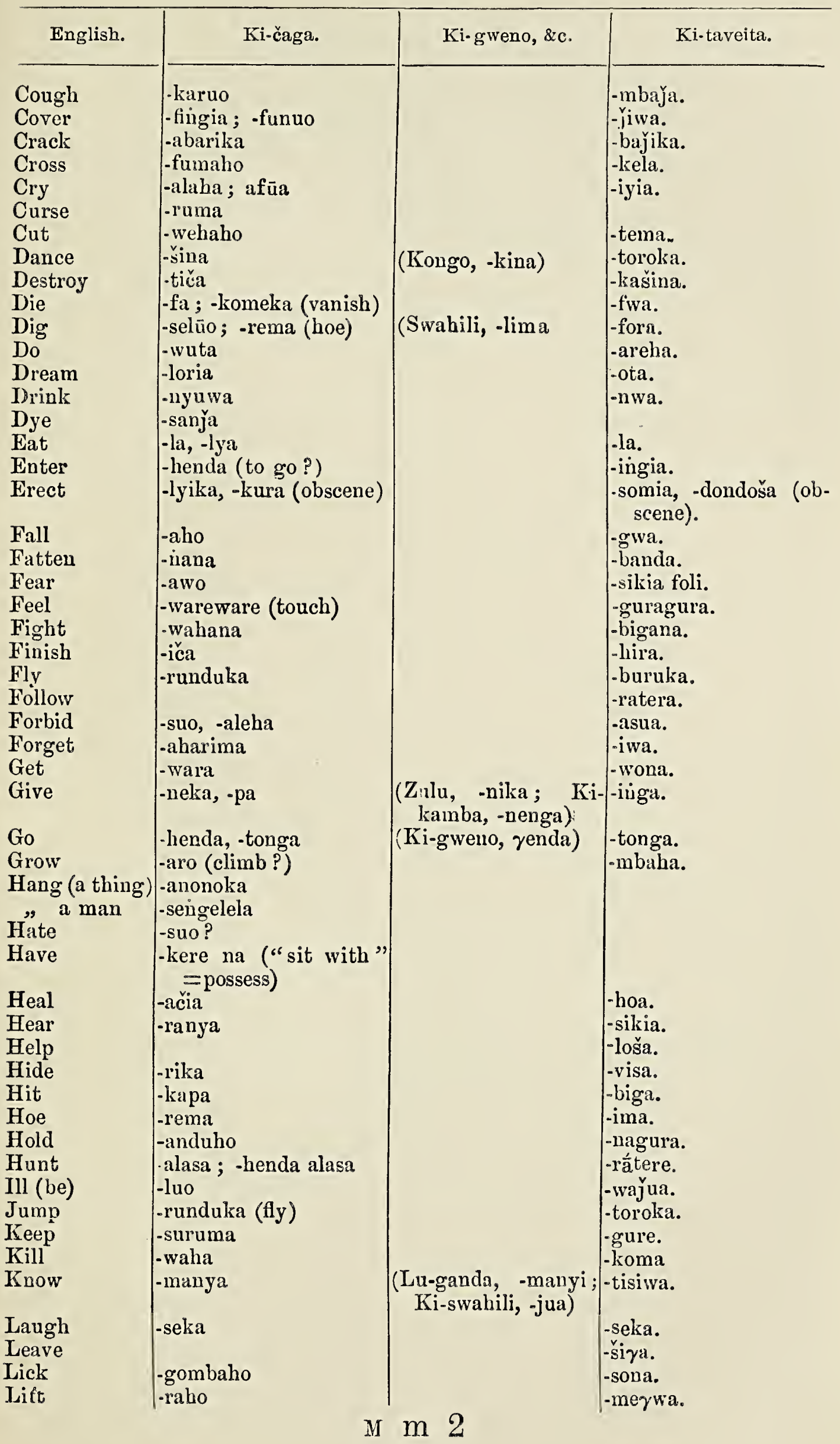




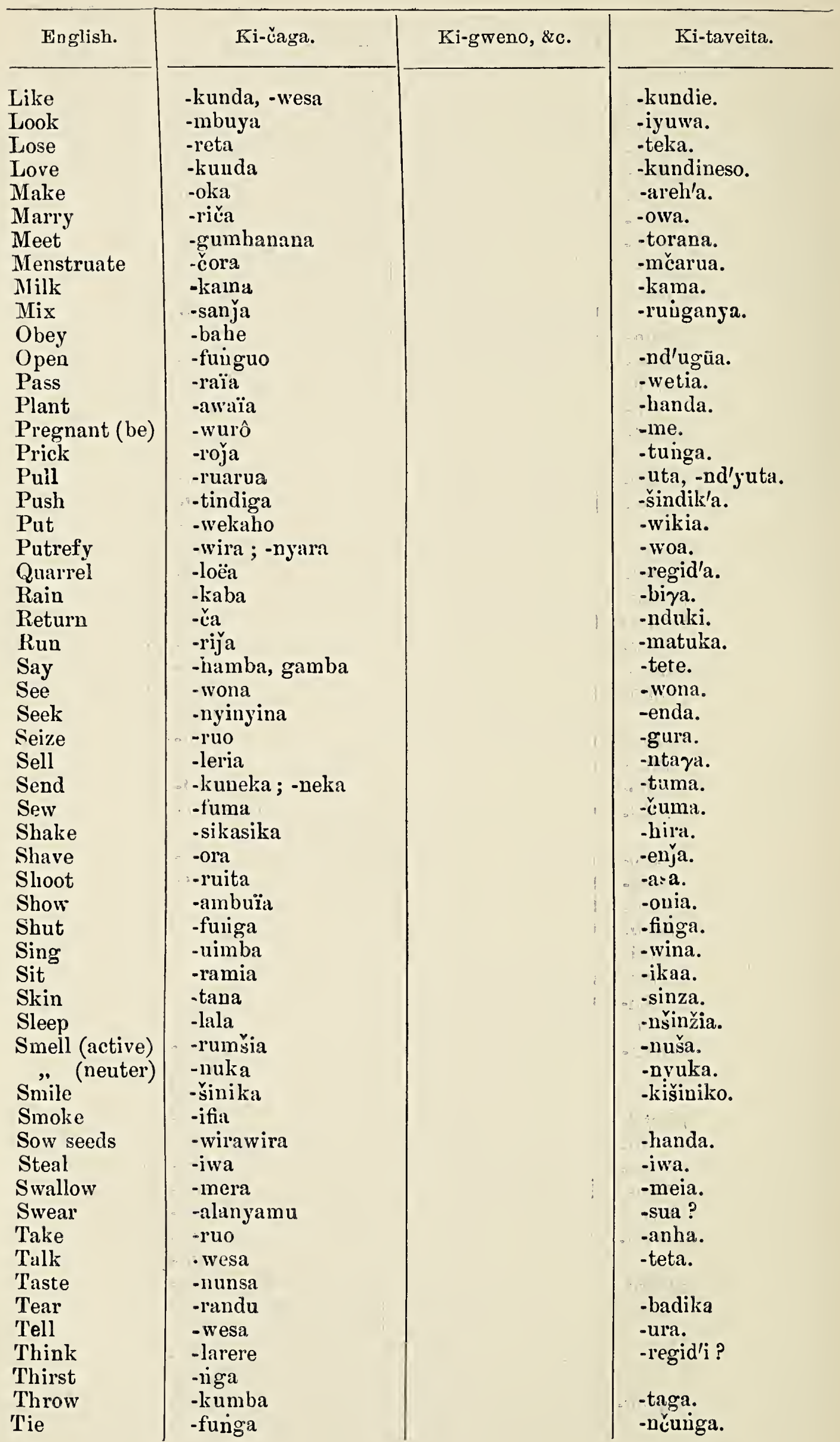




\begin{tabular}{|c|c|c|c|}
\hline English. & $\mathrm{Ki}$ čaga. & Ki-gweno, \&c. & Ki-taveita. \\
\hline $\begin{array}{l}\text { Tire } \\
\text { 'Touch } \\
\text { Tremble } \\
\text { Understand } \\
\text { Urinate } \\
\text { Vanish } \\
\text { Vomit } \\
\text { Walk } \\
\text { Want } \\
\text { Wash } \\
\text { Wear } \\
\text { Weave } \\
\text { Weep } \\
\text { Whisper } \\
\text { Whistle } \\
\text { Wish } \\
\text { Write } \\
\text { Yawn }\end{array}$ & $\begin{array}{l}\text {-lemo } \\
\text {-angasaho ; -wareware } \\
\text {-arerema } \\
\text {-rikia } \\
\text {-hama } \\
\text {-komeka } \\
\text {-arēga } \\
\text { - henda mbuho } \\
\text {-kunda } \\
\text {-sanja } \\
\text {-raë } \\
\text {-oga } \\
\text {-afua } \\
\text {-weweria } \\
\text {-murori } \\
\text {-kunda } \\
\text {-reh'a } \\
\text {-lya mwaë }\end{array}$ & $\begin{array}{c}\text { (Ki-nyilka, komelsa, } \\
\text { to vanish, die.) }\end{array}$ & $\begin{array}{l}\text {-detaëka. } \\
\text {-tonga kusela. } \\
\text {-kunda. } \\
\text {-odia. } \\
\text {-doka. } \\
\text {-eia. } \\
\text { - weweda. } \\
\text {-biga mrosi. } \\
\text {-kunda. } \\
\text {-tama. } \\
\text {-biga miaïo. }\end{array}$ \\
\hline
\end{tabular}

\section{Some Tenses of the Verb in Ki-čaga and Kf-taveita.}

\section{(The pronominal particle attached to the verb is in italics.)}

Ku-neka, To give. Present.

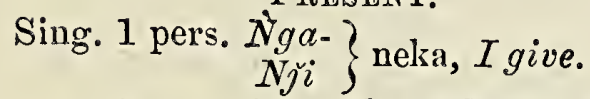
, 2 , Wu-neka, Thou givest.

, 3 , A.veka, He gives.

Plur. 1 „Lu-neka, We give.

, 2 , Mu-neka, Icugive.

" 3 , Wa-neka, They give.

Past (Imperfect).

Sing. 1 pers. Li-ka-nji-nekn, I was " 2 , Li-ka-wu-neka, giving. $\& c$. wast giving.

\section{Past (Perfect).}

Sing. 1 pers. Nj$^{\prime}$-li-neka, I gave. \&c. \&c.

Sing. FUTdRe \&c. \&c.

IMPERATIVE.

Sing. 2 pers. Neka, Give thou. Plur. 2 ," Nekani, Give ye.
Ku-tonga, To go.

Present.

Sing. 1. pers. Ni-hu-ni-tonga, $I$ am going.

" 2 ,U.k'-u-tonga, Thou art

, 3 , E-kw-e-toinga, $\stackrel{\text { going. }}{H e}$ is

Plur. 1 , Tu-ku-tu-tonga, $\stackrel{\text { going. }}{W e}$

going.

" 2 , Mu-ku-mu-tonga, Youare

, 3 ,Wa-ku-roa-tonga, They are going.

(This a curious affirmative form of the present in common use; the true simple present has become the past.)

\section{Past (Perfect).}

Sing. 1 pers. $N a$-toiga, 1 went.

" 2 "Wu-tonga, Thou went.

" 3 , $E$-tonga, He went. \&c. \&c.

\section{FUTURE.}

Sing. 1 pers. $N a$-ku-tonga, $I$ shall go.

$$
\text { \&c. Imperative. }
$$

Sing. 2 pers. Toliga, Go thou.

Plur. 2 "Tongani, Go ye. 
I cannot ascertain the subjunctive (if there is any), nor am I able to make out some of the more complicated tenses of the verb. It seems to me that both in Ki-čaga and Ki-taveita-as in Ki-swahili and some other North-eastern Bantu tongues-the verbal forms have undergone considerable degradation and obliteration, just as happens in our own English tongue. There is no trace of that mode of forming the preterite tense by a true inflection, which may be observed in the majority of existing Bantu languages, and which was certainly present in the mother-speech.

The negative is formed (in connection with the verb) by incorporating certain particles with the pronominal prefixes. These together form the following mode of expressing negation :-

\section{KI- ̌̀aGA.}

Sing. 1 pers. Si-neka, I give not.

., 2 " 4 Hu-neka, Thou givest

, 3 , Ha-neka, He gives not.

Plur. 1 pers. Halu-neka, We give not.

, 2 , Ham'-neka, You give not.

" 3 " Hawa-neka, They give
Ki-taveita.

Sing. 1 pers. Si-toinga-mi, I go not. " 2 , Tu-toinga-we, Thou goest not.

, 3 , Te-tonga-e, He goes not.

Plur. 1 " Tetu-tonga-'swi, We go not.

, 2 "Tem'-tonga-'nwi, You go

3 not. not. " 3 ", Tewa-touga-'wo, They go

(In Ki-taveita the negation is always emphasized by repeating after the verb the full forms of the personal pronoun, such as: mi, 'we, 'nwi, 'swi, \&c. Si-tonga-mi would literaliy be "I am not going, I!" in the sense of the French, "Je ne vais pas, moi!"

A very emphatic negative adverb in Ki-čaga is Ôte, "no, certainly no," "not at all."

Among the adverbs, prepositions, and conjunctions are:-

Na, and, with.

$$
\text { KI-čAGA: }
$$

Tiu, to.

Wa, on.

Kwa, for, in order.

-a (wa, ya, za, la, \&c., according to con. cord), of.

Wala, but.

Gana, or.

Kiki? why?

Neku? Ako? where?
Na, and, with.

KI-TAVEITA.

$\mathrm{Ku}$, to.

$\mathrm{Ha}$, on.

Kwa, for, in order.

-a (wa, ya, kia, ja, la, \&c., according to Ela, but. concord), of:

Kini? why?

Kahe? where?

4 These forms in Ki-caga are rather unsettled. I have sometimes heard them pronounced $G u, G a, \& c$., and sometimes $K u, K u$. The more archaic-form prevailing in many Bantu languages would be $K u$, $K a, K a t u, \&$ c. This becomes $H u, H a$ in Swahili, $A$ in Zulu, To, Ta in Lu-ganda, $S u, S a$ in Ki-nyan ${ }^{2}$, and so on. The archaic form of the negative prefix was $\mathrm{KA}$. 


\section{CHAPTER XXI.}

THE COMMERCIAL PROSPECTS OF E. EQUA'TORIAL AFRICA.

As an anticipatory reply to the inquiries of such of my readers as may be of a commercial turn, I conclude this work on the district of Kilima-njaro by a short summary of its commercial prospects and capabilities. If in my natural histcry or geographical statements I occasionally repeat information already given in previous chapters, I deprecate the critic's impatience; I do so because the general reader is not likely to peruse this chapter, and my commercial friends will probably not have wasted their time over the other portions of the book; consequently it will be suggested to neither that he has seen these facts stated before, while at the same time their reiteration may serve to accentuate-what I believe to be-their great importance from the point of view in which this chapter is written.

Let me, then, first sketch out the physical geography of this country, which I have broadly described as Eastern Equatorial Africa. For present purposes, it may be delineated as follows:-By the River Ruvu, or Pangani, on the south; then westwards, following the 4th degree of south latitude to the 32nd degree of east longitude, including the basin of the Victoria Nyanza lake, and round again to the east, from the 
northern border of the lake, by Baringo, to Kenia, the Tana river, and the coast.

The most marked characteristics of this region are its immense isolated mountain-masses, in most cases volcanic, such as Kenia and Kilima-njaro, the latter the highest known peak in Africa, its spacious level plains, or, more strictly speaking, plateaux, and its freedom from marshy or swampy ground, as contrasted with other parts of Africa. The water supply is fairly abundant, and equally distributed, though there is but one river, the Tana, or Pokomo, which is at all navigable. Besides the huge Victoria Nyanza, there are a few very much smaller lakes, one or two of which are salt, and the majority fresh. The highlands; up to 10,000 feet, and also the banks and rivers of streams, are generally clothed with forests of splendid timber, the plateaux are often covered with scattered bush and short grass-not the terrible giant grass of six to eight feet high, which obstructs so much of African country; while many districts I can only compare to beautiful natural lawns, whereon you meet with springy turf, closely cropped by the browsing antelopes, and here and there a group of handsome shady trees, disposed with so much regularity that it would seem as if man and not Nature had planted them. Such is the country that lies between Paré and Usambara, or in the vicinity of Lake J̌ipé, or again, to the south of Kilima-njaro, and also in many districts to the north, as we hear from Thomson.

These vast regions are very unequally populated. On the coast there is a fringe of slightly civilized races, nominally under the dominion of the Sayyid of Zanzibar. These people belong principally to the Bantu family of negroes, which includes all the in- 
habitants of Africa from the Victoria Nyanza to the Cape and Fernando Po to Mombasa, with very few exceptions. There are also Gallas on the north between the Sabaki and the Dana rivers, a few invading Somalis in the same district, Arabs of pure blood and Arab hybrids of every degree throughout the length of the littoral, and about four thousand Banyans and other natives of British India who come there to trade and sometimes to settle. To add to this medley of races, there are remains here and there of ancient Persian and Portuguese colonization, but, as I have before said, the bulk of the coast population is Bantunegro, a stock which seems to absorb and assimilate easily most foreign strains. The lingua-franca spoken is the celebrated Swahili language, one of the Bantu tongues, which promises to be the French of Eastern Africa.

On penetrating inland from the coast, the country is for the first hundred miles, as a rule, very thinly inhabited, except on certain mountainous districts, or along the coast of the Ruvu, the Sabaki, or the Tana rivers, and what people there are belong to the Bantu stock, and speak languages related to Swahili. Whenever you meet with people speaking Bantu languages in this part of Africa, you find they are invariably settled agriculturists, and never nomads. As a contrast to them, may now be mentioned the celebrated Masai, a negro race of splendid physical development. The Masai are semi-nomads, that is to say, each tribe has its home country wherein the married men and women settle, and move about within a circumscribed radius, while the warriors, who are forced to remain unmarried, range over immense areas, for the sake of plunder. These people were once, and are still in a 
lesser way, the scourge of Eastern Equatorial Africa. They have made previously well-populated, prosperous districts abandoned wildernesses, driving away all the cattle, killing such of the inhabitants as resisted, and leaving the remainder to die of starvation. But of late years they no longer play the same havoc. Between the coast and Kilima-njaro they are rarely to be met with, and in such cases as when they are encountered away from their homes, the white traveller will not find them very hard to deal with. Commerce is slowly but surely humanizing the Masai. They most of them prefer trading to fighting now. Yearly they are visited by many native caravans from the coast, who go to buy ivory with iron, wire, cloth, and beads. Certain tribes of the Masai, generally known as Wa-kwavi by the coast people, have abandoned entirely this roving robber life, and now occupy large districts as quiet, thrifty agriculturists. The Masai are all of them great cattle-keepers, and possess not only innumerable herds of splendid kine, but also keep numbers of donkeys as beasts of burden. These asses are very fine animals, resembling exactly the Ethiopean wild ass, from which stock they are certainly derived. The Masai are a people who in time will become amenable to civilization, I am sure, and commerce will temper their wild ways. They are very different from the mad fanatics we have been fighting in the Soudan, and if all Europeans behave as well to them as Mr. Joseph Thomson has done, we should soon be welcomed as traders and settlers in their midst.

It may be roughly said, then, that between the coast and the Victoria Nyanza, the plains or plateaux are inhabited by the Masai and their helot races ${ }_{f}$ and 
the mountains and mountain-ranges by Bantu people. These latter evidently occupied the land prior to the incursion of the Masai from the north, and existed in former times in greater numbers than at the present day. Of late, however, their fortunes have begun to revive. Forced, during their struggle for existence, to take to the highlands that were difficult of access to an invader, they have become a more hardy, independent race than their relations on the coast, and have also, in their wish to turn their mountain soil to the best advantage, become skilful and laborious agriculturists. Now their relations with the Masai are becoming sensibly improved, the Masai raids have ceased before the rude fortifications of the hill tribes, and both parties are able to trade on equal terms. The inhabitants of the mountains bring their honey and regetables, their smiths' work, and dressed skins, and exchange them against the ivery, rhinoceros horns, and natron salt that are collected by the rovers of the plains. These two distinct races, whose contact was formerly so provocative of bloodshed and rapine, are now exchanging peaceably their products, but also their ideas, manners, and customs. The Bantu of Kilima-njaro and Taveita loves to copy the Masai costume and mode of fighting, he incorporates many Masai words and salutations into his own tongue, while the once nomadic and restless Masai are increasingly taking to agriculture in the vicinity of Bantu settlements, and are changing from lawless robbers into quiet and honest tillers of the soil.

Around the Victoria Nyanza lake, the population becomes very dense, and probably the littoral people alone may be estimated at from ten to twelve millions. With one small exception they are Bantu, and speak 
languages of an archaic form, and more resembling the typical Bantu mother-speech than any other we have yet met with. The exception is a small enclosure of Nilotic negroes settled in the country of Kavirondo on the eastern shore of the lake, who have never yet come into contact with Europeans. We know something of their language from the Swahili traders, and we find it to belong to the same group as the Šiluk of the White Nile.

Besides the races above enumerated, dwarf tribes are reported in the unknown country lying between the Victoria Nyanza and Kilima-njaro, and there are also curious helot tribes dwelling among the Masai as hunters or smiths or slaves, who speak languages of their own, and remain at present unclassified in their affinities.

Of all the people I have mentioned in this hasty recapitulation, the Bantu offers the greatest hope for civilization. $\mathrm{He}$ is so industrious, so imitative, so inquiring, that he is instinctively attracted towards the white man. He is a born trader, and will travel miles to sell a fowl, while his appreciation of Manchester stuffs and Birmingham beads should ensure him the favour of British merchants.

The animal and vegetable products of this vast region are typically African. I might reiterate that it is a sportsman's paradise. Such quantities of big game were surely never met with elsewhere. If you want confirmation of my statements on this point, read Mr. Thomson's book, "Masai-land." In some districts you may stand on a hillock and see the plains at your feet covered with compact herds of antelopes, moving in squadrons, with straggling companies of giraffes, with scattered flocks of ostriches. Buffaloes 
abound so as to be dangerous. Rhinoceroses are so numerous that their horns are an important item in the trade, for they may be bought in the interior for a few pence worth of cloth, and sold on the coast for three and four rupees each. Hippopotami are abundant in the rivers and lakes. The Vice-Consul at Lamu, on the coast near the Pokomo river, informs me that when properly prepared (which is done by cutting the skin into long thin strips and drying it in the sun), hippopotamus hides will fetch $5 l$. apiece in Natal. But the great wealth of this country lies in its ivory, which is preferred to any other in the Zanzibar market. The elephant abounds in the neighbourhood of Kilima-njaro to the extent of many thousands. He here becomes quite a mountaineer, and ranges through the magnificent forests that clothe the upper slopes of this giant among African peaks. The natives waylay his forest tracks with artfully devised pitfalls and traps, preferring this more cowardly way of procuring their ivory to facing the elephant in the chase. Other tribes to the north and west of Kilimanjaro kill the elephant with poisoned arrows, or javelins, or sharp swords. Indeed, there is one district on the northern borders of Masai-land where, according to Mr. Thomson, "elephants are said to swarm unmolested and their ivory to rot untouched, for the people of the surrounding region have no trading relations with any one, and do not know the value of that precious article. A tusk: worth 150l. in England. may be picked up for nothing, or bought from any native for a pennyworth of beads, \&c., \&c." However this may be, whether the elephants are slain for their ivory, or whether, as in the tales of Sinbad the Sailor, there are districts in which the tusks may be simply 
gathered from among the bones of elephants who for centuries have died and died unnoticed in these untravelled wilds, ivory is procured somehow and in such quantities-even with the absurdly inadequate means of exploitation and porterage-that there is always more than enough to supply the many native caravans led by Moslem natives from the coast, which annually traverse this country between the Indian Ocean and the Victoria Nyanza lake. Another item of trade should not be forgotten, namely, the valuable and handsome wild beast skins, which may either be procured in the chase, or very cheaply purchased from the natives: A leopard skin may be bought for about two or three shillings' worth of goods, and will sell on the coast for eight or nine. Lions' skins are less easy to obtain from the natives, as that animal is rarely killed by them, but European sportsmen might shoot him to any extent, as he is both common and bold. Monkey skins; of the handsome variety of white-tailed colobus, which is alone found in this region, are valuable, and fetch a good price on the coast.

Ostriches are exceedingly numerous in the vicinity of Kilima-njaro. When living at Taveita in the summer and autumn of 1884, I and my men used to largely subsist on their eggs, which were brought us in numbers by the natives, and sold for about a pennyworth of cloth each. Sometimes by searching we would ourselves discover nests. In the month of October I bought twelve young ostriches from the natives at the rate of an ell of cloth apiece. I could have purchased many more, and started an ostrich farm had I wished, but as I was returning shortly to the coast I did not feel disposed to commence the undertaking. I tried to bring these young ostriches 
away with me, but they all died before reaching Zanzibar, as they suffered a great deal from the effects of the land transit, being very young. Of course to any ornithologist this country is exceedingly interesting, but to those whom I am more immediately addressing, rare or beautiful birds will not serve as a sufficient inducement for opening up a new country; still I might remark, for economic reasons, that there are abundance of guinea fowl, francolin, pigeons, and bustards, and all these serve materially to supply the traveller with palatable food.

I cannot say much for the reptiles of this country, as there are few species which would attract the traveller's attention, and none which, as far as I know, would be useful commercially, unless the crocodiles of Lake J̌ipé might furnish some of the leather which is now so fashionable for dressing-bags; but the very scarcity and unobtrusiveness of the reptiles is a negative advantage. Like most parts of Africa I have ever visited, the snakes here are very few and infrequent in their appearance. Most species, too, are non-venomous.

In many of the streams, rivers, and lakes there are fish in great quantities, representing most of the African fresh-water genera. There are few that are not edible, and some species are remarkably good to eat, and of considerable size and weight. While at Taveita I was often able to feed the entire caravan during a week or more on the fish caught in the small River Lumi; and at Jipé they are so plentiful that a fish-smoking establishment, similar to those on the Upper Congo, might be set going to provide food for long journeys. There are few things that Swahili porters like better than a fish diet. 
The insects are not likely to offer anything commercially interesting, nor indeed any of the lower invertebrate forms. I might, however, in their case lay stress on the same favourable fact as with regard to the snakes, viz. the scarcity or absence of noxious forms. Thus there is no tsetse fly, such as, but a short distance southward, interferes with the introduction of horses and cattle. Mosquitoes only exist in certain districts, near rivers or lakes, and are entirely absent from most parts of the country. Fleas and bed-bugs are unknown, nor has the American jigger, which is such a pest on the Congo, been introduced. White ants are not very numerous, and do not exist at all above a moderate elevation. The tænia intestinal worm, so often heard of in other parts of Africa, is here never to my knowledge met with.

I might mention that a small edible fresh-water crab is found in the rivers.

As to the vegetable productions, they are, apart from those cultivated and introduced by man, certainly valuable. There is particularly fine timber growing in many parts, particularly on Kilima-njaro and in the mountainous districts to the northward, and again on the west of the Victoria Nyanza. The forests in Usambara and in Paré, both districts near the coast, are full of magnificent lofty trees, which are much prized at Zanzibar for shipbuilding. On the coast and in Zanzibar, timber sells for 25 to 50 dollars per 50 cubic feet, according to quality.

Gums are produced in the interior, both copal and a kind called false copal. India-rubber can be procured from at least one creeper, the Landolphia florida, and I think also another, a species of fig. Coffee grows wild, especially on the northwards of the district, 
where it is the same species as the Abyssinian plant, which, it is supposed, being first introduced from the kingdom of Kaffa to the south of Abyssinia, thence derives its name. Coffee-planting would succeed admirably in districts like Usambara, which may be regarded as the natural home of this shrub, which is, indeed, indigenous to the African continent. I might mention that cardamums are produced here, and semsem seed is also largely reported for making spurious olive oil.

On the trees growing in the Kilima-njaro and Usambara forests, orchilla weed, in incredible quantities, is found growing. When delivered half clean, that is to say, mixed with sticks and rubbish, on the coast, it fetches from 3 to $3 \frac{1}{2}$ dollars per frasilah of $35 \mathrm{lbs}$.

As regards minerals, iron ore is found in some abundance, and copper apparently also; since the natives possess rude rings and ornaments of this metal which have not come from the coast. Nitrate of soda covers vast plains to the south, west, and north of Kilima-njaro.

There is good building stone in many parts of the country. Limestone often appears.

And now, having briefly noted some of the productions with which this part of Africa is naturally endowed, I may mention others which owe their introduction or development to the agency of man.

Vast herds of cattle are kept not only by the Masai, whose very raison-d'etre, as it were, consists in cattle breeding, but also by the agricultural races on the borders of Lake Victoria Nyanza, and in the mountain districts everywhere. When I was residing on Kilimanjaro I not only purchased excellent beef at about ten shillings a bullock, but also procured daily so much 
milk that I was able to make cream, butter, and cheese in plenty. The oxen are not, as a rule, so large as the Cape breeds, and, indeed, come from quite another stock, being descendants of Asiatic humped varietythe zebu-introduced into Africa by the ancient Egyptians. The hides are held in such little account by the natives that they may be purchased for the merest trifle. As I have already mentioned, the Masai keep large herds of fine strong asses, which they are always ready to sell cheaply.

Goats and sheep are most abundant. The goats are small, plump, and great milk-givers. The sheep belong to the fat-tailed variety, and offer really excellent juicy, tender mutton. Those who have visited Usambara will agree with me that the mountain mutton of East Africa rivals in tenderness and shortness that furnished by the Welsh and Highland sheep. Like all African sheep, they are hairy and without wool. Fowls are not kept by the Masai, but are met with in great quantities on Victoria Nyanza, and among all of the agricultural Bantu races. On Kilima-njaro they might he purchased at the rate of one ell of cloth each, averaging a cost, when the local value of cloth is estimated, of $2 \frac{1}{2} d$. each. In two days, at Mandara's capital, I purchased eighty fowls. S'ome of them are a very handsome breed, pure white, with very long tail feathers in the male. Another variety is plump and dumpy, with exceedingly short legs. 'The hens are very good layers.

The vegetable productions of the natives' cultivation are the banana, the sweet potato, the edible arum root, the sugar-cane, Indian corn, mtama, or red millet, and many unnamed varieties of peas and beans.

A little rice is grown in some districts, namely, at 
Taveita and on the River Tana. Tobacco is everywhere abundant, and exceedingly cheap.

I might mention my own almost incredible experience with the cultivation of European vegetables on Kilima-njaro. Immediately after my arrival, I planted the eyes of a few potatoes, onion bulbs, and the seeds of mustard, cress, radishes, turnips, carrots, peas, beans, spinach, borage, sage, tomatoes, cucumbers, and melons. Everything came up and flourished amazingly. In three months' time I had a dozen fine cucumbers from one plant, and so many potatoes that I was able to give them away to my men, as well as supplying my own table. I had everything else in abundance in a short space of time. Before leaving, I had planted my land at Taveita with wheat and coffee, limes, oranges, mangoes, and cocoanuts. I also distributed numbers of useful seeds among the natives.

I should have mentioned in its proper place before the vegetables, that there is a great quantity of delicious honey produced throughout this district. The wax is of very good quality, but the natives have no use for it, and merely throw it away.

I might now, perhaps, briefly summarize the principal trade products, and in some cases give their cost in the interior and on the coast. At present, no doubt, the most paying thing is ivory. This may be bought in the Masai countries, between the Victoria Nyanza and the coast, at the rate of from one to two shillings a pound, according to quality. When I refer to money in the interior, I mean money's worth in cloth or other trade goods. On the coast ivory sells from six to ten shillings a pound, sometimes reaching a higher price.

Hides may be almost got for nothing in the interior, and merely cost the expense of transit. On the coast 
they are sold, when dry, at about one dollar for seven pounds.

Rhinoceros horns I have already alluded to. They find a ready sale on the coast, fetching on an average, five shillings apiece.

Live-stock of all kinds may be purchased cheaply in the interior, and find a ready market on the coast.

There is even another source of profit in which, although many people laugh when I suggest it, I see nothing ridiculous, viz. the capture and sale of wild animals. If it can pay Hamburg and Austrian firms to hunt, and employ hunters on the confines of Abyssinia, for the purpose of supplying the zoological gardens of the world with wild animals, why should not the same thing be done here, where animal life is present to a degree which puts Abyssinia and the Eastern Soudan to shame. If you can get from $100 l$. to 200l. for a young rhinoceros, elephant, hippopotamus, or giraffe, with lesser sums, in proportion, for large antelopes, zebras, buffaloes, ostriches, lions, leopards, snakes, and crocodiles, surely it is worth while to capture them in districts like these, that are actually nearer the sea than the hunting-grounds of the German firms, and where the natives are already familiar with such a trade, and with the mode of capturing wild animals alive? When I was on Kilimanjaro and Taveita, the natives were always bringing me live creatures for sale, and I have already mentioned how cheaply I bought young ostriches.

Another important trade product would be orchilla weed, which may be gathered for nothing in the vast forests of Kilima-njaro. I have already mentioned its selling price on the coast.

Iron, copper, and nitrate of soda might pay profit 
on their transit, when communications between the coast and interior are facilitated.

Nevertheless, it is to be admitted that the special wealth of this country lies in its agricultural future. There are districts that might become the granaries of the world, possessing, over a large area, a European climate. There are other regions peculiarly adapted by their elevation for the culture of quinine. Sugarcane already grows half wild, and its cultivation might be increased to any extent. Coffee, tea, cacao, vanilla, would thrive in countries and districts remarkably suitable for their favourable growth. Above all, the question arises that if it can pay people to open up and trade with other parts of Africa, why should these magnificent fertile lands remain untouched, when they possess a climate superior in its salubrity to any other part of the continent?

In the neighbourhood, and near the base of Kilimanjaro, the greatest heat I registered was $81^{\circ}$; in the warmest part of the interior, $91^{\circ}$. The average night temperature in hilly districts is $60^{\circ}$; in the plains, $68^{\circ}$. Except on the loftiest mountains, and on the Victoria Nyanza lake, where it rains a few days in every month, the seasons in Eastern Equatorial Africa are regular in their divisions of wet and dry. From June to the end of October there is almost no rain, and from November to May there is an abundant rainfall during certain months. On Kilima-njaro the climate up to 8000 feet is that of a Devonshire summer; above that elevation you may have it as cold as you like, the higher you go.

I hope I have now said sufficient to show you that if Africa is worth opening up at all, the region which lies between the coast and Victoria Nyanza is eminently so. 
There is no doubt that Africa is the New World of the nineteenth century. What America was to Europe in the sixteenth and seventeenth centuries, that Africa is now. Within the last two years, England, France, Germany, Portugal, Spain, Italy, Belgium, and even Sweden have taken decided steps towards founding African colonies. Consequently I argue from this that if land in Africa is worth having, how much more profitable would it be in a fine country with a healthy climate lying between a great lake and the Indian Ocean.

Having explained to you that from my point of view this region is worth possessing, I now wish to indicate to you as briefly as possible the best way of opening it up to trade and civilization. Selecting some good port on the coast-and there are three or four to choose from, within a limit of a hundred miles of coast-linethe expedition should establish themselves firstly in the healthy and beautiful country of Usambara. The road to the interior runs either to the north or south of this little Switzerland, and joins to the west of it. In Usambara the first station should be established, as the country is very healthy. Here, too, the land might be sown and planted with all kinds of crop, for the proximity to the sea would render exportation easy and cheap. From Usambara you should cross the rich and fertile valley of the Mkomazi river and enter the hill country of Paré, the trade route continuing along the level plain at the foot of the hills. The scenery of Paré I can only call enchanting. There are wooded crags, waterfalls, secluded Alpine valleys, and splendid views. The people are pleasant to deal with, and food is plentiful. From Paré you might proceed to Ugwéno, over against Lake J̌ipé, the road still following the 
plains, and the stations being established in the hills. From Ugwéno it is a short distance to Kilima-njaro, which offers splendid sites for large settlements, and has also no scarcity of food. From Kilima-njaro there are two routes to be opened up. One, or the most important, leads past Mount Méru, another pleasant site for a trading station, straight to Speke Gulf, on the Nyanza. The other is more or less Thomson's track, leading to Lake Baringo and the north-west. This is the richest country for ivory. Hither every year come the Swahili caravans, who trade nearly to the borders of Abyssinia and the Nile. In all important districts stations might be founded after Stanley's style along the Congo, and these would, in time, become centres of civilization, cultivation, and trade. Although there is no doubt that a railway, under British auspices, made to connect the Victoria Nyanza with the coast, would give the entire trade of Eastern Central Africa into our hands, yet such an enterprise seems at present utterly impossible. British capitalists, shipowners, and manufacturers have lost the spirit of "merchant adventurers;" and now regard every venture that does not immediately promise interest on preliminary outlay, with pardonable timidity. Nevertheless, it seems to me that there are still young energetic men in our country who love a roving life, and who do not shrink from entering the wild regions of Africa because there is no railway to take them. Such as these flock year after year into the unpleasing regions between the Cape Colony and the Zambesi, attracted by the love of sport or a sheer unreasoning, English desire to pry into new countries. Why do not some of them band together, and instead of spending their money, time, and energies on barren 
Bechuana-land, boldly push into the countries west and north of Kilima-njaro, trading, shooting, and exploring? I can at least promise them far greater abundance of game than in the much shot over regions of South Africa, while they will never be likely to meet with such unhealthy districts as the Zambesi valley. "But the Masai?" people timidly suggest. Well, the Masai are not, after all, worse than the Kaffirs, Zulus, or even Hottentots were to the first explorers of Southern Africa. They want a little managing, that is all, and every fresh European will-or ought to-find his path smoothed by his predecessors. Besides, in some of the finest country there are no Masai. Along the direct route between the Victoria Nyanza and the coast only a strip of about 100 miles, viz. about a fourth of the distance, is ranged over by Masai and is annually traversed by Swahili caravans.

The first consideration in the development of this country is to encourage trade and create agriculture. Along many of the native tracks, as they at present exist, there is no obstacle for stout waggons, at any rate, as far into the interior as the precincts of Méru and Kilima-njaro, that is to say, half way to the Victoria Nyanza. Mules in plenty may be purchased in Zanzibar, and will do well in the country, or asses might be bought from the Masai. Oxen, doubtless, might also be trained to draw waggons as on the coast. As I have before remarked, there is no tsetse fly in the country, so that even horse-breeding might be attempted in time. ${ }^{1}$ Human labour is plentiful on the coast and fairly cheap. You may hire good stout carriers at the rate of five dollars a month, and the cost

1 In Samburu, to the north of Masai-land, horses are abundant, and are often brought down to the Zanzibar coast for sale. 
of their food is about twopence a day. Many of these men make very decent soldiers and guards, as Stanley has found on the Congo. As a rule the Zanzibar porters are faithful, trustworthy men-I have always found them so, and have even discovered very fine qualities in their nature too. At any rate, if they fall out with a white man it is generally his fault; a very little discipline, together with a kind and quiet manner, will always keep them in order. Many of them can read and write their own language in the Arabic character, so that if you wish to communicate with them at a distance you can do so by letter. The cost of keeping these men in the country would very much lessen after the first year or two, as you might soon grow sufficient food on your plantations to support the entire expedition. These Zanzibaris are very easily satisfied. They will subsist tranquilly on a few handfuls of maize a day, or a little rice and dried fish, or simply bananas; while if you manage to bring down some zebra or antelope with your rifle they are overjoyed. In two days ten men will construct you a spacious dwelling with a grass-thatched rain-tight roof, and in a much shorter time will build their own simpler habitations. They are singularly handy, and can plant gardens, make roads, trap animals, cure skins, construct bird-cages, wash clothes, mend them, make them, cook a dinner, and arrange a nosegay with equal facility. They are much more ingenious than English navvies, much more enduring of hardships, and much more courteous in behaviour. Without doubt, they are the means, the force, by which Eastern Africa will be opened up.

The white men who should form the pioneers of any commercial enterprise in Central Africa must be 
young, vigorous, and active, not, as they are so often, usé, battered men, who have failed in other careers, and try Africa as a last chance. They should possess sufficient education to be inspired with an intelligent interest in the wonderful nature that will surround them. There is no more miserable person in Africa than your utterly uncultured man; he pines and sickens for want of sympathy with his surroundings, while he who is so far alive to natural history as to be moved by the interesting fauna and flora of Equatorial Africa will never be lonely, nor have time to be ill. If any of them have a taste for sport, he will be never unhappy, for this country surely offers, without exception, the most splendid hunting-ground in the world. Nor, in such a case, will his sport be mere useless butchery of beautiful animals. He will be able to supply his caravan with fresh meat, at no expense, and may secure many valuable skins and hides. In the case of elephants, a sportsman is a positive acquisition to the party, as he can procure ivory for nothing. I have, personally, known men in Southwestern Africa who have made their fortunes over ivory and ostrich feathers.

That the opening-up of this country would secure a new field for commerce, I am convinced. Wherever I went the natives were anxious to trade-more anxious to trade than to fight, always. Constantly they have said to me, "Why won't you come here, and set up a shop"-for shop they employ the word duka, which the Swahilis have taught them-_" and let us exchange our goods for yours?" At places nearly two hundred miles from the coast I have found people who had never seen a white man before, in the possession of Maria Theresa dollars and Indian rupees, with which 
they came to buy cloth from me. They had, of course, received this currency from the coast traders, but it only shows they are beginning to understand the value of money; nay, more, Mandara, the chief of Moši, on Kilima-njaro, wanted me to open a banking account for him at Zanzibar, and he had a distinct though. crude idea of drawing cheques. Even the fiercest people here have wants for extraneous things that must be satisfied. Then again, if you introduce commerce and a ready market, you suppress the slave trade. Chiefs now sell their people into slavery because the Arabs will not buy anything else, slaves being the most profitable investment for the coast trader; but once convince them-and Africans are much more practical than you think-that more money is to be gained by employing their serfs to cultivate the soil at home and produce food stuffs and other products for sale, and I am sure the expatriation of these wretched people will cease. Again, at the present moment one chief makes war against another to procure prisoners and sell them as slaves, but commercial instinct will introduce peace by turning the sword into a reaping-hook, and covering the devastated fields with fair and marketable harvests. These people are well worthy of civilization-yes, even the fierce and roving Masai, who are already being softened wherever they impinge on the rendezvous of coast trade.

I would suggest that in any undertaking to open up Eastern Equatorial Africa, Kilima-njaro should be made the centre of operations, both on account of its fine climate and the placability of its inhabitants, and for the further reason that the intervening country between Kilima-njaro and the coast is quite safe for travelling. 
I have no doubt some, if not many, of my readers have received several of these statements with irritable incredulity. It is, somehow or other, vaguely annoying to the placid nature of an Englishman, who has made enough to live on and only wants to live quietly, to come across travellers-whose works he skims through in his easy-chair-that insist on bringing to his notice new and wonderful tracts of land which are possible El Dorados, and in which he must take an interest and invest his money, or they will never leave him in peace and will constantly din into his ears the appalling news that he has let slip an unrecoverable opportunity of showing his patriotism and his commercial perspicacity. How well we know those cries and laments that ever and anon sweep through the public press and assail John Bull at his breakfasttable or worry his return from business. "You have lost the granary of Africa, or the granary of America," as the case may be. "You are about to abandon the garden of Asia to the French, Russians, Germans!" and so on. I must say I rather sympathize with my readers if they display any restless petulance after reading such a chapter as this. The feeling arises partly from a lurking conviction of an element of truth in the statements, and partly from resentment at not being allowed to ignore these advantages which they must either take up themselves or see pass into the hands of aliens. "Why can't you let us alone?" they feel inclined to exclaim, "we've got quite enough for our immediate wants, we have no need to embark in fresh enterprises." Or they try to satisfy themselves and crush their disturber by anxiously endeavouring to oppose argument to argument and disprove all beguiling statistics. Yes, I am very sorry, 
dear reader, if I have worried and bored you by inserting a leaf or two of commercial propaganda into what you thought, when you ordered it from the library, was just going to be an average African bookadventures with lions, tossings by buffaloes, encounters with nasty natives, and so on. Believe me, I have done so disinterestedly. I am not an African trader, nor do I intend to be. I am not getting up a company to develop East Africa and speculate in land. If a railway is made to Kilima-njaro, I shall probably hear of its accomplishment from the forests of Borneo or the snow-peaks of the Andes', and remember I once visited that part of the world. Scientific pursuits and a love of rambling have led me to this richly endowed region as they may next year lead me elsewhere, and I have thought it well to let my countrymen know what advantages it possesses, so that when British merchants and philanthropists are bewailing the loss of the great African sanatorium, they cannot at least plead ignorance of its existence or advantages.

Having said this much I leave my poor remarks to the kind consideration of the general public, by whom, and Mr. Mudie, we authors of a day receive our raisond'être. 



\section{INDEX.}

Note. All African names of countries, languages, or peoples, which are not found under the initial letter in this index, should be looked for under the initial of the root form. Thus for Ki-taveita (the language of Taveita), see Taveita, Ki-; for Usambara, Sambara, U-; Wa-čaga, Caga, Wa-; Bu-nyoro, Nyoro, Bu-. Tnasmuch as the prefix in these cases constantly varies with the meaning of the root, it is necessary to recognize the unvarying root, alone, in this index.

ABDALtAH, $61,131,146,189,190$, $199,225,239,302$.

Abyssinia, 2, 3, 5, 98, 334, 353, $363,398,452,545,551$.

Acacia, 55, 74, 81, 117, 137, 209, 329,336 .

Aden, 15, 320, 321,

Africa, flora of, 334, et seq.: re. sources of, 148 .

-, Eastern, 308, 323, 535, et seq.

-, languages of, 446 .

Agreement with Mandara, 110.

211.

Albert Nyanza, the, 297, 400.

"Albino, my," 304.

Albizzia, 209.

Alcelaphus Cokei, 65, 301, 355.

Aloes, 51, 90, 92, 117, 154, 229, $330,336$.

Alphabet, Lepsius' Standard, ix, 476 , et seq.

Alps, the, 5.

African, 3.

America, 3, 4, 9, 274.

Anas, 359.

Anemones, 234, 336 .
Ant-bear, 300, 353, 424.

Antelopes, 216, 218, 300, 310, 355 .

- and ant-hills, 65,355 .

Ant-hills, 65, 355 .

An 2 hropology, 395-445.

Ants, 176, 220, 296.

Arabia, 335.

Arabic, 460 .

Arab mongrels, 98.

Arabs, 6, 8, 97, 105, 181, 210, 308, $311,314,403,408$.

Arab town, an, 316.

Arnold, Edwin, vii.

Artemisia, 235, 334, 335.

Arums, 119, 442, 487.

Aruša, 397, 405.

Aryan languages, 460, 466, 480, 488.

Asses, 210, 304, 421, 423, 538, 546 .

Association, British, 3, 6, 245.

Athmani, 58, 61, 131, 186, et seq., 247, et seq.

Author, the, entrusted with command of Kilima-njaro Expedition, 6 ; arrives at Zanzibar, 16 ; falls ill, 41 ; asserts sway over porters, 48 ; is miserable at Kitimbiriu, 194; rejects Man- 
dara's ultimatum, 196; is besieged, 197 ; frames projects of escape, 200; endures great anxiety, 200; resolves to quit Moši, 204; falls into ambush, 206 ; catches leopard in trap, 211 ; goes hunting, 216, et seq.; ascends Kilima-njaro, 229, et seq.. 259, et seq.; flight from Wa-kibošo, 237 ; takes leave of Mandara, 240; frees Mabruki's slaves, 248; enters Maranu, 251; humours its chief, 256; has accident to knee-cap, 261, et seq.; ascends Kibô, 266 ; returns to camp, 276 ; muses on the possibilities of a European settlement, 286; has difficulties with Wa-rombo, 288 ; anxiety to avoid bloodshed, 288; fights with Wa-rombo, 293; receives deputation of $\mathrm{Wa-rombo}$, 295 ; sets out for coast, 297 ; ill at Lake Jipe, 299; meets the Masai, 303 : escapes by a ruse, 303 ; enjoys mute hospitality at the Pangani Mission-station, 316, et seq.; royages in Arab dau, 318; returns to Zanzibar, 319 ; reaches London, 321.

Baboons, 118, 212, 223, 310, 350, 351.

Baker, Sir Samuel, 450.

"Baloza," the, 98, 100, 104, 106, 187, 226, 257.

Balsams, 92, 148, 230, 330.

Banana, the, 442, 487.

- beer, 175 . plantations, 75, 88, 91, 117, 118, 124, 209, 287, 289, 307. leaves, 140,155 .

Bananas (fruit), 148, 151, 155, 193, 212, 215, 264, 306, 424.

-, Wild (Musa Ensete), 209, 331, et seq., 336.

Bantu, meaning of the word, 478 , 488.
$4.24,426,447,474$, et seq., 478, et seq.

Bantu races, 78, 247, 312, 396, et seq., 539, et seq.

Baobab-trees, 304, 329, 336, 430.

Barawuio, Em-, 313, 407.

Barbel, a, 363.

Bari people, 397, 421.

- language, 400,450 , et seq., 455 , 466, 474, 481, 501, et seq.

Baringo, Lake, 397, 450, 536, 551.

"Baroni," the (Baron v. d. Decken), 10, 101, 106.

Bats, 352.

Battle with Wa-kibošo, 177.

Bauhinia, 80.

Beads (for trading), 45, 154; (ornaments of), 429.

Beans, 149, 155, 442, 547 .

Bed, a native's, 214.

Bees, 92, 363, 424, 485.

Beetles, 5, 260, 363, 372-377.

Begonias, 230, 260.

Belgians, 99.

Bell, Prof. Jeffrey, on a nematoid worm, 364.

Berber language, 429, 475.

Birds, 5, 192, 356-361, 377-387, 543.

Blackberries, 154, 155, 193.

Blair, General, 15, 321.

Bleek, Dr., 446, 448, 488.

Blessbok, the, 354 .

Blood-drinking, 425, 442.

Bloody scene, a, 176.

Bombax tree, 329.

Bondei, Wa-, 398.

Boni, Wa-, 401 (language), 401, 501.

Bonney, Professor, on the geology of Kilima-njaro, 328.

Borassus flabelliformis, 154, 329.

Borneo, 4.

Bracken fern, 118, 125, 151, 330, 336.

Brambles, 117, 154, 230, 330.

Bread, 83, $142,148$. 
Breakfast-table, 143, 148.

British Association, the, 3, 6, 245.

for, 100 .

Buceros, 356, et seq.

Buffalo, 66, 164, 216, 267, 277, 279, 287, 354, 485, et seq., 540.

Bulom language, 480.

Bura of Taita, 64, 65, 287.

Bushbuck, the, 354 .

Bushmen, 427, 447, 482, 484.

Butter, 142, et seq., 148, 155, 193.

Buttercups, 336.

Butterflies, 5, 14, 192, 194, 235, $363,367$.

- feeding on blood, 176.

Chlophyllum, 329.

Cameroons, the, Mountains, 3, 335, $352,489$.

Camp at Habari, 83 ; at Mkuyuni, 85 ; at Mandara's, 90 ; on Kilima-njaro, 233, 260; at Marañu, 253 ; in Msai (Kimawenzi), 285 ; River Lumi, 292; delights of, 83 ; meals in, 84.

- of Masai, 304.

Canis, 353.

Cannibalism, 352.

Cape of Good Hope, 5, 335.

Carapace of kites' feathers, 170.

Cardamums, 545.

Carduus, 267.

Carnivora, 352.

Carrots, 131, 149, 547.

Cattle, 315, 421, 486, 545. of Africa, 421, et seq., 441,

—_ of Wa-čaga, 441.

— of Masai, 304, 421, 538.

Cephalophus, 354.

Cephas, the cook, $62,106,131,146$, 179, 190, 237.

Cercopithēcus, 352.

Chameleon, 260, 361.

Champagne, 52, 53.

Chella Mountains (Angola), 279, 310,354 .
Chervil, 234, 268.

Chief, the, of Mačame, 9, 124.

Maranu, 255, et seq.

Paré, 306.

Usambara, 307.

Cicadas, 222.

Circumcision, 487.

- of Wa-čaga, 438.

foot-note). of Masai, 412 (and of Wa-taveita, 433.

Civet, 353.

Clematis, 87, 148, 336.

Climate of Kilima-njaro, 299, 322, et seq., 549 ; (Kitimbiriu), 194.

Clitorea, 37, 51, 329.

Cloth, for trade, 44; a "hand" of, 155.

Clouds on Kilima-njaro, 136, et seq. ; 154, 208.

Clover, 121.

Ćobus antelopes, 310.

Cocoa-nut, 59.

- -- palm, 329.

Coffee, 148, 544, 545, 549 .

Cold, at Kitimbiriu, 145 ; on higher levels, 275, 280.

Coleoptera, 372-377.

Collectors, natural history, 12, 13, 136, 192.

Collocasia, 424, 442.

Colobus Guereza, var. caudatus, 37, 1.74, 352.

- Kirkii, 37, 38.

Colobus skins, $89,170,174,414$, 542.

Commelyna, 50, 329 .

Commerce of Kilima-njaro district, 535 , et seq.

Congo, River, 2, 6, 98, 99, 149, 210, $350,442,482,551$.

"Concord," the, in Aryan languages, 461; in Bantu, 459, 490 ; in Ki-čaga, \&c., 499, et seq.; in Galla, 460; in Hottentot, 460; in Semitic languages, 460 .

Cooley, Mr. Desborough, 9. 
Copal, 544.

Copper, 487, 545, 548.

Corissa, 51.

Cow, 121, 131, 142, 147, 148, 155, 198, 304,

Crabs, 363, 365, 544 .

Cream, 142, 143, 193.

Creepers, strange, 82.

Crinum lilies, 37, 51.

Crocodiles, 298, 361, 443, 543 .

Crotons, 37.

Crows, 176, 304.

Cucumbers, 131, 149, 547.

Cust, Mr., R.N., 446, 478.

Cycads, 329.

Cynocephatus, 350.

Cynoglossum, 235, 267, 333.

Caga, 8, 96, 135, 210, 215, 250, 299, $326,351,443$.

--, agriculture of, 125, 440 .

- climate of, 139.

-, Wa- (people of), 78, 91, 95, $96,97,123,154,210,213,229$, $233,238,249,398,428,436$, et seq,; domestic animals of, 441, et seq.; their huts, 91,157 ; mode of fighting, 175, 176; swords, 176 ; smiths, 440 ; utensils, 440 ; their language (Ki-čaga), 95, 111, $157,161,252,289,494$, et seq.

Cala, Lake, 281, 290.

“DACCA," s.s., 321.

Dahalo, Wa-, 401.

Daus, Arab, 25, 318.

Day, a typical, at Kitimbirin, 144, et seq.

Decency, natives' want of, 76,90 , $433,437$.

Decken, Baron von der, 9, 10, 12, 101, 106, 190.

Didunculus, 4.

Dierama, 267.

Digo, A-, 398.

Dinka language, 400, 421,451, 475, 501 , et seq.

Dishes, wooden, of Wa-čaga, 142.
Dissotis, 92, 121, 147 .

Dodo, the, 4.

Dogs of Kilima-njaro, 353; of Masai, 421, 423.

Doko people, The, 431.

Domestic animals, 421, 441, 486.

Donkey, vide Ass.

Doorway, Ćaga, 157, 229.

$\longrightarrow$, Taveita, 74 .

$\longrightarrow$ Maranu, 250.

Dorobo, En-, 294, 401, 402, 421, 448.

Dowding, Captain, 320.

Dracana, 90, 117, 151, 154, 172, $229,330,336$.

Drakensberg Mountains, 334 .

Ducks, 298, 359.

$\longrightarrow$, Muscovy, 29 4, 296, 484 .

Dwarf races, 400 .

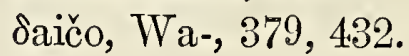

Earrings of Masai, 410, 481; of Wa-taita, 430.

Eastern Africa, see Africa, Eastern.

Efik language, 480 .

Eggs, 143, 148, 155.

Egrets, 298, 359.

Egypt, 15, 321, 484.

Egyptians, Ancient, 421, 546.

El.ä̈s palm, 329.

Elands, 66, 301, 310, 354 .

Elche, palm groves of, 311 .

Elephant-gun, 167.

Elephants, 206, 207, 233, 260, 279, 213, et seq., 287, 294, 310, 354, $485,541$.

Emin-Bey, Dr., 450.

Enciso, 7.

En-dorobo, vide Dorobo, En-.

England, 99.

English (Wa-ingrezi), 99, 310.

— "Manowari," 100, 135.

Mission, 317.

- vegetables, 131, 149 .

Equator, snow under the, 3, 8, 9.

Equus, 354.

Erhardt, Rev., 448, 452. 
Evica, 233, 261.

Euphorbias, 51, 58, 81, 307, 312.

European settlements on Kilimanjaro, 286, et seq., 290, 298.

Euryops, 270, 333.

"Everlasting" flowers, 233, 235, 270, 333, 334.

Expedition, the Kilima-njaro, 3.

for, $3,13,14,296$.

Fanrine in East Africa, 1884, 215.

Faraǰi, 61, 131, 146, 147, 229, 299.

Farijala, 131, 146.

Farler, Archdeacon, 403.

Fauna of Kilima-njaro, 350-394.

Fauna and flora of Kilima-njaro, $3,5,12$.

tains and islands, 4,5 .

high moun-

Africa, 6.

Ferns, 117, 230, 231, 235, 260, 269, $330,334,336$.

—_, tree-, 231, 260, 333, 336.

Fever caught at Zanzibar, 41 ; at J̌ipé, 299.

- , causes of, 41.

Fig-trees, 329.

Fire, making, 436,

Fireworks, author's display of, 179 , 188, 294.

Fischer, Dr., 12, 13.

Fish, 209, 212, 213, 298, 363, 434, $441,543$.

Flies, 176.

Flora of Kilima-njaro, 267, et seq., 329 , et seq., 335, et seq., 337-349.

- Abyssinia, 334, et seq.

- South Africa, 334, et seq.

Flour, maize, 83, 148 ; millet, 155 .

Fly-catcher, 356.

Food in Africa, 84.

Forests of Bura, 65 ; enchanted, 59 , 81 ; of Kilima-njaro, 152, et seq., 233 ; of Kimawenzi, 282, et seq.; of Paré, 306, et seq., 544; of
Taveita, 74, 80, 209, 322, 330 ; terrors of the, 285 ; of Usarnbara, 310,544 .

Forge, a Caga, 440.

Forget-me-nots, 336.

Fowls, 142, 143, 147, 155, 158, 198, 213,294 , et seq., 421; introduction of, into Africa, 483, et seq., 546.

Francolin, 218, 358, 343.

French.(Wa-fransa), 22, 99.

Frere Town, 42.

Frogs, 362 ; tree-, 222.

Frost, 233.

Fula people (Fulbe), 452.

- language (Fulde), 447, 451, 4.52, 474, 478 .

GALAGO, the, 37,352 .

Galla Land, 398, 401, 4.32, 438. language, 401, 450, et seq.,

460, 474, et seq., 479, 501, et seq.

- people, 210, 312, 398, et seq.

Game, big, 216, 301, 354.

- country, the, $219,301$.

Ganda, Bu-, 210,483; Lu- (the language), 400, 479, 483, 488, 490.

Gazelles, 354 .

Geese, 298, 359.

Gender, recognition of in Bantu, 474.

475. Galla, 474, Masai, 474. Semitic, 474.

Genet, 353.

Geographical Society, Royal, 10, $11,14$. of Paris, 8.

youth, 2.

Geography, physical, of the Kilimanjaro district, $322,395,535$, et seq. Geology of Kilima-njaro, 328, et seq. Geraniums, 235, 336.

Germans, the (Wa-dači), 99, 100, 314.

Giraffe, the, 216, 301, 310, 354, 485, 540 . 
Gissing, Capt., 15, 41, 48, 130.

Gladioli, 230, 267, 333.

Gnu, the, 66, 310, 354 .

Goats, 90, 91, 121, 128, 142, 145, $147,155,158,172,198,211,213$, 227, 264, 294, et seq., 315, 422, 441,546 .

God, names of, $215,430,438$.

Godman, Mr. F.D., on the lepidoptera of Kilima-njaro, 367.

Gonja, 307, et seq.

Gora, 48, 49, 51.

Grammar, Masai, 455-476.

Graphic, plates from, 46 .

Graphiurus, 354.

Grasses, 119.

Great personages, 101.

Greffulhe, M., 401.

Guinea-fowls, 310, 358, 543.

Guides from Marañu, 259, 263, 280, 285.

Gums, 544.

Gwéno, Ki-, 125, 494, et seq.

- U-, 65, 125, 286, 297, 443, 550.

—, Wa-, 125, 210, 297, 396,398, 428, 443 .

"HabarI" River, 82, 207.

Haggard, Lieut., 15.

Hamitic languages, 398, 447, 460, $474,475,478$.

"Hand" of cloth, 15.5 .

Handford, Rev. J., 41.

Hartebeests, 65, 66, 301, 354, 355.

Hausa language, 447, 475, 478.

Heaths, 233, 235, 261, 334, 336.

Helot tribes, 424.

Hemlock, 234.

Herero; Oči-, language, 493.

Hibiscus, 37, 87, 92, 148, 330.

Hides, 547, et seq.

Hindus at Zanzibar, 27, 28.

Pangani, 316, 317.

Hippopotami, 298, 354, 443, 485, $486,541$.

Hippotragus niger, 69, 301, 354.
Hippotragus equinus, 224.

Honey, 65, 92, 148, 155, 26t, 424, $442,547$.

boxes, 93 . guide (indicator), 424.

Hornbills, 356, et seq.

Hottentot languages, 447, 460, 474, 480.

Houses, building at Kitimbiriu, 139, 143.

- of Gonja, 307.

Masai, 420.

Hunters, native, 66, 216, 220.

Hunting and travel, 68.

Hyena, 162, 195, 211, 220, 222, 353, $423,434,439$.

-, a human, 217.

Hyphoene Thebaïca, 154, 310, 329.

Hyraxes, 234, 264, 279, 354 .

Ibrahim, 63, 131, 146, 303.

Ichneumon, 353.

Indian corn, 151,155 .

India, 308, 335, 363.

India-rubber, 544 .

creeper, 336,544 .

Indicator, 424.

Insectivora, 352.

Insects, 544 .

Irises, 234, 235, 267, 333.

Iron, $297,440,487,545,548$.

Irrigation of plantations, 139, 149 , 441.

Ivory, $210,294,424,541,547$.

Jackal, 353.

"Japan," 4,

Java, the, 15.

J̌emsi, En-, 210, 397.

Jipé, Lake, 66, 72, 125, 287, 297 , et seq., 310, 321, 359, 363, 407, 443,543 .

"Johnston," 76.

Jub, River, 401.

Jumba Kimemeta, 98, 184, 185.

Juwano people, 401. 
Kadu Stanley, 63, 131, 139, 149, $225,239$.

Kaffir language, 483, 488.

Kahe, Wa-, 398, 428, 443 .

Kamasia, 397.

Kamba, A-, 78, 210, 220, 397, 399, $428,431$.

-, Ki-, 494.

Kambani, U-, 210, 287, 397.

Kaputei, 397.

Kara, Wa-, 397.

Kavirondo, 210, 397, 399, 401, 540.

Kenia, Mount, 2, 8, 9, 397, 418, 431, 536.

Kibô, 1, 7, 10, 80, 105, 110, 124, 129 , $136,147,152,229,234$, 266, et seq., $277,298,335$.

Kibonoto, 443.

Kibôšo, 165. 181, 244, 443.

- people of (Wa-kibôšo), $169,175,177$, et seq., 226, 233, 235, 236, et seq., 262, et seq.

-, war with, 194.

feated by, 200.

Krigelia Africana, 37.

Kihungwe, 309.

Kikoro, 210, 407.

Kikuyu, Wa-, 397, 432.

Kilaki, 228, 232.

Kilema, 443 ; Upper, 262. , River, 85, 260.

Kilima-njaro, Mount, 1, 6, 7, 9, 80, $226,300,310,320,396,418$; altitude of, $1,2,10,276$; anthropology of, $395-445$; ascents of, 10, 11; beetles of , 372-394; birds of, 356-394; butterflies of, 367 ; climate of, 323 , et seq.; colonization of, 122 ; derivation of name, 1; discovery of, 7; early history of, 6; European visitors to, 7 , et seq., $79,100,101$; Expedition, vii., 3, 12, 14 ; fauna of, 350-394; fauna and flora of, $3,5,12$; flora of, 234, 329, et seq., $330,337-349$; first sight of, 71 ; geology of, 1; languages of, $448-496$; last view of, 298 ; mammals of, 350-387; northern side of, 10,294 ; poem to, v., 336 ; politics of, 79, 182, 244; pronunciation of, $x$; purpose in going to, 180,245 ; reptiles of, 361 ; sanatorium, a future, 306 ; situation and extent of, $1,3,327$; snows of, $1,3,8,9,14,79,137$, 325 ; spurs on buttresses of, 119 , 127; start for, 40 ; states of, 232; by sunrise, 137; vicinity of, 72,215 .

Kimañgelia, 294, 326, 443.

Kimawenzi, 1, 10, 80, 124, 152, 234, $260,264,273,286,325$.

Kingfisher, 149.

Kini Balu, Mount, 5 .

Kioñgwe, 60, 61, 102, 104, 106, 116, et seq., 185, 204, et seq., 212, 225, $239,246,303,315$.

Kirk, Sir John, iii., 13, et seq., 94, $98,100,109,180,182,184,225$, $226,240,256,281,319$; house of, $20,21,23$; at home, 39; at Mbrwéni, 38.

Kirua, 165, 181, 244, 443.

Kisiwani, 306.

Kisolutini, 42, 48.

Kisongo, 397, 404, 407.

Kitchen-garden, author's, 131, 142, 149.

Kites, 128, 356.

Kitimbiriu, walk to, 118 ; site for, 120 ; arrival at, 121 ; position of, 122 ; future of, 122 ; view from, 123; residence in, 129, 142, et seq.; typical day at, 144, et seq.; author leaves, August 18th, 206 ; returns to, 212,229 , 238 ; remembrance of, 320.

Kiulu Mountains, 287, 396.

Konono, El-, 402, 411, 421.

Kosova, 397.

Krapf, Dr. (the missionary), 8, 9 $130,432,446,448,452,489$. 
Kudu, 277, 279, 354 .

Kwavi, Wa- (Masai), 78, 210, 312, et seq., 396, et seq., 405, et seq., $419,424,432$.

Láio, 363.

Laikipia, 397.

Laitokitok, 397, 404 .

Lamu, 15, 398, 401, 541.

Landolphia florida, 544.

Landscapes, descriptive, $65,80,88$, 124, 127, 129, 137, 152, et seq., 156.

Lanes, the Caga, 229, 230.

Laùgo, language of, 4.50 .

Languages of Africa, 446 .

- Kilima-njaro, 448, ct seq.

Lanjora, 70.

"Laputa," 71.

Last, Mr., 449.

Latuka people, 397.

$$
501 .
$$

language, 450 , et seq., 455 ,

Lava, 264, et seq.

Lawson, Mr. Ed. L., vii.

League, hostile, of Kibôso, \&c., 204.

Legend of Solomon, 129.

Leighton, Sir Frederick, 32.

Leopards, 66, 152, 164, 211, 284, $352,485,542$.

Lepidopter $\alpha, 367$.

Lepsius, Dr. (Standard Alphabet), ix, 44, 451 .

Lilies, 301.

Limestone, 301, 54.5 .

Lions, 66, 73, 85, et seq., 137, 152, et seq., 156, 162, 211, 216, 222, $352,485,542$.

Lissochilus orchids, 51 .

Lizard, 235, 361.

Lobelia Deckeni, 267, 333.

Lonchitis pubescens, 332.

Loranthus, 154.

Lumbwa, 397.

Lumi River (of T'aveita), 79, 218, 220, 288, 289, et seq., 297, 326, 434.
Lūr language, 400, 451, 501.

Luvu River, vide Ruvu.

MABRUKI, 57, 61, 181, 185, et seq., 191, 247, et seq.

Mačme, 9, 124, 443.

Madagascar, 5, 485.

Madi language, 450 .

Magdiš $u, 17$.

Magic, 159, 160.

Magician, author a, 264, 294, 295.

Maidens, African, 151.

Maize (Indian corn), 151, 155, 424, 442.

Makonde lanşuage, 493.

Malindi, 17, 326, 401 .

Mamba, 244, 286, 443.

Mammals of Kilima-njaro, 350 , $387-394$.

Mandara, vii., 11, 79, 89, 90, et seq., 109, 114; et seq., 130, 155, 213, 225 , et seq., 236 , et seq., 287, 314, $319,404,555$; appearance of, 91 , 103, 106; biography of, 95 , et seq.; courtiers of, $88,106,108$, $131,175,181,183,186$, et seq., 241 ; covetousness of, 188 ; character of, 206 ; conversations with, 105; 134, 169, 181, 202 ; first sight of, 103 ; fortifications 172; Mandara and Mabruki, 187, et seq.; mother of, 96 ; quarrels with neighbours, 165, 194; his reasons for slave-trading, 180 ; his relations with Sir John Kirk, 98, 101 ; rule of, 164; slavetrading of, $95,165,181$; soldiers of, $89,98,169,171,174,177,187$, 195, 197, 226, 229, 234, 236, et seq.; treatment of European visitors, 11, 101; town of, 119 , $156,172,198$; wives of, 111 , 112; Mandara's interviews with author, 104, 106, 110, 133, 169, 181,240 ; messages to author, 189, 190, et seq., 196; ideas about rent, 191; threats, 194, 196 ; 
ultimatum, 196; alliance with Masai, 204; leave-taking with author, 240, et seq.

Mandingo language, 447, 478.

Maùge, 192, 197, 198.

Mango, 329.

Marainu, 165, 181, 243, 248, 443 ; mission to, 245, et seq.; chief of, 247,255 , et seq. ; his mother, 253 ; his palace, 254; his soldiers, 292. Market at Kitimbiriu, 154, 155.

Marriage among Masai, 415.

Wa-taita, 431.

Wa-čaga, 437.

Wa-taveita, 433.

Masai, the 6, 7, 74, et seq., 78, 95, et seq., 165, 185, 209, et seq., 238, 289, 294, 302, et seq., 312, et seq., 397, et seq., 4.02, et seq., 443, 481, 537, 552; of Aruša, 97, 204, 397; of Kisongo, 204, 397; history of, 405 ; physical appearance of, 408 , et seq.; warriors, 403 ; mode of circumcision, 412 (foot-note); dress of, 414, marriage amongst, 415 , et seq.; burial of, 416 , et seq.; religion of, 417, et seq.; political constitution of, 418 ; blood-drinking of, 425 ; houses of, 419, et seq.; morals of, 419; domestic animals of, 421 ; utensils of, 420 ; future of, 426 .

Masai-land, 6, 11, 12, 210, 401, 425, 541.

Masai language, the, 400, 402, 448, et seq., 453-476, 501, et seq.

Matthews, General, 31, 105.

Matumbato, 397.

Man, El-, 424.

Maunigu, 54, 56, 58, ct seq., 65 .

Mauritius, 4 .

Mazindi, 310, et seq.

Mbe, Wa-. 397.

Mbugu, Wa-, 309, 310, 403.

Meal, 151, 155.

Means of transport in East Africa, 42.
Medical aid, demands for, 111, et seq.

Melons, 131, 547 .

Méru, Mount, 126, 127, 129, 178, $325,335,397,443,551$.

Mguu, 131.

Miers, E.'I., Mr., on the river-crabs of Kilima-njaro, 365.

Milk, 142, 148, 155, 157, 213, 214, $315,425,442$.

“Milkman, my," 157, 213.

Millet, 151, 424, 442.

Miltsin, Mount., 2.

Mint, 330.

Mission at Mombasa, 43.

- - Universities',311,316, et seq.

Missionaries, 8, 310.

Mkindu palm, 153.

Mkomazi River, 309, 312, 550.

Mkuyuni River, 85, 206, 207.

Mohammedanism, 4.08.

Mohammedans $v$. Clıristians, 43 .

Mombasa, 6, 7, 11, 15, 40, et seq., $307,399,452$.

- inhabitants of, 43 .

- missions of, 43 .

- slave-trade of, 97.

Monitor Niloticus, 361.

Monkeys, $117,160,212,350$, et seq., 485.

Moši, 10, 11, 79, 84, 87, 91, 94, et seq., 165, 212, 225, 323, 443.

114,144 .

—- invasion of, by Wa-kibôšo, 171.

-

Moths, 235.

Mountains, isolated, 4.

- of Paré, 301, 304, et seq. of Usambara, 310.

Mpala (pallah) antelope, 218, 301, 354.

Mpokomo, 95, 443.

Mpoingwe language, 493.

Msai, 443.

Mtesa of Bu-ganda, 63, 98, 149.

Musa Ensete, 331. 
Mustard and cress, 131, 149.

Mrale palm, 214.

Mwatate, 64 .

NAIVAŠA, Lake, 12

Nandi, countr'y of, 397 .

Natal, 3, 304, 363, 481, 485.

Natron salt, 424 .

Ndara of Taita, 59, 60, 64 .

Negro languages, 447.

- - and Bantu races, distinction between, 426, et seq., 482.

Negroes, 398, 482.

-, Nilotic, 399, 427, 482.

Neotragus, 354.

New, Rev. Charles, 10, 11, 12, 101, 106, 190, 193.

Ṅgiri, 326, 397.

Nguru, 449.

Nंgurunigani, 301, 310.

Niger, River, 478.

Nile, River, 210, 397, 399, 451, 475, 478, 481.

Nitrate of soda, 545,548 .

Njemps, vide J̌emsi, En-.

Nuba grammar, Lepsius', 400.

languages, 447, 451, 478 .

Nyamwezi, U-, 405.

Nyara, Bu-, 397.

“Nyika," the, 330, 395.

Nyika, A-, 398, 432.

- Ki-, 494 (and in vocabularies).

Nyoro, Bu-, 210.

$\longrightarrow, \mathrm{Ki}-$, 400, 483, 488, 493.

Orgob, El, 313.

Oliver, Professor, on the flora of Kilima-njaro, 337, et seq.

Onions, 131, 149, 547.

Orchids, 92, 121, 330, 336.

-_, Lissochilus, 51, 330.

Orchilla-lichen, 231, 235, 284, 332, 545,548 .

Oriole, a lovely, $350^{\circ}$.

Ornithology of Kilima-njaro, 377387.
Orthography of African words, ix. Orycteropus AEthiopicus, 300, 353. Osprey, H.M.S., 320.

Ostriches, 312, 293, 296, 300, 301, 359 , et seq., $485,540,542$.

Oxen, vide Cattle.

Ozi, River, 401.

PAcking goods of Expedition, 44, et seq.

Palms, 137, 153, 154, 336.

$\longrightarrow$, Borassus, 154, 329.

$\longrightarrow$ Cocos (cocoa-nut), 329.

- Elä̈s, 329.

—, Hyphœene, 154, 311, 329.

—, Phœenix (Mkindu), 153, 329. 329.

Palumbus arquativix, 358.

Pandanus, 329.

Pangani, 297, 315, et seq., 327, 398.

route, 184 .

Paré, country of, $297,301,304,306$, 309 , 536, 550; people of, 210, 306,309 , 398; language of, 307, 396.

Parinarium, 209.

Parrot, the grey, 485.

Party, author's, 48 ; number of, 48.

Peas, 149, 155, 158, 547.

Pelicans, 298, 359.

Persian influence, traces of, in Zanzibar, 17, 18, 537.

Phacochœerus, 422.

Pig, the, 422, 485.

Pigeons, 218, 296, 358.

Pinarochroa hypospodia, 270, 356.

Pira Doji, 30.

Plantations, the author's, at Kitimbiriu, 139, 149.

Plover's, 298.

Pokomo, Wa-, 397 ; Ki-, 494.

Polypodies, 336 .

Porters, food of, 46 ; dispute with, 48; Christian, 49; punishment of, 49 ; Rabai, 52, 101, 115, 120, 129, 130; without prevision or 
forethought, 56 ; Swahili, 146 ; maladies of, 146 .

Portuguese, the, $6,7,537$.

Potatoes, 149 ; sweet, 424, 546 .

Pottery, Oriental, in Zanzibar, 25. of Wa-čaga, 440 .

Prefixes, Bantu, 161, 491, et seq., 497, et seq.

Presents for Mandara, 106, 191, 241. $227,238$. from Maudara, 90, 179, to Marana $a, 255$. Wa-rombo, 295. Semboja, 315. Taveita, 78, 211.

Pythons, 361.

QuANZa, River, 210.

Queen, her Majesty the, 98, 105, 199, 308.

Quinine, the cultivation of, 549 .

Rabat, 48.

- men of, $63,101,115,120$, 129, 130.

Radishes, 131, 143, 149, 547 .

Rain, 300, 324, et seq.

Rapliza palms, 80, 154, 32.9, 434.

, fibre of, 45 .

Ravens, 235, 271, 277, 356 .

Ravenstein, Mr. E. G., 7, 478.

Rebmann, Rev. J., 7, 8, 9, 100, 108.

Religious beliefs among natives, $434,439,444,487$.

Reptiles of Kilima-njaro, 361, 543.

Rhinoceros, 216, 294, 301, 354, 485, 541.

Rice, 546, et seq.

River of Gonja, 307.

Rivers of Kilima-njaro, 326, et seq.

Roan antelope, 224.

Robinson Crusoe, 164 .

Rocks, curious, 270.

Rodentia, the, 353 .

Rombo, 281, 283, 287, 289, et seq., $295,326,443$.

- inhabitants of (Wa-), 287, 288, et seq., 443,494 .
Rombo the best approach to Kilima-njaro, 289.

Rori, Wa-, 397.

Royal Society, 6, 245.

Ruminantia, 354 .

Ruvu or Luvu River, 286, 297, 309, $315,327,396$, et seq., 405, 535 .

the, 315,550 .

SABAKr, River, 396, 399, 401, 537.

Sable antelope, 69, 301, 354 .

Sambara, U-, 297, 307, 309, et seq., $316,396,536,546,550$.

-

$\longrightarrow$ W Wa-, 210, 309, 398.

Samburu, 51.

- - Lake, 210, 552. language, 451 .

Samia, Ba-, 397.

Saniga, U-, 297; Wa-, 297.

Sanya, Wa-, 401.

Saracenic architecture of Zanzibar, 36,37 .

Savages, attack of, on Kiongwe, 166.

Scenery of Čaga, 230; of Paré, 307 ; of Africa, 324.

Sclater, Mr. P. L., vii., 3.

Seasons, rainy, 324.

Seeds of English vegetables, 131, 136.

Semboja, the chief, $307,309,312$, et seq.

Semitic languages, 398, 441.

Senecio Johnstoni, 233, 268, 337.

Seri, U., 232, 233, 236, 287, 294 326, 443; Wa-, 294.

Settlement, first, on Kilima-njaro vide Kitimbiriu.

- at Taveita, 208.

feet), 262.

UpperKilēma $(11,000$

Msai (8500 ft.), 285.

European, on Kilima-

njaro, 286, 290, 298.

Shaw, Rev. Downes-, 42, 48, 494.

Sheep, 135, 136, 147, 155, 211, 214, 
$229,230,234,302,306,315,422$, 546.

Shelley, Captain, on the birds of Kilima-njaro, 377-387.

Sickness among men at Upper Kilima-njaro, 280.

Sierra Leone, 478.

Sigirari, 397, 404.

Silurus, 363.

" Skarm," making a, 221.

Slave-traders, 96, 247,

— trading, 8, 11, 96,97,99, 18i , 247,555 .

Slaves, 97, 181, 212, 232, 247, 555,

Small-pox, 303, 487.

Snakes, 361 .

Snider rifles, 187, 252, 257, 292.

Snow, 7, 9, 279, 325, et seq.

- - on Kibô, 137, 152, 274, 325.

Kimawenzi, 152, 264, et seq., 325 .

\section{- Mount iléru, 3?5.}

"Snow Fiend," Mountain of the, 137.

Snuff, 424.

Sogonoi, Es-, 397.

Somali Land, 308.

- language, 501 . people, 398, et seq., 537 .

Spears, Masai, 421. —, Čaga, 176.

Spitting, the ceremony of, 213,411 , 438.

Sport, 298, 301, 540, 554.

Sporting picnic, a, 225 .

Sportsman's paradise, a, 301, 540 .

Spring, a warm, 269.

Squills, 66, 81.

Squirrels, 361.

Stanley, Mr. H. M., 116, 149, 398.

Sterculia, 209.

Stonechat, a, 270.

Storks, 298, 359.

-, marabou, 304, 423.

Struthius Danaoides, 359.

Strychnia, 153, 154, 330.
Sugar-cane, 64, 214, 424, 546, 549.

Sük, 397 ; language, 449, 451.

Sumatra, 4.

Sun-birds, 154, 269, 356.

Swahili language, 33, 36, 76, 104, $157,169,190,214,315,316,459$, 537.

398, 403, 436 .

traders, 6, 77, 79, 85, 98, $225,252,294,314,399,405,551$.

Switzerland, an African, 136, 164.

Sycamore-trees, 85, 119, 137, 209.

Silha language, 479 .

Šiluk people, 399, 501; language, 421, 447, 451, 478, 501, et seq., 540.

Sira, $232,443$.

Šuli language, 451, 541, et seq.

TA, Wa-, 401.

Taita, country of, $60,64,131,136$, 142, 165, 396, 428, 494.

- language (Ki-), 428, 431. , people of (Wa-), 60, 64, 65, 210, 215, et seq., 398, 428, et seq.

Tana, River (or Dana), 397, et seq., 401, 481, 536.

Taru, 54 .

Taveita, 74, 75, 205, 208, 212, 213, 290, 295, 297, 307, 320 .

- a a thor's settlement in, 206, 208,297 ; T. a congeries of nations and tongues, 210 ; elders of, 77 , et seq., 211,436 ; forest at, 209 ; river of, 77,79 (bridge over, $79,80)$.

- language of (Ki-taveita), 435, 494, et seq., 521, et seq.

- people of (Wa-taveita), 75,

76, 78, 209, 211, 214, 243, 398, 428, 432 ; their houses, 209, 214.

Temperature on Kilima-njaro, 275, 322 , et seq., 549.

Thelphusa, 363, 365 .

Thermometer, readings of, 323 , et seq. 


\section{INDEX.}

Thirst, sufferings from, 57, 291.

Thistles, 267.

Thomas, Mr. Carmichael, vii.

Thomas, Mr. Oldfield, on the mammals of Kilima-njaro, 387.

Thomson, Mr. Joseph, 6, 10, 11, 76, 98, 101, 106, 208, 252, 288, $326,397,399,404,449,538,540$, $541,551$.

Thorng, 81.

Thunderstorms on Kilima-njaro, $261,265$.

Timber, 544.

'Tobacco, 155, 264, 424, 547.

Tomatoes, 131, 547.

Trade goods in E. Africa, 44, et seq. Traders, native, 264, 540, 554 .

- Swahili, 77, 79, 85.

Tragelaphus, 354 .

Travel, African, 12, 68.

Tree-ferns, 231, 336.

Tumale language, 480 .

Turaco, the (Turacus Hartlaubi), $12,233,260,358$.

Turnips, 131, 149, 547.

Tutwa, Wa-, 397.

UGWENo, vide Gweno, U..

Ukambani, vide Kambani, U-.

Ulcers, 111, 14.7, 266.

Uru, 27\%, 443 .

Useri, vide Seri, U..

VARANus lizards, 209, 212, 361.

Vegetables, European, 547.

Venice, a vegetable, 209.

Victoria Nyanza, 1, 2, 9, 98, 210, $324,395,399,488,494,535,538$, et seq.

Nile, $98,488,551$.

View from Mandara's town, 111.

— towards Mačame, 124. Méru, 126.

Ugweno, 125.

Violets, 336.

Virapan(Indian servant), 40,49,57,
$58,136,145,148,168,178,190$, 214, 232, 266, 301, 302, 351.

Vocabularies, collecting, 160 .

\&c., 501.

of Masai, Latuka, Ki-čaga, Ki-ta-

veita, \&c., et seq., 521 .

401. - Waboni and Galla,

- Šuli, Kavirondo,

Bari, \&c., 400.

Volcano, Kilima-njaro an extinct, 1,326 .

Vultures, 128, 176, 177, 216, 220, 304, et seq., 359, 423.

WAGGONs used for transport, 552 .

Wakefield, Rev. Thomas, 42, 48.

War fires, 169.

Wart-hog (Phacochcerus), 216, 218, $422,424$.

Wasps, 269, 363.

Water-birds, 359 . falls, 307. of Jipé, 298.

Watercourses, artificial, of Čaga, $117,118,120,121,123$.

Waterhouse, Mr. Charles O, on the Coleopter a Kilima-njaro, 372 377.

Wax, 547.

Wilderness, African, 58, 81, 395.

Wild animals, sale of, 548 .

- flowers, 50, 87, 91, 147, 148, $230,233,235,267,329$.

Wing of ostrich, 359 .

Wolof, the, Negroes, 427.

Worm, note on a nematoid, 364 .

XYLORORUS, 363.

YAO people, the, 61, 299.

ZAMBESI, 98, 334, 422, 493, 552.

- Expedition, the, 19.

Zanzibar, 13, 15, 248, 319 .

- architecture of, 36, 37 ; army of, 35; history of, 17 ; houses 
of, 28 ; population of, 35 ; position of, 17 ; streets of, 35 ; trade of, 35 ; vegetation of, 37 ; zoology of, 37 .

Zanzibar, Sultan of (Sayyid Baryašs), 20, 98, 99, 100, 307, 313,315; his appearance, 32 ; character, 34; clock-tower, 29 ; flag, 313 ; income, 35 ; a visit to, 31 ; his palace, 31 .

Zanzibaris, 13, 553.

$\longrightarrow$, author's, 40, et seq., 48, $49,52,63,109,115$, et seq., 130,
$146,166,179,184,195,266,270$, 318.

Zebras, 66, 68, 216, 220, 224, 301. 485.

Zegūha, or Zegūa, Wa-, 307, 310, 398.

Ziwani, 52, 54 .

Zoology, the, of Kilima-njaro, 350 -394 .

Zanzibar, 37.

Zulu, 288, 430, 482, 488, et seq. Zunigu, Wa- (white man), 317.

THE END. 


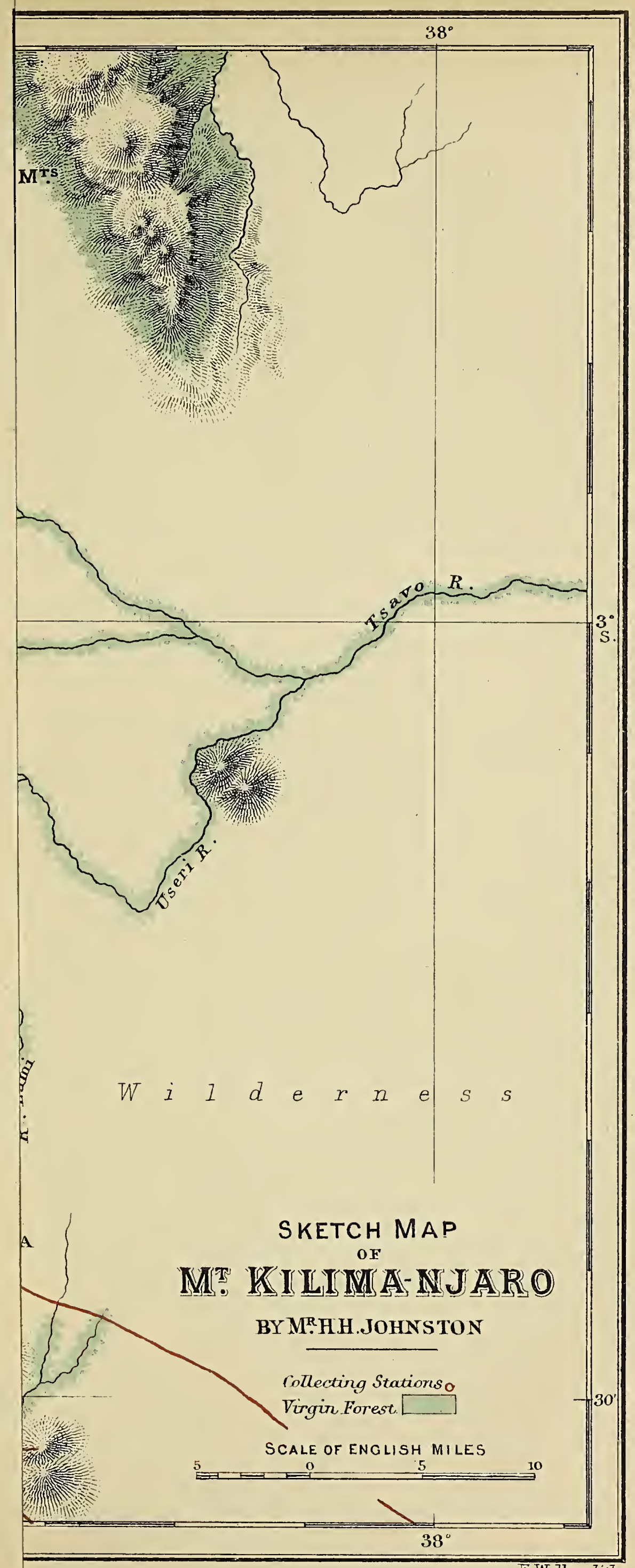




A LIST OF

KEGAN PAUL, TRENCH, \& CO.'S PUBLICATIONS. 


\section{KEGAN PAUL, TRENCH, \& CO.'S P U B L I C AT I O N S.}

\section{CONTENTS.}

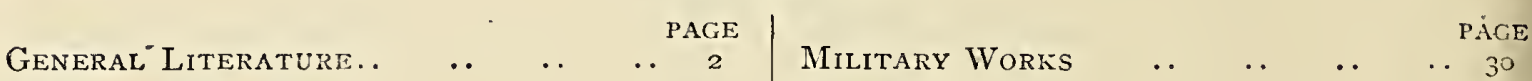

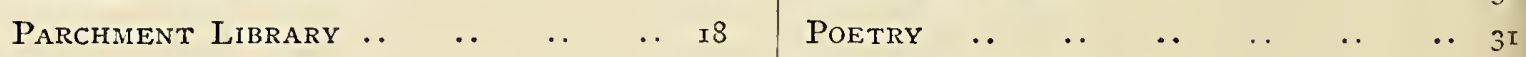
\begin{tabular}{llllll|llllllll} 
Pulpit Commentary &.. &. &. &. &. & 20 & Works of Fiction &.. &. & . & . & .. & 35
\end{tabular}

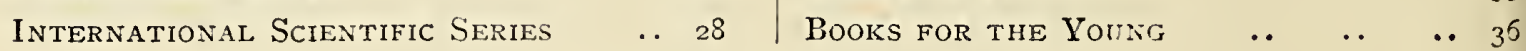

A. K. H. B.-Froni a Quiet Place. A New Volume of Sermons. Crown 8vo. 5 s.

ALEXANDER (William,D.D., Bishop of Derry)-The Great QuesTION, and other Sermons, Crown 8vo. 6s.

ALLEN (Rev. R.) M.A.-Abraham; his Life, Times, and Travels, 3,800 years ago. Second Edition. Post 8vo. 6s.

ALLIES (T. W.) M.A.-Per Crucem ad Lucem. The Result of a Life. 2 vols. Demy 8 vo. 25 s.

A Life's Decision. Crown 8vo. $7 s .6 d$.

AMHERST (Rev. W.J.)-The History of Catholic Emancipation and the Progress of the Catholic Church in the British Isles (Chiefy in Evgland) From 1771-1820. 2 vols. Demy 8vo. 24s.

AMOS (Prof. Sheldon)-The History and Principles of the Civil LAw of Rome. An aid to the study of Scientific and Comparative Jurisprudence. Demy 8vo. I6s.

Ancient and Modern Britons: a Retrospect. 2 vols. demy 8vo. $24 s$. ANDERDON (Rev. W. H.)--Evenings with the Saints. Crown 8vo. 5 s. ANDERSON (David) - 'Scenes' in the Commons. Crown 8vo. 5 s. ARISTOTLE-The Nicomachean Ethics of ARistotle. Translated by F. H. Peters, M.A. Second Edition. Crown 8vo. $6 s$.

ARMSTRONG (Richard A.) B.A. - Latter-Day Teachers. Six Lectures. Small crown 8 vo. $2 s .6 d$.

AUBERTIN $\left(J \cdot J_{.}\right)$-A Flight to Mexico. With 7 full-page Illustrations and a Railway Map of Mexico. Crown 8vo. 7 s. $6 d$.

Six Months in Cape Colony and Natal. With Illustrations and Map. Crown 8vo. $6 s$.

BADGER (George Percy) D.C.L.-An English-Arabic Lexicon. In which the equivalents for English Words and Idiomatic Sentences are rendered into literary and colloquial Arabic. Royal 4to. 8os. 
BAGEHOT (Walter)-The English Constitution. New and Revised Edition. Crown 8vo. 7s. $6 d$.

Lombard Street. A Description of the Money Market. Eighth Edition. Crown 8vo. 7s. 6d.

Essays on Parliamentary Reform. Crown 8vo. 5 s.

Some Articles on the Depreciation of Silver, and Topics CONNECTED With it. Demy 8 vo. 5 s.

BAGOT (Alan) C.E.-Accidents in Mines : Their Causes and Prevention. Crown 8vo. $6 s$.

The Principles of Colliery Ventilation. Second Edition, greatly enlarged, crown 8 vo. 5 s.

The Principles of Civil Engineering in Estate Management. Crown 8vo. 7s. $6 d$.

BAKER (Sir Sherston, Bart.)-The Laws Relating to Quarantine. Crown 8vo. I2s. $6 d$.

BAKER (Thomas)-A Battling Life; chiefly in the Civil Service. An Autobiography, with Fugitive Papers on Subjects of Public Importance. Crown 8vo. 7s. 6d.

BALDWIN (Capt. J. H.) - The Large and Smali Game of Bengal and the North-Western Provinces of India. Small 4to. With 20 Illustrations. New and Cheaper Edition. Small 4to. Ios. $6 d$.

BALLIN ( $A d a$ S. and F. L.)-A Hebreiv Grammar. With Exercises selected from the Bible. Crown 8vo. $7 s .6 d$.

$B A L L$ (John, F.R.S.) - Notes of a Naturalist in South America.

BARCLAY (Edgar)-Mountain Life in Algeria. Crown 4 to. With numerous Illustrations by Photogravure. I $6 s$.

BARLOW $(\mathcal{F} . W$.$) M.A.-The Ultimatum of Pessimism. An Ethical$ Study. Demy 8vo. $6 s$.

Short History of the Normans in South Europe. Demy 8vo. 7 s. $6 d$.

BAUR (Ferdinand) Dr. Ph., Professor in Maulbronn.-A Philological. Introduction to Greer and Lativ for Students. Translated and adapted from the German by C. Kegan Paul, M.A., and the Rev. E. D. Stone, M.A. Third Edition. Crown 8vo. 6s.

BA YLY (Capt. George)_Sea Life Sixty Years Ago. A Record of Adventures which led up to the Discovery of the Relics of the long-missing Expedition commanded by the Comte de la Perouse. Crown 8vo. 3s. 6d.

BELLASIS (Edruard)-The Money Jar of Plautus at the Oratory ScHOOL : An Account of the Recent Representation. With Appendix and I6 Illustrations. Small 4to. $2 s$.

The New Terence at Edgbaston. Being Notices of the Performances in I880 and I88I. With Preface, Notes, and Appendix. Third Issue. Small 4to, is, $6 d$.

$B E N N($ Alfred $W$.) - The Greek Philosophers. 2 vols. Demy 8vo. $28 s$. BIBLE FOLK-LORE.-A Study in Comparative Mythology. Large crown 8 vo. Ios. $6 d$. 
BIRD (Charles) F.G.S.-Higher Education in GERMany and ENGLAND : Being a Brief Practical Account of the Organisation and Curriculum of the German Higher Schools. With Critical Remarks and Suggestions with reference to those of England. Small crown 8vo. 2s. $6 d$.

BLACKBURN (Mrs. Hugh)-Bible Beasts and Birus. A New Edi. tion of 'Illustrations of Scripture by an Animal Painter.' With Twenty-two Plates, Photographed from the Originais, and Printed in Platinotype. 4to. cloth extra, gilt edges, $42 s$.

BLACKLEY (Rev. W. S.)-Essays on Pauperism. I6mo. sewed, Is.

BLECKLY (Henry)-Socrates ANd the Athenians: an Apology。 Crown 8vo. 2s. $6 d$.

BLOOMFIELD (The Lady)-Reminiscences of Court and Diplo. MATIC Life. New and Cheaper Edition. With Frontispiece. Crown 8vo. 6s.

BLUNT (The Ven. Archdeacon)-The Divine Patriot, and otherer SERMons, Preached in Scarborough and in Cannes. New and Cheaper Edition. Crown 8vo. 4 s. $6 d$.

BLUNT (Wilfrid S.)-The Future of Islan. Crown 8vo. 6s.

IDEAS ABOUT INDIA. Crown 8vo. cloth, $6 s$.

3ODDY (Alexander A.)-To KAIRwÂN the Holy. Scenes in Muhammedan Africa. With Route Map, and 8 Illustrations by A. F. JACAssEy。 Crown 8vo. 6s.

BOSANQUET (Bernard)-Knowledge aNd REality. A Criticism of Mr. F. H. Bradley's 'Principles of Logic.' Crown 8vo. 9s.

BOUVERIE-PUSE $Y(S . E . B$.$) -Permanence and Evolution. An$ Inquiry into the supposed Mutability of Animal Types. Crown 8vo. $5 s$.

BOWEN (H. C.) M.A.-STUdies in ENGLish, for the use of Modern Schools. 7th Thousand. Small crown 8vo. is. $6 d$.

English Grammar for Beginners. Fcp. 8vo. is.

Simple English Poems. English Literature for Junior Classes. In

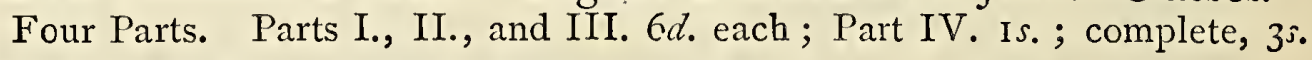

BRADLEY $(F . H$.$) -The Principles of Logic. Demy 8vo. x6s.$

BRIDGETT (Rev. T. E.)- History of the Holy Eucharist in Great Britain. 2 vols. Demy 8vo. iss.

BRODRICK (The Hon. G. C.)-Political Studies. Demy 8vo. i $4 s$.

BROOKE (Rev. S. A.)-Life and Letters of the Late Rev. F. W. Robertson, M.A. Edited by.

I. Uniform with Robertson's Sermons. 2 vols. With Steel Portrait, 7s. 6d.

II. Library Edition. 8vo. With Portrait, I2s.

III. A Popular Edition. In I vol. 8vo. $6 s$.

ThE Fight of Faith. Sermons preached on various occasions. Fifth Edition. Crown 8vo. 7 s. $6 d$.

The Spirit of the Christian Life. Third Edition. Crown 8vo. 5 s.

Theology in the English Poets.-Cowper, Coleridge, Wordsworth, and Burns. Fifth Edition. Post 8vo. 5 s.

Christ in Modern Life. Sixteenth Edition. Crown 8vo. 5 . Sermons. First Series. Thirteenth Edition. Crown 8vo. $5 s_{0}$ Sermons, Second Series. Sixth Edition. Crown 8vo. $5^{\text {s. }}$ 
BROWNE (H. L.)-Reason and Religious Belief. Crown 8vo. 3s. $6 d$.

BROWN (Rev. T. Baldwin) B.A.-The Higher Life: its Reality, Experience, and Destiny. Sixth Edition. Crown 8vo. $5^{5}$.

Doctrine of AnNihilation in the Light of the Gospel of Love. Five Discourses. Fourth Edition. Crown 8vo. 2s. 6d.

The Christian Policy of Life. A Book for Young Men of Business. Third Edition. Crown 8vo. 3s. $6 d$.

BROWN (Horatio F.)-Life on THE LAGooNs. With two Illustrations and a Map. Crown 8vo. 6 s.

BURDETT (Henry C.)-HeLP IN Sickness : Where to Go and What to Do. Crown 8 vo. Is. $6 d$.

Helps to Health : The Habitation, The Nursery, The Schoolroom, and The Person. With a Chapter on Pleasure and Health Resorts. Crown 8vo. Is. 6d.

BURKE (The late Very Kev. T. N.)-His Life. By W. J. Fitzpatrick. 2 vols. With Portrait. Demy 8vo. 30 s.

BURTON (Mrs. Richard)-The InNer Life of Syria, Palestine, and THe Holy Land. Post 8vo. 6 s.

CAPES (J.M.)-The Church of the Apostles: an Historical Inquiry. Demy 8vo. $9 s$.

Carlyle and the Open Secret of His Life. By Henry laarkin. Demy 8vo. I 4 s.

CARPENTER (W. B.) LL.D., M.D., F.R.S., \&.C-The PRINCIPLES of Mental Physiology. With their Applications to the Training and Discipline of the Mind, and the Study of its Morbid Conditions. Illustrated. Sixth Edition. 8vo. I2s.

Catholic Dictionary-Containing some account of the Doctrine, Discipline, Rites, Ceremonies, Councils, and Religious Orders of the Catholic Church. By Wildiam E. Addis and Thomas Arnold, M.A. Third Edition, demy 8vo. 2Is.

CHARLES (Rev. R. H.) -Forgiveness, and other Sermons. Crown 8vo. CHE YNE (Rev. Canon, M.A., D.D., Edin.)-Job AND Solomon; or, the Wisdom of the Old Testament. Demy 8vo.

The Prophecies of Isalah. Translated with Critical Notes and Dissertations. 2 vols. Third Edition. Demy 8vo. 25 s.

Circulating Capital. Being an Inquiry into the Fundamental Laws of Money. An Essay by an East India Merchant. Small crown 8vo. 6s.

CLAIRAUT-Elements of Geometry. Translated by Dr. Kaines. With 145 Figures. Crown 8vo. $4 s .6 d$.

CLAPPERTON (Jane Hume)--Scientific Meliorism and the EvoLUTION OF Happiness. Large crown 8 vo. 8s. $6 d$.

CLARKE (Kev. Henry James) A.K.C.-The Fundamental Science. Demy 8vo. Ios. 6d.

CLA YDEN $(P . W$.$) -SaMuel Sharpe-Egyptologist and Transla-$ TOR OF THE BIBLe. Crown 8vo. $6 s$.

CLODD (Edward) F.R.A.S.-ThE CHILDhoOd OF THE WORLD: a Simple Account of Man in Early Times. Seventh Edition. Crown 8vo. $3^{s}$. A Special Edition for Schools, Is. 
CLODD (Edward)-continued.

The Childhood of Religions. Including a Simple Account of the Birth and Growth of Myths and Legends. Eighth Thousand. Crown 8vo. 5 s.

A Special Edition for Schools. Is. $6 d$.

JESUS OF NAZARETH. With a brief sketch of Jewish History to the Time of His Birth. Small crown 8vo. 6s.

COGHLAN (J. Cole) D.D.-The Modern Pharisee, and other Sermons. Edited by the Very Rev. H. H. Dickinson, D.D., Dean of Chapei Royal, Dublin. New and Cheaper Edition. Crown 8vo. 7s. 6d.

COLE (George R. Fitz-Roy)--The Peruvians at Honte. Crown 8vo. $6 s$. COLERIDGE (Sara)-Memoir and LetTers of SARA Coleridge. Edited by her Daughter. With Index. Cheap Edition. With one Portrait. $7 s .6 d$.

COLLECTS EXEMPLIFIED (The) - Being Illustrations from the Old and New Testaments of the Collects for the Sundays after Trinity. By the Author of 'A Commentary on the Epistles and Gospels.' Edited by the Rev. Joseph JACKSON. Crown 8vo. 5 s.

CONNELL $(A . K$. $)$-Discontent and Danger in India. Small crown 8vo. 3s. $6 d$.

The Economic Revolution of India. Crown 8vo. 4 s. $6 d$.

COOK (Keningale, LL.D.)-The Fathers of Jesus. A Study of the Lineage of the Christian Doctrine and Traditions. 2 vols. Demy 8vo. $28 s$.

CORR (The late Rev. Thomas)-Essays, Tales, Allegories, and Poems. Crown 8vo.

CORY (William)-A Guide to Modern English History. Part I.MDCCCXV.-MDCCCXXX. Demy 8vo. 9s. Part II.-MDCCCXXX.MDCCCXXXV. I5s.

COTTERILL $(H . B$.$) -An Introduction to the Study of Poetry.$ Crown 8vo. 7s. 6d.

$\operatorname{COTTON}(H . J . S)-.\mathrm{New}$ India, or India IN Transition. Third Edition. Crown 8vo. $4 s .6 d$. Popular Edition, paper covers, $I s$.

COUTTS (Francis Burdett Money)-The TraIning of the Instinct of Love. With a Preface by the Rev. Edward Thring, M.A. Small crown 8vo. 2s. $6 d$.

COX (Rev. Sir George W.) M.A., Bart.-The Mythology of the AryaN Nations. New Edition. Demy 8vo. 16s.

Tales of Ancient Greece. New Edition. Small crown 8vo. 6s.

A Manual of Mythology in The form of Question and Answer. New Edition. Fcp. 8vo. 3s.

An Introduction to the Science of Comparative Mythology AND FOLK-LORE. Second Edition. Crown 8vo. 7s. $6 d$.

COX (Rev. Sir G. W.) M.A., Bart., and JONES (Eustace Hinton)Popular Romances of the Middle Ages. Third Edition, in I vol. Crown 8vo. 6s.

COX (Rev. Samuel) D.D.-A Commentary on the Book of Job. With a Translation. Demy 8vo. ${ }^{5} 5$.

Salvator Mundi ; or, Is Christ the Saviour of all Men? Tenth Edition. Crown 8vo. $5^{s}$. 
COX (Rev. Samuel)-continued.

The Larger Hope : a Sequel to 'Salvator Mundi.' Second Edition. 16 mo. Is.

The Genesis of Evil, and other Sermons, mainly expository. Third Edition. Crown 8vo. 6 s.

Balaam : An Exposition and a Study. Crown 8vo. 5 s.

Miracles. An Argument and a Challenge. Crown 8vo. 2s. $6 d$. CRAVEN (Mrs.) - A Year's Meditations. Crown 8vo. 6s.

CRAWFURD (Oswald) - Portugal, Old AND NEw. With Illustrations and Maps. New and Cheaper Edition. Crown 8vo. $6 s$.

CROZIER (John Beattic) M.B.-The Religion of the Future. Crown 8vo. 6 s.

CRUISE (F.R., M.D.)-Thomas à Kempis. Notes of a Visit to the Scenes in which his Life was spent, with some Account of the Examination of his Relics. Demy 8vo. Illustrated.

CUNNINGHAM (W., B.D.)-Politics AND Economics: An Essay on the Nature of the Principles of Political Economy, together with a Survey of Recent Legislation. Crown 8vo. 5 s.

DANIEL (Gerard)-Mary Stuart : a Sketch and a Defence. Crown 8 vo. 5 s.

DANIELL (Clarmont)-The Gold Treasure of India : An Inquiry into its Amount, the Cause of its Accumulation, and the Proper Means of Using it as Money. Crown 8vo. 5 s.

Discarded Silver : a Plan for its Use as Money. Small crown 8 vo. $2 s$.

DARMESTETER (Arsène)-The Life of Words as the Symbols OF IDEAS. Crown 8vo. 4 s. $6 d$.

DAVIDSON (Rev. Samul) D.D., LL.D.-Canon of the Bible: Its Formation, History, and Fluctuations. Third and revised Edition. Small crown 8 vo. 5 s.

The Doctrine of Last Things, contained in the New Testament, compared with the Notions of the Jews and the Statements of Church Creeds. Small crown 8 vo. $3 s .6$.

DAWSON (Geo.) M.A.-Prayers, with a Discourse on Prayer. Edited by his Wife. First Series. New and Cheaper Edition. Crown 8 vo. 3s. $6 d$.

Prayers, with a Discourse on Prayer. Edited by George St. Clair. Second Series. . Crown 8 vo. $6 s$.

Sermons on Disputed Points and Special Occasions. Edited by his Wife. Fourth Edition. Crown 8vo. 6s.

Sermons on Daily Life and Duty. Edited by his Wife. Fourth Edition. Crown 8vo. $6 s$.

The Authentic Gospex, and other Sermons. Edited by George St. Clair. Third Edition. Crown 8vo. $6 s$.

Biographical Lectures. Edited by George St. Clair, F.G.S. Large crown 8 vo. $7 s .6 d$. 
DE JONCOURT (Madame Marie)-Wholesome CoOkery. Third Edition. Crown 8vo. 3s. $6 d$.

Democracy in the Old World and the New. By the Author of 'The Suez Canal, the Eastern Question, and Abyssinia,' $\&$ c. Small crown 8vo. 2s. $6 d$.

DENT (H. C.) - A Year in Brazil. With Notes on Religion, Meteor. ology, Natural History, \&c. Maps and Illustrations, Demy 8vo. I8s.

Discourse on the Shedding of Blood, and The Laws of War. Demy 8vo. 2s. $6 d$.

DOUGLAS (Rev. Herman)-Into the Deep; or, The Wonders of the Lord's Person. Crown 8vo. 2s. $6 d$.

DOWDEN (Edzard) LL.D.-ShaKSPERE : a Critical Study of his Mind and Art. Seventh Edition. Post 8vo. I2s.

Studies in Literature, I789-I877. Third Edition. Large post 8 vo. $6 s$.

Dulce Domum. Fcp. 8vo. 5 s.

DU MONCEL (Count)-The Telephone, the Microphone, and the Phonograph. With 74 Illustrations. Second Edition. Small crown 8vo. 5 s.

DURUY (Victor)-History of Rome and the Roman People. Edited by Professor MAHAFFY, with nearly 3,000 Illustrations. 4to. 6 Vols. in I2 Parts, 30s. each volume.

EDGEWORTH (F. Y.)-Mathematical Psychics. An Essay on the Application of Mathematics to Social Science. Demy 8vo. 7 s. $6 d$.

Educational Code of the Prussian Nation, in its Present Form. In accordance with the Decisions of the Common Provincial Law, and with those of Recent Legislation. Crown 8vo. 2s. 6d.

Education Library. Edited by Sir Philip Magnus :-

An Introduction to the History of Educational Theories. By Oscar Browning, M.A. Second Edition. 3s. $6 d$.

Old Greer Education. By the Rev. Prof. Mahaffy, M.A. Second Edition. 3s. 6d.

School Management ; including a General View of the Work of Education, Organization, and Discipline. By Joseph Landon. Fifth Edition. Crown 8vo. 6s.

EDWARDES (Major-General Sir Herbert B.)-MEMoRIALS of HIS Life AND LeTTERs. By his WIFE, With Portrait and Illustrations. 2 vols. Demy 8vo. 36 s.

ELSDALE (Henry)-Studies in Tennyson's Idylls. Crown 8vo. 5 s.

EMERSON'S (Ralph Waldo) Life. By Oliver Wendell Holmes. [English Copyright Edition.] With Portrait. Crown 8vo. 6s.

Enoch, The Prophet. The Book of. Archbishop Laurence's Translation. With an Introduction by the Author of the 'Evolution of Christianity.' Crown 8vo. 5 s.

ERANUS. A Collection of Exercises in the Alcaic and Sapphic Metres. Edited by F. W. Cornish, Assistant Master at Eton. Second Edition. Crown 8vo. $2 s$.

EVANS (Mark)-The Story of our Father's Love, told to Children. Sixth and Cheaper Edition. With Four Illustrations. Fcp. 8vo. Is. 6d. 
Faith of the Unlearned, The. Authority, apart from the Sanction of Reason, an Insufficient Basis for It. By 'One Unlearned,' Crown 8vo. 6s.

'FAN KWAE' at Canton before Treaty Days, r825-r844. By An Old Resident. With Frontispiece. Crown 8vo. 5 s.

FEIS ( Jacob)-Shakspere and Montaigne : An Endeavour to Explain the Tendency of Hamlet from Allusions in Contemporary Works. Crown 8 vo. 5 s.

Frve o'Clock Tea. Containing Receipts for Cakes of every description, Savoury Sandwiches, Cooling Drinks, \&c. By the Author of 'Breakfast Dishes' and 'Savouries and Sweets.' Fcp. 8vo. Is. 6d., or Is. sewed.

FLOREDICE ( W. H.)-A Month among the Mere Irish. Small crown 8 vo. 5 s.

Frank Leward. Edited by Charles Bampton. Crown 8vo. $7 s .6 d$.

FULLER (Rev. Morris) - The LoRd's Day ; or, Christian Sunday. Its Unity, History, Philosophy, and Perpetual Obligation. Sermons. Demy 8 vo. IOs. $6 d$.

GARDINER (Samuel R.) and J. BASS MULLINGER, M.A.Introduction to the Study of English History. Second Edition. Large crown 8vo. 9s.

GARDNER (Dorsey) - Quatre Bras, Ligny, and Waterloo. A Narrative of the Campaign in Belgium, I815. With Maps and Plans. Demy 8 vo. I6s.

GELDART (E. M.)-Echoes of Truth. Sermons, with a Short Selection of Prayers and an Introductory Sketch, by the Rev. C. B. Upron. Crown 8 vo. $6 s$.

GEORGE (Henry)-Progress and Poverty : an Inquiry into the Causes of Industrial Depressions, and of Increase of Want with Increase of Wealth. The Remedy. Fifth Library Edition. Post 8vo. 7s. 6d. Cabinet Edition, crown 8vo. 2s. $6 d$.

$*_{*}^{*}$ Also a Cheap Edition, limp cloth, Is. $6 d$; ; paper covers, I $s$.

Social Problems. Crown 8vo. 5 s.

** Also a Cheap Edition, paper covers, is.

Protection, or Free Trade. An Examination of the Tariff Question, with especial regard to the Interests of Labour. Crown 8vo. 5 s.

GLANVILL (Joseph)-Scepsis Scientifica ; or, Confest Ignorance, the Way to Science; in an Essay of the Vanity of Dogmatising and Confident Opinion. Edited, with Introductory Essay, by JOHN OwEN. Elzevir 8vo. printed on hand-made paper, $6 s$.

Grossary of Terms and Phrases. Edited by the Rev. H. Percy Smith and others. Medium 8 vo. 7 s. $6 \%$.

GLOVER (F.) M.A.-Exempla Latina. A First Construing Book, with Short Notes, Lexicon, and an Introduction to the Analysis of Sentences. Second Edition. Fcp. 8vo. $2 s$.

GOLDSMID (Sir Francis Henry) Bart., Q.C., M.P.-MemoIr of. Second Edition, revised. Crown 8vo. 6s.

GOODENOUGH (Commodore J. G.)-MeMoIR of, with Extracts from his Letters and Journals. Edited by his Widow. With Steel Engraved Portrait. Third Edition. Crown 8vo. $5^{s}$. 
GORDON (Major-Gen. C. 'G.)-His Journals at Kartoum. Printed from the Original MS. With Introduction and Notes by A. EGMroNT HAKE. Portrait, 2 Maps, and 30 Illustrations. 2 vols. Demy 8vo. 2Is. Also a Cheap Edition in I vol., $6 s$.

Gordon's (General) Last Journal. A Facsimile of the last Journal received in England from General Gordon. Reproduced by Photolithography. Imperial 4to. $63.3 s$.

Events In HIS Life. From the Day of his Birth to the Day of his Death. By Sir H. W. Gordon. With Maps and Illustrations. Demy 8vo. I8s.

GOSSE (Edmund) - Seventeenth Century Studies. A Contribution to the History of English Poetry. Demy 8vo. Ios. 6d.

GOULD (Rev. S. Baring) M.A.-Germany, Present and Past. New and Cheaper Edition. Large crown 8 vo. 7 s. $6 d$.

The Vicar of Morwenstow : a Life of Robert Stephen Hawker, M.A. New and Cheaper Edition. Crown 8vo. $5 s$.

GOWAN (Major Walter E.) - A. Ivanoff's Russian Grammar. (I6th Edition). Translated, enlarged, and arranged for use of Students of the Russian Language. Demy 8vo. 6s.

GOWER (Lord Ronald)-My Reminiscences. Limp Parchment, Antique, with Etched Portrait, IOs. $6 d$.

Last Days of Mary Antoinette. An Historical Sketch. With Portrait and Facsimiles. Fcp. 4to. 10s. 6d.

Notes of a TOUR From Brindisi to Yokohama, i883-I884. Fcp. 8vo. $2 s .6 d$.

GRAHAM (William) M.A.-The Creed of Science, Religious, Moral, and Social. Second Edition, revised. Crown 8vo. $6 s$.

The Social Problem in its Economic, Moral, and Political Aspects. Demy 8vo. I 4 s.

GREY (Rozuland).-In Sunny Switzerland. A Tale of Six Weeks. Small crown 8vo. 5 s.

Lindenblumen, and other Stories. Small crown 8vo. 5 s.

GRIMLEY (Rev.H. N.) M.A.-Tremadoc Sermons, Chiefly on the Spiritual Body, the Unseen World, and the Divine Humanity. Fourth Edition. Crown 8vo. 6s.

The Temple of Humanity, and other Sermons. Crown 8vo. 6 s.

GUSTAFSON (Axel)-The Foundation of Death. A Study of the Drink Question. Fourth Edition. Crown 8vo. 5 s.

Some Thoughts on Moderation. Reprinted from a Paper read at the Reeve Mission Room, Manchester Square, June 8, i885. Crown 8vo. Is.

haDDON (Caroline)-The Larger Life, Studies in Hinton's Eтhics. Crown 8vo. 5 s.

HAECKEL (Prof. Ernst)-The History of Creation. Translation revised by Professor E. Ray Lankester, M.A., F.R.S. With Coloured Plates and Genealogical Trees of the various groups of both plants and animals. 2 vols. Third Edition. Post 8 vo. $32 s$.

The History of the Evolution of Man. With numerous Illustrations. 2 vols. Post 8vo. $32 s$.

A Visit to Ceylon. Post 8vo. 7 s. $6 d$.

Freedom in Science and Teaching. With a Prefatory Note by T. H. Huxley, F.R.S. Crown 8 vo. 5 s. 
HALF-Crown SERIES :-

A Lost Love. By Anna C. Ogle (Ashford Owen).

Sister Dora : a Biography. By Margaret Lonsdale.

TRUE WORDS FOR BRAVE MEN : a Book for Soldiers and Sailors. By the late CHARLES KINGSLEY.

NOTES OF TRAVEL : being Extracts from the Journals of Count voN MOLTKE.

English Sonnets. Collected and Arranged by J. Dennis.

Home Songs for Quiet Hours. By the Rev. Canon R. H. Baynes. Hamilton, Memorrs of Arthur, B.A., of Trinity College, Cambridge. Crown 8vo. $6 s$.

HARRIS (William)-The History of the Radical Party in ParliaMENT. Demy 8vo. I5s.

HARROP (Robert)-BolingBroke. A Political Study and Criticism. Demy 8vo. I 4 s.

HART (Rev. T. W. T.)-Autobiography of Judas Iscariot. A Character-Study. Crown 8vo. 3 s. $6 \%$.

HAWETS (Rev. H. R.) M.A.-CURRENT CoIN. Materialism-The Devil - Crime - Drunkenness - Pauperism - Emotion - Recreation - The Sabbath. Fifth Edition. Crown 8vo. 5s.

Arrows IN THE AIr. Fifth Edition. Crown 8vo. $5^{s}$.

Speech In SEason. Fifth Edition. Crown 8vo. 5 s.

Thoughts fOR the Times. Fourteenth Edition. Crown 8vo. 5 s.

Unsectarian Family Prayers. New Edition. Fcp. 8vo. is. 6d.

HAWKINS (Edwards Comerford) - SPIRIT AND FoRM. Sermons preached in the Parish Church of Leatherhead. Crown 8 vo. $6 s$.

HAWTHORNE (Nathaniel)-WORKs. Complete in $\mathrm{x}_{2}$ vols. Large post 8 vo. each vol. 7 s. 6 d.

VOL. I. TWICE-TOLD TALES.

II. MOSSES fRom an OLd Manse.

III. The House of the Seven Gables, and The Snow Image.

IV. The Wonder Book, TaNGlewood Tales, and Grandfather's Chair.

V. The Scarlet LetTer, and The Blituedale Romance.

VI. The MARble FaUn. (Transformation.)

VII, \& VIII, OUR OLD HOME, and ENGLISH NOTE-BOOKS.

IX. AMErican Note-Books.

X. French and Italian Note-Books.

XI. Septimius Felton, The Dolliver Romance, Fanshawe, and, in an appendix, THE ANCESTRAL FOOTSTEP.

XII. Tales and Essays, and other Papers, with a Biographical SKETCH OF HAWTHORNE.

HEATH (Francis George)-AUTumnat Leaves. Third and Cheaper Edition. Large crown 8vo. $6 s$.

Sylvan Winter. With yo Illustrations. Large crown 8vo. I4s.

HEGEL-The INTRoduction to HEGEL'S PhILOSOPHY of Fine ART. Translated from the German, with Notes and Prefatory Essay, by BERNARD Bosanquet, M.A. Crown 8vo. 5 s.

HENNESSY (Sir John Pope)-RALEGH IN IRELAND, WITH HIS LETTERS ON IRISH AFFAIRS AND SOME CONTEMPORARY DOCUMENTS, Large crown 8vo. printed on hand-made paper, parchment, ros. $6 d$. . . 
heNR Y (Philip) -Diaries and Letters. Edited by Matthew Henry LEE, M.A. Large crown 8vo. 7 s. 6 .

HiNTON $(J$.$) -The Mystery of Pain. New Edition. Fcp. 8vo. is.$

LIFE AND LETTERS. With an Introduction by Sir W. W. Guld, Bart., and Portrait engraved on Steel by C. H. JeEns. Fifth Edition. Crown 8vo. 8s. 6d.

Philosophy and Religion. Selections from the MSS. of the late James Hinton. Edited by Caroline Haddon. Second Edition. Crown 8 vo. 5 s.

The Law Breaker and The Coming of the Law. Edited by Margaret Hinton. Crown 8vo. $6 s$.

Hodson of Hodson's Horse; or. Twelve Years of a Soldier's Life in India. Being Extracts from the Letters of the late Major W. S. R. Hodson. With a vindication from the attack of Mr. Bosworth Smith. Edited by his brother, G. H. Honson, M.A. Fourth Edition. Large crown 8vo. 5 s.

HOLTHAM (E. G.)-Eight YEARs IN JAPAN, I873-I88r. Work, Travel, and Recreation. With 3 Maps. Large crown 8vo. $9 s$.

Homology of Economic Justice: An Essay by an East India Merchant. Small crown 8vo. $5^{s .}$

hooper (Mary)-Little Dinners: How to Serve them with Elegance and Economy. Twentieti Edition. Crown 8vo. 2s. $6 d$.

Cookery for Invalids, Persons of Delicate Digestion, and Children. Fifth Edition. Crown 8vo. 2s. 6 d.

Every-Day Meals. Being Economical and Wholesome Recipes for Breakfast, Luncheon, and Supper. Sixth Edition. Crown 8vo. 2s. 6d.

HOPKINS (Ellice)-WORK AMONGST WORKING Men. Fifth Edition. Crown 8vo. $3^{\text {s. } 6 d \text {. }}$

HORNADA $Y(W . T$.$) - Two Years in a Jungle. With Illustrations.$ Demy 8vo. $21 s$.

HOSPITALIER (E.)-The Modern Applications of Electricity. Translated and Enlarged by Julius MaIER, Ph.D. 2 vols. Second Edition, revised, with many additions_and numerous Illustrations. Demy 8vo. I2s. $6 d$. each volume.

Vor. I.-Electric Generators, Electric Light.

II.-Telephone : Various Applications : Electrical Transmission of Energy.

HOWARD (Robert) M.A. - The Church of England and other Religious Communions. A Course of Lectures delivered in the Parish Church of Clapham. Crown 8vo. $7 s .6 d$.

HUMPHREY (Rev. William)--The Bible ANd Belief. A Letter to a Friend. Small crown 8vo. 2s. $6 d$.

HUNTER (William C.) - Bits of Old China. Small crown 8vo. 6s.

HUNTINGFORD (Rev. E.) D.C.L. - The APOCALYPSE. With a Commentary and Introductory Essay. Demy 8vo. 9s.

HUTCHINSON $(H$.$) - Thought Symbolism and Grammatic Illu-$ sions : Being a Treatise on the "Nature, Purpose, and Material of Speech. Crown 8ro. 2s. $6 d$.

HUTTON (Rev. Charles F.)-Unconscious Testimony ; or, the Silent WitNess of the Hebrew to the Truth of the Historical SCRIPTURES. Crown 8vo. 2s. $6 d$.

HYNDMAN (H. M.)-The Historical Basis of Socialism in ENGLand. Large crown 8vo. 8s. $6 d$. 
IDDESLEIGH (Earl of)-The Pleasures, Dangers, ANd Uses of Desultory Reading. Fcp. 8vo. in Whatman paper cover, $\mathbf{I} s$.

IM THURN (Everard $F$.)-AMong THE Indians of Guiana. Being Sketches, chiefly Anthropologic, from the Interior of British Guiana. With 53 Illustrations and a Map. Demy 8vo. I8s.

JACCOUd (Prof. S.)-The Curability and Treatment of Pulmonary Phthisis. Translated and Edited by Montagu Lubbock, M.D. Demy 8 vo. I 5 s.

JaUnt in A Junk: A Ten Days' Cruise in Indian Seas. Large crown 8vo. $75.6 d$.

JENKINS $(E$.$) and RAYMOND (J)$-The ARCHITECT'S LEGAL HaNDBOoK. Third Edition, Revised. Crown 8vo. $6 s$.

JENKINS (Rev. Canon R. C.) -HERALdRy : English and Foreign. With a Dictionary of Heraldic Terms and I 56 Illustrations. Small crown 8vo. 3s. $6 d$.

Story OF THE CARAFFA. Small crown 8vo. $3 s .6 d$.

JERVIS (Rev. W. Henley)-The Gallican Church and the RevoLUTron. A Sequel to the History of the Church of France, from the Concordat of Bologna to the Revolution. Demy 8vo. 18 s.

JOEL $(L$.$) -A Consul's Manual and Shipowner's ANd Shipmaster's$ Practical Guide in their Transactions Abroad. With Definitions of Nautical, Mercantile, and Legal Terms ; a Glossary of Mercantile Terms in English, French, German, Italian, and Spanish; Tables of the Money, Weights, and Measures of the Principal Commercial Nations and their Equivalents in British Standards; and Forms of Consular and Notarial Acts. Demy 8vo. I2s.

JOYCE (P. W. ) LL.D. Eoc.-Old Celtic Romances. Translated from. the Gaelic. Crown 8vo. $7 s .6 d$.

KAUFMANN (Rev. M.) B.A.-Socialism : its Nature, its Dangers, and its Remedies considered. Crown 8vo. 7s. $6 d$.

UTOPIAS ; or, Schemes of Social Improvement, from Sir Thomas Mare to Karl Marx. Crown 8vo. 5 s.

KAY (David) -Education and Educators. Crown 8vo. $7 s .6 \pi$.

$K A Y$ (Joseph)-Free Trade In LAND. Edited by his Widow. With Preface by the Right Hon. Jorn Bright, M.P. Seventh Edition. Crown 8 vo. 5 s.

* * Also a cheaper edition, without the Appendix, but with a Review of Recent Changes in the Land Laws of England, by the Right Hon. G. Osborne. Morgan, Q.C., M.P. Cloth, Is. 6d. ; Paper covers, is.

KELKE ( $W . H . H$.$) - An Epitone of English Grammar for the:$ Use of STUdents. Adapted to the London Matriculation Course and Similar Examinations. Crown 8vo. 4s. $6 d$.

KEMPIS (Thomas à)-OF the Imitation of Christ. Parchment Library Edition, parchment or cloth, $6 s$.; vellum, $7 s .6 d$. The Red Line Edition, fcp. 8vo. red edges, 2s. 6d. The Cabinet Edition, small 8 vo. cloth limp, Is. ; or cloth boards, red edges, $1 s .6 d$. The Miniature Edition, 32mo. red edges, is.

** All the above Editions may be had in various extra bindings.

KETTLEWELL (Rev. S.) M.A.-Thomas À KeMPIS AND THE Brothers of Common Life. 2 vols. With Frontispieces. Demy 8vo. $30 s$.

** Also an Abridged Edition in I vol. With Portrait. Crown 8vo. 7 s. $6 d$. 
KIDD (Joseph) M.D.-The Laws of Therapeutics; or, the Science and Art of Medicine. Second Edition. Crown 8vo. 6s.

KINGSFORD (Anna) M.D.-The Perfect Way in Diet. A Treatise advocating a Return to the Natural and Ancient Food of Race. Small crown 8 vo. $2 s$.

KINGSLEY (Charles) M.A.-LetTers ANd Memories of his Life. Edited by his WIFE. With Two Steel Engraved Portraits and Vignettes. Fifteenth Cabinet Edition, in 2 vols. Crown 8vo. 12s.

* * Also a People's Edition in I vol. With Portrait. Crown 8vo. $6 s$.

All SaInts' Day, and other Sermons. Edited by the Rev. W. HARRISON. Third Edition. Crown 8vo. 7 s. $6 d$.

True Words for Brave Men. A Book for Soldiers' and Sailors' Libraries. Eleventh Edition. Crown 8vo. 2s. 6d.

KNOX (Alexander A.)-The New Playground; or, Wanderings in Algeria. New and Cheaper Edition. Large crown 8vo. 6s.

Land Concentration and Irresponsibility of Political Power, as causing the Anomaly of a Widespread State of Want by the Side of the Vast Supplies of Nature. Crown 8vo. 5 s.

LANDON (Joseph)-School Management ; including a General View of the Work of Education, Organisation, and Discipline. Fifth Edition. Crown 8vo. $6 s$.

LAURIE (S. S.)-Lectures on The Rise and Early Constitution of UnIVERSTTIES. With a Survey of Medieval Education. Crown 8vo. $6 s$.

LEE (Rev. F. G.) D.C.L.-The OTHER WorLd; or, Glimpses of the Supernatural. 2 vols. A New Edition. Crown 8vo. I5s.

Letters From an Unknown Friend. By the Author of "Charles Lowder.' With a Preface by the Rev. W. H. Cleaver. Fcp. 8vo. Is.

LEWARD (Frank)-Edited by Chas. Bampton. Crown 8vo. 7 s. $6 d$.

LEWIS (Edrward Dillon)-A Draft Code of Criminal Law and Procedure. Demy 8vo. $21 s$.

Life of a Prig. By One. Third Edition. Fcp. 8vo. 3s. $6 d$.

LILLIE (Arthur) M.R.A.S.-The Popular Life of Buddha. Containing an Answer to the Hibbert Lectures of $\mathbf{r} 88 \mathrm{I}$. With Illustrations. Crown 8 vo. $6 s$.

Buddhism in Christendom; or, Jesus, the Essene. Demy 8vo. with numerous Illustrations.

LLOYD (Walter)-The Hope of THE WorLd : An Essay on Universal Redemption. Crown 8vo. 5 s.

LONGFELLOW (H. Wadsworth)-Life. By his Brother, SAmueL LONGFELIow. With Portraits and Illustrations. 2 vols. Demy 8vo. 28 s.

LONSDALE (Margaret)-SISTER DORA: a Biography. With Portrait. Cheap Edition. Crown 8vo. 2s. $6 d$.

GEORge ELIOT: Thoughts upon her Life, her Books, and Herself. Second Edition. Small crown 8vo. Is, $6 d$.

LOUNSBUR Y (Thomas R.)-Janes Fenimore Cooper. With Portrait. Crown 8vo. 5 s. 
LOWDER (Charles)-A Biography. By the Author of 'St. Teresa.' New and Cheaper Edition. Crown 8vo. With Portrait. 3s. $6 d$.

L ÜCKES (Eva C. E.)-LeCtures on General Nursing, delivered to the Probationers of the London Hospital Training School for Nurses. Crown 8vo. 2s. $6 d$.

LYALL (William Rowe) D.D.-Propedeia Prophetica ; or, The Use and Design of the Old Testament Examined. New Edition, with Notices by George C. Pearson, M.A., Hon. Canon of Canterbury. Demy 8vo. 1os. 6d.

LYTTON (Edward Bulwer, Lord)-Life, LetTers, AND LiteraRY Remains. By his Son the EarL of LytTon. With Portraits, Illustrations, and Facsimiles. Demy 8vo. cloth. Vols. I. and II. 32s.

MACAULAY $(G . C$.) - Francis Beaumont : A Critical Study. Crown 8 vo. 5 s.

MACCALLUM (M. $W$.$) - Studies in Low German ANd High$ German Literature. Crown 8vo. $6 s$.

MACHIA VELLI (Niccolo)-His Life and Times. By Prof. Villari. Translated by Linda Villari. 4 vols. Large post 8 vo. $48 s$.

Discourses on the First Decade of Titus Livius. Translated from the Italian by Ninian Hill Thomson, M.A. Large crown 8vo. I2s.

The Prince. Translated from the Italian by N. H. T. Small crown 8 vo. printed on hand-made paper, bevelled boards, $6 s$.

$M A C K E N Z 1 E$ (Alexander)-How INDIA IS Governed. Being an Account of England's work in India. Small crown 8vo. $2 s$.

MAC RITCHIE (David)-Accounts of the Gypsies of India. With Map and Illustrations. Crown 8vo. $3 s .6 d$.

MAGNUS (Lady)-About the Jews since Bible Times. From the Babylonian Exile till the English Exodus. Small crown 8ro. $6 s$.

MAGUIRE (Thomas)-Lectures on Philosophy. Demy 8vo. $9 s$.

MAIR (R. S.) M.D., F.R.C.S.E.-The MediCAL GuIdE For ANGLoIndians. Being a Compendium of Advice to Europeans in India, relating to the Preservation and Regulation of Health. With a Supplement on the Management of Children in India. Second Edition. Crown 8vo. 3s. $6 d$.

MALDEN (Henry Elliot)-VIENNA, I683. The History and Consequences of the Defeat of the Turks before Vienna, September 12, 1683, by John Sobieski, King of Poland, and Charles Leopold, Duke of Lorraine. Crown 8vo. $4 s .6 d$.

Many Voices.-A Volume of Extracts from the Religious Writers of Christendom, from the First to the Sixteenth Century. With Biographical Sketches. Crown 8vo. cloth extra, red edges, $6 s$.

MARKHAM (Capt. Albert Hastings) R.N.-The Great Frozen SEA : a Personal Narrative of the Voyage of the Alert during the Arctic Expedition of r875-6. With Six Full-page Illustrations, Two Maps, and Twenty-seven Woodcuts. Sixth and Cheaper Edition. Crown 8vo. $6 s$.

MARTINEAU (Gertrude)-Outline Lessons on Morals. Small crown 8 vo. 3 s. $6 d$.

MASON (Charlotte M.)-Home EDUCATion. A Course of Lectures to Ladies, delivered in Bradford in the winter of 1885-1886. Crown 8vo. $3 s .6 d$. 
MAUDSLE $Y(H$.$) M.D. - Body AND Will. Being an Essay Concerning$ Will, in its Metaphysical, Physiological, and Pathological Aspects. 8vo. I2s.

Natural Causes and Supernatural Seemings. Crown 8vo. $6 s$.

McGRATH (Terence)-Pictures from Ireland. New and Cheaper Edition. Crown 8 vo. $2 s$.

MEREDITH (M. A.) - Theotokos, the Example for Woman. Dedicated, by permission, to Lady AGNES Wood. Revised by the Venerable Archdeacon DENISON. 32mo. Is. $6 d$.

MILLER (Edzard)-The History AND Doctrines of IRvingism; or, the so-called Catholic and Apostolic Church. 2 vols. Large post 8vo. 15 s.

The Church in Relation to the State. Large crown 8vo. $4 s$.

MILLS (Herbert)-Poverty AND the STATE; or, Work for the Unemployed. An Enquiry into the Causes and Extent of Enforced Idleness, together with a statement of a remedy practicable here and now. Crown 8 vo.

MITCHELL (Lucy M.)-A History of Ancient Sculpture. With numerous Illustrations, including six Plates in Phototype. Super royal, 42s.

Selections from Ancient Sculpture. Being a Portfolio containing Reproductions in Phototype of 36 Masterpieces of Ancient Art, to illustrate Mrs. Mitchell's 'History of Ancient Sculpture.' I8s.

MITFORD (Bertram) - Through the Zulu Country. Its Battlefields and its People. With five Illustrations. Demy 8vo. I 4 s.

MOCKLER (E.)-A Grammar of the Baloochee Language, as it is spoken in Makran (Ancient Gedrosia), in the Persia-Arabic and Roman characters. Fcp. Svo. 5 s.

MOLESWORTH ( W. Nassau)-History of the Church of EngLAND FROM 1660. Large crown 8vo. 7 s. $6 d$.

MORELL $(J . R$.)-Euclid Simplified in Method and Language. Being a Manual of Geometry. Compiled from the most important French Works, approved by the University of Paris and the Minister of Public Instruction. Fcp. 8vo. 2s. $6 d$.

MORGAN (C. Lloyd)-The Springs of Conduct. An Essay in Evolution. Large crown 8vo. cloth, 7 s. $6 d$.

MORISON (James Cotter)-The Service of MaN. An Essay towards the Religion of the Future. Demy 8 vo.

MORRIS (George)-The Duality of all Divine Truth in oUr LORd Jesus Christ : For God's Self-Manifestation in the Impartation of the Divine Nature to Man. Large Crown 8vo. $7 s .6 d$.

MORSE (E. S.) Ph.D.-FIRST Book of Zoology. With numerous Illustrations. New and Cheaper Edition. Crown 8vo، 2s. 6d.

NELSON $(J . H$.$) M.A.-A Prospectus of the Scientific Study of$ THE HiNdû Law. Demy 8vo. 9 s.

Indian Usage and Judge-made Law in Madras. Demy 8 vo.

NEWMAN (Cardinal)-CHARACTERISTICS FROM THE WRITINGS OF. Being Selections from his various Works. Arranged with the Author's personal Approval. Seventh Edition. With Portrait, Crown 8vo. 6s.

$*_{*}^{*}$ A Portrait of Cardinal Newman, mounted for framing, can be had, $2 s .6 d$. 
New Social Teachings. By Politicus. Small crown 8vo. 5 s. NE WMAN (Francis William)-Essays ON DIET. Small crown 8vo. 2s. New Truth and the Old Faith: Are they Incompatible? By a Scientific Layman. Demy 8vo. ros. $6 d$.

NICOLS (Arthur) F.G.S., F.R.G.S.-Chapters From the Physical History OF THE EARTH : an Introduction to Geology and Palæontology. With numerous Illustrations. Crown 8 vo. 5 s.

NOEL (The Hon. Roden)-Essays on Poetry and Poets. Demy Svo. I2s.

NOPS (Marianne)-Class Lessons on Euclid. Part I. containing the First Two Books of the Elements. Crown 8vo. 2s. 6 .

Nuces : Exercises on the Syntax of the Public School Latin Primer. New Edition in Three Parts. Crown 8vo. each $\mathbf{I} s$.

** The Three Parts can also be had bound together in cloth, $3 s$.

OATES (Frank) F.R.G.S.-MATABELE LAND and the Victoria FALls. A Naturalist's Wanderings in the Interior of South Africa. Edited by C. G. OATES, B.A. With numerous Illustrations and 4 Maps. Demy 8vo. 2 Is.

O'CONNOR (T. P.) M.P.-The Parnell Movement. With a Sketch of Irish Parties from 1843 . Large crown 8vo. $7 s .6 \%$.

OGLE (W.) M.D., F.R.C.P.-ARistotle on the Parts of Animals. Translated, with Introduction and Notes. Royal 8vo. I2s. $6 d$.

O'HAGAN (Lord) K.P.- Occasional Papers and Addresses. Large crown 8 vo. $7 s .6 d$.

O'MEARA (Kathleen)-Frederic Ozanam, Professor of the Sorbonne: his Life and Work. Second Edition. Crown 8vo. 7s. 6d'

Henri Perreyve and his Counsels to the Sick. Small crown 8vo. 5 s.

One and a Half in Norway. A Chronicle of Small Beer. By Either and Both. Small crown 8 vo. 3 s. $6 d$.

O'NEIL (The late Rer. Lord).-Sernons. With Memoir and Portrait. Crown 8vo. 6s.

Essays AND AdDResses. Crown 8vo. 5 s.

Only Passport to Heaven, The. By One who has it. Small crown 8vo. Is. 6 .

osbor Re (Rev. W. A.)-The Revised Version of the New TestaMent. A Critical Commentary, with Notes upon the Text. Crown 8vo. 5 s.

OTTLEY (Henry Bickersteth)-The Great Dilemma : Christ His own Witness or His own Accuser. Six Lectures. Second Edition. Crown 8vo. 3 s. $6 d$.

Our Public Schools-Eton, Harrow, Winchester, Rugby, Westminster, Marlborough, The Charterhouse. Crown 8vo. 6s.

OWEN (F. M.)-John Keats : a Study. Crown 8vo. $6 s$.

Across the Hrlls. Small crown 8vo. is. $6 d$.

OWEN (Rev. Robert) B.D.-Sanctorale Catholicum; or, Book of Saints. With Notes, Critical, Exegetical, and Historical. Demy 8vo. I8s. 
OXONIENSIS-Romanism, Protestantism, AngliCanism. Being a Layman's View of some Questions of the Day. Together with Remarks on Dr. Littledale's 'Plain Reasons against Joining the Church of Rome.' Small crown 8vo. 3s. $6 d$.

PALMER (the late William)-Notes of A Visit To RUSSIA IN I840-4̆i. Selected and arranged by John H. Cardinal Newman. With Portrait. Crown 8vo. $8 s .6 d$.

Early Christian Symbolism. A series of Compositions from FrescoPaintings, Glasses, and Sculptured Sarcophagi. Edited by the Rev. ProvosT Northcote, D.D., and the Rev. Canon Brownlow, M.A. With Coloured Plates, folio, 42s. ; or with plain plates, folio, $25 s$.

PARChMENT Library. Choicely printed on hand-made paper, limp parchment antique or cloth, $6 s$. ; vellum, $7 s .6 d$. each volume.

M ilton's POETICAL WORKS. 2 vols.

Chaucer's Canterbury Tales. 'The Prologue; The Knightes Tale; The Man of Lawes Tale; The Prioresses Tale; The Clerkes Tale Edited by Alfred W. Polland.

Selections from the Prose Writings of Jonathan Swift. With a Preface and Notes by Stanley Lane-Poole, and Portrait.

ENGLish SACRED LyRICS.

Sir Joshua Reynolds' Discourses. Edited by Edmund Gosse.

Selections from Milton's Prose Writings. Edited by Ernesta MYers.

The Book of Psalms. Translated by the Rev. Canon Cheyne, D. D.

The Vicar of Wakefifld. With Preface and Notes by Austin DOBSON.

English Comic Dramatists. Edited by Osward Crawfurd.

ENGLISH LYRICS.

The Sonnets of John Milton. Edited by Mark Pattison. With Portrait after Vertue.

French Lyrics. Selected and Annotated by George Saintsbury. With miniature Frontispiece, designed and etched by H. G. Glindoni.

Fables by Mr. John Gay. With Memoir by Austin Dobson, and an etched Portrait from an unfinished Oil-sketch by Sir Godfrey Kneller.

Seject Letters of Percy Bysshe Shelley. Edited, with an Intro. tion, by Richard GarnetT.

The Christian YEAR; Thoughts in Verse for the Sundays and Holy Days throughout the Year. With etched Portrait of the Rev. J. Keble, after the Drawing by G. Richmond, R.A.

Shakspere's Works. Complete in Twelve Volumes.

Eighteenth Century Essays. Selected and Edited by Austin Dobson. With a Miniature Frontispiece by R. Caldecott.

Q. Horati Flacci Opera. Edited by F. A. Cornish, Assistant Master at Eton. With a Frontispiece after a design by L. Alma TADEma. Etched by Leopold Lowenstam.

Edgar Allan Poe's Poems. With an Essay on his Poetry by ANDREW LANG, and a Frontispiece by Linley Sambourne.

SHAKSPERE'S Sonnets. Edited by EDWARD DOWDEN. With a Frontispiece etched by Leopold Lowenstam, after the Death Mask. 
PARCHMENT LiBRARY-continued.

English Odes.' Selected by Edmund Gosse. With Frontispiece on India paper by Hamo Thornycroft, A.R.A.

Of the Imitation of Christ. By Thomas à Kempis. A revised Translation. With Frontispiece on India paper, from a Design by W. B. Richmond.

Poems : Selected from Percy Bysshe Shelley. Dedicated to Lady Shelley. With Preface by Richard GarnetT and a Miniature Frontispiece.

** The above Volumes may also be had in a variety of leather bindings.

The Poetical Works of John Milton. 2 vols.

Letters and Journals of Jonathan Swift. Selected and edited, with a Commentary and Notes, by Stanley Lane Poole.

De Quincey's Confessions of an English Opium Eater. Reprinted from the First Edition. Edited by Richard GarnetT.

The Gospel according to Matthew, Mark, and Luke.

PARSLOE (Joseph) - OUR RaIlways. Sketches, Historical and Descriptive. With Practical Information as to Fares and Rates, \&c., and a Chapter on Railway Reform. Crown 8vo. $6 s$.

PASCAL (Blaise)-The Thoughts of. Translated from the Text of Auguste Molinier by C. Kegan Paul. Large crown 8vo. with Front ispiece, printed on hand-made paper, parchment antique, or cloth, $12 s$. ; vellum, I $5 s$.

PAUL (C. Kegan)-Biographical Sketches. Printed on hand-made paper, bound in buckram. Second Edition. Crown 8vo. 7 s. $6 d$.

PAUL (Alexander)-Short Parliaments. A History of the National Demand for Frequent General Elections. Small crown 8vo. 3s. $6 d$.

PEARSON (Rev. S.)-WEek-DAY Living. A Book for Young Men and Women. Second Edition. Crown 8vo. 5 s.

PENRICE (Major J.)-Arabic AND English Dictionary of THE: KORAN, 4to. $2 \mathrm{I} s$.

PESCHEL (Dr. Oscar) - 'The Races of MaN and their Geographical Distribution. Second Edition, large crown 8vo. 9s.

PETERS (F. H.)-The Nicomachean Ethics of Aristotle. Translated by. Crown 8vo. $6 s$.

PHIPSON $(E$.$) -The ANimal Lore of Shakspeare's TMme. Including$ Quadrupeds, Birds, Reptiles, Fish, and Insects. Large post 8vo. 9s.

PIDGEON (D.)-AN ENGINEER'S Holiday; or, Notes of a Round Trip from Long. $0^{\circ}$ to $0^{\circ}$. New and Cheaper Edition. Large crown 8vo. 7 s. $6 d$.

Old World Questions and New World Answers. Large crown 8vo. $7 s .6 d$.

Plain Thoughts for Men. Eight Lectures delivered at the Foresters" Hall, Clerkenwell, during the London Mission, 1884. Crown 8vo. 1s. 6d.; paper covers, Is .

POE (Edsar Allan)-Works of. With an Introduction and a Memoir by RICHARD HENRY STODDARD. In 6 vols. with Frontispieces and Vignettes. Large crown 8 vo. $6 s$, each vol. 
PRICE (Prof. Bonamy)-Chapters on Practical Political Economy. Being the Substance of Lectures delivered before the University of Oxford. New and Cheaper Edition. Large post 8vo. $5^{s}$.

PRIG'S BEDE: The Venerable Bede Expurgated, Expounded, and Exposed. By the Prig, Author of 'The Life of a Prig.' Fcp. 8vo. 3s. 6d.

Pulpit Commentary (The). Old Testament Series. Edited by the Rev. J. S. Exell and the Rev. Canon H. D. M. SPENCE.

Genesis. By Rev. T. Whitelaw, M.A. With Homilies by the Very Rev. J. F. Montgomery, D.D., Rev. Prof. R. A. Redford, M.A., LL.B., Rev. F. Hastings, Rev. W. Roberts, M.A. ; an Introduction to the Study of the Old Testament by the Venerable Archdeacon FARRAR, D.D., F.R.S.; and Introductions to the Pentateuch by the Right Rev. H. CoTTERILL, D.D., and Rev. T. Whitelaw, M.A. Eighth Edition. One vol. I5s.

Exodus. By the Rev. Canon Rawlinson. With Homilies by Rev. J. Orr, Rev. D. Young, Rev. C. A. Goodhart, Rev. J. Urquhart, and Rev. H. T. Robjorns. Fourth Edition. Two vols. I8s.

Leviticus. By the Rev. Prebendary Mevrick, M.A. With Introductions by Rev. R. Coltins, Rev. Professor A. Cave, and Homilies by Rev. Prof. Redford, Ll.B., Rev. J. A. Macdonald, Rev. W. Clarkson, Rev. S. R. AldRIDGe, LL.B., and Rev. McCheyne EDGar. Fourth Edition. 15 s.

Numbers. By the Rev R. Winterbotham, LL.B. With Homilies by the Rev. Professor W. Binnie, D.D., Rev. E. S. Prou'T, M.A., Rev. D. Young, Rev. J. Waite; and an Introduction by the Rev. Thomas WhiteLAw, M.A. Fifth Edition. I 5 s.

Deuteronomy. By Rev. W. L. Alexander, D.D. With Homilies by Rev. D. Davies, M.A., Rev. C. Clemance, D.D., Rev. J. OrR, B.D., and Rev. R. M. EDGAr, M.A. Third Edition. I5s.

Joshua. By Rev. J. J. Lias, M.A. With Homilies by Rev. S. R. A.tdridge, Ll.B., Rev. R. Glover, Rev. E. De Pressenst, D.D., Rev. J. Waite, B.A., Rev. F. W. Adeney, M.A.; and an Introduction by the Rev. A. Plummer, M.A. Fifth Edition. I2s. $6 d$.

IUDGES AND RUTH. By the Bishop of Bath and Wells and Rev. J. Morison, D.D. With Homilies by Rev. A. F. Muir, M.A., Rev. F. W: Adeney, M.A., Rev. W. M. Statham, and Rev. Professor J. Thomson, M.A. Fourth Edition. IOs. $6 d$.

I Samuel. By the Very Rev. R. P. Smith, D.D. With Homilies by Rev. Donald Fraser, D.D., Rev. Prof. Chapman, and Rev. B. Dale. Sixth Edition. I 5 s.

Kangs. By the Rev. Joseph Hammond, LL.B. With Homilies by the Rev. E De Pressense, D.D., Rev. J. Waite, B.A., Rev. A. Rowland, Ll.B., Rev. J. A. Macdonald, and Rev. J. Urguhart. Fourth Edition. I5s.

I Chronicles. By the Rev. Prof. P. C. Barker, M.A., LL.B. With Homilies by Rev. Prof. J. R. Thomson, M.A., Rev. R. Tuck, B.A., Rev. W. Clarkson, B.A., Rev. F. Whitfield, M A., and Rev. Richard GLOVER. I5s.

Ezra, Nehemiah, and Esther. By Rev. Canon G. Rawlinson, M.A. With Homilies by Rev. Prof. J. R. Thomson, M.A., Rev. Prof. R. A. REDFord, LL.B., M.A., Rev. W. S. Lewis, M.A., Rev. J. A. MACDONALD, Rev. A. Mackennal, B.A., Rev. W. Clarikson, B.A., Rev. F. Hastings, Rev. W. Dinwiddie, LL.B., Rev. Prof. Rowlands, B.A., Rev. G. Woon, B.A., Rev. Prof. P. C. Barker, LL.B., M.A., and Rev. J. S. Exell, M.A. Sixth Edition. One vol. I2s. $6 d$. 
Pulpit Commentary (The). Old Testament Series-continued.

Jeremiah (Vol. I.). By the Rev. Canon Cheyne, D.D. With Homilies by the Rev. F. W. Adeney, M.A., Rev. A. F. Muir, M.A., Rev. S. Conway, B.A., Rev. J. Waite, B.A., and Rev. D. Young, B.A. Second Edition. I5s.

Jeremiah (Vol. II.), and Lamentations. By the Rev. Canon Cheyne, D.D. With Homilies by Rev. Prof. J. R. Thomson, M.A., Rev. W. F. Adeney, M.A., Rev. A. F. Murr, M.A., Rev. S. Conway, B.A., Rev. D. YOUNG, B.A. I 5 s.

Pulpit Commentary (The). New Testament Series.

St. Mark. By the Very Rev. E. Bickersteth, D.D., Dean of Lichfield. With Homilies by the Rev. Prof. Thomson, M.A., Rev. Profo Given, M.A., Rev. Prof. Johnson, M.A., Rev. A. Rowland, LL..B., Rev. A. Muir, M.A., and Rev. R. Green. Fourth Edition. 2 Vols. 2 I $s$.

The Acts of the Apostles. By the Bishop of Bat'h and Wells, With Homilies by Rev. Prof. P. C. Barker, M.A., Rev. Prof. E. Johnson, M.A., Rev. Prof. R. A. Redford, M.A., Rev. R. Tuck, B.A., Rev. W。 Clarkson, B.A. Second Edition. Two vols. 2 Is.

I Corinthians. By the Ven. Archdeacon Farrar, D.D. With Homilies by Rev. Ex.Chancellor Lipscomb, LL.D., Rev. David Thomas, D.D., Rev. Donald Fraser, D.D., Rev. Prof. J. R. Thomson, M.A., Rev. R. Tuck, B.A., Rev. E. HurNdall, M.A., Rev. J. Waite, B.A., Rev. H. BREMNER, B.D. Second Edition. 15s.

in Corinthians and Galatians. By the Ven. Archdeacon Farrar, D.D., and Rev. Preb. E. Huxtable. With Homilies by Rev. Ex-Chancellor Lipscomb, LL.D., Rev. David Thomas, D.D., Rev. Donald Fraser, D.D., Rev. R. Tuck, B.A., Rev. E. Hurndall, M.A., Rev. Profo J. R. Thomson, M.A., Rev. R. Finlayson, B.A., Rev. W. F. Adeney, M.A., Rev. R. M. Edgar, M.A., and Rev. T. Croskerry, D.D. Price 2Is.

Ephesians, Philippians, and Colossians. By the Rev. Prof. W. G. Blaikie, D.D., Rev. B. C. Caffin, M.A., and Rev. G. G. Findlay, B.A. With Homilies by Rev. D. Thomas, D.D., Rev. R. M. Edgar, M.A., Rev. R. Finlayson, B.A., Rev. W. F. Adeney, M.A., Rev. Prof. T. Croskerry, D.D., Rev. E. S. Prout, M.A., Rev. Canon Vernon Hutton, and Rev. U. R. Thomas, D.D. Price 2 Is.

Hebrews and James. By the Rev. J. Barmby, D.D., and Rev. Prebendary E. C. S. Greson, M.A. With Homiletics by the Rev. C. Jerdan, M.A., LL. B., and Rev. Prebendary E. C. S. Gibson. And Homilies by the Rev. W. Jones, Rev. C. New, Rev. D. Young, B.A., Rev. J. S. Bright, Rev. T. F. Lockyer, B.A., and Rev. C. Jerdan, M.A., LL.B. Price I5s.

PUNCHARD (E. G.) D.D.-Christ of Contention. Three Essays. Fcp. 8vo. $2 s$.

PUSE $Y$ (Dr.)-Sermons for the Church's Seasons from Advent To TRINITY. Selected from the published Sermons of the late EDWARD Bouterie Pusey, D.D. Crown 8 vo. 5 s.

RADCLIFFE (Frank R. Y.)-The New Politicus. Small crown 8vo, 2s. $6 d$.

RANKE (Leopold von)-Universal History. The Oldest Historical Group of Nations and the Greeks. Edited by G. W. Prothero. Demy 8ro. I6s.

RENDELL $(J \cdot M$.)--Concise Handbook of the Island of Madeira, With Plan of Funchal and Map of the Island. Fcp. 8vo. Is. 6a. 
REYNOLDS (Rev. J. $W$.)-The Supernatural in Nature. A Verification by Free Use of Science. Third Edition, revised and enlarged. Demy 8vo. I4s.

The Mystery of Mrracles. Third and Enlarged Edition. Crown 8vo. $6 s$.

The Mystery of the Universe: Our Common Faith. Demy Svo. I4s.

RIBOT (Prof. Th.) - Heredity: a Psychological Study on its Phenomena, its Laws, its Causes, and its Consequences. Second Edition. Large crown 8vo. 9 s.

ROBERTSON (The late Rev. F. W.) M.A.-Life AND LetTers of. Edited by the Rev. Stopford Brooke, M. A.

I. Two vols., uniform with the Sermons. With Steel Portrait. Crown 8vo. 7 s. $6 d$.

III. Library Edition, in demy 8vo. with Portrait. I2s.

TII. A Popular Edition, in I vol. Crown 8vo. $6 s$.

¿Sermons. Four Series. Small crown 8vo. $3^{s .6}$.

"The Human Race, and other Sermons. Preached at Cheltenham. Oxford, and Brighton. New and Cheaper Edition. Small crown 8vo. 3s. 6d.

Notes on Genesis. New and Cheaper Edition. Small crown 8vo. 3 s. $6 \%$.

Expository Lectures on St. Paul's Epistles to the Corinthians. A New Edition. Small crown 8vo. 5s.

LECTURES AND ADDREsses, with other Literary Remains. A New Edition. Small crown 8vo. 5 s.

An . Analysis of 'Tennyson's 'In Memoriam.' (Dedicated by Permission to the Poet-Laureate.) Fcp. 8vo.2s.

The Education of the Hüman Race. Translated from the German of Gotthold Ephraim Lessing. Fcp. 8vo. 2s. $6 d$.

The above Works can also be had bound in half-morocco.

** A Portrait of the late Rev. F. W. Robertson, mounted for framing, can be had, $2 s .6 \%$.

ROMANES $(G . J$ ) -Mental Evolution in Animals. With a Posthumous Essay on Instinct, by Charles Darwin, F.R.S. Demy 8vo. I2s.

ROSMINI SERBATI (A.) Founder of the Institute of Chariiy-LIFE. By Father Lockinart. 2 vols. Crown 8vo. I $2 s$.

Rosmini's ORIGiN of IDEAS. Translated from the Fifth Italian Edition of the Nuovo Saggio. Sull' origine delle idee. 3 vols. Demy 8vo. Ios. 6d. each.

Rosmini's Psychology. 3 vols. Demy 8vo. [Vols. I. \& II. now ready, IOs. $6 d$. each.

RULE (Martin) M.A.-The Life and Times of St. Anselm, Archbishop of Canterbury and Primate of the Britains. 2 vols. Demy 8vo. $32 s$.

SAMUELL (Richard).-SEvEN, the Sacred Number. Its Use in Scripture and its Application to Biblical Criticism, with a Chapter on the Bible and Science. Crown 8 vo.

SAMUEL (Sydney $M$.) - Jewish Life in the East. Small crown 8vo. 3s. $6 d$. 
SAYCE (Rev. Archibald Henry)-Introduction to the ScIence of LANGUAGE. 2 vols. Second Edition. Large post 8vo. 2 Is.

SCOONES ( $W$. Baptiste)-Four Centuries of English LetTers : A Selection of 350 Letters by 150 Writers, from the Period of the Paston Letters to the Present Time. Third Edition. Large crown 8vo. $6 s$.

SEE (Prof. Germain)-Bacillary Phthisis of the Lungs. Translated and Edited for English Practitioners, by William Henry Weddell, M.R.C.S. Demy 8vo. Ios. $6 d$.

SHAKSPEARE-Works. The Avon Edition, I 2 vols. fcp. 8vo. cloth, $\mathbf{I} 8 s . ;$ in cloth box, $2 \mathrm{I} s$. ; bound in 6 vols., cloth, I $5 s$.

SHELLEY (Percy Bysshe).-Life. By EDward Dowinen, LL.D. With Portraits and Illustrations, 2 vols., demy 8 vo. 36 s.

SHILLITO (Rev. Joseph)-Womanhood : its Duties, 'Temptations, and Privileges. A Book for Young Women. Third Edition. Crown 8vo. 3 s. $6 d$.

SIDNEY (Algernon)-A Review. By Gertrude M. Ireland BlackBURNe. Crown 8vo. $6 s$.

Sister Augustine, Superior of the Sisters of Charity at the St. Johannis Hospital at Bonn. Authorised Translation by HANS THARAU, from the Gerruan 'Memorials of Amalie von Lasaulx.' Cheap Edition. Large crown 8vo. 4s. $6 d$.

Skinner (JAmes). A Memoir. By the Author of 'Charles Lowder.' With a Preface by the Rev. Canon Carter, and Portrait. Large crown 8vo. 7 s. $6 d$.

* Also a Cheap Edition, with Portrait. Crown 8vo. 3s. 6 .

SMEATON (Donald).-The Karens of BurmaH. Crown 8vo.

SMITH (Edruard) M.D., LL.B., F.R.S.-Tubercular Consumption in its Early and Remediable Stages. Second Edition. Crown 8vo. 6s.

SMITH (Sir W. Cusack, Bart.)-OUr WAR ShIPs. A Naval Essay. Crown 8 vo. 5 s.

Spanish Mystics. By the Editor of 'Many Voices.' Crown 8vo. 5 s.

Specimens of English Prose Style from Malory to Macaulay. Selected and Annotated, with an Introductory Essay, by George SaIntsbury. Large crown 8vo., printed on hand-made paper, parchment antique, or cloth, I $2 s$.; vellum, I 5 s.

SPEDDING (James)-Reviews and Discussions, Literary, Political, and Historical inot Relating to Bacon. Demy 8vo. i2s. $6 d$.

Evenings with A Reviewer; or, Bacon and Macaulay. With a Prefatory Notice by G. S. Venables, Q.C. 2 vols. Demy 8vo. I 8 s.

STAFFER (Paul)-Shakspeare ANd Classical Antiquity : Greek and Latin Antiquity as presented in Shakspeare's Plays. Translated by EmILY J. Carey. Large post 8vo. I2s.

STATHAM (F. Reginald)-Free Thought and True Tyought. A Contribution to an Existing Argument. Crown 8vo. $6 s$.

Stray Papers on Education and Scenes from School Life. By B. H. Second Edition. Small crown 8vo. $3 s .6 d$.

STREATFEILD (Rcv. G. S.) M.A.-LinCOLNSHIRE AND THE DANES. Large crown 8vo. 7 s. 6 . 
STRECKER-WISLICENUS-ORganic Chemistry. Translated and Edited, with Extensive Additions, by W. R. Hodgkinson, Ph.D., and A. J. Greenaway, F.I.C. Demy 8vo. I2s. $6 d$.

SuAkin, I885; being a Sketch of the Campaign of this Year. By an Officer who was there. Second Edition. Crown 8vo. 2s. $6 d$.

SULLY (James) M.A.-Pessimism : a History and a Criticism. Second Edition. Demy 8vo. I 4 s.

Sunshine AND SEA. A Yachting Visit to the Channel Islands and Coast of Brittany. With Frontispiece from a Photograph and 24 Illustrations. Crown 8vo. 6s.

SWEDENBORG (Eman.)-De Cultu et Amore Dei, ubi Agitur de Telluris ortu, Paradiso et Vivario, tum de Primogeniti seu Adami Nativitate, Infantia, et Amore. Crown 8vo. $6 s$.

On the Worship and Love of God. 'Treating of the Birth of the Earth, Paradise, and the Abode of Living Creatures. Translated from the original Latin. Crown 8vo. 7 s. $6 d$.

Prodronus Philosophiæ Ratiocinantis de Infinito, et Causa Finali Creationis; deque Mechanismo Operationis Animæ et Corporis. Edidit Thomas Murray Gorman, M.A. Crown 8vo. 7s. 6d.

Tacitus' Agriccla : A Translation. Small crown 8vo. $2 s .6 d$.

TARRING (Charles James) M.A.-A Practical Elementary Turkish Grammar. Crown 8vo. 6:.

TA YLOR (Rev. Isaac)-The Alphabet. An Account of the Origin and Development of Letters. With numerous Tables and Facsimiles. 2 vols. Demy 8vo. $36 s$.

TAYLOR (Jeremy)-The Marriage Ring. With Preface, Notes, and Appendices. Edited by Francis Burdett Money Coutts. Small crown 8vo. $2 s .6 d$.

TAYLOR (Sedley)-Profit Sharing between Capital and Labour. To which is added a Memorandum on the Industrial Partnership at the Whit. wood Collieries, by Archibald and Henry Briggs, with Remarks by Sedley TAYLOR. Crown 8vo. 2s. $6 d$.

'They Might Have Been Together Tull the Last.' An Essay on Marriage, and the Position of Women in England. Small crown 8vo. 2s.

THOM (John Hamilton)-LAws OF LifE AFTER THE MIND OF Christ. Two Series. Crown 8vo. 7 s. $6 d$. each.

THOMPSON (Sir H.)-Diet in Relation to Age aNd Activity. Fcp. Svo. cloth, Is. $6 d$. ; Paper covers, Is.

TIDMAN (Paul F.)-Gol.D AND Silver Money. Part I.-A Plain Statement. Part II.-Objections Answered. Third Edition, Crown 8vo. I $s$.

TIPPLE (Rev. S. A.)-Sunday Mornings at Norwood. Prayers and Sermons. Crown 8vo. $6 s$.

TODHUNTER (Dr. J.) -A Study of Shelley. Crown 8vo. 7 s.

TOLSTOI (Count Leo)-ChrisT's Christianity. Translated from the Russian. Large crown 8vo. 7 s. 6 . 
TRANT (William)-Trade Unions: Their Origin and Objects, Influence and Efficacy. Small crown 8vo. Is. 6d. ; paper covers, Is.

TREMENHEERE (H. Seymour) C.B.-A Manual of the PrinCIPLES OF GOVERNMENT AS SET FORTH BY THE AUTHORITIES OF ANCIENT and Modern Times. New and enlarged Edition. Crown 8vo. 3s. 6 $\%$. Cheap Edition, Is.

TRENCH (The late R. C., Archbishop)-Sermons New and Old. Crown 8vo. 6s.

Notes on the Parables of OUR Lord. Fourteenth Edition. 8vo. I2s.; Popular Edition, crown 8vo. 7s. $6 d$.

Notes ON THE Miracles OF OUR LORd. Twelfth Edition. 8vo. I2s.; Popular Edition, crown 8vo. 7s. 6d.

Studies in the Gospels. Fifth Edition, Revised. 8vo. ros. $6 d$.

Brief Thoughts and Meditations on Some Passages in Holy Scripture. Third Edition. Crown 8vo. 3s. $6 d$.

Synonyms of the New Testament. Tenth Edition, Enlarged. 8 vo. I2s.

On the Authorised Version of the New Testament. Second Edition. 8vo. $7 s$.

Commentary on the Epistle to the Seven Churches in Asia. Fourth Edition, Revised. 8vo. 8s. $6 d$.

The Sermon on the Mount. An Exposition drawn from the Writings of St. Augustine, with an Essay on his Merits as an Interpreter of Holy Scripture. Fourth Edition, Enlarged. 8vo. Ios. $6 d$.

Shipwrecks of Faith. Three Sermons preached before the University of Cambridge in May I867. Fcp. 8vo. 2s. 6d.

Lectures on Medieval Church History. Being the Substance of Lectures delivered at Queen's College, London. Second Edition. 8vo. I2s.

English, Past and Present. Thirteenth Edition, Revised and Improved. Fcp. 8vo. 5 s.

On the Study of Words. Nineteenth Edition, Revised. Fcp. 8vo. 5 s.

Select Glossary of English Words Used Formerly in Senses Different from the Present. Fifth Edition, Revised and Enlarged. Fcp. 8vo. 5 s.

Proverbs and Their Lessons. Seventh Edition, Enlarged. Fcp. 8vo. 4 s.

Poems. Collected and Arranged Anew. Ninth Edition. Fcp. 8vo. $7 s .6 d$.

Poems. Library Edition. 2 vols. Small crown 8vo. Ios.

Sacred Latin Poetry. Chiefly Lyrical, Selected and Arranged for Use. Third Edition, Corrected and Improved. Fcp. 8vo. $7 s$.

A Household Book of English Foetry. Selected and Arranged, with Notes. Fourth Edition, Revised. Extra fcp. 8vo. 5s. 6d,

An Essay on the Life and Genius of Calderon. With Translations from his 'Life's a Dream ' and ' Great Theatre of the World.' Second Edition, Revised and Improved. Extra fcp. 8vo. 5s. 6d. 
TRENCH (The late R. C., Archbishop)-continued.

Gustavus Adolphus in Germany, and other Lectures on the 'Thirty Years' War. Second Edition, Enlarged. Fcp. 8vo. 4s.

Plutarch : his Life, his Lives, and his Morals. Second Edition, Enlarged. Fcap. 8vo. 3s. 6 6 .

Remains of the Late Mrs. Richard Trench. Being Selections from her Journals, Letters, and other Papers. New and Cheaper Issue. With Portrait. 8 vo. $6 s$.

TUKE (Daniel Hack) M.D.-Chapters in the History of the INSANE IN THE BRITISH IsLES. With Four Illustrations. Large crown $8 \mathrm{vo.}$ I2s.

TWINING (Louisa)-Workhouse Visiting and Management DURING Twenty-five Years. Small crown 8vo. $2 s$.

TYLER (J.)-The Mystery of Being; or, What Do We Know? Small crown 8vo. $3^{s .6 d}$.

VAUGHAN (H. Halford)-New READINGS AND RENDERINGS OF Shakespeare's Tragedies. 3 vols. Demy 8vo. I $2 s .6 d$. each.

VILLARI (Professor)-Niccolò Machiaveldi and his Times. Translated by Linda Villari. 4 vols. Large crown 8vo. 48 s.

VILLIERS (The Right Hon. C. P.)-Free Trade Speeches of. With Political Memoir. Edited by a Member of the Cobden Club. 2 vols. With Portrait. Demny 8vo. 25s.

** Also a People's Edition, in I vol. crown Svo. limp 2s. 6d.

VOGT (Lieut.-Col. Hermann)-The Egyptian War of I882. A Translation. With Map and Plans. Large crown 8vo. 6s.

$\operatorname{VOLCKXSOM}(E . \quad W . v$.$) -Catechism of Elementary Modern$ CheMistry. Small crown 8 vo. 3 s.

WALLER (Rev. C. B.)-The Apocalypse, reviewed under the Light of the Doctrine of the Unfolding Ages, and the Restitution of All Things. Demy 8 vo. I2s.

WALPOLE (Chas. George)-A Short History of Ireland from the Earliest Times to the Union with Great Britain. With 5 Maps and Appendices. Second Edition. Crown 8vo. 6s.

WARD (William George) Ph.D. - Essays on the Philosophy of THEIsM. Edited, with an Introduction, by WILfRID WARD. 2 vols. demy 8vo. 21 s.

WARD (Wilfrid) - The Wish to Believe: A Discussion concerning the Temper of Mind in which a reasonable Man should undertake Religious Inquiry. Small crown 8 vo. 5 s.

WARTER $(J . W$. - -AN Old Shropshire OAK. 2 vols. demy 8vo. 28 s.

WEDDERBURN (Sir David) Bart., M.P.-LIFE oF, Compiled from his Journals and Writings by his Sister, Mrs. E. H. Percival. With etched Portrait, and facsimiles of Pencil Sketches. Demy 8vo. I 4 s.

WEDMORE (Frederick)-The Masters of Genre Painting. With Sixteen Illustrations. Post 8 ro. 7 s. 6 . 
White (H. C.)-Reform of the Church Establishment. The Nation's Rights and Needs. Crown 8 vo.

WHITNE Y (Prof. William Dwight)-Essentials of English Grammar, for the Use of Schools. Second Edition, crown 8vo. 3s. $6 d$.

WHITWORTH (George Clifford)-An ANgLo-Indian Dictionary : a Glossary of Indian Terms used in English, and of such English or other NonIndian Terms as have obtained special meanings in India. Demy 8vo. cloth, I2s.

WILLIAMS' (Rozuland) D.D.-Psalms, Litanies, Counsels, and Collects for Devout Persons. Edited by his Widow. New and Popular Edition. Crown 8vo. 3s. $6 d$.

Stray Thoughts Collected from the Writings of the late Rowland Wrlliams, D.D. Edited by his Widow. Crown 8vo. 3 s. $6 d$.

WILSON (Lieut.-Col. C. T.)-The Duke of Berwick, Marshal of France, I702-I734. Demy 8vo. I5s.

WILSON (Mrs. R. F.) - The Christian Brothers : their Origin AND WORK. With a Sketch of the Life of their Founder, the Ven. Jean Baptiste, de la Salle. Crown 8vo. $6 s$.

WOLTMANN (Dr. Alfred), and WOERMANN (Dr. Karl)History of Painting. Vol. I. Ancient, Early, Christian, and Mediæval Painting. With numerous Illustrations. Super-royal 8vo. 28s.; bevelled boards, gilt leaves, 3os. Vol. II. The Painting of the Renascence. Cloth, 42s. ; cloth extra, bevelled boards, 45 s.

YOUMANS (Eliza A.)-First Book of Botany. Designed to cultivate the Observing Powers of Children. With 300 Engravings. New and Cheaper Edition. Crown 8vo. 2s. 6 .

YOUMANS (Edward L.) M.D.-A Class Book of Chemistrx, on the Basis of the New System. With 200 Illustrations. Crown 8vo. 5 s.

Y. Z.-Parochial Parleys on the Athanasian Creed, The Inspiration of the Bible, ScientTfic Heresies, and other kindred subjects. Between the Rev. Hugh Hierous, M.A., M.C.U., and his Parishioner, Theophilos Truman. Edited by Y.Z. Crown 8ro. $6 s$. 


\section{THE INTERNATIONAL SCIENTIFIC SERIES.}

I. Forms of WATER : a Familiar Exposition of the Origin and Phenomena of Glaciers. By J. Tyndall, LL.D., F.R.S. With 25 Illustrations. Ninth Edition. Crown 8vo. 5 s.

II. Physics and Politics; or, Thoughts on the Application of the Principles of 'Natural Selection' and 'Inheritance' to Political Society. By Walter Bagehot. Seventh Edition. Crown 8 vo. $4 s$.

III. Foods. By Edward Smith, M.D., LL.B., F.R.S. With numerous Illustrations. Ninth Edition. Crown 8vo. 5 s.

IV. MIND AND BoDy : the Theories of their Relation. By Alexander Bain, LL.D. With Four Illustrations. Seventh Edition. Crown 8vo. $4 s$.

V. The Study of Socrology. By Herbert Spencer. 'Twelfth Edition. Crown 8vo. 5 s.

VI. ON the Conservation of Energy. By Balfour Stewart, M.A., LL.D., F.R.S. With 14 Illustrations. Sixth Edition. Crown 8vo. $5^{s}$.

VII. Antmal Locomotion ; or, Walking, Swimming, and Flying. By J. B. Pettigrew, M.D., F.R.S., \&c. With I30 Illustrations. Third Edition. Crown 8vo. 5 s.

VIII. Responsibility IN Mental Disease. By Henry Maudsley, M.D. Fourth Edition. Crown 8vo. $5^{s}$.

IX. The New Chemistry. By Professor J. P. Cooke. With 3I Illustrations. Eighth Edition, remodelled and enlarged. Crown 8vo. 5 s.

X. The Science of Law. By Professor Sheldon Amos. Sixth Edition. Crown 8vo. $5^{s}$.

XI. Antmal Mechanism: a Treatise on Terrestrial and Aërial Locomotion. By Professor E. J. Marey. With II 7 Illustrations. Third Edition. Crown 8 vo. 5 s.

XII. The Doctrine of Descent and DARIVINISM. By Professor Oscar Schmidt. With 26 Illustrations. Sixth Edition. Crown 8vo. 5 s.
XIII. The History of THE CONFLict Between Religion and Science. By J. W. Draper, M. D., LL.D. Nineteenth Edition. Crown 8vo. 5s.

XIV. FUNGI: their Nature, Influences, Uses, \&c. By M. C. Cooke, M.D., LL.D. Edited by the Rev. M. J. Berkeley, M.A., F.L.S. With numerous Illustrations. Third Edition. Crown 8vo. 5 s.

$\mathrm{XV}$. The Chemical Effects of Ligh't and Photography. By Dr. Hermann Vogel. Translation thoroughly revised. With 100 Illustrations. Fourth Edition. Crown 8vo. $5^{\text {s. }}$

XVI. The Life and Growth of LaNGUAGE. By Professor William Dwight Whitney. Fifth Edition. Crown 8 vo. 5 s.

XVII. Money and the Mechanism of EXCHANGE. By W. Stanley Jevons, M.A., F.R.S. Seventh Edition. Crown 8vo. 5 s.

XVIII. The Nature of Lrght. With a General Account of Physical Optics. By Dr. Eugene Lommel. With I 88 Illustrations and a Table of Spectra in Chromo-lithography. Fourth Edit. Crown 8vo. 5 s.

XIX. Animal Parasites and Mess. MATES. By P. J. Van Beneden. With 83 Illustrations. Third Edition. Crown 8vo. 5 s.

XX. Fermentation. By Professor Schiitzenberger. With 28 Illustrations. Fourth Edition. Crown 8vo. 5 s.

XXI. The Five Senses of Man. By Professor Bernstein. With 9I Illustrations. Fifth Edition. Crown 8vo. 5 s.

XXII. The Theory of Sound In ITS Relation to Music. By Professor Pietro Blaserna. With numerous Illustrations. Third Edition. Crown 8vo. $5 s$.

XXIII. Studies in Spectrum AnalySIS. By J. Norman Lockyer, F.R.S. Fourth Edition. With six Photographic Illustrations of Spectra, and numerous Engravings on Wood. Crown 8vo. 6s. $6 d$. 
XXIV. A History of the Growth of the Steam Engine. By Professor R. H. Thurston. With nunierous Illustrations. Third Edition. Crown 8vo. $6 s .6 d$.

XXV. Education as a Science. By Alexander Bain, LL.D. Sixth Edition. Crown 8vo. 5 s.

XXVI. The Human Species. By Prof. A. De Quatrefages. Third Edition. Crown 8vo. 5 s.

XXVII. MOdern Chromatics. With Applications to Art and Industry. By Ogden N. Rood. With I30 original Illustrations. Second Edition. Crown 8 vo. 5 s.

XXVIII. The CRAYFish : an Introduction to the Study of Zoology. By Professor T. H. Huxley. With $\mathbf{8 2}$ Illustrations. Fourth Edition. Crown 8 vo. 5 s.

XXIX. The BraIN AS AN ORgan OF Mind. By $\mathrm{H}$. Charlton Bastian, M.D. With numerous Illustrations. Third Edition. Crown 8vo. 5 s.

XXX. The Atomic Theory. By Prof. Wurtz. Translated by G. Cleminshaw, F.C.S. Fourth Edition. Crown 8 vo. $5^{s}$.

XXXI. The Natural Conditions of EXISTENCE AS THEY AFFECT ANIMAL Life. By Karl Semper. With 2 Maps and 106 Woodcuts. Third Edition. Crown 8vo. 5 s.

XXXII. General Physiology of Muscles and Nerves. By Prof. J. Rosenthal. Third Edition. With Illustrations. Crown 8vo. 5 s.

XXXIII. Sight : an Exposition of the Principles of Monocular and Binocular Vision. By Joseph Le Conte, LL.D. Second Edition. With 132 Illustrations. Crown 8vo. 5 s.

XXXIV. ILlusions : a Psychological Study. By James Sully. Second Edition. Crown 8vo. 5s.

XXXV. VOLCANOES: WHAT THEY ARE AND WHAT THEY TEACH. BY Professor J. W. Judd, F.R.S. With 92 Illustrations on Wood. Third Edition. Crown 8vo. $5 s$.

XXXVI. SUICIDE : an Essay on Comparative Moral Statistics. By Prof. H. Morselli. Second Edition. With Diagrams. Crown 8vo. 5 s.
XXXVII. The Brain and ITs FuncTiOns. By J. Luys. Second Edition. With Illustrations. Crown 8vo. 5 s.

XXXVIII. MYTH AND ScIence : an Essay. By Tito Vignoli. Second Edition. Crown 8vo. 5 s.

XXXIX. The Sun. By Professor Young. With Illustrations. Second Edition. Crown 8vo. 5 s.

XL. Ants, BeEs, And Wasps : a Record of Observations on the Habits of the Social I-ymenoptera. By Sir John Lubbock, Bart., M.P. With 5 Chromolithographic Illustrations. Eighth Edition. Crown 8vo 5 s.

XLI. Animal Intelligence. By G. J. Romanes, LL.D., F.R.S. Fourth Edition. Crown 8vo. 5 s.

XLII. The Concepts and Theories of Modern Physics. By J. B. Stallo. Third Edition. Crown 8vo. 5s.

XLIII. Diseases of Memory : an Essay in the Positive Pyschology. By Prof. Th. Ribot. Third Edition. Crown 8 vo. 5 s.

XLIV. Man before Metals. By $\mathrm{N}$. Joly. Third Edition. Crown 8 vo. $5 s$.

XLV. The Science of Politics. By Prof. Sheldon Amos. Third Edit. Crown. 8vo. 5 s.

XLVI. Elementary Meteorology. By Robert H. Scott. Third Edition. With numerous Illustrations. Crown 8 vo. 5 s.

XLVII. The Organs of Speech and THEIR APPLICATION IN THE FORMATION OF ARTiculate Sounds. By Georg Hermann von Meyer. With 47 Woodcuts. Crown 8vo. 5 s.

XLVIII. FAlLacies : a View of Logic from the Practical Side. By Alfred Sidgwick. Second Edition. Crown 8vo. 5 s.

XLIX. ORigin of Cultivated Plánts. By Alphonse de Candolle. Crown 8 vo. $5^{s .}$

L. Jelly Fish, Star Fish, and Sea URChins, Being a Research on Primitive Nervous Systems. By G. J. Romanes. Crown 8vo. 5 s.

LI. The Common Sense of the ExaCt Sciences. By the late William Kingdon Clifford. Second Edition. With Ioo Figures. $5 s$. 
LII. Physical Expression : Its Modes AND PRINCIPLES, By Francis Warner, M.D., F.R.C.P. With 50 Illustrations. $5 s$.

LIII. AnthropoId Apes. By Robert Hartmann. With 63 Illustrations. $5 s$.

LiV. The Mammalia in their Relation to Primeval Times. By Oscar Schmidt. With 5 I Woodcuts. 5 s.
LV. Comparative Literature. By H. Macaulay Posnett, LL.D. $5 s$.

LVI. EarthquaKes AND OTHER EARTh Movements. By Prof. John Milne. With 38 Figures. $5 s$.

LVII. Microbes, Ferments, and Moulds. By E. L. TrouessarT. With 107 Illustrations. $5 s$.

\section{MILITARY WORKS.}

BARRINGTON (Capt.F.T.)-ENGLAND on the Defensive; or, the Problem of Invasion Critically Examined. Large crown 8vo. with Map, 7s. $6 d$.

BRACKENBURY (Col. C. B.) R.A. - Military HaNdBooks For RegiMENTAL OFFICERS :

I. Military Sketching and ReCONNAISSANCE. By Colonel F. J. Hutchison and Major H. G. MacGregor. Fourth Edition. With I5 Plates. Small crown 8vo. $4 s$.

II. The Elements of Modern TACTICS PRACTICAlly applied to English Formations. By Lieut.Col. Wilkinson Shaw. Fifth Edit. With 25 Plates and Maps. Small crown 8 vo. 9 s.

III. Field Artillery : its Equipment, Organisation, and Tactics. By Major Sisson C. Pratt, R.A. With I2 Plates. Second Edition. Small crown 8 vo. $6 s$.

IV. The Elements of Military Administration. First Part: Permanent System of Administration. By Major J. W. Buxton. Small crown 8vo. $7 s, 6 d$.

V. Military Law : its Procedure and Practice. By Major Sisson C. Pratt, R.A. Second Edition. Small crown 8vo. 4s. 6d.

VI. Cavalry in Modern 'War. By Col. F. Chenevix Trench. Small crown 8vo. $6 s$.

VII. Field Works. Their Technical Construction and Tactical Application. By the Editor, Col. C. B. Brackenbury, R.A. Small crown 8vo.

BRENT (Brig.-Gen. F. L.)-MobILIZABLE FORTIFICATIONS AND THEIR CONTROLLING INFLUENCE IN WAR. Crown 8vo. 5 s.
BROOKE (Major C. $K$.) -A SYSTEM OF Field Training. Small crown 8vo. $2 s$.

CLERY (C.) Lieut. -Col.-Minor TACTICS. With 26 Maps and Plans. Sixth and cheaper Edition, revised. Crown 8vo. 9s.

COLVILE (Lieut.-Col. C. F.)-MrLTARY TRIBUnals. Sewed, $2 s .6 d$.

CRAUFURD (Capt. H. F.)-SUGgESTIONS FOR THE MILITARY TRAINING OF A COMPANY OF INFANTRY. Crown 8vo. Is. $6 d$.

HAMILTON. (Capt. Ian) A.D.C. -ThE Fighting of The Fu'TuRe. Is.

HARRISON (Lieut.-Col. R.) - THE OFFICER'S MEMORANDUM BOOK FOR PEACE AND WAR. Third Edition. Oblong 32mo. roan, with pencil, $3 s .6 d$.

Notes on Cavalry Tactics, ORganiSATION, \&c. By a Cavalry Officer. With Diagrams. Demy 8vo. I2s.

PARR (Capt. H. Hallam) C.M.G.-The DRESS, HoRses, AND EQUIPMENT OF INFANTRY AND STAFF OfFICERS. Crown 8vo. Is.

SCHAW (Col. H.)-The Defence AND AtTaCK of Positions and LocaliTIEs. Third Edition, revised and corrected. Crown 8vo. 3 s. $6 d$.

STONE (Capt. F. Gleadowe) R.A.-TACTiCal Studies from the FrancoGERMAN WAR OF I870-7I. With 22 Lithographic Sketches and Maps. Demy 8vo. 3os.

The Campaign of Fredekicissburg, November to December, I862: a Study for Officers of Volunteers. By a Line Officer. Crown 8vo. With Five Maps and Plans.

WILKINSON (H. Spenser) Capt. 20th Lancashive R.V.-CitizEN Soldiers. Essays towards the Improvement of the Volunteer Force. Crown Svo, 2s. $6 d$. 


\section{POETRY.}

ADAM OF ST. VICTOR-ThE LiTURGICAL POETRY OF ADAM OF ST. Victor. From the text of Gautier. With Translations into English in the Original Metres, and Short Explanatory Notes. By Digby S. Wrangham, M.A. 3 vols. Crown 8vo. printed on hand-made paper, boards, $2 \mathrm{I} s$.

AUCHMUTY (A. C.)-PoEMs of ENGLISH HERoISM : From Brunanburgh to Lucknow; from Athelstan to Albert. Small crown 8vo. Is. $6 d$.

BARNES (William)-PoEMS OF RURAL LIFE, IN THE DORSET DiAleCT. New Edition, complete in one vol. Crown 8vo. 8s. $6 d$.

BAYNES (Rev. Canon H. R.)-Home SONGS FOR QUIET Hours. Fourth and cheaper Edition. Fcp. 8vo. $2 s .6 d$.

BEVINGTON (L. S.)-KEY Notes. Small crown 8vo. 5 .

BLUNT (Wilfrid Scawen)-The WiNd AND THE Whirlwind. Demy 8 vo. Is. $6 d$.

The Love Sonnets of Proteus. Fifth Edition. I 8 mo. cloth extra, gilt top, $5 s$.

BOWEN (HI. C.) M.A.-Simple ExGLISH PoEms. English Literature for Junior Classes. In Four Parts. Parts I. II. and III. $6 d$. each, and Part IV. Is., complete 3 s.

$B R Y A N T$ (W. C.) - PoEms. Cheap Edition, with Frontispiece. Small crown 8vo. 3s. $6 d$.

Calderon's Dramas : the Wonderworking Magician-Life is a Dream - the Purgatory of St. Patrick. Translated by Denis Florence MacCarthy. Post 8vo. Ios.

Camoens Lusiads. Portuguese Text with English Translation, by J. J. Aubertin. Second Edition. 2 vols. Crown 8vo. I2s.

CAMPBELL (Lewis) -SOPHOCLES. The Seven Plays in English Verse. Crown 8vo. 7s. 6d.

CERVANTES. - JOURNEY TO PARNASSUS. Spanish Text, with Translation into English Tercets, Preface, and Illustrative Notes, by JAMES Y. Gibson. Crown 8vo. I2s.
CERVANTES-continued.

Numantia; a Tragedy. Translated from the Spanish, with Introduction and Notes, by James Y. Gibson. Crown 8vo., printed on hand-made paper, 5 .

CHAVANNES(Mary Charlotte).-A Few TRANSLATIONS FROM VICTOR HUGO, AND OTHER POETs. Small crown 8 vo. $2 s .6 d$.

CHRISTIE (A. Ұ.)-THE END OF MAN. With 4 Autotype Illustrations. 4to. Ios. $6 d$.

CLARTE (Mary Cowden)-HONEY FROM THE WeED. Verses. Crown 8vo. $7 s$.

COCKLE (Mrs. Moss)-Fantasias. Small cr. 8vo. 2s. $6 d$.

COXHEAD (Ethet)-BIRDS AND BABIES. Imp. I6mo. With 33 Illustrations. 2s. $6 d$.

DANTE-The Divina Commedia of Dante Alighieri. Translated, line for line, in the 'Terza Rima' of the original, with Notes, by FREDERICK K. H. Haselfoo't, M.A. Demy 8 vo.

DE BERANGER.-A SELECTION Fron HIS Songs. In English Verse. By William ToynbeE. Small crown 8vo. $2 s .6 d$.

DENNIS (f.) - ENGLISH SonNETS. Collected and Arranged by. Small crown 8vo. 2s. $6 d$.

DENT (Mrs. William)-CEYLON : a Descriptive Poem, with Notes. Small crown 8vo. is. $6 d$.

DERR $Y$ and RAPHOE (Williain Alexander) Bishop of, D.D., D.C.L.St. Augustine's HolidaY, and other Poems. Crown 8vo. 6s.

DE VERE (Aubrey)-Poetrcal Works:

I. The Search after ProserPINE, \&c. $6 s$.

II. The Legends of St. Patrick, \&c. $6 s$.

III. Alexander the Great, Sc. $6 s$.

The Foray of Queen Meave, and other Legends of Ireland's Heroic Age. Small crown 8vo. 5 s. 
DE VERE (Aubrey)-continued.

LEGENDS OF THE SAXON SAINTS. Small crown 8vo. 6s.

DILLON (Arthur)-RIver SoNgS and other Poems. With I3 Autotype Illustrations from designs by Margery May. Fcp. 4to. cloth extra, gilt leaves, ros. $6 d$.

DOBSON (Austin)-OLdWORLD IDYLLS, and other Verses. Sixth Edition. I 8 mo. cloth extra, gilt tops, $6 s$.

At THE Sign OF THE LyRE. Fourth Edition. Elzevir 8vo., gilt top, $6 s$.

DOMETT (Alfred)-RANOLF AND AmOHIA : a Dream of Two Lives. New Edition revised. 2 vols. Crown 8 vo. I2s.

Dorothy : a Country Story in Elegiac Verse. With Preface. Demy 8vo. 5 s.

DOWDEN (Edrvard) LL.D.-SHAKSPERE'S SONNETS. With Introduction and Notes. Large post 8vo. $7 s .6 d$.

Dulce Cor: being the Poems of Ford Berêton. With Two Illustrations. Crown 8vo. 6s.

BUTT (Torn)-A Sheaf Gleaned in French Fields. New Eäition. Demy 8vo. Ios. $6 d$.

AnCient Ballads AND Legends of Hindustan. With an Introductory riemoir by Edmund Gosse. Second Edition. I8mo. Cloth extra, gilt top, $5 s$.

EDWARDS (Miss Betham)-PoEms. Small crown 8 vo. 3 s. $6 d$.

ELDRYTH (Mazd)-MARGARET, and other Poems. Small crown 8vo. $3 s .6 d$.

All Souls' Eve, ' No God,' and other Poems. Fcp. 8vo. 3s. 6d.

ELLIOTT (Ebenezer), The Corn Law Rhymer-Poems. Edited by his Son, the Rev. Edwin Elliott, of St. John's, Antigua. 2 vols. crown 8vo. I $8 s$.

ENGLISH Verse. Edited by W. J. LinTON and R. H. STODDARD. In 5 vols. Crown 8vo. each $5 s$.

I. Chaucer to Burns.

2. Translations.

3. Lyrics of the Nineteentil CenTURY.

4. Dramatic Scenes and CharacTERS.

5. Ballads and Romances.
EVANS (Anne)-Poems ANd Music. With Memorial Preface by ANN Thackeray Ritchie. Large crown 8vo. $7 s$.

FOSKETT (Edward)-PoEms. Crown 8 vo. $6 s$.

GOODCHILD (Fohn A.) - SoMnin Medici. Small crown 8vo. Two Series, 5s. each.

GOSSE (Edmund $W$.$) -New Poems.$ Crown 8vo: 7 s. $6 d$.

FirdaUsi In EXILE, and other Poems. Elzevir 8vo. gilt top, $6 s$.

GRINDROD (Charles) - PLAYS FROM ENGilish History. Crown 8vo. 7s. $6 d$.

The Stranger's Story and his Poem, The Lament of Love: An Episode of the Malvern Hills. Small crown 8vo. 2s. $6 d$.

GURNEY (Rev. Alfred) - THE VisION OF THE EUCHARIST, and other Poems. Crown 8vo. 5 s.

A Christias FagGot. Small crown 8vo. 5 s.

HE YWOOD (F.C.) - Herodias. A Dramatic Poem. New Edition revised. Small crown 8vo. $5 s$.

Antonius. A Dramatic Poem. New Edition, Revised. Small crown 8vo. 5 .

HICKEY (E. H.)-A SCULPTOR, and other Poems. Small crown 8vo. $5^{s}$.

HOLE ( $\left.W . G_{0}\right)$-PROCRIS, and other Poems. Fcp. 8vo. 3 s. $6 d$.

KEATS (Fo $m)$ - POETICAL WORKS. Edited by W. T. ARnol.D. Large crown 8vo. choicely printed on handmade paper, with Portrait in eau forte. Parchment, or cloth, I2s.; vellum, $15 s$.

KING (Mrs. Hamilton)-THE Disciples. Eighth Edition, with Portrait and Notes. Crown 8vo. 5 s.

A Book of Dreams. Crown 8 ro. $3 s .6 d$. KNOX (The Hon. Mrs. O. N.)-FOUR Pictures from a Life, and other Poems. Small crown Svo. $3 s_{0} 6 d$.

Kosuros; or, The Hope of the World. Sinall crown Sro. 3s. $6 d$. 
LANG $(A$.$) -XXXII Ballades IN BluE$ ChInA. Elzevir 8vo. parchment, or cloth, $5 s$.

Rhymes $\grave{A}$ LA Mode. With Frontispiece by E. A. Abbey. Elzevir 8vo. cloth extra, gilt top, $5^{s}$.

LASCELLES (fohn)-GOLDEN FETTERS, and other Poems.' Small crown 8vo. 3 s. $6 d^{\text {? }}$.

LAWSON (Right Hon. Mr. Fustice)Hymi Usitati Latine Rediti, with other Verses. Small 8vo, parchment, 5s.

LESSING'S NATHAN THE WISE. Translated by Eustace K. Corbett. Crown 8 vo. $6 s$.

Living ENglish Poets. MDCCClxxxil. With Frontispiece by Walter Crane. Second Edition. Large crown 8vo. printed on hand-made paper. Parchment, or cloth, I2s. ; vellum, I 5 s.

LOCKER (F.)-LONDON LyRICS. New Edition, with Portrait. I8mo cloth extra, gilt tops, $5^{s}$.

LOVE IN IDLENESS. A Volume of Poems. With an etching by W. B. Scott. Small crown 8 vo. 5 s.

Love Sonnets of Proteus. With Frontispiece by the Author. Elzevir 8vo. 5s.

LUMSDEN (Lieut.-Col. H. W.)-BeOWULF : an Old English Poem. Translated into Modern . Rhymes. Second and revised Edition. Small crown 8 vo. 5 s.

LYSAGHT (Sidney Royse).-A ModerN IDEAL. A Dramatic Poem. Small crown 8vo. 5 s.

$M A G N U S S O N$ (Eirikr) M.A., and PALMER (E. H.) M.A.-JOHAN LUDVIG RUNEBERG'SLYRICAL SONGS, IDYLls, AND EPIGRAMS. Fcp. 8vo. $5 s$.

MAKCLOUD (Even).--BALLADS OF THE WESTERN HighLANDS AND IsLaNDS of Scotland. Small crown 8vo. 3s. $6 d$.

$M C ' N A U G H T O N\left(\mathcal{F} . H_{0}\right)$-ONNALINDA. A Romance. Small crown 8vo. $7 s .6 d$.

M.D.C. - PASSAGES FROM SOME JOURNALS, and other Poems. Small crown 8vo. 3 s. $6 d$.
M. D. C.-Three Lyrical Dramas : Sintram, The Friends of Syracuse, The Lady of Kynast. Small crown 8vo. 3s. 6d.

The KaleEFeH AND THE WAG; or, the Quintuple Deceit. An Extravaganza in Two Acts. Crown 8vo. Is.

Chronicles OF CHRistopher CoLumbus : a Poem in Twelve Cantos. Crowri 8vo. $7 s .6 d$.

MEREDITH (Owen) [The Earl of Lytton] LuCrLE. New Edition. With 32 Illustrations. I6mo. $3 s .6 d$. ; cloth extra, gilt edges, $4 s .6 d$.

MORRIS (Lervis) - POETICAL WORKS. New and Cheaper Editions, with Portrait, complete in 3 vols. $5 s$. each.

Vol. I. contains Songs of Two Worlds. Eleventh Edition.

Vol. II. contains The Epic of Hades. Twentieth Edition.

Vol. III. contains Gwen and the Ode of Life. Sixth Edition.

The Epic of Hades. With 16 Autotype Illustrations after the drawings by the late George R. Chapman. 4to. cloth extra, gilt leaves, 2 Is.

THE EPIC OF HADES: Presentation Edition. 4to. cloth extra, gilt leaves, IOs. $6 d$.

Songs Unsung. Fifth Edition. Fcp. 8vo. 5s.

GrClA : a Tragedy in Five Acts. Fcp. 8vo. $5^{s}$.

The Lewis Morris Birthday Book. Edited by S. S. Copeman. . With Frontispiece after a design by the late George R. Chapman. 32mo. cloth extra, gilt edges, $2 s$; ; cloth limp, $1 s, 6 d$.

MORSHEAD (E. D. A.)-ThE House Atreus. Being the Agamemnon, Libation-Bearers, and Furies of $F$ s. chylus. Translated into EnglishVerse. Crown 8vo. $7 s$.

The Suppliant Maidens of $Æ$ EschyLus. Crown 8 vo. $3 s .6 d$.

MOZLEY (F. Rickards).-The Romance of Denneld. A Poem in Five Cantos. Crown 8vo. 7 s. $6 d$.

MULHOLLAND (Rosa). - VAGRANT VERSES. Small crown 8vo. 5 s.

NOEL (The Hon. Roden)-A LitTLE. CHILD's MONUMENT. Third Edition. Small crown 8vo, 3 s. $6 d$. 
NOEL (The Hon. Roden)-continued.

THE Red FlaG, and other Poems. New Edition. Small crown 8vo. $6 s$.

The House of Ravensburg. New Edition. Small crown 8vo. $6 s$.

Songs of the Heights and Deeps. Crown 8vo. 6 s.

OBBARD (Constance Mary).-Burley BeLls. Small crown 8vo. 3s. $6 d$.

O'HAGAN (fohn) - THE SONG OF ROLAND. Translated into English Verse. New and Cheaper Edition. Crown 8vo. 5 s.

PFEIFFER (Emily)-THE RHYME OF THE LADY OF THE ROCK AND How IT Grew. Small crown 8vo. 3s. $6 d$.

Gerard's Monument, and other Poems. Second Edition. Crown 8vo. $6 s$.

UNDER THE Aspens: Lyrical and Dramatic. With Portrait. Crown 8vo. 6s.

PIATT (7. Ұ.)-IDYLS AND LYRICS OF THe OHIo Valley. Crown 8vo. 5 s.

PIATT (Sarah M. B.)-A VoyAge To THE Fortunate IsLes, and other Poems. I vol. Small crown 8vo. gilt top, 5 s.

In Primrose Time. A New Irish Garland. Small crown 8vo. $2 s .6 d$.

PREVOST (Francis)-MELILOT. Small crown 8 vo. 3 s. $6 d$.

RARE POEMS OF THE I6TH AND I7TH Centuries. Edited by W. J. Linton. Crown 8vo. 5 s.

RHOADES (fames)-THE GeORGICS OF VIRGIL. Translated into English Verse. Small crown 8vo. $5^{s}$.

ROBINSON $(A$. Mary $F$. )-A Handful OF HoNEYSUCKLe. Fcp. 8vo. 3s. $6 d$.

The Crowned Hippolytus. Translated from Euripides. With New Poems. Small crown 8vo. cloth, 5 s.

ROUS (Lieut.-Col.)-CONRADIN. Small crown 8vo. $2 s$.

SCHILLER (Friedrich)-WALLENSTEIN. A Drama. Done in English Verse, by J. A. W. Hunter, M.A. Crown 8vo. 7 s. $6 d$.

SCHWARTZ, (F. M. W.)-Nivalis : a Tragedy in Five Acts. Crown 8 vo. $5 s$.

SCO'T (E. F. L.) - The ECLOGUES OF VIRGIL. Translated into English Verse. Small crown 8vo. 3 s. $6 d$.
SCOTT (George F. E.)-ThEodorA, and other Poems. Small crown 8vo. 3s.6d.

SEYMOUR (F. H. A.)-RIENZI. A Play in Five Acts. Small crown 8 vo. 5 s.

ShaKsPERE'S Works. The Avon Edition, 12 vols. fcp. 8 vo. cloth, I 8 s.; and in box, 21s.; bound in 6 vols. cloth, $15 s$.

SHERBROOKE (Viscount)-POEMS OF A LiFE. Second Edition. Small crown 8vo. $2 s .6 d$.

SMITH (F. W. Gilbart)-THE LoveS OF VANDYCK : a Tale of Genoa. Small crown 8vo. 2s. $6 d$.

The Log O' THE 'Norseman,' Small crown 8vo. $5^{s}$.

Songs of Coming Day. Small crown 8 vo. $3^{\text {s. }} 6 d$.

SOPHOCLES: The Seven Plays in English Verse. Translated by Lewis Campbell. Crown 8 vo. $7 s .6 d$.

SPICER (Henry)-HASKA : a Drama in Three Acts (as represented at the Theatre Royal, Drury Lane, March Ioth, 1877). Third Edition, crown 8vo. 3 s. $6 d$.

URIEL Acosta, in Three Acts. From the German of Gatzkow. Small crown 8vo. 2s. $6 d$.

SYMONDS (Fohn Addington) - VAGA. BUNDUli Libellus. Crown 8 vo. $6 s$.

Tasso's Jerusalem Delivered. Translated by Sir John Kingston James, Bart. 2 vols. printed on hand-made paper, parchment, bevelled boards, large crown 8vo. $21 s$.

TA YLOR (Sir H.) - Works Complete in Five Volumes. Crown 8vo. 30s.

Philip van Artevelde. Fcp. 8 vo. 3s. $6 d$.

THE Virgin Widow, \&c. Fcp. 8vo. 3s. $6 d$.

The Statesman. Fep. 8vo. 3s.6d.

TAYLOR (Augustus) - PoEms. Fcp. 8 vo. 5 s.

TODHUNTER (Dr. Ұ) - LAURELLA, and other Poems. Crown 8vo. 6s. 6d.

Forest Songs. Small crown 8vo.3s.6d.

The True Tragedy of Rienzi : a Drama. Crown 8vo. 3s. 6a.

Alcestis : a Dramatic Poem. Extra fcp. 8vo. 5 s.

Helena in Troas. Small crown 8 vo. 2 s. $6 d$. 
TYLER (M. C.) - ANNe Boleyn : a Tragedy in Six Acts. Small crown 8vo. 2s. $6 d$.

TYNAN (Katherine)-LOUISE DE LA VALLIERE, and other Poems. Small crown 8vo. 3s. $6 d$.

WATTS (Alaric Alfred and Emma Mary Howitt) - AURORA : a Medley of Verse. Fcp. 8vo. cloth, bevelled boards, 5 s.

WEBSTER (Augusta)-IN A DAY : a Drama. Small crown 8vo. 2s. $6 d$.

DisGuises : a Drama. Small crown 8vo. 5 s.

Wet Days. By a Farmer. Small crown 8 vo. $6 s$.
WOOD (Rev. F. H.)-ECHOES OF THE Night, and other Poems. Small crown 8 vo. $3^{s .} 6 d$.

WORDSWORTH BIRTHDAY BOOK, THE. Edited by ADELAIDE and VIOLET WORDSWORTH. 32mo. limp cloth, Is. $6 d$. ; cloth extra, $2 s$.

YOUNGMAN(Thomas George)-PoEms. Small crown 8 vo. $5^{s}$.

YOUNGS (Ella Sharpe)-PAPHUS, and other Poems. Small crown 8 vo. 3s. $6 d$.

A Hearts Life, Sarpedon, and other Poems. Small crown 8vo. 3s. $6 d$.

\section{WORKS OF FICTION.}

'ALL BUT :' a Chronicle of Laxenford Life. By PeN OLIVER, F.R.C.S. With 20 Illustrations. Second Edit. Crown 8vo. 6s.

BANKS (Mrs. G. L.)-GoD's ProviDENCE House. New Edition. Crown 8 vo. 3 s. $6 d$.

CHICHELE (Mary)-DOING AND UNDOING : a Story. Crown 8vo. $4 s .6 d$.

Danish Parsonage. By an Angler. Crown 8vo. $6 s$.

GRAY (Maxzell)-THE SILENCE OF Dean Maitland. A Novel. 3 vols. Crown 8vo. 3is. $6 d$.

HUNTER (Hay)-CRIME OF CHRISTMAS DAY. A Tale of the Latin Quarter. By the Author of 'My Ducats and My Daughter.' Is.

HUN'ER (Hay) and WHYTE (Walter) MY DUCaTS AND My Daughter. New and Cheaper Edition. With Frontispiece. Crown 8vo. $6 s$.

HURST AND HANGER. A History in Two Parts. 3 vols. $31 s$. $6 d$.

INGELOW (Fean)-OFF THE SkELLIGS. A Novel. With Frontispiece. Second Edition. Crown 8vo, 6s,

FENKINS (Edward)-A SECRET OF Two Lives. Crown 8vo. $2 s .6 d$.

KIELLAND (Alexander L.)-GARMAN AND WoRsE. A Norwegian Novel. Authorised Translation by W. W. Kettlewell. Crown 8vo, 6s.

$L A N G$ (Andrew)-IN THE WRONG PARADISE, and other Stories. Crown 8 vo. $6 s$.
MACDONALD (G.)-DONAL GRANT. A Novel. New and Cheap Edition, with Frontispiece. Crown 8vo. 6s.

Castle Warlock. A Novel. New and Cheaper Edition. Crown 8vo. 9s.

MALCOLM. With Portrait of the Author engraved on Steel. Sixth Edition. Crown 8vo. 6s.

The MARquis of Lossie. Fifth Edition. With Frontispiece. Crown 8 vo. $6 s$.

St. George and St. Michael. Fourth Edition. With Frontispiece. Crown 8vo. $6 s$.

Paul Faber, Surgeon. Crown 8vo. $6 s$.

Thomas Wingfold, Curate. Crown 8vo. $6 s$.

What's Mine's Mine. Second Edition. With Frontispiece. Crown 8vo. 6s.

AnNals of a QUiET NeIGHBOURHoOD. Fifth Edition. With Frontispiece. Crown 8vo. 6s.

The Seaboard Parish : a Sequel to 'Annals of a Quiet Neighbourhood.' Fourth Edition. With Frontispiece. Crown 8vo. $6 s$.

Wilfred Cumbermede. An Autobiographical Story. "Fourth Edition. With Frontispiece. Crown 8vo. 6s.

MALET (Lucas)-COLONEL ENDERBY'S Wife. A Novel. New and Cheaper Edition. With Frontispiece. Crown 8 vo. $6 s$.

MUT.HOLLAND (Rosa) - MARCELLA GraCE. An Irish Novel. Crown 8vo. $6 s$. 
PALGRAVE (W. Gifford)--HERMANN AGHA : an Eastern Narrative. Third Edition. Crown 8vo, $6 s$.

SHAW (Flora L.) -CASTLE BLAIR; a Story of Youthful Days. New and Cheaper Edition. Crown 8vo. $3 s .6 d$

STRETTON (Hesba) - THROUGH A NEEDle's EYe. A Story. New and Cheaper Edition, with Frontispiece. Crown 8vo. "6s.

TAYLOR (Col.Meadows) C.S.I., M.R.I.A.

SeETA. A Novel. New and Cheaper Edition. With Frontispiece. Crown 8vo. $6 s$.
Tippoo Sultaun : a Tale of the Mysore War. New Edition, with Frontispiece. Crown 8vo. 6s.

RALPH DARNell. New and Cheaper Edition. With Frontispiece. Crown 8vo. $6 s$

A Noble Queen. New and Cheaper Edition. With Frontispiece. Crown 8vo. $6 s$.

The Confessions of a Thug. Crown 8vo. 6s.

TARA : a Mahratta Tale. Crown 8vo. - $6 s$.

Within Sound of THE SEA. New and Cheaper Edition, with Frontispiece. Crown 8vo. $6 s$.

\section{BOOKS FOR THE YOUNG.}

Brave Men's Footsteps. A Book of Example and Anecdote for Young People. By the Editor of 'Men who have Risen.' With Four Illustrations by C. Doyle. Eighth Edition. Crown 8vo. $3^{\text {s. } 6 d \text {. }}$

COXHEAD (Ethel)-BIRDS AND BABIES. With 33 Illustrations. Imp. $16 \mathrm{mo}$. cloth gilt, $2 s .6 d$.

DAVIES (G. Christopher) - RAMBLES AND ADVENTURES OF OUR SCHOOL Field Club. With Four Illustrations. New and Cheaper Edition. Crown 8vo. 3s. $6 d$.

EDMONDS (Herbert) - WELL-SPENT LIVES: a Series of Modern Biographies. New and Cheaper Edition. Crown 8vo. 3 s. $6 d$.

EVANS (Mark)-THE STORY OF OUR FATHER's Love, told to Children. Sixth and Cheaper Edition of Theology for Children. With Four Illustrations. Fcp. 8vo. Is. 6d.

MAC KENNA (S. Ұ.)-PLUCKY FELLows. A Book for Boys. With Six Illustrations. Fifth Edition. Crown 8vo. 3 s, $6 d$.

REANEY (Mrs, G. S.)-WAKING AND WORKING; or, From Girlhood to Womanhood. New and Cheaper Edition. With a Frontispiece. Cr. 8yo. 3s. $6 d_{\text {? }}$
'REANEY (Mrs. G. S.)-continued.

BLESSING AND BLESSED : a Sketch of Girl Life. New and Cheaper Edition. Crown 8vo. 3s. 6d.

Rose GuRnEy's Discovery. A Book for Girls. Dedicated to their Mothers. Crown 8vo. 3 s. $6 d$.

ENGLish Girls: Their Place and Power. With Preface by the Rev. R. W. Dale. Fourth Edition. Fcp. 8vo. 2s, $6 d$.

Just ANyone, and other Stories. Three Illustrations. Royal I6mo. Is. $6 d$.

Sunbeam WILlie, and other Stories. Three Illustrations. Royal $16 \mathrm{mo}$. Is. $6 d$.

Sunshine Jenny, and other Stories. Three Illustrations. Royal I6mo. Is. $6 d$.

STORR (Francis) and TURNER (Hazes). Canterbury ChImes; or, Chaucer Tales Re-told to Children. With Six Illustrations from the Ellesmere MS. Third Edition. Fcp. 8vo. 3s. 6d.

STRETTON (Hesba)-DAVID LLOYD'S LAST WILL. With Four Illustrations. New Edition. Royal $16 \mathrm{mo}$. 2s. $6 d$.

WHITAKER (Florence)-CHRISTY'S INHERITANCE : A London Story. Illustrated. Royal I 6 mo. Is. $6 d$. 

An.

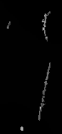

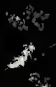


